\title{
The Contribution of \\ Natural Design Elements to the \\ Sustained Use of Public Space in a \\ City Centre
}

By

\section{Ensiyeh Ghavampour}

\author{
A thesis \\ Submitted to the Victoria University of Wellington \\ In fulfilment of the requirements for the degree of \\ Doctor of Philosophy in Architecture
}

Victoria University of Wellington

2014 

To my parents,

Mahdi Ghavampour and Batool Kavian Manesh, and to all users of small urban spaces 



\section{Abstract}

An increasing similarity in urban designs negatively impacts on urban space through a loss of meaning. Although the importance of meaning is stressed in the literature, this aspect of urban space has been neglected in the recent past at a time when sustainable development is also needed. A review of literature reveals that natural elements within physical settings have meaning for people and that the meanings are socially constructed by the users of the spaces. The contribution of meaning, activity, and physical elements in urban space is described in the Theory of Place. Investigating the affordance of these three components in the sustained use of small urban spaces in a city centre, where public space is at a premium and compatibility of design elements a pre-requisite, forms the focus of this study.

This research aims to bridge the gap between theory and practice by using the Theory of Place to assess natural design elements in small urban spaces. An investigation of theory, design characteristics and activity was conducted in four small urban spaces in the city centre of Wellington, New Zealand. The investigation used structured surveys with a facet approach, and photographic observation and GIS mapping of behaviour to answer the research question: Is it possible that natural design elements in public spaces influence the sustained use of a place? In addition, if observations of sustained use are related to natural design elements, is there a theoretical basis for this assertion and can it be examined through research? To answer these questions Study One examines the linkages between physical setting, social activity and meaning by investigating the behavioural and cognitive-affective affordance of natural elements. With the results indicating a preference for natural over artificial design elements, Study Two investigated more closely how natural and artificial elements combine in design and which physical elements are likely to have strong links with other components of place. Study Three tests the validity of the theoretical findings of the initial studies by mapping user's behaviour in small urban spaces.

The convergence of the theoretical and observational research results emphasises the advantages of using both approaches in an investigation of place. Investigation of the link between meaning and activity through observation is an inferential interpretation which gives rise to the need to use complementary theoretical research with reliable predictive power. While designers should consider theory in design they should also be aware of the practical importance of creating meaningful combinations of design elements that meet the diverse needs and changing users and uses over time. 


\section{Table of Contents}

ABSTRACT

TABLE OF CONTENTS..........................................................................................................II

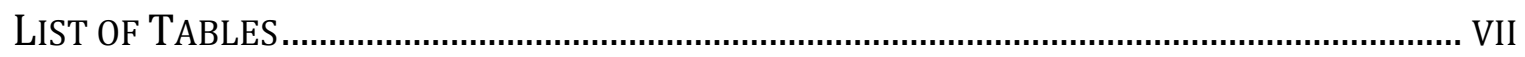

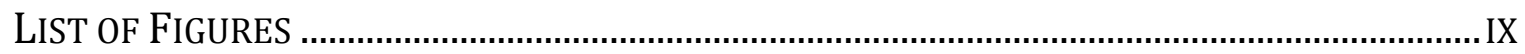

PREFACE AND ACKNOWLEDGEMENTS ........................................................................... XIII

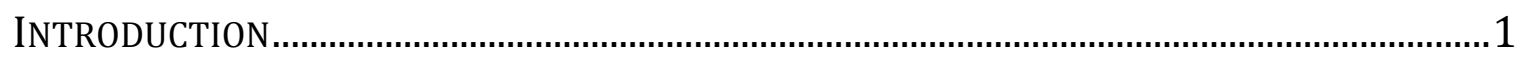

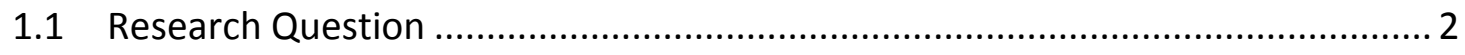

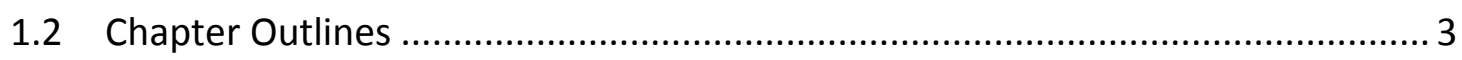

Chapter 1 NATURE IN Public SPACE ...............................................................................

1.1 Green Space before Industrialization........................................................ 8

1.2 Green Space after Industrialization.......................................................... 11

1.3 Increasing interest in Small Urban Spaces ...................................................... 13

1.4 Defining Nature in Urban Populations ....................................................... 17

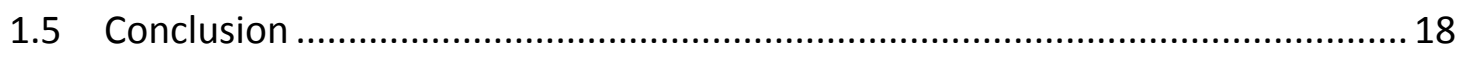

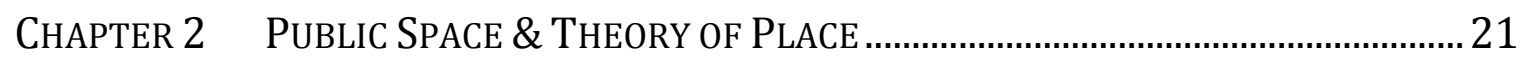

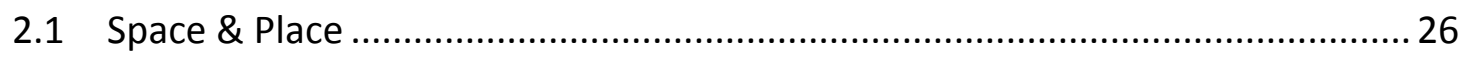

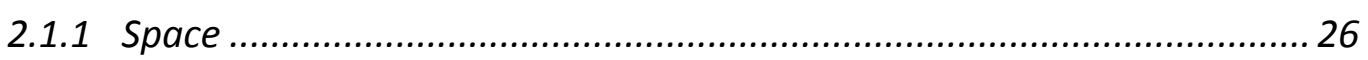

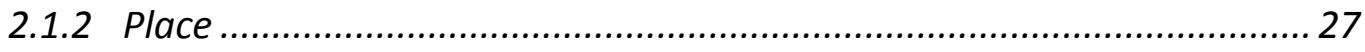

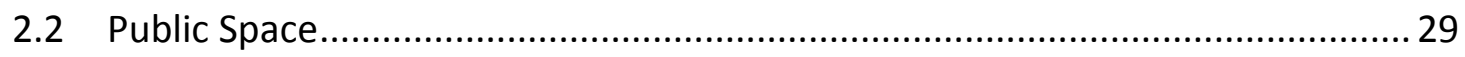

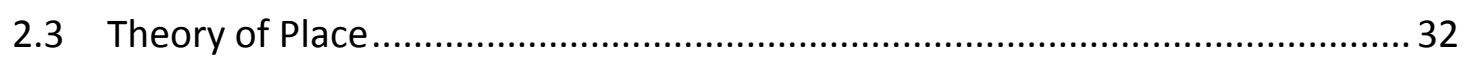

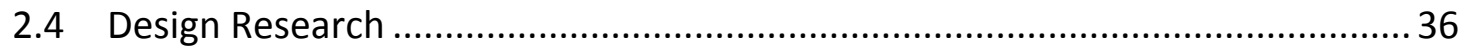

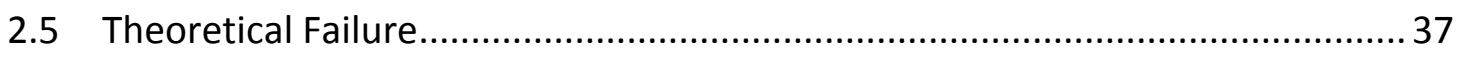

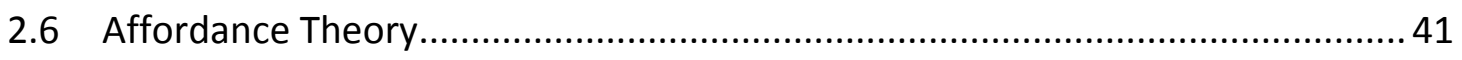

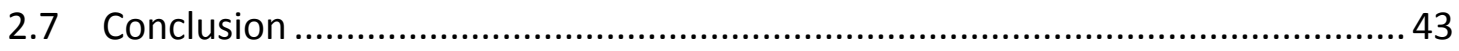

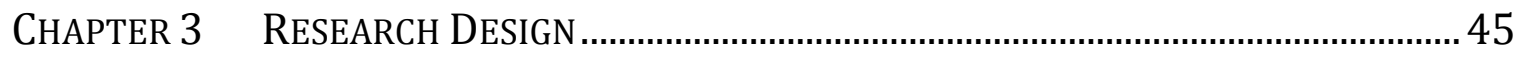

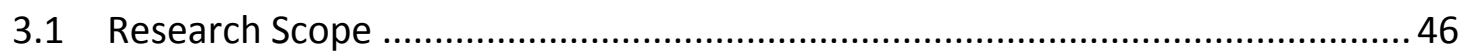

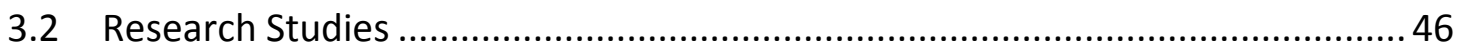

3.2.1 Study One: Affordance of Design Elements......................................... 46

3.2.2 Study Two: Design Elements in Public Space........................................ 47

3.2.3 Study Three: Behaviour in Public Space ............................................ 47 
3.2.4 Research Methods \& Analyses: Studies One \& Two. 48

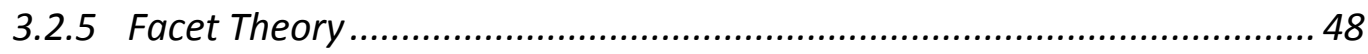

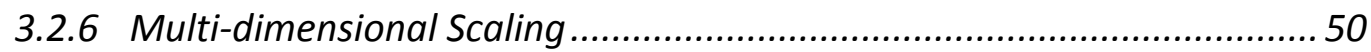

3.3 Research Methods \& Analyses: Study Three ...................................................51

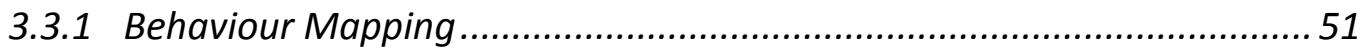

3.3.2 GIS Analysis of Behavioural Observations ..........................................54

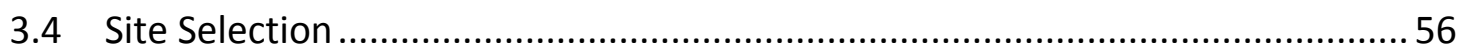

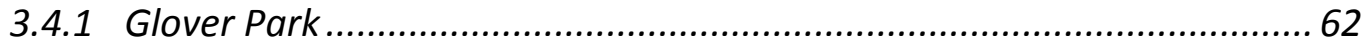

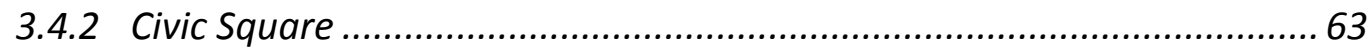

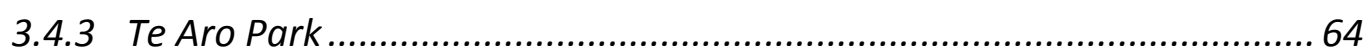

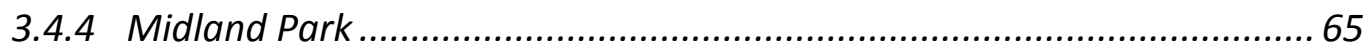

CHAPTER 4 STUDY ONE: AFFORDANCE OF DESIGN ELEMENTS........................................ 69

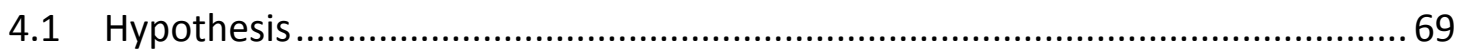

4.2 Meaning and Conception: The Affective and Cognitive Affordance of Place ..... 70

4.3 Activity and Experience: The Behavioural Affordance of Place ..........................72

4.4 Design Elements: The Material Affordance of Place........................................... 73

4.5 Mapping Sentence for Study One .................................................................. 76

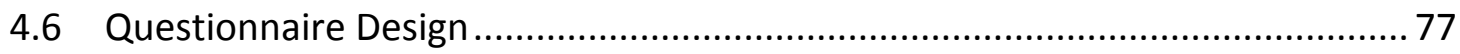

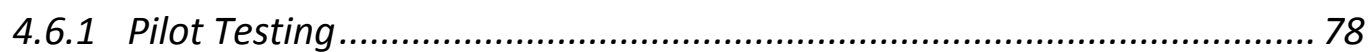

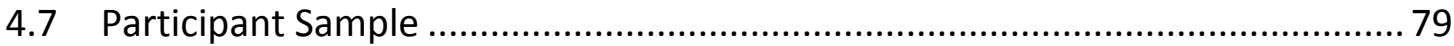

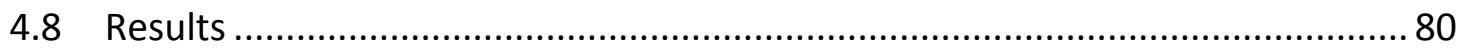

4.8.1 Natural Design Elements................................................................... 83

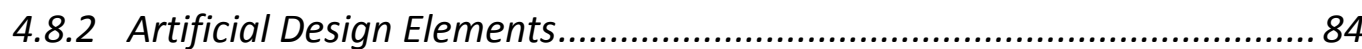

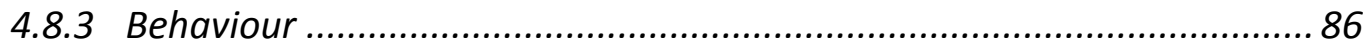

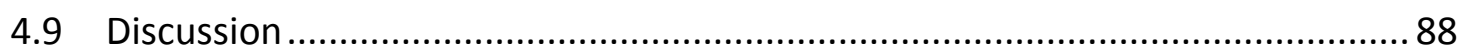

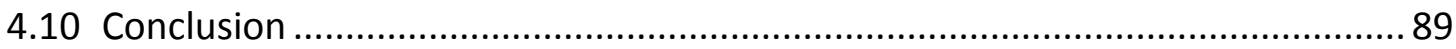

Chapter 5 Design Elements In Public SPACE …...................................................... 91

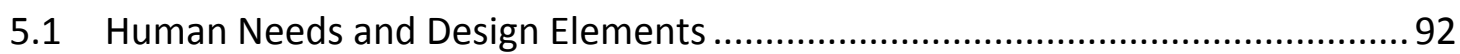

5.1.1 Comfort and Design Elements ............................................................. 95

5.1.2 Safety and Design Elements .............................................................. 96

5.1.3 Belonging and Design Elements ......................................................... 98

5.1.4 Cognitive and Aesthetic Needs and Design Elements ........................... 99

5.2 Framework for Investigating Design Elements ............................................. 104

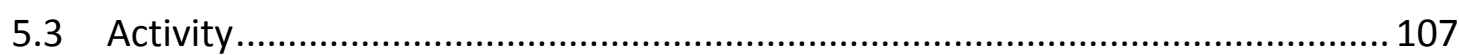

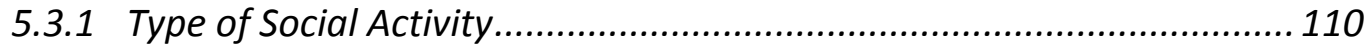

5.4 Mapping Sentence for Study Two .............................................................. 111

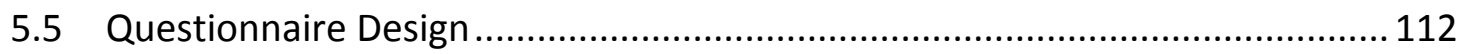


5.5.1 Pilot Testing.

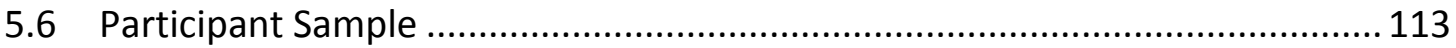

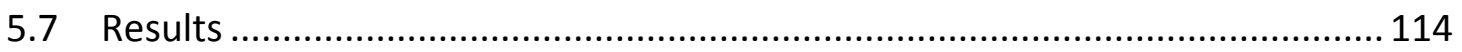

5.7.1 Spending Time Alone and Time with People ....................................... 119

5.7.2 Chance Contact with New People ......................................................... 122

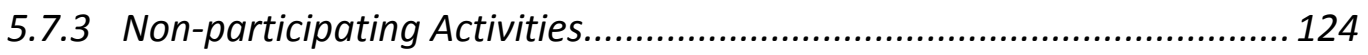

5.7.4 Result of Part Three of Questionnaire ................................................ 126

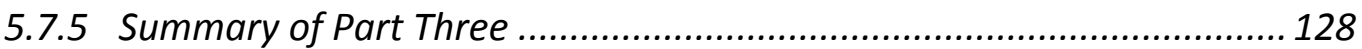

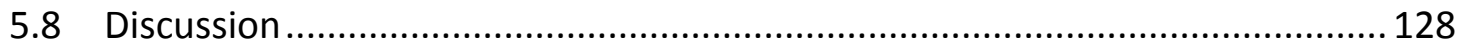

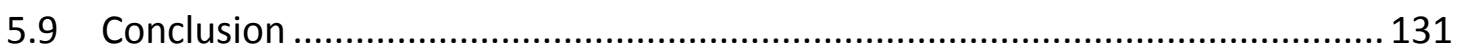

ChaPtER 6 STUDY THREE: BEHAVIOUR MAPPING ...................................................... 133

6.1 Natural Elements and Observed Behaviour................................................... 133

6.2 Framework for Behaviour Mapping ............................................................... 134

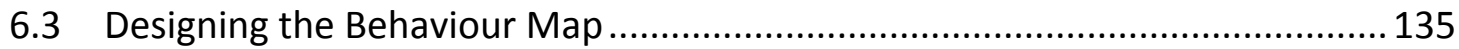

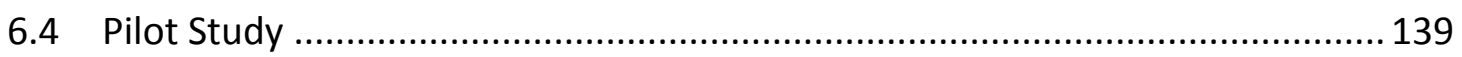

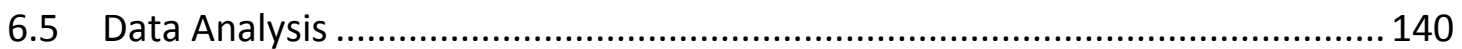

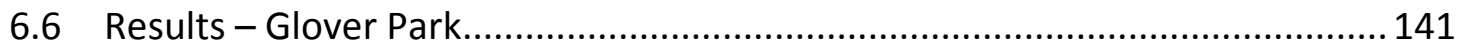

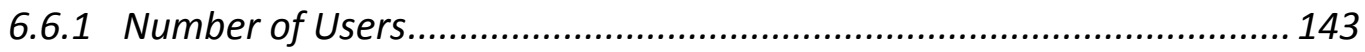

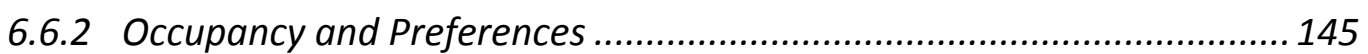

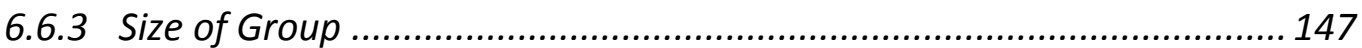

6.6.4 Use of Spaces by Age and Gender .................................................... 153

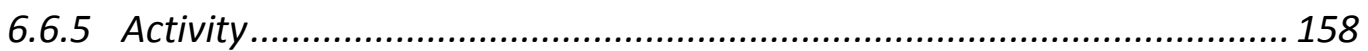

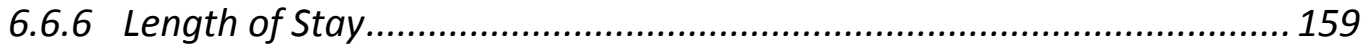

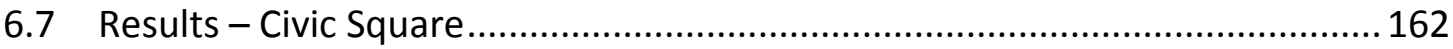

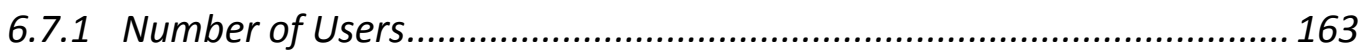

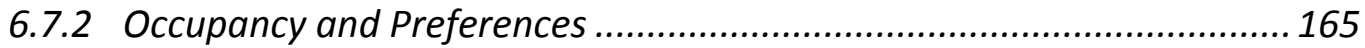

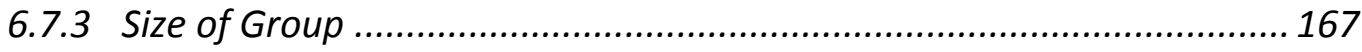

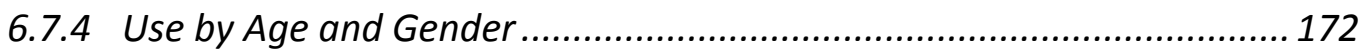

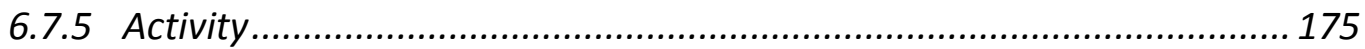

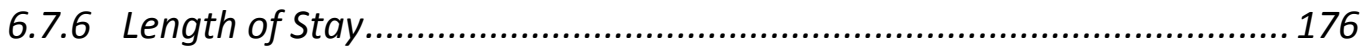

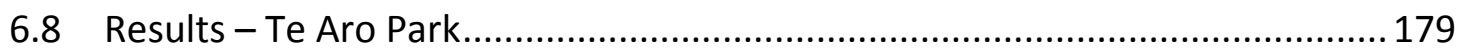

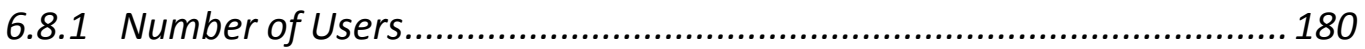

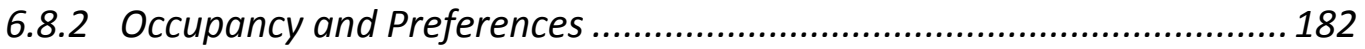

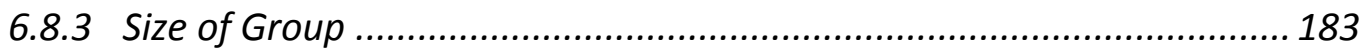

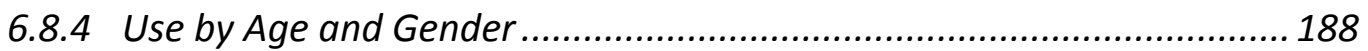

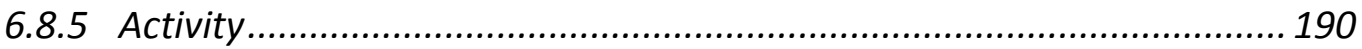

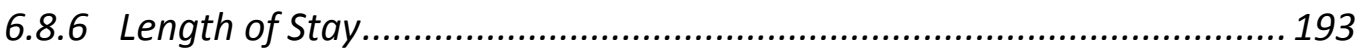

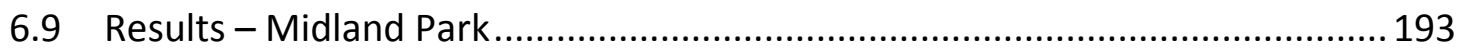




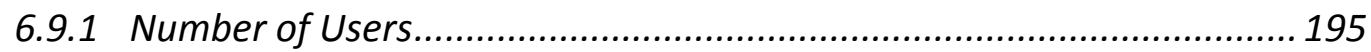

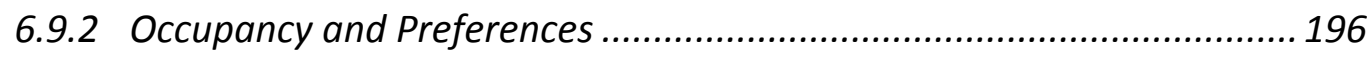

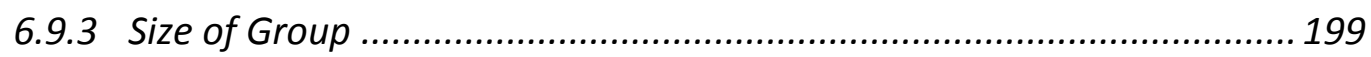

6.9.4 Use by Age and Gender ................................................................. 206

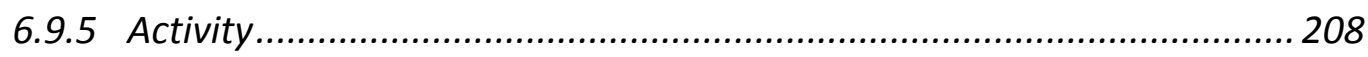

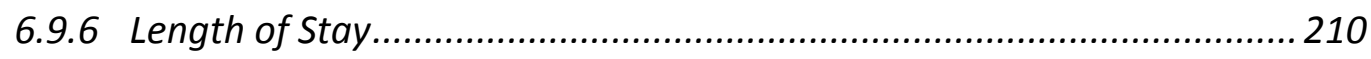

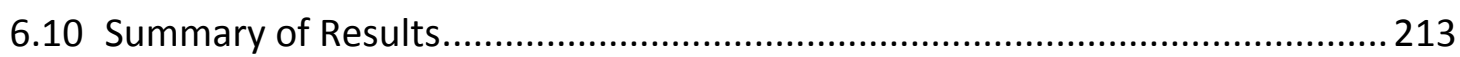

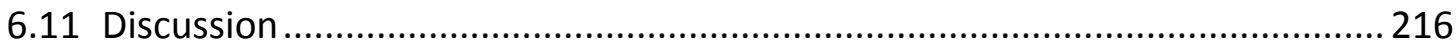

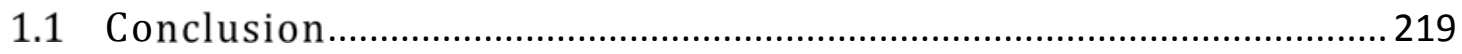

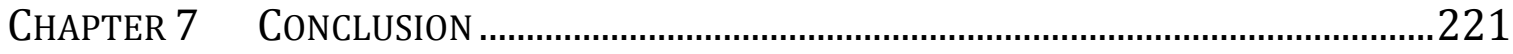

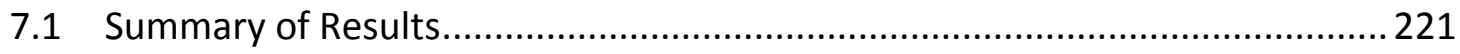

7.1.1 Study One: Affordance of Design Elements........................................ 221

7.1.2 Study Two: Design Elements in Public Space........................................ 222

7.1.3 Study Three: Observed Behaviour in Public Space .............................. 223

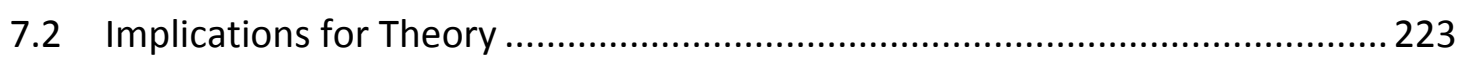

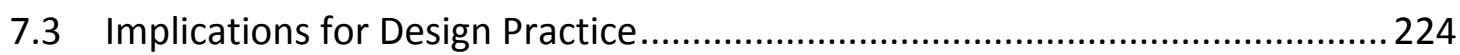

7.4 Implications for Design Research Methods ............................................... 227

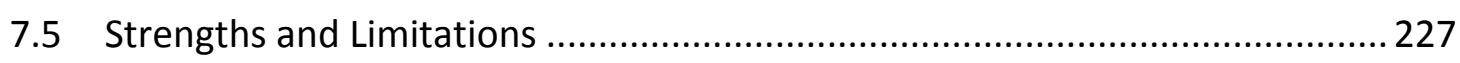

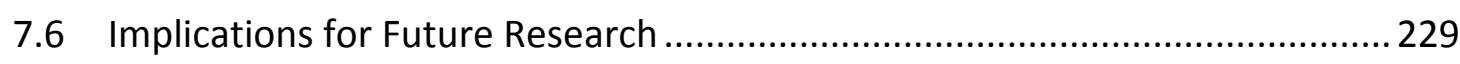

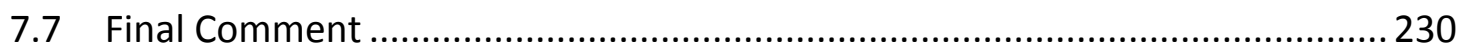

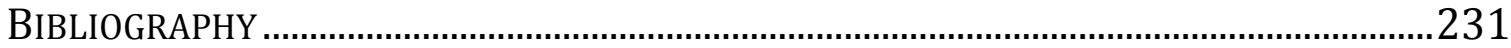

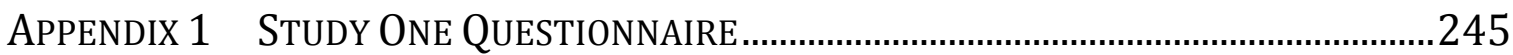

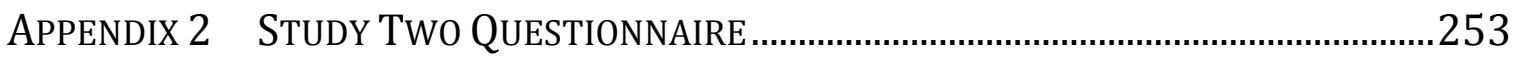

APPEndix 3 COMPARISON OF StUdy PARTICIPANTS AND DATA COLLECTION DATES 265

APPENDIX 4 PILOT TESTING FOR PHOTOGRAPHIC INTERVAL ........................................267 


\section{List of Tables}

Table 2-1: Categories of public space (Carr et al., 1992, pp. 79-85) …………………………............ 31

Table 3-1: Scoring of data collection sites .....................................................................................60

Table 4-1: Mean preferences for natural and artificial design elements............................................82

Table 4-2: Affective-cognitive affordance of design elements ...........................................................84

Table 4-3: Affective-cognitive affordance of behaviour ........................................................................

Table 5-1: Comparing human needs in different studies ..................................................................95

Table 5-2: Design elements and human needs..................................................................................... 105

Table 5-3: Arrangement of design elements ...................................................................................... 106

Table 5-4: Intensity of social activity $(\mathrm{Gehl}, 1987)$..........................................................................110

Table 5-5: Order of preferences according to involving activity facet ...........................................116

Table 5-6: Mean preferences for natural and artificial design elements..........................................117

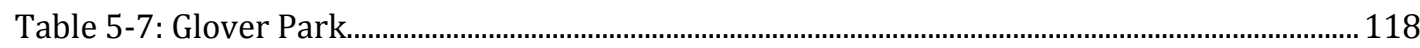

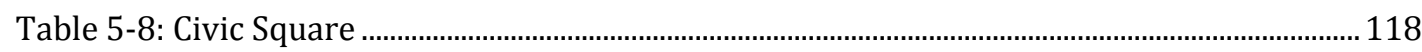

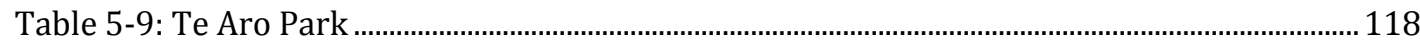

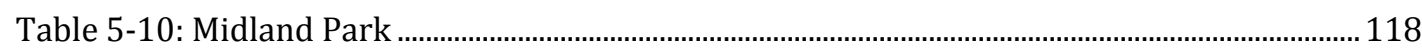

Table 5-11: Means of preferences according to two activities (café and having people

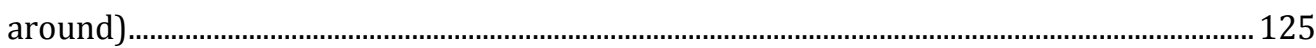

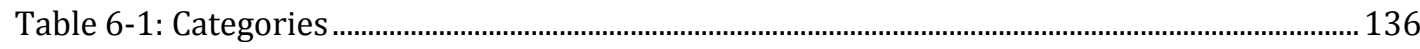

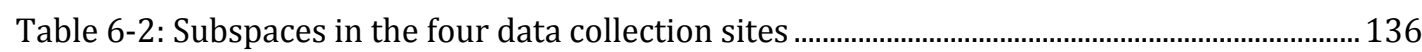

Table 6-3: Number of users during one day of observation, Glover Park.......................................... 144

Table 6-4: Use of subspaces by people alone and in groups ..............................................................148

Table 6-5: Size of group and use of subspaces, Glover Park ………………………………………...152

Table 6-6: Number of users by age and gender .................................................................................... 154

Table 6-7: Number of groups in subspaces by gender .................................................................... 155

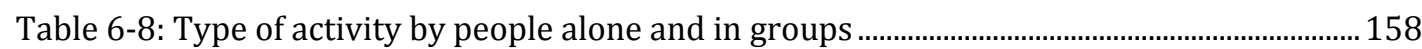

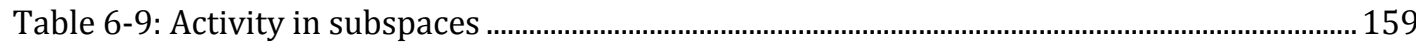

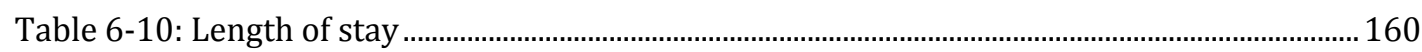

Table 6-11: Number of users during one day of observation, Civic Square ......................................164

Table 6-12: Use of subspaces by people alone and in groups ...........................................................167

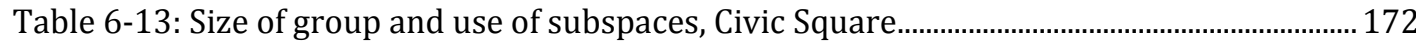

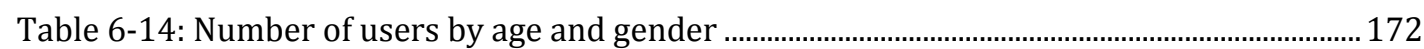

Table 6-15: Number of groups in subspaces by gender.................................................................... 173

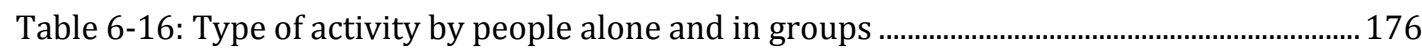

Table 6-17: Type of activity by subspace

Table 6-18: Length of stay (Group here means one person or group of two or more people).177

Table 6-19: Number of users during one day of observation, Te Aro Park ........................................ 181

Table 6-20: Use of subspaces by people alone and in groups ............................................................184

Table 6-21: Size of group and use of subspaces, Te Aro Park .............................................................187

Table 6-22: Number of users by age and gender ................................................................................. 188

vii 
Table 6-23: Number of groups in subspaces by gender. 189

Table 6-24: Type of activity by people alone and in groups …...................................................... 190

Table 6-25: Type of activity by subspace ...................................................................................................... 192

Table 6-26: Length of stay (Group here means one person or group of two or more people) 193

Table 6-27: Number of users during one day of observation, Midland Park ............................... 196

Table 6-28: Use of subspaces by people alone and in groups .............................................................. 200

Table 6-29: Size of group and use of subspaces, Midland Park ........................................................... 204

Table 6-30: Number of users by age and gender .................................................................................. 206

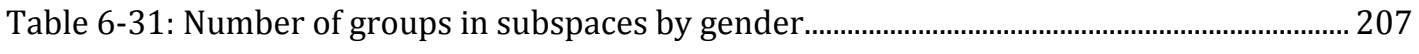

Table 6-32: Type of activity by people alone and in groups ................................................................... 209

Table 6-33: Activity in subspaces ................................................................................................... 209

Table 6-34: Length of stay (Group here means one person or group of two or more people) 210

Table 6-35: Comparison of subspace use as a percentage of its maximum occupancy.............. 214

Table 6-36: Use of subspaces by people alone and in groups ............................................................ 215

Table 6-37: Length of stay ( 1 =once, $2=$ twice , $\geq 3$ =three or more times) in four data collection

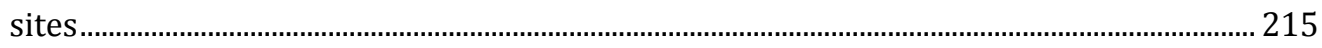

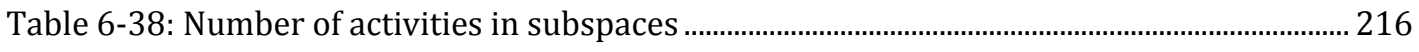

Table 6-39: Number of people by age in the four sites....................................................................... 216

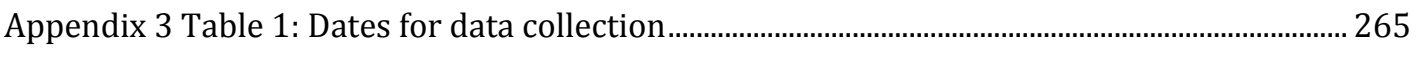

Appendix 3 Table 2: Comparison of participants in Studies One and Two.................................. 266 


\section{List of Figures}

Introduction Figure 1: Use of similar ideas across the world, Miami,USA; Mexico City, Mexico;

Brisbane, Australia .1

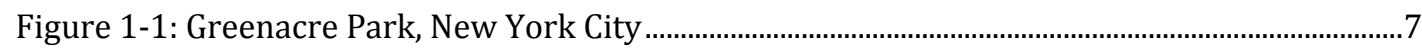

Figure 1-2: Paley Park, New York City ........................................................................................................

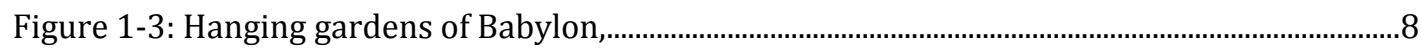

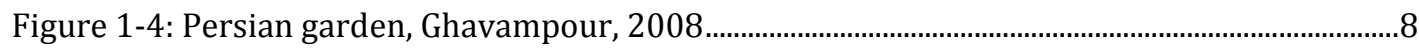

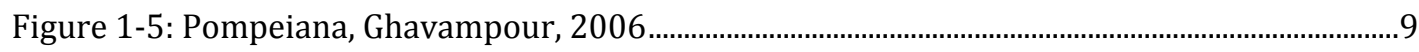

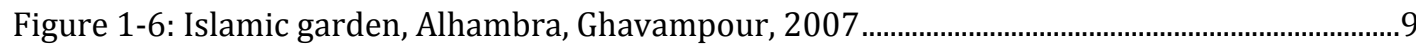

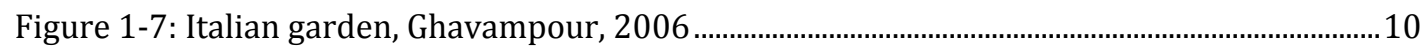

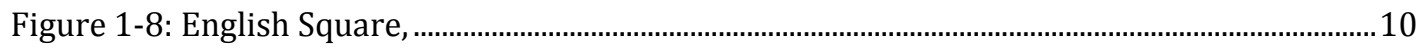

Figure 1-9: Polesdon Lacey, Park design by Bonsor, Brenda Vale, 2014 .........................................11

Figure 1-10: South Marine Park, South Shields, Brenda Vale, 2014 .................................................11

Figure 1-11: Green space in modern cities, Ghavampour, 1\&2 Strasbourg, 2008 .........................12

Figure 1-12: Green space in modern cities, Ghavampour, Lisbon, 2007 .........................................12

Figure 1-13: Green space in modern cities, Ghavampour, Zurich, 2010...........................................12

Figure 2-1: Public space and social life, Piazza Spagna, Room, Piazza del DuomoMillan .............21

Figure 2-2: Roman plaza, http://www.italian-architecture.info/ROME/RO-012.htm ...................22

Figure 2-3: Modern life in a Roman plaza, Ghavampour, 2007 .........................................................22

Figure 2-4: Contribution of urban space in traditional cities, Venice 2007, Ghavampour .............23

Figure 2-5: Horace Dodge Fountain, Michigan, United Stateshttp://moco-

choco.com/2012/11/04/top-30-eye-pleasing-fountains-around-the-globe/, . .25

Figure 2-6:Fountain of Wealth, Suntec City, Singapore, http://moco-

choco.com/2012/11/04/top-30-eye-pleasing-fountains-around-the-globe/ .................... 25

Figure 2-7: Components of sense of place (Punter, 1991, p. 27) ..........................................................34

Figure 2-8: Policy direction to foster place making (Montgomery, 1998, p. 98) ............................34

Figure 2-9: A visual metaphor of the nature of places (Canter, 1977a, p. 158)...............................35

Figure 2-10: Graphic representation of the relationship between the quality of outdoor spaces

and the rate of occurrence of outdoor activities (Gehl, 1987, p.13) .........................................37

Figure 3-1: Mapping sentence (Levy, 2005, p. 175)............................................................................ 49

Figure 3-2: Representation of photographic data in GIS ..................................................................5

Figure 3-3: All designed public space within the City Centre/Te Aro of Wellington ......................57

Figure 3-4: Categorized spaces within the study area ...........................................................................58

Figure 3-5: Scored space base on pedestrian accessibility .....................................................................59

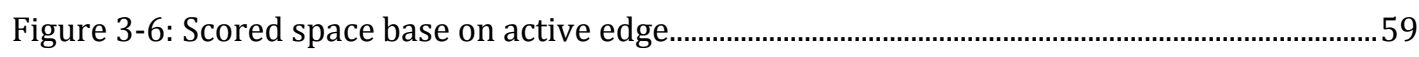

Figure 3-7: Scored space base on visual permeability.............................................................................59

Figure 3-8: Scored space base on structured social activities..............................................................59

Figure 3-9: Overlapped map shows final score for places .................................................................61

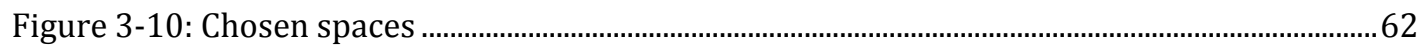

Figure 3-11: Location of four data collection sites ...........................................................................67 
Figure 4-1: The two principal components of the affective quality of places (Russell \& Pratt,

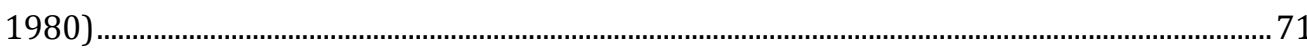

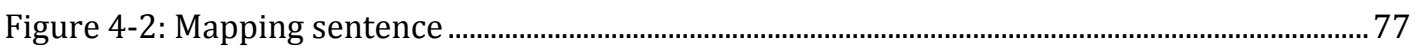

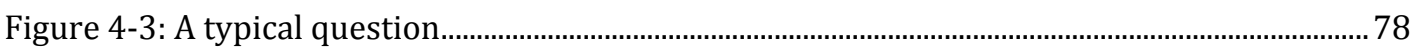

Figure 4-4: Two dimensional spatial representation of 48 items (stress=0.07, N=158)..............82

Figure 4-5: Two dimensional spatial representation of 24 natural items classified by design

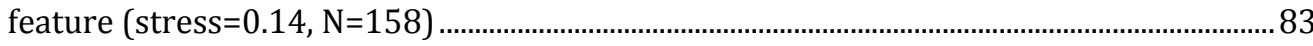

Figure 4-6 Two dimensional spatial representation of 24 natural items classified according to affective-cognitive affordance (stress=0.14, N=158) .................................................................... 84

Figure 4-7: Two dimensional spatial representation of 24 artificial items classified according to

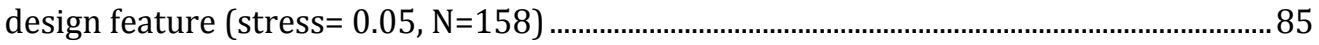

Figure 4-8: Two dimensional spatial representation of 24 artificial items classified according to

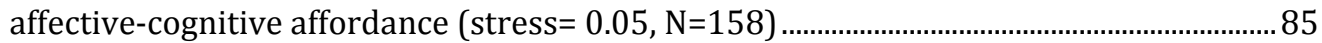

Figure 4-9: Two dimensional spatial representation of 24 items when being alone (stress=0.06,

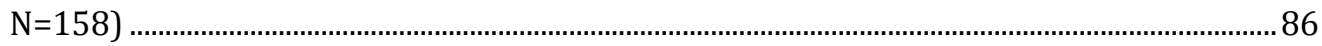

Figure 4-10: Two dimensional spatial representation of 24 items when with friends (stress $=0.04, \mathrm{~N}=158$ ) 86

Figure 5-1: The self-fulfilling prophecy of place/activity expectation (Canter, 1977a, p. 121)108

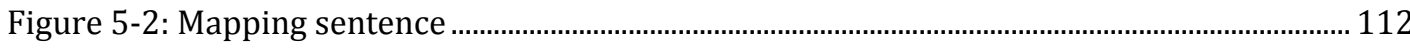

Figure 5-3: A typical question for the Study Two survey ................................................................ 113

Figure 5-4: Two dimensional representation of 96 items (stress= 0.12, N=160) ....................... 115

Figure 5-5: Two dimensional spatial representation of 64 items when spending time alone and meeting with friends classified by design elements (stress $=0.17, \mathrm{~N}=160$ ). 120

Figure 5-6: Two dimensional spatial representation of 32 natural items classified by design elements (stress $=0.2, \mathrm{~N}=160$ ) 121

Figure 5-7: Two dimensional spatial representation of 32 artificial items classified by design elements (stress $=0.18, \mathrm{~N}=160$ ). 122

Figure 5-8: Two dimensional representation of 32 items for chance contact with new people classified according to design elements (stress=0.18, $\mathrm{N}=160$ )

Figure 5-9: Two dimensional spatial representation of 16 natural items for chance contact with new people (stress=0.15, $\mathrm{N}=160$ ) 123

Figure 5-10: Two dimensional spatial representation of 16 artificial items for chance contact with new people (stress $=0.12, \mathrm{~N}=160$ )

Figure 5-11: Two dimensional spatial representation of 96 elements classified according to

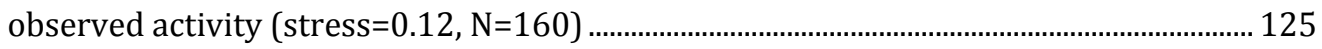

Figure 6-1: Subspaces defined in Glover Park.................................................................................... 137

Figure 6-2: Subspaces defined in Civic Square ...................................................................................... 137

Figure 6-3: Subspaces defined in Te Aro Park .................................................................................... 138

Figure 6-4: Subspaces defined in Midland Park ...................................................................................... 138

Figure 6-5: One round of photography, March 2013, Midland Park ............................................... 139

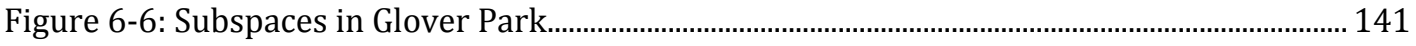

Figure 6-7: Description of subspaces, Glover Park …....................................................................... 143 
Figure 6-8: Map of occupancy during one day, Glover Park.................................................................. 145

Figure 6-9: Hourly occupancy maps, Glover Park............................................................................... 147

Figure 6-10: Comparison between people alone and in groups....................................................... 149

Figure 6-11: Use by people alone as a percentage of maximum occupancy, Glover Park ..........150

Figure 6-12: Map of occupancy by people alone and in groups all day, Glover Park................... 151

Figure 6-13: Occupancy map based on size of group, Glover Park .................................................. 153

Figure 6-14: Male and female preferences when alone ...................................................................... 155

Figure 6-15: Male and female group preferences ................................................................................ 155

Figure 6-16: Preferences for males alone and in groups .................................................................... 155

Figure 6-17: Preferences for females alone and in groups ................................................................. 155

Figure 6-18: Map of occupancy for people alone and in groups by gender excluding mixed

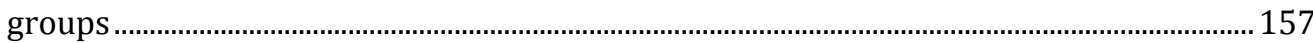

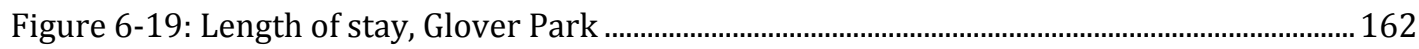

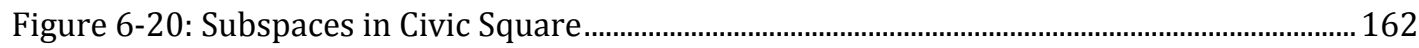

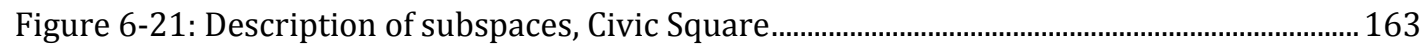

Figure 6-22: Map of occupancy during day, Civic Square..................................................................... 165

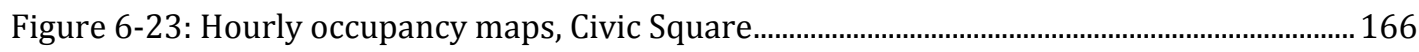

Figure 6-24: Comparison between people alone and groups, Civic Square..................................... 168

Figure 6-25: Use by people alone as percentage of total occupancy for each hour, Civic

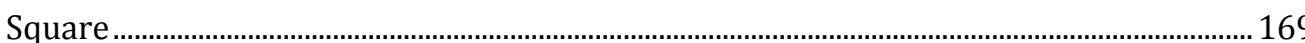

Figure 6-26: Map of occupancy by people alone and in groups, Civic Square ...............................170

Figure 6-27: Occupancy map based on size of group, Civic Square .................................................. 171

Figure 6-28: Comparison between male and female alone preferences ....................................... 173

Figure 6-29: Comparison between male and female group preferences ......................................... 173

Figure 6-30: Comparison between male alone and male group preferences................................. 173

Figure 6-31: Comparison between female alone and female group preferences.......................... 173

Figure 6-32: Map of occupancy for people alone and in groups by gender, Civic Square........... 175

Figure 6-33: Length of stay, Civic Square .......................................................................................... 179

Figure 6-34: Subspaces in Te Aro Park............................................................................................ 179

Figure 6-35: Description of subspaces, Te Aro Park............................................................................... 180

Figure 6-36: Map of occupancy during one day, Te Aro Park............................................................ 182

Figure 6-37: Hourly occupancy maps, Te Aro Park .............................................................................. 183

Figure 6-38: Comparison between people alone and groups, Te Aro Park..................................... 184

Figure 6-39: Use by people alone as percentage of maximum occupancy during day, Te Aro

park

Figure 6-40: Map of occupancy by people alone and in groups, Te Aro Park ............................... 186

Figure 6-41: Occupancy map based on size of group, Te Aro Park..................................................... 188

Figure 6-42: Comparison between male and female alone preferences ......................................... 189

Figure 6-43: Comparison between male and female group preferences ......................................... 189

Figure 6-44: Comparison between males alone and male group preferences............................... 189

Figure 6-45: Comparison between female alone and female group preferences ......................... 189

Figure 6-46: Map of occupancy for people alone and in groups by gender, Te Aro Park ........... 190 
Figure 6-47: Length of stay, Te Aro Park 192

Figure 6-48: Subspaces in Midland Park ……................................................................................ 193

Figure 6-49: Description of subspaces, Midland Park ...................................................................... 195

Figure 6-50: Map of occupancy during one day, Midland Park ...................................................... 197

Figure 6-51: Hourly occupancy maps, Midland Park …..................................................................... 199

Figure 6-52: Comparison between people alone and in groups ....................................................... 201

Figure 6-53: Percentage of maximum occupancy by people alone, Midland Park, no repeat

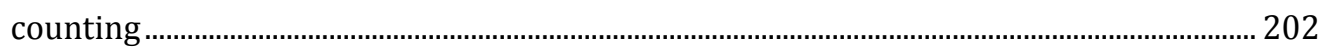

Figure 6-54: Map of occupancy by people alone and groups, Midland Park ................................ 203

Figure 6-55: Occupancy map based on size of group............................................................................ 205

Figure 6-56: Male and female preferences when alone ............................................................... 207

Figure 6-57: Male and female group preferences................................................................................ 207

Figure 6-58: Preferences for males alone and in groups..................................................................... 207

Figure 6-59: Preferences for females alone and in groups.................................................................. 207

Figure 6-60: Map of occupancy for people alone and in groups by gender .................................. 208

Figure 6-61: Length of stay, Midland Park................................................................................................. 212

Figure 7-1: Grass with appropriate shape attracts people in groups, Ghavampour, 2013 ........ 223

Figure 7-2: Trees with appropriate shade attract people for a longer time, Ghavampour, 2013.

Figure 7-3: Trees with appropriate shade attract people for longer time, Ghavampour,

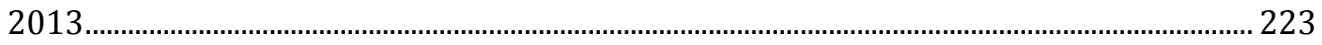

Figure 7-4: Vacant grass under Building shade, Ghavampour, 2013 .......................................... 226

Figure 7-5: Vacant edge with natural elements, Ghavampour, 2013........................................... 226

Figure 7-6: Benches with triangular shape, Ghavampour, 2013 ....................................................... 226

Figure 7-7: Recesses and sense of enclosure, Ghavampour, 2013 ................................................ 226

Appendix 4 Figure 1: Uses of space with 5 minute intervals............................................................... 267

Appendix 4 Figure 2: Uses of space with 10 minute intervals ...................................................... 268

Appendix 4 Figure 3: Uses of space with 15 minute intervals .......................................................... 268 


\section{Preface and Acknowledgements}

Seeing a crowd watching the magic fountain in the Plaza de España, Barcelona, or in Rome throwing coins into the water at the Fontana di Trevi or sitting on the steps of the Piazza di Spagna after midnight were wonderful experiences which inspired my interest in public space. In contrast with these joyful experiences were my visits to many European public spaces with beautiful designs but no users. These latter experiences were both boring and thought provoking with the question of what made these huge differences becoming shaped in my mind. Back in my own country, visits to traditional cities in Iran evoked the memory of those successful public spaces. However the activity was different, as they were completely intertwined with the life of the people. Everybody knew the old tree in the middle of that square, there was a collective memory of the water the square used to contain, and a social memory of the different ceremonies that had taken place in those gathering places. My earlier research on a number of traditional public spaces found most of them were constructed from three main elements - trees, water and a holy building. These elements were not just objects but also had roots in the belief, religion and life of the users of these public spaces. The shade of trees and presence of water in that dry climate had value for people. This idea of nature and its use in public space formed a paper for a young researcher workshop in Leipzig. Later I expanded these ideas to my research in New Zealand. Does nature have a different meaning in a different country with a different culture, and is it intertwined with the life of urban spaces? This thesis documents the journey I have been taking to find out more about nature and natural elements in urban space. However, this hard and wonderful journey would not have been possible without the help and encouragement of many people.

I want to thank my supervisor, Brenda Vale for her advice, guidance, encouragement, unconditional support, and for always embracing my new ideas, which have led me to new discoveries. You have made my journey on this attractive and complex topic both pleasant and enriching. Thanks also to Morten Gjerde for your input. I am grateful to the Faculty of Graduate Research for my Doctoral Scholarship and financial support and Victoria University of Wellington for all your academic, administrative, and technical support. Thanks to Paul Hillier for the camera and the chance to develop a new method of 
behaviour mapping and also to Eric Camplin for your technical advice. I acknowledge the International Association of People Environment Studies (IAPS) for providing me, a young researcher, with the benefit of your members' expertise. I especially appreciate the young researcher's 2010 workshop in Leipzig and Dr. Mark Del Aguila for crystallising my research proposal and constantly encouraging me to explore the many challenges ahead. This is also a place to acknowledge the Environmental Design Research Association (EDRA 2005) for running the Active Place Design Exhibition, crucial for my interest in place making. Thanks to Dr. Seyed Amir Mansouri, Manager of Nazar Research institute in Iran and leader of several group trips to Europe, who initially inspired my interest in public places.

I wish to express my appreciation to my parents for supporting me to study so far away. Their prayers sustained me. It would be impossible for me to have finished my thesis without the help and kindness of Sandy and Mark Moore, my host family, and their emotional support during my surgery. She was a wonderful mum when my biological mother could not be here during my surgery. They have become family to me. Thanks to the medical team who restored me to health. To all my friends who helped me adapt to life in NZ and helped me with my writing skills, thanks Jocelyn Willson, Caitlyn Lee, and Jonathan Peacey. Finally I thank all my friends and colleagues in the Student Research Centre who kept me on track. 


\section{Introduction}

"Our responses to places we have experienced are natural insofar as we share the basic apparatus with which we were equipped for survival in nature. These natural responses form a foundation upon which we build our complex, culturally determined feeling about places, and they fill our world with meaning, depth, and richness far beyond the necessary rudiments of pure survival"(Crowe, 1995, p. 73).

The need for meaningful (Knox, 2005; Montgomery, 1998), active, multi-functional, and convenient public places within the city has been stressed in urban studies (Carmona, 2010; J. Jacobs, 1961), but in practice small urban spaces seem to be becoming more artificial and more stylised (Cities, 2014). A Competitions to regenerate public spaces in many countries typically creates pedestrian plazas, water front developments, and cosmopolitan cultural facilities, whether or not these relate to the cultural context (Knox, 2005). Increased similarity of urban designs between cities (Figure1) has a negative impact on urban space through a loss of identity and meaning (Carmona,2010; Jacobs \& Appleyard, 1987; Rapoport, 1982; Relph, 1976; Sitte, 1986; Tuan, 1977: Jodaan, Puren, \& Roos, 2008).

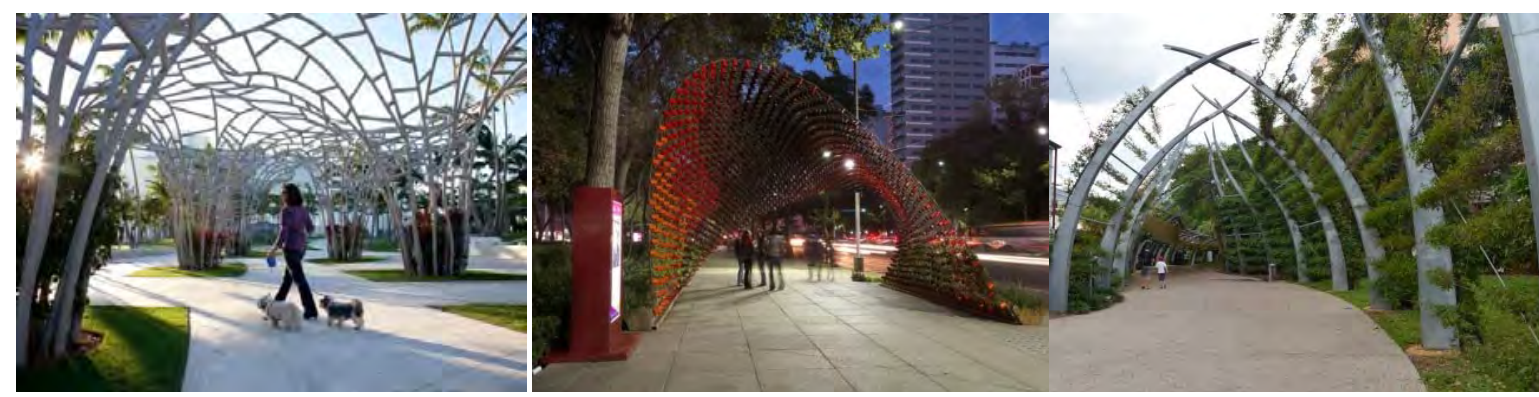

Introduction Figure 1: Use of similar ideas across the world, Miami,USA; Mexico City, Mexico; Brisbane, Australia

file://K:/literature/Marco\%20A.\%20Garcia\%20_\%20LA201\%20Situating\%20Landscape.htmP public space in: http://www.evolo.us/architecture/sinuous-pavilion-in-mexico-city-built-with1497-coffee-mugs-rojkind-arquitectos/\#more-21592

Ghavampour,2013

Place making has become short term place marketing, seeking to sell the location to attract more visitors (Carmona, 2010, pp. 30-32), often leading to a loss of capacity to sustain the social life of small urban spaces (Knox, 2005). In response, researchers and 
practitioners have used the Theory of Place to describe successful spaces and design new places where links between activity, physical setting, and meaning are stressed (Montgomery, 1998; Project for public space, 2000; Punter, 1991; Relph, 1976), although how meaning relates to and also enhances activity has not been clearly described (Lewicka, 2011).

Design guidelines based on the Theory of Place (Canter, 1976; Relph, 1976) and observations of successful public spaces have generated checklists of design quality attributes. However, the application of 'place' as a design tool has lost connection with the ecological tradition that is implicit in the relational models of place (Canter, 1976; Relph, 1976). Place is not a bounded territory of three discrete entities, but a niche described as a system of experiences including the social and cultural aspects of activities occurring in the context (Canter, 1997). Often design guidelines have not enabled the designer to understand the character of the site (Jordaan, Puren, \& Roos, 2008) or create meaningful urban spaces that understand the real needs of users (Beer, 1991). McHarg (1969) argues that characterless and meaningless public space is a consequence of ignoring nature. Any development should be affected and guided by the inherent possibilities and constraints of that particular site, whether these are historical, physical, or biological. A need for incorporating nature in the design of cities is not new (Paquot, 2005).

\subsection{Research Question}

Globalization and modernism with its functional separation has led to a decrease in the social life of public spaces and a need for the creation of place which is intertwined with the everyday life of local residents (Madanipour, 2003). The literature review (see section 1.4) reveals that natural elements within physical settings have meaning for people, connect with being human and can influence people's activities. Natural elements hold meanings which are socially constructed and are not separated from the observer. Natural elements, as part of the environment, are something that people respond to directly through the meanings they ascribe to them.

Since the 1970s, when separation between people and their environments was recognised in urban studies, the design and planning professions have turned to sociology 
and environmental psychology as a source of valuable research to discover how people use, like or behave in given physical settings (Beer, 1991; Moudon, 1992). In spite of this shift, the need to incorporate the results of these studies into the design process is still being stressed (Beer, 1991; Golicnik \& Thompson, 2010; Hubbard, 1992; Stokols, 1995) and there is a need to further investigate them in order to establish a theoretical basis for answering the research question. This then leads on to the key question of this thesis.

Are natural design elements in public space an influence on the use of that space, and in answering this question, does the Theory of Place provide a theoretical basis for this assertion that can be examined through research?

In this thesis, place is defined as a location that has meaning for people and a comparison between natural and artificial design elements is used to test the theoretical basis for social activity in small urban spaces. Three studies are undertaken:

Study One examines the theoretical structure of the relationship between physical environment (i.e., natural and artificial design elements), activity and meaning.

Study Two investigates the relationship between natural elements and social activity when natural design elements are used in combination with other design elements.

Study Three is an observation of behaviour in the context of natural design elements in small urban spaces in a city centre.

\subsection{Chapter Outlines}

\section{Chapter One}

Chapter One reviews nature in the design of public space in cities before and after industrialization. The chapter then reviews the emergence of small urban green space in cities today and provides a definition of 'natural' as it applies to design elements.

\section{Chapter Two}

Chapter Two reviews public space, public space research and the Theory of Place. Space is first described in order to establish a clear distinction between space and place with critics in urban studies arguing modern design mostly creates space and not place (Arefi, 1999; Relph, 1976; Tibbalds, 1992). In this study 'place' is the theoretical core of this 
research. The Theory of Place and design research on place within the review of the literature indicates that the theory alone does not adequately explain to designers how to apply it. Affordance Theory is proposed as a means of linking the components of place.

\section{Chapter Three}

Chapter three presents the research design and scope of the three studies undertaken in this thesis. The research methods of Facet Theory, and behaviour mapping using photography and GIS, are described. The chapter concludes with details of the selection and description of data collection sites.

\section{Chapter Four}

Study One is described in Chapter Four. The chapter begins by reviewing literature related to the three components of place, physical setting, activity, and concept or image and their link to social activity. It discusses the cognitive-affective, behavioural and physical affordance of place. The contribution of natural elements is also discussed. The hypothesis is introduced and Facet Theory is suggested as one approach for testing the hypothesis and dealing with multi-variables, and the process of designing a questionnaire based on Facet Theory is then explained. Following the pilot testing of the questionnaire, a survey at the four data collection sites resulted in 158 completed questionnaires. A comparative analysis of the whole sample is then described and discussed.

\section{Chapter Five}

Chapter Five describes a detailed investigation of the effect of natural design elements. This investigation of design elements begins with a discussion of human needs, and follows with a description of place, and the design elements related to each. It goes further with a discussion of activity and its link to the conception of place. Activity here is divided into observed activity and involving activity. The process of designing a questionnaire based on Facet Theory to investigate these issues is then explained. The process of testing the questionnaire with several participants and the adjustments made is described. The survey of the four data collection sites (resulting in 160 completed questionnaires) is set out and the comparative analysis of the whole sample is then described and discussed. 
Chapter Six

Study Three and its results are found in Chapter Six of thesis. The chapter starts by reviewing the results of the few studies that have used behaviour mapping with a focus on natural design elements. It then goes on to define a method for behaviour mapping based on still photographs and GIS. The process for the photography based on the framework of Study Two is set out. Then usage of the different subspaces in each data collection site is analysed, looking at number of users, occupancy, group size, type of activity, and length of stay. The chapter ends by identifying the effect of design elements on the usage of place looking at examples of successful and unsuccessful examples of each subspace.

\section{Chapter Seven}

Chapter Seven provides a summary of the research and results of the three studies. Strengths and limitations are acknowledged and implications for theory, practice and future research are reviewed. 


\section{Chapter 1 \\ Nature in Public Space}

"A city, as a built place, is often seen as the antithesis of nature, since buildings and pavements displace forest and fields. Yet in most cities, the artificial human landscape includes elements of living nature selectively woven into its hard fabric" (Lawrence, 1993, p. 90).

Historically, the construction and composition of small urban spaces has incorporated natural elements relevant to the local cultural context (Madanipour, 1996, p. 35). Natural elements have a long standing link with affording people meaning in public space. The meanings (conceptions) "...are created from different social and cultural contexts and nature becomes indistinguishable from the context" (Greider \& Garkovich, 1994, p. 6). Migge (1990) in Garden Culture of the twentieth century argues that the human interest in gardens, the ancestors of small urban parks (Jones \& Wills, 2005) (Figures 1-1 and 1-2), always exists when a sufficiently dense population is concentrated in one area.

"It is a fact that the city, in both positive and negative terms, gives birth to the will to garden: this is also what has caused the creation of great garden epochs since the world began. The metropolis a mother of gardens! (Pearce et al., 1990, pp. 57-58)

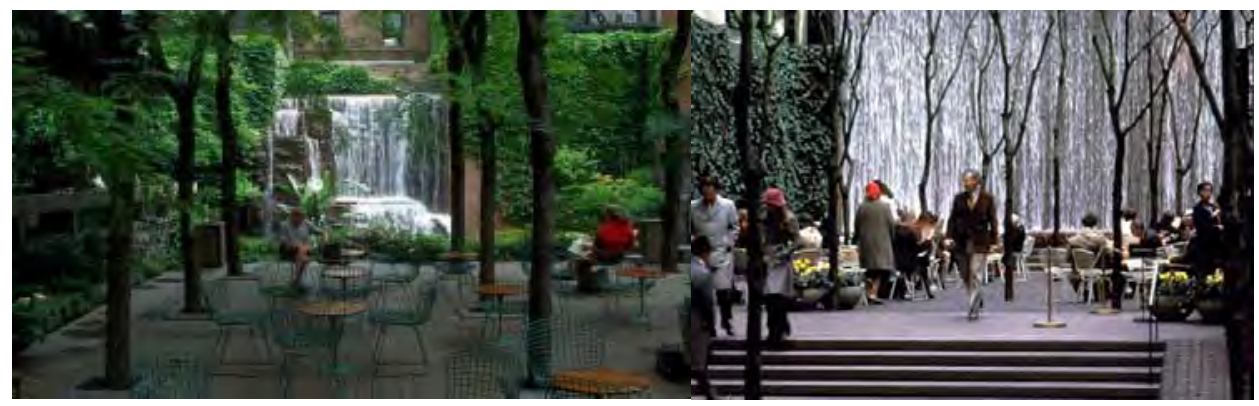

Figure 1-1: Greenacre Park, New York City Figure 1-2: Paley Park, New York City http://guestofaguest.com/newyork/nyc/new-yorks-secret-gardens http://streetswiki.wikispaces.com/Po cket+Parks

Recognising that the man-made often contains what appears to be natural, Glacken (1967, pp. 3-5) referred to three earlier hypotheses about the human relationship with the environment:

a) The earth was divinely designed for the benefit of humans, 
b) The environment affects the character of human life in different places, and

c) People have modified and changed the environment.

He claimed that nature is always mediated by the influence of humans. Using evidence of older civilizations like Egypt and Greece he proposed that human beings were the creators of order, including ordering the natural world, or at least part of it. Based on different perceptions of nature over time it was used in the city for different purposes.

\subsection{Green Space before Industrialization}

The idea of having green space in the city stretches back thousands of years (Dempsey, 2012), and today is found in modern city parks and plazas. Humana Park (2000 BC) and other hunting parks in Assyria, Nineveh (705 BC), the hanging gardens of Babylon (604 BC) (Figure 1-3), and the Persian paradise (539 BC) (Figure 1-4) are early examples of the human power to create artificial landscapes.

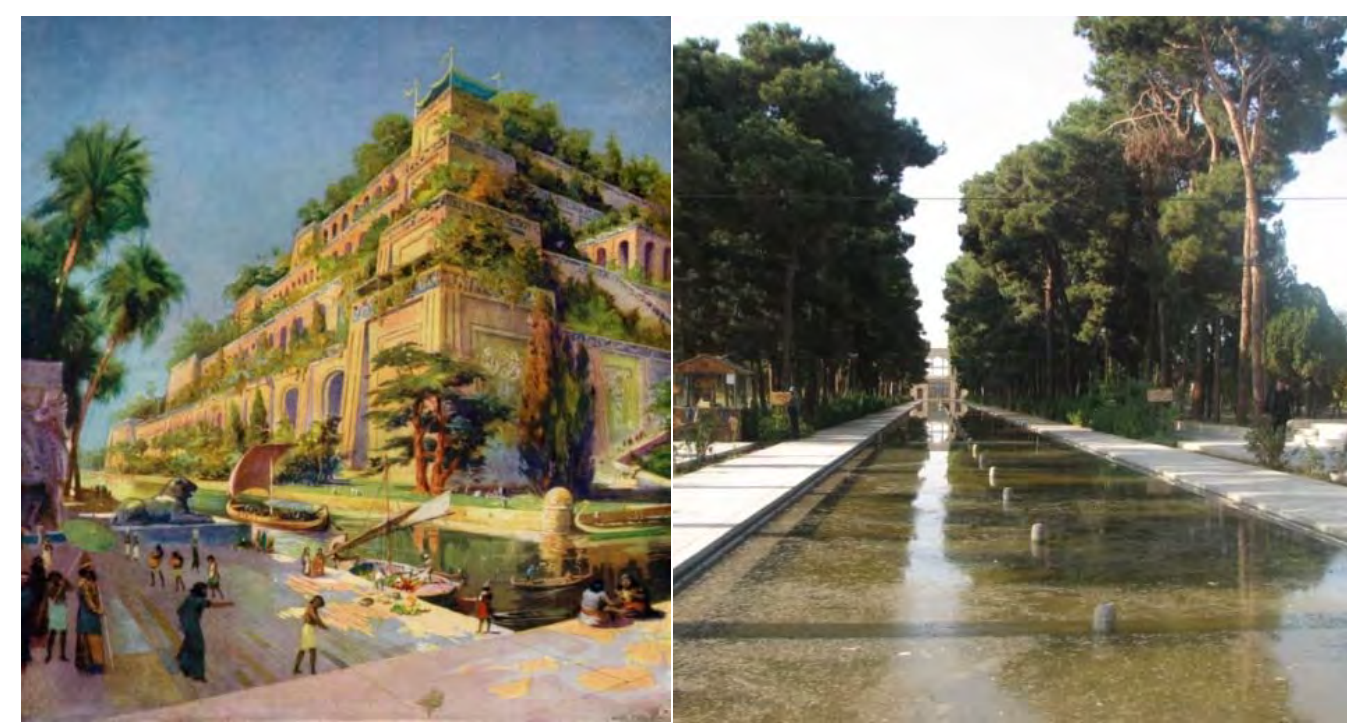

Figure 1-3: Hanging gardens of Babylon, http://images.nationalgeographic.com/w

Figure 1-4: Persian garden, Ghavampour, $\mathrm{pf} /$ media2008

content/photos/000/680/68047-

cb1370014786.jpg

Different human viewpoints have introduced nature to the city in different ways and for different purposes. The Greeks and Romans brought nature into the social life of its urban residents. The Greeks saw green in the city as a sacred place and a place for civic life. The Romans understood the value of open spaces for the health and happiness of Roman citizens. Roman parks were practical, being used for recreation and entertainment. For 
example, in Rome Porticus Pompeiana, 55 BC, (Figure 1-5) was a great open space with green areas, sheltered areas, and water features, showing a combination of aesthetics and function as a place of entertainment (Jones \& Wills, 2005, pp. 9-17).

Chinese and Japanese gardens were influenced by Taoism and Buddhism. The Chinese believe that every landscape element has power and energy, and there is no separation between spirit and matter, man and nature (McIntosh, 2005, p. 19). Islamic gardens on the other hand are symbols of paradise (Figure 1-6). The four rivers that flow out from the middle of such a garden are the key elements of an Islamic garden (Mclntosh, 2005). An enclosed garden fosters harmony and order by setting boundaries and religious gardens in Europe under the influence of Christianity and Judaism are enclosed. In the early church in the Middle Ages the space outside the church was the place where paradise could exist and a garden was a symbolic place for meditation and prayer, where each individual flower illustrated some aspect of Christian faith (Prest \& Prest, 1981).

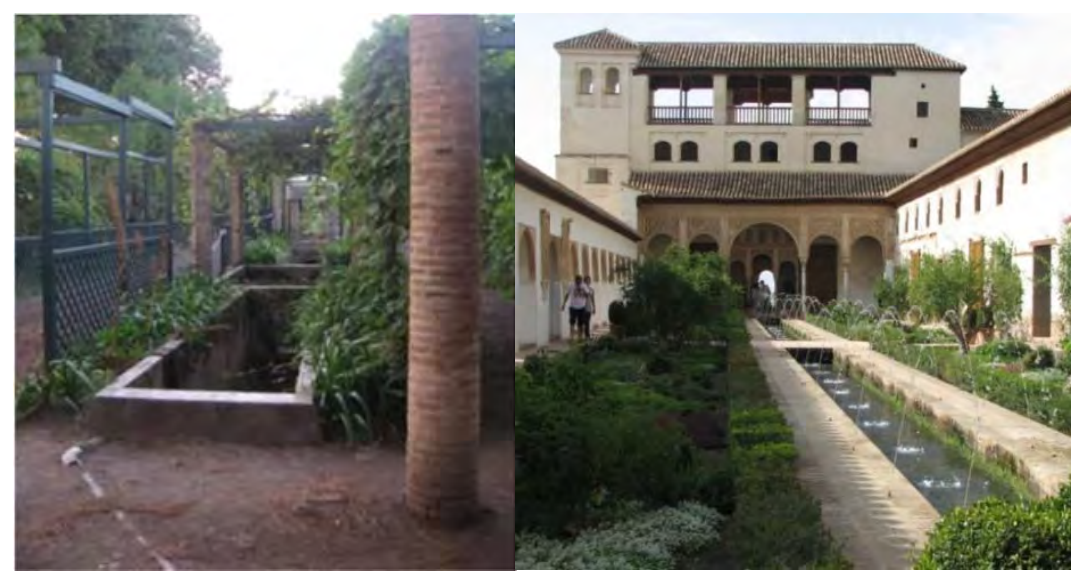

Figure 1-5: Pompeiana, Ghavampour, 2006
Figure 1-6: Islamic garden, Alhambra, Ghavampour, 2007

The Italians brought nature into their city by creating villa gardens in the $16^{\text {th }}$ century with their terraces, groves and ornamental ponds, all showing the authority of man (Figure 17). As McHarg (1969, p. 71) stated, "The garden is offered as proof of man's superiority." In the Renaissance era the French picked up the humanistic view and made a different landscape through imposing new patterns, often very simple and applied at a larger scale and to a flat landscape. Here the ornamental qualities of plants in pattern making are more important than the plants themselves. Here there are no ecological concepts (McHarg, 1969, pp. 71-72).

England in the $17^{\text {th }}$ and $18^{\text {th }}$ centuries nature was used in three different types of space in; 
the large parks of large estates, residential squares, and house gardens. The first two are more relevant to this study and will be considered in more detail. In the middle of the $17^{\text {th }}$ century residential, garden squares were created in English cities. The Italian concept of the plaza was used by English planners to create large open places in the new residential neighbourhoods of the expanding city (Lawrence, 1993). This was the culmination stage of the transmutation of the empty open plaza to the garden square, which took place from the early $18^{\text {th }}$ century onward, and was contingent on its secure enclosure (LongstaffeGowan, 2012, p. 4), meaning such a garden became semi-private rather than public space (Chadwick, 1966) (Figure 1-8).

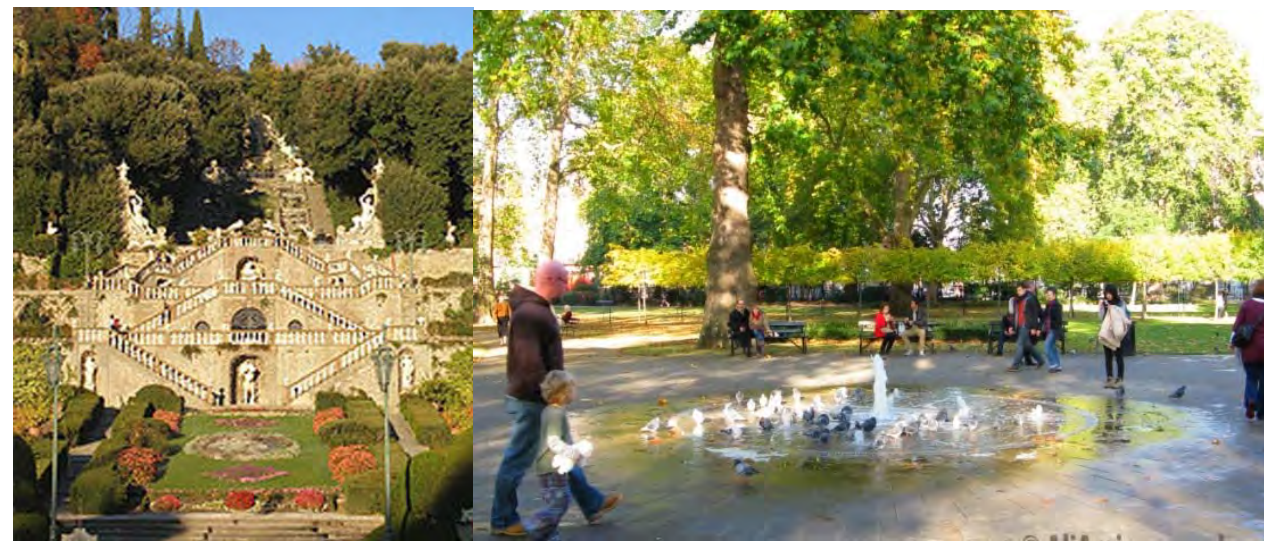

Figure 1-7: Italian garden, Figure 1-8: English Square, Ghavampour, 2006 http://aliamirmoayed.com/wpcontent/uploads/2011/10/London_Russell_Squar e_2.jpg

Lawrence (1993, p. 90) also addresses the evolving social and aesthetic functions of the London square in the urban fabric. "The residential squares in London developed in seventeenth and eighteenth centuries into a unique urban landscape form that introduced rural landscape values into the urban fabric in ways that continue to shape urban landscape ideas today." He continues by saying they not only introduced nature into the town, but their deployment and elaboration also reflected the evolving social values.

In the large parks belonging to the houses of the rich, landscapes represent the ideal garden, like the dreams of painters, and unlike the walled garden, which in England was often a functional space for growing food or herbs. English gardeners saw all nature as a garden (McHarg, 1969) and wished to create an aesthetic unity (Chadwick, 1966; Jones \& Wills, 2005). The use of native (Figure 1-9) plants in the parks landscaped by designers 
such as Repton and Brown created communities that reflected natural processes. Function and the objective quality of nature from a Romanticist viewpoint shaped green spaces in the $18^{\text {th }}$ century (McHarg, 1969). This same approach was later transferred to large $19^{\text {th }}$ century city parks which were created for ordinary people (Figure 1-10).

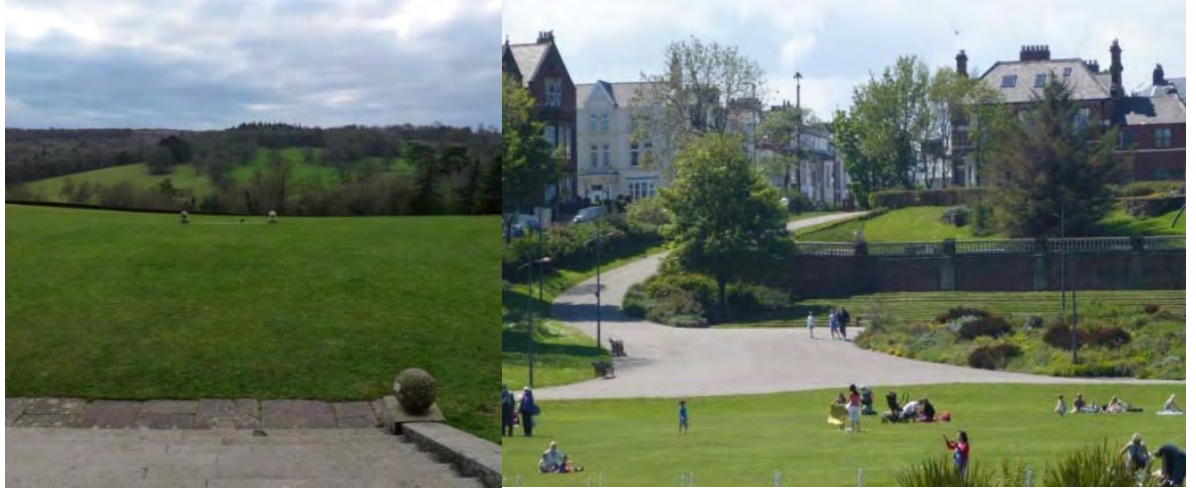

Figure 1-9: Polesdon Lacey, Park Figure 1-10: South Marine Park, South design by Bonsor, Brenda Vale, Shields, Brenda Vale, 2014 2014

\subsection{Green Space after Industrialization}

Until the $19^{\text {th }}$ century changes in the use of green spaces happened gradually. Human beings used nature in the form of gathering places, and for entertaining, hunting, and pleasure by making selective landscapes. Any modification that happened was in harmony with nature and no signs of vast modification can be seen, from the times of ancient Greece until the modern era (McHarg, 1969; Williams, 2005). However modern thinking brought two problems into the city; industrialization, and urbanization. Both potentially exclude nature from the social life of residents unless, as in the London squares, new urban forms are developed to bring some natural elements into the urban fabric. In many modern cities the use of nature has been reduced to decorative trivia (Figures 1-11 to 13).

The rapid urban expansion that happened in England after the industrial revolution meant it was difficult for the workers to be able to connect with nature by walking out of the city in their free time. This led to working class demands for parks to serve as multi-purpose recreational landscapes, and as places for sport, social clubs, and play grounds (Chadwick, 1966; Jones \& Wills, 2005), like South Marine Park at South Shields in UK. Up to this time gardens and green spaces were open to specific people but this was the turning point in 
the use of nature for democratic gathering. This force in the 19th century led to two practices: opening gardens to the public and creating new parks as a place for pleasure and entertainment (Jones \& Wills, 2005). A large number of parks were created after 1850s and their aim was to create countryside in the cities. Olmsted's Central Park in New York was designed to improve the quality of the environment for the working-class (Dempsey, 2012). The concept of social reform influenced parks in both the 19th and 20th centuries. Whereas parks in the 19th century were created for pleasure, in the 20th they tended to act as open spaces (Cranz, 1978), although Young (1995) argues that parks in the 20th century were subject to modernization and were divided into parts dedicated to special groups and uses

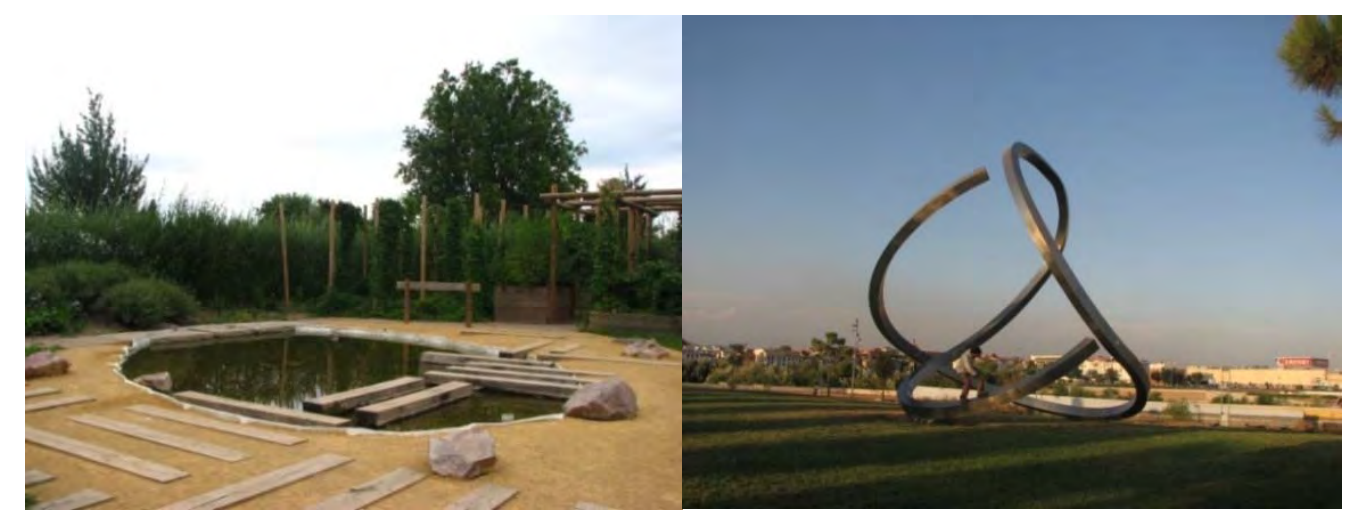

Figure 1-11: Green space in modern cities, Ghavampour, 1\&2 Strasbourg, 2008

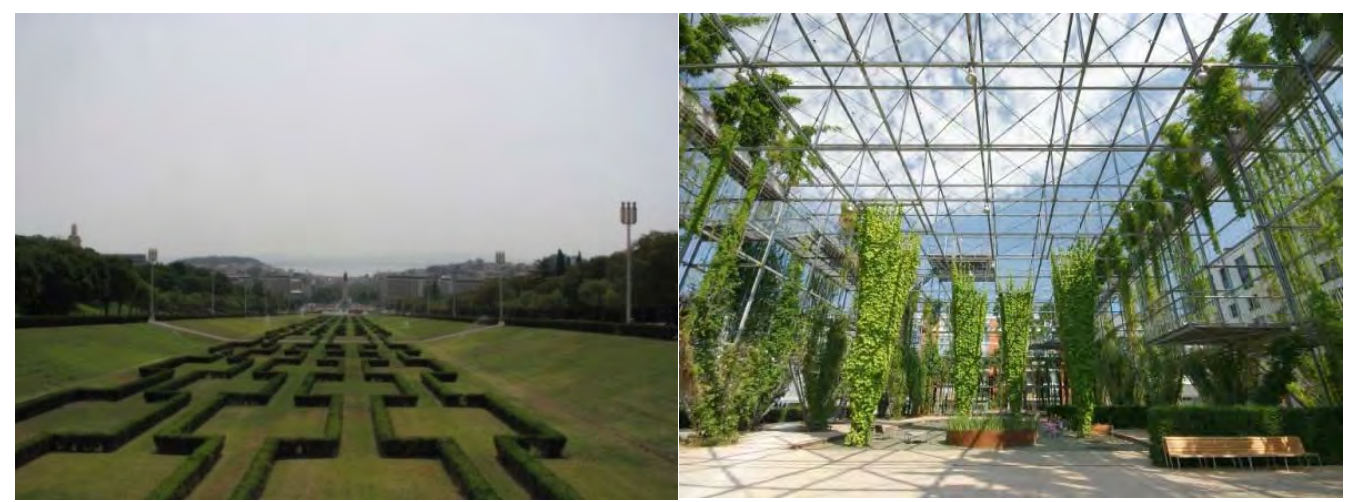

Figure 1-12: Green space in modern cities, Figure 1-13: Green space in modern cities, Ghavampour, Lisbon, 2007 Ghavampour, Zurich, 2010

However parks and green space in the $21^{\text {st }}$ century are valued for different aspects. Thompson (2002, pp. 59-72) stated the current different demands made on public green space include places for the expression of diversity, both personal and cultural, places as a social network, places for refuge and contact with nature, and places as part of an ecological network. She proposed creating a loose-fit landscape as a new and flexible pattern to answer these and different future demands. 


\subsection{Increasing interest in Small Urban Spaces}

McHarg (1969) In his book Design with Nature compared levels of exploration in the history of landscape. He reviewed the human relationship with its world in the time of hunter-gathering and aboriginal peoples and argued their awareness and knowledge of the environment, which was intertwined with their religious beliefs, let them be sustained and live in harmony with nature. In fact they saw themselves as an integral part of universal nature. Following this he defined four different exploration attitudes across the world with national associations. For him, rejecting the cosmography of the past started in the $16^{\text {th }}$ century with the Renaissance humanistic view that emerged in Italy. Unlike the primitive peoples, human beings started to see themselves in competition with nature, and not as part of a preordained natural order. A century later at the point of early colonisation gardens were anthropomorphic and simple, as in those of $18^{\text {th }}$ century France (the second attitude). The third attitude, based on McHarg's analysis, can be seen in England in the $18^{\text {th }}$ century when they created gardens and parks as part of local ecosystems using native planting. Here much more similarity can be seen with the view of primitive peoples, although these new parks and gardens were for recreation, whereas hunter gatherers and aboriginal people relied on their natural landscapes for their survival. The last is the modern era with its large scale changes to the environment. Glacken (1967) suggested that not only had the amount and rate of change vastly increased from the ancient to modern eras but also the awareness of these changes.

The large scale modification of the environment that has come with industrialisation and the increasing trend for people to live in cities (Mumford, 1969; Pickett et al., 2001; UNDoE, 2006) has separated people from nature (McKibben, 1989, p. 205; Williams, 2005, p. 79). As a result rural land has been converted to urban uses and this pattern has become a concern because of loss of landscape (Department of Economic and Social Affairs, 2009). In turn this has given rise to a need for sustainable development and, as part of this, a call for nature to be used in urban areas (Bettencourt, Lobo, Helbing, Kühnert, \& West, 2007; Van den Berg, Hartig, \& Staats, 2007). Sustainability ideas that press for compact and green cities show an increasing demand for small green spaces in urban areas (Chiesura, 2004). 
Sustainable urban development is criticized because it has tended to neglect the meaning of green space in the city and has focused on creating large green spaces or preserving untouched green space that have ecological quality but that have no role in the social life of urban residents (Budruk, Thomas, \& Tyrrell, 2009; Chiesura, 2004; Lapage, 2007; Mumford, 1969). The cost of providing infrastructure for an ever increasing and vast urban scale has suggested that compact cities might be the answer

However, even before sustainability became a mainstream idea, the fact people have tended to use nearby open places in their everyday life for social interaction, the need to be in contact with nature and the lack of land have all highlighted the important role of small green spaces in the city (Forsyth, Musacchio, \& Fitzgerald, 2005; Mumford, 1969). So far most studies have focused on large parks (Nilsson et al., 2011; Schipperijn, Bentsen, Troelsen, Toftager, \& Stigsdotter, 2013; Stigsdotter et al., 2010). Small urban space has been given little attention in urban politics and urban studies (Catt, 1995; Mumford, 1969; Nordh, Alalouch, \& Hartig, 2011; Nordh, Hartig, Hagerhall, \& Fry, 2009; Nordh \& Østby, 2013). Instead urban planning policies have attempted to preserve untouched areas and create large green open spaces and urban parks in order to solve ecological concerns (Forsyth et al., 2005) and enhance people's wellbeing (Catt, 1995; Chiesura, 2004). Although Forsyth et al. (2005) show that the small urban parks can have ecological effect, efforts are generally focused on large scale urban parks in cities. In turn, these are spaces which, because of the pressure on land in growing cities and increasing land prices, are less likely to survive within the city because they are seen as ripe for residential development (Chiesura, 2004). This means the design of small space may become more critical. These small spaces have their design roots in urban gardens (Jones \& Wills, 2005), which were essentially private. There is also a need to know more about the design of small urban spaces that will lead to their sustained use (Forsyth et al., 2005; Seymour, 1969). Studies also show that a park nearby is more likely to be used than large parks further away (S. M. Gold, 1977; Grahn \& Stigsdotter, 2003; Neuvonen, Sievänen, Tönnes, \& Koskela, 2007; Peschardt \& Stigsdotter, 2013). The results of a study (Peschardt \& Stigsdotter, 2013) in the city of Copenhagen show that small urban spaces have different roles from large parks, mostly because the number of small urban green spaces are greater than larger parks and also because these are more immediately related to work 
place or home.

This idea together with sustainable development concepts has created a demand for small green spaces in urban areas.

Today there are a few small spaces which do not also integrate green space into their design (Fajardo, 2007). However, Migge (1990, p. 75) emphasises that today's parks (gardens) should be used in a practical way, “...people do not want shrubs and tree museums in the park that belongs to them." He claims that the gardens of now should satisfy the needs of the majority of people and that people should actively use them on weekdays as well as on their days off so that they do not just become "Sunday gardens."

In the context of sustainable development which emphasises managing resources wisely as a way to meet the needs of society for a considerable period of time (Pearce et al., 1990), the importance of the design of small urban space is even more pronounced. Such design should formulate:

"...the best possible way to accommodate people and finding the optimal configuration that offers leisure areas, an oasis for contemplation or an ideal meeting spot...One of the principal functions a square has to take into account is that citizens must be given a place to "breath", "relax", stroll, and do outdoor activities which cannot be done at home, precisely for a lack of space". (Fajardo, 2007, p. 6).

The importance of design of public space is more pronounced in city centres that are mostly intensively used and where land is limited and expensive. As a result, small parks are limited areas which have to be carefully designed to meet as many of people's needs as possible in an efficient way (Forsyth et al., 2005). Small urban parks can be a park in the city centre or a small midtown park (Zion, 1969), or these can be neighbourhood parks in places where people work and live (J. Jacobs, 1969), or they can be a small park in public housing and in high rise building complexes (Robbins, 1969), or even a park street (Breines, 1969). They can be used for recreation, rest, play and community social gathering and community gardening. The midtown park that is enclosed and sheltered from noise is for adults and its purpose is rest for office workers. The idea behind this park is based on the concept of a small outdoor room, with a human scale. In addition to being 
easily accessible, parks should be important in themselves, not merely an incidental adjunct to some housing project, or treated as waste space (Seymour, 1969).

Seymour (1969) in the book Small Urban Spaces named Bowling Green as the first pocket park, created in 1733 in New York. Although the idea later had its opponents, today the needs of people working in cities have increased the desire for small and convenient open places (Seymour, 1969). This idea has specifically received more interest in low-income neighborhoods.

In 1733 New York's Common Council claimed that making the city liveable for people both now and in the future would mean a need for the proper use of small public space (Seymour 1969). There are several ideas about size of small parks (Forsyth et al., 2005; Iwashita, 1988) but all agree that it is smaller than a city block. The most famous and detailed work on downtown small spaces is that of Whyte (1980), that in turn has led to guidelines for design of public space. Markus and Francis (Marcus \& Francis, 1998) have also created guidelines for the design of small urban parks. Another study mostly related to the ecological quality of small urban parks was done by (Forsyth et al., 2005). They investigated the effects of small parks on the climate and later focused on other ecological qualities of parks. In their Designing Small Parks they comment that although small parks are so important in metropolitan areas, their design rarely reflect this. Also they mentioned that because generally people think that a park needs to be large to have ecological quality small urban parks have not received sufficient attention. They also claimed that this is because of the Olmsted tradition of creating large urban parks. The other category of research on small urban parks has mostly focused on their restorative quality (Nordh et al., 2011; Nordh et al., 2009; Nordh \& Østby, 2013). However, there is a lack of research on design of the small urban spaces which explains how design links with restorative quality (Karmanov \& Hamel, 2008; Velarde, Fry, \& Tveit, 2007). Iwashita (1988) has also reviewed the pocket park and its different forms in different climates and concluded that design of small parks should be adapted to each different climate and culture. Most of these studies provide a checklist to be used in design of small parks. The natural elements involved in these studies are usually grass, water features, trees, and flowers and (Nordh et al., 2011; Nordh et al., 2009; Nordh \& Østby, 2013). 


\subsection{Defining Nature in Urban Populations}

When talking about nature in urban contexts, it is necessary to find out what people think is natural what is man-made. To do this, psychological research has looked at the effect of nature, and its apparent antithesis, the built environment, on human behaviour. Wohlwill (1983, pp. 7-8), in a discussion of the relationship between man and nature, described three different definitions of nature that are summarised below:

a) Nature, as something including both life sciences and the physical sciences, that follows the laws of matter and energy

b) Natural, as seeing nature as an ecosystem, and by this definition natural is brought back to something that refers to the organic processes in the biological world,

c) Natural environment, that includes organic and inorganic matter that is not a product of human activity, thus it includes sand, mountains, water, plants and animals and excludes cities, towns and factories.

Wholwill (1983) indicated that between these three definitions the third definition was more relevant to the field of psychology. Although he found it difficult to create a sharp distinction between man-made and nature and was confronted with problems of exceptions, such as artificial lakes, which may have the same sense as real ones, the lack of remote areas that have not witnessed human activity, and garden and parks that are samples of nature but created by people, he ultimately concluded that this distinction is unavoidable.

"It can, in fact, be suggested that without postulating such a sharp distinction it is impossible to do justice to the differences in the ways in which people respond to the natural environment, as opposed to the built or artificial environment" (Wohlwill, 1983, p. 11).

Wohlwill used Gibson's ecological view (Gibson, 1950) in forming his definition of nature. Gibson claimed that visual properties first affect people's perception. Gibson in his first work mostly emphasised the visual array of the object and environments. However, his work on affordance had more focus on function than visual properties. In this view the difference between man-made and natural is the difference between the type of information received and the emotion that this evokes. 
Several studies (S. Kaplan, 1987; Ulrich, 1983) have emphasised the visual character of nature, like forms and texture, which lead to complexity, order and unity, and which relate to the affective effect of the environment and people's preferences within it. It has also been shown that people get greater relaxation and restoration from natural phenomena rather than man-made ones (S. Kaplan, 1995; S. Kaplan, Kaplan, \& Wendt, 1972) (See section 4.4). It was also noted that some attributes of nature, such as growth, seasonal change, and olfactory and aural phenomena, cannot be substituted by artificial equivalents (Wohlwill, 1983). Several studies that compared the natural and built environment have shown that human contact with nature has psychological (Van den Berg et al., 2007) and social (Chiesura, 2004) advantages. Further, the presence of natural elements in urban spaces influences individual and social behaviour (Appleyard, 1978; Coley, Sullivan, \& Kuo, 1997; Knecht, 2004; Taylor, Kuo, \& Sullivan, 2002; Ulrich, 1983; Ulrich et al., 1991) and has economic, physiological, perceptual (visual and sensory), and symbolic functions (Smardon, 1988).

Sauer (1925) focused on the material elements of culture and their representation in the land. In line with his ideas Busch $(1989$, p. 7) comments that "Each culture constructs its own world out of an infinite variety of nature.... [nature is] socialized ... recognized [and] made into material manifestation of social structure." Greider et al. (1994) stated cultural groups used symbols to define the natural environment and fit it into their on-going everyday life.

In this instance, each person's culture and experience affect their definition of spatial beauty and will be the key factor in their choice and use of space. By defining nature as a social construction, these geographers emphasised a close and long standing relationship between man and nature. Psychologists however, by defining the differences between the effect of the natural environment and its apparent reverse, the built environment, on people's behaviour proved that no matter what culture people come from they have an innate connection with nature.

\subsection{Conclusion}

Nature has been used in the design of cities throughout history but industrialization and urbanization has separated man and nature (McHarg, 1969; Williams, 2005) with the 
result that nature is often excluded from the social life of urban residents. A response to this issue is the concept of sustainability - being in harmony with nature - which stresses the use of nature in design of cities. Small urban spaces have been a focus of interest due to their contribution to social life. 


\section{Chapter 2 \\ Public Space \& Theory of Place}

"Public space should be conceived of as an outdoor room within a neighbourhood, somewhere to relax, and enjoy the urban experience, a venue for a range of different activities, from outdoor eating to street entertainment; from sport and play areas to a venue for civic or political functions; and most importantly of all a place for walking or sitting out. Public spaces work best when they establish a direct relationship between the space and the people who live and work around it" (Thompson, 2002, 61).

Public spaces are valued for their multidimensional benefits. Carmona $(2008$, p. 7$)$ stated these as being economic, human health related, social, and environmental. Zucker (1970, p. 1) defined their physical and psychological functions (Figure 2-1) .

"Their physical and psychological values do not depend on size or scale... they create a gathering place for the people, humanizing them by mutual contact, providing them with shelter against the haphazard traffic, and freeing them from the tension of rushing through the web of streets".

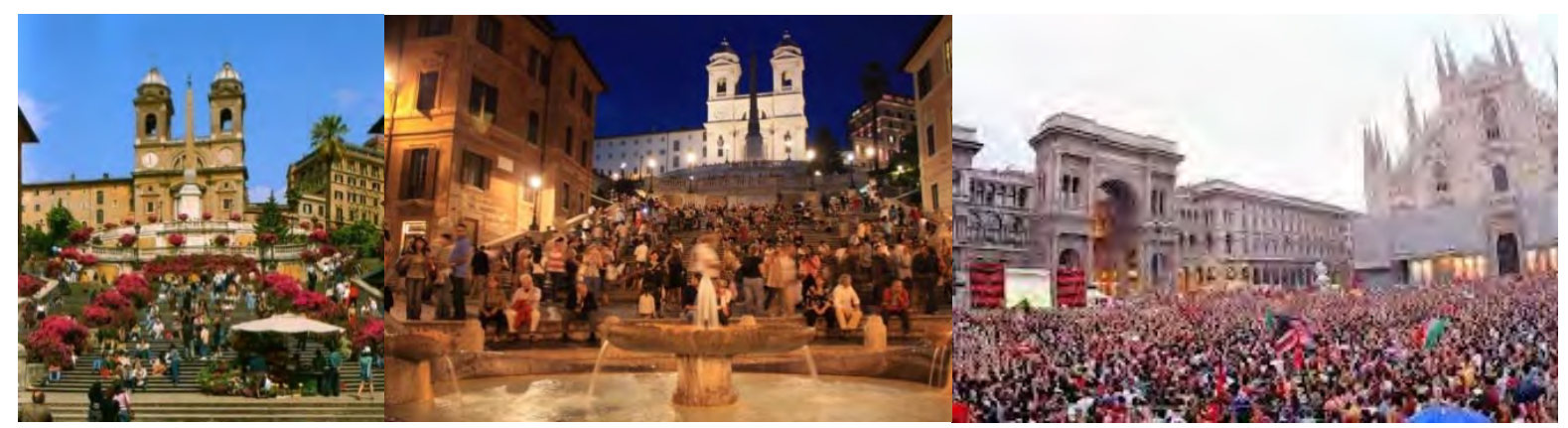

Figure 2-1: Public space and social life, Piazza Spagna, Room, Piazza del DuomoMillan

- https://encrypted-tbn3.gstatic.com/images?q=tbn:ANd9GcQR21NT1171dkcJCKBb1i69YTboD2Lq bpFs5Q3YrN5CrDSX2hk

- https://encrypted-tbn2.gstatic.com/images?q=tbn:ANd9GcTZ7Bztb7T3eRx7BpP1pzVBIj6UcfubIlvTKxPcT5IuVUQVIYh

- http://4.bp.blogspot.com/gU_mzhLo604/Ty6FtZIujbI/AAAAAAAALVM/NDy9fE5S4XI/s1600/Ro ma_Piazza_Spagna.JPG

Carr et al. (1992) valued them for their role in people's life. They enabled social exchange and represented public and private at different times and in different societies. Early urban open spaces were used for multiple activities to do with community, religion, 
commercial gathering, and less put aside for one activity, although some examples of physical and functional separation were seen in Middle Eastern cities, where temple square and market square were separated (Crouch, 1981, p. 7). In contrast Greek cities mixed the uses of public spaces, making them a place for common life (Crouch, 1981; Madanipour, 2003). Open spaces in Roman cities were built in three shapes: enclosed rooms for offices, temples and other uses were situated behind rows of columns; streets with cafés, houses, fountains and shops contributed to social life (Figures 2-2, 2-3); and recreational open spaces like baths, theatres and stadiums were for the public and some had gardens linked to them (Crouch, 1981).

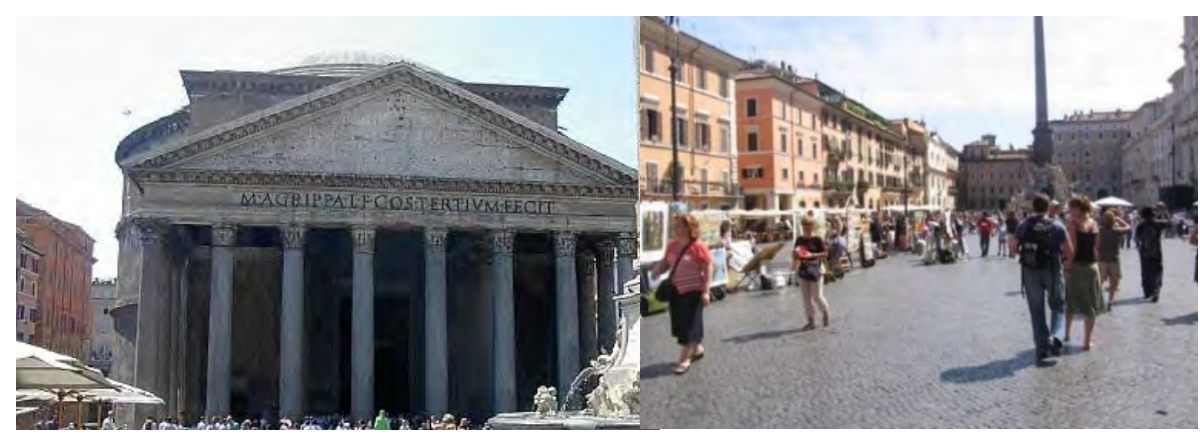

Figure 2-2: Roman plaza,

Figure 2-3: Modern life in a Roman http://www.italianplaza, Ghavampour, 2007 architecture.info/ROME/RO-012.htm

After the collapse of the Roman Empire, social life was reconstituted in the northern part of Europe. The cathedral square had both religious and commercial use (Carmona et al., 2008) and not only the exterior square but also some the part of church interior worked as a space for gathering (Crouch, 1981). In the Renaissance with the coming together of social life and art, open space again became a place for social life. The use of the plaza for community gathering in Spanish cities and the green squares in London played an important role in the social life of the residents. The latter also gave a nostalgic view of the lost country side, although they were not accessible to the public (Carmona et al., 2008; Crouch, 1981). Zucker (1970, p. 4) argues urban public spaces in Italy and France, because of the climate and the temperament of the people, "led to a form of public life, and life in public, which made street and square the natural locale for community activities and representation."

By the 1700 s public life started to be transformed because of both psychological and economic phenomena and public spaces started to lose their role in public life (Arendt, 
1958; Sennet, 1978; Sitte, 1986). By the 1700s cities were growing and behaviour in public spaces changed. Being seen and seeing strangers became a major social activity in cities (Brill, 1989).

In reaction to the detrimental changes in cities after the industrial revolution the reform movement started in the 1830s in Great Britain and spread to Europe and the United States. American cities led the reform and changed the mood in favour of open public space and the definition of public space changed. Parks and gardens were created for public use as the people needed fresh air. However, by the mid-1800s, they had lost their inclusive attraction and social function and became most occupied by poor people (Brill, 1989).

By the late $19^{\text {th }}$ century the process of modernization had speeded up and rapid urban growth continued. The functionalism of modernism changed the life of city squares (Madanipour, 2003). With the appearance of free standing buildings in the city, most public spaces were defined by the left over parts with no relationship with the surrounding buildings (Sitte, 1986), making spaces where sociability was becoming impossible (Madanipour, 2003). Increased traffic and densities made them become places in the backdrop of social life in contrast to public space in traditional cities which contributes to public life (Figure 2-4 and 2-5).

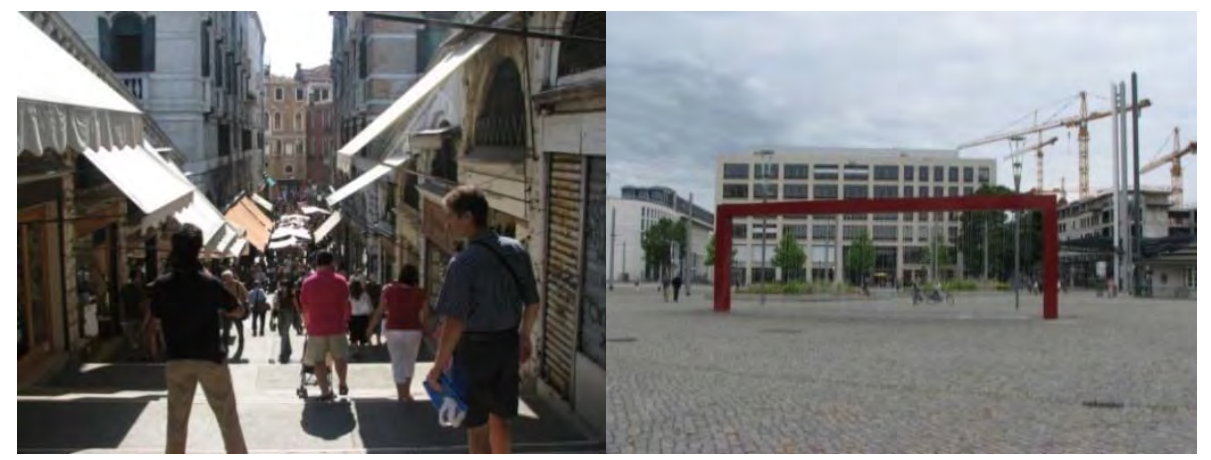

Figure 2-4: Contribution of urban space in traditional cities, Venice 2007, Ghavampour

Figure 2-5: Contribution of urban space modern cities, Leipzig 2010, Ghavampour

Modernism was criticised for creating space to move through rather than places to encourage social activity (Madanipour, 2003; Sennet, 1978). Technological innovation and privatization caused the fragmentation of the city (Madanipour, 2003). Young (1995) reviewed the process of spatial segmentation and specialization in the American park showing how the characteristics of modernisation (the tendency towards increasing 
complexity through segmentation and specialization) changed the social life of urban parks. This decline in social life has been emphasised by writers like Sitte (1889), Arrent, (1958), Sennet, (1987), and Robert et al. (1985). Brill (1989, p. 9) in contrast argues that social life has been transferred to other areas of the city, and those who argue that social life only happens in exterior public space-such as in the traditional plazas and squares of Europe-he sees as nostalgic. He argues that part of modern social life happens in a virtual world through the introduction of technology. Chidister (1998) concludes privatization has led to spaces only being used by one segment of the population or their function being limited to use by office workers at lunch time, suggesting a lack of interest in public space. Banerjee (2001) claimed that the decline of the public realm is a result of this growing trend for privatized spaces, such as shopping malls and other such settings that are privately owned and managed, and that these are now the true public space. He added to the discussion new concerns about public space, questioning the equity of its distribution and overall adequacy. He also suggested the decline of public realm is paralleled with a decline in the social sprit. Putnam $(1995,1996)$ related this decline to exposure to television, the internet and the privatization of recreational activity.

Globalization appears to be homogenising and standardising cultures and places. As a response developers have tried to create different landscapes, theme parks, shopping malls, and festival marketplaces and have renovated historic districts, to provide distinctive settings in order to attract more consumers (Knox, 2005). However these efforts still seem to result in more convergence and more similarity and standardisation of places (Carmona, 2010).

"Globalization has generated a 'fast world' - a world of restless landscapes in which the more places change the more they seem to look alike, the less they are able to retain a distinctive sense of place, and the less they are able to sustain public life"(Knox, 2005, p. 3).

Similar materials, landscape features and plants can be seen in different places with their different cultures and climates (Figures 2-5, 2-6), while before this fast world people gradually modified and adjusted place in a way that suited their needs and expressed their values (Soja, 1980). 


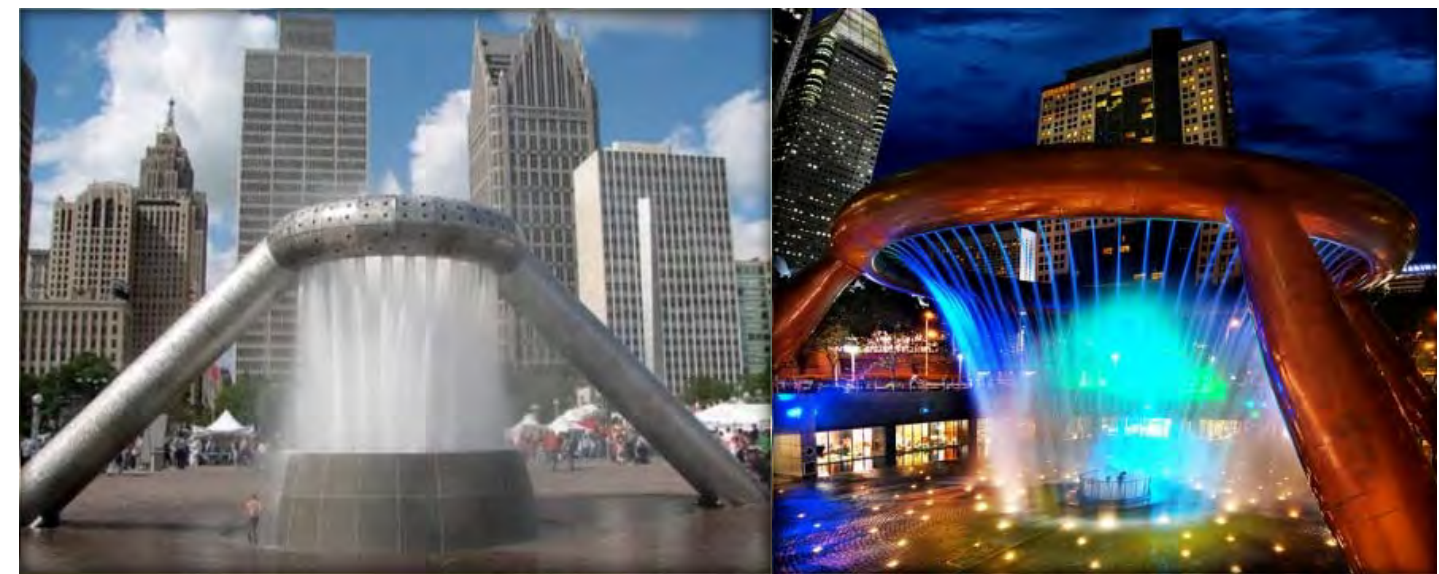

Figure 2-5: Horace Dodge Fountain, Michigan, United Stateshttp://mocochoco.com/2012/11/04/top-30-eye-pleasingfountains-around-the-globe/,

Figure 2-6:Fountain of Wealth, Suntec City, Singapore, http://mocochoco.com/2012/11/04/top-30-eyepleasing-fountains-around-the-globe/

Place in many cities in the globe is part of competing to attract tourists, businesses, media firms and customers (Knox, 2005; Madanipour, 2003). This has resulted in increasingly themed, marketed, re-imagined, designed, and packaged place (Knox, 2005). Cities often contain the same spaces, such as pedestrian plazas, waterfront developments, and areas for festival and sporting events. Although globalization may have some benefit for cities, such as creating a safer and attractive environment, the meaning of place is lost (Madanipour, 2003). However, Dovey (2010) argues that because creating different place is interesting for global marketing strategies, globalization leads to place differentiation. However, the trend for ignoring the context of public space in the process of design is also mentioned by Banerjee (2001). He criticized the trend of earlier American designers that romanticized European urban spaces, and tried to recreate them without success. Although this practice failed several times it has been continued and has created similar open spaces in city centres in the vain hope that form will create activity. This idea of design that can change behaviour has also received recent interest.

"Designers are making the new. Designers change the world; they are not so interested in what is, so I distinguish knowledge of from knowledge for. What designers need is knowledge for changing the world, not knowledge of what it is. They want to tell us how things are. Designers want to change it. Design is not interested in describing what is, but changing what is. The second thing is, as you design something you learn something, all the time" (Schaik and Johnson 2011, 141). 


\subsection{Space \& Place}

Changes in the nature of urban space could become more understandable by reviewing the relationship between 'place' and 'space'. "Place is part of space and it has meaning. However, despite this contrast between place and space, between security and freedom, the meaning of the two concepts often merge [sic]" (Madanipour, 1996, p. 23). What is the difference between space and place and who owns public space? This part of the literature review explores these questions to arrive at definitions that will be used throughout the thesis.

\subsubsection{Space}

The word 'space' is derived from 'spatium', which in classical Latin meant a distance or a stretch (Elden, 2009, p. 262). Space is a key topic in geography and has been interpreted in different ways based on differing views of the relationship between the environment and human beings over time.

Between 1950 and 1960 the essentialist view in geography resulted in an absolute understanding of space seeing it as a grid with $x, y$, and $z$ dimensions. It was thus treated as an objective and empirical space. Between 1960 and 1970 a rational view of space was developed in reaction to the absolute view. Behavioural geographers who looked to psychology stated that space is not an object and each individual has a different understanding of space, this being shaped in their mental processes (J. R. Gold, 1980; Kirk, Lösch, \& Berlin, 1963; Porteous \& Douglas, 1977). They argued that people's responses to the environment are based on how they perceive it and are not based on what it really is. Humanistic thought (Relph, 1976; Tuan, 1974a, 1977) rejected both behavioural and absolute thinking by stressing that these social phenomena cannot be studied in the same way as physical phenomena. Those that followed this viewpoint also argued that behaviourism separated object and subject. Following the relational view, between 1970 and 1980 structural thinking tried to link the behavioural and humanistic views, claiming understanding human behaviour is possible through understanding the social structure (Marx, 1977). Lefebvre (1991) tried to bridge the gap between object and subject. He saw a relationship between physical space (nature), mental space (formal abstraction about space), and social space (the space of human action). He emphasized that these three 
elements (spatial practice, representation of space, and space of representation) both make a space and are intertwining. He also pointed out a gap between mental and real space. "He criticized the modern epistemology and its predecessors in philosophical thought, which see space as a "mental thing" or a "mental place" (Madanipour, 1996, p. 16). Lefebvre (1991) introduced the concept of social spaces to bridge the gap between real and mental space and argued that social space is a social product and every society has its own space. He thus tried to fill the gap between an objective and subjective understanding of space, referring to the process by which space is produced. In this view space is a social and political product and is a product of everyday life.

\subsubsection{Place}

After the 1970s and as a reaction to modernism and its standardisation, which it was felt led to the destruction of local identity, the concept of place was receiving increased attention (Cresswell, 2009; Rapoport, 1982; Relph, 1976). Meaning was incorporated in the definition of place (Tuan, 1977) as well as the idea that space can change relatively quickly whereas the speed of change in a place would be much slower. A slower pace of change meant a slower pace of identity change and a more coherent set of relationships between social and physical space (Madanipour, 1996, pp. 24-25). "Place is a part of space that has meaning and value...This is in contrast to the openness and freedom of undifferentiated space. If space is allowing movement to occur, place provides a pause" (Madanipour, 1996, p. 23).

Geographers have typically separated space and place but were not successful in explaining how they were related (Seamon \& Sowers, 2008). However Relph (1976) argued that space is not a void or a container for holding place. In his view the unique quality of place is its power to order and to focus human intentions, experiences, and actions spatially.

"Space is amorphous and intangible and not an entity that can be directly described and analysed. Yet, however we feel or know or explain space, there is nearly always some associated sense or concept of place. In general it seems that space provides the context for places but derives its meaning from particular places" (Relph, 1976, p. 8). 
Because of this close link the process of evolving a definition of place is almost similar to that of space as reviewed. The idea of place has its roots in classical Greek philosophy. Plato (428- 348 BC) developed the terms 'Chora' and 'Topos' in the context of an account of the process of becoming. "Becoming, in Plato's term, is a process that involves three elements - that which becomes, that which is a model for becoming, and the place or setting for becoming" (Cresswell, 2009, p. 169). 'Topos' is mostly used interchangeably with 'Chora' but its meaning is more specific (Cresswell, 2009). To Aristotle, place comes first because everything that exists has to have a place, or in other words has to be located (Casey, 1997, p. 52).

In the 1970s, when rational and absolute views were undermined with the advent of existentialism, Martin Heidegger focussed on the subjective meaning of existence for the individual by stressing the specificity and uniqueness of each person's experience of the world. The idea of being in the world was developed into the notion of "dwelling". In Heidegger's view, dwelling is a representation of the way people make the world meaningful. Indeed Heidegger's theory (1971, pp. 143-162) tries to bridge the gap between subject and object. This view affected the future work of human geographers. Norberg-Schulz (1996), in his work The phenomenon of place, partly influenced by Heidegger (1971), reintroduced the concepts of character, identity, and spirit of place. He suggested space and character form the structure of place, where space is related to the three dimensional organisation of place and character refers to the general atmosphere. In the urban design field the creation of new locations which were mostly monofunctional (Jordaan et al., 2008) led to a move toward human geography in order to understand the problem of the city. Researchers (Lynch, 1960; Rapoport, 1977; Tuan, 1974b, 1977) mostly focused on how people gather information through their senses and how in turn this information is then assimilated in a cognitive process (environmental cognition) (Jordaan et al., 2008). The underlying idea is that in order to understand the environment people connect individual symbols in the form of a cognitive map (Rapoport, 1977). "Meanings are attached to both the physical and the social environment, and are represented as such in their cognitive maps" (Rapoport, 1977, p. 168). Lynch in his study (1960) shows how environmental meanings are spatially represented in the form of edges, nodes, paths, districts, and landmarks. Later Lynch (1984) in Good City Form and Bentley 
et al. (McGlynn, Smith, Alcock, Murrain, \& Bently, 1985) in Responsive Environments: a manual for designers both introduced the need for a quality of the built environment which will meet user's needs. Another theory that talks about place is the concept of behavioural setting. Barker (1968) introduced this concept in the field of ecological psychology. Behaviour setting includes a physical pattern (the milieu), a standing pattern of behaviour (a recurrent behaviour of a group, such as a football game or a piano lesson) that both work as a unit in a period of time. This approach leads on to using observation to understand people's preferences. However, these studies of place moved to consideration of people's activities in a physical context in the Theory of Place. Once place was defined with a social approach, public space, as a physical part of the public realm that is intertwined with people's everyday life, received more research attention and has been defined differently.

\subsection{Public Space}

In spite of differences between place and space, most literature related to urban design uses the term public space instead of public place, so in the context of this research public space will be assumed to be the same as public place. Public space as a physical part of the public realm has been defined variously based on ownership, access and control, whether it is interior or exterior, and function.

However, the most important distinguishing feature of a definition comes back to the idea of being public and being private. Public as an adjective is used for people as a whole, or something that is used by all people and is open to all. As a political term it means something that is provided by government, and as a noun it refers to people in general. Benn and Gaus (1983, pp. 7-10) suggest three dimensions for 'publicness' and 'privateness': access, agency and interest. Access is further made into four subdivisions: physical access, access to activities, access to information, and access to resources. Agency can be both public (government or local government) and private, and the interest dimension can also be divided into public and private. Madanipour (1996, p. 148) used these different dimensions to define public space as "space that allows all the people to have access to it and activities within it, which is controlled by a public agency, and which is provided and managed in the public interest". Others like Carr et al. (1992) and Tibbalds 
(1992) accept both dimensions of agency and define these spaces as being accessible to all while acknowledging that they might be controlled privately or publicly. Public spaces are places that are

“...open, publicly accessible places where people go for group or individual activities. While public spaces can take many forms and many assume various names such as plaza, malls, and playgrounds, they all share common ingredients...Some are under public ownership and management, whereas others are privately owned but open to the public" (Carr et al., 1992, p. 50).

The second issue is distinguishing between open and enclosed spaces. Carr et al. (1992), Madanipour (1996), and Tibbalds (1992) accept both exterior and interior spaces that are open to the public as public spaces. "It is all parts of the urban fabric to which the public have physical and visual access, thus it extends from the streets, parks and squares of a town or city into the buildings which enclose and line them" (Tibbalds, 1992, p. 1). Carmona, Magalhaes, \& Hammond (2008, pp. 4-5) suggested both broad and narrow definitions of public space. The first includes all parts of the built and natural environment, private and public, internal and external, urban and rural, to which all people have access. In their narrow definition they exclude private and internal space, as well as the open countryside. In terms of function Gehl (2003) classified spaces into five categories: main city square, recreation square, promenade, traffic square, and monumental square. Carr et al. (1992) suggest even broader categories and subcategories (Table 2-1). The five types of spaces suggested by Carr et al, (1992) initially investigated are downtown park, mini/vest pocket park, pedestrian mall, traffic restricted street, and square or plaza (See section 3.1). Social activity is identified as stationary activity occurring in a place when a person is alone or in a group (See section 3.1). 
Table 2-1: Categories of public space (Carr et al., 1992, pp. 79-85)

\begin{tabular}{|l|l|}
\hline Category & Subcategory \\
\hline Public parks & $\begin{array}{l}\text { Public/central park, downtown parks, commons, neighbourhood park, } \\
\text { mini park }\end{array}$ \\
\hline Squares and plazas & Central square, corporate plaza, memorial, markets \\
\hline Streets & $\begin{array}{l}\text { Pedestrian sidewalks, pedestrian mall, transit mall, traffic restricted } \\
\text { streets, town trail }\end{array}$ \\
\hline Playgrounds & Playground, schoolyard \\
\hline Community open spaces & Community garden/park \\
\hline Greenways and parkways & Interconnected recreational and natural areas \\
\hline Atrium/indoor marketplace & Atrium, marketplace/down-town shopping centre \\
\hline Found/neighbourhood spaces & Found space/everyday open spaces \\
\hline Waterfronts & Waterfront, harbours, beaches, riverfront, piers, lakefronts \\
\hline
\end{tabular}

Although public spaces are defined differently there is no argument over the positive role of public space in social life. "Public space is the stage upon which the drama of communal life unfolds" (Carr et al., 1992, p. 3). "It is these places that we use and in which we encounter each other: where we meet and enjoy and participate in that communal life we call "city"” (Halprin, 1981, p. 4).

The use made of a space is the most significant criterion for measuring its level of successfulness (Gehl, 1987; Gehl \& Gemzoe, 1996; Marcus \& Francis, 1998; Whyte, 1980). Studies also indicate that what attracts people most is other people (Gehl, 1987; Whyte, 1980). Whyte (1980) defined sociable plazas as places people come to in groups, as this action shows they have decided to use a particular public space. The studies of Gehl (1987) apart from showing that what attracts people most is other people suggest people spend longer in a well-designed, well used place (Gehl, 1987). A place is well-designed if it affords different types of activity (Jane Jacobs, 1961; Marcus \& Francis, 1998; Montgomery, 1998) and attracts people of different ages and cultures (Carr et al., 1992; Francis, 1987; Montgomery, 1998). "Successful public spaces are characterised by the presence of people" (Carmona 2010, p. 205). Successful public spaces are those which attract more people and have a sense of people being animated in a safe environment (Carmona, 2010, 
p. 206). Successful public spaces are those which are used by more people, for longer times, and by different age and gender groups. In response to the lack of successful public spaces in modern planning studies of place have tried to explain what will make a place.

\subsection{Theory of Place}

Emerging from the philosophical thinking on place, the Theory of Place defined meaning, physical setting and activity as three components of place (Agnew, 1987; Canter, 1977a; Dovey, 2010; Massey, 1994; Montgomery, 1998; Relph, 1976). Theoreticians argue places with meaning generate activity and they emphasise the experiences of place (Relph, 1976; Tuan, 1977). However, how this relationship can generate activity has not been described clearly.

Relph (1976), with a humanistic view, introduced his three components of identity of place: physical setting, activities and meaning. Indeed his relational view of place sees it not as a bounded territory but as a unit that is shaped by the social, cultural and economic context. For him sense of place arises from human feelings and their interaction with physical spatial elements (Carmona, 2010). "While place meanings are rooted in the physical setting and its activities, they are not a property of them but a property of human interaction and experiences of those places" (Relph, 1976, p. 47). Relph (1976, p. 48) also stressed that physical appearance, activities, and meaning are the raw material and the dialectical link between them is a structure of identity because they are interrelated attributes. Further he introduced the spirit of place or sense of place as an important dimension of identity that is more tangible than the linked components of appearance, activities and meaning.

Place is mentioned as a core concept for behavioural studies (Applyard, 1981; Canter, 1977a; Rapoport, 1982; Moudon, 1992). Those focused on place studies look at the link between the three components of place (Canter, 1997b; Montgomery, 1998), putting stress on the experience of place. They have claimed that physical setting is understood through a combination of physical characteristics, activities within it, and people's conception of the whole (Canter, 1977a; Relph, 1976).

Agnew (1987) also saw a place as falling within social disciplines and identified three 
components: locale, the setting in which social relationships are constituted; location, the geographical area encompassing the setting for social interaction; and sense of place, the local structure of feeling. He emphasised that in order to fully capture the meaning of place all these three elements should be taken into account. Thus, meaningful places emerge in a social context and through social relations, they are geographically located and at the same time related to their social, economic, and cultural surroundings, and as such they give individuals a sense of place. Cresswell (2009) saw place as a combination of materiality, meaning and practice. He pointed out that all of these components are linked.

"The material topography of place is made by people doing things according to the meaning they might wish a place to evoke. Meanings gain a measure of persistence when they are inscribed into the material landscape but are open to contestation by practices that do not conform to the expectations that come with place" (Cresswell, 2009, p. 170).

In urban design studies Punter (1991) and Montgomery (1998) took a further step and defined variables for each component of place that could be considered in the process of design. Punter (1991) suggested these were activity, physical setting, and meaning (Figure 2-7). Montgomery (1998) claimed none of the models was useful in practice and tried to define attributes for each component, coming up with activity, form, and image (Figure 33). Punter and Montgomery linked the three components by suggesting that together they create a sense of place (or place in the case of Montgomery, Figure 2-8). Punter discussed the separate link between physical setting and meaning but not that between activity and meaning. Montgomery also failed to discuss the link between meaning and activity. However, the main aim of the place theories and place-making approach is to understand place identity and reproduce it but it seems that urban planners and designers do not have the power to determine a place identity (See Introduction). 


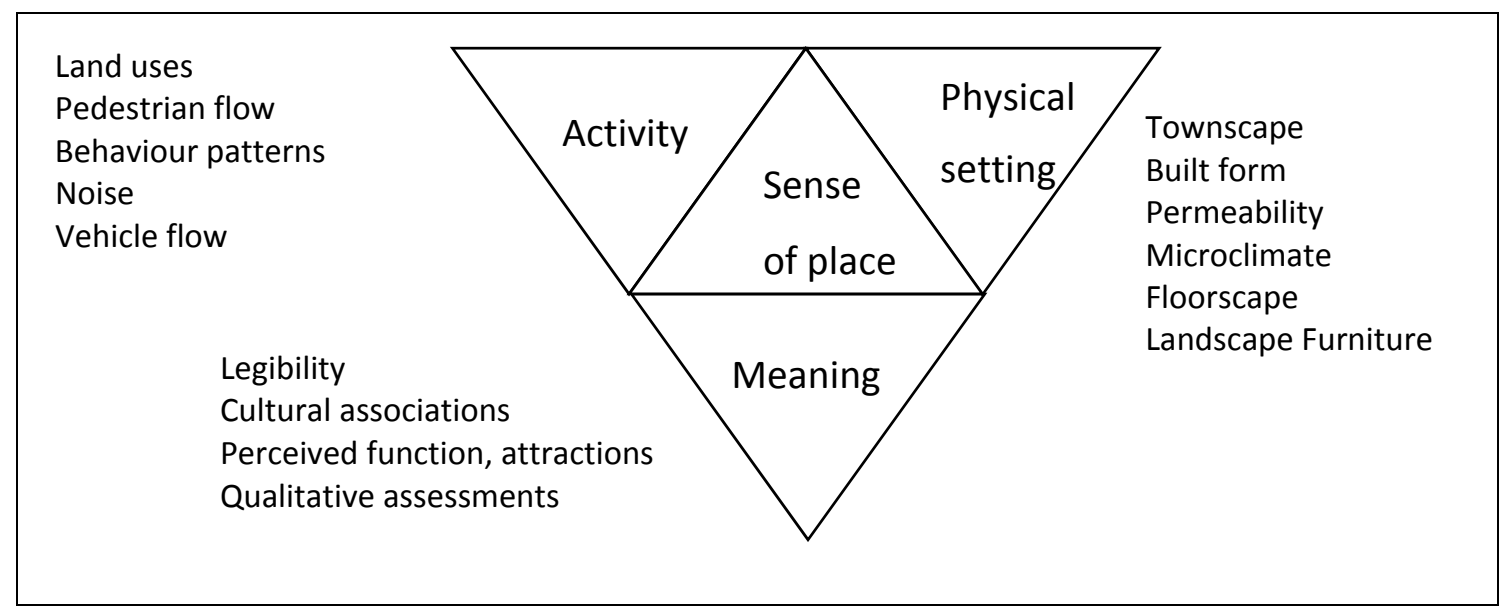

Figure 2-7: Components of sense of place (Punter, 1991, p. 27)

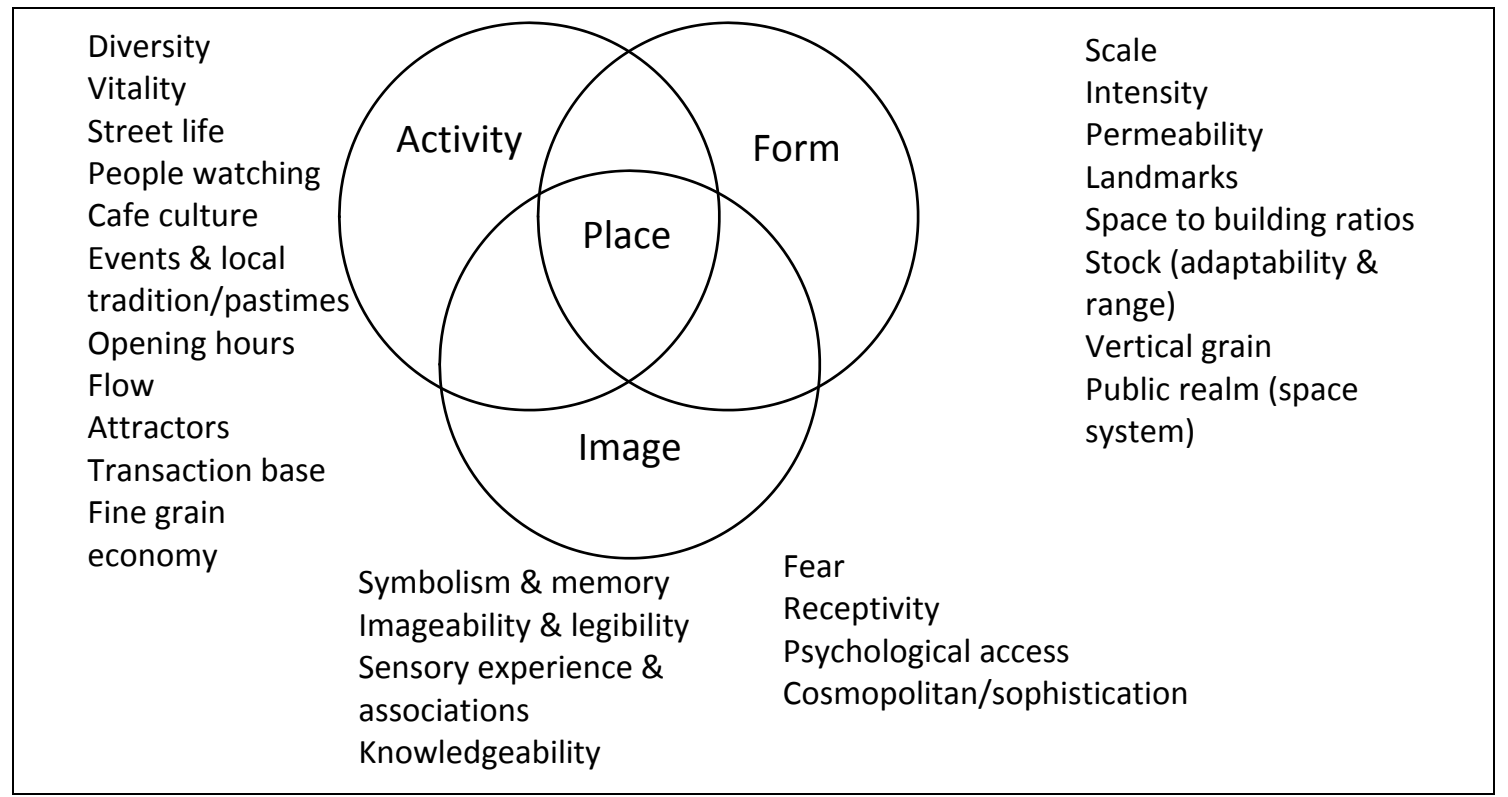

Figure 2-8: Policy direction to foster place making (Montgomery, 1998, p. 98)

Canter used the word 'place' in a different way as he used the term to describe a system of experiences including the individual, social, and cultural aspects of occurring activities (Canter, 1997b). Canter's (1977a) model of place needs its three components to be seen together (Figure 2-9). He claimed that is not possible to fully understand a place without understanding the activity anticipated in a place, its physical parameters, and people's conception of it. He suggested that using his place model makes it possible to look for physical attributes which are more likely to have connections with other components. He emphasised place should be studied in several ways covering each component to give a complete picture of place. A further implication of his model means it is possible to start identification of place from each of the components that exist in it. For example if the physical form exists the first stage is to identify the major physical attributes of the area, 
the second stage is to identify conception related to each of the grouped physical attributes, and then to identify activities occurring in these groups.

Canter (1977a) considered activities, conceptions, and physical attributes as the three main elements of place making. The model he offered (Figure 2-9) shows a place is a consequence of the relationship between action, concept, and physical attribute.

"We have not fully identified the place until we know a) what behaviour is associated with, or it is anticipated will be housed in, a given locus, b) what the physical parameters of that setting are, and c) the description, or conception, which people hold of that behaviour in that physical environment" (Canter, 1977a, pp. 58-59).

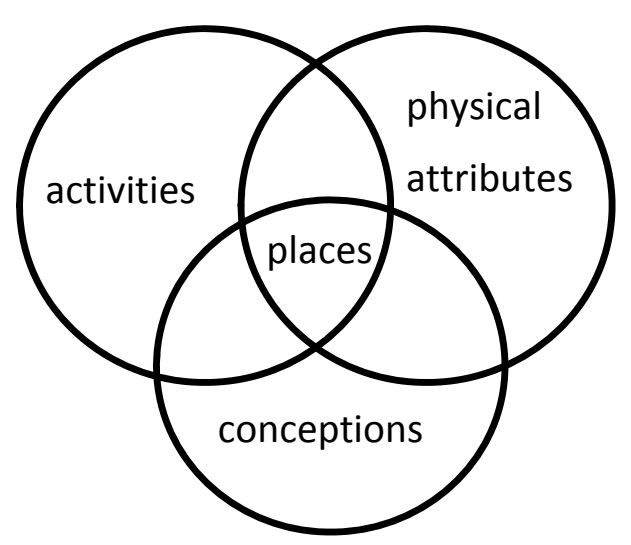

Figure 2-9: A visual metaphor of the nature of places (Canter, 1977a, p. 158)

Based on this statement he developed his model and later suggested the existence of four aspects of place. Functional differentiation derives from the activity that each place is likely to have, for example which typical action take places in different rooms of a house. The second aspect, place objective, is similar to the idea of conception in his first model and amounts to the different goals that a person has in a place. The next is scale of interaction, for example there is difference between the scale of home and city. The last, aspect of design, influences the place experiences and is really close to the idea of the physical in his first model. The four facets of this model can be summarised as:

Facet A) A functional differentiation (central, peripheral)

Facet B) Place objectives (personal, social, cultural)

Facet C) Scale of interaction (immediate, local, distant) 
Facet D) Aspects of design (function, space, form) (Canter, 1997b, pp. 125-130).

As Guftafson (2001, p. 6) argued, although Relph and Canter look at place from different disciplines, with Relph as a humanistic geographer placing emphasis on authenticity and Canter as a psychologist seeing place as a technical term, their models have important similarities.

\subsection{Design Research}

In contrast with the theoretical focus of the theory of place on the objective and subjective aspects of the environment, the applied research in design studies has observed social activity in the place. These researchers claim that social place should afford different activities and fulfil human needs through use of the physical setting.

Gehl's studies (1987) show there is a relationship between activity and physical setting. He used direct observation and found a relationship between quality of design and type of activity. He identified three types of activity (Figure 2-10). The first, necessary activities are those that are repetitive, such as going to school or to work. The participant in this type has no choice because they have to do it. They are independent of exterior conditions. The second optional activities are activities which would happen if time and place make them possible such as walking, sitting and sunbathing. They are dependent on exterior physical conditions. In good quality places people tend to stay longer when involved with these activities. Additionally a wide range of activity is observed in places that invite people to stay. The third resultant activity (social activity) is defined as an activity that depends on the presence of others in public spaces. Such activities evolve from the two other types. Social activity is the consequence of people moving and being in the same space. Activities support each other whenever necessary and when this happens optional activity is given a better opportunity to appear. These types, depending on their situation, can be different in different places, schools, and workspaces. Gehl concluded, "When the quality of outdoor areas is good, optional activities occur with increasing frequency. Furthermore, as levels of optional activity rise, the number of social activities usually increases substantially" (Gehl, 1987, p. 13). 


\begin{tabular}{|l|c|c|}
\hline & poor & good \\
\hline Necssarv activities & 0 & \\
\hline Optional activities & $\circ$ & \\
\hline Resultant activties (social activities) & 0 & \\
\hline
\end{tabular}

Figure 2-10: Graphic representation of the relationship between the quality of outdoor spaces and the rate of occurrence of outdoor activities (Gehl, 1987, p.13)

Marcus and Francis (1998, pp. 9-10) investigated the topology of successful spaces and tried to define guidelines for different types of space. They claim the most important factor for a successful space is its ability to accommodate multiple needs. Such space needs to be easily accessible, beautiful, furnished, provide a feeling of security and safety, offer relief from urban stress, be geared to the needs of the main users, encourage and engage the feelings of users, fulfil physiological needs, be accessible for children, support a philosophical program, incorporate components that users can change or manipulate, allow users options, be easily and economically maintained, and be designed with equal attention to visual art and social setting. In a similar way Carr et al. (1992, p. 1) defined the three dimensions of successful public spaces as need, right, and meaning. Successful public spaces "...are responsive to needs of users, democratic in their accessibility, and meaningful for the larger community and society" (Francis, 2003, p. 1). They also argued that spaces which have no role in people's life and are not used occur because the human perspective has been neglected. Investigating the components of successful public space Whyte (1980) and Gehl (1987) stressed the importance of the link between physical setting and activity, while Marcus and Francis and Carr et al. emphasised human need (See section 5.1) by suggesting the environment must have meaning for people. However this latter link is not defined well and it seems the link between physical setting and activity is defined more strongly than that between meaning and physical setting.

\subsection{Theoretical Failure}

Both theoretical and design studies of place or place making identify similar components for place but are focussed on detailing different aspects. Theory is interested in describing why something is happening whereas design research wants to know what is happening. 
Theoretical research focuses on the link between meaning and physical setting, and how this relates to activity, while design research is interested in the link between physical setting and activity.

In both approaches people have contact with a setting and generate activity but the processes of this interaction have not been adequately addressed (Lewicka, 2011). Designers gauge spaces based on their tangible properties, for example the objective quality of space and number of users (Gehl, 1987; Whyte, 1980), whereas theoreticians have looked deeply at the intangible properties of space like meaning and sense of place (Relph, 1976; Tuan, 1977)

Beer (1991) mentioned the lack of direct influence of theory (environmental psychology) on how cities are planned as a reason for the separation between theory and practice. He claimed that because theoretical knowledge is not satisfying the needs of designers, the latter find it hard to apply the findings of environmental psychology in process of design.

"Urban Designers and Landscape Architects have to search specifically for a means of bridging the gap between the often rather theoretical aims of the planning process and the need to produce specific environment settings for particular people at a given moment in time" (Beer, 1991, p. 362).

Canter (2008, p. 666) argued that environmental psychology ignored the process of making a place. "It ignored the fact that the built environment is indeed built. These areas of applied psychology have had so little influence because they did not engage with the processes by which places come about." He added "that it is not possible to find a theory to cover all that the environment is...I have suggested that recognizing that what we are studying is not a built environment but Place".

Beer also questioned guidelines that try to make an easy route for designers and give them a list of what they need to put in their design. He believes that these guidelines have nothing to do with understanding the real needs of people's lives or use of the place. Holden (2012) emphasised using theory in the process of creating design guidelines. He claimed that most design guidelines are not developed through community consultation nor based in accepted theory. He claimed that design guidelines should use both theory and practice. 
The separation between theory and practice is not a new issue. Schon $(1983,1991)$ explained the background to this problem.

\begin{abstract}
"As one would expect from the hierarchical model of professional knowledge (the model of technical rationality), research is institutionally separate from practice, connected to it by carefully defined relationships of exchange. Researchers are supposed to provide the basic applied science from which to derive techniques for diagnosing and solving the problem of practice. Practitioners are supposed to furnish researcher with problems for study and with test of the utility of research results. The researcher's role is distinct from, and usually considered superior to, the role of practitioner (Schon, 1983, p.26).
\end{abstract}

Schon $(1983,1991)$ and Malbert (1998) proposed collaboration between research and practice as a solution to this issue that went further than exchange of knowledge. Schon proposed a reflective research approach that would incorporate the skills of a researcherpractitioner. "....The reflective researcher may take the role of consultant to the practitioners...the practitioner may take time to become a reflective researcher, moving in and out of research and practice careers" Schon (1983, 323-324).

The reviews of urban design plans in the United States (Southworth, 1989) and the United States and Canada (Linovski \& Loukaitou-Sideris, 2013) show designers rarely use urban theories and also that they pay less attention to socio-cultural goals, like design for different groups, than in the past. Murray (n.d.) states that the semiotic and intellectual approach is widening the gap between urbanism and users of spaces, with the corollary that the gap between an intellectual approach to urban design and the everyday life of people needs to be bridged.

Palermo (2014, p. 4) claimed that place making is the solution to this problem because its considers the context. He also felt there is a need to highlight attempts to re-launch a true place-based approach as a means of solving the problem of contemporary design. "Indeed, some successful cases would seem to support this hypothesis....Perhaps it is the theory that is late (Palermo, 2014, p. 6). However, Abdelazeem (2011) states that architects and urban designers are often driven by theories and that theories of place have focused on ideologies rather than human activities. Although place making is the 
study of the relationship between people and place, the lack of a tool or methodological framework for studying the relationship between place and social practice remains a problem.

In the last ten years the participatory approach has received increasing interest from researchers, but still remains more based on scholarship than engagement (Boyer, 1990). Strydom et al. (2013) used this approach in the first phase of redevelopment of a public space and stated that actively involving the community in the process of design is a cornerstone for place-making. However, they added that the effect of this process in empowering a community to transform local spaces into public spaces should be explored.

This lack of clarity is also mentioned by Jordan et al. (2008), claiming that one difficulty of place making is that there is no clear idea of how to proceed when making a place, with the added complexity of not knowing whose meanings to use as a guide to place-making (Jordaan et al., 2008).

"...the point is that the theory of planning and that of design do not provide results which are always coherent with this vision inspired by fundamental points of good practice, to the contrary, what it prompts may even be controversial, if not deviant"(Palermo, 2014, p. 4).

The distance between theory and practice can be seen in the two different approaches to the Theory of Place. However, studies have rarely linked these two approaches. Looking for the theoretical explanation of why or how natural design elements might enhance social activity shows Theory of Place is not able to explain how meaning leads to activity. However, Affordance Theory just reveals the link between physical setting and activity. Thus a study of place, and of nature and social activity in place, suggests the need for a joint theoretical foundation that includes Theory of Place and Affordance Theory. The concept of affordance "is increasingly used among designers because it adds conceptual clarity to the understanding of the link between the environment, human behaviour, and values and needs fulfilment"(Lang, 1994, p. 165). 


\subsection{Affordance Theory}

Gibson also looked at perception of the environment and used the word affordance in his article Theory of Affordance (1977) and his later work the Ecological approach to visual perception (1979). He viewed the person-environment relationship as being something immediate that is based on practical activity rather being something analytical. "The affordances of the environment are what it offers the animal, what it provides or furnishes, either for good or ill" (Gibson, 1979, p. 127). Gibson believed that perception related to environment and that research in this area had to respect this fact (Kyttä, 2003, p. 26). He defined a new definition of stimuli information based on ecological information that he termed "Ecological reality". In the psychological approach meaning is primarily linked to the functional meaning picked up from the environment while also involving emotion and interaction. In ecological perceptual psychology, activity and perception are not separate. Perception is oriented towards finding the affordances of an environment, derived from invariants. Perception and action mix; action reveals new affordance and the perception of new affordance creates new action (Kyttä, 2003, p. 32). Based on Gibson's view affordance is a relational concept between perceiver and object. He disagrees with the object-subject division.

\footnotetext{
"An important fact of the affordances of the environment is that they are in a sense objective, real, and physical, unlike values and meanings, which are often supposed to be subjective, phenomenal and mental. But actually, an affordance is neither an objective property nor a subjective property: or it is both if you like....it is equally a fact of the environment and a fact of behaviour" (Gibson, 1979, p. 129).
}

This approach is objective because its existence does not depend on the actor's existence, values, interpretation, experience, or mental state. It is subjective because specifying affordances needs an actor as a frame of reference. Affordances are real ecological entities with the potential to be used.

For Gibson (1979) affordance exists in the environment whether people use it or not, but he goes on to say that perception is largely dependent on the perceiver. Heft (1989) differentiated between potential affordance and actualized affordance. Based on his view 
existing potential affordance does not guarantee its utilization. Greeno (1994) named individual perception and motivation as prerequisites for actualization. "Actualized affordances include perceived affordances, utilized affordances, and shaped affordances which are affected by individual intention, ability and also social and cultural factors. Individual and sociocultural factors determine when and where they are used" (Kyttä, 2003, p. 55).

Affordance includes emotion as Gibson proposes that meaning and value are not secondary but are perceived when the object is, which could be fascinating for some affordances as not everyone might have the same emotional response.

"The perceiving of an affordance is not a process of perceiving a value-free physical object to which meaning is somehow added in a way that no one has been able to agree upon; it is a process of perceiving a value-rich ecological object. Any substance, any surface, any layout has some affordance for benefit or injury to someone" (Gibson, 1979, p. 140).

Theory of Affordance is usually applied to social situations in which people are face to face. Affordances emerge only when the different characteristics of individuals, such as their physical dimensions and abilities, social needs and personal intentions, are matched with the features of the environment (Heft, 1989).

Gibson disagrees with the separation of culture and the natural environment. "It is also a mistake to separate the cultural environment from the natural environment, as if there were a world of mental products distinct from the world of material products" (Gibson, 1979, p. 130).

Gibson $(1986$, p. 129) also noted that affordances are "...equally a fact of the environment and a fact of behaviour... yet [are] neither. An affordance points both ways, to the environment and the observer".

"[They are captured by the individual] yet are conceived as features associated with the environment whether or not an individual organism apprehends them...[They describe] specific action in reciprocal interaction with external environmental features (from which emerges both context and meaning)" (Jenkins, 2008, p. 36). 
This is similar to the claims of Canter (1977) and Relph (1976) about the linkage between physical setting, concept, and activity.

\subsection{Conclusion}

Review of Theory of Place and its use by designers of public space indicates a theoretical limitation to the theory. Application guidelines for the Theory of Place can lead to placeless designs because the theory does not describe how activity, design elements and meaning are linked. Affordance Theory, which emerged from the same ecological tradition as the Theory of Place, describes the linkage between meanings, objects and behaviour (Sheehy, 2004, p. 97). "An affordance ... is defined by a pairing of an organism (and by extension, its potential or realized behaviour) with specific environment features, embedded in a situation or context" (Jenkins, 2008, p. 44). Taken together, this suggests the need to find a way to link these two ideas together in any investigation of place. In this research Affordance Theory is used to define the components of Theory of Place in more detail in a way that makes their linkage clearer. 


\title{
Chapter 3 \\ Research Design
}

\begin{abstract}
"Any pattern of the built world affords certain activities or aesthetic interpretation. These patterns enlarge or constrain our options for behaviours-physical and mental-depending on the overall configuration and properties of the layout of the built environment"(Lang, 1994, p. 164).
\end{abstract}

This research aims to bridge the gap between theory and practice by examining the Theory of Place (Canter, 1977a) through the lens of Affordance Theory (Gibson, 1950, 1979). In three separate studies (Chapters 4-6), the dynamic link between Affordance Theory and Theory of Place are investigated using data collected in four small public spaces in Wellington, New Zealand. The affordance and use of natural and artificial design elements are addressed in two structured surveys and a third study of observing behaviour. Integrating the results of the different methods of investigation over the three studies will enable the link between elements of place to be examined from different viewpoints, as suggested by Canter (1977a).

Study One tests the linkage between physical setting, social activity and meaning in a place by investigating the cognitive-affective affordance of natural elements using a survey based on the facet approach. The second study investigates more closely which physical attributes are likely to have a strong link with other components of place. Human needs, which form a central concept in this study, are used to define the physical attributes. Similar to Study One, Study Two uses a Facet Theory approach. Study Three uses behaviour mapping as a method based on affordance and behavioural setting. Here still photographs and GIS are used to collect data for behaviour mapping. All data collection was conducted in the same locations and each study pilot tested in one of the locations prior to it being used in the main data collection.

Through these three studies this research aims to:

1. Assess a theoretical framework to describe the relationship between design elements and the use of small urban public spaces for social activity. 
Identify preferred design elements for social activity in small urban public sp

2. aces.

3. Validate the theoretical framework through observation of behaviour in small urban public spaces.

\subsection{Research Scope}

This research also focuses on external spaces in the city centre that are open to the public over 24 hours. The five types of spaces suggested by Carr et al, (1992) initially investigated are downtown park, mini/vest pocket park, pedestrian mall, traffic restricted street, and square or plaza (See section 2.2). Social activity is identified as stationary activity occurring in a place when a person is alone or in a group (See section 2.2). Successful public spaces are those which are used by more people, for longer times, and by different age and gender groups (Section 2.2).

Affordance of the physical environment can be manipulated by comparing the effect of natural design elements or artificial design elements on activity and meaning for the users of small urban public spaces. The natural elements investigated here are typically used in small public spaces in cities, and comprise trees, shrubs, fountains, grass, and natural materials like wood and stone (Nordh et al., 2011; Nordh et al., 2009; Nordh \& Østby, 2013). These elements are similar to design elements that have been used historically in gardens (the ancestor of small parks) and public parks to create a sense of nature.

\subsection{Research Studies}

\subsubsection{Study One: Affordance of Design Elements}

As briefly mentioned in the introduction this study uses a facet approach to test the linkage between physical setting, activity, and meaning within the framework of Place Theory, with a particular focus on natural elements.

The aim is to catch the overall preferences for the incorporation of natural elements in the design of a small public space. Affordance Theory and the Place Theory model together defined the five facets in the mapping sentence (material, design elements, behavioural, cognitive, and affective affordance (See section 4.5). 


\subsubsection{Study Two: Design Elements in Public Space}

Study Two also uses a facet approach to evaluate the effect of design elements and observed activity on social activity in a place. Studies looking at the physical form and its relationship with psychology and behaviour are rare because of the difficulty of deciding about the physical attributes, which can be great in number (Canter, 1977a). To avoid this problem, a framework for Study Two was constructed based on different human needs. Studies have claimed people describe a place by their feeling and activity (Canter, 1977a; Carr et al., 1992). Consequently, the mapping sentence investigated the link between materials and design elements (how these contribute to a positive description of place through meeting human needs), participating activity, and non-participating activity (See section 5.4).

\subsubsection{Study Three: Behaviour in Public Space}

The third study uses behaviour mapping to observe people's behaviour at the four data collection sites. It uses the subspace framework of Study Two as a basis for mapping and analysis observations so that results can be compared across the four data collection sites. For each subspace at each site, the behaviour maps recorded length of stay, number of users, size of groups, type of activity (diversity in activity shows affordance), and gender and estimated age (diversity in users group) (Section 2.2). The comparisons between sites are made using similar subspaces across the four sites.

Data collection in these small and sometimes crowded places had to be sufficiently detailed for analysis of each space, and to enable comparisons between spaces for natural elements like sun and shade, and to be able to capture some emotional effect of natural elements on people, such as how relaxed they are in the space or the direction they are facing. Considering the research needs, still photographs taken at timed intervals were used for collecting data. The photographs were coded and information entered into GIS for representation and analysis. In addition direct observation and written description were used to capture the context of the case studies, and initial understanding of patterns of behaviours and type of activities in the subspaces (See sections 6.2, 6.6 to 6.9). 


\subsubsection{Research Methods \& Analyses: Studies One \& Two}

\subsubsection{Facet Theory}

Canter's Theory of Place integrated environmental psychology with architectural issues, as the model suggests place experience combines individual, social, and cultural aspects (Canter, 1997b). He further stressed the need for a method by which to understand the complex linkage between the three components of Theory of Place (activity, physical attributes, and concept).

"The Theory of Place draws attention to the essentially multi-variate nature of that experience. This is central because the personal, social and cultural aspects have to be studied together. Furthermore, the studies have to be carried out in such a way that it is possible to identify any existing dominant core of such experiences for any particular setting. Another demand of the theory is that comparison can be made, from one architectural discourse to another, between the patterns of relationships between components" (Canter, 1997b, p. 113).

He stated the links between components in the study of place need to be tested without any prior assumptions. To study this complex linkage Canter suggested using Facet Theory for place study. Facet Theory was introduced and developed by Guttman $(1954,1965)$ and used in psychology by Canter (1982, 1983a). However for Canter (1983b, 1997b) this facet approach just provided a structural framework and was not a theory in the normal way this term is used, but rather a systematic approach to theory testing designed for complex issues in the behavioural sciences. Facet theory draws on the principles of mathematical set theory to define variables (Brown, 2012). Dancer (1990, p.327) states:

"The suitability of facet theory as a tool for formulating definitions of behavioural constructs comes from the clarity and precision it brings to the process of identifying basic components of a set of variables and the relation these components bring to empirical data."

Canter (1997b) stresses that this approach is appropriate when dealing with multi-variate hypotheses. This theory hypothesises a relationship between a definitional system for a universe of observation and aspects of the empirical structure of those observations. In 
fact this theory is based on a definition framework for observation, empirical structures for observation, and the search for relationships between the defined system and the empirical structure (R. Guttman \& Greenbaum, 1998). The link between theoretically derived hypotheses and empirical research is established through a mapping sentence.

Basically the method allows the testing of hypotheses concerning the correspondence between a conceptualization of the phenomenon under investigation and its empirical reality, as demonstrated through analyses of data.

Each mapping sentence has two main parts, the facets and a verb which connect these (Figure 3-1). A facet is a set of attributes or variables. Each sentence must have the three facets of population facet, content facet, and range. The population facet contains the respondent, stimuli and a response and is symbolised by ' $X$ ', which together with the content facet of the set $A B C$.....Z makes up the 'Domain'. The domain of a mapping sentence is thus the set of $X A B C D$, giving all possible combinations in the form xabc...n. The $R$ facet is the range of possible responses (Levy, 2005, p. 175).

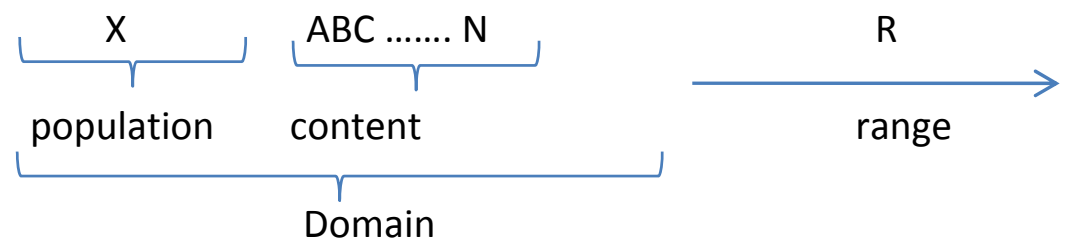

Figure 3-1: Mapping sentence (Levy, 2005, p. 175)

The mapping sentence defines the population of interest and defines the range of responses of this sample population to a number of conceptually distinct facets reflecting the content of the hypotheses, with the elements in each facet being mutually exclusive and covering all phenomena under consideration. They may include sub-categories. Elements of a facet must be exclusive and facets should be distinctive from each other conceptually. Sub-categories should not be similar in different facets as each facet might have different elements or sub-categories. So the number of derivable sentences from the structured mapping sentence could be very large depending on the number of facets and their elements. Shirom (1991) defined four stages and aspects for this theory;

(a) The design of individual facets;

(b) The construction of a mapping sentence expressing the composite of all facets and 
elements within the facets;

(c) The construction of an appropriate research instrument and;

(d) The application of an appropriate multidimensional statistical technique

Facet Theory has been used in social studies (Levy \& Guttman, 1985). Hans et al. (1985) used the facet approach in a study of child development, and it has also been used to study hospital wards (Canter \& Kenny, 1981, 1982), house satisfaction (Canter \& Rees, 1982) and obesity (Gough, 1985).

\subsubsection{Multi-dimensional Scaling}

Participant responses to the items in the facet questionnaires are to be recorded on seven category Likert response scales. Likert scales are one of a number of methods widely used to generate ordinal records of satisfaction, feelings, attitudes or preferences (Svensson, 2001). Ordinal scaling can also be achieved by choosing between alternative categories (yes/no) or indicating intensity along a line. Ordinal data is different from the nominal data labels used to record eye colour or gender and enables the researcher to evaluate the relative significance or importance of items where the absolute differences between categories is unknown (Stevens, 1946). Ordinal measurements make it easy to understand which situations people prefer when it is not possible to measure absolute preferences. Interval and ratio level measurements provide records of variables (height, weight, etc.) that have metric (parametric) properties (eg. $4 \mathrm{~kg}$ is twice as heavy as $2 \mathrm{~kg}$ ). In the present research, the less preferred and more preferred character of the Likert response scales is ordinal and the appropriate analyses are non-metric and non-parametric inferential statistics (Jamieson, 2004).

The numerical records of participant responses to each item are recorded using the integers one to seven. When combined across participants, this produces multivariate data sets with an item response for each participant. These item responses are ordinal records, and are therefore non-metric. Multi-Dimensional Scaling (MDS) is used to describe the multi-variate structure of the data. MDS is an appropriate statistical analysis with which to describe the multivariate structure data collected with a Facet Theory questionnaire, because the mapping sentences propose a set of regional hypotheses. In Study One it is used to describe affordance of design elements and, in Study Two, design 
elements in public space. MDS presents each item as a point in a multidimensional Euclidian space such that items with a similar pattern or response are located closer together than items with dissimilar response patterns (Gutman, 1968). The location of each item is determined by a measure of similarity or dissimilarity to all of the other items. The graphical representation of Euclidan distances between item response patterns enables users of MDS to inspect a visual representation of their data structure. Although the spatial representation of items may not be an exact representation (Groves, 1992), minimising the Goodness of Fit Index (s-stress) provides the optimal representation of items in the given dimensionality.

MDS has recently been included in the SPSS Alscale package which is used for the data analyses in Studies One and Two. The Alscale syntax will: "analyze/scale/multidimentional scaling (allscale)/create distance from data (measure Euclidean distance S-stress convergence $=0.001$, Minimum s-stress value $=0.005$, Maximum iteration $=30$ "

S-stress is a measure of the Goodness of Fit between the observed data and the spatial representation of that data. A stress value of 0.200 indicates a poor fit to the data, 0.100 fair, 0.05 is good, 0.025 is excellent and 0.000 is perfect (Kruskal, (1964).

Interpretation of regional preferences is further informed using mean preference ratings of items within regions (Groves \& Wilson, 1993). Means assist in the interpretation of the MDS data representation, and non-parametric Friedman's statistics are used to assess the probability of the regional structure occurring by chance. The cut-off for chance was assessed such that if the $p$ value is less than 0.05 the probability of the result occurring is $<5$ in 100. When more than three levels are compared using Friedman's statistics, Wilcoxon post hoc tests are used to compare each pair of levels.

\subsection{Research Methods \& Analyses: Study Three}

\subsubsection{Behaviour Mapping}

Canter (1977a) argued observation is a valuable method of place study, and in referring to Michelson (1975) suggested three procedural categories of identification and description:

1) Sketching (asking people to draw their own representation of the city) 
2) Descriptions (asking people to give an account of the place)

3) Behaviour (behaviour mapping).

Behavioural maps are used in place studies to investigate physical settings and activity occurring therein using context defined codes to record human activity in a physical space (Bechtel \& Zeisel, 1987, p. 23). The method was developed by Ittelson et al. (1970) based on behaviour setting research and shaped by the affordance approach (Cosco, Moore, \& Islam, 2010). Behaviour mapping consists of preparing a scale map, coding the type of activity, determining the time for observation, and providing a system for recording, coding, and analysing the collected data (Ittelson et al., 1970). Behaviour mapping has been found to be a valuable method for gaining insight into the use of space and how designs work (Bechtel \& Zeisel, 1987). It is mostly used at the micro scale to map indoor and outdoor space (Bechtel \& Zeisel, 1987) to gain accurate information in minimum time (Marcus \& Francis, 1998).

Depending on the type of research, different observation techniques have been proposed and used. These include verbal description, a pre-coded checklist, still photographs, floor plan table (a table related to elements on a particular floor plan), drawn behaviour maps, marking up a printed map, and film or video tapes, with the chosen method dependent on the scale and nature of the research problem (Zeisel, 1984).

\subsubsection{Behaviour mapping matrix and drawn behaviour map}

Pencil and paper recordings were used in early research for scoring a behaviour mapping matrix or marking on a printed map. The behaviour mapping matrix used by Ittelson (1970) has tables consisting of rows showing location and columns representing type of activity. This method of coding was mostly useful for indoor space or when the case is relatively simple. Another way is to make use of a drawn map. In this method location of the activity occurring is shown by marking on a printed paper map using symbols for different attributes as previously defined by the researcher. These might include type of activity, gender, and duration of stay. With printed maps, data are recorded on the map in such a way that the observer can connect an activity with a space at a glance. Sometimes the space is large or too busy and the map is divided into subspaces with several observers needed to cover one place at the same time. Golicnik and Marusic 
(2012) concluded that using a behaviour mapping matrix is appropriate for activities when their main character is movement, like walking, while marking up printed maps is more useful for static activities, like sitting and eating. However, with both methods there are limitations as shown below:

4. Accuracy of transferring location of observed activity to printed map.

5. Missing data, as the observer might not be able to enter all data at a particular time, like a busy lunch time.

6. Detailed data is not provided because observers focus on the categories of the matrix/mapping framework.

7. Unique or new behaviours can be missed.

\subsubsection{Photography and Film}

Miles et el. (1998) developed use of film and time-lapse photography for behaviour mapping. Film enables the researcher to understand quickly if a behaviour does or does not fit in the environment (Marcus \& Francis, 1998, p. 346). Observable aspects of behaviour can be captured without any loss, the process is quick and a skilled observer is not needed. Because filming can recreate events and be run several times, researchers do not need to worry about their comprehensive understanding of what is happening at the time of photography. In addition, filming might provide new conceptual opportunities (Evans, Smith, \& Pezdek, 1982), is accurate (Bechtel \& Zeisel, 1987), and gives much more detail of complex or brief events, which in live observation need several skilled teams to cover all in the same detail. It is also less expensive and study can be done in more depth, and during analysis filming and photography give more opportunities to view the space from several aspects without missing data. Film makes it easier to understand similarities and where replicated events or behaviour are happening in different places, and is an effective means of communication (Francis, 1989). Photographs can be viewed at different speeds, or used for counting different users or certain types of activity. Photographs are appropriate for observing general behaviour but not facial expression (Bechtel \& Zeisel, 1987, p. 30). Manual analysis of the pictures is time consuming, for example Whyte (1980) needed 100 man-hours in front of the film to evaluate six hours of videos. Yan and Forsyth (2005) developed a quicker system. They used a head detector for detecting people in a specific place, like around a fountain or passing through, and 
single frames of the video and associated data for recording length of stay. However they did not collect type of activity or other attributes. Again filming and photography have limitations:

8. Photography and filming are never used alone, and are mostly used for informing the results of surveys.

9. The process of entering and analysing them might take a lot of time.

10. Without a defined framework there is a risk of gathering unmanageable amounts of information.

11. The photographer may attract people's attention and influence their behaviour.

12. Poor quality photos may lead to missing some information.

\subsubsection{Digital Records}

Digital techniques like GPS tracking have recently been used for data gathering and representation. A GPS device can be used for tracing pedestrians or cyclists, and this makes it possible to collect a large and accurate data base (More, 1985; Nielsen, Hovgesen, Lassen, \& Godtved, 2005). This technique enables the researcher to enter more attributes related to behaviour and setting. Golicnik (2011) and van Andel (1985) used paper-based methods and GIS. Rostami (2013) and Joardar (1977) mixed photographs and paper based maps.

\subsubsection{GIS Analysis of Behavioural Observations}

Geographic information system (GIS) is a computer system designed to capture, store, manipulate, analyse, manage, and present all types of geographical data. Use of GIS for the digital recording and representation of data in behavioural studies is increasing (Golicnik \& Marusic, 2012). A GIS system can include multiple sources of data and be updated with more information as it becomes available. It is an effective tool for representation and translation of recorded evidence into empirical knowledge. Use of GIS enables the researcher to have insights into the different dimensions of the usage stage. "GIS behavioural maps can show the results which have arisen from deeper investigation, e.g. how often a certain activity has happened, how intensively it has occurred per certain temporal unit, how the patterns of each certain activity were differentiated with regard to the presence of others, and so on" (Golicnik \& Marusic, 2012). 
However, there are limitations to where and how GIS input data can be collected:

13. Collecting GIS input data using GPS tracking might influence behaviour because people are aware they are being traced.

14. Consistency of data collection requires trained teams when multiple observers are involved.

15. Digitising the data can introduce errors during transferral of data to digital versions.

In this research data collected by photography was transferred to GIS with each person represented by one dot on the base map in the Arc map 10.1 (Figure 3-2).

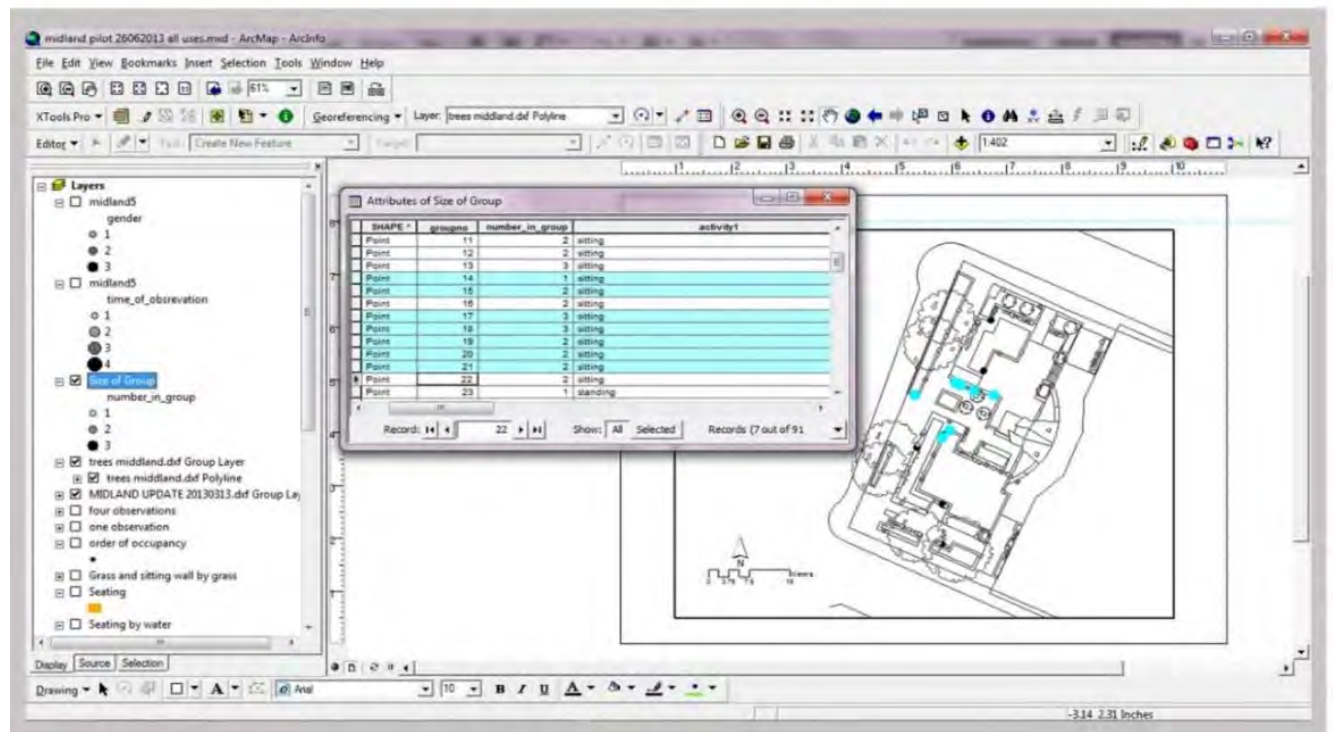

Figure 3-2: Representation of photographic data in GIS

Attributes attached to each dot include whether a person was alone or in a group, size of group, gender, age, activity, first time a group was observed, and last time a group was observed. This enabled maps for hourly use to be generated, for different ages, gender, and also number of users for each subspace.

The comparison of GIS behavioural maps are divided into two parts:

- $\quad$ analyses of behaviour at each site and comparisons between its subspaces; and

- comparision of behaviour in similar subspaces in similar categories across the four data collection sites.

These two steps also contain two kinds of analysis: quantitative and qualitative. The former compares the number of users in terms of age, gender, time, and number of 
activities that occurred in the place, and lengh of stay within subspaces. The latter focuses on quality of design factors that may not be represented by numbers, like sun and building shade, using occupancy maps. It is noted that some subspaces include natural elements like trees that will provide shade, such as the entrance in Midland Park. Thus the effect of trees will also appear in the quantitative analysis.

\subsection{Site Selection}

According to the literature different factors affect the use of space and these consist of macro and micro scale design elements (Carmona, 2010; Carr et al., 1992; Gehl, 1987; Marcus \& Francis, 1998; Whyte, 1980). Accessibility, land use, permeability, and structured social events as important macro factors were used to select the data collection sites. Spaces which have different degrees of these factors were chosen, aiming to be able to generalize the results of this study. All the spaces in this study are in the centre of Wellington. Wellington City sits at the southern end of the North Island of New Zealand and is adjacent to Cook Strait, the water body separating the North and South Islands. Miskell and Straatviet (2011) explain that the identity of Wellington and how it is perceived, is strongly influenced by politics (it is the Capital City), climate (it is known as the Windy City), topography (it is also a Harbour City) and culture (it has been called the Creative Capital). They go on to explain the city has a population of 195,000 within a region of 478,000 people. Daily there is a worker influx of 73,000 people to the city by train, bus, harbour ferry and highway. The urban structure of the city is a compilation of two generally different urban fabrics. The city centre with its high rise buildings and commercial characteristics is a centre of activity. The main areas that encompass the social life of the city are located in this part (Te Aro and the City Centre-the area bounded in black in Figure 3-3), and these are where the main pedestrian paths and attractive malls are situated. Beyond this area the character of Wellington city is more suburban, and outside the scope of this research. The first step in this research was to map all public spaces in the defined area, for convenience referred to as the city centre in the remainder of this thesis (Figure 3-3). 


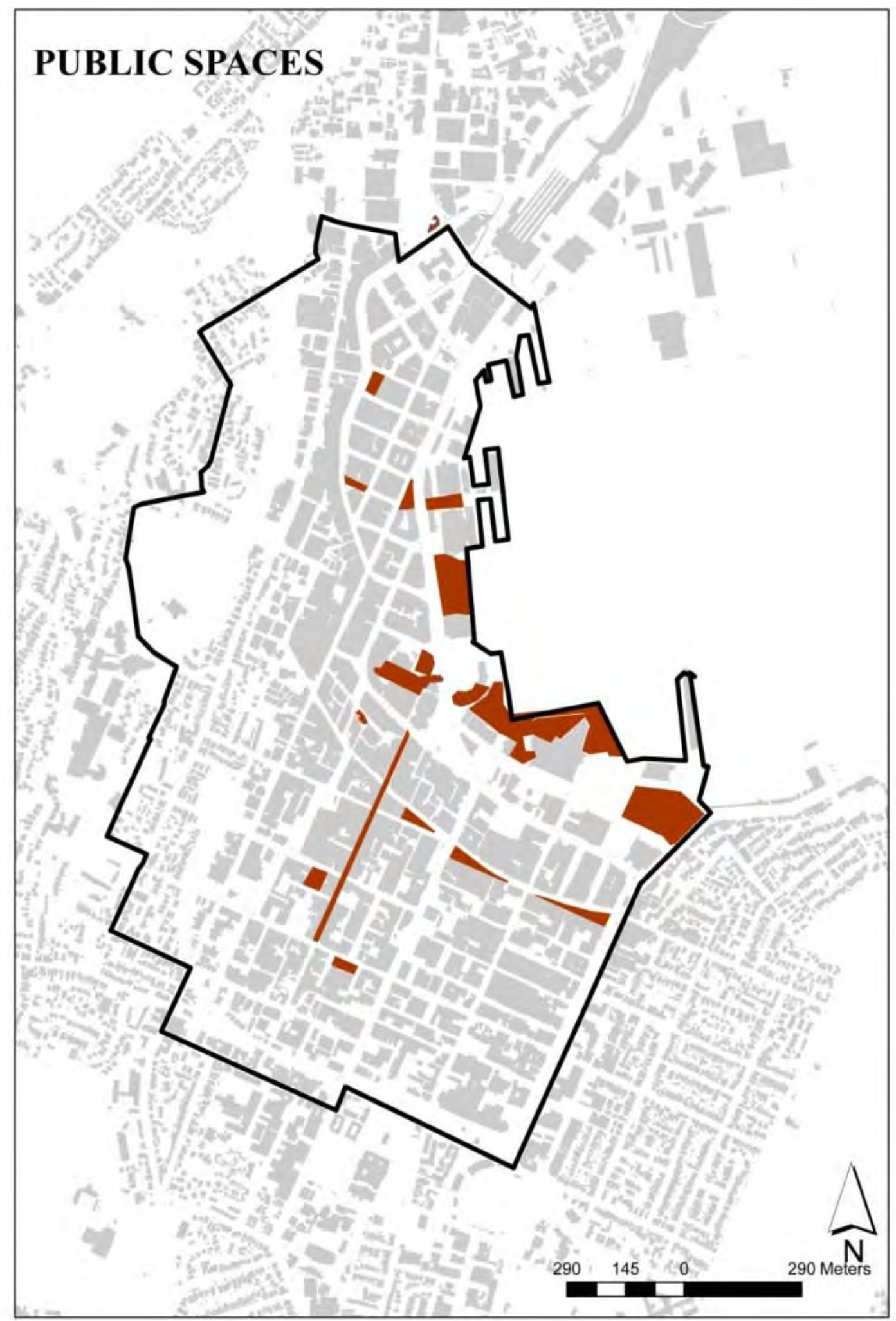

Figure 3-3: All designed public space within the City Centre/Te Aro of Wellington

Then all spaces in the city centre were categorized into the five groups of Table 8 in an effort to cover all types of public space in the mapped area (Figure 3-4). 


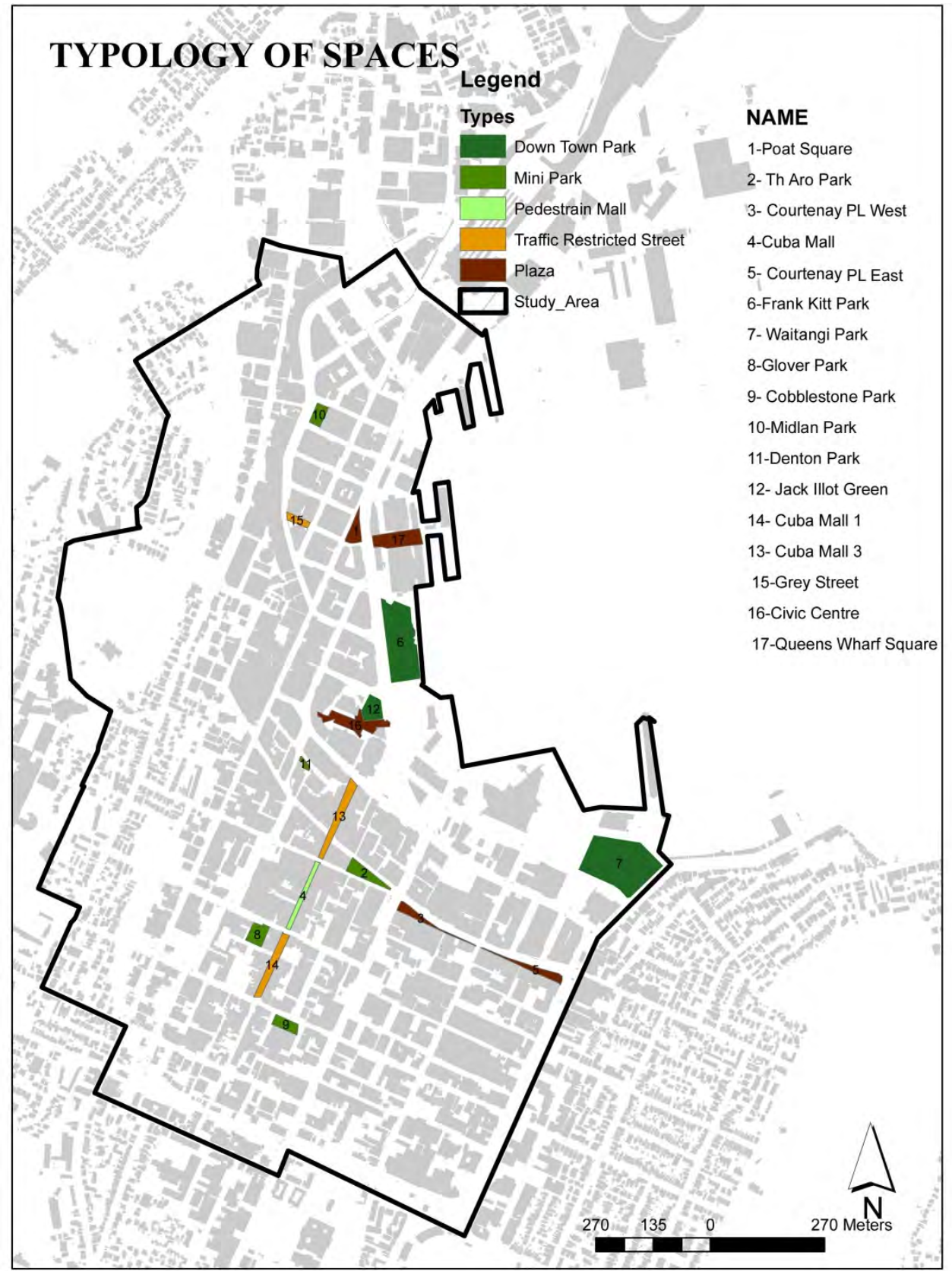

Here traffic restricted means one way and $50 \mathrm{kph}$ or less

Figure 3-4: Categorized spaces within the study area

A second categorization was carried out based on factors of accessibility (Figure 3-5), active edge (Figure 3-6), visual permeability (Figure 3-7) and occurrence of structured social events (Figure 3-8). The scoring system used for these categorizations is detailed in Appendix 1. The first Movement Infrastructure Analysis Report (2011) completed for Wellington City Centre was used to score pedestrian accessibility. Spaces were divided into four groups based on active land use around - Café, shop, place to eat. For each place 
the level of visual access from pedestrian routes was the scored for permeability. Physical context analysis for central Wellington (2011) and annual events in Wellington available from the City Council website (http://wellington.govt.nz/events/annual-events) were used to rank each place for structured social activity. The final decision on scoring was made during a meeting with the two supervisors (Brenda Vale and Morten Gjerde) as experts.

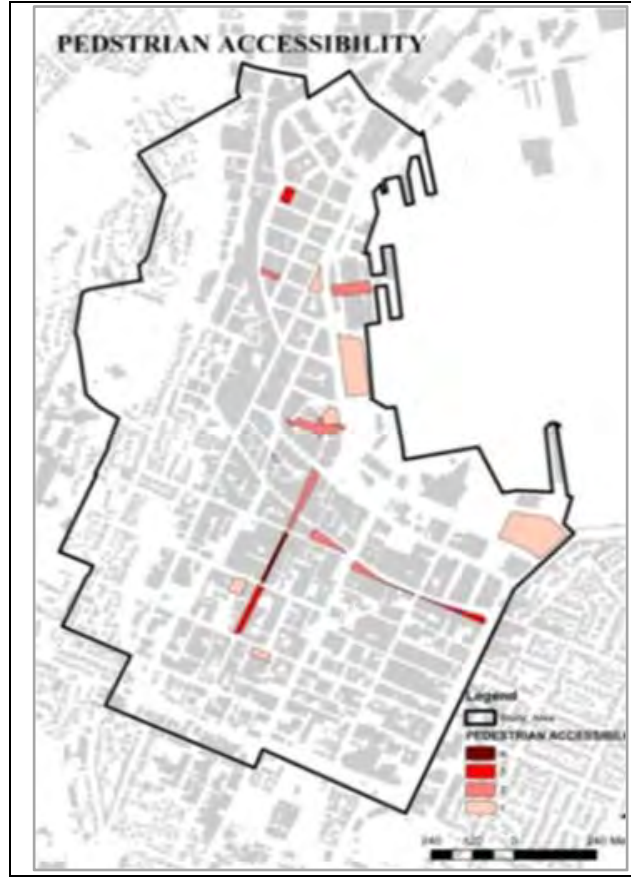

Figure 3-5: Scored space base on pedestrian accessibility

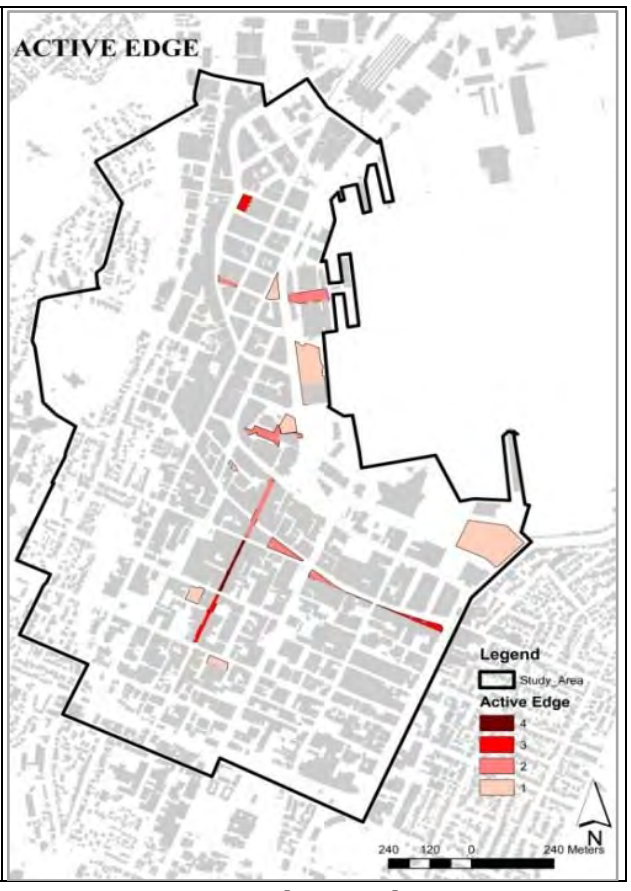

Figure 3-6: Scored space base on active edge

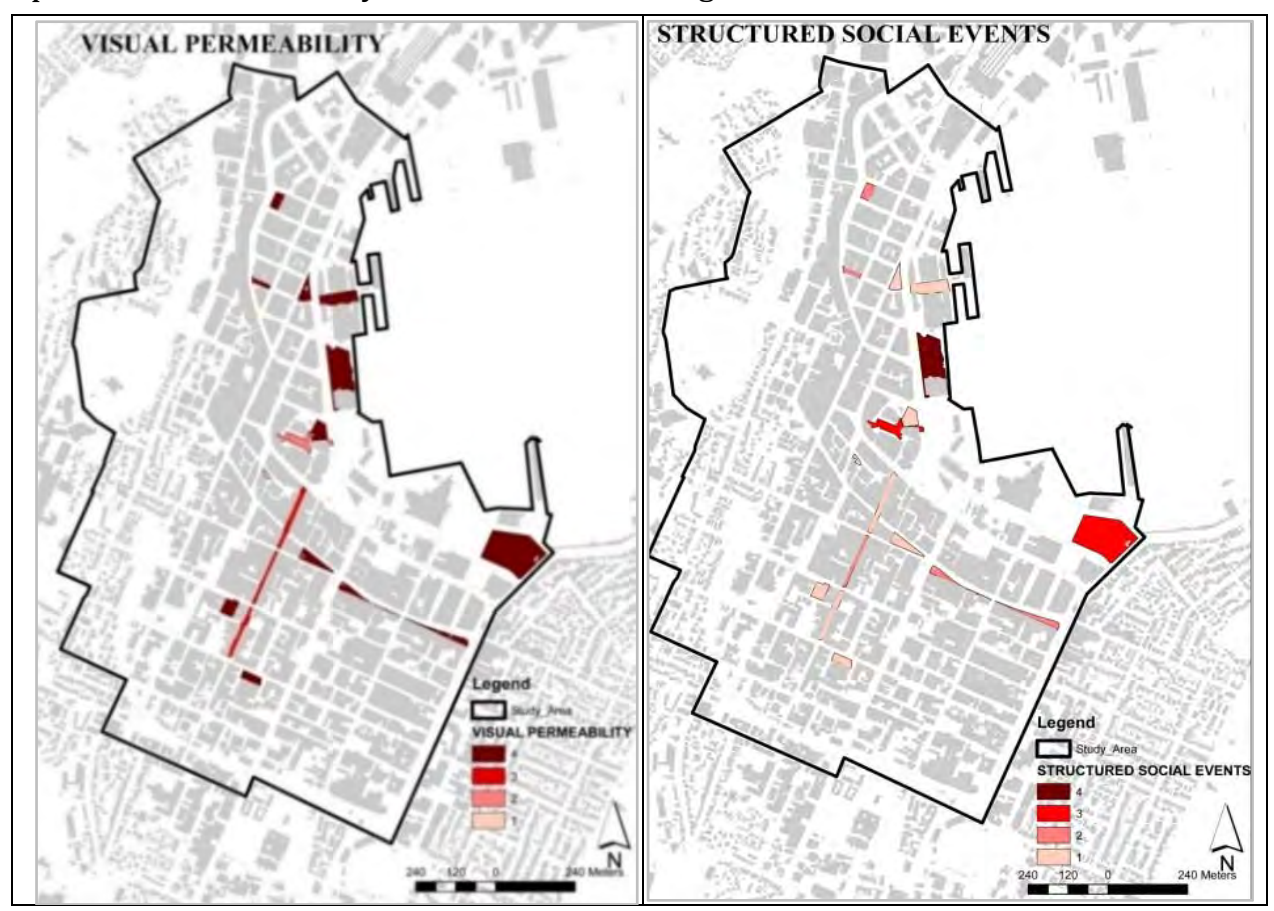

Figure 3-7: Scored space base on visual permeability

Figure 3-8: Scored space base on structured social activities 
Table 3-1: Scoring of data collection sites

\begin{tabular}{|c|c|c|c|c|c|}
\hline & $\begin{array}{l}\text { Pedestrian } \\
\text { accessibility }\end{array}$ & $\begin{array}{l}\text { Active } \\
\text { edge }\end{array}$ & $\begin{array}{l}\text { Visual } \\
\text { permeability }\end{array}$ & $\begin{array}{l}\text { Structural } \\
\text { social activity }\end{array}$ & $\begin{array}{l}\text { Final } \\
\text { score }\end{array}$ \\
\hline 1-Post Office & 1 & 1 & 4 & 1 & 7 \\
\hline 2-The Aro Park & 3 & 2 & 4 & 1 & 10 \\
\hline 3- Courtenay PL West & 3 & 2 & 4 & 2 & 11 \\
\hline 4-Cuba Mall & 2 & 3 & 4 & 4 & 13 \\
\hline 5- Courtenay PL East & 3 & 3 & 4 & 2 & 12 \\
\hline 6-Frank Kitts Park & 1 & 1 & 4 & 4 & 10 \\
\hline 7- Waitangi Park & 1 & 1 & 4 & 3 & 9 \\
\hline 8-Glover Park & 2 & 1 & 4 & 1 & 8 \\
\hline 9- Cobblestone Park & 1 & 1 & 4 & 1 & 7 \\
\hline 10-Midland Park & 3 & 3 & 4 & 2 & 12 \\
\hline 11-Denton Park & 2 & 1 & 1 & 1 & 5 \\
\hline 12- Jack Illot Green & 1 & 1 & 4 & 1 & 7 \\
\hline 13- Cuba Mall 3 & 3 & 2 & 3 & 1 & 9 \\
\hline 14- Cuba Mall 1 & 3 & 3 & 3 & 1 & 10 \\
\hline 15-Grey Street & 3 & 2 & 4 & 2 & 11 \\
\hline 16-Civic Square & 2 & 2 & 2 & 3 & 9 \\
\hline 17-Queens Wharf & 1 & 2 & 4 & 1 & 8 \\
\hline
\end{tabular}

Overlapping these four maps highlighted eight possible different score aggregations which were used to compare the sites, the aim being to choose sites with differing scores (Figure 3-9, Table 3-1). The purpose of doing this was to ensure that the sites had different physical characteristics and the sample covered a variety of small urban spaces. 


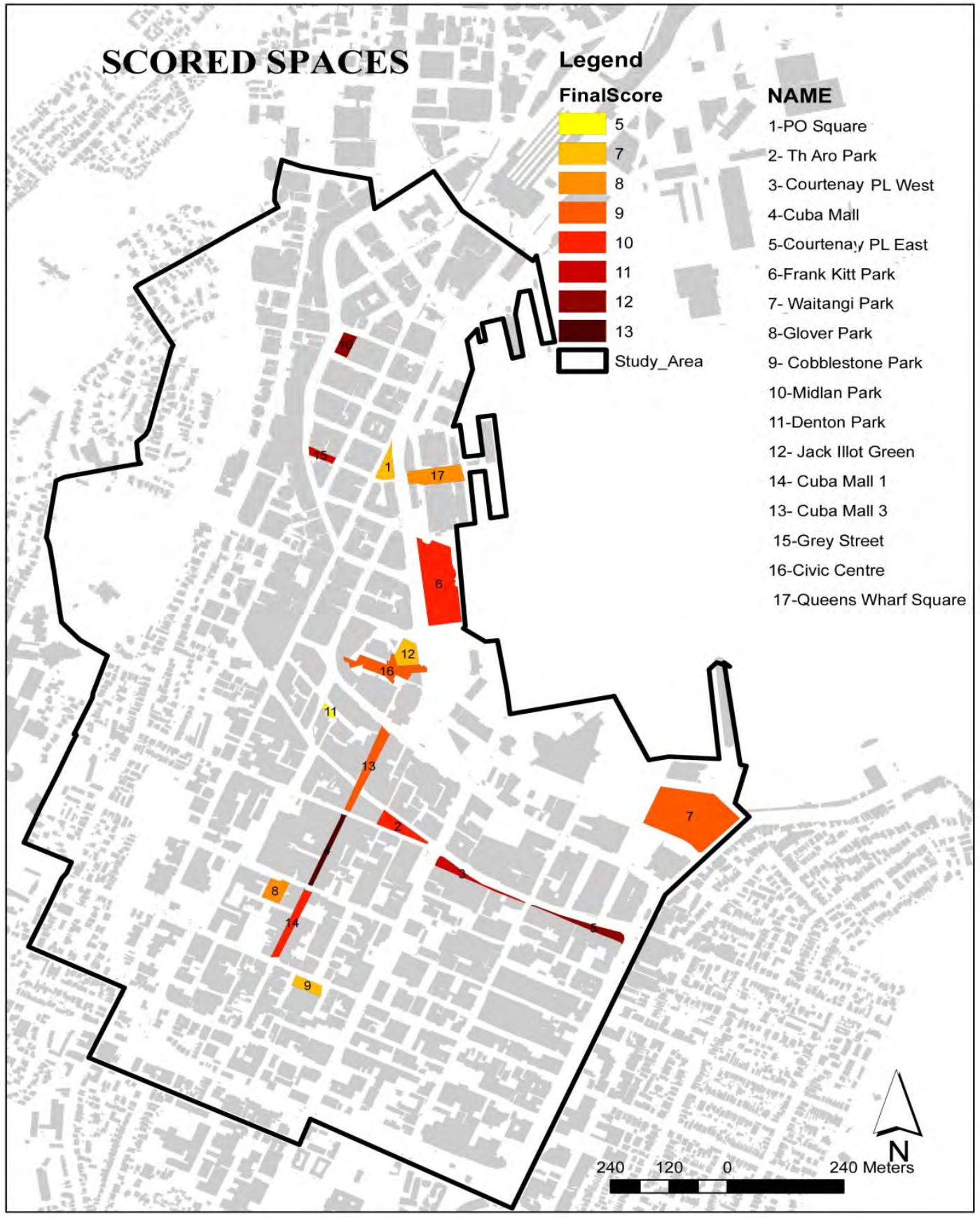

Figure 3-9: Overlapped map shows final score for places

The third important parameter was that each chosen space has separate and balanced proportions of hard and soft landscape. Initially four spaces (highlighted in red in Figure 3-10) with 30-70\% soft landscape were chosen for Study One and one space (highlighted in yellow) with similar characteristics was chosen for the pilot study (Figure 3-10). Having a variety in score and types was considered in the process of choosing spaces. Civic Square is the only space in terms of its proportions of hard and soft landscape close to the chosen spaces for study. Other spaces without an acceptable balance were excluded at this stage, 
which meant the study focussed on mini-parks and plazas. Although Cobblestone Park had $70 \%$ soft landscape because much of this and the hard landscape was under tree cover, which was different from any of the other chosen sites, it was eliminated at this stage.

After choosing the sites several observations on different days were made to assess their characteristics as being suitable for further investigation. During these observations so few people used Post Office Square that it became unsuitable for further study, and was replaced by Civic Square, which continued to be used for pilot testing for Studies One and Two as well as final data collection, although busy Midland Park was chosen as the pilot testing site for Study Three, as a crowded place was needed to assess the feasibility of proposed method.

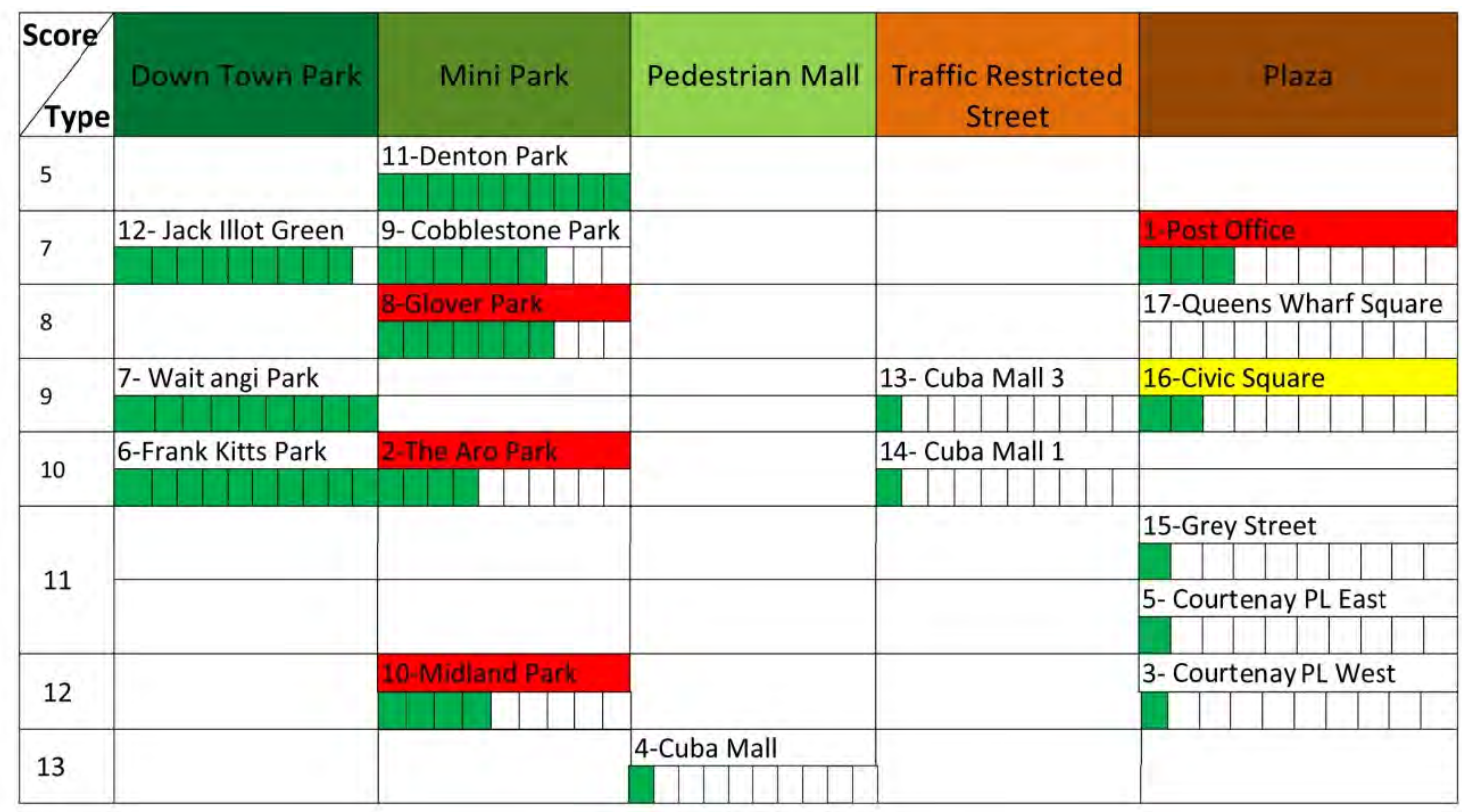

soft landscape pilot study First study

Figure 3-10: Chosen spaces

\subsubsection{Glover Park}

In 1964 Lewis Glover, a trade union secretary, left money to Wellington City Council to create a park in the city centre. After the council spent some time acquiring land, Glover Park was opened to the public in 1971 but two years later it had become a place for drinking and somewhere for the homeless to sleep (Martyn, 2011). The park was neither safe nor attractive except to homeless people. In 2006 Wellington City Council spent \$1.2 
million to transform the park from a dark and unconnected place to an attractive one. Visibility was added to limit its use for sleeping. Glover Park now seems to work well although in the central city framework there is disagreement about its usability. "Although recently upgraded, Glover Park lacks activities on its edges that can contribute some purpose to the space. Its location is disconnected from main pedestrian routes. Its role is social" (Miskell \& Straatviet, 2011, p. 113).

Glover Park is near Cuba Street the main pedestrianized route in Wellington. There is a bar to the North-West side and a tall wall of the building borders the South East. To the North East side of the Park is a collector road with a secondary road to the South West, both roads showing a low level of pedestrian movement (Figure 3-10). In contrast with these, the path through the middle of the park is used as a shortcut for pedestrians. An informal interview with some of users showed the café on the SW side was a reason for them to come to the park, although the parking lot and lack of activity on this side makes it feel 'dead'. Because of lack of visual permeability from Cuba Street and its un-active edges this park does not attract a lot of people. Another reason for this lack of users could be that the memory of this place is not positive because this park used to be a place for the homeless. However, after redevelopment this negative background is gradually changing. Teenagers and young people mostly use this space and they spend a long time there. Also people that are working around use Glover Park in their lunch hour. The initial inspection suggested this park was the quietest of the four data collection sites.

\subsubsection{Civic Square}

The civic centre project brief was for a new library, conversion of the existing library into the City Gallery, extension and refurbishment of City Council buildings, earthquake strengthening and refurbishment of the Old Town Hall, creation of car parking space, and design of a new public space (Civic Square). Imperative for the development was a link to the developing waterfront. In 1988 architect lan Athfield played a chief part in the civic centre project and was directly responsible for the design of the new library, a new children's museum and the square itself. Athfield created a civic square which was intended as a stage for public life (Wellington City Council, 2008). Gehl (2004) in his study of Wellington city centre mentioned Civic Square as a 'living room' with a wide variety of activities. He admired this place because of its location in the heart of the city (Gehl \& 
Wellington City Council, 2004, p. 24). Like Glover Park the route through the middle of Civic Square is well used to access the waterfront and the bottom of Cuba Street. Except for a café in the North West side square that is rather hidden from the main view, the other sides of Civic Square are formed by public buildings comprising the library, city gallery, and City Council buildings. The people using this place are different from Glover Park users, being more diverse, and apparently from a higher socioeconomic level, as most are using laptops, mobile phones or reading books. Civic Square users include people wanting to visit the city gallery and library, people waiting for meetings with council staff and officials, or those watching structured events. Children also come because of the presence of the children's museum (Capital E). Like all squares in the heart of the town, many workplaces are within walking distance. Civic Square is a place for holding events and festivals. It links the city centre and water front with a bridge, although there are some reservations about it.

"The enclosed space should work as the town square and its identity is strong in this respect, but it lacks edge activities which can contribute to sustained public life and activity. It has some awkward level changes, but is well-used at lunch times in fine weather and as an access route to the city centre, the Sea Bridge and waterfront" (Miskell \& Straatviet, 2011, p. 113).

\subsubsection{Te Aro Park}

Te Aro Park has an old name of "pigeon park" because of the many pigeons around it. In the 1850s Te Aro Pa was important in Wellington, being occupied by more than 200 people at its peak occupancy. It remained an open space in this part of the city for many years but has since been redesigned as public art at an urban scale. In the late 1980s there was an act to create a new public park in Te Aro, and this heritage site in central Wellington was chosen, and in 1992 Rapira Davies, a Maori artist, developed a proposal for its redevelopment. The name of the "pigeon park" was changed to Te Aro Park after the design. However, still there are still many pigeons around.

"As the park is located at a historically significant pa site, Rapira Davies chose to shape the park like a waka; its prow at the apex. The series of pools remind the viewer of the Te Aro stream. On the handmade clay tiles are printed signs of nature and inscriptions of the 
names of significant people, places and events connected to the area" (Squizlers (Lane et al), 2011, p. 1).

Te Aro Park is full of symbols but is also unloved by most of its users. Its design has been criticised for its poor maintenance, untidy detail, and indeterminacy of function because of its spatial language, triangular seats, and use of pottery in various forms. In spite of the considerable budget for the design of the park, as urban art the park is not as popular now as formerly (Architectural Centre, 2011). It is admired because of its cultural significant but does not function well.

"This park has cultural significance as part of the site of Te Aro. Its landscape treatment and water feature makes it difficult to use, limiting spaces for sitting and walking through it, and the poor quality "Oaks Building" detracts from its quality. Its role is limited and the space mainly has social use" (Miskell \& Straatviet, 2011).

Te Aro Park has the worst location of all four data collection sites. It has a triangular shape and is surrounded by three roads, is noisy and its design does not have any edge to separate the park from the surrounding roads and create some privacy for its users. Users of this Park are workers that come at lunchtime, young people, and occasionally some homeless people. The fountain does not seem to work as the focal point of the park. Talking with some people sitting around the water with their children revealed that they are enjoying the pigeons and water in the park. In contrast, talking with other Wellingtonians and the park cleaner revealed that pigeon poo, the toilets to one side that attract a lot of drunk people, and presence of homeless people are reasons for not using this public place. The early observations of Te Aro Park show that compared with the other sites, it is not 'alive' and is not a destination.

\subsubsection{Midland Park}

The site of the Spanish-styled Midland Hotel in the Wellington CBD became the property of the City Council in the late 1970s for conversion to a park in the city, which was built in 1983 at a cost of $\$ 80,000$. As part of a long term infrastructure plan it was listed for an upgrade in 2010. The design team decided to retain the park, keeping some of the existing materials and design patterns to remind everybody of the old loved Midland Park. Lighting, infrastructure and seating were replaced and a drainage issue in the grass area 
solved. The entrance of the park was improved so it would stay as a green area in the CBD (Gordon, 2011). It is the busiest small park in the CBD and used most by workers at lunch time. This is the most successful public space in Wellington due to its close relationship with Lambton Quay which allows people to drift between the park and the street. Midland Park offers a strong recreational opportunity along a highly used walking route (Miskell \& Straatviet, 2011). Midland Park is situated close to the Golden Mile (the main shopping street and pedestrian route through the centre of Wellington). Numerous nearby shops, offices, and bus stops attract many people to this park. Its design has created a buffer from the main street that makes it a green, quiet place where people can have a break from their shopping or work. Observation of this park showed not only that it is crowded on weekdays but also that it is popular with families at weekends. However, because of the lack of green space nearby this park is really over used in the lunch hour and does not offer a choice of places to sit, as usually users have to choose the first available place to sit and eat in their limited lunch time. 


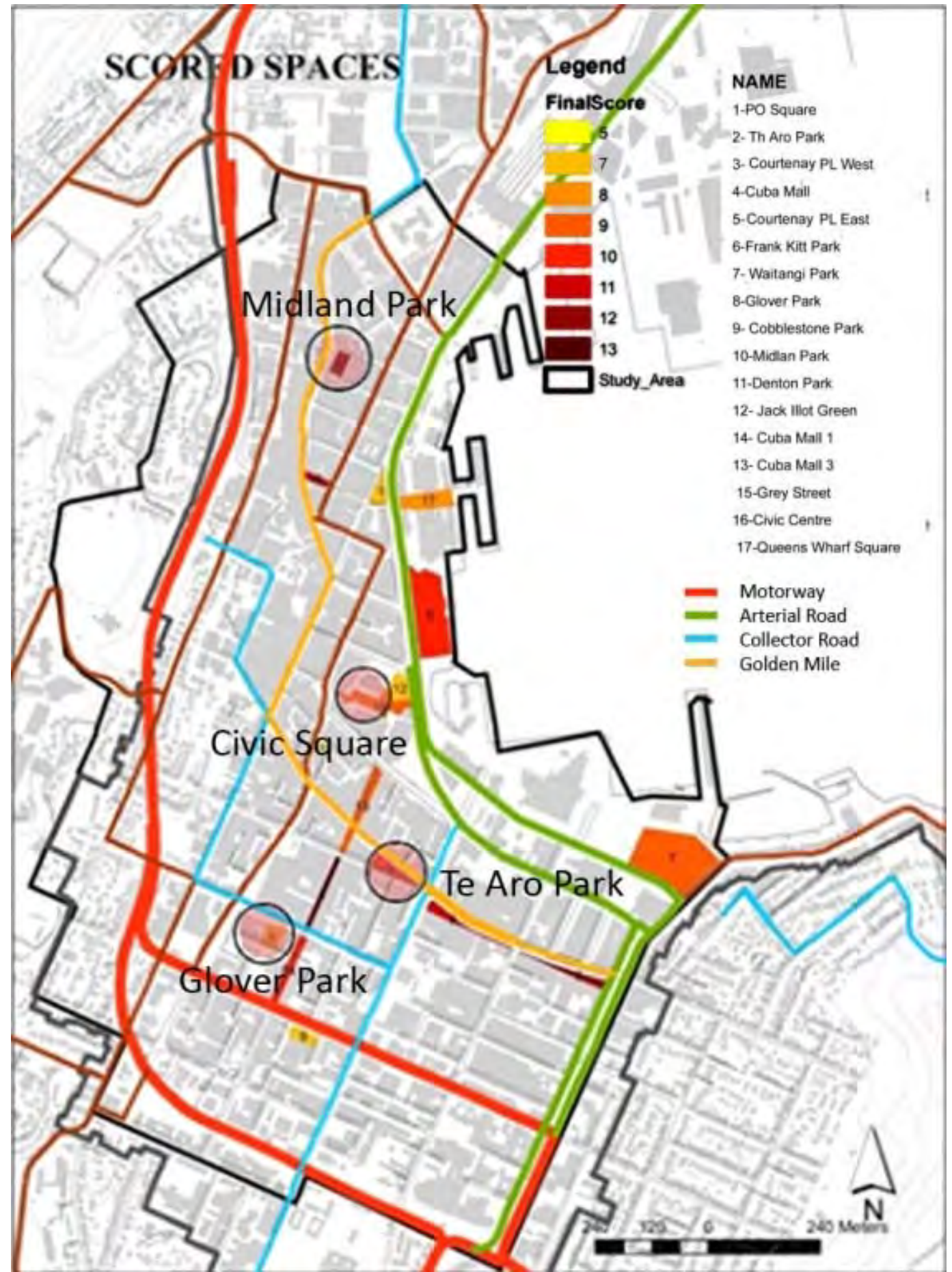

Figure 3-11: Location of four data collection sites 


\title{
Chapter 4 \\ Study One: Affordance of Design Elements
}

\begin{abstract}
"The natural environment is transformed through symbols and concepts that organize people's relationships in the social world. Every single landscape element (water, metal, wood, plants) can evoke different meanings in different contexts and will not be received similarly by members of groups with different points of view" (Greider \& Garkovich, 1994, p. 6).
\end{abstract}

Study One examines the linkage between the three components of place, these being physical setting, activity and concepts. It uses a facet approach within the framework of Theory of Place and has a focus on natural design elements. Together Affordance theory and Theory of Place are used to investigate preferences for natural design elements in the design of a small public open space (See section 3.2.1).

Places are used when physical setting provides a positive affective response and cognitive evaluation. This is because sense of place occurs when a setting becomes functionally and aesthetically meaningful. Perceived place is affected by the character of the physical setting, an individual's conception of place, and the activity range. The study of what makes a used place is the search for an appropriate model which describes the interrelationships between setting, mental image and behaviour (Motloch, 2000). Using Theory of Place and Affordance Theory, five facets were defined to form a mapping sentence. The facets are discussed below.

\subsection{Hypothesis}

The review of the literature suggests that the presence of natural elements in public spaces is associated with increased social activity in those spaces because of the physical, perceptual and behavioural affordance of those elements. This further suggests that natural elements can contribute to people's sense of place through a positive evaluation of a space which in turn enhances use of that space. This leads to the following hypothesis for Study One. 
Hypothesis:

Social activity in public space is a function of the affective and cognitive affordance of natural elements in public space.

\subsection{Meaning and Conception: The Affective and Cognitive Affordance of Place}

In The Meaning of the Built Environment Rapoport (1982) argues that people respond to environments based on the meanings the environment has for them and their reactions are affected by images and ideas. However, meaning is not separate from function and environmental quality is a function of the meaning of material objects. The initial affective image of the material objects of the space shapes people's initial analysis of it which in turn affects the decisions people make about the place. The meaning of the environment (conception) forms initial experience (affects) and influences on-going interaction (cognition) (Gibson, 1979; Kaplan, 1987; Rapoport, 1982).

Meaning of the environment is a result of the affective and cognitive component of place. Motloch (2000) claims the first is the process of appraising a setting and the second is an evaluation process, although both are interrelated. While some studies have viewed feeling as a product of thought (Tuan, 1978), others argue that affect is not proceeded by a cognitive process but is precognitive and constitutes the initial level of response to an environment (Ittelson, 1973; Ulrich, 1983; Zajonc, 1980). Zajonc (1980) states that affect can accrue with little information. Ulrich argues affect affects the cognitive process; if feelings are strong they can dominate the latter. He stated that whereas emotions are universal, the cognitive meaning arising from a given emotion can vary with age, culture, experience. Ulrich (1983, p. 90) sees affect as a synonym for emotion, with affect coming from the first reaction to an environment. The first level of reaction is a generalized affect such as like or dislike, which then motivates behaviour. There are many words which can describe the affective quality of space, like boring, disgusting, or relaxing. To deal with this is useful to consider that there are two prime sets of emotions for people; a general feeling of positivity like feeling good or happy, and a feeling of arousal like interest, and desire to be active (Hull \& Harvey, 1989). After factor analysis of 105 adjectives, Russell and Pratt (1980, p. 313) showed that environmental affect consists of two primary 
dimensions (pleasantness and arousal). The combination of pleasant and arousing gives rise to a feeling of excitement; unpleasant and arousing brings distress; a pleasant and sleepy environment is relaxing; and a sleepy unpleasant place is gloomy (Yik, Russell, \& Steiger, 2011) (Figure 4-1).

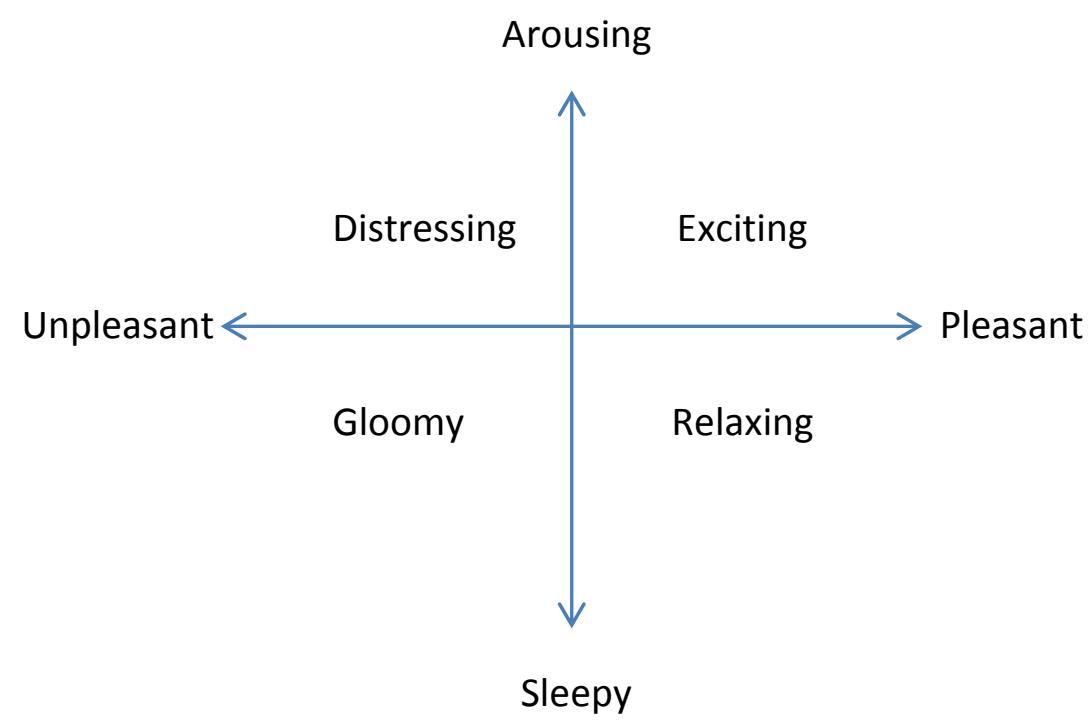

Figure 4-1: The two principal components of the affective quality of places (Russell \& Pratt, 1980)

Maslow (1970) defined two cognitive needs; need to know and aesthetic needs. The former gives information about the surroundings and gives rise to two demands. Firstly the setting should be legible and understandable and secondly it should provide opportunity for involvement (Motloch, 2000).

Regarding cognitive affordance, Nasar (1987) refers to Lynch's concept of imageability to define urban cognition. He defines imageability (clear identity and structure) as things which give people knowledge about the environment. Imageability and legibility bring a sense of safety and security (Lynch, 1960; Motloch, 2000). Demand for a legible, understandable setting is stressed in other studies (S. Kaplan, 1987; Lynch, 1960; Maslow, 1970). Lynch (1960) defined legibility as how easy it is to see the part as a coherent whole image. He referred to shape, colour or arrangement making a powerful structure and sharp image. Montgomery (1998) defined legibility as the degree of organization of different elements in a recognizable pattern which affects imageability. According to Montgomery (1998) each place has identity and an image. While in his view identity is objective (what a place looks like) image is a combination of identity as an objective thing with people's perception and their feeling of place. Lynch defined imageability as the 
physical qualities which are related to structure and identity. This includes meaning and relationships to beliefs and ideas. In Lynch's concept the paths, landmarks, districts, nodes and edges that form the structure of a city contribute to its imageability.

In Study One 2 types of Affective Affordance are used. Based on the work of Russell and Pratt (1980) and Yik, Russell and Steiger (2011), relaxing and exciting were chosen here to represent the positive activation and deactivation of an affect. The occurrence of a negative activation or deactivation of an affect is reflected in the response rating. In this model, relaxing places are pleasant, peaceful, and tranquil. Exciting places also are interesting and energizing.

In Study One 2 types of Cognitive Affordance are used. The two important cognitive components of imageability are legibility and being meaningful (Lynch, 1960). A place is legible when it is understandable or has clear structure, and meaningful when it has clear identity and obvious arrangement.

\subsection{Activity and Experience: The Behavioural Affordance of Place}

The feeling and meaning people ascribe to physical settings together influences their action and type of activity. Ulrich $(1983$, p. 93) stated that feeling is inseparably linked to action and affective response is not independent of behaviours. "It is assumed that an individual's affective reaction motivates or serves as an action impulse for adaptive behaviour or functioning." He showed that activity is dependent on the degree of affect. While interest and pleasantness (strong preference) lead to on-going activity and sustained performance, moderate interest, including calm and peacefulness, leads to psychological restoration and non-vigilant attention. Dislike accompanied by fear or uncertainty leads to vigilant attention and avoidance.

Gehl (1987) considered types of activity and their relationship with the quality of spaces and stressed that long lasting activities are more likely to occur in spaces with better environmental quality. Gehl also sorted social activities in terms of intensity, from noncommunal contacts (being alone and seeing and hearing people) to emotionally involved connections (being with friends and close family) (See section 5.3.1). He showed that design elements effect the time spent in a place, the number of people involved and the 
type of activity. Lennard and Lennard (1987) mentioned three types of social activity grouping social life in public place into three categories. These are being with known, familiar or unknown persons, connections to others without speech, and being in public in a group.

In Study One there are 2 types of Behavioural Affordance. Behaviour in space is divided into two types, whether the behaviour is by a person alone, or with a group (Lennard \& Lennard, 1995; Gehl,1987).

\subsection{Design Elements: The Material Affordance of Place}

The role of material objects in forming the initial affective image and evaluation and ongoing interaction has been emphasised in environmental studies (Gibson, 1979; Kaplan, 1987; Rapoport, 1982). Material objective and subjective design elements contribute to generating activity through their effect on people's perceptions, and can create a link between the components of place. Rapoport (1982, p. 14) argues that environmental quality is a function of the meaning of material objects. Ulrich (1983) argues that a feeling of like-dislike arises from visual contact with the environment and that this affective reaction is then modified by the process of cognition.

Nasar (1989) named naturalness, complexity, order, and openness, as the salient attributes of an environment which can lead to evaluation of urban scenes as offering excitement or calmness. He states that all the aesthetic values mentioned relate to physical variables; collative, organizing, psychophysical, ecological/content (naturalness), and spatial attributes.

Collative variables, including complexity, lead to excitement. In natural settings contrast in colour, texture and shape increases complexity (Wohlwill, 1982), and in urban settings, surface, overall shape and roofline act in a similar way (Groat, 1984). Organizing variables provide structure and lead to order and unity. Psychophysical variables include, size, light, colour and contrast. Ecological variable relate to content like naturalness and architectural style. Spatial variables include openness and refuge (the protective feeling of the observation point).

Ulrich (1983) in his discussion about the visual properties which influence affective 
reactions named complexity, structural properties, focality, depth, ground texture, threat/tension, deflected vistas, and water. He defined complexity as the number of independently perceived elements in a scene, based on the idea that the level of dissimilarity between them increases complexity. Structural elements contribute to cognition and speed up recognition. The structuring of a setting can be achieved by the presence of a homogeneous texture, redundant elements, and grouping of elements. Focality variables are some of the most important structuring variables that contribute to complexity. Focality is related to the existence of an area which attracts the observer's attention. A group of features, textures, and landform can also work as a focal point. Depth and spaciousness also have a significant positive effect on preference. Depth influences perception in three dimensions. Ground surface textures in a natural environment are important for defining depth. They “...affect complexity and structure of the two-dimensional visual array" (Ulrich, 1983, p. 102). Studies by Ulrich (1977) show smooth textures should evaluate positively as they offer the ability for movement while rough texture reduces preferences and should generate dislike. Ground texture also contributes to complexity. Environments with deflected vistas increase mystery and curiosity. The role of texture is also emphasised by Motloch (2000). Ulrich described water as one of the elements which evokes interest. Studies which focus on activity and design elements such as street furniture and natural features like trees and water influence the use of space (Gehl, 1987; Whyte, 1980). In summary physical attributes (surface, feature and furniture) form a positive affective response and cognitive evaluation.

Nasar and Abdulkarim (Abdulkarim \& Nasar, 2014) studied the restrictiveness of liveable features in public space including seats, sculpture and food. They found that these elements improve restrictiveness and that liveable features assist in making public space less restrictive.

Natural elements are materials which have had a long standing link with affording people meaning in public space (Greider \& Garkovich, 1994, p.6). Small urban spaces have often incorporated natural elements in their construction and composition (Madanipour, 1996, p. 35; (Fajardo, 2007)). Studies that distinguish between the two domains of the natural and man-made and people's reactions to natural versus artificial environments show natural elements and natural materials have affective, cognitive and behavioural 
affordance. (S. Kaplan et al., 1972; Sheets \& Manzer, 1991; Ulrich, 1976, 1986; Ward, 1977). An early study by Wohlwill and his colleagues (1973, p. 172) showed a very consistent preference for natural scenes as opposed to those of the man-made environment (S. Kaplan, 1987, pp. 3-32; Tyrväinen et al., 2014; Van den Berg, Jorgensen, \& Wilson, 2014). Not only are reactions to nature and built environments different, but these results were also found to be stable and repeatable across cultures (S. Kaplan, 1987, pp. 3-32).

Kaplan (1983, pp. 132-138) when investigating the role of the environment distinguishes between content and process, and claims that people respond to the natural world in two distinct ways. In the content domain, specific kinds of nature, for example trees or water, seem to be important and in the process domain people are satisfied with having a configuration of natural elements, whether these are trees, shrubs, grass or other natural phenomena. So not only is the existence of nature important but its objective properties should also be considered. Studies shows trees are the most dominant elements in an urban landscape (Alexander, Ishikawa, \& Silverstein, 1977; S. M. Gold, 1976; R. Kaplan, 1983). The investigations of Wohlwill (1973, p. 172), and Kaplan (1983) show a very consistent preference for natural scenes as opposed to those of the man-made environment. Kaplan further suggests people recognize their residential environment through its natural features.

Natural materials also contribute to the cognitive affordance of place. Kaplan (R. Kaplan, 1983) discusses the visual character of nature, like its forms and textures, which leads to complexity, order and unity, and which relates to the affective-cognitive effect of the environment and people's preferences. In line with this, Ulrich (1983) states vegetation correlates with order, unity, upkeep, and openness. He valued natural elements for their structural properties, noting their movement, sound and smoothness make them different from artificial elements. Research (Kuo, Sullivan, Coley, \& Brunson, 1998; Nordh et al., 2011) has also shown that grass and trees are the components that most influence people's decision making when finding a place for rest. The results of a study by Nordh et al. (Nordh et al., 2011) show the average importance for a restorative condition was high for grass, followed by trees, and people around the water. Flowers and bushes were at the bottom of the list. 
For Study One 3 types of material and design elements in the form of furniture, surface and features are used, as research has shown these influence people's preferences (Nasar, 1989; Ulrich, 1983; Motloch, 2000). Studies that compare the effect of natural elements indicate that people respond to natural and built environments differently (Kaplan; Wohlwill, 1983) and that this is repeatable across cultures. In the present research, artificial (non-natural environments) are used to represent the absence of natural elements in the design. These are then combined with the three types of design elements creating six elements.

- Natural Furniture: wood and stone

- Artificial Furniture: plastic and metal

- Natural Surface: grass, stone and wood

- Artificial Surface: painted, concrete and tiled

- Natural Feature: trees, water, plants

- Artificial Feature: sculptures, artefacts, decorations

\subsection{Mapping Sentence for Study One}

Figure 4-2 details the mapping sentence:

People (x) prefer something (behavioural affordance) in public spaces with (material) (design elements) because of the place's (affective) and (cognitive) affordance.

The combination of the four facets in the mapping sentence generates $2 \times(2 \times 3) \times 2 \times 2=48$ questions

The aim of the mapping sentence is to:

- Examine the affordance of natural and artificial design elements in public space;

- Investigate the role of affective, cognitive and behavioural affordances in public space; and

- Evaluate the contribution of natural and artificial design elements in public space. 


$\left.\begin{array}{l}\text { Behaviour } \\ \text { When } \\ \text { [I] } \\ \text { spend } \\ \text { time }\end{array} \quad \begin{array}{l}\text { in } \\ \text { public } \\ \text { spyself } \\ \text { spaces, } \\ \text { I prefer } \\ \text { places } \\ \text { with }\end{array} \quad \begin{array}{l}\text { Design Elements } x \text { Materials } \\ \text { plastic and metal furnishings } \\ \text { grass, stone or wooden surfaces } \\ \text { painted, concrete or tiled surfaces } \\ \text { trees, water and plant features } \\ \text { sculptures, artefacts and decorative features }\end{array}\right)$

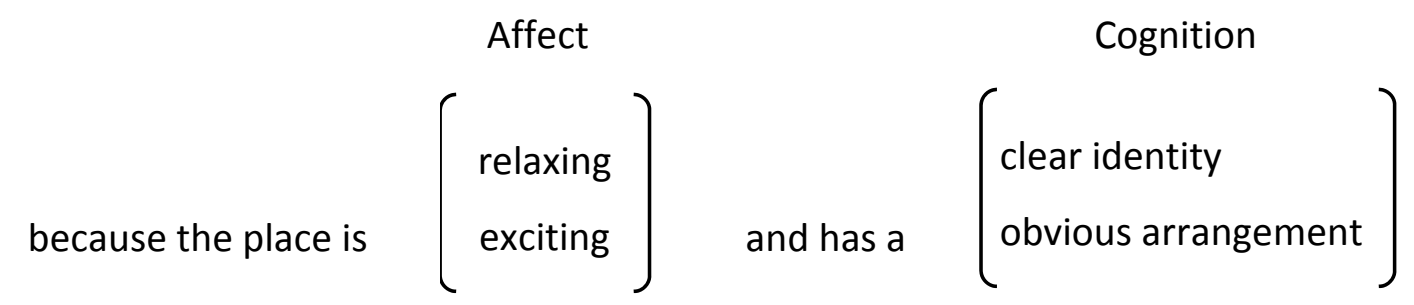

$\begin{array}{llccr}\text { Strongly moderately slightly } & \text { neutral } & \text { slightly } & \text { moderately } & \text { strongly } \\ \text { disagree disagree disagree } & & \text { agree } & \text { agree } & \text { agree }\end{array}$

Figure 4-2: Mapping sentence

\subsection{Questionnaire Design}

In the order to investigate the hypothesis it was decided to conduct a survey of people using each of the four data collection sites. Facet Theory was used to design a questionnaire through establishing the mapping sentence.

A questionnaire with three parts was used for the data collection. Part one consisted of demographic and general questions including; gender, ethnicity, age, suburb of residence, the length of living in Wellington, education, occupation, place of work, and frequency of using public space. The questions in parts two and three were defined by the wording of the mapping sentence. As there are $2 \times(2 \times 3) \times 2 \times 2$ elements in the latter, this resulted in 
48 questions. The 48 questions split in two groups separated by the behaviour facet (being alone or with friends). Part two has 24 questions starting with the phrase 'when I spend time by myself' and part three comprises 24 questions starting with the phrase 'when I spend time with my friends'. A written instruction explaining this division was provided and the researcher was also present to answer questions as all questionnaires were distributed by asking people using the spaces of they were willing to take part in the survey. A typical question is shown in Figure 4-3 and the complete questionnaire in Appendix 1.

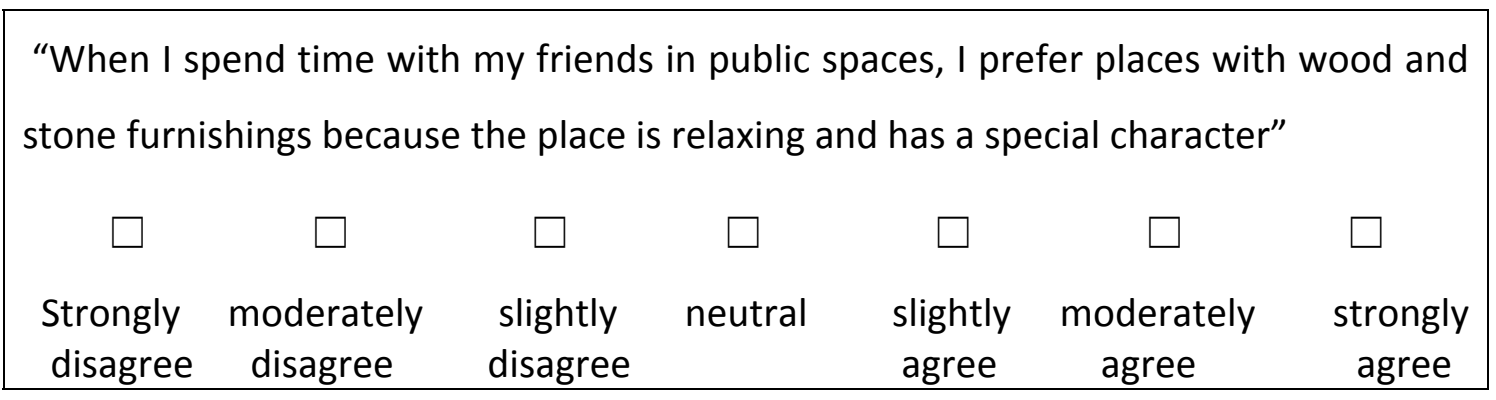

Figure 4-3: A typical question

\subsubsection{Pilot Testing}

As described in Section 3.8 Civic Square was selected for a pilot study to refine the methods of data collection. However, before starting pilot testing in Civic Square, 10 students were asked to give feedback about the wording and format of the questionnaire and also to estimate the time for answering it. This led to minor changes to terminology in the cognition section, where 'clear structure' and 'special character' were respectively used instead of 'obvious arrangement' and 'clear identity'. The aim of doing pilot testing in Civic Square was to compare participation between online and on site questionnaires. For 63 flyers distributed in Civic Square, 15 people answered on site and 10 people online by use of Qualtrics. Comparison of average times for completion showed that people online completed in almost half the time of those on site and did this by ticking the same answer to a series of questions. The on-site group filled the questionnaire with more variability in their answer. As a result an on-site questionnaire was chosen as the method of data collection. The results of pilot testing were not used in the main study. 


\subsection{Participant Sample}

Data was collected (See Appendix 3) at the four data collection sites in the city centre of Wellington (Section 3.4). To collect the best possible random sample of people using the public spaces, the interviewer moved around each space and approached the next available user. People were asked if they were willing to take part and then questionnaires were handed out and collected. All participants were required to sign the consent form. Questionnaires' were distributed on workdays and at weekends in the morning, lunchtime and afternoons across the four data collection sites on different days, with the hope of receiving a broad range of respondents. For each site 40 questionnaires (split into 20 over the day at the weekend, and 10 in the morning or after lunch time and 10 at lunch time on a weekday) were filled by people using the space for social activity. However, there is always the possibility of not collecting all possible because of using the questionnaire with this method of sampling. It might be that those who agreed to take part had a different view of the public space than those who refused. Also because of lack of any statistics about the typical or average number of users of each public space there was no base number for how many questionnaires to distribute to make a reasonable sample. The number used in Study One was the result of discussion with the VUW statistics consultant. Altogether 160 questionnaires were collected but two participants were excluded from the sample because of incomplete data. The 158 participants included 77 male and 78 female, and 3 who did not specified gender, aged between 14-64 years with a mean age of 31.8 years. In terms of living in Wellington, 10 years was the average period. The 158 participants were composed of $61.4 \%$ NZ European, 13.9\% European, 8.9\% Asian, 3.8\% Maori, 2.5\% American/African, 1.9\% Middle Eastern/Latin and 2.5\% other ethnicity. Of the sample, $67.7 \%$ had tertiary qualifications, $23.4 \%$ secondary and $6.3 \%$ trade qualifications, with $1.3 \%$ other and $1.3 \%$ who did not answer this question. From the sample of 158 people $53.8 \%$ work in the city centre and $65 \%$ use public space more than 2 or 3 days a week. Although a count was not kept, approximately $30 \%$ of people refused the invitation to fill out the questionnaire; this number was greater in Midland Park, especially at lunch time. Two non-completed questionnaire from Glover Park and Civic Square were excluded from the final analysis. 


\subsection{Results}

The two dimensional spatial representation of the 48 questions in the survey splits into two separate regions for the artificial design natural elements (Figure 4-4). This result is consistent across sites with two separate regions evidenced in the results at the four data collection sites. These means were similar for both weekdays and weekends (Table 4-1). Within the artificial region (Figure 4-4), the 24 artificial items form three sub-groupings consisting of artificial furnishing (plastic, metal), artificial surfaces (painted, concrete or tiled), and artificial features (sculpture, artefacts, decorative features). Both groups of users of surface and furniture also divide into being alone and being with friends. However, this separation between being alone and in a group does not apply to artificial features. The 24 items in the natural region form 2 sub-groups that include natural furnishing (wood and stone), and a cluster of natural surfaces (grass, stone, wood) with natural features (trees, water, plants). While natural surfaces and features are intertwined, natural furnishing is slightly separate from them. In contrast with the artificial region there is no separation between being alone and being with friends (Figure 4-4). Preferences for design elements move from right to left, with right being more preferred. Where possible, clusters are identified by drawing an elliptical boundary around them, while the thick line separates regions. However, it does not mean that items within a cluster have no relationship to those outside.

Inspection of the means supported the spatial representation results. The means for natural and artificial design elements, broken down by behaviour and sites (Table 4-1) indicate:

- A preference for natural elements over artificial elements on weekdays and weekends, and in both situations of being alone or with friends. This finding is consistent for the four data collection sites. A Friedman test was conducted to evaluate differences in medians between two materials: natural (Median $=130.5$ ) and artificial (Median $=96)$. The test was significant $\chi 2(1, N=158)=131.9, p<0.000$, indicating a significantly higher preference for natural materials. For other situations, weekday, weekend, different sites, being alone, and group, the same test also gave $p<0.000$.

- For both natural and artificial design elements, features receive the highest preference, followed by surfaces, with furnishings being given the lowest rating. A 
Friedman test was conducted to evaluate differences in medians between three natural design elements: feature (Median $=48)$, surface (Median $=44)$, and furnishing (Median=40). The test was significant $\chi 2(2, N=158)=122.015, p<0.000$, indicating significant differences in the preference ratings for the three natural design elements. Follow-up pairwise comparisons were conducted using a Wilcoxon test. The median preference for feature was significantly greater than the median preferences surface $(p<0.000)$ and furnishing $(p<0.000)$, with the median preference for surface significantly greater than the median preference for furnishing $(p<0.000)$. A Friedman test was conducted to evaluate differences in medians between three artificial design elements: feature (Median = 40), surface (Median = 31.5), and furnishing (Median=28). The test was significant $\chi 2(2, N=158)=149.247, p<0.000$, indicating significant differences in the preference ratings for the three artificial design elements. Follow-up pairwise comparisons were conducted using a Wilcoxon test. The median preference for feature was significantly greater than the median preferences for surface $(p<$ $0.000)$ and furnishing $(p<0.000)$, with the median preference for surface significantly greater than the median preference for furnishing, $(p<0.000)$.

- Artificial surfaces and artificial furnishings receive negative preference ratings (i.e., means $<$ four).

- A preference for natural furnishings is consistently higher with friends than being alone. Friedman test was conducted to evaluate differences in medians between natural furnishing when being alone (Median = 19) and with friends (Median = 20). The test indicated a significantly higher preference for natural furnishings when with friends $(\chi 2=6.877, d f=1, N=158, p<0.009)$. 
Table 4-1: Mean preferences for natural and artificial design elements.

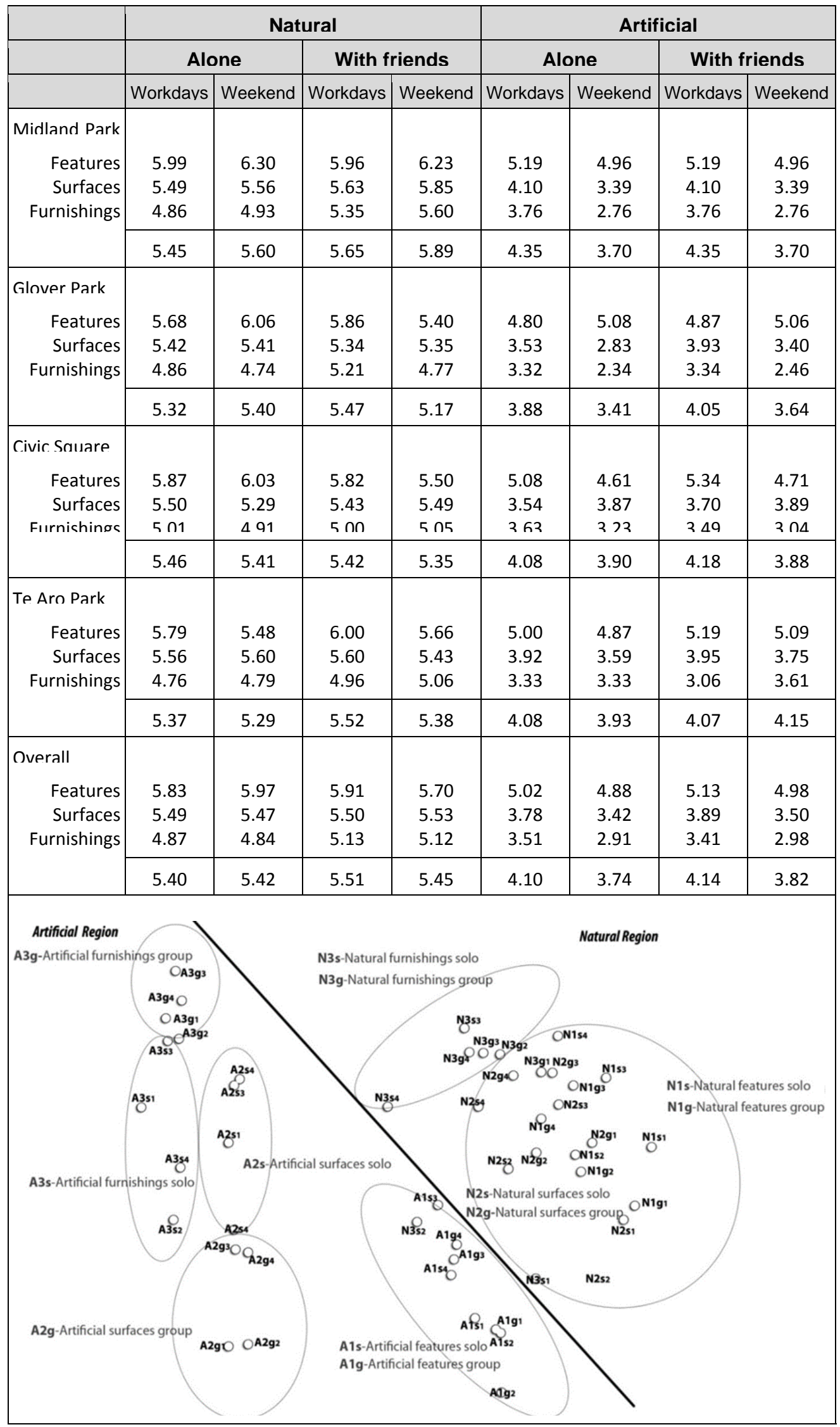

Figure 4-4: Two dimensional spatial representation of 48 items (stress=0.07, N=158) 


\subsubsection{Natural Design Elements}

Based on the overall preference for natural elements over artificial elements, separate analyses were conducted for the 24 natural items and the 24 artificial items. The 24 natural items were analyzed within a two dimensional space by design feature (Figure 45) and affective-cognitive affordance (Figure 4-6). There are three separate regions of furnishings, surfaces and features. Natural furnishings are slightly apart from surfaces and features. Separation within surfaces and features when alone and with friends is more obvious than for furnishings. The spatial ordering from upper left to lower right shows the highest position for natural features and the lowest for furnishings (Table 4- 1). In order to make the cluster more obvious lines are used to link all similar elements together. The colour of the line has no meaning. Two lines are also used to define three separate regions.

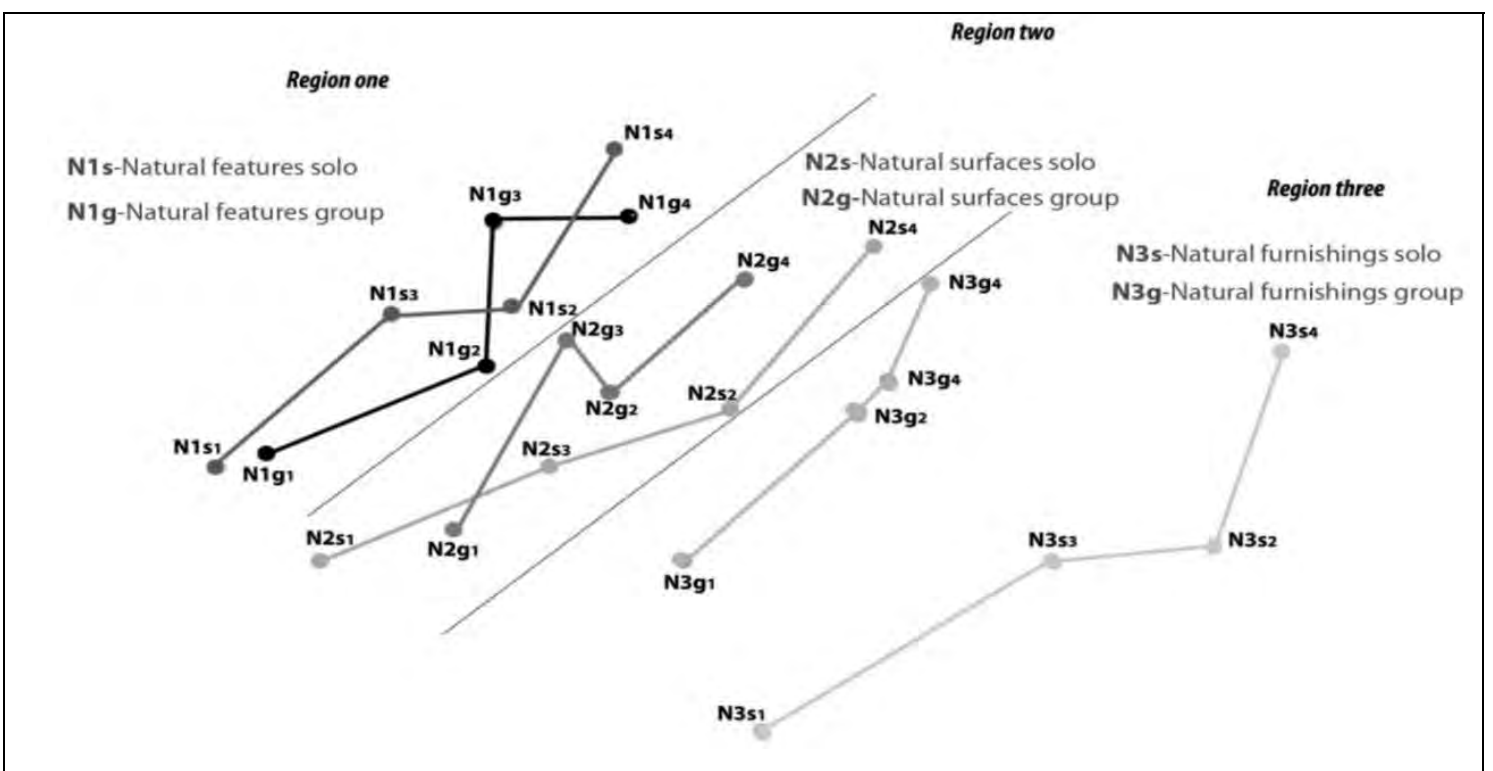

Figure 4-5: Two dimensional spatial representation of 24 natural items classified by design feature (stress $=0.14, \mathrm{~N}=158$ )

There are three main regions for the affective-cognitive affordance of natural design features (Figure 4-6), these being relaxing and having a special character, an intertwined group of relaxing and having a clear structure with exciting and having a special character, and a group of exciting and having a clear structure. The affective-cognitive ratings move from lower left to upper right (Figure 4-6). Lines link all similar cognitive-affective attributes together (e.g. all "relaxing and have a special character") and for each of them a different a colour was used. 


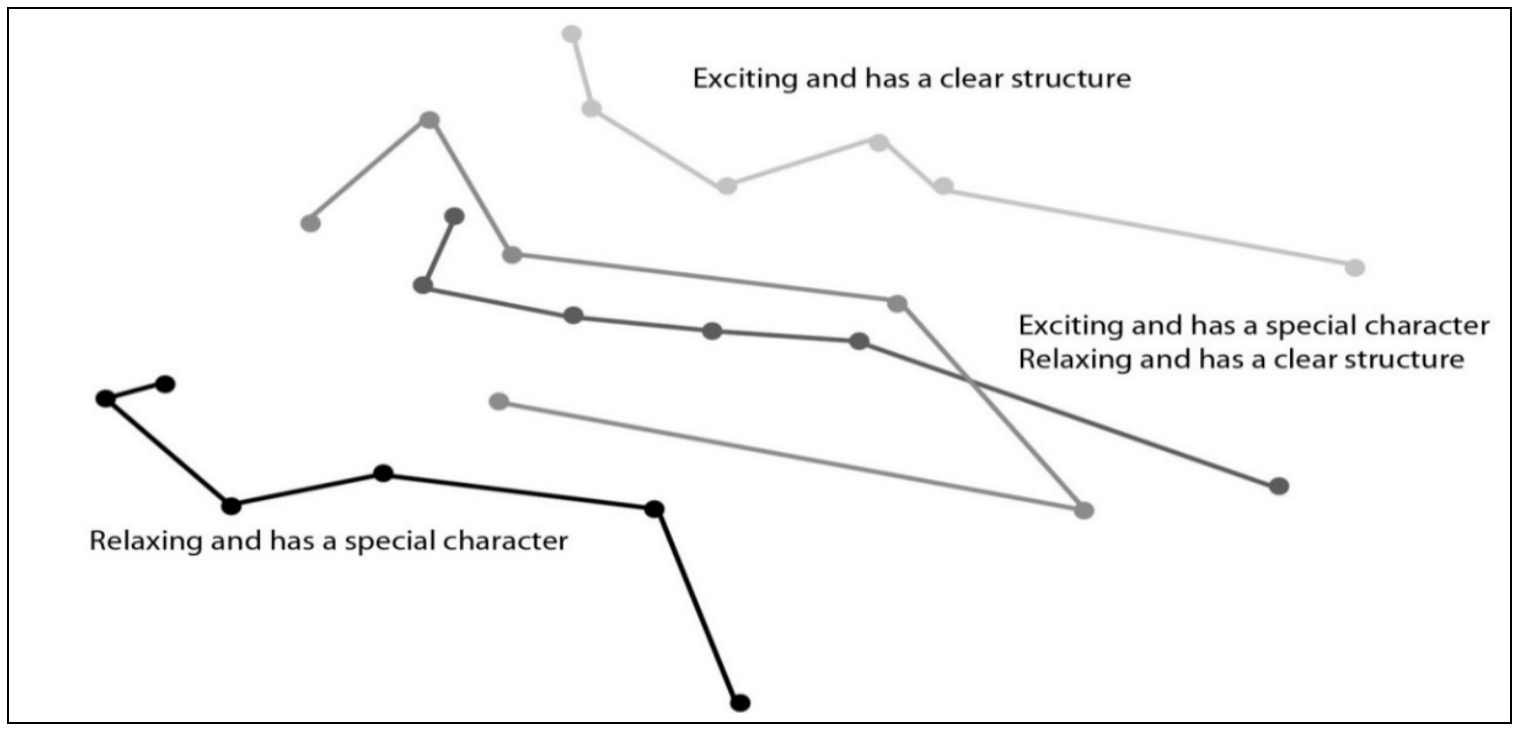

Figure 4-6 Two dimensional spatial representation of 24 natural items classified according to affective-cognitive affordance (stress $=0.14, \mathrm{~N}=158$ )

The preference for natural elements is linked to their higher sense of relaxation and giving specific character to the space and is ranked lower for their exciting character and their effect on legibility of place (Table 4-2).

Table 4-2: Affective-cognitive affordance of design elements

\begin{tabular}{|r|c|c|c|c|}
\hline \multicolumn{2}{|c|}{} & \multicolumn{2}{|c|}{ Relaxing } & \multicolumn{2}{c|}{ Exciting } \\
\hline & Special Character & Clear Structure & Special Character & Clear Structure \\
\hline Natural & & & & \\
Furnishings & 5.42 & 4.99 & 4.89 & 4.66 \\
Surfaces & 5.97 & 5.56 & 5.35 & 5.11 \\
Features & 6.30 & 5.84 & 5.79 & 5.47 \\
\cline { 2 - 5 } & 5.90 & 5.47 & 5.34 & 5.08 \\
\hline Artificial & & & & 3.28 \\
Furnishings & 3.03 & 3.22 & 3.27 & 3.66 \\
Surfaces & 3.60 & 3.60 & 3.71 & 4.87 \\
Features & 5.11 & 4.79 & 5.23 & 3.93 \\
\cline { 2 - 5 } & 3.92 & 3.87 & 4.07 & \\
\hline
\end{tabular}

\subsubsection{Artificial Design Elements}

The spatial representation of 24 artificial items is based on analysis of design elements and their affective-cognitive affordance. Unlike natural items each design element forms a separate group consisting of furnishings, surfaces, and features (Figure 4-7). Within the furnishing and surface clusters there is no difference between design elements according 
to their cognitive-affective affordance (Figure 4-8). They both received negative ratings. In contrast, artificial features were rated positively for their exciting character and the meaning they give to the space, followed by their contribution to sense of relaxation and meaning of place. They received positive ratings (Table 4-2).

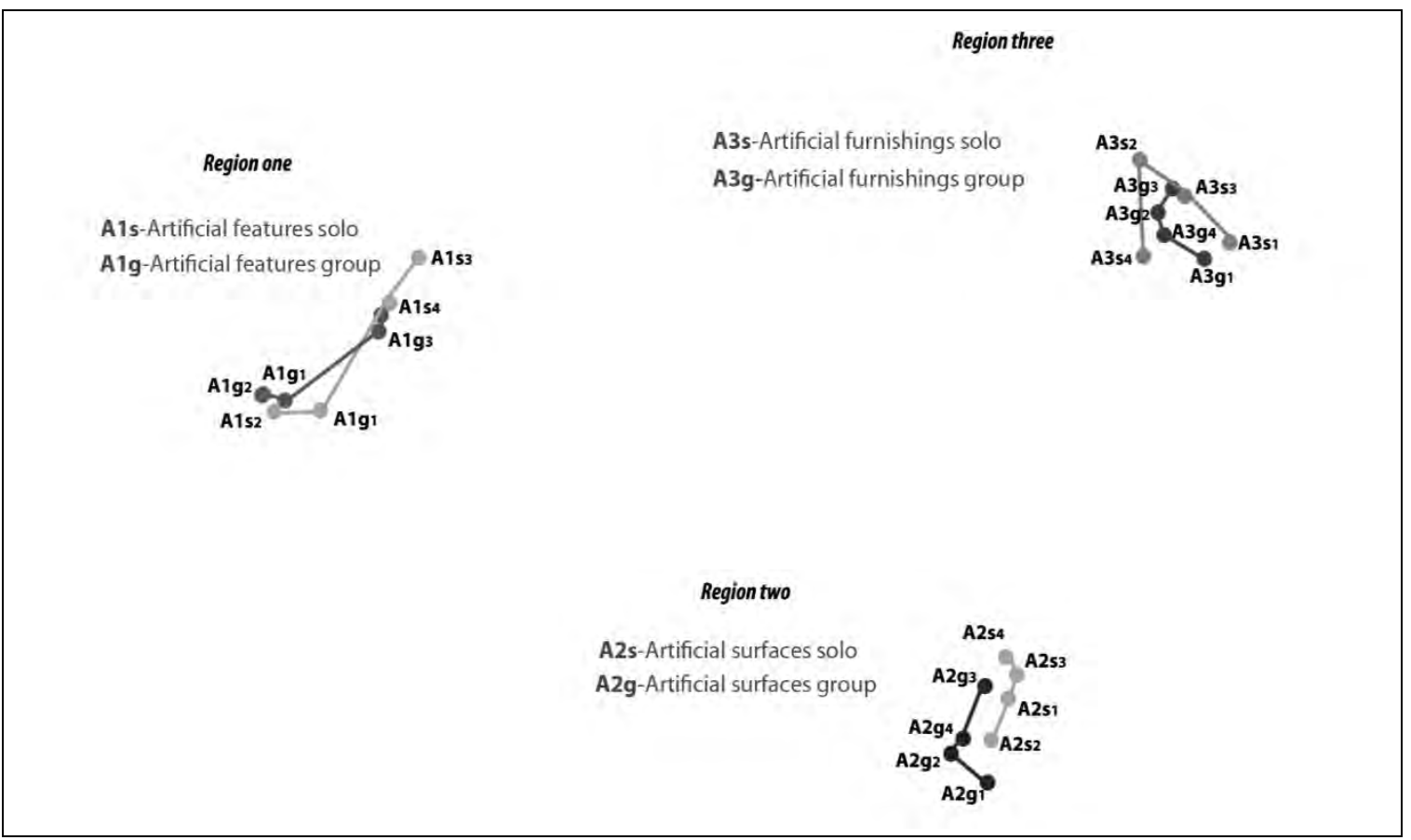

Figure 4-7: Two dimensional spatial representation of 24 artificial items classified according to design feature (stress $=0.05, \mathrm{~N}=158$ )

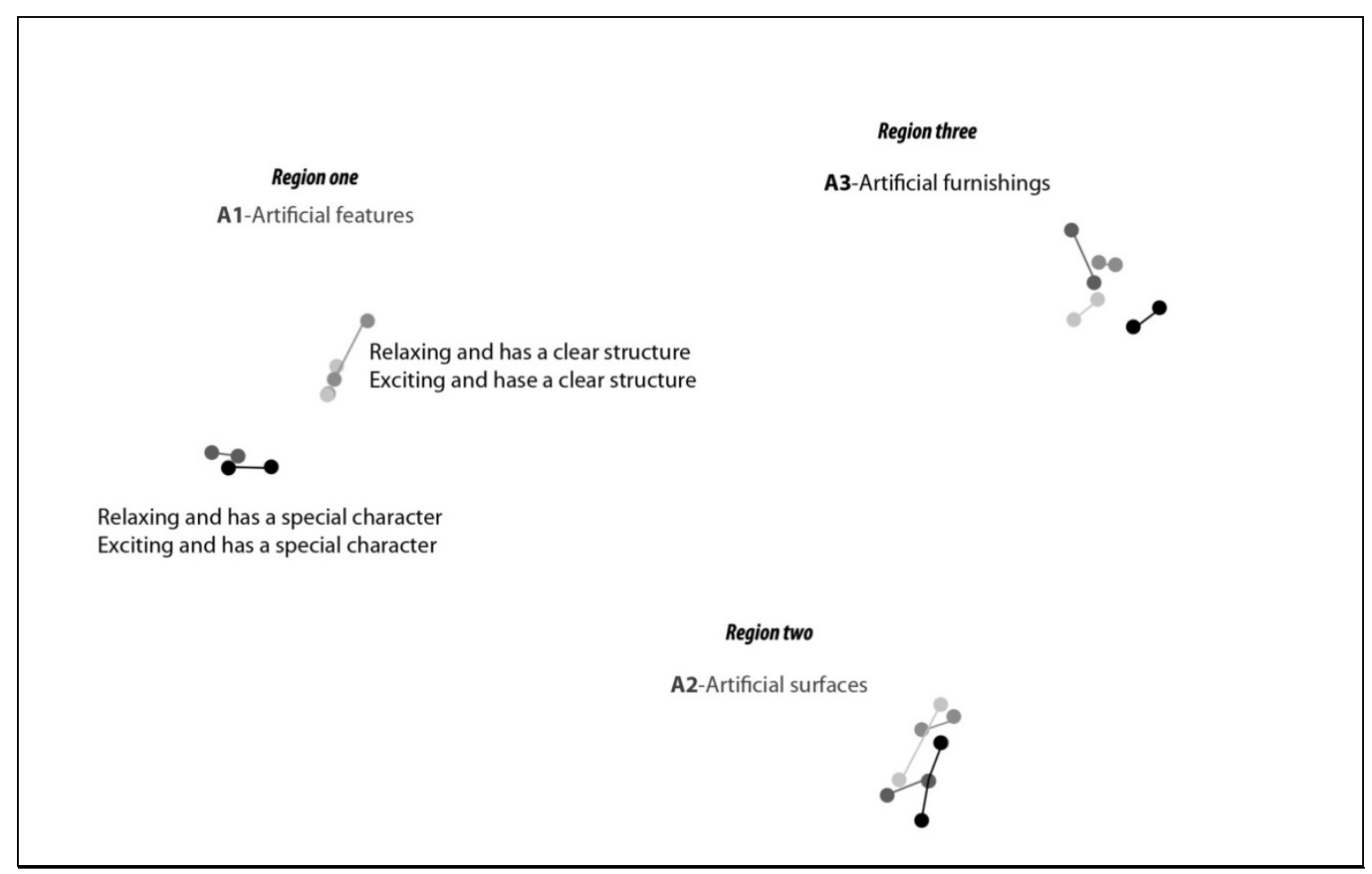

Figure 4-8: Two dimensional spatial representation of 24 artificial items classified according to affective-cognitive affordance (stress $=0.05, \mathrm{~N}=158$ ) 


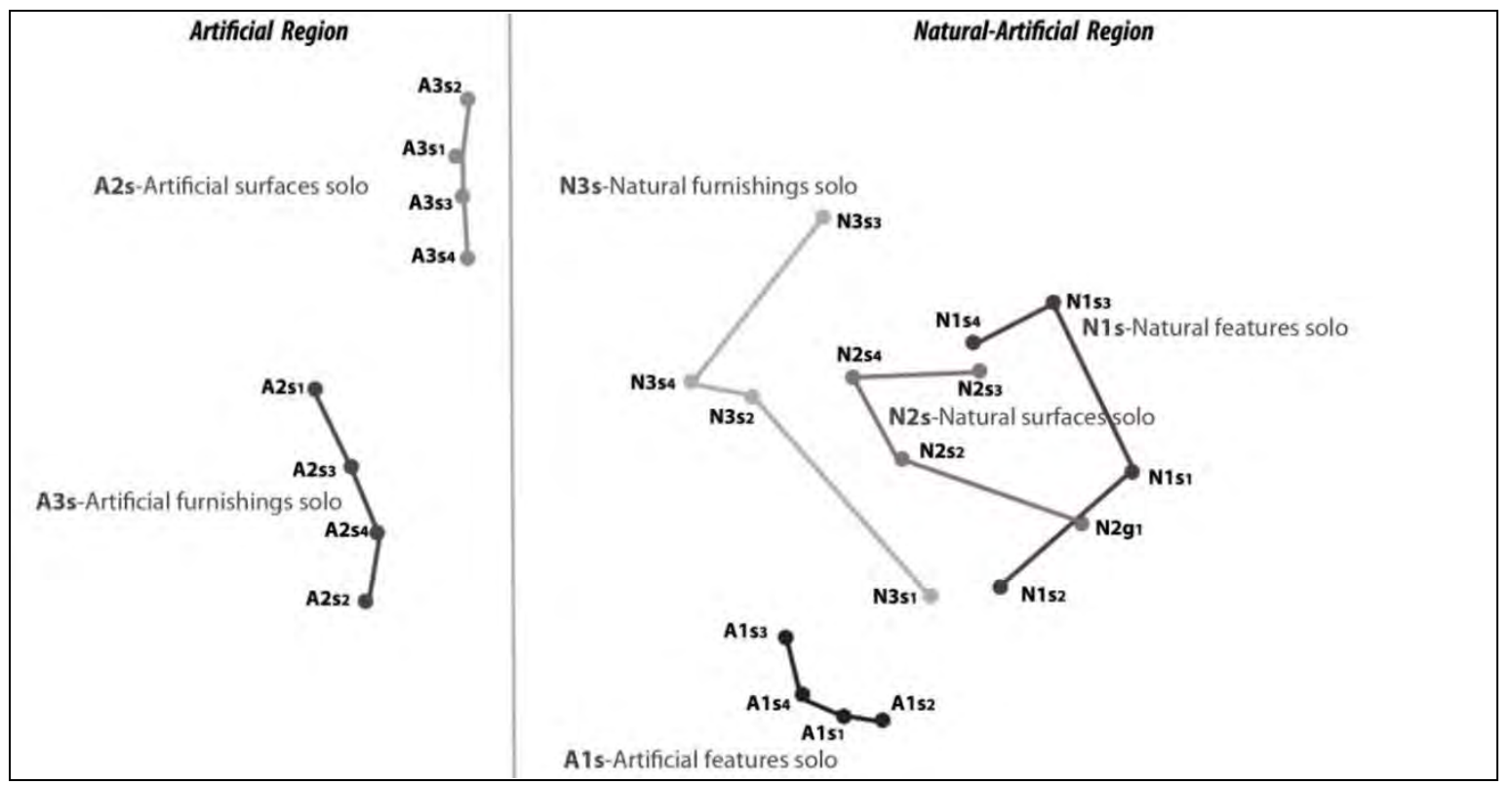

Figure 4-9: Two dimensional spatial representation of 24 items when being alone (stress=0.06, $\mathrm{N}=158$ )

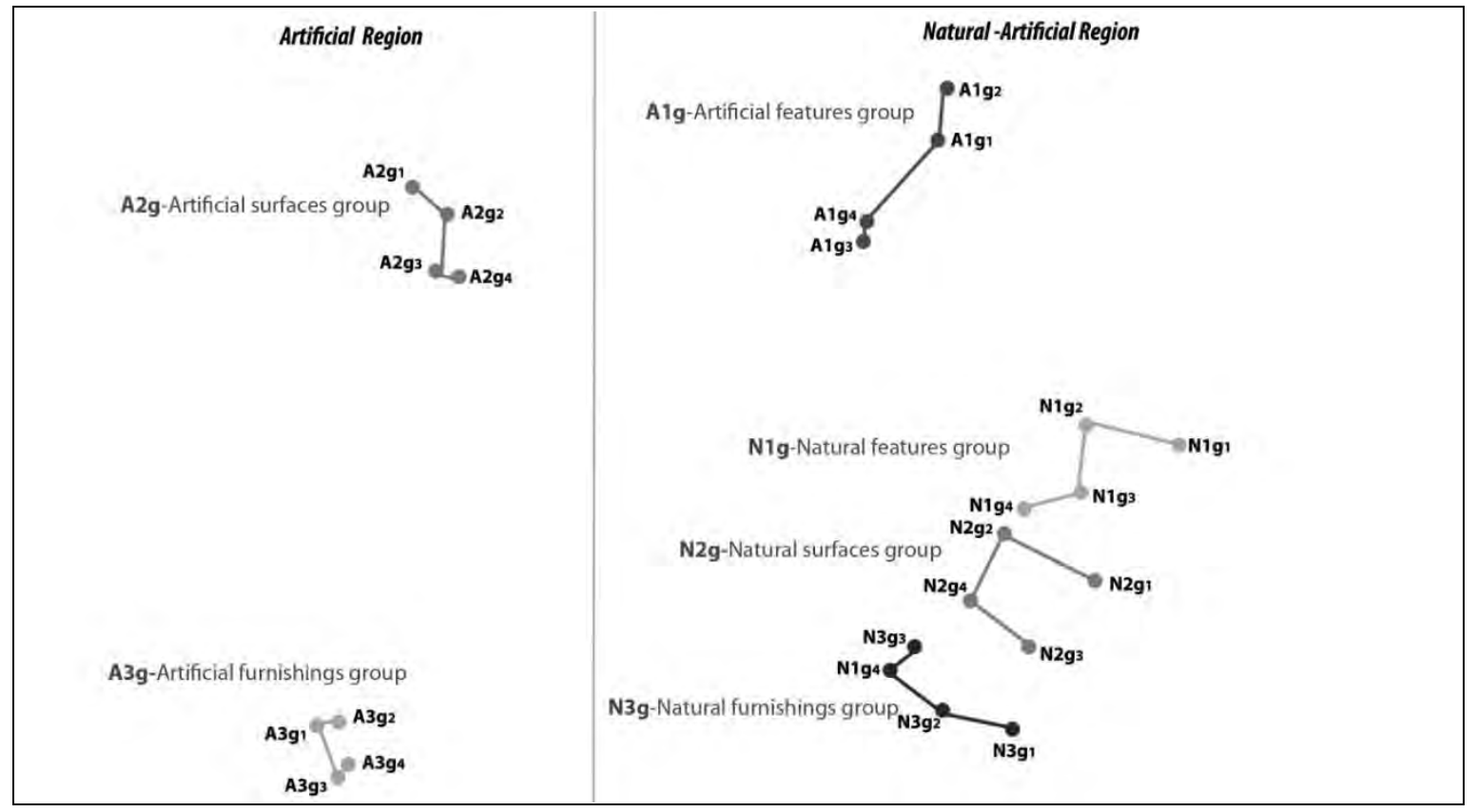

Figure 4-10: Two dimensional spatial representation of 24 items when with friends (stress=0.04, $\mathrm{N}=158$ )

\subsubsection{Behaviour}

Separate analysis was done for the 24 items when being alone and being with friends. The two regions represented when being alone contain artificial design elements, consisting of artificial furnishings and surfaces, and an artificial-natural region including artificial features and all natural elements. However, the artificial features are completely separate from the natural elements. Within the cluster of natural elements surfaces and natural 
features are intertwined and natural furnishings form a separate cluster (Figure 4-9). The mean preference ratings increase from left to right with artificial furnishings and surfaces receiving a negative rating (mean $<$ four) and natural surfaces and features receiving the highest ratings (See Table 4-1). Regarding the affective-cognitive affordance, natural elements make the environment relaxing more than exciting and bring character to the space more than making it legible. Artificial features with special character are preferred with no distinction between relaxing and exciting (Table 4-2).

Similar regions are observed when being with friends. However the distinction between design elements is more pronounced. Natural design elements remain close to but are not intertwined with artificial features (Figure 4-10). There is a separation between natural and artificial design elements and the distinction between natural features, surfaces and furnishings is more apparent. Preferences increase from left to right. When being with friends, special character is scored higher than having a clear structure and there is a preference for relaxing over exciting. Artificial features for both being alone and with friends are preferred for their special character and feeling of excitement (Table 4$3)$.

Table 4-3: Affective-cognitive affordance of behaviour

\begin{tabular}{|c|c|c|c|c|c|c|c|c|}
\hline & \multicolumn{4}{|c|}{ Alone } & \multicolumn{4}{|c|}{ With Friends } \\
\hline & \multicolumn{2}{|c|}{ Relaxing } & \multicolumn{2}{|c|}{ Exciting } & \multicolumn{2}{|c|}{ Relaxing } & \multicolumn{2}{|c|}{ Exciting } \\
\hline & $\begin{array}{c}\text { Special } \\
\text { Characte }\end{array}$ & $\begin{array}{c}\text { Clear } \\
\text { Structure }\end{array}$ & $\begin{array}{c}\text { Special } \\
\text { Characte }\end{array}$ & $\begin{array}{c}\text { Clear } \\
\text { Structure }\end{array}$ & $\begin{array}{c}\text { Special } \\
\text { Characte }\end{array}$ & $\begin{array}{c}\text { Clear } \\
\text { Structure }\end{array}$ & $\begin{array}{c}\text { Special } \\
\text { Characte }\end{array}$ & $\begin{array}{c}\text { Clear } \\
\text { Structure }\end{array}$ \\
\hline \multicolumn{9}{|l|}{ Natural } \\
\hline Furnishings & 5.39 & 4.97 & 4.64 & 4.42 & 5.46 & 5.01 & 5.14 & 4.90 \\
\hline Surfaces & 6.10 & 5.59 & 5.25 & 4.97 & 5.84 & 5.53 & 5.44 & 5.25 \\
\hline \multirow[t]{3}{*}{ Features } & 6.40 & 5.97 & 5.77 & 5.47 & 6.20 & 5.72 & 5.81 & 5.48 \\
\hline & 5.96 & 5.51 & 5.22 & 4.95 & 5.83 & 5.42 & 5.46 & 5.21 \\
\hline & \multicolumn{2}{|c|}{5.74} & \multicolumn{2}{|c|}{5.09} & \multicolumn{2}{|c|}{5.63} & \multicolumn{2}{|c|}{5.34} \\
\hline \multicolumn{9}{|l|}{ Artificial } \\
\hline Furnishings & 2.96 & 3.25 & 3.30 & 3.32 & 3.10 & 3.20 & 3.24 & 3.23 \\
\hline Surfaces & 3.57 & 3.59 & 3.66 & 3.56 & 3.64 & 3.61 & 3.75 & 3.75 \\
\hline \multirow[t]{3}{*}{ Features } & 5.04 & 4.73 & 5.21 & 4.82 & 5.18 & 4.85 & 5.26 & 4.92 \\
\hline & 3.86 & 3.85 & 4.06 & 3.90 & 3.97 & 3.89 & 4.08 & 3.97 \\
\hline & \multicolumn{2}{|c|}{3.86} & \multicolumn{2}{|c|}{3.98} & \multicolumn{2}{|c|}{3.93} & \multicolumn{2}{|c|}{4.03} \\
\hline
\end{tabular}




\subsection{Discussion}

The aim of Study One was to examine the effect of natural elements for the users of four small urban spaces based on Theory of Place. The results also show Affordance Theory is a valuable tool for describing the linkage between the three components of place. The results indicate that the meaning (cognitive-affective affordance) of natural elements utilised in the design, whether as features, surfaces, or furnishings is related to social activity in the place (Ulrich, 1983). Natural elements enhance activity in place through the meaning they give to it. The higher preference for features and surfaces over furnishings for both natural and artificial elements shows that the overall evaluation of the space, or the sense of initial feeling, is more important than evaluation of detail and furnishings. This finding is in line with theoretical arguments which suggest the initial affective response may form the cognitive evaluation (Rapoport, 1982; Zajonc, 1980). It also shows that structuring and organizing design elements (features and surfaces) contribute more to the meaning of the space than furnishings. This is consistent with studies that have mentioned focality and texture as aesthetic attributes of a place which contribute to its complexity and lead to a positive affect (Ulrich, 1983; Nasar, 1989). It also agrees with the studies of Kaplan (1983), Gold (1977), and Alexander et al. (1977) which show people have different reactions to various features of a natural setting with a higher preference for trees.

Overall, natural elements provide a relaxing place with special character more than an exciting place with a clear structure. However when people are with friends, the character of the space is important for social interaction, and being relaxed and exciting receive similar preferences, although when users are alone the relaxing character of natural elements is preferred. The higher rating for exciting artificial features with special character indicates that interesting features encourage use of the space (Ulrich, 1983), and they may enhance restrictiveness (Abdulkarim \& Nasar, 2014).

In this study preference is examined as a theoretical process. Two types of behaviour described as being with friends and being alone are examined alongside a broad understanding of natural design elements (furnishings, surfaces, and features). However, these broad preferences cannot be broken down into finer detail as there is no indication of what natural means to each participant. For example, natural might mean a domestic 
garden to one person and a forest to another. Although the process of decision making is the same the use of specific examples could lead to a different outcome based on individual preferences in a specific context. Although all the data collection sites were in Wellington with similar kinds of planting, there is no guarantee that all participants interpreted 'natural' to mean what they could see in each place. However, by using general descriptions average results for the whole group are indicative of a consistent process being used by each individual.

\subsection{Conclusion}

Study One used Facet Theory to examine linkages between the three components of Theory of Place. The results indicate that design elements with meaning enhance social activity through creating a sense of place, and that the cognitive and affective meanings of natural design elements are important when choosing a public space for social activity. Solo use of a public space is mostly valued for the relaxing quality of natural design elements, while social interactions with friends are preferred in design environments with exciting character. Both solo and group users prefer spaces with natural design elements but their reasons for this are different. This result leads to the second study, a more detailed investigation of natural design elements and social activity related to different combinations of design elements. 


\section{Chapter 5 \\ Design Elements in Public Space}

"We must understand that good urban places have a structure and an underlying dynamic of activity. Unless this is properly understood, it is more likely that rather than a successful urban place, what will be produced is an artefact" (Montgomery, 1998, pp. 94-95).

Using the framework of the Theory of Place, the aim of Study Two is to investigate the influence of natural elements on social activity when used or combined with other design elements in a public space. This research follows up the results of Study One, which indicate a preference for natural over artificial elements but which do not show on what this preference is based or which design elements trigger this preference. Additionally, the level of preference for artificial features was close to that of natural elements, which suggests a combination of elements may be preferred (See Section 4.8)

Kaplan (1983) found a combination of design and natural elements was preferred over what appeared to be a natural landscape. Similarly Montgomery (1998) in a discussion of how to recognize successful space stated that observing a successful one is simple but it is much more difficult to know why a place is successful and how this success can be generated in a physical setting. He criticized approaching this problem through providing a check list of desirable criteria because of the inevitable focus on surface appearance with this approach. Spaces that include some or all of these desired elements may still be left empty, suggesting that more is needed than simply following a checklist. Successful combinations will vary according to the situation of the space and the needs of its users. For example, a space that is near where people work is likely to be heavily used during breaks and lunchtimes, especially if it is the only such space in the vicinity, and this could have very little to do with its design. However, if a number of small public spaces are compared and the same combination is equally well used at different times, then it may be the combination of activities and design elements in the space that is important. This is the approach taken in this study.

Francis (1989) stated that people become involved in public space through human action, 
visual involvement, and their values or feeling about place. That is the structure of the physical environment in terms of its specific shape and particular material uses will both contribute to meeting human needs and to human evaluation of place (Lang, 1994). In the redefined functionalist approach Lang (Lang, 1994) emphasised physical setting and people's needs, stating that satisfying people's needs through the physical setting shapes people's concept of place: "We act within our biogenic and sociogenic environment in many ways. We act to sustain ourselves and/or them [the physical spaces], we act to change ourselves and or/them depending on our perception of our needs" (Lang, 1994, p. 28). Observation and case study investigations following this functional approach have provided quality criteria and guidelines to create a long list of necessary design elements for fulfilling human needs (Lennard \& Lennard, 1995; Marcus \& Francis, 1998; Smith, Nelischer, \& Perkins, 1997; Whyte, 1980).

\subsection{Human Needs and Design Elements}

Considering human needs as a basis for design was introduced by modernism with a functionalist approach (Lang, 1994). Lang criticised modernism for using a limited model of the human being. When it came to the functionalist approach he stated (1994, p. 151) that a more complete view of the human model was now possible based on empirical research and drawing on the work of clinical psychologists. However he added that any understanding of human needs will always be incomplete. In his book Urban design: the American experience he picked up Maslow's hierarchical model of basic human needs, describing it as a useful starting point for considering human behaviour and design objectives (Lang, 1994, p. 25).

Maslow (1954) identified five sets of needs: survival, safety and security, belonging, esteem, and self-actualization. He also defined a second set of needs: cognitive, and aesthetic. He began with the physiological needs for human survival: water, food, air and warmth, although Lang (1994) reformulated these as a range varying from the need for health to the need for comfort. In urban design a major concern is to create a comfortable environment rather than just providing for survival. Moving to security and safety needs, Lang (1994) states safety is a combination of several needs which have physiological and psychological concerns. The former means being safe from physical harm and the latter 
being aware of where a person is and that they have control of their environment. The third group of affiliation needs are more related to belonging. Being a member of a group brings both individual and group identity. The aesthetic attributes of where a person lives are important for human identity. Esteem needs are shown through each individual having control of their own life. In design it means use of architectural symbols or having territorial control through real or symbolic barriers (Lang, 1994). Self-actualizing needs mean something that people can be without regard to others. Maslow translated this as individuation. This need is most dependent on prior satisfaction of other lower needs (Lang, 1994; Maslow, 1954).

Lang (1994) argued Maslow's (1954) second set of cognitive and aesthetic needs to be parallel with the other needs including survival, safety and security, belonging, esteem, and self-actualization. The former is the need for knowing, learning, recognizing, and looking for relationships and meaning. The latter is the need for beauty. This need puts emphasis on the effect of the aesthetic quality of an environment and on the sense of belonging and esteem. This need is further divided into formal and symbolic aesthetics (Lang, 1994, p. 161). However, Maslow's hierarchy of needs has been criticised more recently. The main criticism of this theory is the way Maslow formulated the characteristic of self-actualization and the method and sampling he used. The second criticism that is more relevant to this research is concern over the hierarchy of the needs. The reason for this is that based on his model people living in poverty are not capable of higher needs, while some creative artists or authors that have lived in poverty have achieved selfactualization (McLeod, 2007). Tay and Diener (2011) tested Maslow's theory and concluded that human needs are similar across cultures but that the ordering of the needs is not correct. Their analysis confirmed that:

“...as hypothesized by Maslow (1954), people tend to achieve basic and safety needs before other needs. However, fulfilling the various needs has relatively independent effects on subjective well-being. For example, a person can gain well-being by meeting psychosocial needs regardless of whether his or her basic needs are fully met" (Tay \& Diener, 2011, p. 363). 
dimension of physical setting to define six categories of human needs; sense of safety, sense of belonging, environmental comfort, physical comfort and convenience, sense of control, and sensory pleasure. He stated places which satisfy these needs are likely to encourage social contact and interaction.

Carr el al. in Public Space (1992, pp. 91-97) argue that successful space must fulfil five important human needs; comfort, relaxation, passive engagement with the environment, active engagement with the environment, and discovery. "Comfort is a basic need...Without comfort it is difficult to perceive how other needs can be met" (Carr, 1992, p. 92). The degree of comfort determines the length of time people intend to remain in the place. Carr et al. further claimed that social comfort is as important as environmental and physical comfort. "Social and psychological comfort is a deep and pervasive need that extends to people's experiences in public space" (Carr, 1992, p. 97). Relaxation happens when body and mind are at ease. Relaxation is distinguished from comfort by the level of release. Comfort is seen as a prerequisite for relaxation. Passive engagement is indirect and it involves looking rather than talking or doing. Watching and observing people are popular and frequent activities in urban spaces, so places which provide more opportunity for watching within the physical setting could bring more people into them. Active engagement satisfies people's desire for interaction with other people. As Carr et al (1992) described the situation, having lively encounters in public space is a consequence of direct physical contact rather than just being within or moving across a place. Successful public space by use of design elements could also stimulate interaction between people. Indeed such design can foster the process in which external stimulus promotes people to interact and talk with others. Carr el al. (1992, p. 135) defined discovery as the opportunity to observe the different things present in a space when moving through it.

The necessity for meeting comfort, safety, belonging, and aesthetic needs is raised in many studies (Lennard and Lennard (1987; 1995), Marcus \& Francis (1998), Francis (2003), Gehl (1987), Pasaogullari and Doratli (2004), Shaftone (2008), Mc Glynn et al. (1985) , Ter (2011), Smith et al. (1997), Project for Public Space (2000)).

After reviewing the literature, this study investigates four human needs:
a) comfort
b) safety and security 

c) belonging and esteem
d) cognitive and aesthetic needs,

These are similar to Maslow's hierarchy of human needs, however self-actualization is not included here because many of the issues that deal with this need are related to the social or economic organization of society. Secondly, self-actualization is mostly met when other basic needs have been met (Maslow, 1954). Belonging and self-esteem are also here considered as one category because the main difference between these two is related to social organization, which is not the focus of this research.

The four needs identified here are similar to Mehta's (2006) framework by placing environment and physical comfort into one category and subsuming sense of control within belonging and esteem. Relaxation, as identified in the studies of Carr et al., will be met here in the category of comfort and, active and passive engagement is assumed to be met when aesthetic needs are met (Table 5-1).

Table 5-1: Comparing human needs in different studies

\begin{tabular}{|l|l|l|l|}
\hline Maslow & Carr et al. & Mehta & Thesis \\
\hline Survival & Comfort & Environmental comfort & Comfort \\
\hline Safety and security & Relaxation & Physical comfort and convenience & Safety and security \\
\hline Belonging & Passive engagement & Sense of safety & Belonging and self esteem \\
\hline Esteem & Active engagement & Sense of belonging & Cognitive and aesthetic \\
\hline Self-actualization & Discovery & Sense of control & \\
\hline Cognitive & & Sensory pleasure & \\
\hline Aesthetic & & & \\
\hline
\end{tabular}

\subsubsection{Comfort and Design Elements}

Place should meet physical, psychological, and social comfort. A sunny, sheltered, sittable, safe, green, clean, accessible, convenient, and welcoming place will meet comfort needs (Carr et al., 1992; Lang, 1994; McGlynn et al., 1985; Mehta, 2006; Project for public space, 2000; Ter, 2011). Design characteristics make spaces that vary according to their environmental attributes as well as land use and access points.

Sun has been identified as the greatest attraction for the use of public space (Share, 1978; Liebremann, 1984; Whyte, 1980; Banerjee and Loukaitou-Sedris, 1992 in Mehta 2006). Protection from sun or access to sun provides comfort (Carr et al., 1992; Project for public 
space, 2000). Whyte's studies of several plazas (1980) show sunlight to be an important factor in the use of outdoor spaces, however noting that on sunny days people seek shade and the canopy of trees. Among natural elements, trees are recommended both spatially and for other climatic reasons, such as acting as a wind shelter (Mehta, 2006; Sullivan, Kuo, \& Depooter, 2004; Whyte, 1980). Trees should be close to sitting places that afford a good view of the passing scene. Sitting under trees also provides a satisfying enclosure and sense of protection and safety (Lennard \& Lennard, 1987; Lennard \& Lennard, 1995; Whyte, 1980). Other research suggests a sitting place should get sun and be sheltered or protected from wind (Gehl, 1987; Lang, 1994). Whyte (1980) suggested places which are enclosed on three sides function well, as they provide physical and psychological comfort. Shelter also creates psychological comfort through sense of enclosure.

For a place to be perceived as safe, comfortable, and sittable it needs to afford different activities (Marcus \& Francis, 1998; Pasaogullari \& Doratli, 2004). This aim can be reached through having subspaces with different levels of privacy and enclosure (Lang, 1994), a café or a restaurant and shops around (Jane Jacobs, 1961; Mehta, 2006), and many places to sit of different types (Pasaogullari \& Doratli, 2004; Whyte, 1980). Furthermore, a place to meet social comfort should attract people with different physical abilities and from different cultures (Carr et al., 1992; Lang, 1994; Whyte, 1980). It should be accessible for all with no cultural and physical barrier. It should have a welcoming entrance and be a friendly environment.

In summary a place that meets comfort should have access to sun, shelter(s), different types of seats, subspaces with different degrees of enclosure and privacy, a welcoming entrance and places to eat and drink.

\subsubsection{Safety and Design Elements}

Safety is a physiological and psychological need (Lang, 1994; Lynch, 1960). People feel safe in an environment when the physical setting protects them from physical harm, helps them find their way, mentally organizes the environment, and satisfies their territorial and privacy needs (Lang, 1994). Safety needs are met by having a legible, imaginable, readable, visible, sheltered, enclosed, human scaled, well-maintained, clean, and green space (Carr et al., 1992; Lang, 1994; Lynch, 1960; McGlynn et al., 1985; Montgomery, 
1998; Nasar, 1989; Project for public space, 2000; Smith et al., 1997; Tibbalds, 1992).

Legibility is provided through elements that contribute to the structure of space. Land marks and meeting places, public art, sculpture, and street furniture play an important role in the legibility of place through providing orientation and direction to people ( $\mathrm{S}$. Kaplan, 1987; Lynch, 1960; Montgomery, 1998; Skjaeveland \& Garling, 1997).

Enclosure is also provided by use of structuring elements at an appropriate scale (Nasar, 1989; Ulrich, 1983), and examples of this type of element are edge, screen, and shelter (Skjaeveland \& Garling, 1997). The studies of Gehl (1987) and Alexander (1977) show that edge and pivot point are the places first occupied in a public space, suggesting that people do not like to be exposed in a place. Shelter provides both physical and mental safety through providing protection from any unpleasant sense experiences and from being observed (1997). Having an edge with appropriate height can make an intimate and human scaled place (Skjaeveland \& Garling, 1997). The proportions of surrounding buildings in terms of their horizontality and verticality, and windows and balconies giving on to the space increase the sense of safety and provide for possible future interaction. Entrances create visual enclosure and raise people's awareness of entering into open space (Lennard \& Lennard, 1987; Lennard \& Lennard, 1995). Subspaces, including enclosed places divided by planting and level change and sitting places can encourage people to take ownership of the space (Marcus \& Francis, 1998).

Lang argued space should have internal differentiation, for example through the creation of subspaces, but should also be perceived as a unit. Steps, benches, trees, walls, and ground surface can enhance the definition of territories within a space by enhancing the quality of interaction within it (Lang, 1994). Having subspaces or several small spaces is likely to meet a variety of activities and needs through distribution and segmentation of these (Lang, 1994; Skjaeveland \& Garling, 1997).

Safety has been shown to depend on maintenance, greenery, and the presence of other people (Gehl, 1987; R. Kaplan, 1983; Mehta, 2006; Whyte, 1980). Surface materials should support behaviour safely. If people perceive a place as affording certain activities this affects their use of the place and time spent in it. Each activity needs a special setting (Lang, 1994). Upkeep of surfaces and greenery also enhances the perception of safety (S. M. Gold, 1977; R. Kaplan, 1983; Sheets \& Manzer, 1991). Having a focal point like a tree, 97 
monument, or a piece of public art can make the environment safer by giving the opportunity for clustering activity and attracting more people (Lennard \& Lennard, 1987; Lennard \& Lennard, 1995; Mehta, 2006).

From the discussion above it seems that structuring variables such as shelter, edge, entrance are subspaces that make legible, readable, scaled and enclosed space. Natural and artificial focal points bring more eyes to the place and well-maintained surfaces and greenery provide safe places for different activities.

\subsubsection{Belonging and Design Elements}

A sense of belonging consists of belonging to people, and to a place or to events (Lang, 1994). Connection to place comes through an experience, and place identity emerges when a person's personality merges with a physical setting and environment that together contribute to the development of self-identity (Proshansky, Fabian, \& Kaminoff, 1983; Tuan, 1980). Although some of this is related to social relationships, character, meaningfulness, warmth, sense of place, familiarity, spirituality, continuity, and ownership create a sense of place and enhance belonging.

The character of a built environment and its architecture enables people to identify with a region and brings attachment to a place. Forms and materials, surface texture, changes in levels, or monuments enable the designer to create personality and facilitate differentiated use of place (Lennard \& Lennard, 1987; Lennard \& Lennard, 1995). For making a sense of place its design, resources, and arrangement should reflect the local context (Carr et al., 1992). The characteristics of an environment have symbolic meaning for people and influence the experience of associated meaning (Carr et al., 1992). Use of local architectural style and materials, and considering the local context, are seen as physical attributes that give a space character (Dempsey, 2008) and enhance attachment to the place.

Sense of place can be created by having an enclosed character. The design of the threshold experience and visual enclosure foster a sense of belonging (Lennard \& Lennard, 1987; Lennard \& Lennard, 1995). This quality of space focuses attention on the people and events within. Intimate and personal territories adjacent to buildings bring meaningful experiences. When personal or group territory is defined in a place this affords regular 
use by specific groups giving them the opportunity to manage it and modify it based on the individual or group needs (Carr et al., 1992).

To bond people to the place, both place and the events it contains need to connect people with past memories. People's memories are tied to an identifiable location. Having a focal point such as a fountain, piece of urban art, or memorable sculpture, gives an opportunity for clustering activity, and can provide a place for sitting, for leaning against, and even shelter from the sun. It can also create an identifiable place which contributes to the memory of space and sense of place. These attributes can provide memorable and distinct points for people when meeting (Lennard \& Lennard, 1987; Lennard \& Lennard, 1995; Marcus \& Francis, 1998) and connect them with their past memories. Arranging festivals in public space, and street performance can also bind people to the space (See section

\section{$5.3)$.}

The discussion above suggests that use of a familiar architectural style, materials, and plants, and having an enclosed and characterful space and subspaces all enhance the sense of belonging by increasing place identity.

\subsubsection{Cognitive and Aesthetic Needs and Design Elements}

Attractiveness, beauty, delight, pleasantness, diversity, complexity, order, mystery, spaciousness, enclosure, meaningfulness, being green, and cleanliness are qualities of place that can meet sensorial needs (Carr et al., 1992; Lennard \& Lennard, 1987; Lennard \& Lennard, 1995; Marcus \& Francis, 1998; Pasaogullari \& Doratli, 2004; Project for public space, 2000; Shaftoe, 2008; Smith et al., 1997; Ter, 2011).

Visual richness creates attractiveness, pleasantness, complexity, diversity and joy. A modelled building façade which gives awareness of time through shadows, natural materials which show the slow passage of time, seasonal and varied textures, colours, and building materials that provide sensual stimulation and fulfil curiosity are desired (Lennard \& Lennard, 1987; Lennard \& Lennard, 1995). In a discussion about visual complexity Marcus and Francis (1998) state having density in forms and colours, and different textures for various landscape elements, such as trees, shrubs, a fountain, sculpture, artefacts, space articulations, nooks, corners, and change in level, bring a sense of pleasure. Dempsey (2008) identified level change, screened and unscreened vistas, and 
ornamentation as examples of visual complexity. He also discussed the role of the perception of the visual environment on the character of place and feeling of safety and ease. Mehta (2006) by referring to studies on plazas, concluded street furniture, people's activities, trees, and density and variety of form, texture, and colour of shrubs and plants contribute to complexity and stimulate sensory pleasure. The size and scale of place and the overall height and detail of the surrounding buildings are identified as important factors that enhance aesthetic needs, self-esteem and create human feeling and joy (Gehl, 1987; Lennard \& Lennard, 1987; Lennard \& Lennard, 1995). However diversity can also be provided by affording different activities through having enough furniture, attractive focal points, defined edge, a sitting oasis, movable seats, food and drink, and subspaces with different function and character (Marcus \& Francis, 1998).

Structuring elements, which relate to spaciousness and enclosure, facilitate the cognitive organization of place (S. Kaplan, Kaplan, \& Brown, 1989; Skjaeveland \& Garling, 1997; Ulrich, 1983). Appleton (1996) connected spaciousness with enclosure. Enclosure in his study was understood through elements like edge, screen, shelter, and pivot point (Skjaeveland \& Garling, 1997). This is in line with the finding of Gehl (1987) that seating should be along the edge or around a pivot point. Having a focal point like a piece of public art or a fountain as one of the most important structuring elements can create a sense of joy, delight, and wonder, and enhance creativity, communication, comfort, and interaction (Marcus \& Francis, 1998).

Meaningful space is created when the physical setting assists the symbolic aesthetic. Meaningful place also encourages engagement (Ulrich, 1983). Lennard and Lennard (1987; 1995) describe public art as an important attribute for creating meaning. Such art can be the symbol of a city's identity. Alternatively, pieces of art can be designed to be touched or climbed, can act as a reminder of events and thus provide a point for communication, can stimulate creativity and imagination, can provide comfort and amenities, and can stimulate curiosity. Maintenance, architectural character, well-kept public space, and naturalness create a positive sensual experience and raise symbolic meaning. (Nasar, 1994; Pasaogullari \& Doratli, 2004; Shaftoe, 2008; Skjaeveland \& Garling, 1997).

Nassar (1994) emphasised aesthetic attributes and their effect on preference, dividing 
aesthetic variables into two groups, those that relate to structural forms and those that relate to the content of form. Lang (1994) called these formal aesthetics and symbolic aesthetics. Structural form involves shape, proportion, rhythm, scale, complexity, colour, shadowing, order, hierarchy, spatial relationships, incongruity, ambiguity, surprise and novelty (Nasar, 1994). Content form is not just about physical setting but is related to the meaning that people associate with a place. Nasar (1994) looked at the work of Kaplan and Kaplan (1982), Ward and Russell (1981), and Wohlwill (1976) among others and concluded that enclosure (further defined as openness, spaciousness, density, mystery), complexity (diversity, visual richness, ornamentation, information exchange rate), and order (unity, order, clarity) were the formal variables relevant to an aesthetic response. He further named naturalness, upkeep, intensity of use, and building style as the symbolic aesthetics group. He went on to investigate the effect of the use of vernacular style and building with character on people's preferences (Nasar, 1994). These aesthetic variables are discussed in more in detail in section 4.4.

Skjaeveland and Garling (1997) by referring to Nasar (1994) stated aesthetic content refers to the upkeep and presence of natural elements including planting, having a well maintained space, cleanness, and well painted facades. They identified architectural style, proportion, rhythm, scale, and building form as examples of formal aesthetics. Together, it seems that structural variables, like landmarks and focal points, level change and subspaces, shelter and edge, maintenance, and greenery contribute to aesthetic satisfaction.

Kaplan (1983) claims that nature meets human needs in diverse ways and effects the wellbeing of people. Several studies (Sections 4.4) have compared natural and urban settings and found a higher preference for nature over man-made. These studies mostly compared nature with artificial elements with little focus on specific types of natural element (tree, water, and sun) and their effect on satisfying human needs and human behaviour. Other studies show that even in an urban setting people mention water, trees, and greenery as desirable elements in public space (Balling \& Falk, 1982; Carr et al., 1992; R. Kaplan, 1983). There is no doubt that natural elements, especially vegetation, have climatic effects. Urban trees can positively alter the microclimate through production of shade and wind reduction and glare (Smardon, 1988), and can contribute to physical comfort (Lang, 1994). 
Whyte (1980) noted the importance of shade and relief from sun for user satisfaction. He also named access to sun as a particularly desirable design element. Carr et al. (1992) mentioned nature as an attribute which brings comfort and relaxation.

The effect of greenery on the feeling of safety has been emphasised in different studies (Mehta, 2006). The sight of well-maintained greenery may raise a positive feeling about city services (Smardon, 1988). Careful maintenance of a park can inspire respect. Evidence shows more litter is seen when the grass is not cut. Gold (1977) also added that maintenance reduces vandalism by adding order to the space.

Self-esteem and belonging are enhanced by the use of natural features, as their presence creates a bond with and attachment to place (Carr et al., 1992). The presence of features found in nature has a special meaning for people. Carr et al. (1992) argued the landscape characteristics of water, typical vegetation, and particular colour help to achieve a deeper meaning, with the need to use the qualities of the context to make them unique. Natural elements can suggest a biological connection with their surroundings, which backs up the past experiences that each individual has had with these universal elements. Carr et al. (1992) by referring to Driver and Greene (1977) and Balling and Falk (1982) argued that preference for a specific type of nature is innate and relates back to people's evolutionary history. Following evolutionary theory it is argued that vegetation is preferred because its presence indicates safety and the resource richness of the place and that the human response to trees is primarily uni-dimensional and affective (Balling \& Falk, 1982; S. Kaplan \& Kaplan, 1978). Constructivist theories have stated that this preference is a consequence of people's cultural values and responses are indirect as they are a result of people's evaluation of a setting (Lyons, 1983; in Sheets \& Manzer, 1991; Tuan, 1979).

Natural settings, especially water and vegetation, have psychological effects (Ulrich, 1986). Water has been found to have a positive influence on preference (Brush \& Shafer, 1975; Ulrich, 1981, 1986; Zube, Pitt, \& Anderson, 1975), viewing vegetation and water has produced positive emotional responses (Ulrich, 1981), and studies in suburban parks have shown a relationship between density of vegetation and affective experiences (Hull \& Harvey, 1989). Mature trees generate more emotional pleasure in terms of comfort and satisfaction than immature trees. Mature trees have a positive effect on preferences in neighbourhoods (Marcus, 1982) and streets (Getz, Karow, \& Kielbaso, 1982). Sheet and 
Manzar (1991) compared people's responses to a street with and without trees and found the street lined with trees looked friendlier and made the environment feel more cooperative. They claim that the human response to vegetation is not just aesthetic but is also affective and cognitive. A few studies have focused on the effect of natural elements on people's cognitive evaluation of place (Ward, 1977; Ward \& Russell, 1981) with the result that people classify their setting based on scale and naturalness. To emphasise the cognitive effect of vegetation Zube (1973) suggested that trees may affect people's perception of scale, such that cities with trees may seem smaller.

In a study of visual preference, Kaplan (1983) claimed that the human need for comprehending and making sense is pervasive and a setting should satisfy the human desire for involvement and exploration. In Kaplan's theoretical framework, for an environment to enhance involvement it should have complexity or richness, mystery, legibility and coherence. Natural settings have been rated for mystery and complexity (R. Kaplan, 1983). Some studies (Appleyard, 1978; Lennard \& Lennard, 1995) have pinpointed the aesthetic and visual properties of nature, specifically its colour, form and texture, as satisfying needs. The ability of trees to be a focal point, their role in visual diversity and complexity, and their effect on recalling a building through cognitive mapping have been pointed out by Zube (1973), Rappaport (1970) and Evans (1982). The attractiveness of a park has been correlated with the presence of trees and smooth ground texture (R. Kaplan, 1983). Studies have also compared the aesthetic preference for urban scenes with and without vegetation (Thayer Jr \& Atwood, 1978) and found a preference for scenes with vegetation. Alternatively, preferences in a high-density housing complex (Ulrich \& Addoms, 1981) indicate an urban setting which includes vegetation is rated far higher than one that does not. An urban setting characterized by many trees received more preferences than other built environment scenes (Herzog, Kaplan, \& Kaplan, 1982). Trees can provide a city visual diversity, visual order and aesthetic pleasure (S. M. Gold, 1976). However, the studies of More (1985) show having grass correlates with sleeping and eating in a public place, and even the number or size of trees correlates with specific activities. His study indicates the number of trees is related to eating, play, and music/dance. Shrubs have a negative effect on activities. 


\subsection{Framework for Investigating Design Elements}

Following a review of the relevant literature, comfort, safety and security, belonging, and cognitive and aesthetic needs are selected as the most important needs to be met in the design of a small urban public space. Comfort is assisted by having a place that is both sunny and shady, has enclosure, and is comfortable and accessible, with a sittable environment with different types of seating, shelter, and a welcoming entrance. Enclosure, legibility, and imageability, greenery, and being well-maintained are qualities of a safe space and are created through designing a place with defined edge, human scale, a focal point, and shelter. Sense of belonging is needed for place attachment (Lang, 1994) and comes from people's use of familiar spaces which have used local materials, and have a familiar architecture style. Spaciousness, legibility, imageability, enclosure, and complexity are the most important qualities of place that have the ability to meet aesthetic and cognitive needs. Among design elements maintenance, greenery, well-kept surfaces, structural forms (landmarks, sculpture, fountain, trees, and public art), subspaces, and level change contribute to these qualities. Table 5-2 shows the design elements to be used in assessing the social quality of small urban spaces in this research. The first column of this table lists human needs, the second presents the quality or qualities of space which meet the needs, and the third column sets out design elements that contribute to this quality. Note that some of the design elements may fit in two or three places. Here they are put in the category in which they best fit or where they are more frequently mentioned in the literature. 
Table 5-2: Design elements and human needs

\begin{tabular}{|l|l|l|}
\hline Needs & Description & Design elements \\
\hline Comfort Physical/Social & Sunny & Places to sit \\
& Sittable & Sunny and shady areas \\
& Accessible & Access \\
\hline Safety & Enclosure & Shelter \\
& Edge \\
Segibility & Size and human scale \\
\hline Sense of belonging and self- & $\begin{array}{l}\text { Familiarity } \\
\text { Ownership }\end{array}$ & $\begin{array}{l}\text { Local materials } \\
\text { Building style } \\
\text { Vegetation }\end{array}$ \\
\hline Sense of beauty, pleasantness & $\begin{array}{l}\text { Human scale } \\
\text { Complexity } \\
\text { Order } \\
\text { Mystery } \\
\text { Spaciousness } \\
\text { Enclosure } \\
\text { Legibility }\end{array}$ & $\begin{array}{l}\text { Maintenance (greenery and } \\
\text { Landmarks (sculpture, fountain, } \\
\text { trees) } \\
\text { Level change } \\
\text { Subspace }\end{array}$ \\
& Imageability & \\
\hline
\end{tabular}

Research shows how different design elements contribute to a person's understanding of place by meeting his/her different needs (Dempsey, 2008; Gehl, 1987; Lang, 1994; Lennard \& Lennard, 1987; Lennard \& Lennard, 1995; Marcus \& Francis, 1998; Mehta, 2006; Smith et al., 1997; Sullivan et al., 2004; Whyte, 1980). Table 5.3 summarizes the subspaces to be used in this investigation.

In order to put the subspaces in a design context they are organised based on the three 'aspects of design' used by Canter (1997b) for testing the Theory of Place. Canter used Markus's $(1982,1987)$ three components of design of function, form, and space. The facet 'aspect of design', "...therefore gives rise to a whole basket of hypotheses about how the structure of place experience may take on different forms in relation to the aspects of design that are being considered" (Canter, 1997b, p. 129).

Markus (1982) defined form as discourse dealing with the formal properties of space and its boundaries, and went on the state that it includes all geometrical properties, proportions, articulation, colour, ornamentation, and surface. He summarized these as style. Based on a study of Nassar (1994) form is divided into structural and content form. Here edge, landmark and subspace with level change are selected as structuring elements, and maintenance and style as content form. Function is the activities which occur or are inferred from the furnishing and equipment in spaces. For the design of public space, shelter and sitting place were chosen for their functional affordance. The spatial experience is related to the number and location of entrances, and the sequence and 
linkage of the spaces. In this study entrance is the access point that defines the relationship of a place with its surroundings (Table 5-2) and the reorganization of Table 52 in terms of function, form and space/location results in Table 5-3.

Table 5-3: Arrangement of design elements

\begin{tabular}{|l|l|l|l|}
\hline \multirow{2}{*}{ Aspect of design } & Design elements & \multirow{2}{*}{ Place to sit } & \\
\hline \multirow{2}{*}{ Form } & Physical & Shelter & \\
\cline { 2 - 4 } & Stimatic & Size, enclosure, order, complexity & Landmarks \\
\cline { 3 - 4 } & & & Subspace, level change \\
\cline { 3 - 4 } & \multirow{2}{*}{ Content form } & Style & Edge \\
\cline { 3 - 4 } & & Maintenance & \\
\hline \multirow{2}{*}{ Location } & & Access point & \\
\hline
\end{tabular}

When Table 5-3 is reorganized this generates 8 design elements in 3 categories.

Function: 1) Place to sit

2) Shelter

Form: 3) Landmarks

4) Subspace with level change

5) Edge

6) Building style

7) Maintenance

Location: 8) Entrance

The mapping sentence uses Materials $x$ design elements ( $2 \times 8$ types). Research indicates that natural design elements meet the different needs of people in different ways (Balling \& Falk, 1982; Carr et al., 1992; S. M. Gold, 1976; R. Kaplan, 1983; Lang, 1994; Mehta, 2006; Smardon, 1988; Ulrich \& Addoms, 1981; Zube, 1973 among others). For this reason here materials are divided into the two categories of natural and artificial material and these 
are combined with the eight design elements of place to sit, shelter, landmarks, subspaces with level change, edge, building style, maintenance, and entrance, which created 16 elements in the questionnaire;

Each of these attributes can be formed of natural or artificial materials.

- Natural place to sit: Grass area for sitting

- Artificial place to sit: Different types of bench

- Natural shelter: Sunny and shady areas using trees and shrubs

- Artificial shelter: Sunny and shady areas using man-made shelters

- Natural land marks: Places to sit around fountain/pool, or trees

- Artificial landmarks: places to sit around public art, sculpture or decorative features

- Natural subspace: Small space created by trees and plants

- Artificial subspaces: Small spaces created by steps and low walls

- Natural edge: Trees and plants of suitable height around the edge

- Artificial edge: Buildings of suitable height around the edge

- Natural style: Native and local plants

- Artificial style: Familiar building style

- Natural maintenance: Well-maintained greenery

- Artificial maintenance: Clean and well-kept surfaces

- Natural entrance: Welcoming and visible entrance defined by trees or plants

- Artificial entrance: Welcoming and visible entrance defined by man-made elements.

\subsection{Activity}

How people act in a space is dependent on how the place shapes their conception through its physical and behaviour settings. Canter (1977a) in his book The Psychology of Place proposed that for understanding people's reaction to a place and their actions within it, it is necessary to understand how and what people think.

Canter (1977a) developed this approach and in his Theory of Place states that anticipated behaviour in a physical setting and the behaviour that occurs in a place shape the human 
concept of the place, resulting in activity in it.

"We have not fully identified the place until we know a) what behaviour is associated with, or it is anticipated will be hosted in a given locus, b) what the physical parameters of that setting are, and c) the description, or conception, which people hold of that behaviour in that physical environment" (1977a, p. 158).

In other words, the relationship between action and physical setting is mediated by people's understanding of place. He stated that there are two important aspects to the description of place. The first is the evaluation of the place and the second is range and type of activity associated with it, noting that each description contains evaluation and an expectation linked to the behaviour that seems appropriate for the place. People's expectation of place is effected by observing action in the place which in turn leads to people's action in place (Figure 5-1).

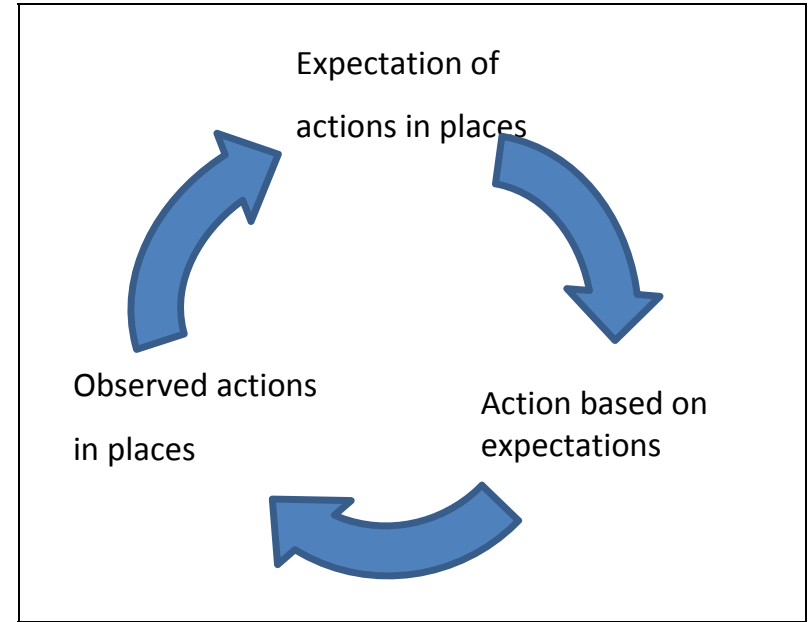

Figure 5-1: The self-fulfilling prophecy of place/activity expectation (Canter, 1977a, p. 121)

"Our expectations are a result of patterns of commonly occurring actions, and in return give rise to actions which fit in with those patterns. This is the reason why the conceptual systems, on one hand are so powerful, and on the other hand are so intertwined with concepts of goal, actions. Because actions are also inescapably linked to achievements of goals, the association between expectations and conceptions further helps to illustrate the dominance of the goaloriented, evaluative component of place conceptions" (Canter, 1977a, p. 121).

The character of space is formed from the types of activities it accommodates. 
Montgomery (1998) defined diversity and vitality as the two factors that produce activity. Vitality refers to the number of people in and around a place at different times, the number of events happening, and having good facilities. Events and activity at different times increase vitality (Lennard \& Lennard, 1987; Montgomery, 1998). Social events bond people together through common experience (Halprin, 1982). Events bring people from diverse backgrounds together (Lennard \& Lennard, 1987). Montgomery (1998) further stated that while "vitality" could be judged based on pedestrian flow and availability of a variety of things to do, while "diversity" refers to a wider range of indices, ranging from different types of land use to different sizes of street market and places for people watching. Diversity is a prerequisite for vitality (Carmona, 2010; Jane Jacobs, 1961), and the combination of activities and diversity in such attributes as tea houses, cafés, galleries, and focal points, creates vitality (Jane Jacobs, 1961). Pubs, restaurants and cafés encourage activity and people watching and bring eyes on to the space (Lennard \& Lennard, 1987; Lennard \& Lennard, 1995; Mehta, 2006; Montgomery, 1998; Whyte, 1980). 'People watching' is a popular activity in a public space. Whyte stated that what is attractive to people is other people, as people tend to sit in a place with pedestrian flow. The results of his observations show that where there are more people the chance for a meeting is highest. People also stop to talk in a place near to an object. People like defined places such as steps or the borders of a pool (Whyte, 1980). Gehl (1987) supported this finding:

"It is generally true that people and human activities attract other people. People are attracted to other people. They gather with and move about with others and seek to place themselves near others. New activities begin in the vicinity of events that are already in progress" (Gehl, 1987, p. 25).

In summary diversity in activities and diversity in land use both create vital public space and affect people's understanding of place.

In Study Two two types of non-participatory activities (observed) are used. Referring to Montgomery (1998), vitality and diversity are selected as attributes or attractors that produce activity. Having people around and a café or places to eat are factors which most affect these in the context of a small urban space (Gehl, 1987; Jane Jacobs, 1961; Lennard \& Lennard, 1987; Lennard \& Lennard, 1995; Whyte, 1980). The facets of observed activity thus become people around and nearby places to eat. 


\subsubsection{Type of Social Activity}

So far the discussion has been about how the physical setting offers expectation of action and activity within people's descriptions and evaluations of place. Based on that evaluation, people will become involved in activity at different levels. As discussed in section 4.3, Gehl (1987) divided social activities into five groups in terms of their intensity. The first non-contact level is seeing and hearing others, the second is chance contact, the third and fourth are being with acquaintances and friends respectively, and meeting with a close friend is identified as the most complex level of contact (Table 5-4). Passive contact is the prerequisite for other more complex contact and being in the same place increases the possibility of chance contact. Daily uses of space increase the chance of establishing and maintaining acquaintances. With frequent meeting friendship is maintained in a simple way. People maintain more and closer contact with people living or working close to them rather than those far away. Gehl also mentioned three types of talking, these being talking between people that are accompanying each other, talking with acquaintances, and talking with a stranger. The first two may happen anywhere and do not require a specific place but for the third people need to be at ease or sitting side by side or engaging in the same activity (Gehl, 1987). People also need something to talk about. Common activities as well as unexpected events generate conversation, the triangulation of Whyte (1980).

Table 5-4: Intensity of social activity (Gehl, 1987)

\begin{tabular}{|l|l|}
\hline \multirow{2}{*}{\begin{tabular}{|l|} 
High intensity \\
Low intensity
\end{tabular}} & close friendships \\
& friends \\
& acquaintances \\
\cline { 2 - 2 } & phance conacts \\
\hline
\end{tabular}

In a similar way, Lennand \& Lennand $(1987$, p. 62$)$ mentioned three forms of social life in public space:

a) Being with a known, familiar or unknown person,

b) Connections with others without speech, and

c) Being in public in a group. 
People may be together in a public space with somebody they know (people they have had previous interaction with or have specific personal knowledge of) or with somebody that they do not know but are familiar with (like a person they see regularly on the way to work) or with people they do not know but are aware of because of their presence in a public space. In the first type people could come to a place with their friends or family or meet them there, or even meet by chance and decide to stay in the place. In the second type of social life there is no direct contact and knowledge, and people become a source of fantasy. For the third type, even observing people brings a shared experience.

The level of involvement with people also differs, ranging from active engagement in social contacts (usually choosing places that are visible) to being a spectator and watching others. The degree of involvement may change between being an active and passive participant (Lennard \& Lennard, 1987).

In Study Two there are three types of participatory (involving) activities. People become involved in social activity at different levels depending on the quality of the space. Referring to Gehl (1987) and Lennard and Lennard (1987; 1995) three types of activity ranging from non-communal to medium and complex activities are selected. These become Spending time alone/people watching, Chance contact with new people, Meeting friends or being with my family.

\subsection{Mapping Sentence for Study Two}

Figure 5.2 gives the full mapping sentence on which the questions are based.

Public space with (design element setting) and (activity occurring) are pleasant for (involving activities).

Putting the number of variables together gives $(8 \times 2) \times 2 \times 3=96$ questions.

After analysis of the first survey and in order to investigate the design elements and their affordance discussed above, a second survey was carried out in the same way as the first and this became Study Two (See appendix 2). The questionnaire design used the same approach as for Study One (See section 4.6). First the facets were defined and then a mapping sentence constructed. Once the questionnaires were completed MDS was used for statistical analysis. 


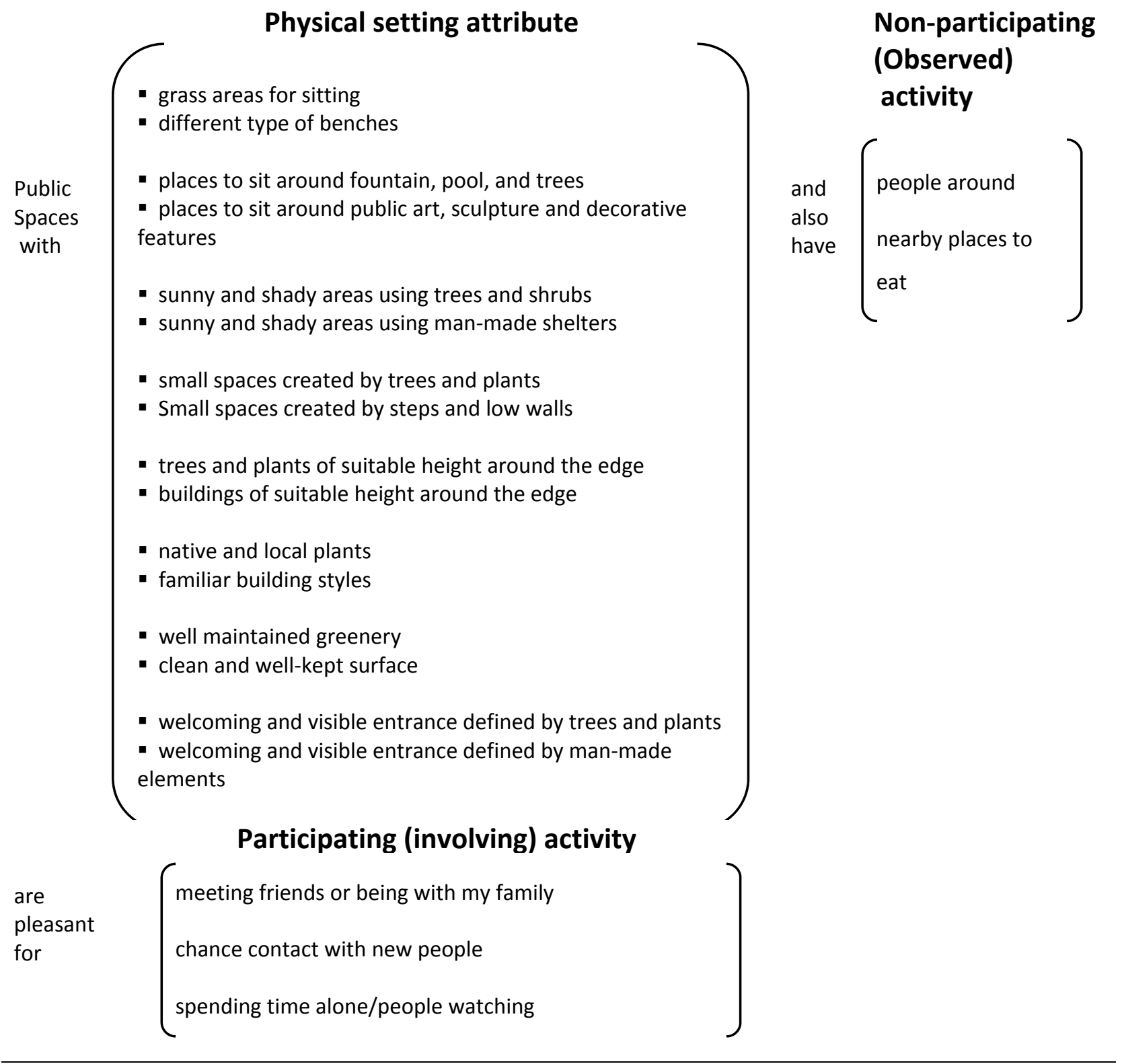

Figure 5-2: Mapping sentence

\subsection{Questionnaire Design}

Similar to Study One a questionnaire with three parts was used for data collection. Part one consisted of demographic and general questions around gender, ethnicity, age, suburb of residence, the length of living in Wellington, education, occupation, place of work, and frequency of using public space. The 96 questions in part two were defined by the wording of the mapping sentence, and split in 16 groups separated by design facets. A typical question is shown in Figure 5-3 and the complete questionnaire in Appendix 2. In part three people were asked to answer questions about the specific park they were using. Discussion of this part will be left until the conclusions where the results of both 
studies One and Two will be compared with those of the behaviour mapping.

\begin{tabular}{|c|c|c|c|c|c|c|c|}
\hline & $\begin{array}{l}\text { Strongly } \\
\text { agree }\end{array}$ & $\begin{array}{l}\text { Moderately } \\
\text { disagree }\end{array}$ & $\begin{array}{l}\text { Slightly } \\
\text { disagree }\end{array}$ & Neutral & $\begin{array}{l}\text { Slightly } \\
\text { agree }\end{array}$ & $\begin{array}{l}\text { Moderately } \\
\text { agree }\end{array}$ & $\begin{array}{l}\text { Strongly } \\
\text { agree }\end{array}$ \\
\hline $\begin{array}{l}\text { - Meeting friends or being } \\
\text { with my family }\end{array}$ & $\square$ & $\square$ & $\square$ & $\square$ & $\square$ & $\square$ & $\square$ \\
\hline $\begin{array}{l}\text { - Chance contact with } \\
\text { new people }\end{array}$ & $\square$ & $\square$ & $\square$ & $\square$ & $\square$ & $\square$ & $\square$ \\
\hline $\begin{array}{l}\text { - Spending time alone/ } \\
\text { people watching }\end{array}$ & $\square$ & $\square$ & $\square$ & $\square$ & $\square$ & $\square$ & $\square$ \\
\hline
\end{tabular}

Figure 5-3: A typical question for the Study Two survey

\subsubsection{Pilot Testing}

Pilot testing for this study has done to test the wording of questionnaire and estimate the time for filling it out. From memory at least 10 people were asked to give this feedback. This led to minor changes in wording of some physical setting attributes.

\subsection{Participant Sample}

As for to Study One data was collected (See Appendix 3) at the four data collection sites (Section 3.4) by handing the questionnaire out to people willing to fill it in on site. This continued at each site until 40 questionnaires had been filled in by people using the space for social activity. By the end 160 questionnaires were collected. Of the 160 participants 42.5\% were male and $57.5 \%$ female, aged between $14-75$ years with a mean age of 28.8 years. In terms of ethnicity the 160 participants were composed of 58.1\% NZ European, 11.3\% Asian, 10.6\% European, 5.6\% Maori, 2.5\% Middle Eastern/Latin, 1.3\% pacific, and $7.5 \%$ other ethnicity. Of the sample $65 \%$ had a tertiary qualification, $29.7 \%$ a secondary qualification, $1.9 \%$ a trade qualification, $2.5 \%$ other or lesser qualifications, and one participant did not respond to this question. The sample was $31.3 \%$ students, $28.1 \%$ working in a private company, $21.9 \%$ working in public service, $6.3 \%$ self-employed, $5 \%$ not employed, 1.3\% retired/work at home, and 5 participants did not answer. Regarding the place of work $62.5 \%$ worked in the city centre. From the sample $11.3 \%$ use public space every day, $33.1 \% 2$ or 3 times a week, $22.5 \%$ most days, $15 \%$ one a week, $12.5 \% 2$ or 3 times a month, and 3.8\% once a month (For comparison with Study One see Appendix 3). 


\subsection{Results}

Again MDS is used for analysing the data (See section 3.2.6).The two dimensional spatial representation (Figure 5-4) of the 96 questions in the surveys split into two separate regions based on involving activities. Facets with chance contact with new people form region one and being with friends and spending time alone form region two. These are consistent for surveys that were filled in on weekdays and at the weekend. Within the chance contact region 32 design elements can be divided into three subspaces. The first preferred spaces have well-kept surface and greenery. The second group is a mixed group of natural and artificial elements, consisting of seven natural design elements and three artificial. The third subgroup is formed by three artificial elements, these being small space created by steps and low walls, buildings around the edge, and places with familiar building style. Although within region two, preferences for design elements when being alone and with friends and family are close, it is possible to insert a line separating them (dashed line in Figure 5-4). In this region first preferred attributes are dominated by natural design elements and consist of five natural design elements (grass area to sit, wellmaintained greenery, places to sit around fountain, pool or trees, sunny and shady areas using trees and shrubs, and native and local plants) and one artificial attribute (well-kept surface). The second subspace is a combination of natural and artificial design elements, these being entrance with natural features, small spaces divided by plants, edge with natural elements, benches, seats around public art, man-made shelter, and entrance with artificial elements. The third subgroup is similar to the third group in region one. Preferences for design elements move from upper right to lower left, with right being more preferred.

As mentioned before, in region two separate clusters for being alone and with family are obvious in all subspaces. Where possible clusters are identified by drawing an elliptical boundary the thick line separates regions, and the thinner lines sub regions (Figure 5-4). In all four data collection sites two main region are obvious. Three groups of preferred attributes can be seen in all sites and separation between being alone and with friends and family exists in all cases, although in Te Aro Park both are more intertwined. As the number of respondents for overall analysis is more than for each site, separation between sub-regions is clearer in the plot of the overall representation than for the separate sites 
(Figures 5-5 to 5-8). Although a spatial representation plot helps to identify clusters, any final decision about clusters must be made using the preference means.

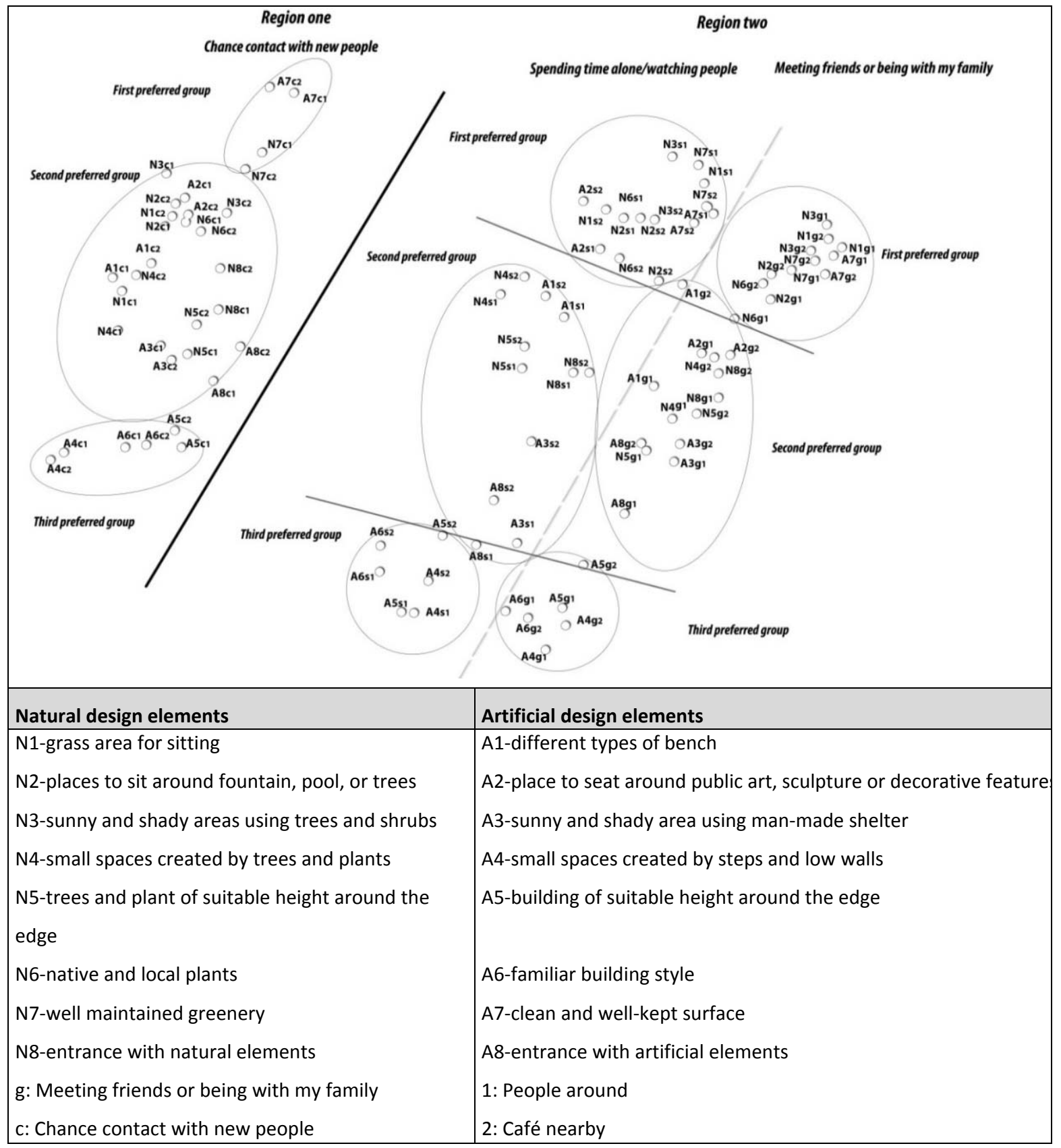

Figure 5-4: Two dimensional representation of 96 items (stress= $0.12, \mathrm{~N}=160$ )

While the order of preferred attributes for being alone and with family is reasonably similar, when it comes to chance contacts there are different preferences for design elements (Table 5-5). 
Table 5-5: Order of preferences according to involving activity facet

(Colours are added to show similar ranking of subspaces in different situations and thick lines demonstrate divided lines between design elements in Figure 5-4).

\begin{tabular}{|c|c|c|c|c|c|}
\hline $\begin{array}{l}\text { Meeting friends or being with my } \\
\text { family }\end{array}$ & Mean & Spending time alone & Mean & $\begin{array}{l}\text { Chance contact with new } \\
\text { people }\end{array}$ & Mean \\
\hline N1-grass area for sitting & 6.32 & N7-well maintained greenery & 5.88 & $\begin{array}{l}\text { A7-clean and well-kept } \\
\text { surface }\end{array}$ & 4.90 \\
\hline A7-clean and well-kept surface & 6.23 & A7-clean and well-kept surface & 5.85 & N7-well maintained greenery & 4.77 \\
\hline N7-well maintained greenery & 6.15 & $\begin{array}{l}\text { N2-places to sit around } \\
\text { fountain, pool, or trees }\end{array}$ & 5.70 & $\begin{array}{l}\text { N8-entrance with natural } \\
\text { elements }\end{array}$ & 4.53 \\
\hline $\begin{array}{l}\text { N2-places to sit around fountain, } \\
\text { pool, or trees }\end{array}$ & 6.14 & N1-grass area for sitting & 5.66 & $\begin{array}{l}\text { N2-places to sit around } \\
\text { fountain, pool, or trees }\end{array}$ & 4.53 \\
\hline N6-native and local plants & 5.97 & N6-native and local plants & 5.59 & N6-native and local plants & 4.48 \\
\hline $\begin{array}{l}\text { N3-sunny and shady areas using } \\
\text { trees and shrubs }\end{array}$ & 5.92 & $\begin{array}{l}\text { N3-sunny and shady areas } \\
\text { using trees and shrubs }\end{array}$ & 5.51 & $\begin{array}{l}\text { A8-entrance with artificial } \\
\text { elements }\end{array}$ & 4.42 \\
\hline N8-entrance with natural elements & 5.85 & $\begin{array}{l}\text { A2-place to seat around public } \\
\text { arts, sculpture or decorative } \\
\text { features }\end{array}$ & 5.42 & $\begin{array}{l}\text { A3-sunny and shady area } \\
\text { using man-made shelter }\end{array}$ & 4.42 \\
\hline $\begin{array}{l}\text { N4-small spaces created by trees } \\
\text { and plants }\end{array}$ & 5.78 & $\begin{array}{l}\text { N8-entrance with natural } \\
\text { elements }\end{array}$ & 5.40 & N1-grass area for sitting & 4.37 \\
\hline $\begin{array}{l}\text { A2-place to seat around public arts, } \\
\text { sculpture or decorative features }\end{array}$ & 5.7 & $\begin{array}{l}\text { N4-small spaces created by } \\
\text { trees and plants }\end{array}$ & 5.33 & $\begin{array}{l}\text { N3-sunny and shady areas } \\
\text { using trees and shrubs }\end{array}$ & 4.34 \\
\hline A1-different types of bench & 5.56 & $\begin{array}{l}\text { A3-sunny and shady area } \\
\text { using man-made shelter }\end{array}$ & 5.29 & $\begin{array}{l}\text { A2-place to seat around } \\
\text { public arts, sculpture or } \\
\text { decorative features }\end{array}$ & 4.34 \\
\hline $\begin{array}{l}\text { A3-sunny and shady area using } \\
\text { man-made shelter }\end{array}$ & 5.51 & A1-different types of bench & 5.24 & $\begin{array}{l}\text { N5-trees and plant of suitable } \\
\text { height around the edge }\end{array}$ & 4.33 \\
\hline $\begin{array}{l}\text { N5-trees and plant of suitable } \\
\text { height around the edge }\end{array}$ & 5.49 & $\begin{array}{l}\text { N5-trees and plant of suitable } \\
\text { height around the edge }\end{array}$ & 5.17 & $\begin{array}{l}\text { N4-small spaces created by } \\
\text { trees and plants }\end{array}$ & 4.32 \\
\hline A8-entrance with artificial elements & 5.41 & $\begin{array}{l}\text { A8-entrance with artificial } \\
\text { elements }\end{array}$ & 5.02 & A1-different types of bench & 4.18 \\
\hline $\begin{array}{l}\text { A5-building of suitable height } \\
\text { around the edge }\end{array}$ & 5.09 & $\begin{array}{l}\text { A4-small spaces created by } \\
\text { steps and low walls }\end{array}$ & 4.8 & $\begin{array}{l}\text { A5-building of suitable height } \\
\text { around the edge }\end{array}$ & 4.17 \\
\hline $\begin{array}{l}\text { A4-small spaces created by steps } \\
\text { and low walls }\end{array}$ & 5.06 & $\begin{array}{l}\text { A5-building of suitable height } \\
\text { around the edge }\end{array}$ & 4.78 & A6-familiar building style & 4.15 \\
\hline A6- familiar building style & 5.01 & A6-familiar building style & 4.62 & $\begin{array}{l}\text { A4-small spaces created by } \\
\text { steps and low walls }\end{array}$ & 3.91 \\
\hline
\end{tabular}

An inspection of the means for natural and artificial elements, broken down by involving activity (Table 5-6) indicates:

- A preference for natural element attributes over artificial elements on weekdays, at the weekend, and in the three situations of spending time alone, with family and friends, and chance contact with new people. However this difference is minor for the latter. A Friedman test was conducted to evaluate differences in medians between two materials: natural (Median $=257)$, artificial $($ Median $=240)$. The test was significant $\chi^{2}(1, N=160)=80.667, p<0.000$, indicating a significantly higher preference for natural materials. A Friedman test was conducted for all situations mentioned above and $p<0.000$.

- There are three groups of preferred attributes in each of the three situations. While both spending time with friends and being alone have similar preferred groupings, 
chance contact is different from them. However for all situations artificial and natural maintenance are at the top of the list and three artificial attributes (small spaces created by steps and low walls, buildings of suitable height around the edge, and familiar building style) are at the bottom of the list.

- Within both spending time alone and meeting friends natural elements almost form the first preferred group and only well-kept surfaces as an artificial attribute are additional. A mixed group of natural and artificial elements form the second preferred group and a group of three artificial attributes receives the lowest preferences.

- The mean preference for all design elements is highest when being with friends and family, followed by spending time alone, with chance contact with new people receive the lowest rating. A Friedman test was conducted to evaluate differences in medians between three activities: being with friends (Median $=185$ ), chance contact with new people $($ Median $=142)$, and being alone $($ Median $=173)$. The test was significant $\chi 2(2$, $N=160)=144.24, p<0.000$, indicating significant differences in the preference ratings for the three artificial design elements. Follow-up pairwise comparisons were conducted using a Wilcoxon test. The median preference for being with friends was significantly greater than the chance contact $(p<0.000)$ and being alone $(p<0.000)$, with the median preference for being alone significantly greater than the median preference for chance contact with new people $(p<0.000)$.

Table 5-6: Mean preferences for natural and artificial design elements

\begin{tabular}{|c|c|c|c|c|c|c|c|c|c|c|c|c|c|}
\hline & & \multicolumn{4}{|c|}{ friends } & \multicolumn{4}{|c|}{ alone } & \multicolumn{4}{|c|}{ chance } \\
\hline & & \multicolumn{2}{|c|}{ Natural } & \multicolumn{2}{|c|}{ Artificial } & \multicolumn{2}{|c|}{ Natural } & \multicolumn{2}{|c|}{ Artificial } & \multicolumn{2}{|c|}{ Natural } & \multicolumn{2}{|c|}{ Artificial } \\
\hline & & $w / d$ & w/e & $w / d$ & w/e & $w / d$ & w/e & $w / d$ & w/e & $w / d$ & w/e & $w / d$ & w/e \\
\hline 1 & place to sit & 6.29 & 6.34 & 5.59 & 5.52 & 5.73 & 5.59 & 5.37 & 5.1 & 4.32 & 4.41 & 4.18 & 4.18 \\
\hline 2 & shelter & 6.00 & 5.84 & 5.45 & 5.69 & 5.67 & 5.34 & 5.39 & 5.18 & 4.32 & 4.36 & 4.29 & 4.54 \\
\hline 3 & land-marks & 6.14 & 6.13 & 5.46 & 5.62 & 5.84 & 5.55 & 5.17 & 5.01 & 4.51 & 4.54 & 4.16 & 4.51 \\
\hline 4 & sub-space & 5.71 & 5.84 & 5.05 & 5.07 & 5.43 & 5.22 & 4.99 & 4.61 & 4.24 & 4.40 & 3.78 & 4.03 \\
\hline 5 & edge & 5.42 & 5.56 & 5.1 & 5.08 & 5.19 & 5.14 & 4.95 & 4.64 & 4.3 & 4.35 & 4.11 & 4.23 \\
\hline 6 & building style & 5.83 & 5.91 & 4.73 & 5.28 & 5.69 & 5.48 & 4.56 & 4.67 & 4.41 & 4.54 & 3.94 & 3.94 \\
\hline 7 & maintenance & 6.11 & 6.18 & 6.19 & 6.26 & 6.00 & 5.75 & 6.01 & 5.68 & 4.72 & 4.81 & 4.91 & 4.91 \\
\hline 8 & access point & 5.71 & 5.99 & 5.22 & 5.59 & 5.4 & 5.39 & 5.05 & 4.98 & 4.38 & 4.68 & 4.33 & 4.33 \\
\hline All & & \multicolumn{2}{|c|}{5.94} & \multicolumn{2}{|c|}{5.43} & \multicolumn{2}{|c|}{5.52} & \multicolumn{2}{|c|}{5.08} & \multicolumn{2}{|c|}{4.40} & \multicolumn{2}{|c|}{4.30} \\
\hline & Weekdays & \multicolumn{2}{|l|}{$(W / d)$} & & & & & \multicolumn{2}{|c|}{ Weekend } & \multicolumn{2}{|l|}{$(\mathrm{W} / \mathrm{e})$} & & \\
\hline
\end{tabular}

The preference for natural over artificial design elements can also be seen for each of the four data collection sites (Tables 5-7 to 5-10). 
Table 5-7: Glover Park

\begin{tabular}{llcccccc}
\hline & \multicolumn{2}{c}{ With my family } & \multicolumn{2}{c}{ Alone } & \multicolumn{2}{c}{ Chance contact } \\
& & Natural & Artificial & Natural & Artificial & Natural & Artificial \\
\hline 1 & place to sit & 6.28 & 5.39 & 5.62 & 5.10 & 3.95 & 3.93 \\
2 & shelter & 5.82 & 5.50 & 5.35 & 5.18 & 4.11 & 4.19 \\
3 & land-marks & 5.99 & 5.20 & 5.52 & 4.84 & 4.31 & 4.18 \\
4 & sub-space & 5.87 & 5.14 & 5.13 & 4.53 & 4.13 & 3.84 \\
5 & edge & 5.62 & 5.22 & 5.11 & 4.88 & 4.23 & 4.10 \\
6 & building style & 5.79 & 5.18 & 5.36 & 4.69 & 4.34 & 3.97 \\
7 & maintenance & 6.70 & 5.99 & 5.77 & 5.64 & 4.66 & 4.70 \\
8 & access point & 5.65 & 5.49 & 5.24 & 5.12 & 4.28 & 4.30 \\
& Overall & 5.89 & 5.39 & 5.39 & 5.00 & 4.25 & 4.15 \\
\hline
\end{tabular}

Table 5-8: Civic Square

\begin{tabular}{|c|c|c|c|c|c|c|c|}
\hline & & \multicolumn{2}{|c|}{ With my family } & \multicolumn{2}{|c|}{ Alone } & \multicolumn{2}{|c|}{ Chance contact } \\
\hline & & Natural & Artificial & Natural & Artificial & Natural & Artificial \\
\hline 1 & place to sit & 6.24 & 5.55 & 5.62 & 5.39 & 4.53 & 4.28 \\
\hline 2 & shelter & 5.83 & 5.63 & 5.46 & 5.59 & 4.39 & 4.58 \\
\hline 3 & land-marks & 6.16 & 5.52 & 5.92 & 4.95 & 4.54 & 4.12 \\
\hline 4 & sub-space & 5.64 & 5.00 & 5.19 & 4.83 & 4.23 & 3.86 \\
\hline 5 & edge & 5.57 & 5.15 & 5.29 & 4.78 & 4.31 & 4.14 \\
\hline 6 & style & 5.72 & 5.02 & 5.64 & 4.63 & 4.40 & 4.23 \\
\hline 7 & maintenance & 6.24 & 6.39 & 5.89 & 5.87 & 4.77 & 4.85 \\
\hline \multirow[t]{2}{*}{8} & access point & 5.97 & 5.50 & 5.45 & 4.91 & 4.68 & 4.54 \\
\hline & All & 5.92 & 5.47 & 5.56 & 5.12 & 4.48 & 4.33 \\
\hline
\end{tabular}

Table 5-9: Te Aro Park

\begin{tabular}{llcccccc}
\hline & & \multicolumn{2}{c}{ With my family } & \multicolumn{2}{c}{ Alone } & \multicolumn{2}{c}{ Chance contact } \\
& & Natural & Artificial & Natural & Artificial & Natural & Artificial \\
\hline 1 & place to sit & 6.39 & 5.68 & 5.91 & 5.30 & 4.41 & 4.18 \\
2 & shelter & 5.88 & 5.45 & 5.55 & 5.06 & 4.40 & 4.38 \\
3 & land-marks & 6.10 & 5.75 & 5.59 & 5.2 & 4.54 & 4.53 \\
4 & sub-space & 5.81 & 4.83 & 5.49 & 4.58 & 4.61 & 3.85 \\
5 & edge & 5.13 & 4.78 & 4.99 & 4.6 & 4.26 & 4.14 \\
6 & style & 6.00 & 4.80 & 5.64 & 4.49 & 4.64 & 4.13 \\
7 & maintenance & 6.13 & 6.13 & 5.98 & 5.88 & 4.93 & 5.01 \\
8 & access point & 5.56 & 5.56 & 5.35 & 5.10 & 4.48 & 4.49 \\
& overall & 5.88 & 5.37 & 5.56 & 5.03 & 4.53 & 4.34 \\
\hline Table 5-10: Midland Park & \multicolumn{5}{c}{ Alone } & Chance contact \\
\hline & & With my family & & & & \\
& & Natural & Artificial & Natural & Artificial & Natural & Artificial \\
\hline 1 & place to sit & 6.38 & 5.68 & 5.73 & 5.23 & 4.41 & 4.35 \\
2 & shelter & 6.33 & 5.68 & 5.88 & 5.65 & 4.40 & 4.40 \\
3 & land-marks & 6.35 & 5.70 & 6.03 & 5.33 & 4.54 & 4.25 \\
4 & sub-space & 5.58 & 5.03 & 5.38 & 5.20 & 4.61 & 3.98 \\
5 & edge & 5.55 & 4.90 & 5.35 & 4.73 & 4.26 & 4.15 \\
6 & style & 6.00 & 4.48 & 5.95 & 4.33 & 4.64 & 3.88 \\
7 & maintenance & 6.35 & 6.38 & 6.20 & 6.28 & 4.93 & 5.00 \\
8 & access point & 5.65 & 5.00 & 5.63 & 4.88 & 4.48 & 4.20 \\
& overall & 6.02 & 5.36 & 5.77 & 5.20 & 4.53 & 4.28 \\
\hline
\end{tabular}




\subsubsection{Spending Time Alone and Time with People}

The 64 items from spending time alone and with friends were analysed within a two dimensional plot by design features (16 design elements) (Figure 5-5). Because for all design elements having people around and café nearby are close together with similar means, in the map only the name of the attribute is given without dividing them eg. A7s1well-kept surfaces and materials (natural, artificial) (Figure 5-6 and5-7). The plots show that:

- There are two clear separate regions for spending time alone and with friends

- There are three separate regions of preferred attributes within these two situations (groups 1-3 below).

Group one: a natural group

a) natural attributes (grass area for sitting, well-kept greenery, sunny and shady areas using trees and shrubs, places to sit around fountain, pool, or trees, native and local plants)

b) artificial attributes (well-kept surfaces)

Group two: a mixed group of natural and artificial elements

a) natural attributes (entrance defined by natural elements, small spaces created by trees and plants, trees and plants of suitable height around the edge)

b) artificial attributes (places to sit around public art, sculpture or decorative features, different types of bench, sunny and shady areas using man-made shelters, and entrance defined by man-made elements)

Group three: an artificial group

a) Artificial attributes (building of suitable height around the edge, small spaces created by steps, familiar building styles).

- Similarity between preferred attributes when being with friends and alone shows this group enhances both type of involving activity. However they are more important for being with friends than being alone.

- Separation between clusters when spending time with family is more obvious than for spending time alone.

- Spatial ordering from upper right to lower left shows the highest position for natural attributes and the lowest for artificial attributes. 


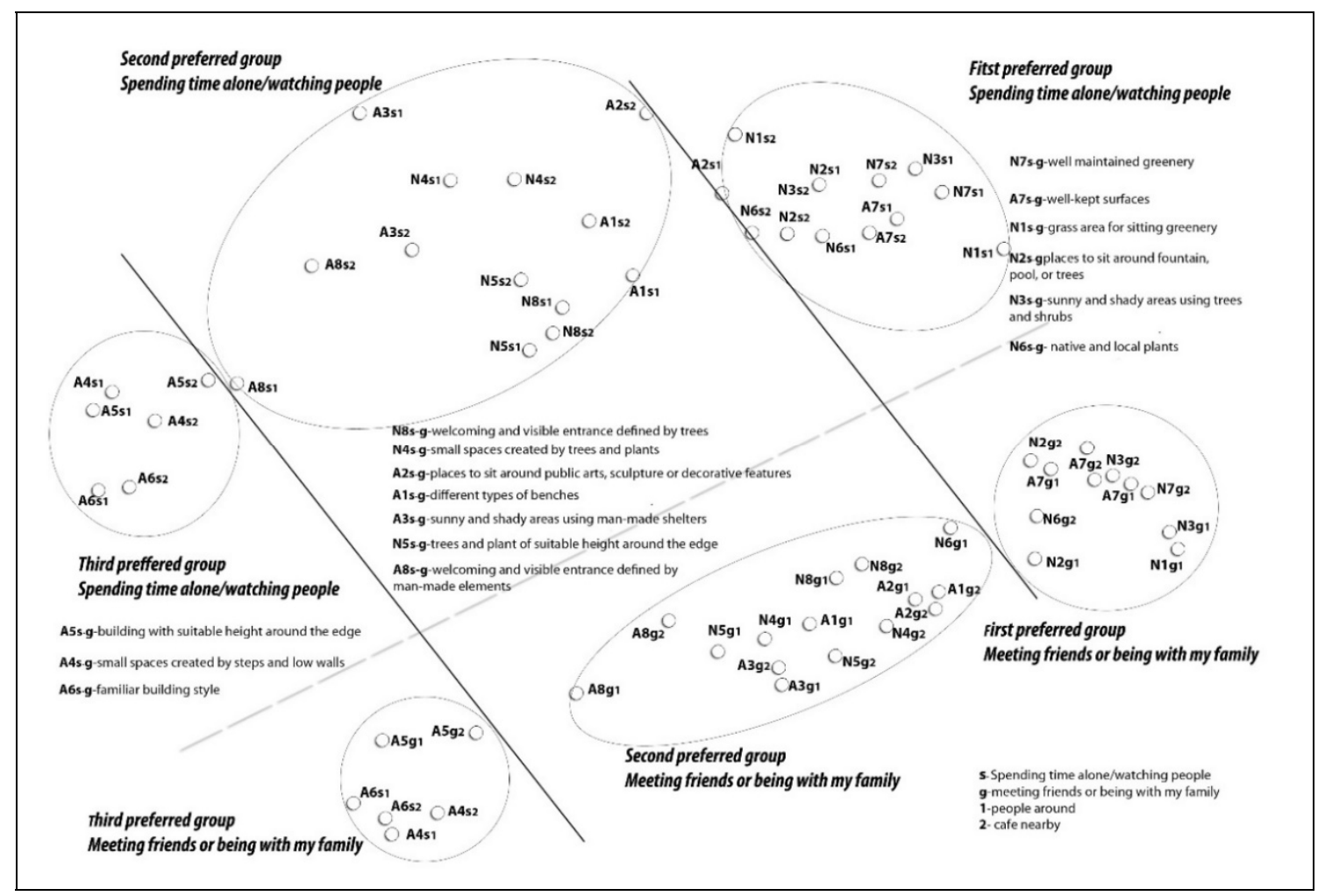

Figure 5-5: Two dimensional spatial representation of 64 items when spending time alone and meeting with friends classified by design elements (stress $=0.17, \mathrm{~N}=160$ )

There are two main regions in natural design elements with spending time alone and with friends being completely separate (Figure 5-10). The first preferred natural design elements are grass area for sitting, well-maintained greenery, sunny and shady areas using trees and shrubs, places to sit around fountain, pool or trees, and native and local plants.

However there are some differences in order of preference between being alone and with friends. When being with friends grass is the first preference, then shade and maintenance received similar ratings, followed by seats around natural features and lastly native plants. When it comes to spending time alone, people preferred well-maintained greenery first, and then natural shade, followed by grass to sit on. Native plants and seats around natural features are the least preferred in this group. 


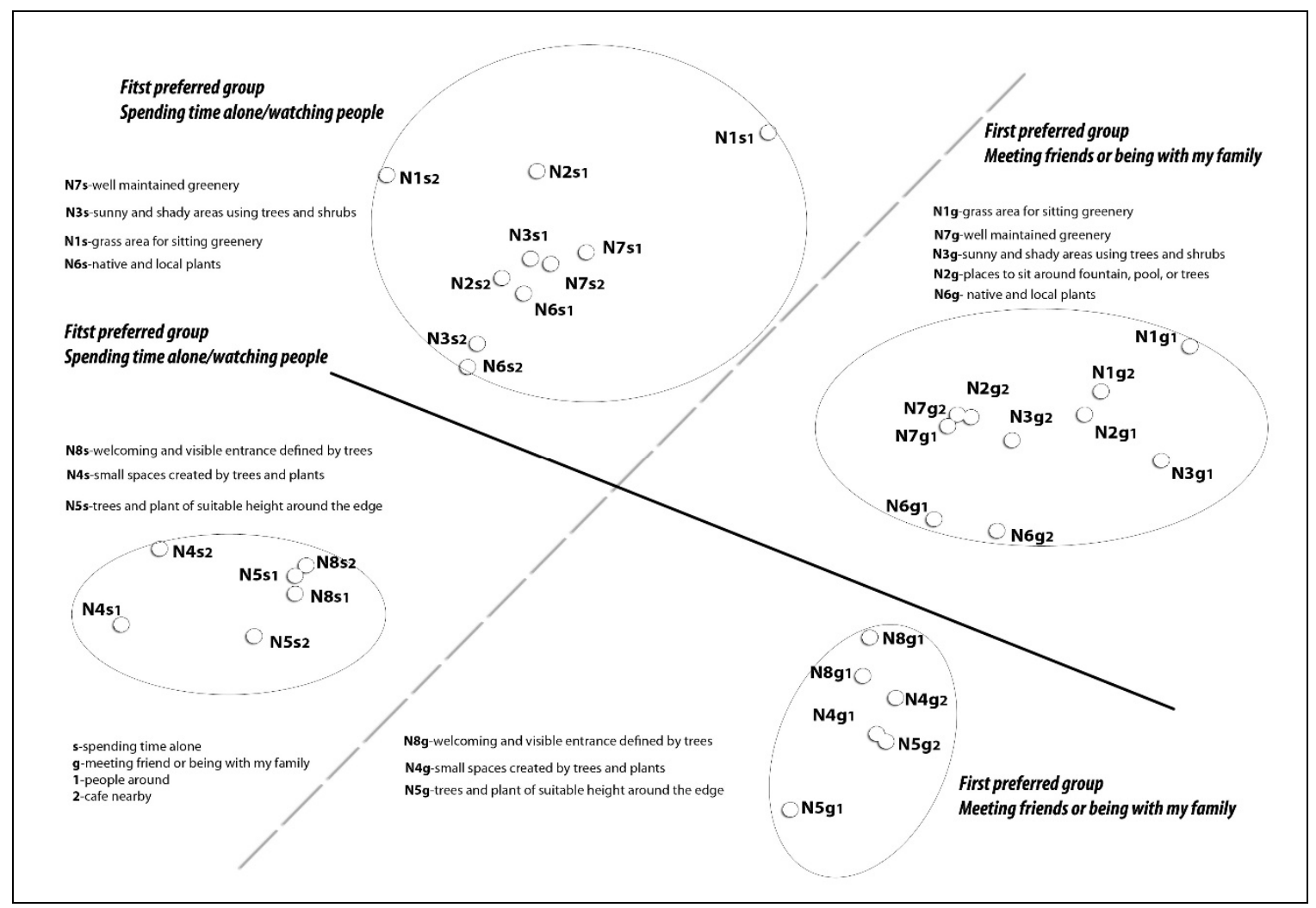

Figure 5-6: Two dimensional spatial representation of 32 natural items classified by design elements (stress $=0.2, \mathrm{~N}=160$ )

The second region consists of entrance with natural design elements, small spaces created with trees and plants, and trees and plants of suitable height around the edge. The order of preference for these three elements is similar for both involving activity situations. Ratings for natural elements move from upper right to lower left, and show the highest preference for grass in meeting with friends and lowest for trees and plants of suitable height around the edge when spending time alone.

There are three main regions in the plot of artificial design elements with spending time alone and with friends being completely separate (Figure 5-11). The order of preference rating for artificial elements is similar for spending time alone and with friends. Well-kept surfaces are clearly the first preferred attribute, followed at a distance by places to sit around public art, sculpture, or decorative features, different types of bench, sunny and shady areas using man-made shelters, and entrance defined by man-made elements, which form the second group. However the first two attributes (benches and seating around sculpture) are separate from the others. The third preferred group consists of buildings with suitable height around the edge, small spaces created by steps and low walls, and familiar building style. Ratings move from upper right to lower left. Well-kept 
surfaces received the highest rating and familiar building style the lowest rating.

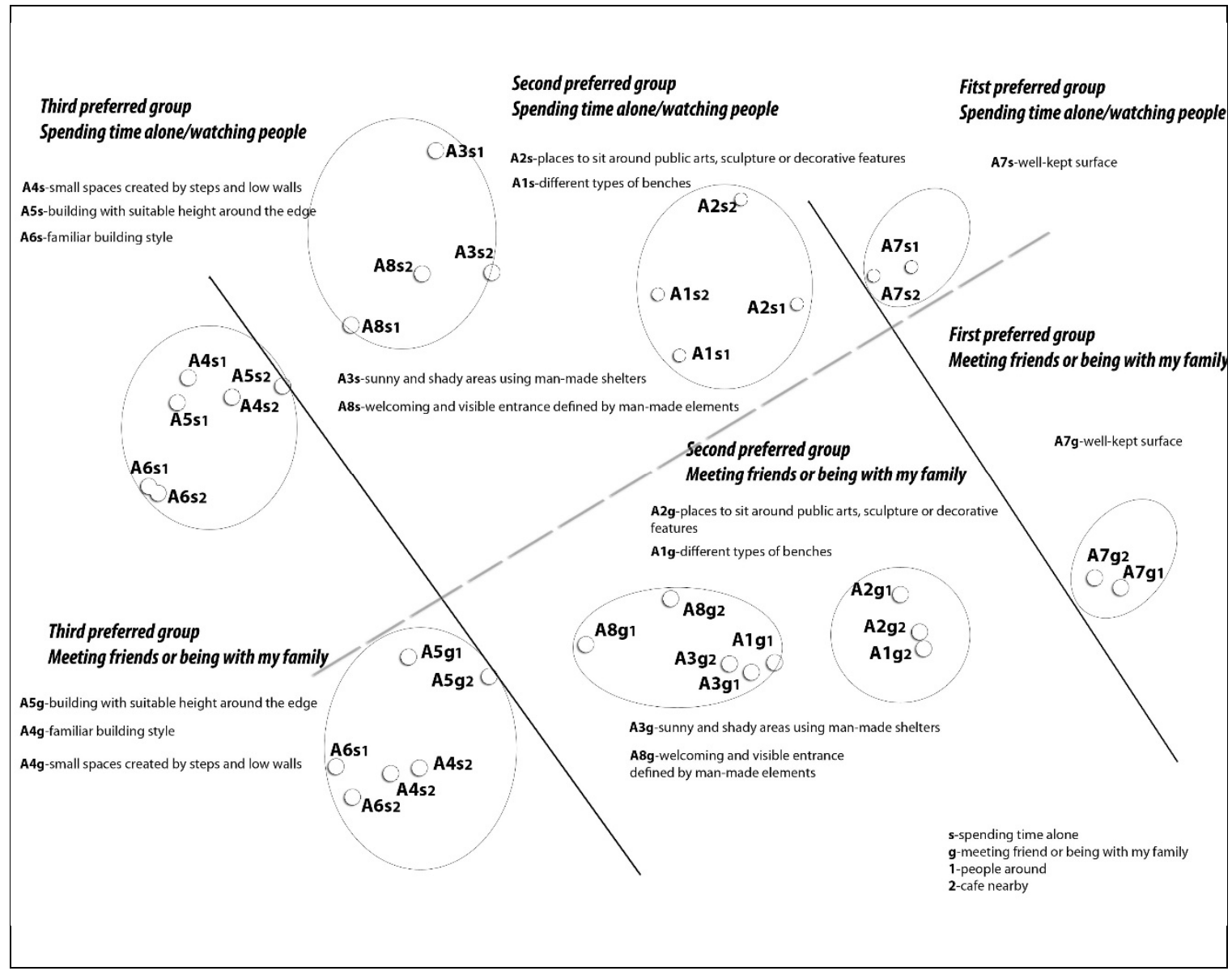

Figure 5-7: Two dimensional spatial representation of 32 artificial items classified by design elements (stress $=0.18, \mathrm{~N}=160$ )

\subsubsection{Chance Contact with New People}

The 32 items for chance contact with new people were analysed within a two dimensional plot by design feature (16 design elements) (Figure 5-8), and material (natural, artificial) (Figures 5-9, 5-10).

Comparison between means shows that except for well-kept surfaces and small spaces created with steps and low walls, which received the highest and lowest ratings respectively, other elements, had similar means. However closer comparison shows wellmaintained greenery, sunny and shady areas using trees and shrubs, entrance with natural elements, native and local plants, entrance with man-made elements, and places to sit around public art, sculpture or decorative features are more preferred than others in this group. 


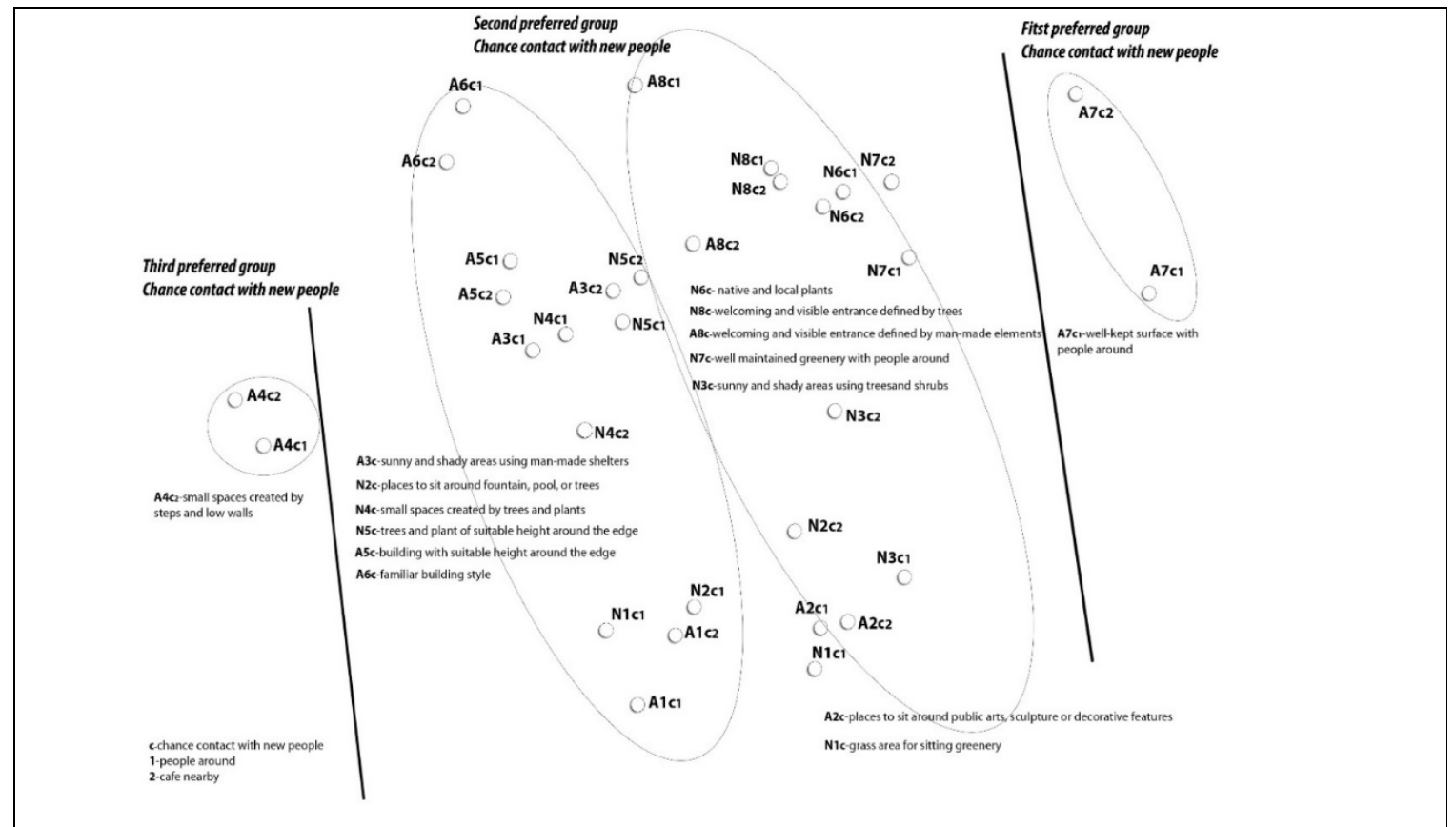

Figure 5-8: Two dimensional representation of 32 items for chance contact with new people classified according to design elements (stress=0.18, $\mathrm{N}=160$ )

There are two main regions in the plot for natural design elements (Figure 5-9). With an ascending preference, well-maintained greenery, sunny and shady area using trees and shrubs, entrance with natural elements, and native and local plants are in the first preferred group. Then follow grass area for sitting, places to sit around fountain, pool, or trees, small spaces created by trees and plants, and trees and plants of suitable height around the edge, as these have similar means and form the second group. However, the difference between these group means is not really significant.

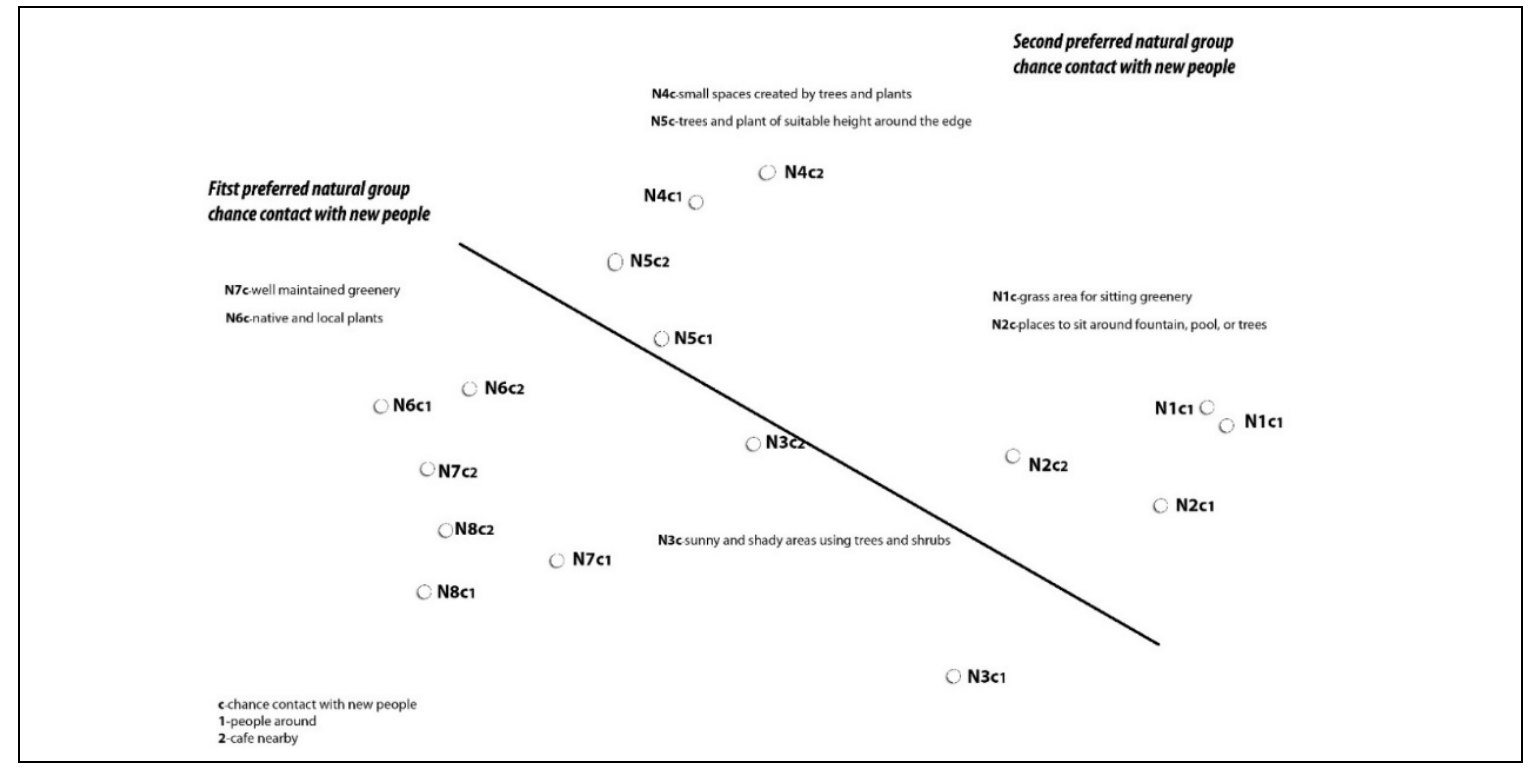

Figure 5-9: Two dimensional spatial representation of 16 natural items for chance contact with new people (stress $=0.15, \mathrm{~N}=160$ ) 
There are four separate clusters for artificial materials (Figure 5-14). Well-kept surfaces received by far the highest rating, followed by entrance with man-made elements, sunny and shady areas using man-made shelters, and places to sit around public art, sculpture or decorative features forming the second group with the same means. With similar ratings, different types of bench, buildings of suitable height around the edge, and familiar building style are categorized in the third group. Small spaces created by steps and low walls are the last preferred element with a negative rating. Ratings move from upper right to lower left.

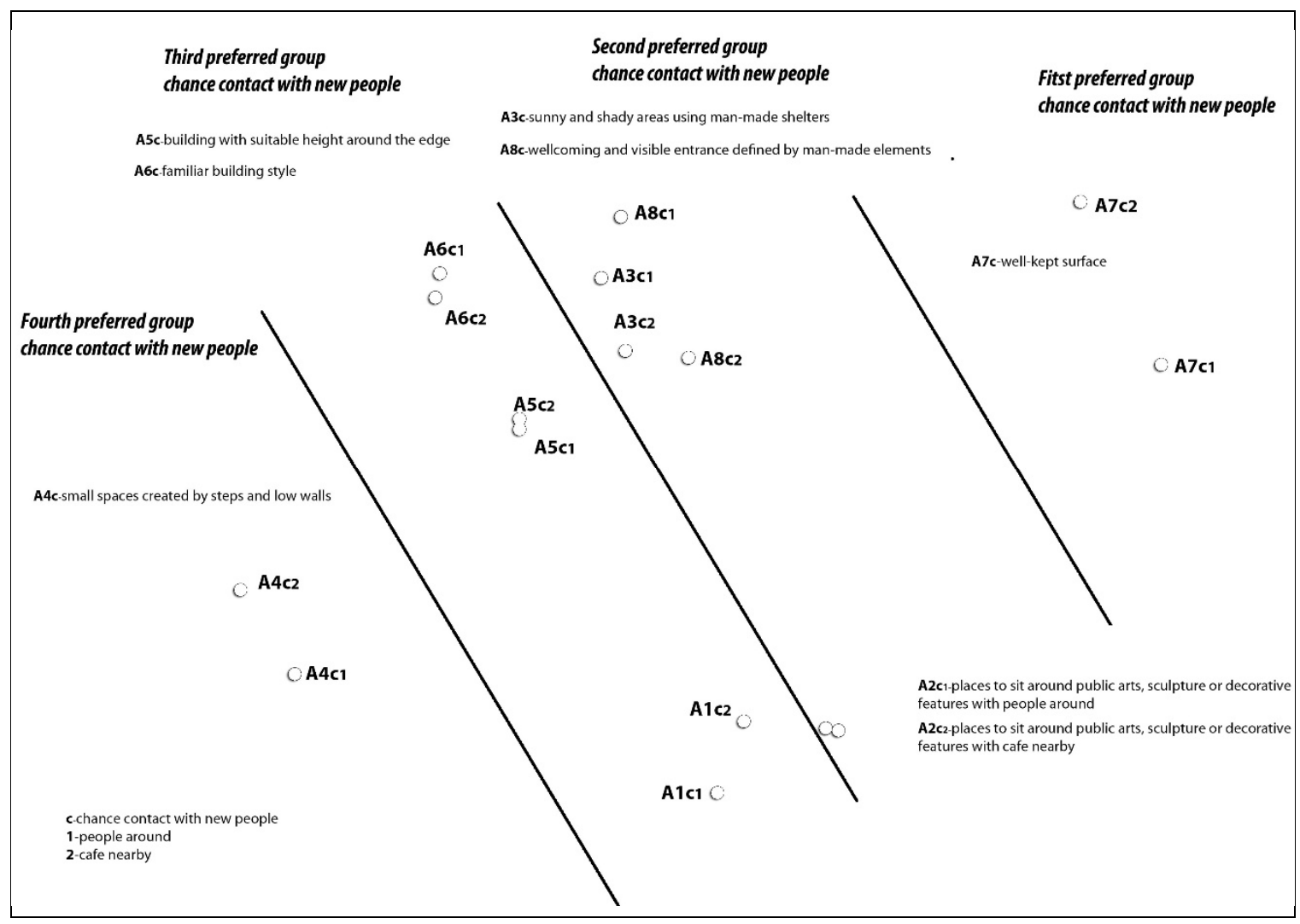

Figure 5-10: Two dimensional spatial representation of 16 artificial items for chance contact with new people (stress $=0.12, \mathrm{~N}=160$ )

\subsubsection{Non-participating Activities}

An investigation of means (Table 5-11) and also two dimensional representations of 96 items (Figure 5-15) shows observing behaviour (people around and café nearby) in three situations received almost similar means. However when people meet their friends and family a preference for café and a nearby place to eat is slightly more than for having people around. Differences between the two observed activities are significant for small space created by natural elements, trees around the edge, and man-made shelter. On average for spending time alone people like to see people around. For being alone 
differences between the two observed activities are bigger than in other situations. Ratings for grass for sitting and people around are much higher than for grass for sitting and café nearby. Both these observed activities received similar preferences for chance contact with new people. Although almost all items in chance contact received similar ratings for observing activity, people in this situation prefer different benches and manmade shelter with café around more than having people around.

Table 5-11: Means of preferences according to two activities (café and having people around)

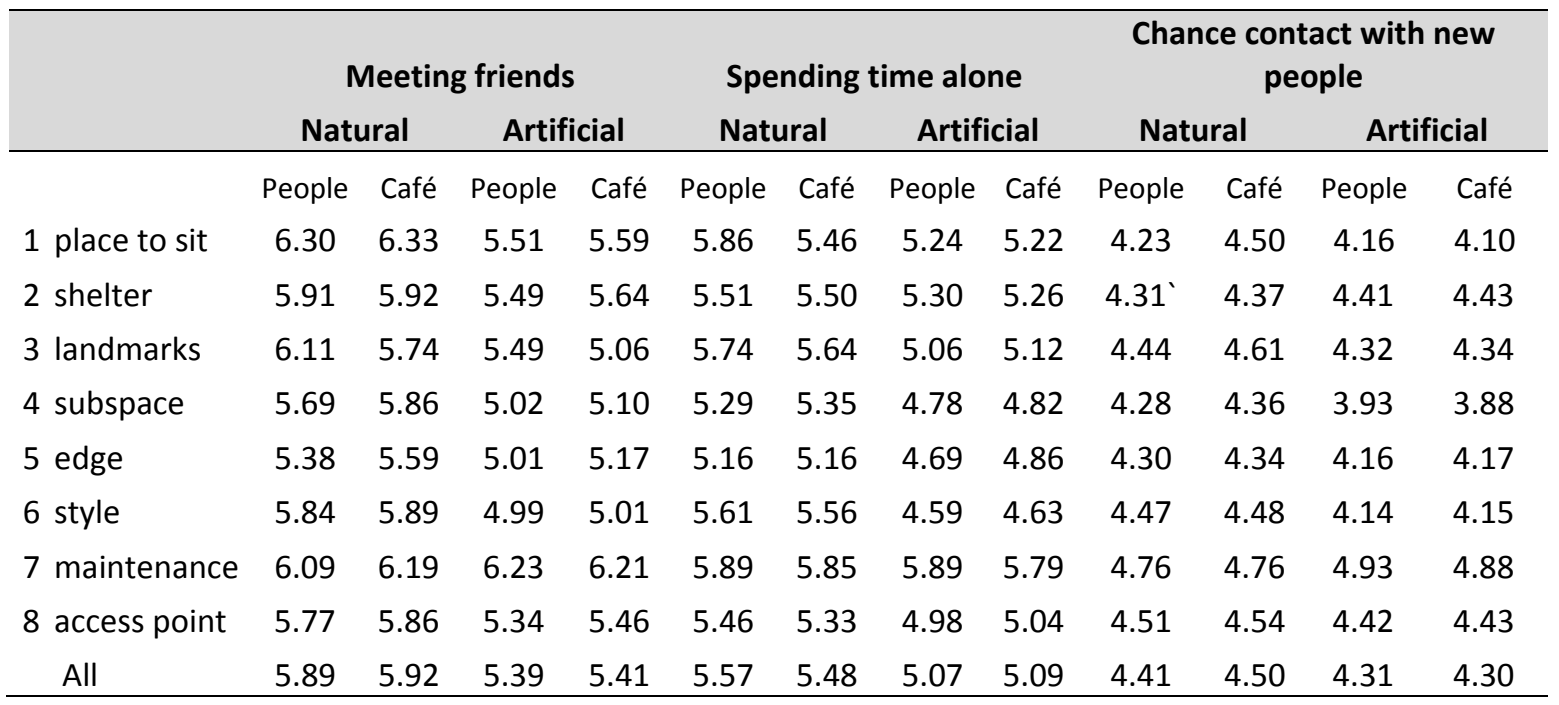

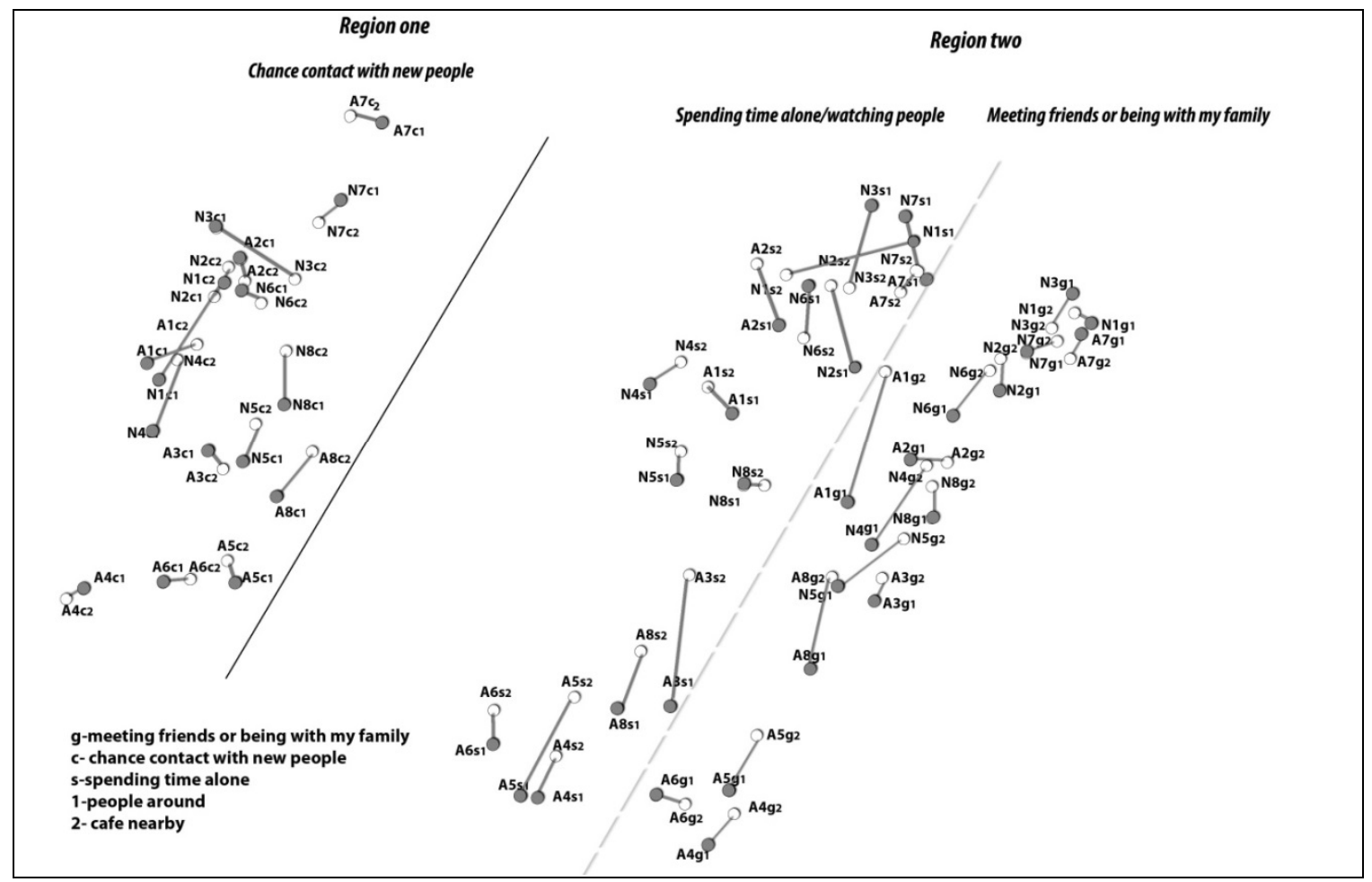

Figure 5-11: Two dimensional spatial representation of 96 elements classified according to observed activity (stress $=0.12, \mathrm{~N}=160$ ) 


\subsubsection{Result of Part Three of Questionnaire}

\section{Glover Park}

Of the sample of $40,42.5 \%$ strongly and $37.5 \%$ moderately rated Glover Park as a pleasant place for meeting family. As a place for spending time alone it is still rated positively but less than when meeting friends. When it comes to chance contact most responses are neutral or negative (37.5\% neutral, $17.5 \%$ moderately disagree, $12.5 \%$ slightly disagree). The level of satisfaction with the available seating is mostly $32.5 \%$, completely $27.5 \%$, somewhat $25 \%$ and neutral $12.5 \%$. Of the sample $32.5 \%$ are mostly satisfied with the amount of greenery, $27.5 \%$ somewhat, and $17.5 \%$ completely satisfied, with $15 \%$ somewhat dissatisfied. The size of Glover Park seems appropriate for most people and its location completely satisfied $60 \%$ of users.

While there is no suitable place to meet new people Glover Park is identified as a good place to meet friends and also for being alone. The user samples were mostly satisfied by its location and the available seats. Size and amount of greenery received positive responses but these were lower than those for seats and location.

\section{Civic Square}

The 40 participants evaluated Civic Square positively for meeting friends and spending time with family (42.5\% strongly agree and 35\% moderately agree, $15 \%$ agree and the rest were neutral), but there is less positivity about rating Civic Square as a pleasant place for being alone (5\% strongly agree, $17.5 \%$ moderately agree, $22.5 \%$ slightly agree, $35 \%$ neutral, $12.5 \%$ slightly disagree, $7.5 \%$ moderately disagree). When it comes to chance contact the responses change to $35 \%$ neutral, $22.5 \%$ slightly agree, $17.5 \%$ moderately agree, and $12.5 \%$ slightly disagree. Only $25 \%$ of people are completely satisfied with the available seating in Civic Square, although almost $50 \%$ are still positive and only $12.5 \%$ are somewhat dissatisfied with it.

Responses for greenery were positive, ranging respectively from satisfied to mostly dissatisfied at $50 \%, 17.5 \% 15 \%, 10 \%$, and $5 \%$. Although responses to the two questions regarding size and location are positive, it seems that users are more satisfied with the location than the size. 
Civic Square is viewed most positively for meeting friends, followed by spending time alone and less for chance contact with new people. Its location and size satisfied more than $95 \%$ of its users, followed by its available seating and, at a lower rating, its greenery.

\section{Te Aro Park}

The 40 people rated Te Aro Park as a pleasant place for meeting friends ( $45 \%$ moderately, $17.5 \%$ slightly, and $15 \%$ strongly agree). For chance contact $30 \%$ were neutral, $25 \%$ moderately agree, and 15\% strongly disagree. Evaluation of the place for spending time alone is similar to meeting with friends, and $70 \%$ of users are positive about the available seating, and $20 \%$ are neutral. Its greenery mostly satisfied $32.5 \%$, somewhat satisfied $22.5 \%$, somewhat dissatisfied $17.5 \%$, and neither satisfied or dissatisfied $12.5 \%$ of users. Overall $67.5 \%$ are positive about its size ( $40 \%$ mostly satisfied, $27.5 \%$ somewhat satisfied, and $17.5 \%$ somewhat dissatisfied). The location of Te Aro Park mostly satisfied $45 \%$, completely satisfied $30 \%$ and somewhat satisfied $15 \%$ of users.

Te Aro Park is most evaluated as suitable for being alone, then with friends, and last for contact with new people. This park is pleasant for its users first for its location, then for its available seats, followed by its good size and last for the amount of greenery.

\section{Midland Park}

When people were asked to evaluate Midland Park $65 \%$ of 40 users strongly agreed, and $20 \%$ moderately agreed that it is suitable for meeting friends. People were less enthusiastic for chance contact with new people with $30 \%$ neutral, $27.5 \%$ slightly agree, and $17.5 \%$ moderately agree. For the suitability of Midland Park for spending time alone $37.5 \%$ strongly agree, $22.5 \%$ moderately agree, and $15 \%$ are neutral. This shows people first rate Midland Park for meeting family and then for spending time alone.

Regarding design elements, $57.5 \%$ were mostly satisfied with the available seating, with $20 \%$ somewhat satisfied. Although only $15 \%$ of people were completely satisfied by the amount of green space in the park, $55 \%$ were mostly satisfied and $22.5 \%$ somewhat satisfied by the amount of greenery. Overall $70 \%$ of people were mostly or somewhat satisfied with the size of Midland Park, while $12.5 \%$ were completely satisfied and $10 \%$ somewhat dissatisfied by its size and scale. The rating for location shows it is well located as $62.5 \%$ were completely and $22.5 \%$ mostly satisfied. 
Midland Park is foremost a pleasant place to meet friends and family, then for spending time alone and last for chance contact. Overall it was mostly evaluated positively because of its location. Highest satisfaction was with the amount of greenery, while positive satisfaction continued with the size of the park and then the available seating.

\subsubsection{Summary of Part Three}

The best place for meeting family is Midland Park, followed by Civic Square, then Glover Park, and lastly Te Aro Park. For chance contact it seems that Civic Square offers more opportunity for meeting new people, with Midland Park next, followed by Te Aro Park and Glover Park. Spending time alone is most pleasant in Glover Park, followed by Civic Square, Midland Park, and then Te Aro Park.

Satisfaction with available seating is highest for Te Aro Park, then Midland Park, Civic Square and Glover Park. Regarding greenery, Midland Park is rated best, then Glover Park, Civic Square and Te Aro Park. Civic Square received the highest rating for its size, then Glover Park, Midland Park and Te Aro Park. In terms of location Civic Square is the highest rated, and then Midland Park and Glover Park are equally rated, followed by Te Aro Park.

\subsection{Discussion}

Using the Theory of Place framework, Study Two examined preferences for micro design elements in the use of a small urban space. The results indicate that people involved in social activity in a place where they are able to observe other activities, provide a positive preference for the place. The higher preferences given to design elements when meeting family and friends followed by spending time alone, and chance contact with new people shows the effect of quality of design on intensity of social activity (Gehl, 1987). Regarding observation of other people's behaviour, there is a difference in preference ratings for the design elements of having people around or having a café nearby. However, the preference for a café is higher than for people around when people are spending time with their friends, and people alone like to see people around more than having a café. In all involving activities (being with friends, chance contact with new people, being alone) there are three levels of preferences for design elements. Although other urban commentators have suggested maintenance is important (See section 5.1.2), the findings 
of this study show that maintenance is the most important factor. Well-kept surfaces and well-maintained greenery attained the highest preferences for all three involving activities. A well-maintained space may provide users a sense of safety (Carr et al., 1992; S. M. Gold, 1977; R. Kaplan, 1983; Sheets \& Manzer, 1991) and attractiveness (Nasar, 1994; Pasaogullari \& Doratli, 2004; Shaftoe, 2008; Skjaeveland \& Garling, 1997), which influences their preference for social activity in the space (Carr et al., 1992; S. M. Gold, 1977; R. Kaplan, 1983; Sheets \& Manzer, 1991). It also shows that in the category of content form maintenance is more important than building style (Table 5-4). In three situations for involving activity, there is a preference for natural over artificial design elements (R. Kaplan, 1983; S. Kaplan et al., 1972; Sheets \& Manzer, 1991; Ulrich, 1976, 1986; Ward, 1977).

The order of preference is similar for items both when spending time alone and with friends, although for spending time with friends grass to sit on received the highest rating, which affirms the affordances of grass to attract bigger groups (Kuo \& Sullivan, 2001). After maintenance, the order of preference for being alone and meeting with friends shows the two top attributes are natural places to sit and a sunny and shady area provided by trees and shrubs. Both these elements are in the function category (Table 5-4) and both are related to comfort and safety needs (Table 5-2). Places to sit attract more people by providing physical comfort (Pasaogullari \& Doratli, 2004; Whyte, 1980). Access to and relief from sun also enhances the sense of comfort (Share, 1978; Liebremann, 1984; Whyte, 1980; Banerjee and Loukaitou-Sedris, 1992 in Mehta 2006). Trees provide physical and psychological comfort through relief from excess sun and wind (Mehta, 2006; Sullivan, Kuo, \& Depooter, 2004; Whyte, 1980; Lang, 1994; Smardon, 1988) and by giving a sense of enclosure (Whyte, 1980). The next preferred elements are native plants and seating around a fountain, pool, or tree. Native plants enhance the sense of beauty (Table 5-2), are a content form element, and bring a sense of belonging by connecting people to the local context (Balling \& Falk, 1982; Carr et al., 1992). Seating around natural landmarks is also related to the sense of beauty and categorized as form (Table 5-2). Seating around landmarks creates comfort, brings safety (S. Kaplan, 1987; Lynch, 1960; Montgomery, 1998; Skjaeveland \& Garling, 1997), and creates a memorable place. Entrance with natural elements and small spaces created by trees and plants are natural design elements that 
appear in the second group, which is a mixed group of natural and artificial elements. However they still received a higher rating than artificial elements. A welcoming entrance brings social comfort (Table 5-2) and is a design object facet in the location category (Table 5-4). Small spaces are a structural variable and create human scale and sense of enclosure and meet people's aesthetic needs. The remaining natural element, which received a lower rating than others and even than some artificial elements, is edges defined by natural elements. In theory it should make the environment safe by bringing a human scale to the space and contributing to the sense of pleasure but this did not emerge in this survey.

Looking at the order of preference for artificial items shows a similarity with the natural categories. However in the artificial group entrance received a higher rating than local materials and building style. In content form (Table 5-4) natural elements more than artificial involve a sense of familiarity and belonging. This is again evidence of the affordance of natural elements over artificial.

With chance contact, the separation between natural and artificial elements is not obvious. Interestingly, both artificial and natural entrances received similar means. It seems that after positive evaluation of the space, which includes judging cleanness and greenery, entrance is important as a structural element (categorized in location in Table 5-4). Seats around sculpture and decorative elements are known to be pleasant for chance contact and they have a higher score than benches and seats around natural landmarks. This supports the finding that people like to sit around a pivot point (Gehl, 1987) this being where triangulation is likely to happen (Whyte, 1980). Similar to spending time alone and with friends, separated space and edge are the last group of pleasant elements for chance contact.

In summary, preference for natural and artificial design elements when being alone and with friends is highest for visual elements (clearness), which helps in evaluating the safety of a place. Next are elements with function which contribute to sense of safety and comfort (grass to sit on and natural shade), then comes sense of belonging and character of sites (native plants and landmarks). Social comfort (entrance) is located after physical comfort and elements defining scale (edge and small space) that contribute to safety and aesthetic needs are the last preferred. The findings here indicate that elements related to 
contact form (maintenance) have more influence on social activity than those related to structural form (excluding building style). Functional elements (seats and shelter) are preferred before structural elements. For the latter (landmarks, subspace, edge) those related to the character of space and safety (landmarks) are preferred. Within this group elements related to location that define scale are less important. For chance contact, the hierarchy of need does not follow the hierarchy of human needs. After maintenance, elements categorized as access point (entrance) and those defining a pivot point (seating around landmarks) are preferred as being likely to attract more people, which leads to increased chance for contact with new people, because in those spaces there is something to talk about. This supports Gehl (1987) in his definition of three types of talking and his claim that for talking with new people, people need to be at ease or sitting side by side or engaging in the same activity.

The lowest preference for some structural elements like edge and subspace, which are emphasised in the literature, may be a result of the questionnaire approach as there may be differences between what people say they will do and what they actually do. Canter (1977a, p.44) notes it is valuable to compare description with observed behaviour. "The observation after all, provides the researcher with direct experience, which enables him to develop his own conceptual account. He is then in the position to compare his cognitive system with that of the participants he has observed".

To paraphrase, observation will inform the theoretical model explored in Study One with direct evidence which will enable the researcher to evaluate whether the model adequately describes the observed behaviour. This leads to the next study (behaviour mapping), where people's behaviour is examined in the designed context.

\subsection{Conclusion}

Study Two was an investigation of preferences for natural design elements in combination with other elements. The results indicate that some groups of elements are preferred over others, and that these preferences are different according to whether a person is using the space alone, with friends, or for chance contact. Setting aside chance contact, the order of preference for being alone or with family and friends is similar and indicates that the same design elements afford both types of activity. However, some elements received 
different preferences for social activity with different intensities. This suggests that for successful public space, designers should not just behave as an 'expert' but should also think like a person using the space, empathising with all their differing needs and changing needs at different times. Further, design elements should not be considered in isolation, with combinations of elements being important for people. 


\title{
Chapter 6 \\ Study Three: Behaviour Mapping
}

\begin{abstract}
"A root meaning of the word "bad" is "open". To be open and free is to be exposed and vulnerable...it is like a blank sheet on which meaning may be imposed. Enclosed and humanized space is place (Tuan, 1977, p. 54)...In experience, the meaning of space often merges with that of place...what begins as undifferentiated space becomes place as we get to know it better and endow it with value" (Tuan, 1977, p. 6).
\end{abstract}

Few studies in the field of urban design have focused on the link between natural design elements and people's behaviour (Frank, Engelke, \& Schmid, 2003). Those that have (See section 6.1) are generally case studies and observations without a theoretical basis making it difficult to compare or generalize their results (Francis, 1987). To avoid this in the current research, this study uses behaviour mapping to evaluate the contribution of natural elements in the behavioural affordance of place, using the theoretical framework developed in Study Two (See section 5.2).

\subsection{Natural Elements and Observed Behaviour}

The question of non-use or under use of urban space was raised by Jane Jacobs (1961) in her discussion on the use of neighbourhood parks. Research since has studied the use of such public space, finding nature is a design element that enhances the social use of space (Carr et al., 1992; Gehl, 1987; Whyte, 1980). Several studies have pointed to nature as an attribute that brings relaxation and physical comfort (Carr et al., 1992; Lang, 1994), and contributes to the sense of safety (Carr et al., 1992; Mehta, 2006), belonging (Balling \& Falk, 1982; Carr et al., 1992), and beauty (R. Kaplan, 1983; Lennard \& Lennard, 1995).

Other studies that did not focus on nature and use of space still revealed the importance of natural elements. For example, in a study of plazas, Whyte (1980) found sun was the greatest attractant in the use of space. He also emphasised the role of trees and water in enhancing people's use of space. Similarly Huang (2006) studied outdoor interactional space in high-rise housing comparing the percentage 
of social interaction in five spatial categories: 'seating space', 'scenic space' (containing landscape elements with visual significance), 'circulation space', 'activity space', and 'vague space'. Among these five spaces, scenic and activity spaces supported more social interaction. Huang's investigation of design elements indicated visual focus (water features and sculptures) and plants (trees, shrubs, and flowers) encourage more social activities. These finding are supported by Sherrod and Downs (1974) and Nasar (1994) who claimed a visually attractive environment affects people's behaviour.

Studies that investigate the role of nature in the social use of outdoor space are mostly focused on common neighbourhood space (Coley et al., 1997; Kuo, Sullivan, et al., 1998; Sullivan et al., 2004). Coley et al. (1997) stated adding trees and grass to a neighbourhood area transforms residents' responses from dislike to like. The same study also found the time spent in a space is related to the presence, location and number of trees. These elements not only increase the number of users but having a greater number of trees also attracts larger groups. Kuo et al. (1998) stated that contact with nature reduced mental fatigue, relieved the feeling of stress, and had a positive effect on moods with all these having an effect on the quality of social interaction. They concluded that trees and grass increased the sense of safety. Kue et al. (1998) studied the preferences of inner-city residents and found that the maintenance of trees and grass affected preferences and sense of safety. In a further investigation (Kuo, Sullivan, et al., 1998) found a positive correlation between the density of trees and preferences.

Apart from trees, plants, and sun, research has also found that water is an attractive element that holds attention and interest (Ulrich \& Addoms, 1981). However, all natural elements are likely to encourage social activity (Huang, 1998) and work to form a meeting place in residential areas (Lems, 2008).

\subsection{Framework for Behaviour Mapping}

As mentioned before, Study Three looks at the effect of natural design elements on the usage of space and their contribution to the use of space. Observations made in Study Three can also inform the results of the two previous studies, as it is an investigation of the emotional-cognitive and functional affordance of natural design elements in a place. Observation was done in the same four data collection sites (See section 3.4), for four 
days with pleasant weather for outdoor activity. Each site was observed for one complete day to find similarities and difference in the pattern of use of public space regarding natural design elements, within places with different design characteristics. The contribution of natural design elements in the use of space was measured by looking at: length of stay, number of users, size of groups, type of activity, and gender and estimated age (See section 3.1). In addition to these quantitative analyses, preferred space and order of occupancy and effect of quality of design on users is discussed. To be able to generalize results, two sets of comparisons were planned:

a) within each site and between its subspaces;

b) between similar subspace categories across the four sites.

In order to complete comparisons a) and b) and collect the required behavioural observations for this research, still photographs and GIS were chosen as they most appropriate methods of data collection (See section 3.3).

\subsection{Designing the Behaviour Map}

Study Two was a preparation for Study Three. Referring to the subspaces defined in Study Two (See section 5.4) and after one week of trial observations during weekdays and weekends, the four data collection sites were divided into a number of subspaces (Table 6-1), with the 16 subspaces in Study Two reduced to 10 within five categories. Between the 16 subspaces identified, not all were found in all four sites (See Table 6-2). However, the effect of artificial and natural shade and maintenance of natural and artificial areas and surfaces was investigated in all subspaces. Edge was divided into two types; outside edge (natural edge), and edge passageway (artificial edge). 
Table 6-1: Categories

\begin{tabular}{|l|l|}
\hline \multicolumn{1}{|c|}{ Category } & \multicolumn{1}{c|}{ Code } \\
\hline A) natural/artificial seating & $\begin{array}{l}\text { A-code1: Grass (1-1) and sitting wall by grass (1-2) } \\
\text { A-code2: Seating proximate to paved area }\end{array}$ \\
\hline B) natural/artificial edge & $\begin{array}{l}\text { B-code3: Outside edge } \\
\text { B-code4: Edge passage way }\end{array}$ \\
\hline $\begin{array}{l}\text { C) seating around natural/artificial } \\
\text { focal point }\end{array}$ & $\begin{array}{l}\text { C-code5: Seating by water } \\
\text { C-code6: Seating by sculpture }\end{array}$ \\
\hline D) natural/artificial entrance & $\begin{array}{l}\text { D-code7: Entrance with natural elements } \\
\text { D-code8: Entrance with no natural elements }\end{array}$ \\
\hline $\begin{array}{l}\text { E) separated spaces divided by } \\
\text { natural/artificial elements }\end{array}$ & $\begin{array}{l}\text { E-code9: Separated space divided by natural elements } \\
\text { E-code10: Separated space divided by stair, short wall }\end{array}$ \\
\hline
\end{tabular}

A brief description of the design elements and character of the subspaces and how they fit into the five categories was prepared for each data collection site (Figures 6-7, 6-21, 6$35,6-49)$. The final decision about the border of subspaces was made based on the level of contribution of design elements in each subspace. For example some part of a sitting wall situated around water fits better in the 'seating by water' subspace than in 'grass' and sitting wall by 'grass'. Obviously there is room for discussion about these subspace categories but those chosen seemed the best fit for the data collection sites. The greatest number of subspaces occurred in Midland Park and the least in Te Aro Park. Civic Square and Glover Park had similar subspace numbers (Table 6-2). Note that code A1 (natural place to sit) is divided into grass and sitting wall close to grass as they offer different affordances.

Table 6-2: Subspaces in the four data collection sites

\begin{tabular}{|l|l|l|l|l|}
\hline Place & Glover Park & Civic Square & Te Aro Park & Midland Park \\
\hline A-code 1-1: Grass & & & & \\
\hline A-code 1-2: Sitting wall by grass & & & & \\
\hline A-code 2: Seating proximate to paved area & & & & \\
\hline B-code 3: Outside edge & & & & \\
\hline B-code 4: Edge passage way & & & & \\
\hline C-code 5: Seating by water & & & & \\
\hline C-code 6: Seating by sculpture & & & & \\
\hline D-code 7: Entrance with natural elements & & & & \\
\hline D-codde 8: Entrance with no natural elements & & & & \\
\hline E-code 9: Separated space divided by natural elements & & & & \\
\hline E-code 10: Separated space divided by stair, short wall & & & & \\
\hline
\end{tabular}


The data collections sites were investigated to select the best point for taking photos. Photos should be taken from a distance in order to have less effect on the users. They should cover spaces from different angles to record all the data. Subspaces and the chosen photography points are shown in Figures 6-1 to 6-4.

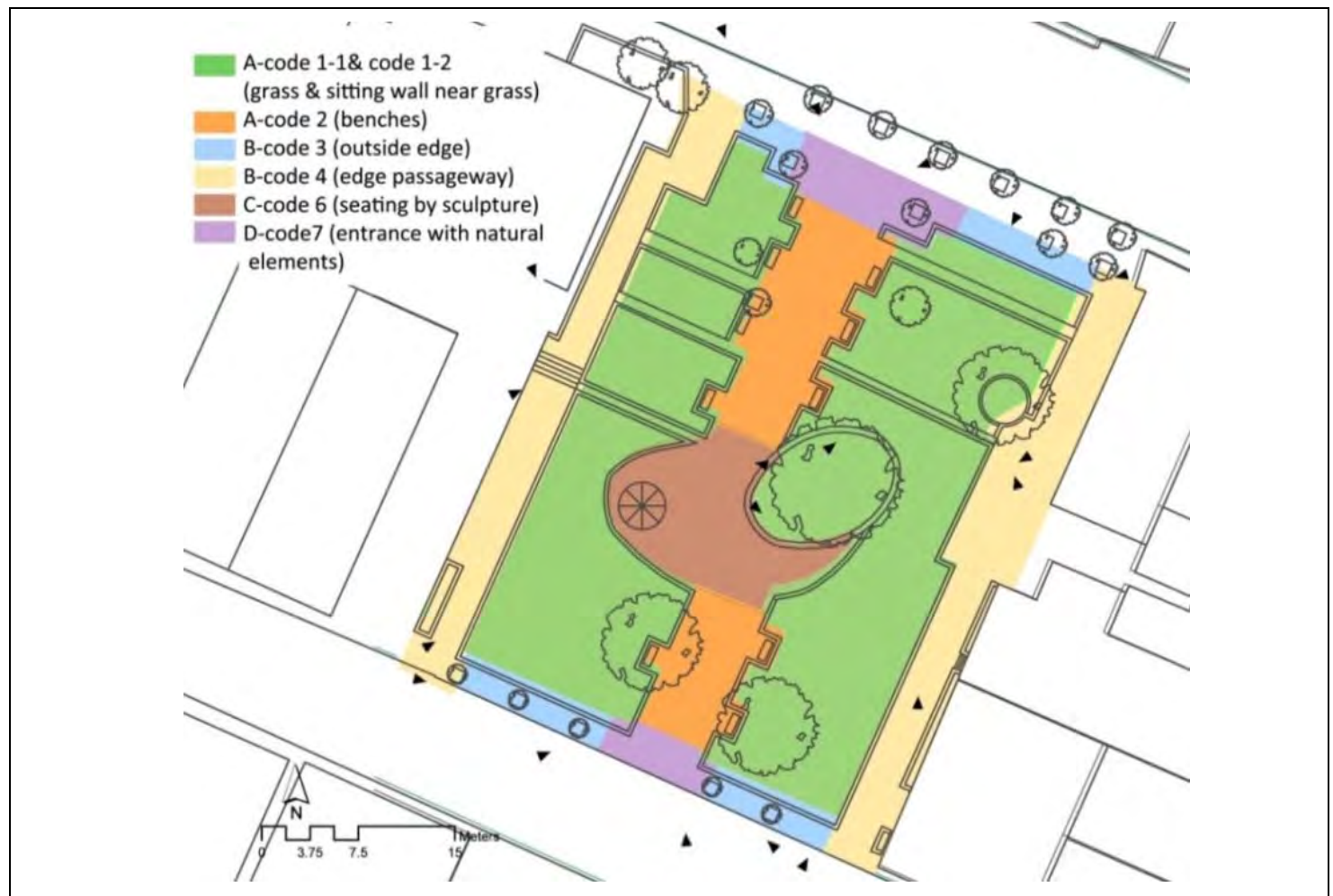

Figure 6-1: Subspaces defined in Glover Park

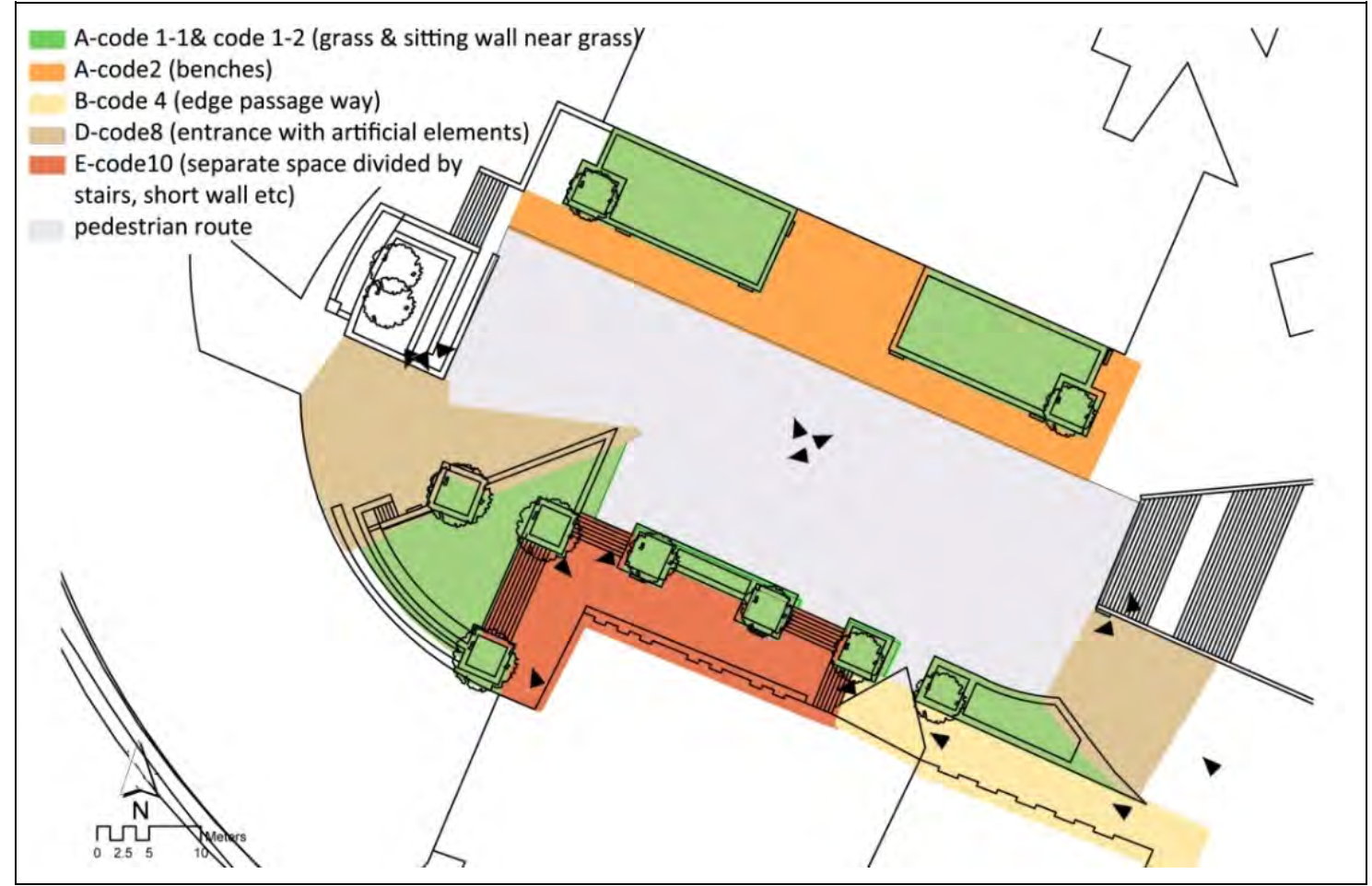

Figure 6-2: Subspaces defined in Civic Square 


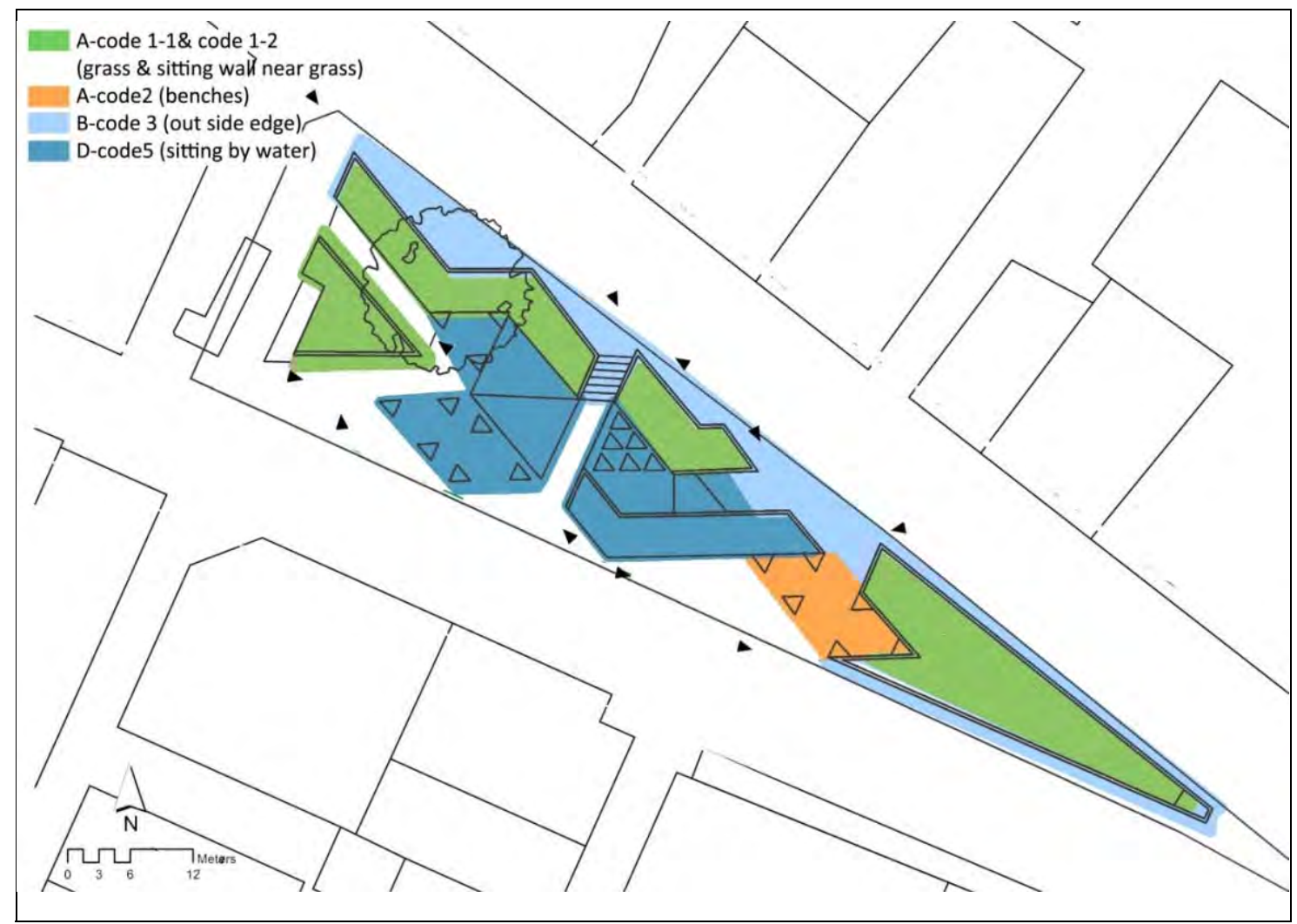

Figure 6-3: Subspaces defined in Te Aro Park

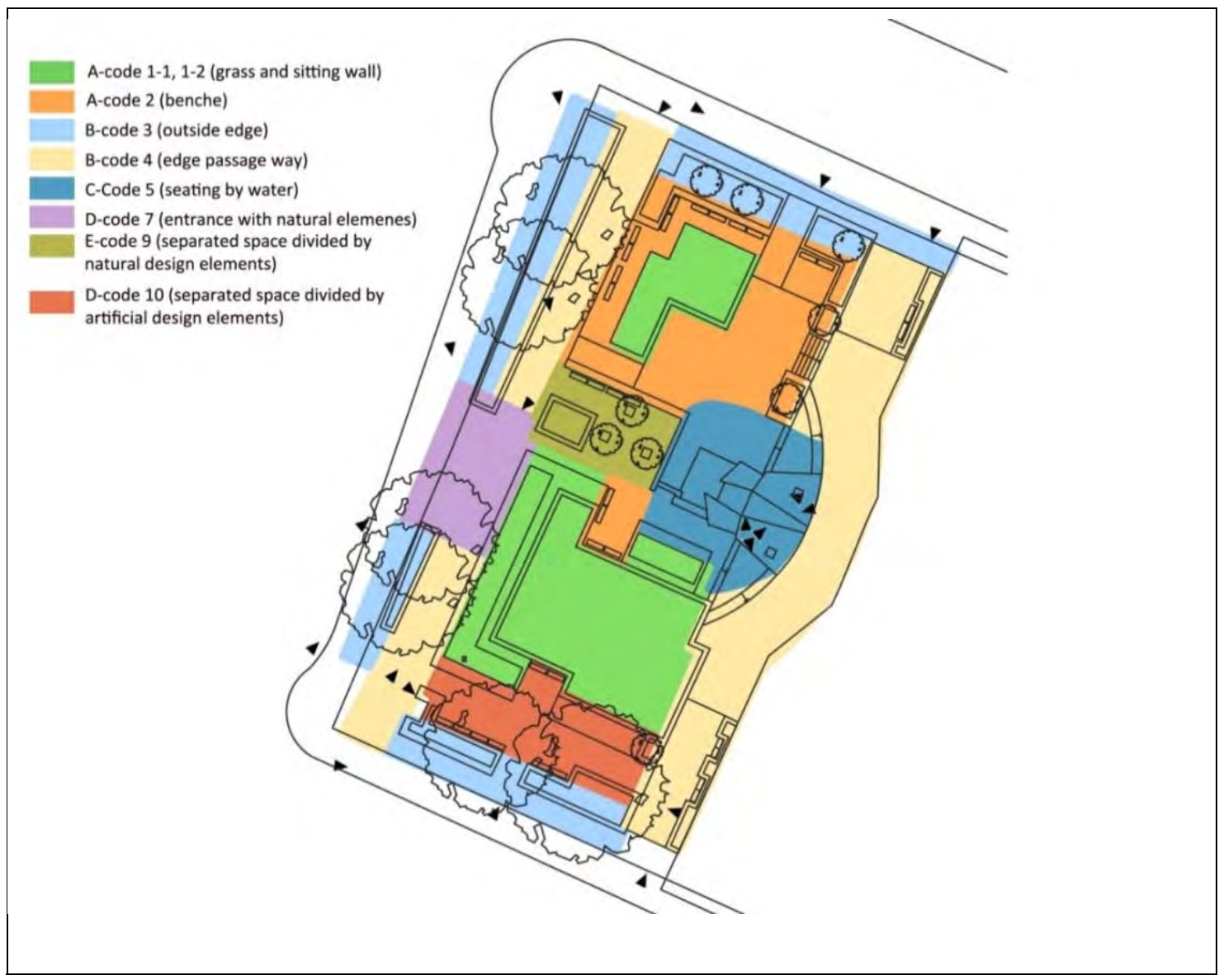

Figure 6-4: Subspaces defined in Midland Park 


\subsection{Pilot Study}

Methods for gathering data and transferring the information were pilot tested in Midland Park as being the most complex of the four sites (See Section 3.4). As the results of the Study One and Two surveys did not show big differences between weekdays and weekends, one sunny weekday (lunch time from 12.00 till 12.40 on a sunny day in March 2013) was chosen for pilot study observation. To capture the overall picture of each place, photography at each point was at 5 minute intervals, this being felt to be a comfortable time for the researcher to move from one point to another. The pilot investigation consisted of 8 rounds of photographs from each predetermined viewpoint, making twenty photos for each round (Figure 6-5).

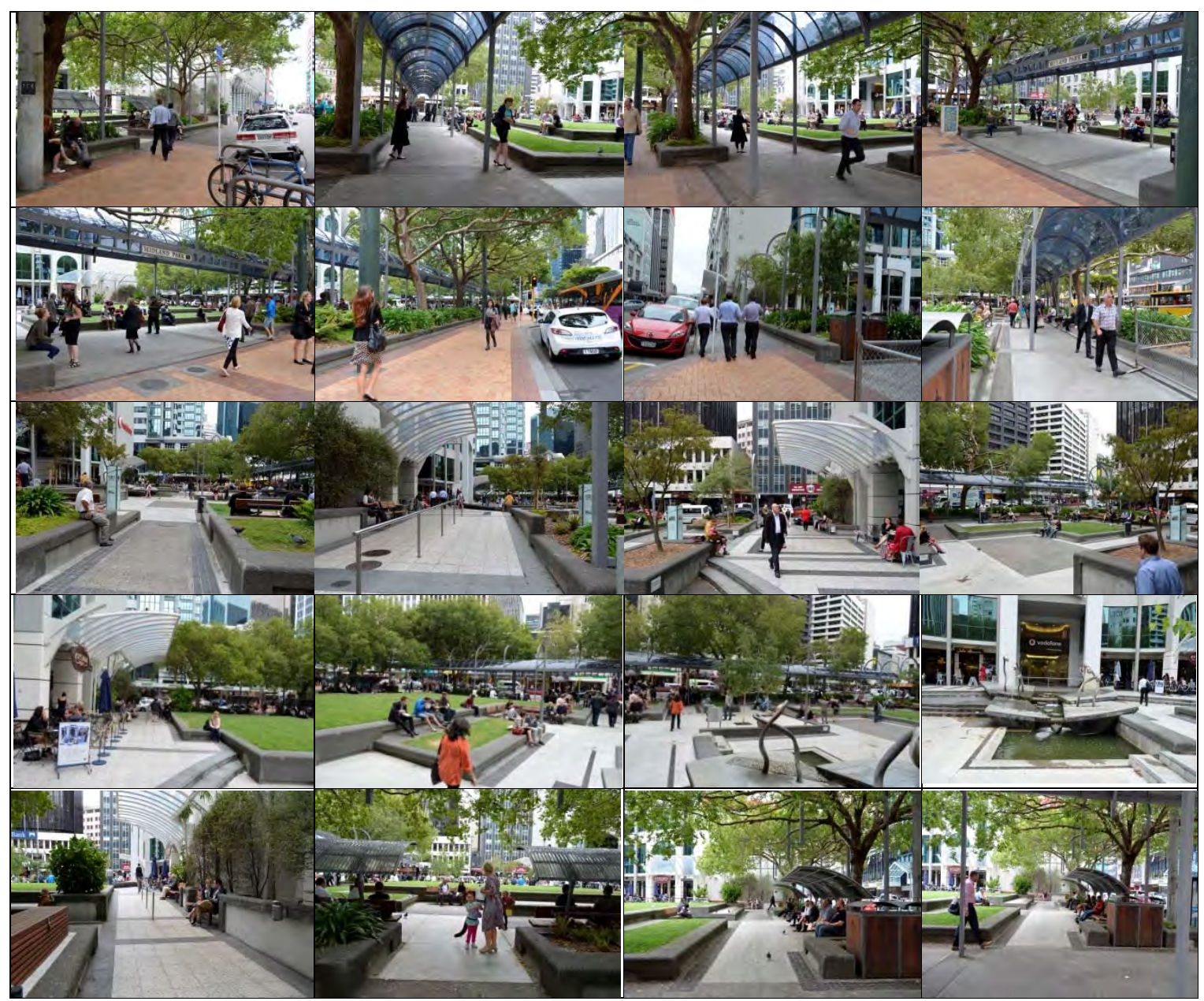

Figure 6-5: One round of photography, March 2013, Midland Park

After 40 minutes of photography at a busy time when the space was crowded, it was realized that for getting accurate information sometimes more than one photo was 
needed, as people may not be facing the camera. Another problem with the short interval between photos was the need to wait for a person to move out of the way of the shot, which sometimes meant having to run very quickly to the next photo point, which drew people's attention. Direct observation shows that at a busy time (lunch time) most people stay in the same place for up to 10 minutes, and with a bigger interval between photographs, reasonably accurate data would still be obtained. However longer than 10 minutes between photographs was felt to have the potential to miss data. Consequently, the interval was increased to 10 minutes. To see the effect of increasing the interval, maps were created for 5, 10 and 15 minutes intervals. Each person was represented by one dot on the base map projected in the Arc map 10.1. Arc map is the main component of ArcGIS. This program is used to view, create, edit and analyse data bases and is also used for creating maps layouts. Attributes attached to each dot included whether a person was alone or in a group, size of group, activity, first time a group was were observed and last time a group was observed. When this was done the same pattern of occupancy was observed, and so there was confidence in adopting the 10 minute interval (See Appendix 4).

Entering the data was also refined at this point and instead of each person being a dot, one dot represents a group (where one person means a group of one) and having one column allocated to the coded activity for each group, the dominant activity in the group was entered. As occupancy maps are produced for one hour and some people use the space for two hours, a column was added to show users from the previous hour in order to avoid counting them twice. To capture the overall picture of each place, for the final study photography was done on $27^{\text {th }}$ March 2013 , on another day when the weather was good, from 08.00 to 17.00 at 10 minute intervals.

\subsection{Data Analysis}

Based on the framework in section 6.2 , the analyses of behaviour mapping are divided into two parts:

a) analysis of behaviour at each site and comparison of its subspaces; and

b) comparison of behaviour in similar subspaces in similar categories across the four data 
collection sites.

These two steps also contain two kinds of analysis: quantitative and qualitative. The former compares the number of users in terms of age, gender, time, and number of activities that occurred in the place, and lengh of stay within subspaces. The latter focuses on quality of design elements that may not be represented by numbers, like sun and shade, using occupancy maps. However, it should be noted that some subspaces include natural elements like trees that will provide shade, such as entrance by natural elements in Midland Park. Thus the effect of trees will also appear in the quantitative analysis.

\subsection{Results - Glover Park}

Glover Park has six subspaces. A description of its design elements and subspaces is shown in Figure 6-6 and described in Figure 6-7.

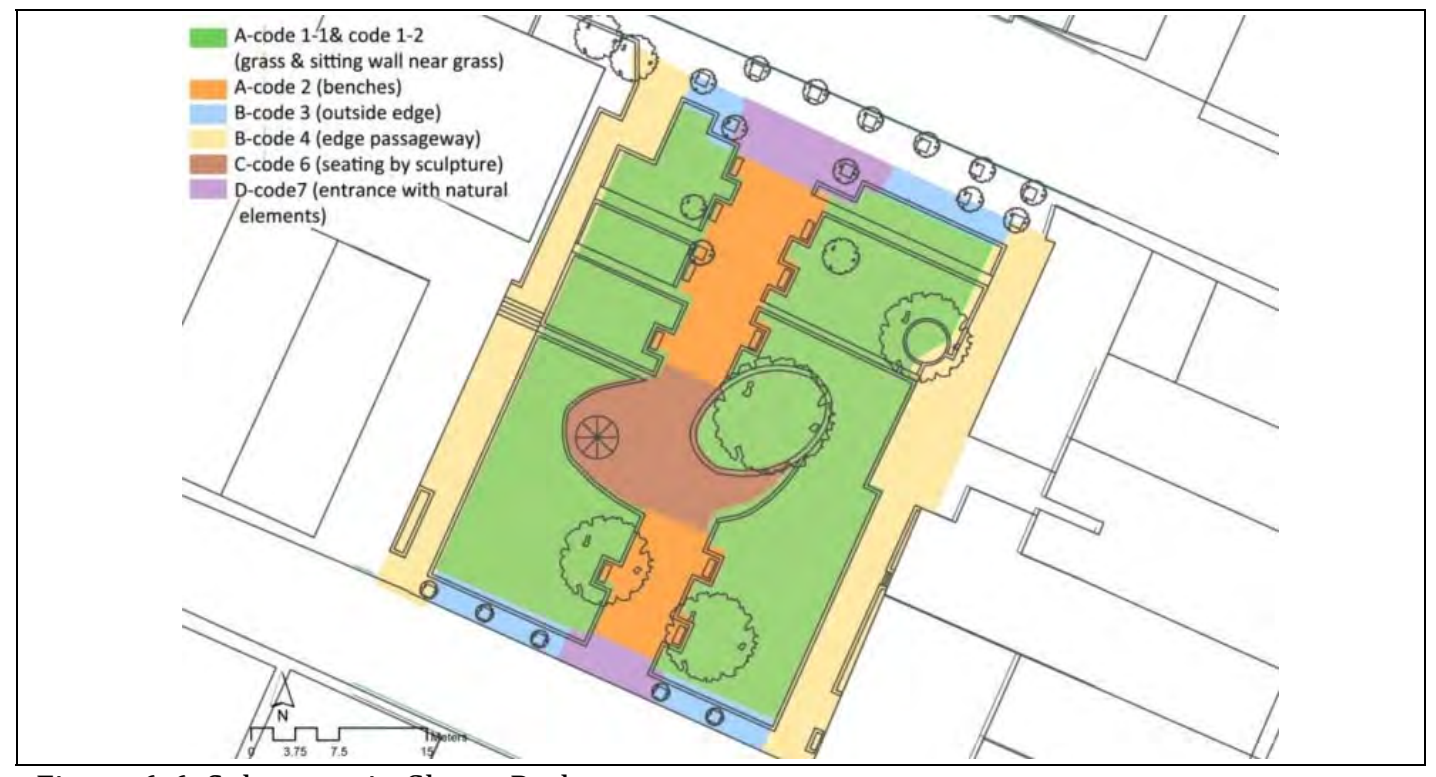

Figure 6-6: Subspaces in Glover Park

\begin{tabular}{|l|}
\hline Category A, code 1: Grass and sitting wall by grass \\
Grass with mature trees and view to main \\
Grass with trees is higher than main part \\
and divided from passage way by short \\
walls.
\end{tabular}




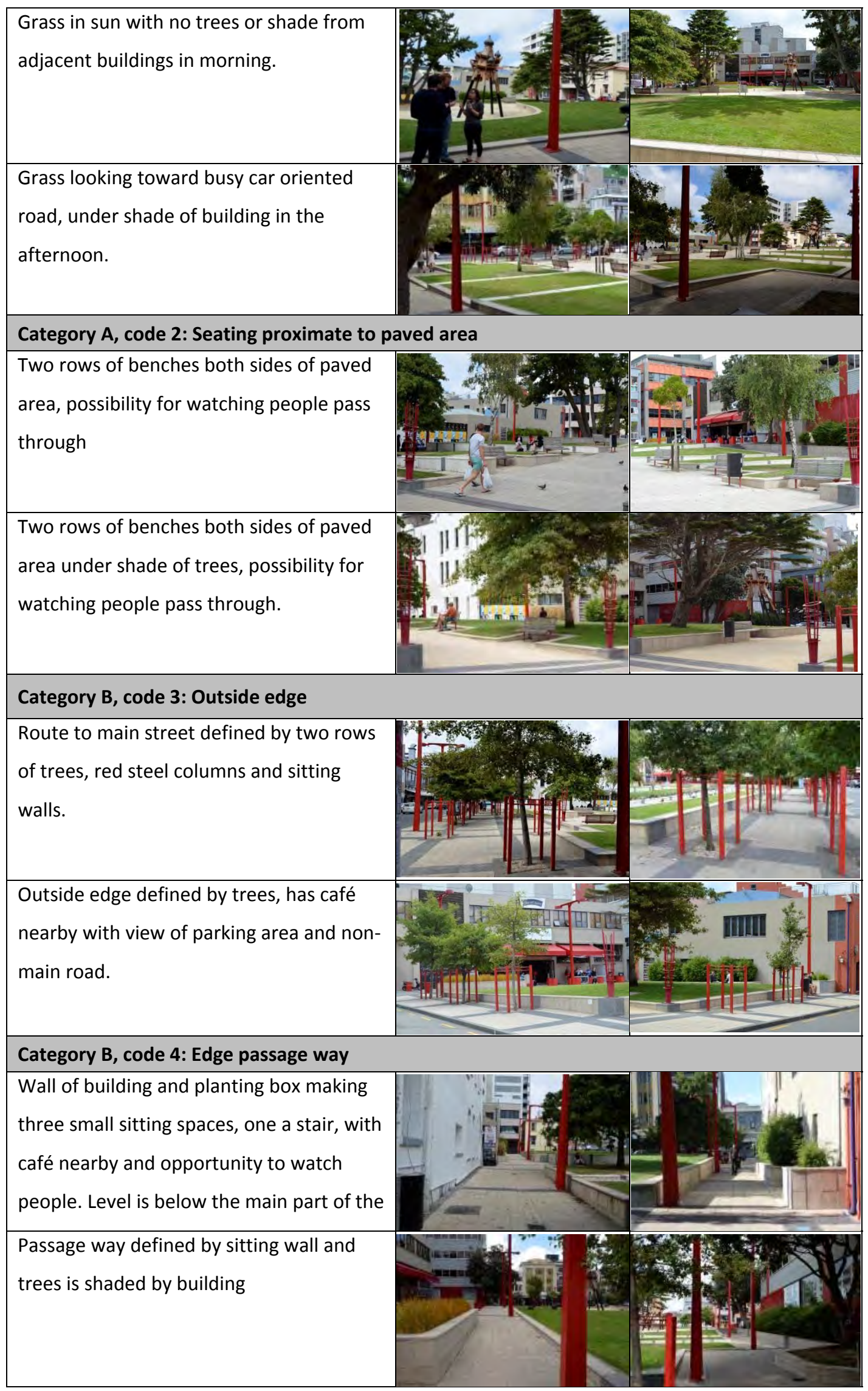




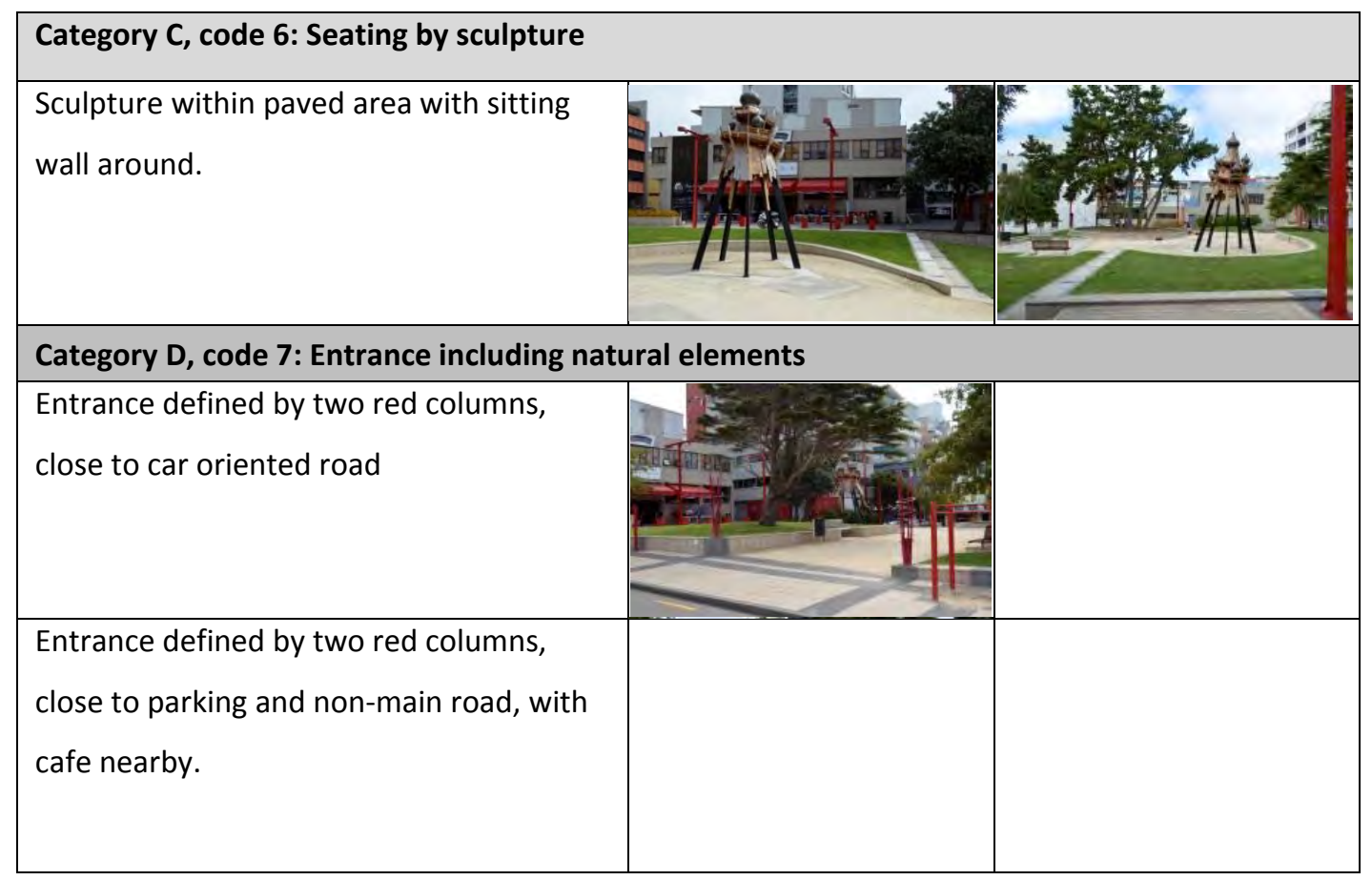

Figure 6-7: Description of subspaces, Glover Park

\subsubsection{Number of Users}

The data for Glover Park consisted of 765 photos taken on one day between 08.00 and 17.00 (See Appendix 3). The number of photos shows a total 276 people used the park in 193 groups of one, two, three or more persons. The three busiest hours were 12.00-13.00, 13.00-14.00, and 15.00-16.00, with 71, 56 and 47 individual users in these times respectively. There were 31 users between $11.00-12.00$ and 14.00-15.00, followed by 23 between 16.00-17.00, with least users from 08.00-11.00 (Table 6-3). Comparison between subspaces indicates most subspaces follow the pattern of the total users, and have their own maximum occupancy between $12.00-13.00$ or $13.00-14.00$, with a dramatic decrease by 15.00 followed by a slight increase to reach a second peak around 16.00 . Unlike this pattern, use of the grass area starts from 08.00 and gradually increases to reach its maximum use between 15.00-16.00. Diagrams on the left of Table 6-3 represent subspace use as a percentage of its use in the maximum occupancy hour (MO). For example grass had its maximum occupancy at 15.00-16.00 with 20 persons. The percentage between $12.00-13.00$ is calculated as (number of people in space between 12.00$13.00 * 100 /$ maximum occupancy during the day), (16*100/20). These diagrams illustrate that while grass, sitting wall by grass, seating in paved area and seating by sculpture were 
used over the day, entrances, edge passage way and outside edge were left vacant after the two busy periods.

In Table 6-3 and in the following tables two significant figures have been used as there is sometimes a need to distinguish between numbers that are very close.

Table 6-3: Number of users during one day of observation, Glover Park

(Colours have been added to indicate intensities of use at a glance)

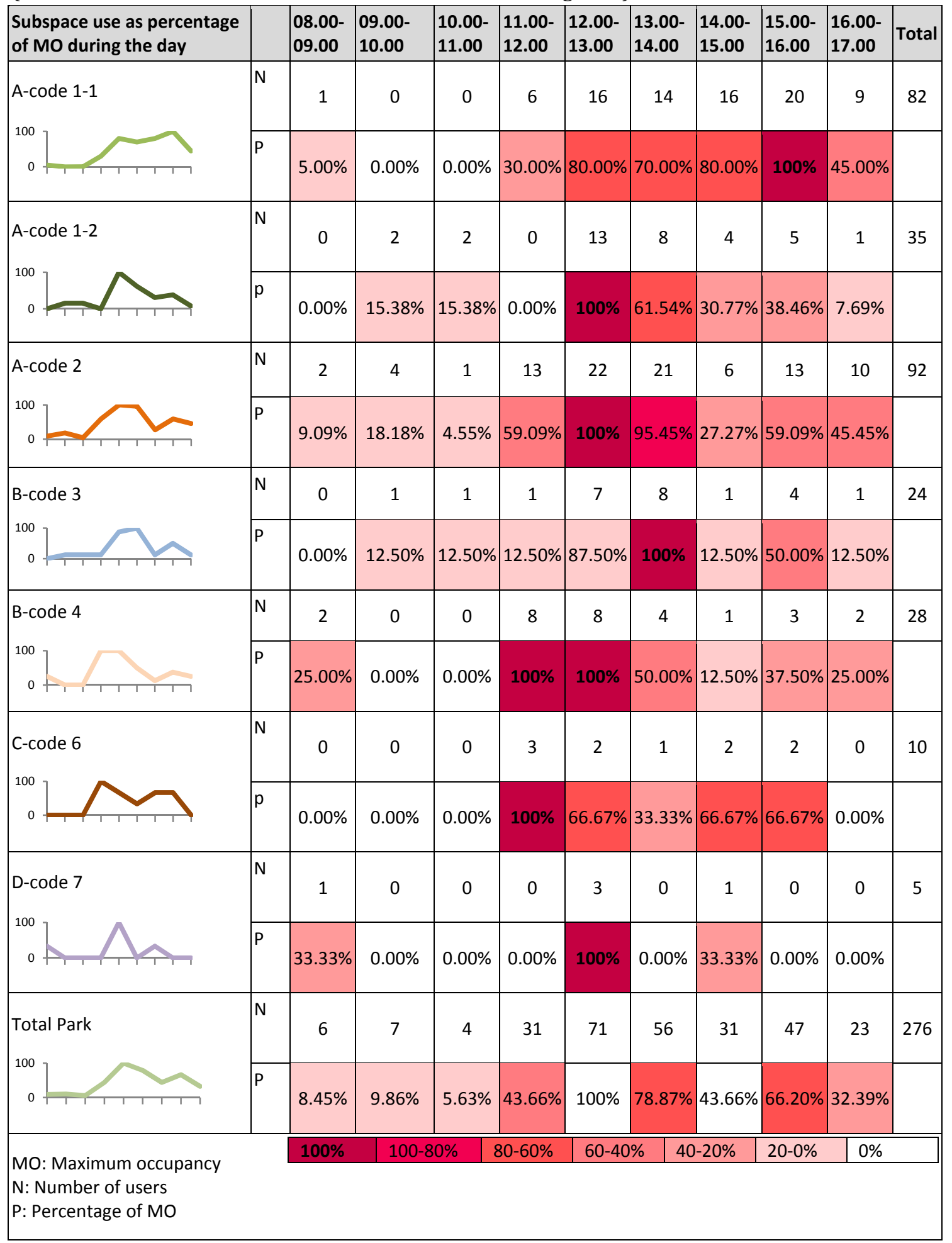




\subsubsection{Occupancy and Preferences}

The pattern of occupancy during the day shows benches in paved areas and grass were used most. While sitting walls by trees were also well used, edge passage way, outside edge, seating by sculpture, and entrance were less preferred. The occupancy map also shows that in all subspaces people used places which are close to trees and have a degree of enclosure, or that receive natural shade created by trees. A combination of natural shade, benches, sitting wall and grass seem the favourite subspaces (Figure 6-8).

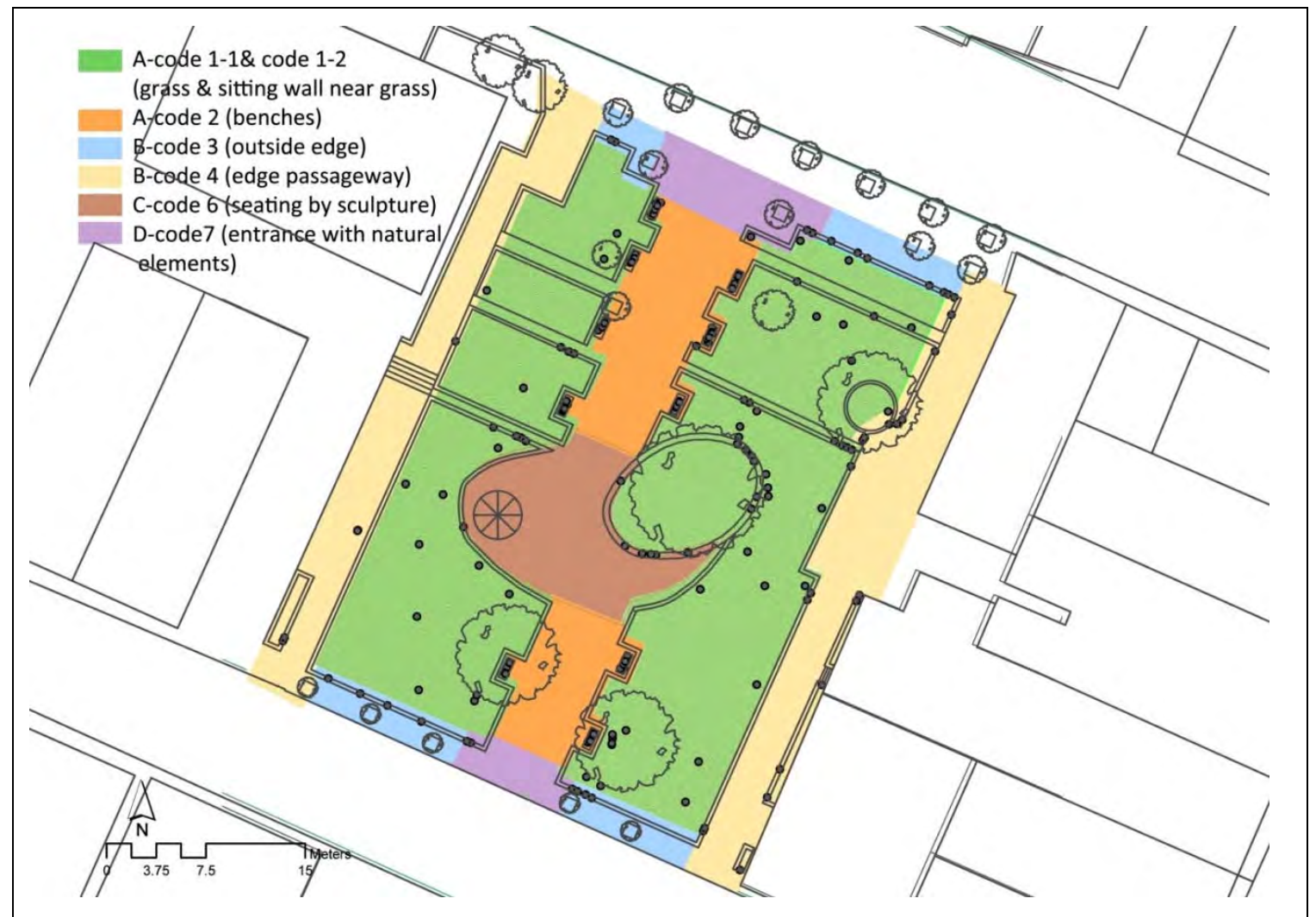

Figure 6-8: Map of occupancy during one day, Glover Park

Early use of space shows seating in a paved area was preferred (Figures 6-9.1-6-9.3). From 11.00-12.00 benches and sitting wall under the shade of trees were occupied (Figure 69.4) and around midday grass and outside edges started to be used more intensively (Figure 6-9.5). The preferred grass areas and entrances are close to trees and borders. At midday almost all grass areas were in the sun and the grass to the east side with more trees was well used. From 13.00 onwards grass to the west side (Figures 6-9.6, 6-9.7) had more users reaching its maximum occupancy between 15.00-16.00 (Figure 6-9.8), which 
corresponds with the second peak occupancy for the whole park. The map of the last hour of observation shows benches and sitting wall close to trees were still preferred but benches under shade were not occupied (Figure 6-9.9).The grass area in the NW corner that is shaded by the adjacent building was rarely used, which suggests a preference for natural shade over artificial (Figure 6-9). This may occur because shade from a building is absolute while shade under a tree is dappled and changes.

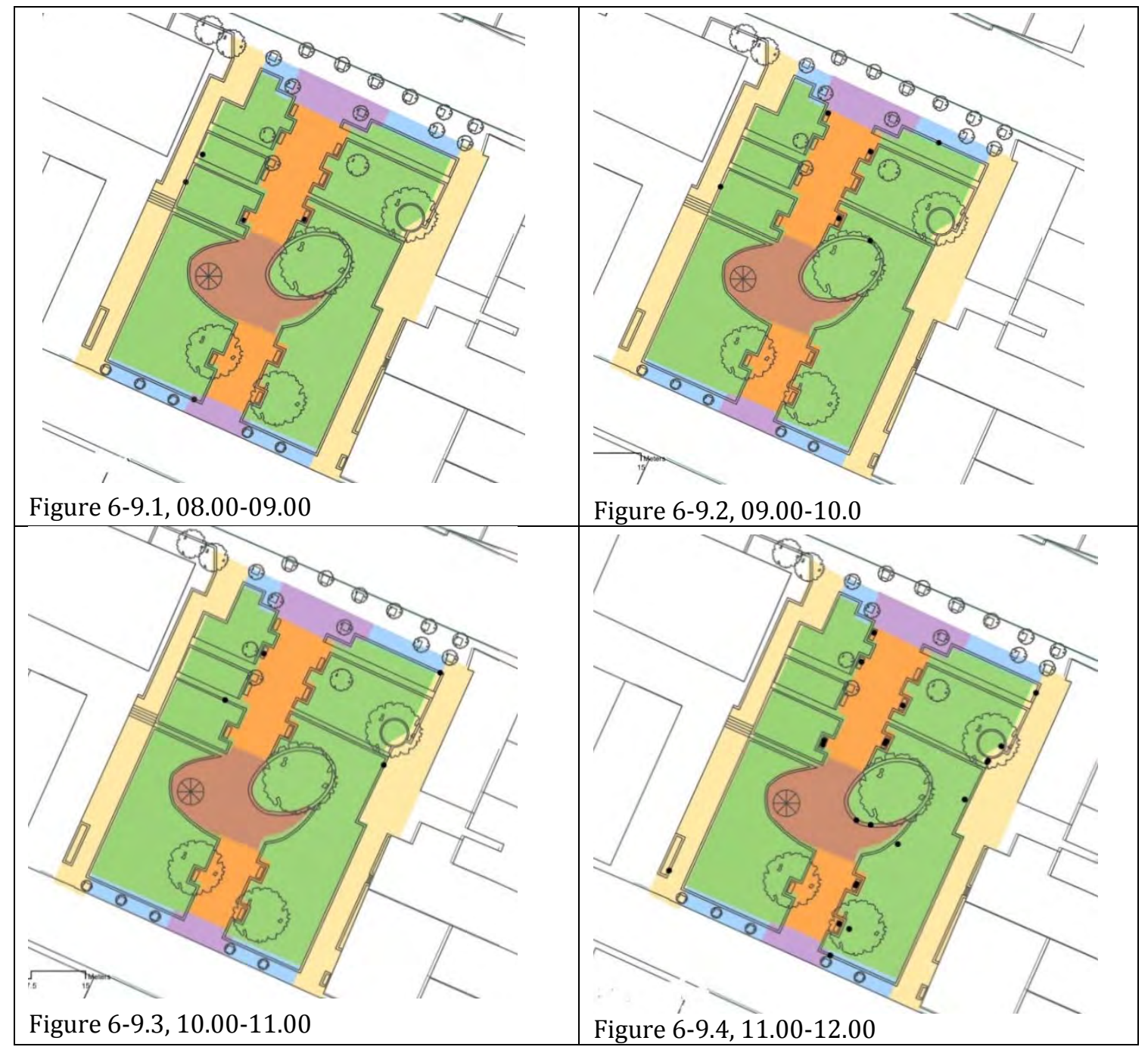




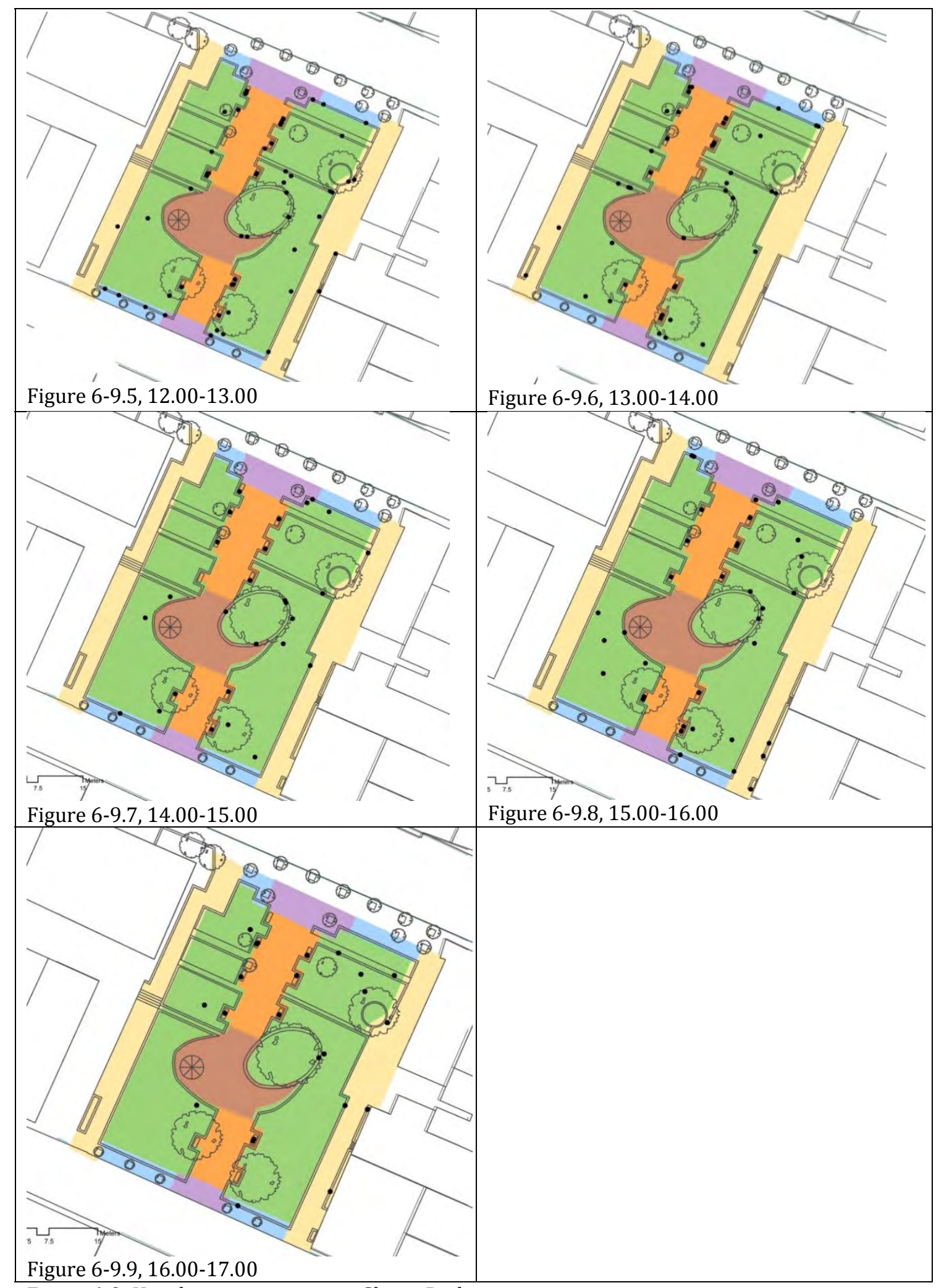

Figure 6-9: Hourly occupancy maps, Glover Park

\subsubsection{Size of Group}

Most use was by people alone (47\%) or people in a group of two (36\%), with groups of three, four, and five people making up the remaining $17 \%$.The percentage of people alone 
as part of total occupancy $\left(T^{*} 100 / A\right)$ for each subspace during the day demonstrates the preferred subspaces for people alone are seating, seating around sculpture, entrance, and sitting wall by grass, at $65.22 \%, 60 \%, 60 \%$, and $60 \%$ respectively. While the number of people alone and in groups using the outside edge are equal, groups have a preference for using edge passage way and grass more than people alone (Table 6-4).

Table 6-4: Use of subspaces by people alone and in groups

\begin{tabular}{|c|c|c|c|c|c|c|c|c|c|c|c|c|}
\hline & & $\begin{array}{l}08.00- \\
09.00\end{array}$ & $\begin{array}{l}09.00- \\
10.00\end{array}$ & $\begin{array}{l}10.00- \\
11.00\end{array}$ & $\begin{array}{l}11.00- \\
12.00\end{array}$ & $\begin{array}{l}12.00- \\
13.00\end{array}$ & \begin{tabular}{|l|}
$13.00-$ \\
14.00
\end{tabular} & $\begin{array}{l}14.00- \\
15.00\end{array}$ & $\begin{array}{l}15.00- \\
16.00\end{array}$ & \begin{tabular}{|l|}
$16.00-$ \\
17.00
\end{tabular} & $\mathbf{T}$ & $\mathbf{P}$ \\
\hline \multirow[t]{3}{*}{ A-code $1-1$} & $A$ & 1 & 0 & 0 & 2 & 1 & 2 & 3 & 3 & 3 & 15 & $18.29 \%$ \\
\hline & $\mathrm{G}$ & 0 & 0 & 0 & 4 & 15 & 12 & 13 & 17 & 6 & 67 & $81.71 \%$ \\
\hline & $T$ & 1 & 0 & 0 & 6 & 16 & 14 & 16 & 20 & 9 & 82 & $100 \%$ \\
\hline \multirow[t]{3}{*}{ A-code 1-2 } & $A$ & 0 & 0 & 2 & 0 & 7 & 8 & 2 & 1 & 1 & 21 & $60.00 \%$ \\
\hline & $\mathrm{G}$ & 0 & 2 & 0 & 0 & 6 & 0 & 2 & 4 & 0 & 14 & $40.00 \%$ \\
\hline & $T$ & 0 & 2 & 2 & 0 & 13 & 8 & 4 & 5 & 1 & 35 & $100.0 \%$ \\
\hline \multirow[t]{3}{*}{ A-code 2} & $A$ & 2 & 2 & 1 & 7 & 16 & 11 & 6 & 9 & 6 & 60 & $65.22 \%$ \\
\hline & $\mathrm{G}$ & 0 & 2 & 0 & 6 & 6 & 10 & 0 & 4 & 4 & 32 & $34.78 \%$ \\
\hline & $T$ & 2 & 4 & 1 & 13 & 22 & 21 & 6 & 13 & 10 & 92 & $100 \%$ \\
\hline \multirow[t]{3}{*}{ B-code 3} & $A$ & 0 & 1 & 1 & 1 & 5 & 0 & 1 & 2 & 1 & 12 & $50.00 \%$ \\
\hline & $\mathrm{G}$ & 0 & 0 & 0 & 0. & 2 & 8 & 0 & 2 & 0 & 12 & $50.00 \%$ \\
\hline & $\mathrm{T}$ & 0 & 1 & 1 & 1 & 7 & 8 & 1 & 4 & 1 & 24 & $100 \%$ \\
\hline \multirow[t]{3}{*}{ B-code 4} & A & 0 & 0 & 0 & 3 & 3 & 2 & 1 & 3 & 2 & 13 & $46.43 \%$ \\
\hline & $\mathrm{G}$ & 2 & 0 & 0 & 5 & 5 & 3 & 0 & 0 & 0 & 15 & $53.57 \%$ \\
\hline & $\mathrm{T}$ & 2 & 0 & 0 & 8 & 8 & 4 & 1 & 3 & 2 & 28 & $100 \%$ \\
\hline \multirow[t]{3}{*}{ C-code 6} & A & 0 & 0 & 0 & 1 & 2 & 1 & 2 & 0 & 0 & 6 & $60.00 \%$ \\
\hline & $\mathrm{G}$ & 0 & 0 & 0 & 2 & 0 & 0 & 0 & 2 & 0 & 4 & $40.00 \%$ \\
\hline & $T$ & 0 & 0 & 0 & 3 & 2 & 1 & 2 & 2 & 0 & 10 & $100 \%$ \\
\hline \multirow[t]{3}{*}{ D-code 7} & $\mathrm{~A}$ & 1 & 0 & 0 & 0 & 1 & 0 & 1 & 0 & 0 & 3 & $60.00 \%$ \\
\hline & $\mathrm{G}$ & 0 & 0 & 0 & 0 & 2 & 0 & 0 & 0 & 0 & 2 & $40.00 \%$ \\
\hline & $T$ & 1 & 0 & 0 & 0 & 3 & 0 & 1 & 0 & 0 & 5 & $100 \%$ \\
\hline \multicolumn{9}{|c|}{ T: Total P: Percentage of total A: Alone G: Group } & \multicolumn{3}{|c|}{ Max occupancy } & Vacant \\
\hline
\end{tabular}

Hourly comparison of number of people alone and in groups shows between 08.00-09.00 and 16.00-17.00 grass attracted more groups than people alone. Use of grass by groups is significanly more than for people alone (Figure 6-10.1). At 09.00-10.00 and 15.00-16.00 the number of groups using sitting wall was more than people alone, but at other times sitting walls were occupied by people alone, suggesting a preferrence for their use by people alone more than groups (Figure 6-10.2). Unlike grass, seating was used more by people alone than groups over the day (Figure 6-10.3). Except between 13.00-14.00 (lunch time) the outside edge subspace was always occupied more by people alone than groups (Figure 6-10.4). The edge passage way attracted more groups throughout the morning until 14.00, after which it was occupied by people alone for the rest of the day. Unlike the other subspaces, use of the edge passage way decreased dramatically during the day (Figure 6-10.5). No groups were observed on seating by sculpture from 12.00-15.00 
(Figure 6-10.6). Entrance was the least popular place and was only used for three hours, mostly by people alone (Figure 6-10.7).

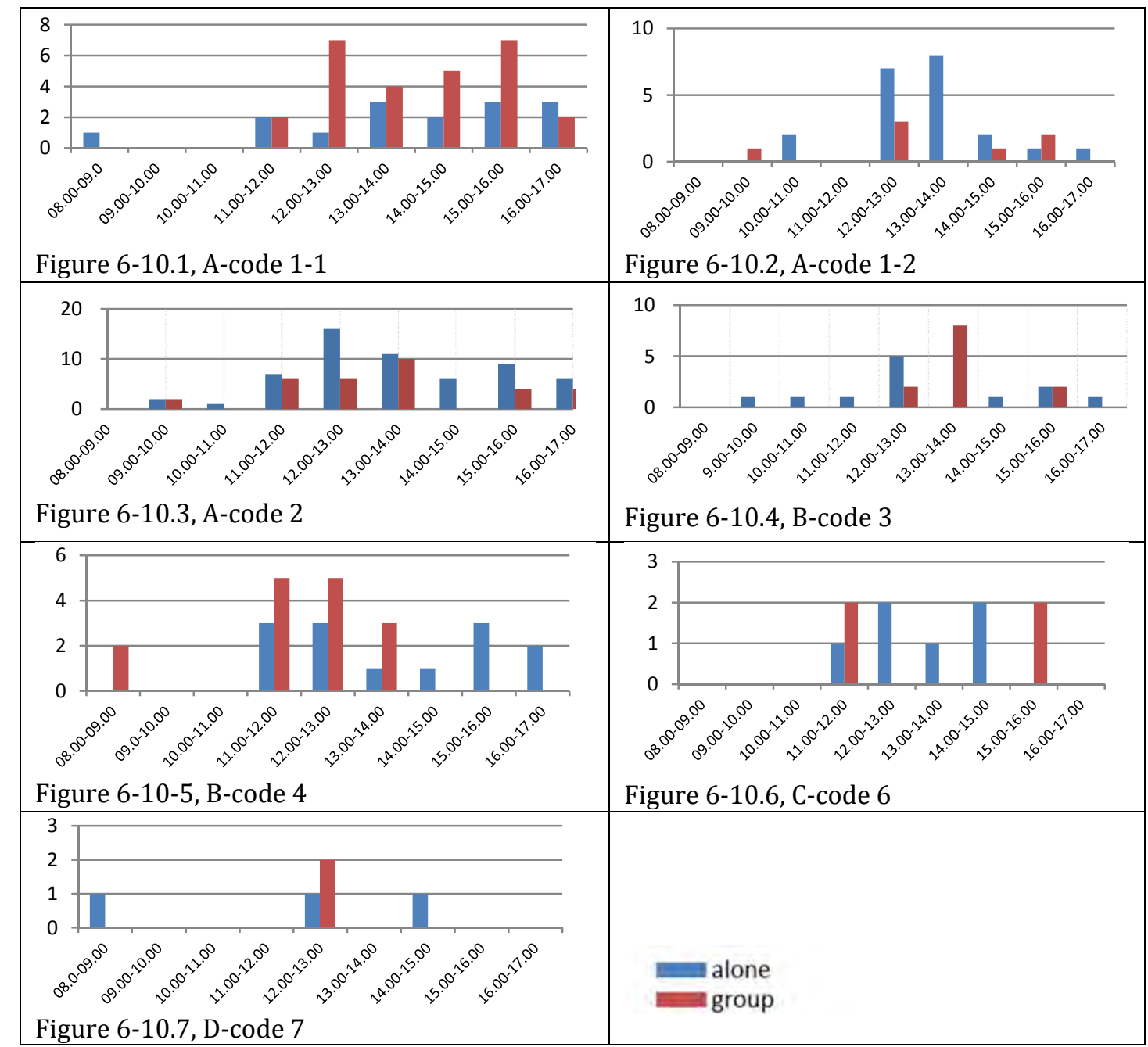

Figure 6-10: Comparison between people alone and in groups

To compare the pattern of use of place by people alone and groups, diagrams were prepared to show the percentage of people alone as part of the maximum occupancy of each subspace during the day. Results illustrate that grass areas are a territory for groups. Over the day less than $20 \%$ of maximum occupancy of grass is by people alone (Figure 611.1). Use of sitting wall by grass by people alone increased over the morning and reached its peak between 13.00-14.00, when it then decreased over the afternoon (Figure 6-11.2). The pattern of using benches followed the pattern of total use with two crowded times between 12.00-13.00 and 14.00-16.00 (Figure 6-11.3). The maximum number of people alone using the outside edges was observed between $12.00-13.00$ (60\%), with a minimum (0\%) between $13.00-14.00$, after which there was a rise to $25 \%$ of maximum between 15.00-16.00 (Figure 6-11.4). The highest number of people alone in edge passage way was 
also seen between $11.00-13.00$ and $15.00-16.00$ (Figure 6-11.5). Seating by sculpture attracted most people alone between 12.00-13.00 and 14.00-15.00 (Figure 6-11.6). Only at lunch time were entrances used by groups (Figure 6-11.7).

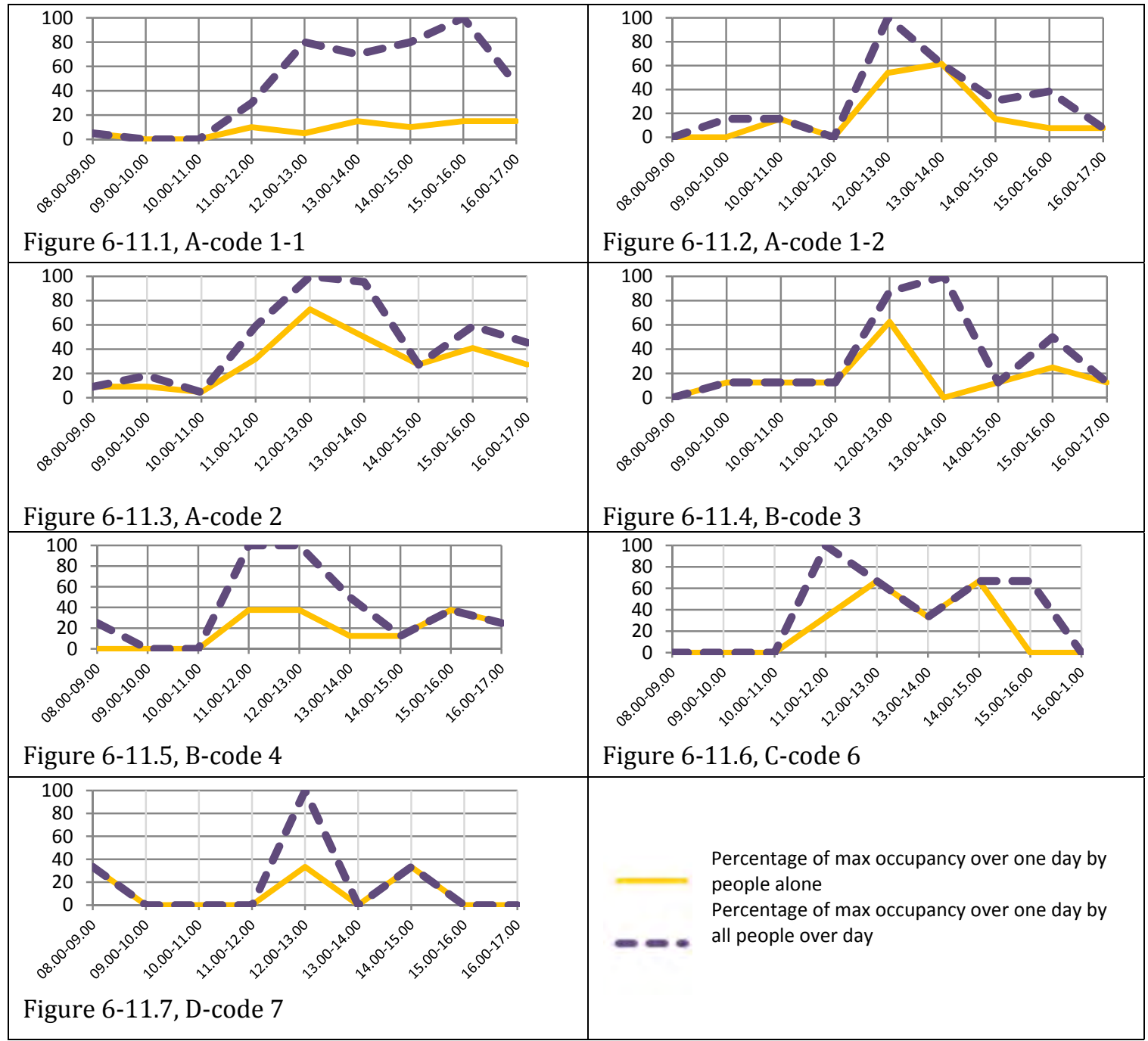

Figure 6-11: Use by people alone as a percentage of maximum occupancy, Glover Park

Separate occupancy maps for people alone and in groups (Figure 6-12) show people alone used seats and sitting walls close to the pedestrian passage while grass area and sitting wall by trees was the favourate place for groups. In fact people alone used space that is situated by ways through the park that enable them to observe others. Inspection of the maps also shows most use was made of sitting walls under trees. It also seems trees are being used not just for the shade they give, since the grass shaded by the building was little used. At the same time people sit by trees even in the early morning or late afternoon when it might be more pleasant to sit in the direct sun. This suggest trees are valued for other reasons. 


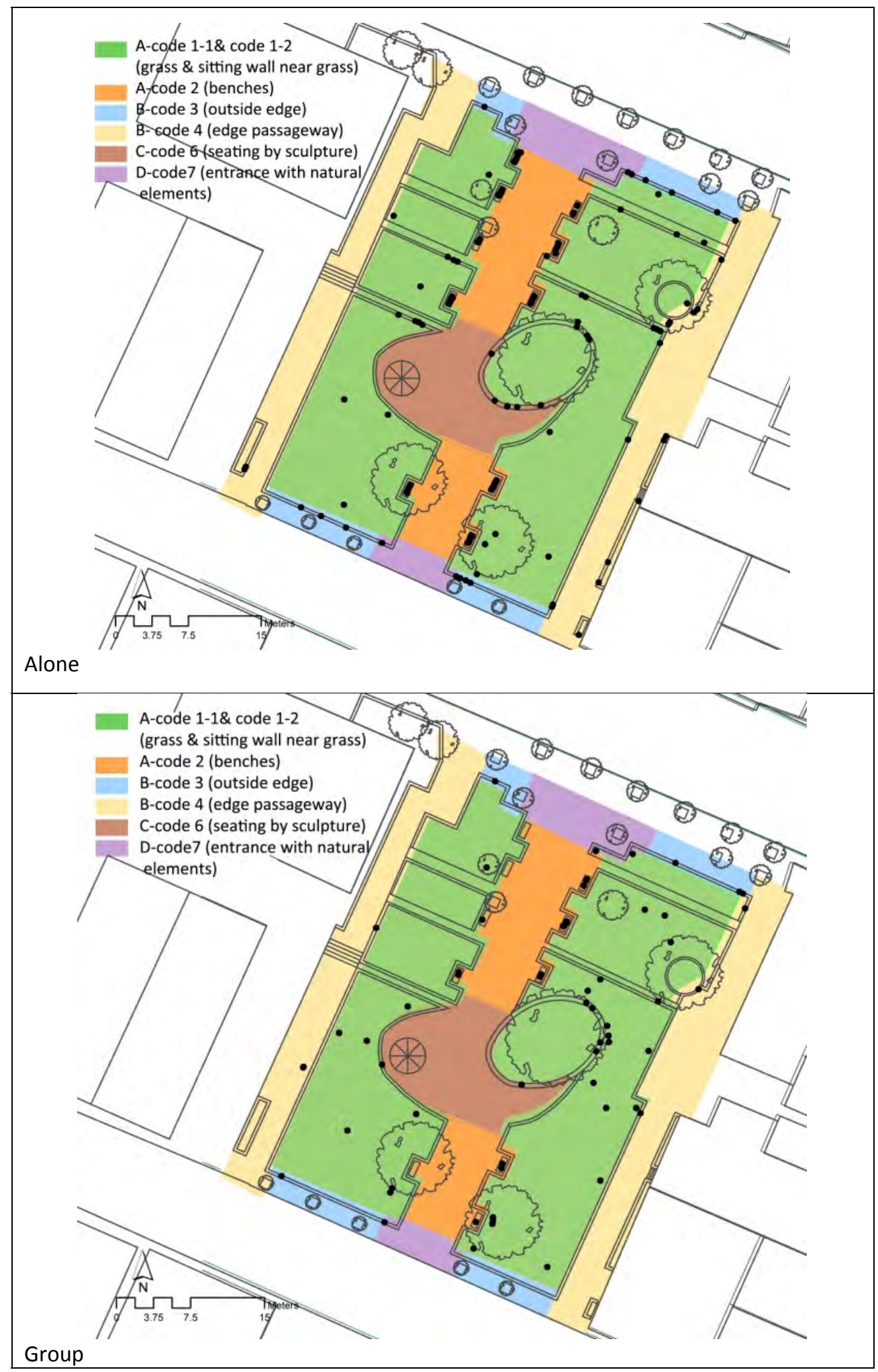

Figure 6-12: Map of occupancy by people alone and in groups all day, Glover Park

Comparison between subspaces in terms of size of group also reveals that grass and edge passage way attracted larger groups while other subspaces were occupied by people alone or people in a group of two. Diversity in group size for the grass subspace reveals the affordance of place (Table 6-5). 
Table 6-5: Size of group and use of subspaces, Glover Park

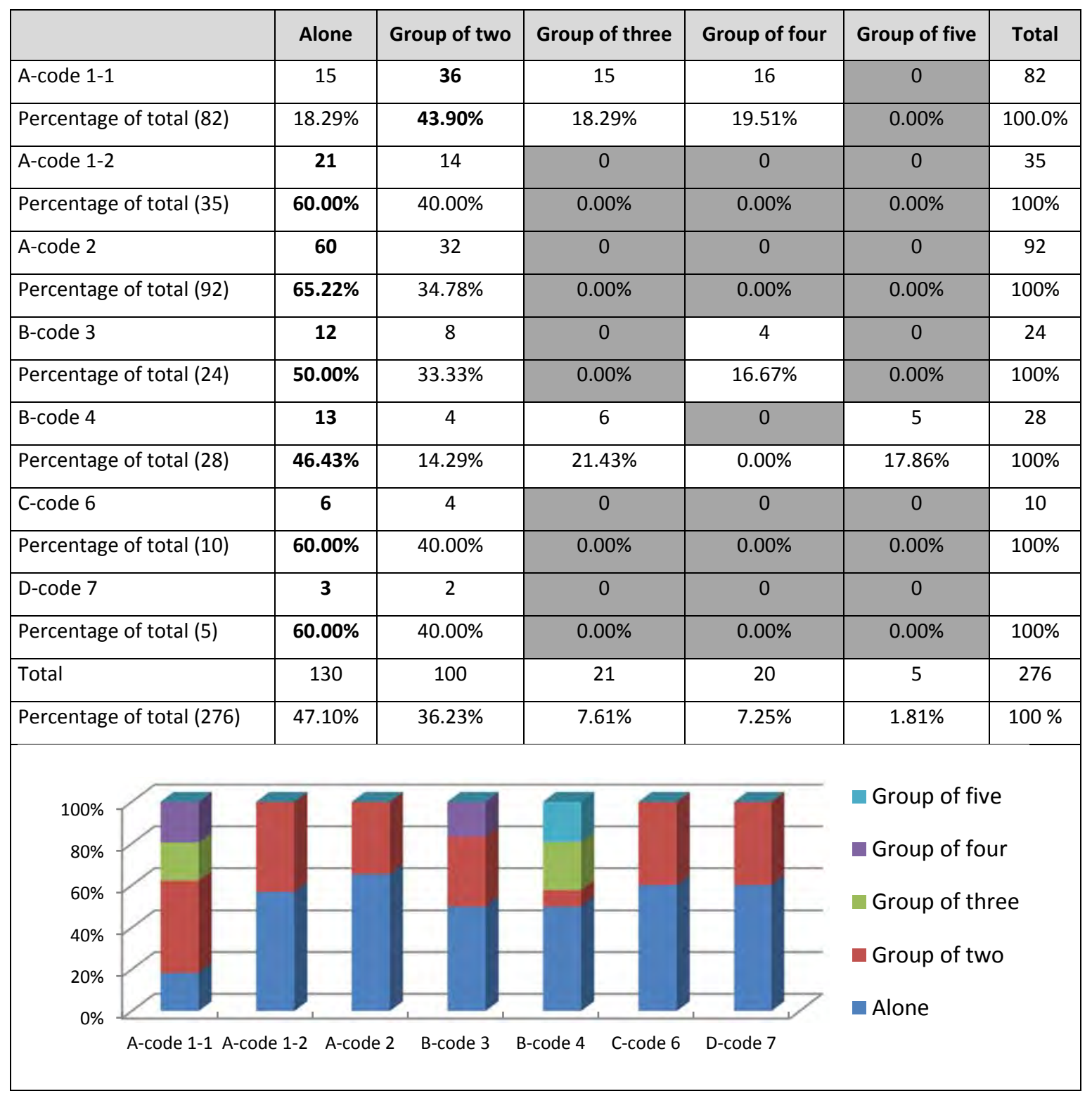

Places used by bigger groups are the edges of each subspace and subspaces close to trees

(Figure 6-13). 


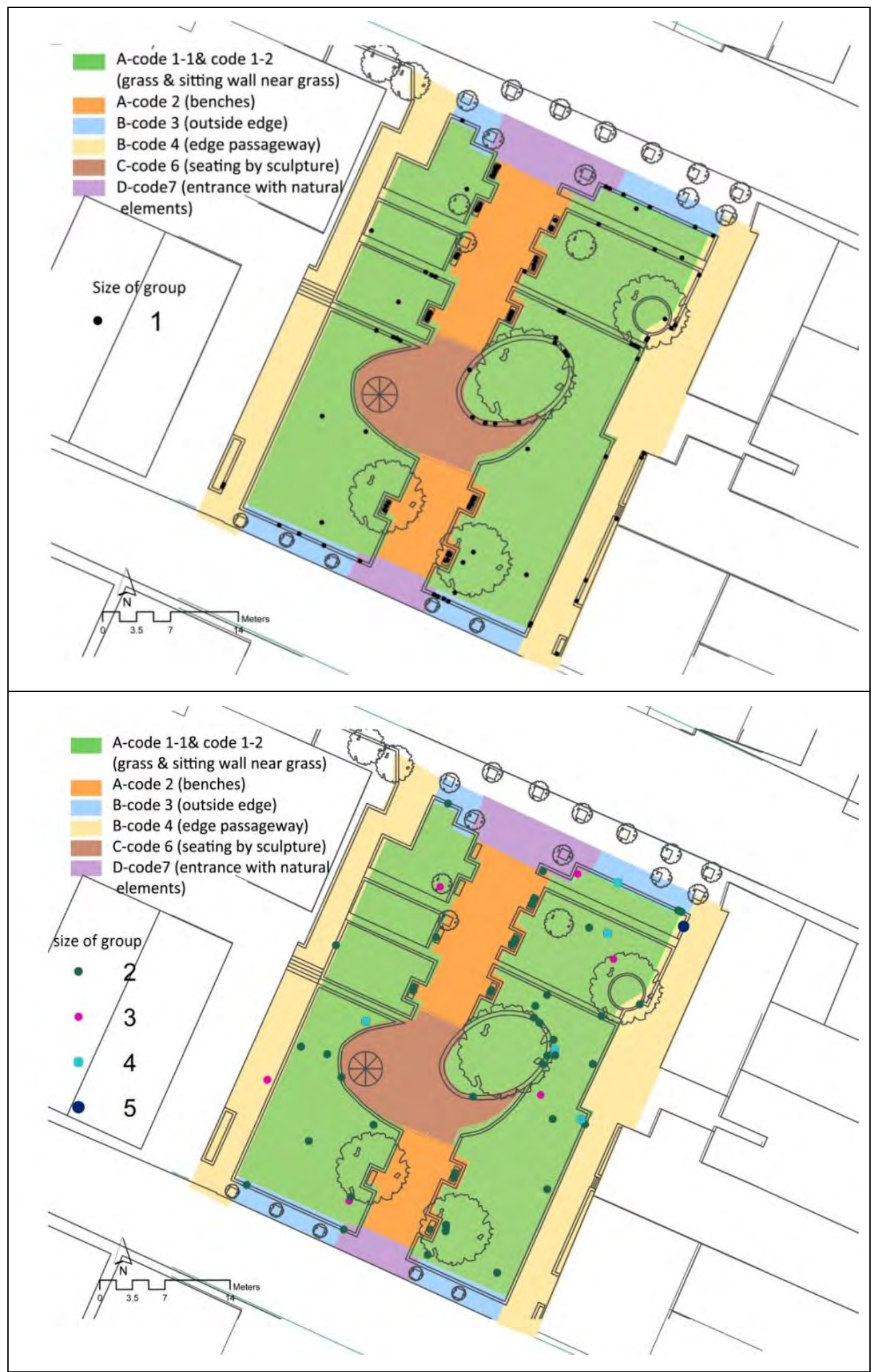

Figure 6-13: Occupancy map based on size of group, Glover Park

\subsubsection{Use of Spaces by Age and Gender}

Analysis of photographs shows teenagers and young adults make up $79.7 \%$ of users, while 
adults and the retired account for $19.2 \%$. Females were observed more than males. Grass and edge passage way are mostly used by teenagers and young adults. Seating and sitting wall are used most by young adults, then teenagers, followed by adults. Teenagers also used the edge passage twice as much as adults and young adults (Table 6-6).

Table 6-6: Number of users by age and gender

\begin{tabular}{|l|c|c|c|c|c|c|c|c|c|c|c|c|c|}
\hline & Child & \multicolumn{3}{|c|}{ Teenager } & \multicolumn{3}{c|}{ Young Adult } & \multicolumn{3}{c|}{ Adult } & \multicolumn{3}{c|}{ Older Adult } \\
\hline & & Male & Female & Total & Male & Female & Total & Male & Female & Total & Male & Female & Total \\
\hline A-code 1-1 & 2 & 17 & 19 & 36 & 18 & 21 & $\mathbf{3 9}$ & 3 & 0 & 3 & 1 & 1 & 2 \\
\hline A-code 1-2 & 0 & 1 & 8 & 9 & 13 & 9 & $\mathbf{2 2}$ & 6 & 1 & 7 & 0 & 1 & 1 \\
\hline A-code 2 & 1 & 8 & 17 & 25 & 28 & 16 & $\mathbf{4 4}$ & 12 & 5 & 17 & 3 & 2 & 5 \\
\hline B-code 3 & 0 & 0 & 9 & $\mathbf{9}$ & 5 & 4 & $\mathbf{9}$ & 2 & 3 & 5 & 0 & 1 & 1 \\
\hline B-code 4 & 0 & 12 & 3 & $\mathbf{1 5}$ & 6 & 0 & 6 & 2 & 3 & 5 & 0 & 2 & 2 \\
\hline C-code 6 & 0 & 1 & 1 & 2 & 5 & 0 & $\mathbf{5}$ & 0 & 3 & 3 & 0 & 0 & 0 \\
\hline E-code7 & 0 & 1 & 1 & $\mathbf{2}$ & 0 & 1 & 1 & 0 & 1 & 1 & 1 & 0 & 1 \\
\hline Total & 3 & 40 & 58 & 98 & 72 & 50 & $\mathbf{1 2 2}$ & 25 & 16 & 41 & 5 & 7 & 276 \\
\hline Percentage of & $1.08 \%$ & $14.50 \%$ & $21.01 \%$ & $35.51 \%$ & $26.10 \%$ & $18.11 \%$ & $44.21 \%$ & $9.10 \%$ & $5.80 \%$ & $14.90 \%$ & $1.80 \%$ & $2.50 \%$ & \\
total (276) & $1.08 \%$ & & & & & & & & & & & & \\
\hline
\end{tabular}

Use of spaces by people alone and in groups by gender indicates preferences for grass and sitting wall by grass are equal for both genders when alone (Table 6-7). While males alone prefer seating, passage way and seating by sculpture, females alone used ouside edges a little more than males (Table 6-7, Figures 6-14, 6-18). Preferences for seating and seating by sculpture for groups for both genders are similar. Outside edge, sitting wall, and grass attract female groups, while edge passage way had more male group users (Table 6-7, Figures $6-15,6-18)$. Mixed groups mostly used the sitting wall followed by benches and grass. Their use of other subspaces rarely happened (Table 6-7). 
Table 6-7: Number of groups in subspaces by gender

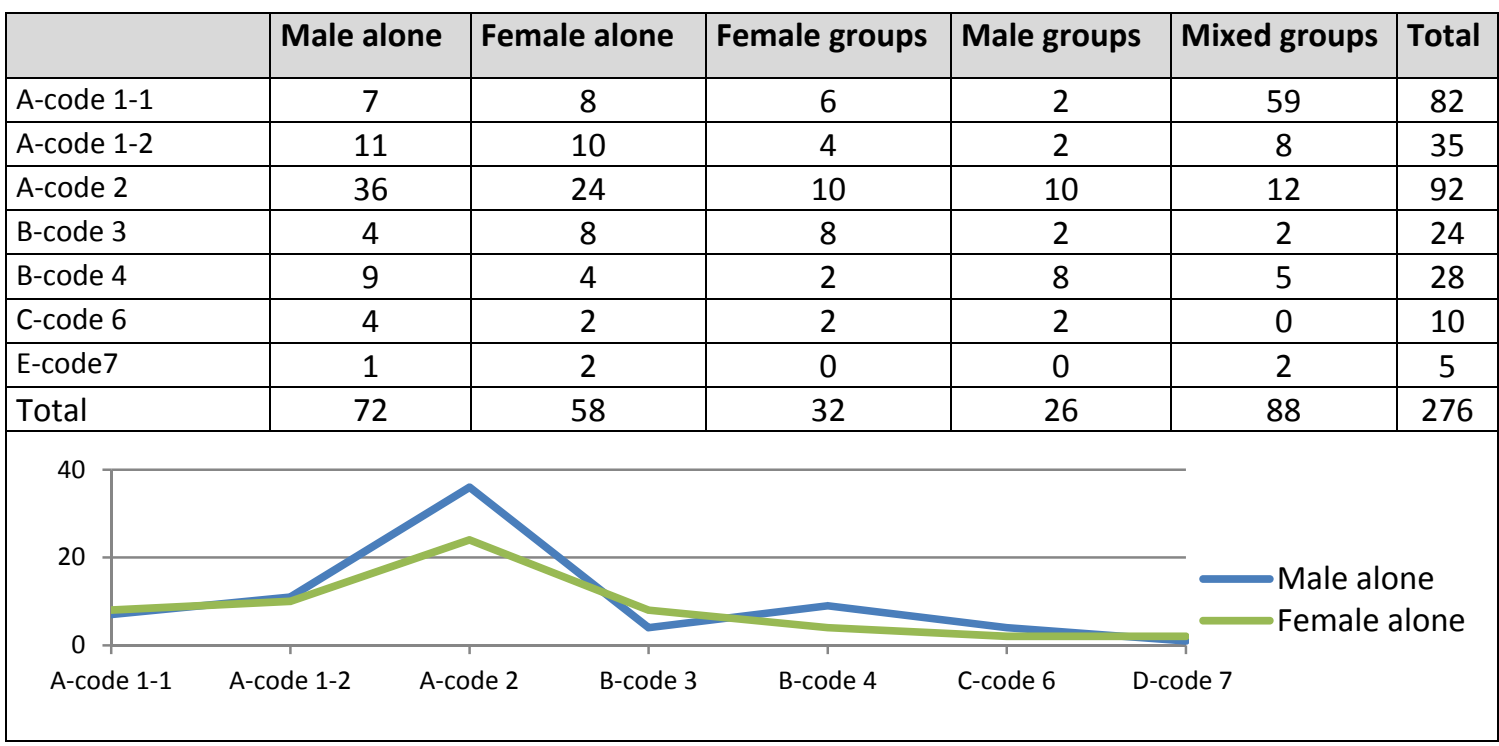

Figure 6-14: Male and female preferences when alone

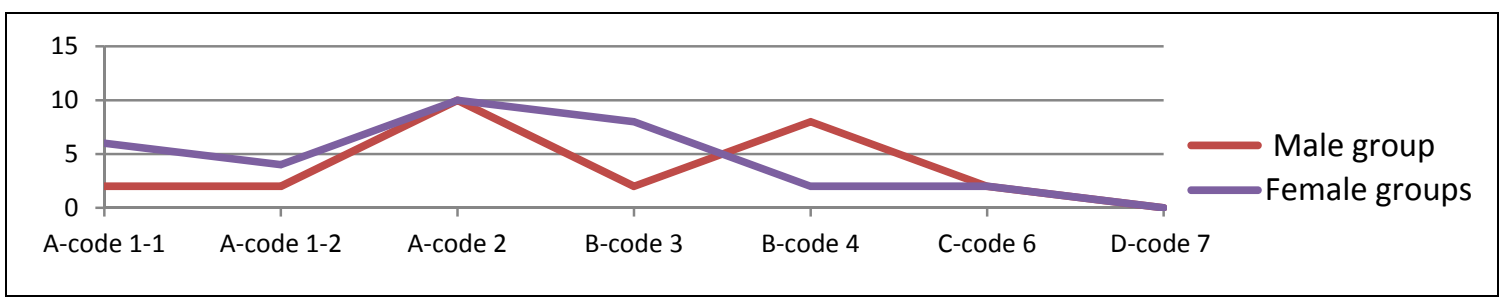

Figure 6-15: Male and female group preferences

Use of subspaces by males alone and in groups is the same, with a very slightly different pattern for females (Figures 6-16, 76-17, 6-18).

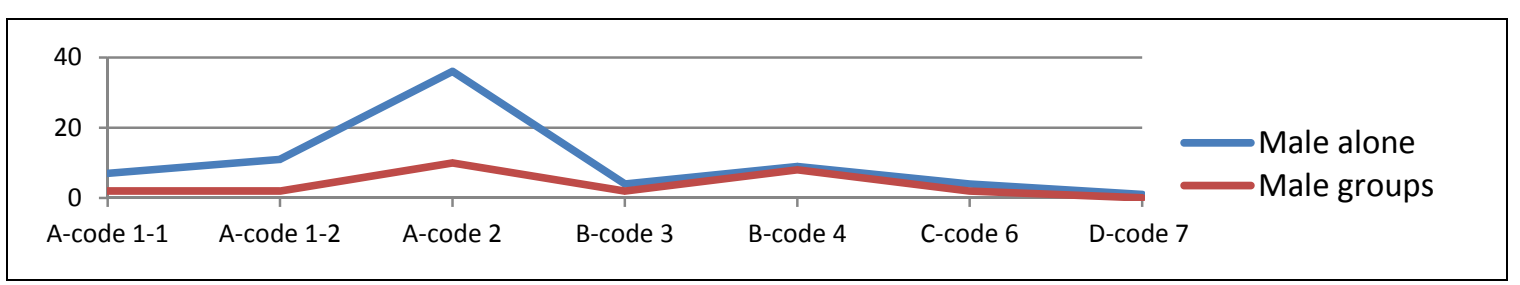

Figure 6-16: Preferences for males alone and in groups

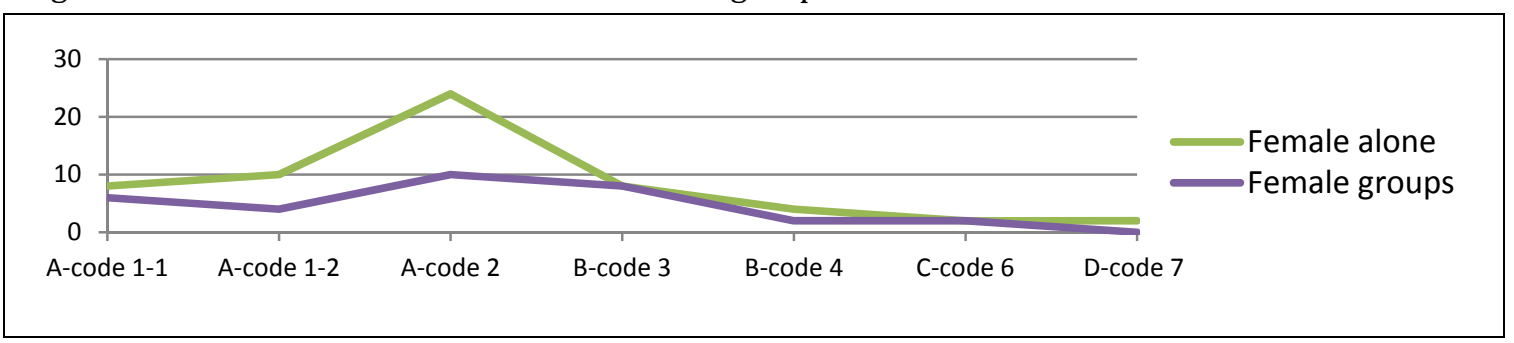

Figure 6-17: Preferences for females alone and in groups 


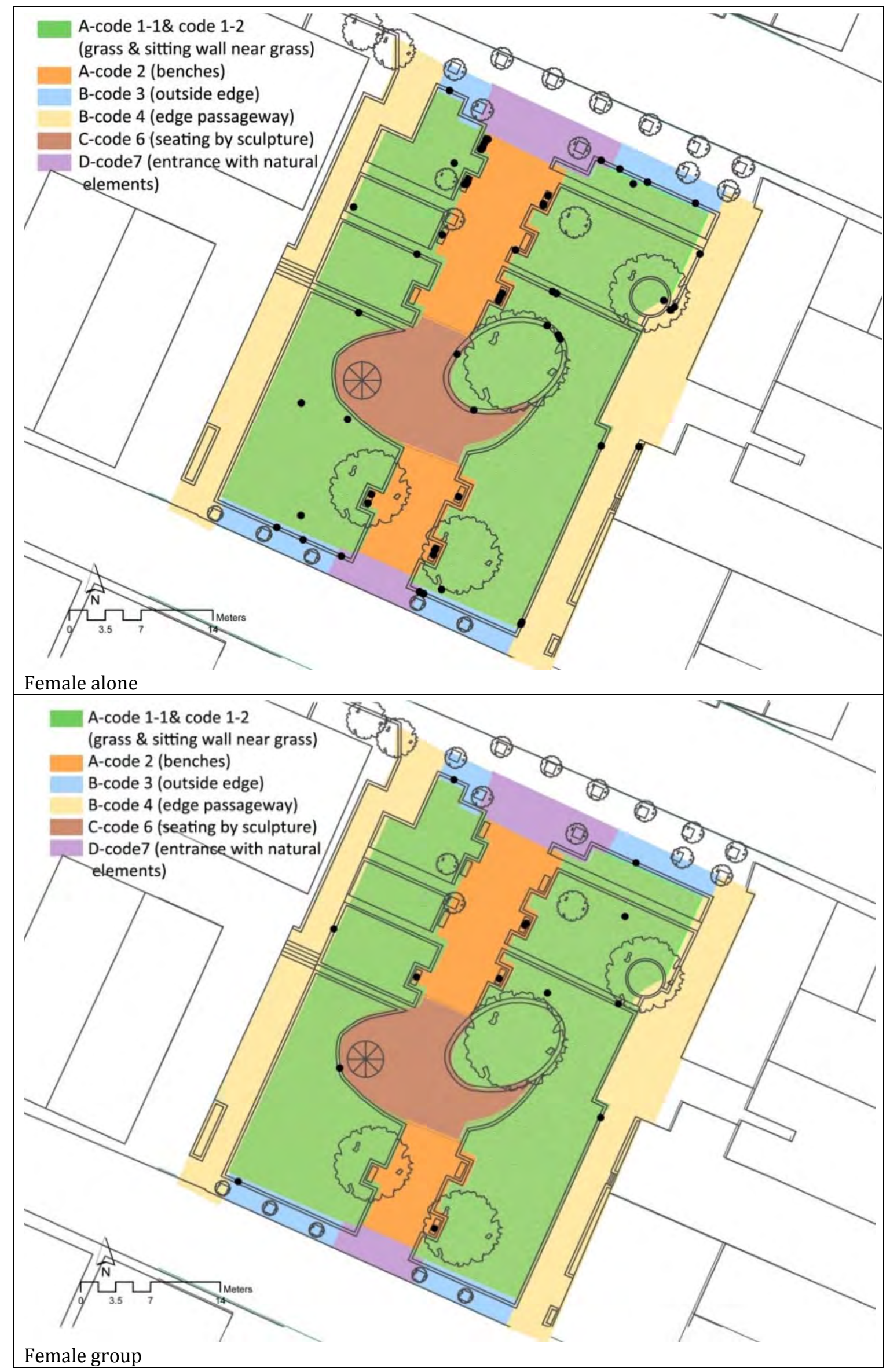




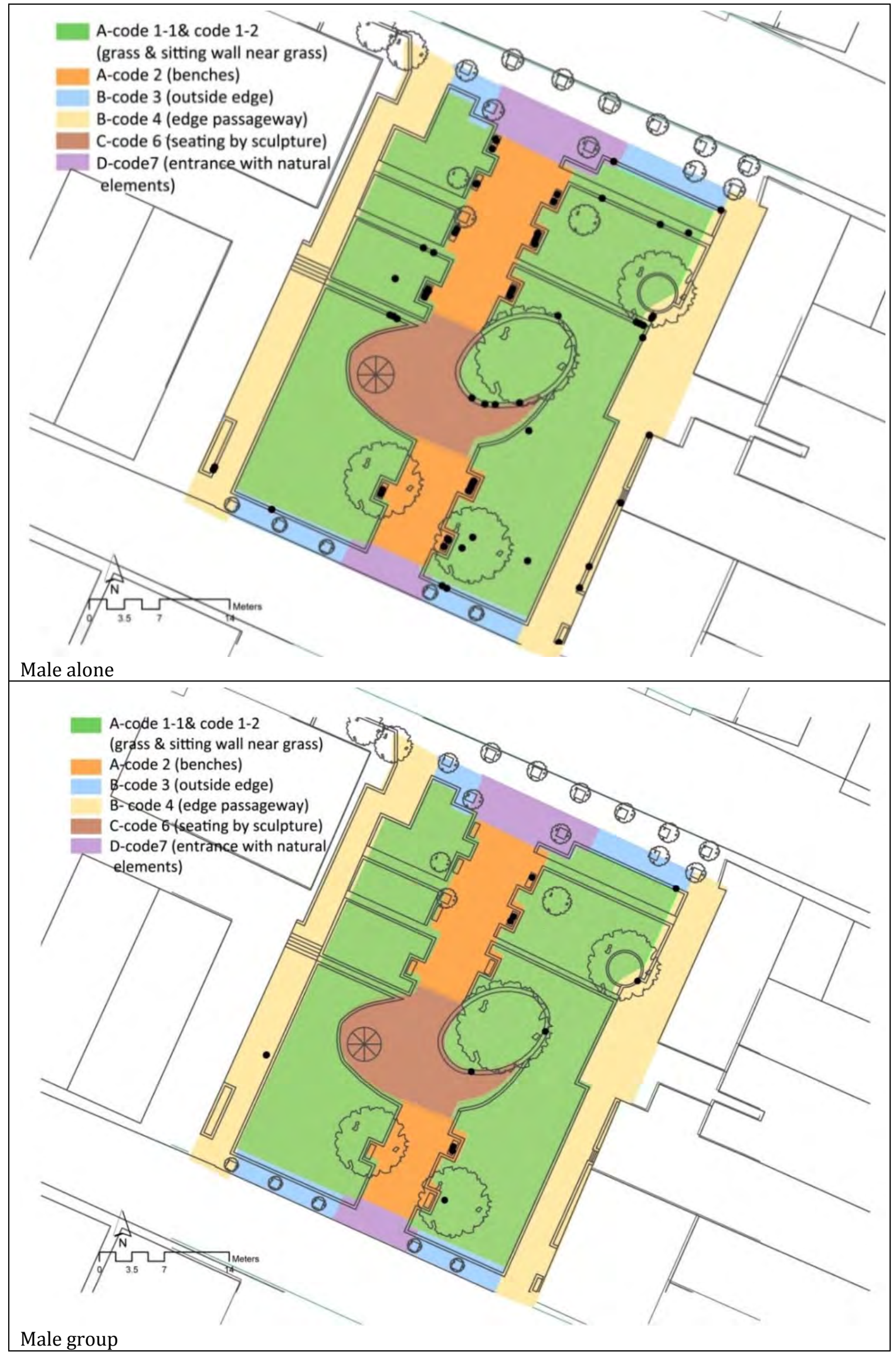

Figure 6-18: Map of occupancy for people alone and in groups by gender excluding mixed groups 
Both males and females alone and in a group seem to like to sit near trees, as sitting wall and grass used by these four categories are close to trees (Figure 6-18).

\subsubsection{Activity}

Activities recorded for each group show Glover Park is mostly used for sitting, eating, and reading. Standing and short time activities like smoking were observed in a few cases. Vigorous activity and other activities, like sleeping, are also represented suggesting Glover Park provides a relaxed and felixible environment. Talking, although initially considered, was deleted from the list of activities as people coming to Glover Park in groups obviously chatted together (Table 6-8).

Table 6-8: Type of activity by people alone and in groups

\begin{tabular}{|l|c|c|c|l|c|c|c|}
\hline Type of activity & \multicolumn{3}{|c|}{ Number } & \multicolumn{2}{c|}{ Type of activity } & \multicolumn{3}{c|}{ Number } \\
\hline & Alone & Group & Total & & Alone & Group & Total \\
\hline Sitting & 29 & 33 & 62 & Standing & 1 & 0 & 1 \\
\hline Sitting - eating & 26 & 19 & 45 & Standing - using mobile & 1 & 0 & 1 \\
\hline Sitting - using mobile & 37 & 1 & 38 & Standing - other & 3 & 2 & 5 \\
\hline Sitting - smoking & 6 & 1 & 7 & & & & \\
\hline Sitting - reading & 17 & 0 & 17 & Lying - sleeping & 3 & 0 & 3 \\
\hline Sitting - eating - reading & 1 & 0 & 1 & Dog walking & 6 & 0 & 6 \\
\hline Sitting - eating - using mobile & 3 & 0 & 3 & Playing & 0 & 2 & 2 \\
\hline Sitting - other & 0 & 2 & 2 & & & & \\
\hline
\end{tabular}

People alone and in groups make equal use of Glover Park for sitting and eating, while smoking, using a mobile phone, dog walking, sleeping, and standing mixed with other activities are observed for people alone.

In terms of diversity of activities in subspaces, grass and seating afforded more activities in contrast with entrance and seating by sculpture where the fewest different types of activity occurred (Table 6-9). 
Table 6-9: Activity in subspaces

\begin{tabular}{|c|c|c|c|c|c|c|c|c|c|c|c|c|c|c|c|}
\hline & \multicolumn{2}{|c|}{ A-code 1-1 } & \multicolumn{2}{|c|}{ A-code 1-2 } & \multicolumn{2}{|c|}{ A-code 2} & \multicolumn{2}{|c|}{ B-code 3} & \multicolumn{2}{|c|}{ B-code 4} & \multicolumn{2}{|c|}{ C-code 6} & \multicolumn{2}{|c|}{ D-code 7} & \multirow[t]{2}{*}{ Total } \\
\hline & $\mathbf{N}$ & $\mathbf{P}$ & $\mathbf{N}$ & $\mathbf{P}$ & $\mathbf{N}$ & $\mathbf{P}$ & $\mathbf{N}$ & $\mathbf{P}$ & $\mathbf{N}$ & $\mathbf{P}$ & $\mathbf{N}$ & $\mathbf{P}$ & $\mathbf{N}$ & $\mathbf{P}$ & \\
\hline Sitting & 18 & $29.03 \%$ & 11 & $17.74 \%$ & 19 & $30.65 \%$ & 4. & $6.45 \%$ & 4 & $6.45 \%$ & 3 & $75.00 \%$ & 3 & $4.84 \%$ & 62 \\
\hline Sitting - eating & 7 & $15.56 \%$ & 9 & $20.00 \%$ & 19 & $42.22 \%$ & 4 & $8.89 \%$ & 3 & $6.67 \%$ & 0 & $0.00 \%$ & 3 & $6.67 \%$ & 45 \\
\hline $\begin{array}{l}\text { Sitting - using } \\
\text { mobile }\end{array}$ & 3 & $7.89 \%$ & 4 & $10.53 \%$ & 21 & $55.26 \%$ & 7 & $18.42 \%$ & 2.0 & $5.26 \%$ & 0 & $0.00 \%$ & 1 & $2.63 \%$ & 38 \\
\hline Sitting - smoking & 0 & $0.00 \%$ & 1 & $16.67 \%$ & 2 & $33.33 \%$ & 1 & $16.67 \%$ & 2 & $33.33 \%$ & 0 & $0.00 \%$ & 0 & $0.00 \%$ & 6 \\
\hline Sitting - reading & 1 & $5.88 \%$ & 2 & $11.76 \%$ & 10 & $58.82 \%$ & 0 & $0.00 \%$ & 3 & $17.65 \%$ & 0 & $0.00 \%$ & 1 & $5.88 \%$ & 17 \\
\hline $\begin{array}{l}\text { Sitting - eating - } \\
\text { reading }\end{array}$ & 0 & $0.00 \%$ & 0 & $0.00 \%$ & 1 & $100 \%$ & 0 & $0.00 \%$ & 0 & $0.00 \%$ & 0 & $0.00 \%$ & 0 & $0.00 \%$ & 1 \\
\hline $\begin{array}{l}\text { Sitting - eating - } \\
\text { using mobile }\end{array}$ & 0 & $0.00 \%$ & 0 & $0.00 \%$ & 2 & $66.67 \%$ & 1 & $33.33 \%$ & 0 & $0.00 \%$ & 0 & $0.00 \%$ & 0 & $0.00 \%$ & 3 \\
\hline Sitting - other & 1 & $50.00 \%$ & 0 & $0.00 \%$ & 1 & $50.00 \%$ & 0 & $0.00 \%$ & 0 & $0.00 \%$ & 0 & $0.00 \%$ & 0 & $0.0 \%$ & 2 \\
\hline Standing & 0 & $0.00 \%$ & 1 & $50.00 \%$ & 0 & $0.00 \%$ & 0 & $0.00 \%$ & 0 & $0.00 \%$ & 1 & $25.00 \%$ & 0 & $0.00 \%$ & 2 \\
\hline $\begin{array}{l}\text { Standing - using } \\
\text { mobile }\end{array}$ & 1 & $100 \%$ & 0 & $0.00 \%$ & 0 & $0.00 \%$ & 0 & $0.00 \%$ & 0 & $0.00 \%$ & 0 & $0.00 \%$ & 0 & $0.00 \%$ & 1 \\
\hline Standing - other & 1 & $20.00 \%$ & 1 & $20.00 \%$ & 1 & $20.00 \%$ & 0 & $0.00 \%$ & 2 & $40.00 \%$ & 0 & $0.00 \%$ & 0 & $0.00 \%$ & 5 \\
\hline Lying - sleeping & 3 & $100 \%$ & 0 & $0.00 \%$ & 0 & $0.00 \%$ & 0 & $0.00 \%$ & 0 & $0.00 \%$ & 0 & $0.00 \%$ & 0 & $0.00 \%$ & 3 \\
\hline Dog walking & 6 & $100 \%$ & 0 & $50.00 \%$ & 0 & $0.00 \%$ & 0 & $0.00 \%$ & 0 & $0.00 \%$ & 0 & $0.00 \%$ & 0 & $0.00 \%$ & 6 \\
\hline Playing & 0 & $0.00 \%$ & 0 & $0.00 \%$ & 0 & $0.00 \%$ & 0 & $0.00 \%$ & 2 & $100 \%$ & 0 & $0.00 \%$ & 0 & $0.00 \%$ & 2 \\
\hline
\end{tabular}

\subsubsection{Length of Stay}

To an extent the time people spend in a place reflects its quality. Although it is not possible to calculate accurately the length of stay using snap shots, it is possible to observe the number of times a person appears in a series of photos and use this for measuring use of place. People used the entrance, edge passage way, and outside edges for a short stay. Users of sitting walls and benches were mostly observed in one or two photos, and grass attracted people for a longer time (Table 6-10). Group here means one person or group of two or more people. 
Table 6-10: Length of stay

\begin{tabular}{|l|c|c|c|c|c|c|c|c|}
\hline $\begin{array}{l}\text { Number of times group } \\
\text { observed subspace }\end{array}$ & & One & Two & Three & Four & Five & Six & Seven \\
\hline \multirow{2}{*}{ A-code 1-1 } & $\mathrm{N}$ & 19 & 12 & 3 & 4 & 1 & 1 & 1 \\
\cline { 2 - 10 } & $\mathrm{P}$ & $46.34 \%$ & $29.27 \%$ & $7.32 \%$ & $9.76 \%$ & $2.44 \%$ & $2.44 \%$ & $2.44 \%$ \\
\hline \multirow{2}{*}{ A-code 1-2 } & $\mathrm{N}$ & 21 & 4 & 2 & 1 & 1 & 0 & 0 \\
\cline { 2 - 10 } & $\mathrm{P}$ & $72.44 \%$ & $13.79 \%$ & $6.90 \%$ & $3.45 \%$ & $3.45 \%$ & $0.00 \%$ & $0.00 \%$ \\
\hline \multirow{2}{*}{ A-code 2 } & $\mathrm{N}$ & 48 & 18 & 6 & 2 & 2 & 0 & 0 \\
\cline { 2 - 11 } & $\mathrm{P}$ & $63.16 \%$ & $23.68 \%$ & $7.89 \%$ & $2.63 \%$ & $2.63 \%$ & $0.00 \%$ & $0.00 \%$ \\
\hline \multirow{2}{*}{ B-code 3 } & $\mathrm{N}$ & 15 & 2 & 0 & 0 & 0 & 0 & 0 \\
\cline { 2 - 10 } & $\mathrm{P}$ & $88.24 \%$ & $11.76 \%$ & $0.00 \%$ & $0.00 \%$ & $0.00 \%$ & $0.00 \%$ & $0.00 \%$ \\
\hline \multirow{2}{*}{ B-code 4 } & $\mathrm{N}$ & 13 & 5 & 0 & 0 & 0 & 0 & 0 \\
\hline \multirow{2}{*}{ C-code 6 } & $\mathrm{P}$ & $72.22 \%$ & $27.78 \%$ & $0.00 \%$ & $0.00 \%$ & $0.00 . \%$ & $0.00 \%$ & $0.00 \%$ \\
\hline \multirow{2}{*}{ D-code 7 } & $\mathrm{N}$ & 5 & 2 & 1 & 0 & 0 & 0 & 0 \\
\cline { 2 - 10 } & $\mathrm{P}$ & $62.50 \%$ & $25.00 \%$ & $12.50 \%$ & $0.00 \%$ & $0.00 \%$ & $0.00 \%$ & $0.00 \%$ \\
\hline
\end{tabular}

Occupancy maps also indicate places occupied longer are close to trees (Figure 6-19).

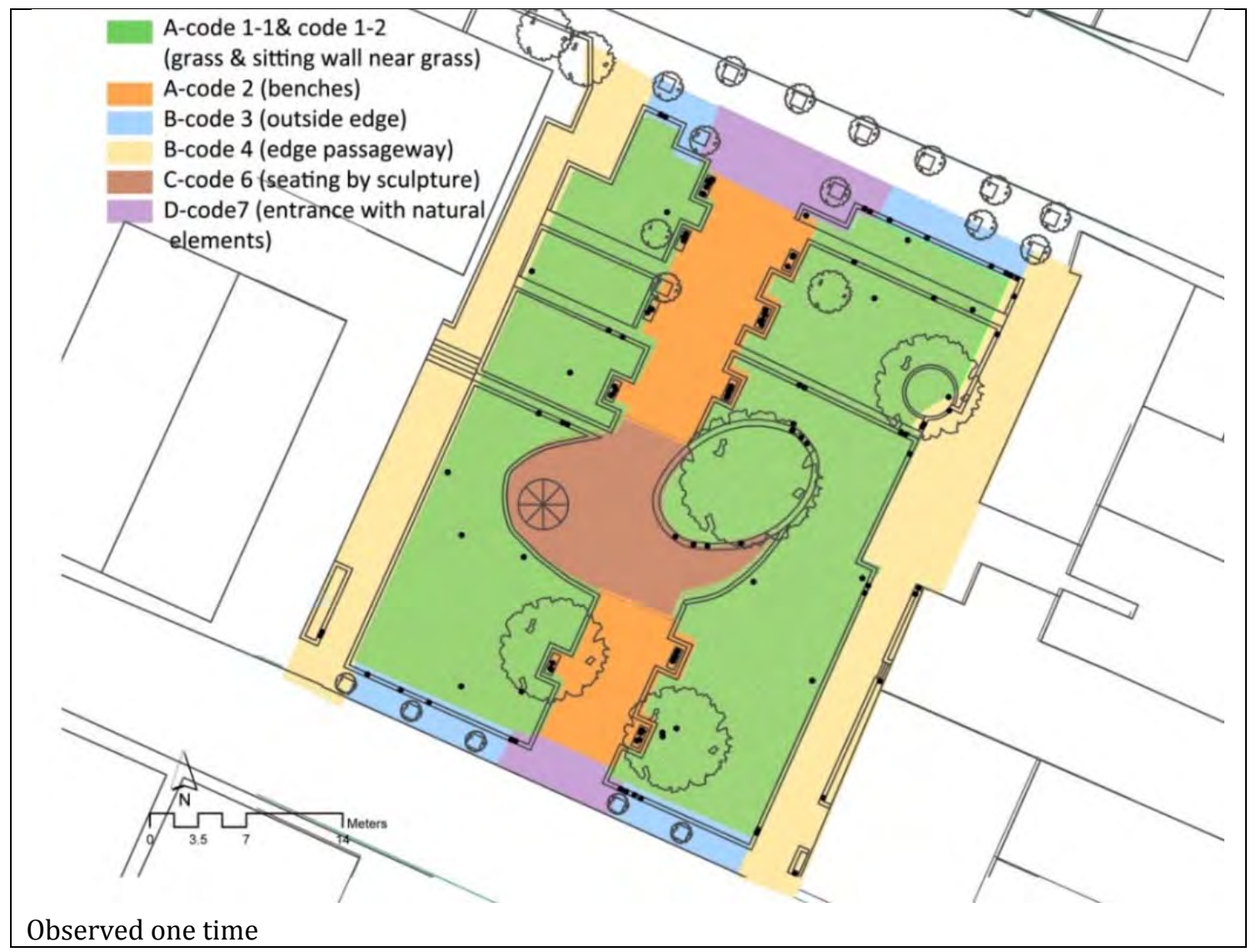




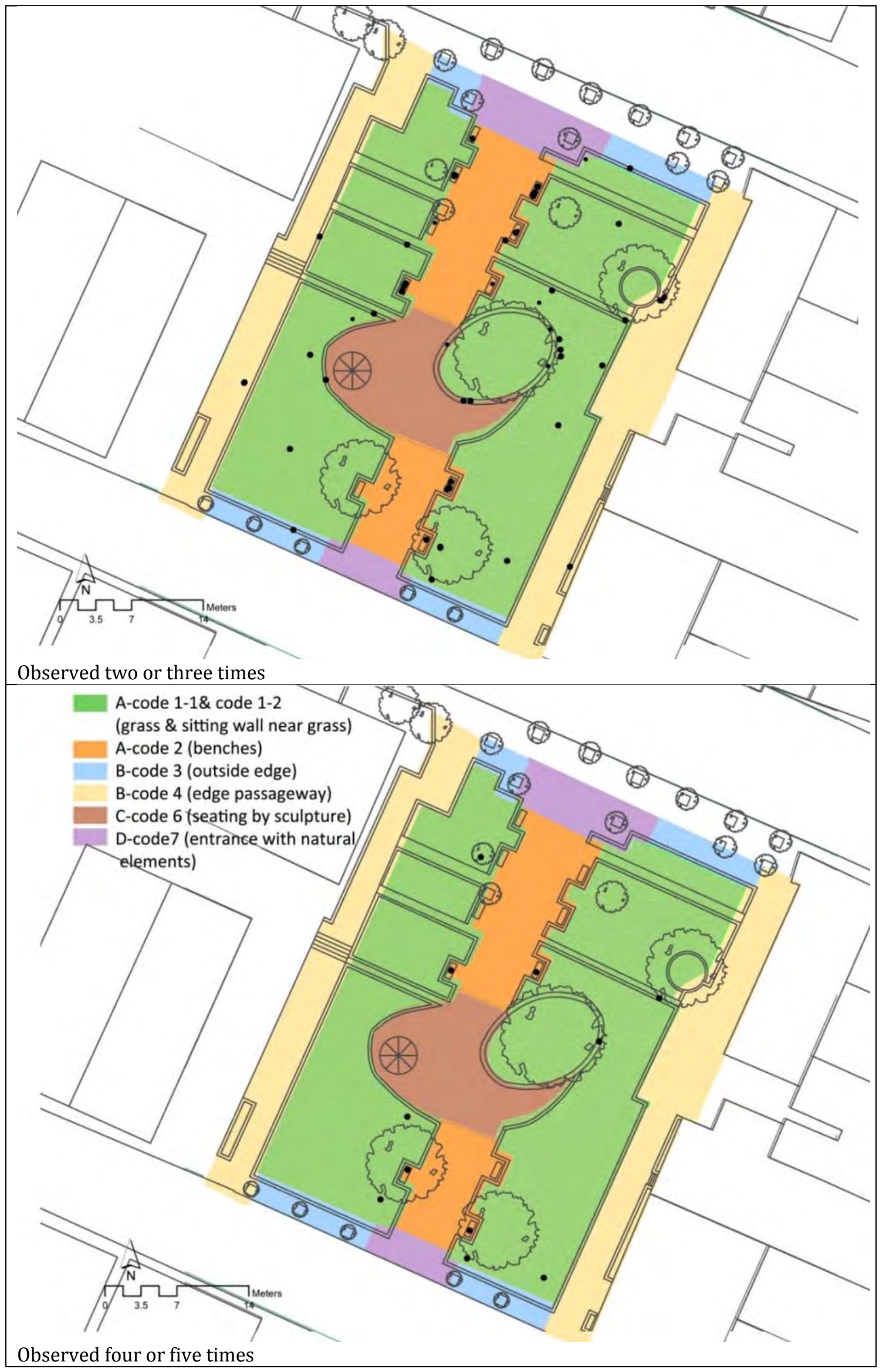




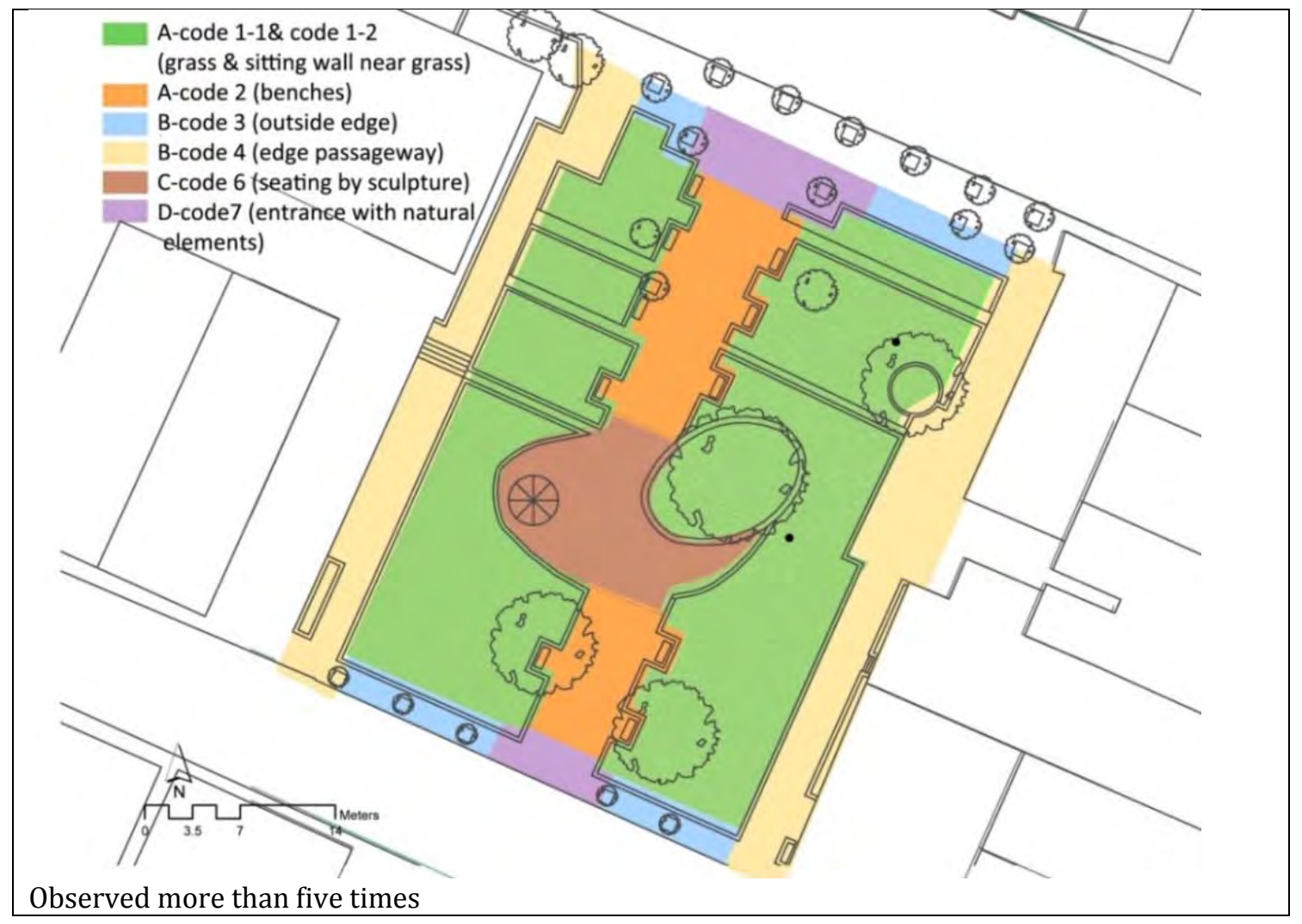

Figure 6-19: Length of stay, Glover Park

\subsection{Results - Civic Square}

Civic Square consists of five subspaces (Figure 6-20) and these with their design elements are described in Figure 6-21.

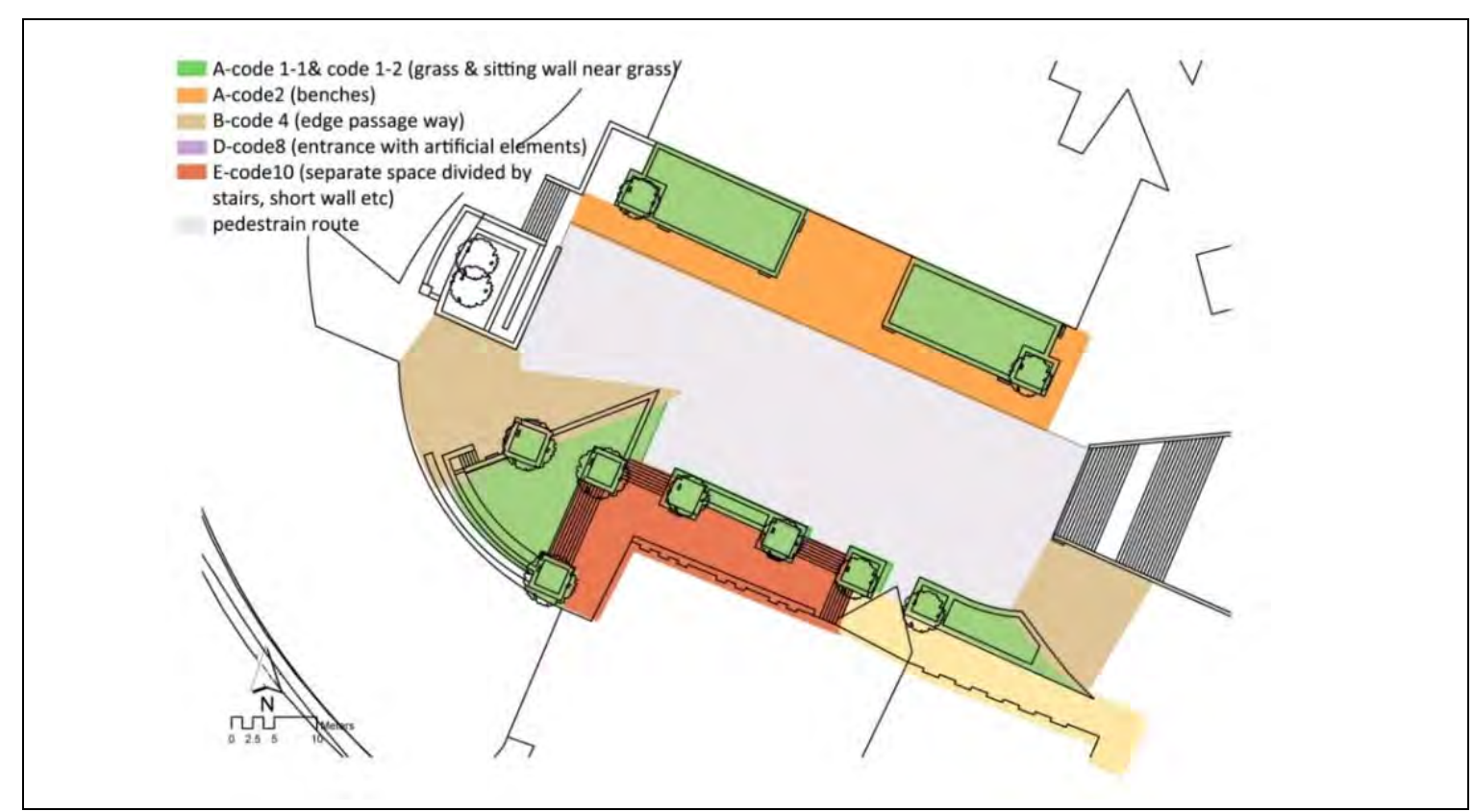

Figure 6-20: Subspaces in Civic Square 


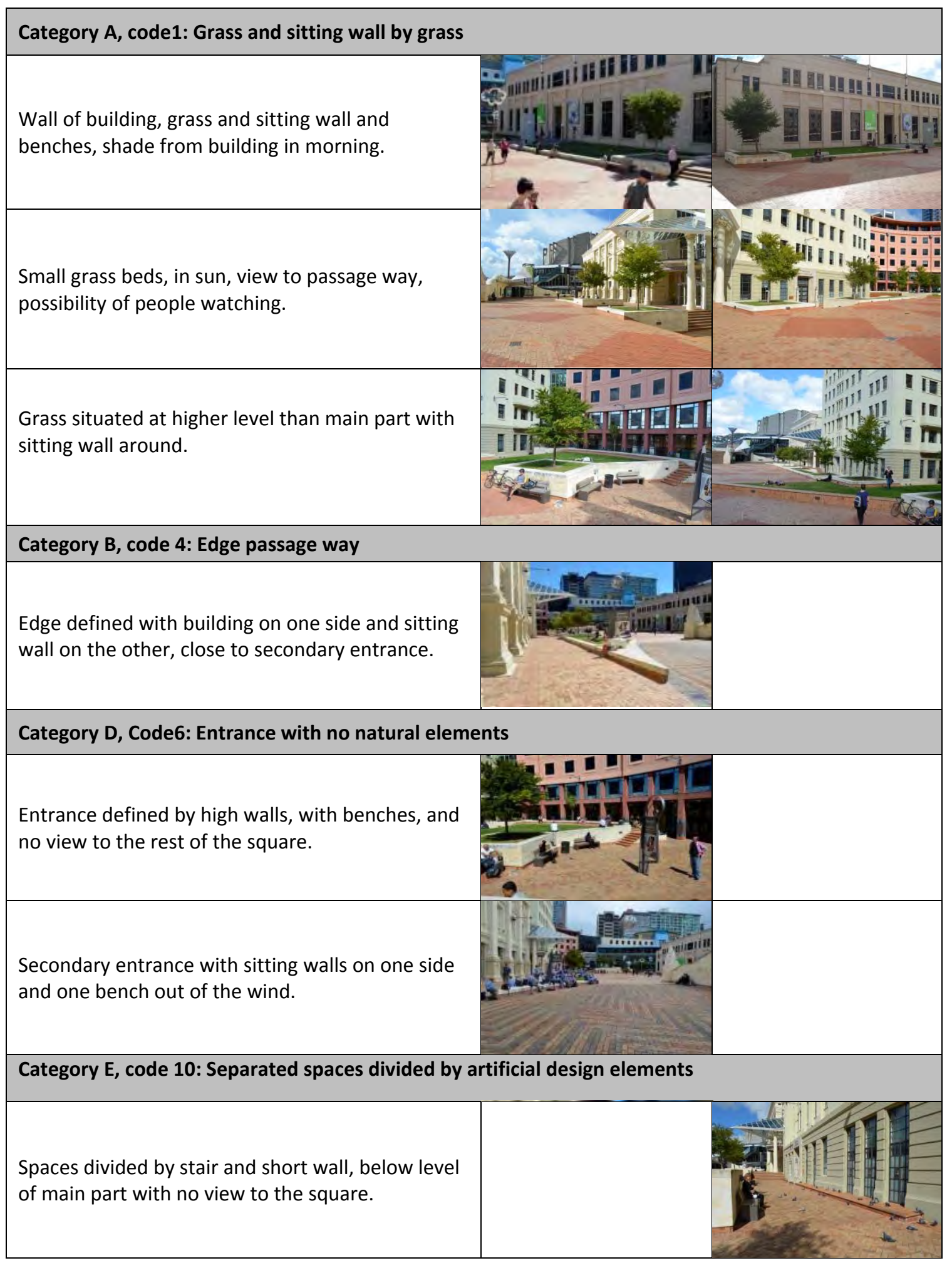

Figure 6-21: Description of subspaces, Civic Square

\subsubsection{Number of Users}

Data was collected in the form of 800 photos taken on one day between 08.00 and 17.00 (See Appendix 3). In total 395 people and 295 people in groups of one, two, or more used the square. The two busiest hours were 12.00-13.00 and 13.00-14.00 with 121 and 69 
users at these times respectively. The third busiest time was between $14.00-17.00$, with a slight decrease immediately after lunch, with an average 45 users each hour, followed by about 25 users between 10.00-11.00 and 11.00-12.00. There were 15 users between 09.00-10.00, with least users between 08.00-09.00 (Table 6-11). Comparison between subspaces indicates that except for grass and benches other subspaces have a similar pattern of use to that of total use, with their own maximum occupancy between 12.00 13.00. Benches are slighty different with a maximum occupancy for two hours between 12.00-14.00 and grass has two peak times between 12.00-13.00 and 16.00-17.00. After a general decrease in use at 14.00 , use of entrance, seating, and separated space stayed stable, with an increase in the use of grass area and sitting walls. Unlike seating, which was well used all day with no significant decrease after peak time, edge passage way was only occupied at the two peak times and was left vacant the rest of the day. In summary, the results show a use of benches from 10.00-17.00 while grass and sitting wall were more used in the afternoon. A consistent use of entrance and separated space was observed (Table 6-11).

Table 6-11: Number of users during one day of observation, Civic Square

\begin{tabular}{|c|c|c|c|c|c|c|c|c|c|c|c|}
\hline $\begin{array}{l}\text { Subspace use as } \\
\text { percentage of MO over } \\
\text { one day }\end{array}$ & & $\begin{array}{l}08.00- \\
09.00\end{array}$ & $\begin{array}{l}09.00 \\
10.00\end{array}$ & $\begin{array}{l}10.00- \\
11.00\end{array}$ & $\begin{array}{l}11.00- \\
12.00\end{array}$ & $\begin{array}{l}12.00- \\
13.00\end{array}$ & $\begin{array}{l}13.00- \\
14.00\end{array}$ & $\begin{array}{l}14.00- \\
15.00\end{array}$ & $\begin{array}{l}15.00 \\
16.00\end{array}$ & $\begin{array}{l}16.00- \\
17.00\end{array}$ & Total \\
\hline \multirow{2}{*}{ A-code $1-1$} & $\mathrm{~N}$ & 0 & 2 & 0 & 0 & 11 & 2 & 2 & 5 & 12 & 34 \\
\hline & $P$ & $0.00 \%$ & $16.67 \%$ & $0.00 \%$ & $0.00 \%$ & $91.67 \%$ & $16.67 \%$ & $16.67 \%$ & $641.67 \%$ & $100 \%$ & \\
\hline \multirow[t]{2}{*}{ A-code 1-2 } & $\mathrm{N}$ & 0 & 3 & 1 & 6 & 49 & 26 & 7 & 15 & 18 & 125 \\
\hline & $p$ & $0.00 \%$ & $6.12 \%$ & $2.04 \%$ & $12.25 \%$ & $100 \%$ & $53.06 \%$ & $14.29 \%$ & $30.61 \%$ & $36.73 \%$ & \\
\hline \multirow{2}{*}{ A-code 2} & $\mathrm{~N}$ & 2 & 2 & 12 & 11 & 15 & 15 & 14 & 12 & 10 & 93 \\
\hline & $P$ & $13.33 \%$ & $13.33 \%$ & $80.00 \%$ & $73.00 \%$ & $100 \%$ & $100 \%$ & $93.33 \%$ & $80.00 \%$ & $66.67 \%$ & \\
\hline \multirow{2}{*}{$\begin{array}{l}\text { B-code } 4 \\
100 \\
0+1+1+1,1\end{array}$} & $\mathrm{~N}$ & 1 & 0 & 0 & 0 & 3 & 2 & 0 & 1 & 0 & 7 \\
\hline & $\mathrm{P}$ & $33.33 \%$ & $0.00 \%$ & $0.00 \%$ & $0.00 \%$ & $100 \%$ & $66.67 \%$ & $0.00 \%$ & $33.33 \%$ & $0.00 \%$ & \\
\hline \multirow{2}{*}{$\begin{array}{c}\text { E-code } 8 \\
100 \\
0\end{array}$} & $\mathrm{~N}$ & 3 & 8 & 7 & 8 & 23 & 18 & 10 & 8 & 5 & 90 \\
\hline & $p$ & $13.04 \%$ & $34.78 \%$ & $30.43 \%$ & $34.78 \%$ & $100 \%$ & $78.26 \%$ & $43.48 \%$ & $34.78 \%$ & $21.74 \%$ & \\
\hline \multirow{2}{*}{ E-code 10} & $\mathrm{~N}$ & 0 & 0 & 3 & 1 & 20 & 6 & 8 & 6 & 2 & 46 \\
\hline & $\mathrm{P}$ & $0.00 \%$ & $0.00 \%$ & $15.00 \%$ & $5.00 \%$ & $100 \%$ & $30.00 \%$ & $40.00 \%$ & $30.00 \%$ & $10.00 \%$ & \\
\hline \multirow{2}{*}{$\begin{array}{c}\text { Total Park } \\
100 \\
0\end{array}$} & $\mathrm{~N}$ & 6 & 15 & 23 & 26 & 121 & 69 & 41 & 47 & 47 & 395 \\
\hline & $P$ & $4.96 \%$ & $12.4 \%$ & $19.01 \%$ & $21.5 \%$ & $100 \%$ & $57.02 \%$ & $33.88 \%$ & $38.84 \%$ & $38.84 \%$ & \\
\hline \multicolumn{2}{|c|}{$\begin{array}{l}\text { MO: Maximum occupancy } \\
\text { N: Number of users } \\
\text { P: Percentage of MO }\end{array}$} & $100 \%$ & \multicolumn{2}{|c|}{$100-80 \%$} & $80-60$ & \multicolumn{2}{|c|}{$60-40 \%$} & $40-20 \%$ & $20-0 \%$ & $0 \%$ & \\
\hline
\end{tabular}




\subsubsection{Occupancy and Preferences}

The pattern of occupancy during the day shows sitting wall and benches in paved areas were used more followed by entrance and separated space. Grass was preferred by fewer people and edge passage way was almost left vacant (Figure 6-22).

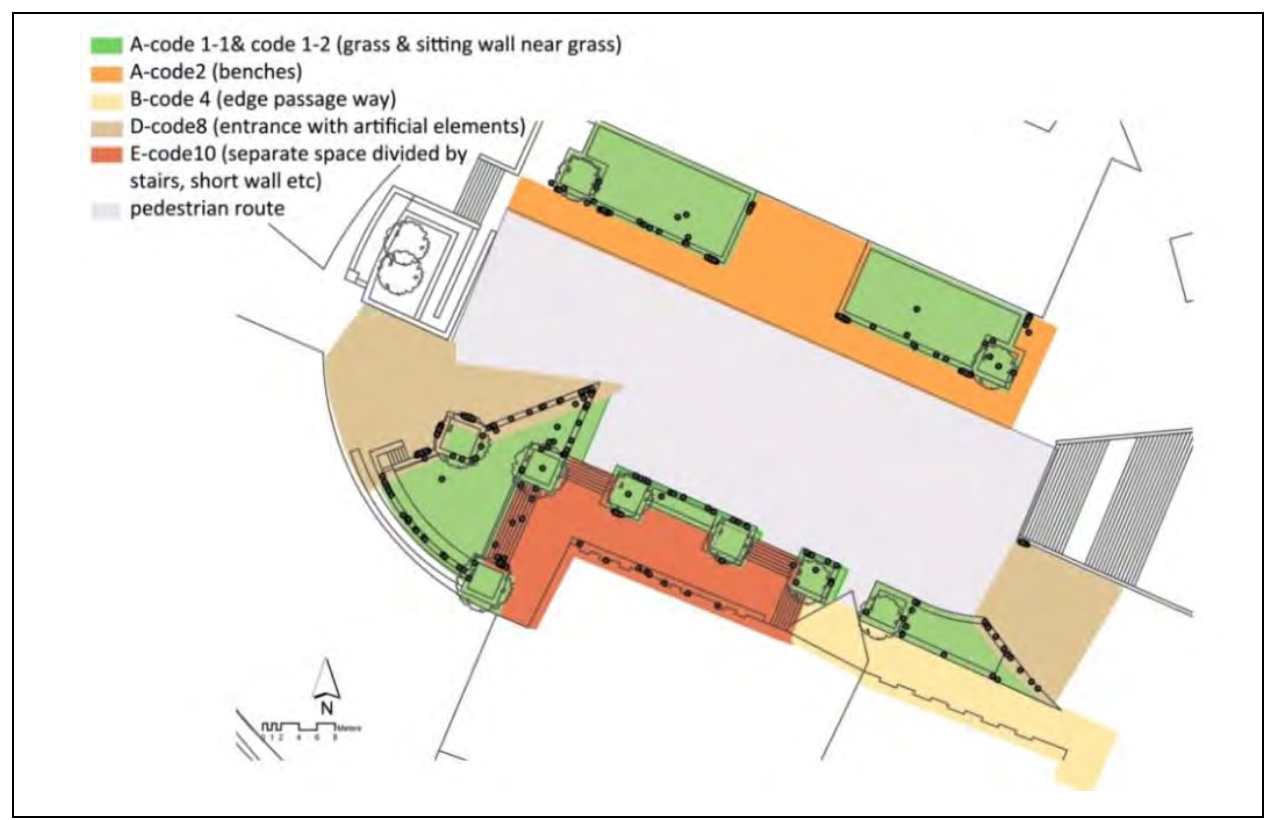

Figure 6-22: Map of occupancy during day, Civic Square

Early use of space shows seating in paved area and entrance was preferred (Figures 6-23.1 to 6-23.4). Around midday all benches by the main entrance to the north-west were full. At the same time sitting wall and separated space in the sun were occupied. All subspaces except the passage way were used to an extent, although the grass was little used (Figures 6-23.5, 6-23.6). At 14.00-15.00 entrance and benches were still being used (Figure 6-23.7). Grass in the south west corner was virtually vacant and only started to be used from 15.00 onward. It seems people do not use grass when it has people sitting around it (Figures 6$23.8,6-23.9)$. An investigation of order of occupancy shows sitting walls were occupied from corners to the middle, and occupancy of the stairs connecting grass to the separated space had a similar pattern. Occupancy in separated space demonstrates a preference for sitting in a defined place. People like the part of the separated space defined by the recesses in the wall at the back that receive the sun (Figures 6-23.5, 6-23.6). 


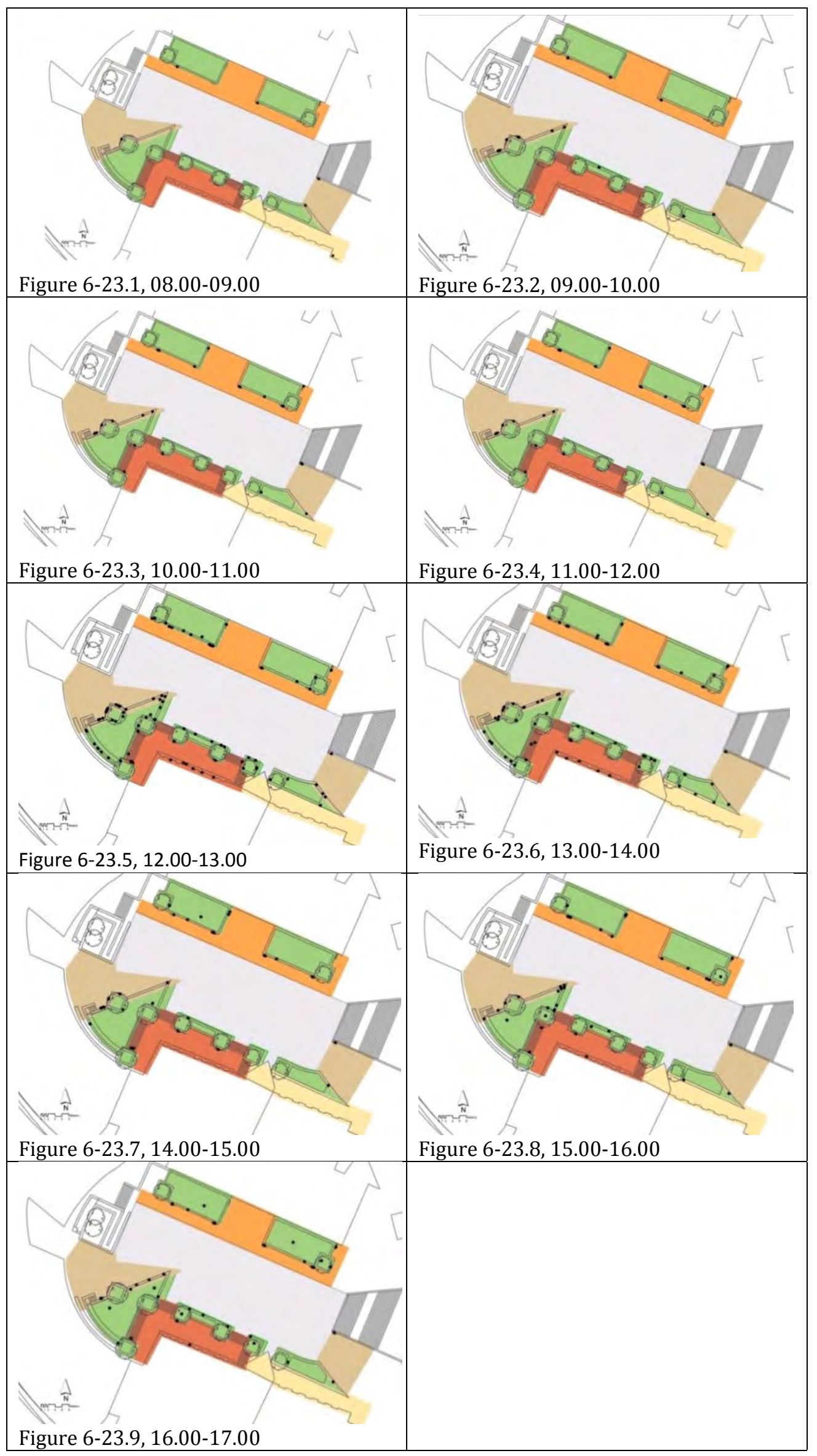

Figure 6-23: Hourly occupancy maps, Civic Square 
Use of the edge passage way indicates seating near grass attracts more people than seating by the building edge. Looking at the effect of natural elements shows that although trees are not mature enough to provide shade and grass under their canopy is not well maintained, sitting under trees or on the sitting wall near trees was observed at lunch time and in the afternoon. The vacant grass to the south east could suggest having a small piece of grass is not a useful design decision space. Unused grass to the north, in the shade of the building also suggests the effect of sun on people's preferences (Figure 6-23).

\subsubsection{Size of Group}

Most use of Civic Square was by people alone (53.16\%) or people in a group of two (36.96\%), with groups of three and four people making up the remaining $10 \%$. The percentage of people alone as part of total occupancy $\left(T^{*} 100 / A\right)$ for each subspace during the day demonstrates grass is preferred by groups, while sitting wall, seating and separated space are preferred by people alone and in groups. Edge passage way and entrance are favourite places for people alone (Table 6-12).

Table 6-12: Use of subspaces by people alone and in groups

\begin{tabular}{|c|c|c|c|c|c|c|c|c|c|c|c|c|}
\hline & & $\begin{array}{c}08.00- \\
09.00\end{array}$ & $\begin{array}{c}09.00- \\
10.00\end{array}$ & $\begin{array}{c}10.00- \\
11.00\end{array}$ & $\begin{array}{c}11.00- \\
12.00\end{array}$ & $\begin{array}{l}12.00- \\
13.00\end{array}$ & $\begin{array}{c}13.00- \\
14.00\end{array}$ & $\begin{array}{c}14.00- \\
15.00\end{array}$ & $\begin{array}{l}15.00- \\
16.00\end{array}$ & $\begin{array}{c}16.00- \\
17.00\end{array}$ & $T$ & $\mathbf{P}$ \\
\hline \multirow{3}{*}{ A-code $1-1$} & $\mathrm{~A}$ & 0 & 0 & 0 & 0 & 2 & 0 & 0 & 1 & 0 & 3 & $8.82 \%$ \\
\hline & $\mathrm{G}$ & 0 & 2 & 0 & 0 & 9 & 2 & 2 & 4 & 12 & 31 & $91.18 \%$ \\
\hline & $\mathrm{T}$ & 0 & 2 & 0 & 0 & 11 & 2 & 2 & 5 & 12 & 34 & \\
\hline \multirow{3}{*}{ A-code $1-2$} & $\mathrm{~A}$ & 0 & 1 & 1 & 4 & 20 & 16 & 5 & 11 & 8 & 66 & $52.08 \%$ \\
\hline & $\mathrm{G}$ & 0 & 2 & 0 & 2 & 29 & 10 & 2 & 4 & 10 & 59 & $47.92 \%$ \\
\hline & $\mathrm{T}$ & 0 & 3 & 1 & 6 & 49 & 26 & 7 & 15 & 18 & 125 & \\
\hline \multirow{3}{*}{ A-code 2} & $\mathrm{~A}$ & 2 & 2 & 7 & 5 & 5 & 9 & 5 & 8 & 7 & 50 & $53.76 \%$ \\
\hline & G & 0 & 0 & 5 & 6 & 10 & 6 & 9 & 4 & 3 & 43 & $46.24 \%$ \\
\hline & $\mathrm{T}$ & 2 & 2 & 12 & 11 & 15 & 15 & 14 & 12 & 10 & 93 & \\
\hline \multirow{3}{*}{ B-code 4} & $\mathrm{~A}$ & 1 & 0 & 0 & 0 & 1 & 2 & 0 & 1 & 0 & 5 & $71.43 \%$ \\
\hline & $\mathrm{G}$ & 0 & 0 & 0 & 0 & 2 & 0 & 0 & 0 & 0 & 2 & $28.57 \%$ \\
\hline & $\mathrm{T}$ & 1 & 0 & 0 & 0 & 3 & 2 & 0 & 1 & 0 & 7 & \\
\hline \multirow{3}{*}{ D-code 8} & $\mathrm{~A}$ & 3 & 4 & 7 & 6 & 15 & 12 & 8 & 4 & 3 & 62 & $68.88 \%$ \\
\hline & $\mathrm{G}$ & 0 & 4 & 0 & 2 & 8 & 6 & 2 & 4 & 2 & 28 & $31.12 \%$ \\
\hline & $\mathrm{T}$ & 3 & 8 & 7 & 8 & 23 & 18 & 10 & 8 & 5 & 90 & \\
\hline \multirow{3}{*}{ E-code 10} & $\mathrm{~A}$ & 0 & 0 & 3 & 1 & 10 & 4 & 2 & 2 & 2 & 24 & $52.17 \%$ \\
\hline & $\mathrm{G}$ & 0 & 0 & 0 & 0 & 10 & 2 & 6 & 4 & 0 & 22 & $47.83 \%$ \\
\hline & $\mathrm{T}$ & 0 & 0 & 3 & 1 & 20 & 6 & 8 & 6 & 2 & 46 & \\
\hline \multicolumn{8}{|c|}{ T: Total P: Percentage of total A: Alone G: Group } & \multicolumn{3}{|c|}{ Max ocupancy } & \multicolumn{2}{|c|}{ Vacant } \\
\hline
\end{tabular}


Hourly comparison of number of people alone and in groups shows grass attracted more groups than people alone (Table 6-12). The use of grass by groups dramatically increased after 15.00 (Figure 6-24.1). Sitting wall got more use by groups than people alone, with two peak use times between $12.00-13.00$ and 16.00-17.00, and although there was less use of sitting wall by people alone the pattern of use is similar (Figure 6-24.2). Seating except between 12.00-13.00 and 14.00-15.00 was used by people alone more than in groups (Figure 6-24.3). Groups only used edge passage way for having lunch (Figure 624.4). In contrast to grass, the entrance always attracted more people alone (Figure 624.5).

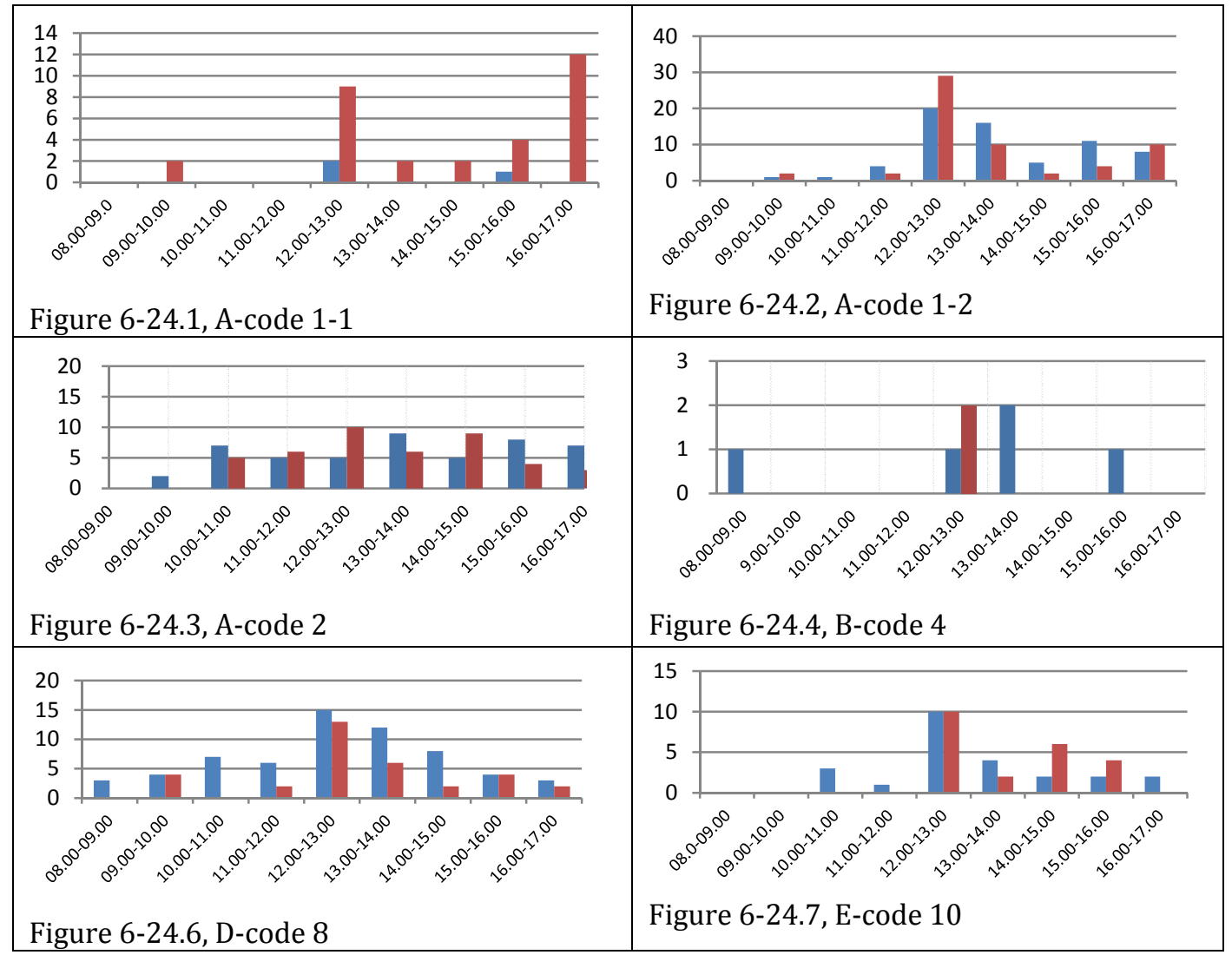

alone group

Figure 6-24: Comparison between people alone and groups, Civic Square

Figure 6-25 shows the percentage of people alone as part of the total maximum occupancy (all people) over an hour for each subspace during the day. All subspaces have their maximum people alone between $12.00-13.00$ or $13.00-14.00$, corresponding with the two peak use times for the whole square (Figure 6-25). The results illustrate that grass areas are a territory for groups. Over the day between $12.00-13.00$ and $15.00-16.00$ less than $10 \%$ of maximum occupancy for grass includes people alone with $0 \%$ for the rest of 
the day (Figure 6-25.1). People alone used sitting wall by grass, passage way and entrance slightly differently from total users (Figure 6-25.2, 6-25.4, 6-25.5). The pattern of use of seating by people alone fluctuated between $40-60 \%$ of maximum occupancy with no specific use pattern (Figure 6-25.3).

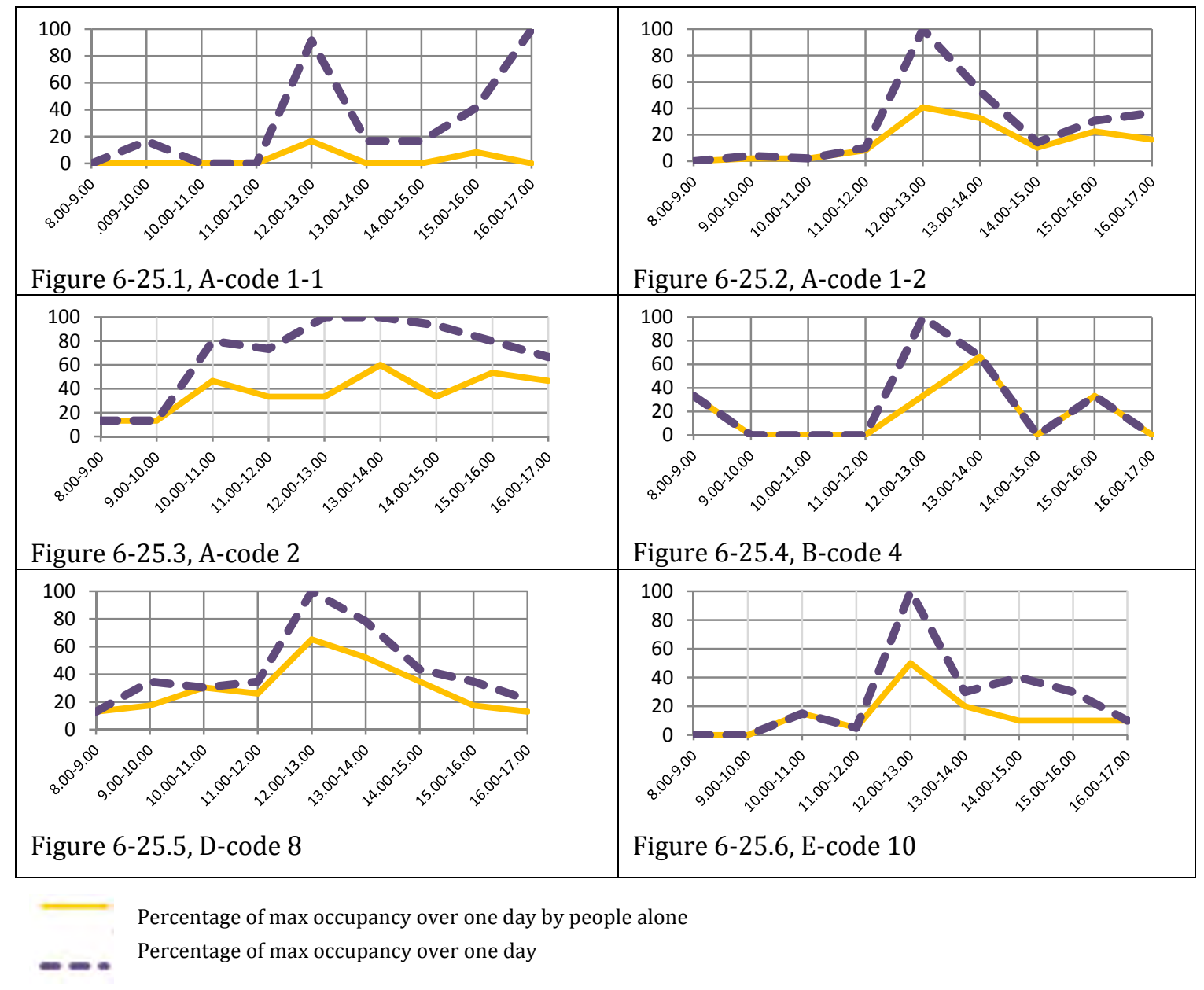

Figure 6-25: Use by people alone as percentage of total occupancy for each hour, Civic Square

Separate occupancy maps for people alone and people in groups (Figure 6-26) show benches and sitting wall on both sides of the pedestrian passage way are lucky to be used by people in either category. These maps illustrate that people alone used spaces separated from the main part that still offer the possiblity of watching others (entrance divided by short wall, subspaces divided by stair and sitting wall at higer level than the main part of square). Groups prefer to sit on the grass or under trees. In contast with people alone, groups seems less sensitive to sitting on grass with no edge or close to a corner. 


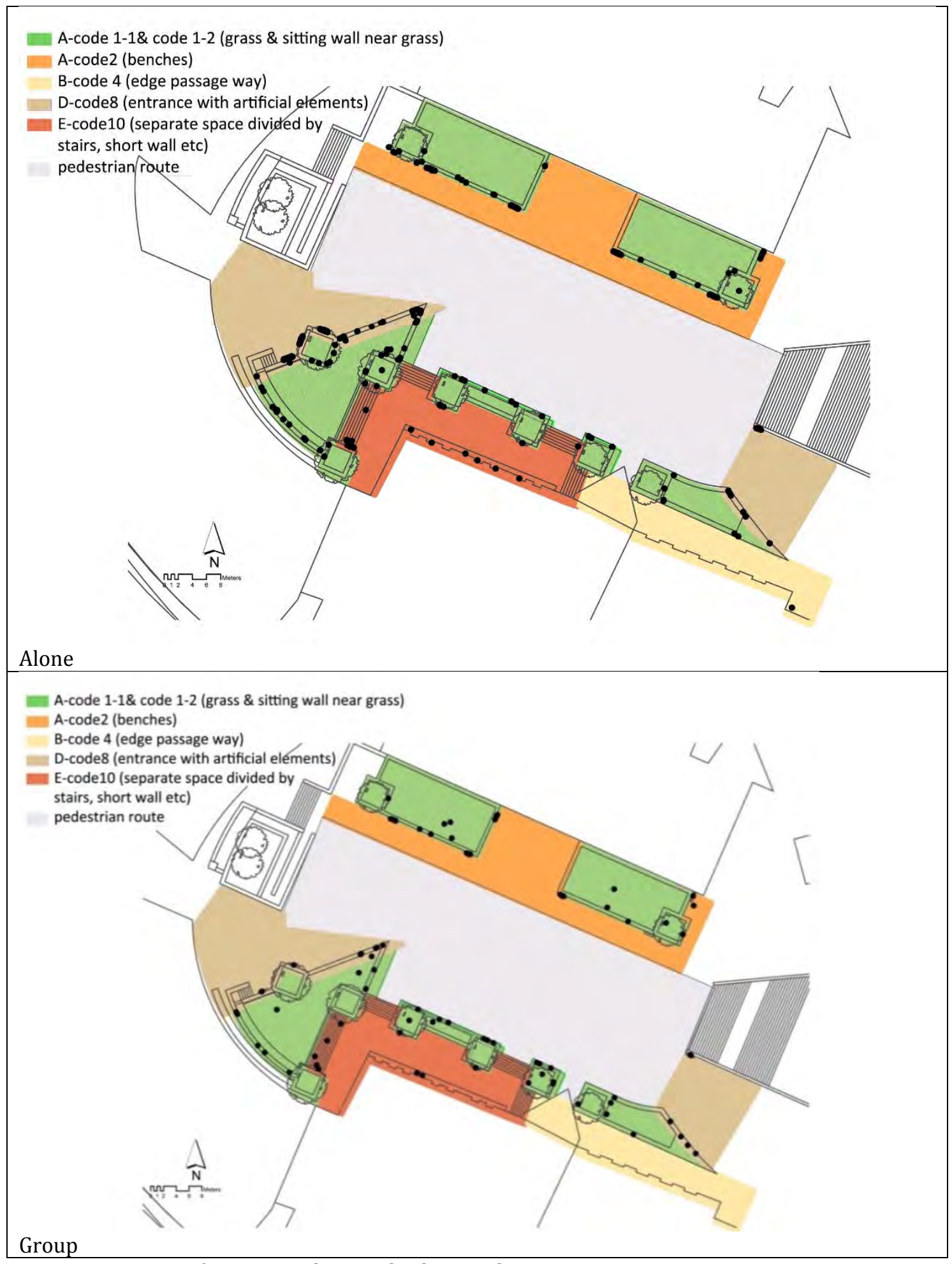

Figure 6-26: Map of occupancy by people alone and in groups, Civic Square

Comparison between subspaces in terms of size of group also reveals that grass and separated space attracted larger groups. Size of group is less diverse for sitting walls and seating. Entrance and edge passage way are only used by people alone or people in a group of two (Table 6-13). The distribution of bigger groups does not reveal any significant 
pattern (Figure 6-27).

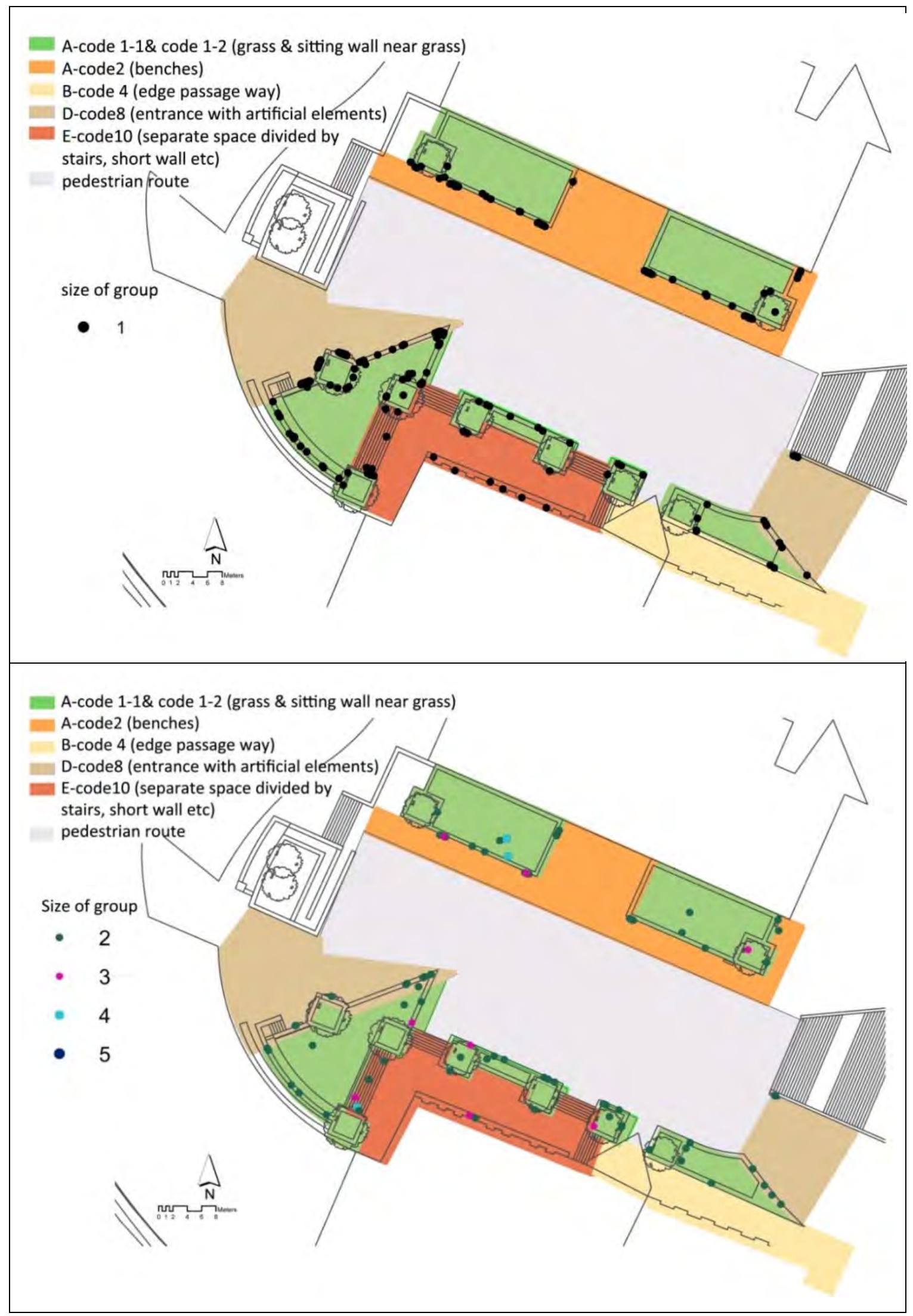

Figure 6-27: Occupancy map based on size of group, Civic Square 
Table 6-13: Size of group and use of subspaces, Civic Square

\begin{tabular}{|l|c|c|c|c|}
\hline \multirow{2}{*}{$\begin{array}{l}\text { Grass } \\
\text { Percentage of total (34) }\end{array}$} & Alone & Group of two & Group of three & Group of four \\
\hline \multirow{2}{*}{$\begin{array}{l}\text { Sitting wall by grass } \\
\text { Percentage of total (125) }\end{array}$} & $8.82 \%$ & $58.82 \%$ & 3 & 8 \\
\hline Seating & 66 & 50 & $8.82 \%$ & $23.53 \%$ \\
\cline { 2 - 5 } Percentage of total (93) & $52.80 \%$ & $40.00 \%$ & $7.20 \%$ & 0 \\
\hline Edge passage way & 50 & 34 & 9 & $0.00 \%$ \\
\cline { 2 - 5 } $\begin{array}{l}\text { Percentage of total (7) } \\
\text { Entrance }\end{array}$ & $53.76 \%$ & $36.56 \%$ & $9.68 \%$ & $0.55 \%$ \\
\cline { 2 - 5 } Percentage of total (90) & $71.43 \%$ & $28.57 \%$ & 0 & 0 \\
\hline Separated space & 62 & 28 & $0.00 \%$ & $0.00 \%$ \\
\cline { 2 - 5 } Percentage of total (46) & $68.89 \%$ & $31.11 \%$ & $0.00 \%$ & 0 \\
\hline Total use & 24 & 12 & 6 & $0.00 \%$ \\
\hline Percentage of total use of Park & $52.17 \%$ & $26.09 \%$ & $13.04 \%$ & $17.39 \%$ \\
\hline
\end{tabular}

\subsubsection{Use by Age and Gender}

Analysis of photographs shows teenagers and young adults each make up $36 \%$ of users, while adults and retired account for $23.04 \%$ and $2.03 \%$ respectively. The number of male and female users is equal. Grass is mostly used by teenagers, while sitting wall, seating, and entrance are used by young adults, and then adults in descending order (Table 6-14).

Table 6-14: Number of users by age and gender

\begin{tabular}{|l|c|c|c|c|c|c|c|c|c|c|c|c|c|}
\hline & Child & \multicolumn{3}{|c|}{ Teenager } & \multicolumn{3}{c|}{ Young Adult } & \multicolumn{3}{c|}{ Adult } & \multicolumn{3}{c|}{ Older Adult } \\
\hline & & Male & Female & Total & Male & Female & Total & Male & Female & Total & Male & Female & Total \\
\hline A-code 1-1 & 2 & 17 & 11 & $\mathbf{2 8}$ & 3 & 1 & 4 & 0 & 0 & 0 & 0 & 0 & 0 \\
\hline A-code 1-2 & 2 & 24 & 18 & 42 & 35 & 19 & $\mathbf{5 4}$ & 15 & 10 & 25 & 2 & 0 & 2 \\
\hline A-code 2 & 1 & 14 & 19 & $\mathbf{3 3}$ & 15 & 18 & $\mathbf{3 3}$ & 10 & 12 & 22 & 4 & 0 & 4 \\
\hline B-code 4 & 0 & 0 & 3 & $\mathbf{3}$ & 1 & 0 & 1 & 2 & 1 & $\mathbf{3}$ & 0 & 0 & 0 \\
\hline D-code 8 & 0 & 14 & 15 & 29 & 16 & 18 & $\mathbf{3 4}$ & 11 & 14 & 25 & 1 & 1 & 2 \\
\hline E-code 10 & 0 & 2 & 9 & 11 & 11 & 8 & $\mathbf{1 9}$ & 9 & 7 & 16 & 0 & 0 & 0 \\
\hline Total & 5 & 71 & 75 & $\mathbf{1 4 6}$ & 81 & 64 & $\mathbf{1 4 5}$ & 47 & 44 & 91 & 7 & 1 & 8 \\
\hline $\begin{array}{l}\text { \% of total } \\
\text { (395) }\end{array}$ & $1.27 \%$ & $17.97 \%$ & $18.99 \%$ & $36.96 \%$ & $20.51 \%$ & $16.2 \%$ & $36.71 \%$ & $11.9 \%$ & $11.14 \%$ & $23.04 \%$ & $1.77 \%$ & $0.25 \%$ & \\
\hline
\end{tabular}

Except for sitting wall by grass, all subspaces attract equal numbers of people alone and in groups for both genders (Table 6-15). Sitting wall has a significantly higher usage by males alone than females alone, followed by entrance and seating as the next two popular spaces for males alone (Figures 6-28, 6-32). This order changes for females alone with 
entrance being the most popular followed by seating and sitting wall by grass. Although female groups did not use grass, there are more female than male groups in the remaining subspaces (Figures 6-29, 6-32). Mixed groups mostly used the grass and sitting wall. Their preference then moved to benches, entrance and separated space (Table 6-15).

Table 6-15: Number of groups in subspaces by gender

\begin{tabular}{|c|c|c|c|c|c|}
\hline & Male alone & Female alone & Male groups & Female groups & Mixed groups \\
\hline A-code 1-1 & 2 & 1 & 6 & 0 & 25 \\
\hline A-code 1-2 & 48 & 18 & 11 & 14 & 34 \\
\hline A-code 2 & 23 & 27 & 10 & 13 & 20 \\
\hline B-code 4 & 3 & 2 & 0 & 2 & 0 \\
\hline D-code 8 & 30 & 32 & 2 & 6 & 20 \\
\hline E-code 10 & 12 & 12 & 2 & 7 & 13 \\
\hline & 118 & 92 & 31 & 42 & 112 \\
\hline
\end{tabular}

Male alone and male group preferences differ (Figures 6-30, 6-32, Table 6-15) while entrance, seating and sitting wall are the three preferred spaces for females both in groups and alone (Figures 6-31, 6-32, Table 6-15).

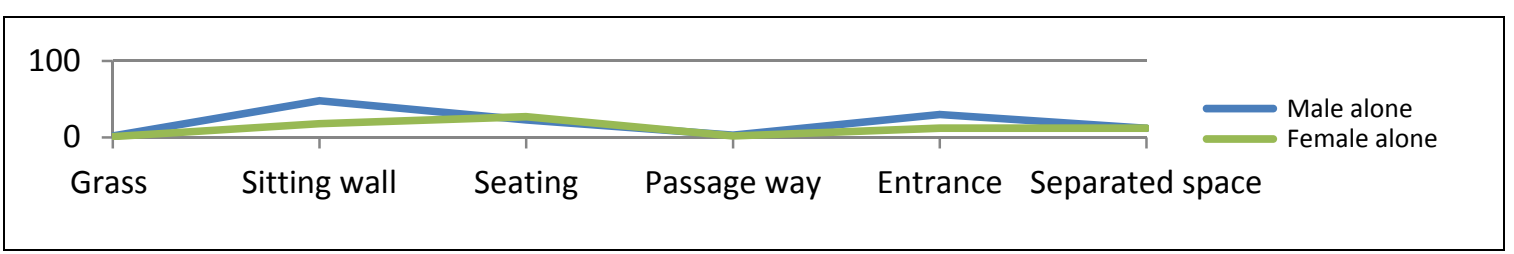

Figure 6-28: Comparison between male and female alone preferences

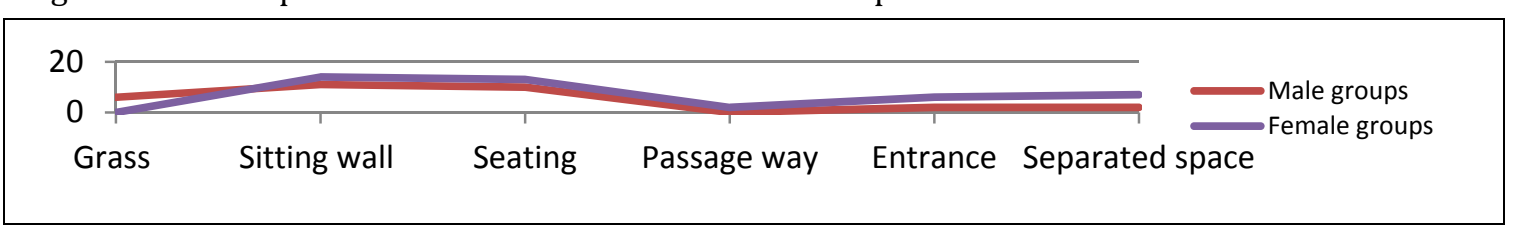

Figure 6-29: Comparison between male and female group preferences

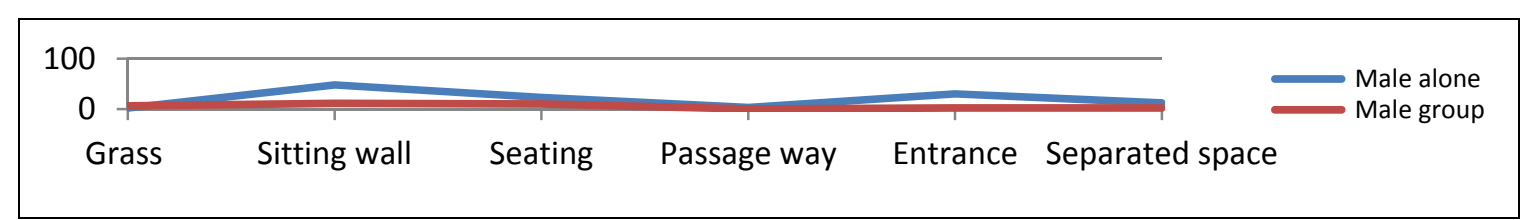

Figure 6-30: Comparison between male alone and male group preferences

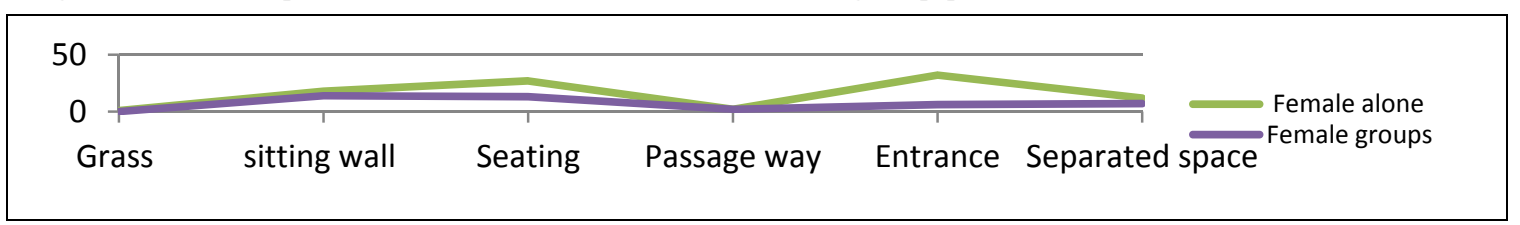

Figure 6-31: Comparison between female alone and female group preferences 


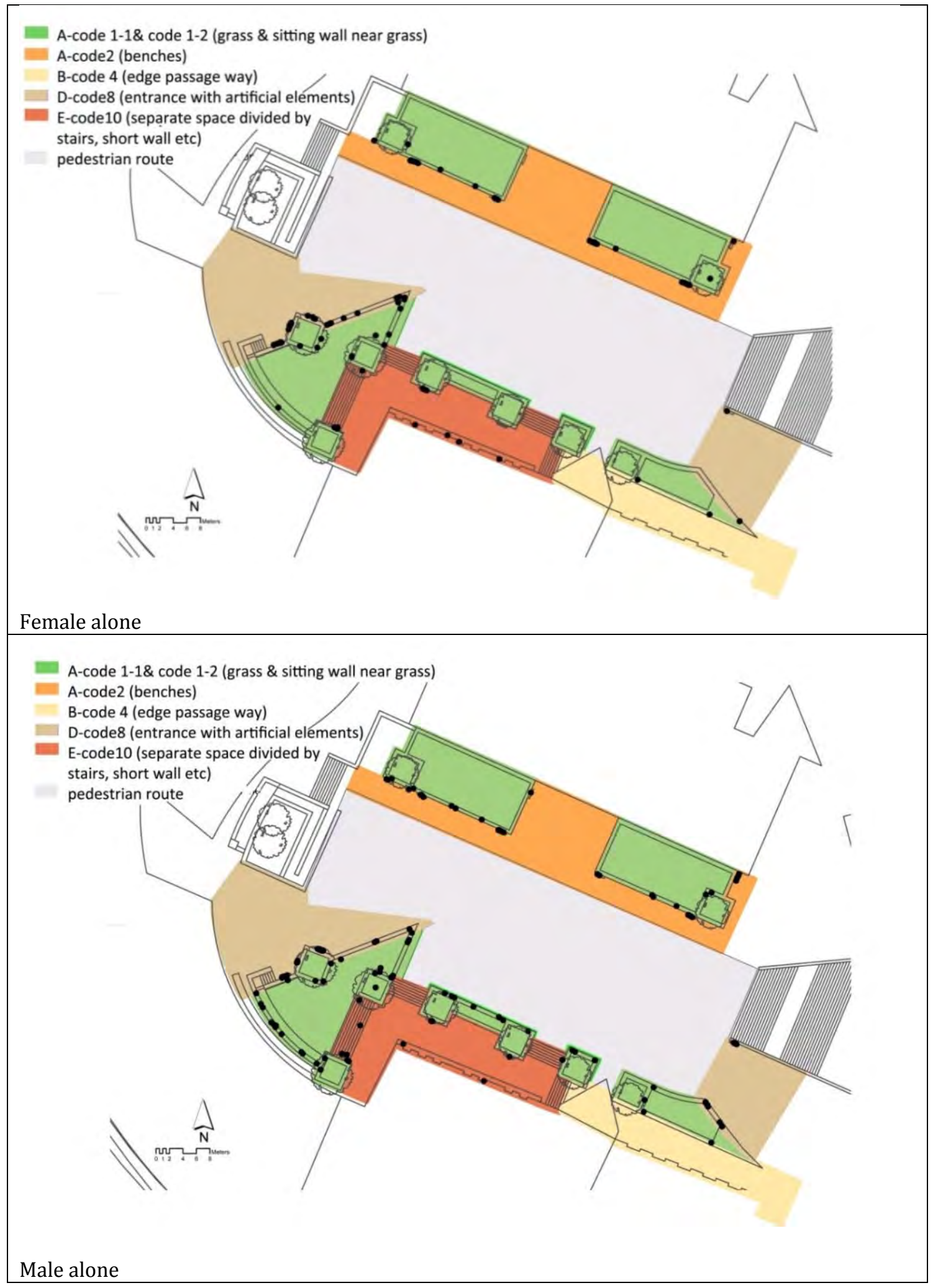




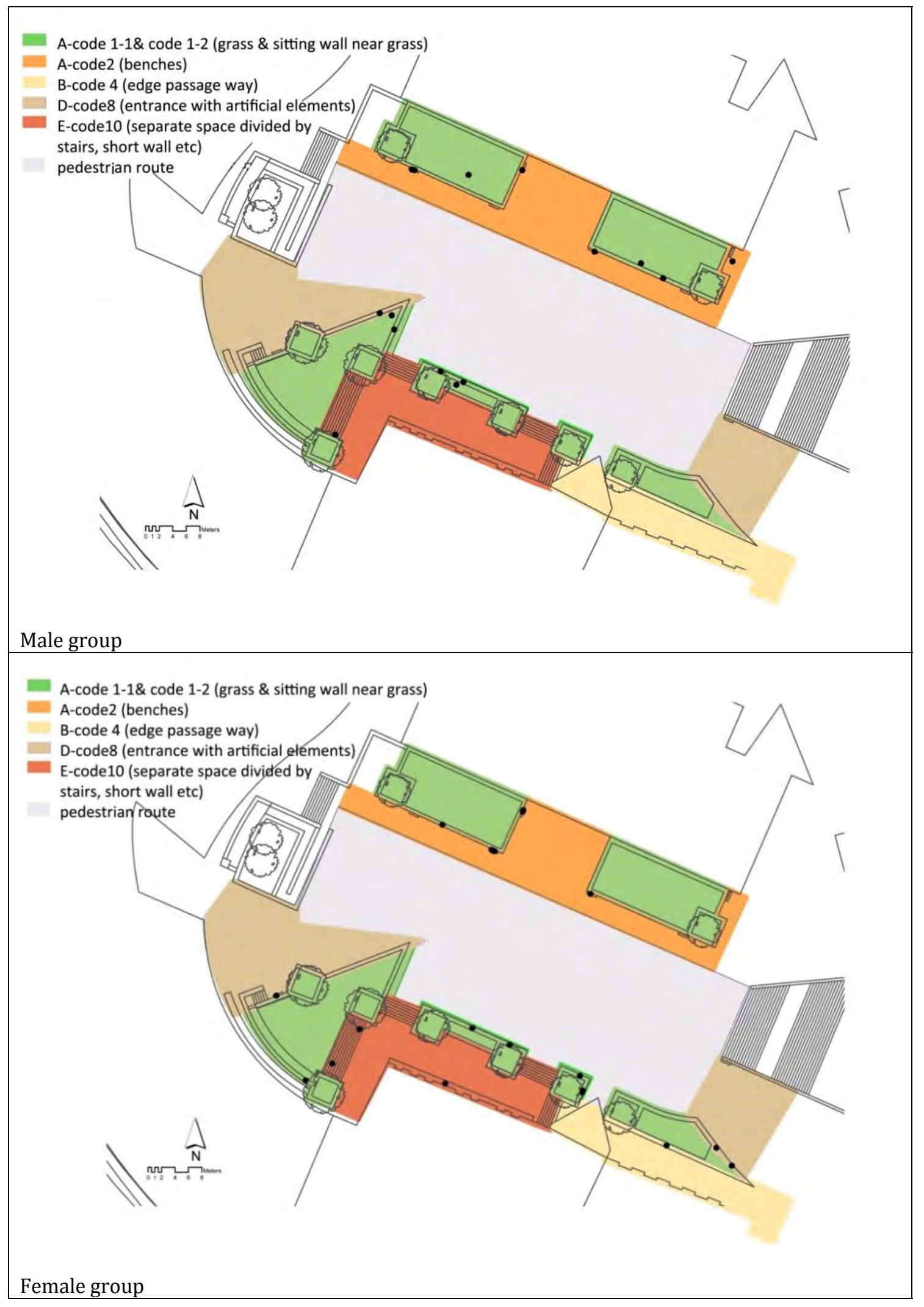

Figure 6-32: Map of occupancy for people alone and in groups by gender, Civic Square

\subsubsection{Activity}

People used Civic Square for various sitting activities. Sitting-eating is observed more 
frequently for people alone than in groups. The number of groups doing other sitting activities is very small in comparison with people alone (Table 6-16).

Table 6-16: Type of activity by people alone and in groups

\begin{tabular}{|l|c|c|c|l|c|c|c|}
\hline \multicolumn{1}{|c|}{ Type of activity } & \multicolumn{3}{c|}{ Number } & \multicolumn{2}{c|}{ Type of activity } & \multicolumn{3}{c|}{ Number } \\
\hline & Alone & Group & Total & & Alone & Group & Total \\
\hline Sitting & 40 & 33 & 73 & Standing & 1 & 3 & 4 \\
\hline Sitting - eating & 63 & 37 & 100 & Standing - using mobile & 2 & 0 & 2 \\
\hline Sitting - using mobile & 56 & 1 & 57 & Standing- smoking & 1 & 0 & 1 \\
\hline Sitting - smoking & 7 & 1 & 8 & Lying - sleeping & 7 & 7 & 14 \\
\hline Sitting - reading & 26 & 3 & 29 & & & & \\
\hline Sitting - eating - reading & 6 & 0 & 6 & & & & \\
\hline Sitting - eating - using mobile & 1 & 0 & 1 & & & & \\
\hline
\end{tabular}

Sitting wall, entrance, and separated space afforded diverse activities. Lying occurred most on the grass, and edge passage way attracted few activities (Table 6-17).

Table 6-17: Type of activity by subspace

\begin{tabular}{|l|c|c|c|c|c|c|c|c|c|c|c|c|c|}
\hline & \multicolumn{2}{|c|}{ A-code1-1 } & A-code 1-2 & \multicolumn{2}{|c|}{ A-code 2 } & \multicolumn{2}{|c|}{ B-code 4 } & \multicolumn{2}{|c|}{ D-code 8 } & \multicolumn{2}{|c|}{ E-code 10 } & $\begin{array}{c}\text { Tota } \\
\text { I }\end{array}$ \\
\hline & $\mathbf{N}$ & $\mathbf{P}$ & $\mathbf{N}$ & $\mathbf{P}$ & $\mathbf{N}$ & $\mathbf{P}$ & $\mathbf{N}$ & $\mathbf{P}$ & $\mathbf{N}$ & $\mathbf{P}$ & $\mathbf{N}$ & $\mathbf{P}$ & \\
\hline Sitting & 2 & $2.74 \%$ & 22 & $30.14 \%$ & 20 & $27.40 \%$ & 0 & $0.00 \%$ & 19 & $26.03 \%$ & 10 & $13.70 \%$ & 73 \\
\hline Sitting - eating & 5 & $5.00 \%$ & 43 & $43.00 \%$ & 17 & $17.00 \%$ & 3 & $3.0 \%$ & 22 & $22.00 \%$ & 10 & $10.00 \%$ & 100 \\
\hline Sitting - using mobile & 0 & $0.00 \%$ & 16 & $28.07 \%$ & 18 & $31.58 \%$ & 1 & $1.75 \%$ & 20 & $35.09 \%$ & 2 & $3.51 \%$ & 57 \\
\hline Sitting - smoking & 0 & $0.00 \%$ & 2 & $25.00 \%$ & 0 & $0.00 \%$ & 0 & $0.00 \%$ & 3 & $37.50 \%$ & 3 & $37.5 \%$ & 8 \\
\hline Sitting - reading & 0 & $0.00 \%$ & 5 & $17.24 \%$ & 11 & $37.93 \%$ & 0 & $0.00 \%$ & 8 & $27.59 \%$ & 5 & $17.24 \%$ & 29 \\
\hline Sitting - eating - reading & 0 & $0.00 \%$ & 1 & $16.67 \%$ & 0 & $0.00 \%$ & 1 & $16.67 \%$ & 3 & $50.00 \%$ & 1 & $16.67 \%$ & 6 \\
\hline Sitting - eating-usingmobile & 0 & $0.00 \%$ & 1 & $100 \%$ & 0 & $0.00 \%$ & 0 & $0.00 \%$ & 0 & $0.00 \%$ & 0 & $0.00 \%$ & 1 \\
\hline Standing & 1 & $25.00 \%$ & 0 & $25.00 \%$ & 1 & $25.00 \%$ & 1 & $25.00 \%$ & 0 & $25.00 \%$ & 1 & $25.00 \%$ & 4 \\
\hline Standing - using mobile & 0 & $0.00 \%$ & 0 & $0.00 \%$ & 2 & $100 \%$ & 0 & $0.00 \%$ & 0 & $0.00 \%$ & 0 & $0.00 \%$ & 2 \\
\hline Standing - smoking & 0 & $0.00 \%$ & 0 & $0.00 \%$ & 1 & $100 \%$ & 0 & $0.00 \%$ & 0 & $0.00 \%$ & 0 & $0.00 \%$ & 1 \\
\hline Lying - sleeping & 8 & $57.14 \%$ & 4 & $28.57 \%$ & 0 & $0.00 \%$ & 0 & $0.00 \%$ & 1 & $7.14 \%$ & 1 & $7.14 \%$ & 14 \\
\hline
\end{tabular}

\subsubsection{Length of Stay}

Comparison between places for length of stay shows recesses in the back wall in separated space were only used for a medium stay, and its stair for a short stay. Grass mostly attracted people for a longer stay, with no observable pattern in other subspaces 
(Figure 6-33, Table 6-18).

Table 6-18: Length of stay (Group here means one person or group of two or more people)

\begin{tabular}{|l|c|c|c|c|c|c|c|c|c|c|c|}
\hline $\begin{array}{l}\text { Number of times group } \\
\text { observed }\end{array}$ & & One & Two & Three & Four & Five & six & Seven & Ten & Twelve & Fourteen \\
\hline \multirow{2}{*}{ A-code 1-1 } & $\mathrm{N}$ & 8 & 2 & 0 & 3 & 0 & 2 & 0 & 0 & 1 & 0 \\
\hline \multirow{3}{*}{ A-code 1-2 } & $\mathrm{P}$ & $50.00 \%$ & $12.5 \%$ & $0.00 \%$ & $18.75 \%$ & $0.00 \%$ & $12.50 \%$ & $0.00 \%$ & $0.00 \%$ & $6.25 \%$ & $0.00 \%$ \\
\hline \multirow{3}{*}{ A-code 2 } & $\mathrm{N}$ & 67 & 19 & 6 & 2 & 0 & 0 & 0 & 0 & 0 & 0 \\
\hline & $\mathrm{P}$ & $71.28 \%$ & $20.21 \%$ & $6.38 \%$ & $2.13 \%$ & $0.00 \%$ & $0.00 \%$ & $0.00 \%$ & $0.00 \%$ & $0.00 \%$ & $0.00 \%$ \\
\hline \multirow{2}{*}{ B-code 4 } & $\mathrm{N}$ & 49 & 13 & 4 & 0 & 1 & 1 & 1 & 0 & 0 & 1.00 \\
\hline & $\mathrm{P}$ & $70.00 \%$ & $18.57 \%$ & $5.71 \%$ & $0.00 \%$ & $1.43 \%$ & $1.43 \%$ & $1.43 \%$ & $0.00 \%$ & $0.00 \%$ & $1.43 \%$ \\
\hline \multirow{2}{*}{ D-code 8 } & $\mathrm{N}$ & 30 & 30 & 0 & 0 & 0 & 0 & 0 & 0 & 0 & 0 \\
\hline & $\mathrm{P}$ & $50.00 \%$ & $50.0 \%$ & $0.00 \%$ & $0.00 \%$ & $0.00 \%$ & $0.00 \%$ & $0.00 \%$ & $0.00 \%$ & $0.00 \%$ & $0.00 \%$ \\
\hline \multirow{2}{*}{ E-code 10 } & $\mathrm{N}$ & 47 & 16 & 6 & 2 & 2 & 1 & 1 & 1 & 0 & 0 \\
\cline { 2 - 13 } & $\mathrm{P}$ & $61.84 \%$ & $27.12 \%$ & $31.58 \%$ & $2.63 \%$ & $2.63 \%$ & $1.32 \%$ & $1.32 \%$ & $0.00 \%$ & $0.00 \%$ & $0.00 \%$ \\
\hline
\end{tabular}

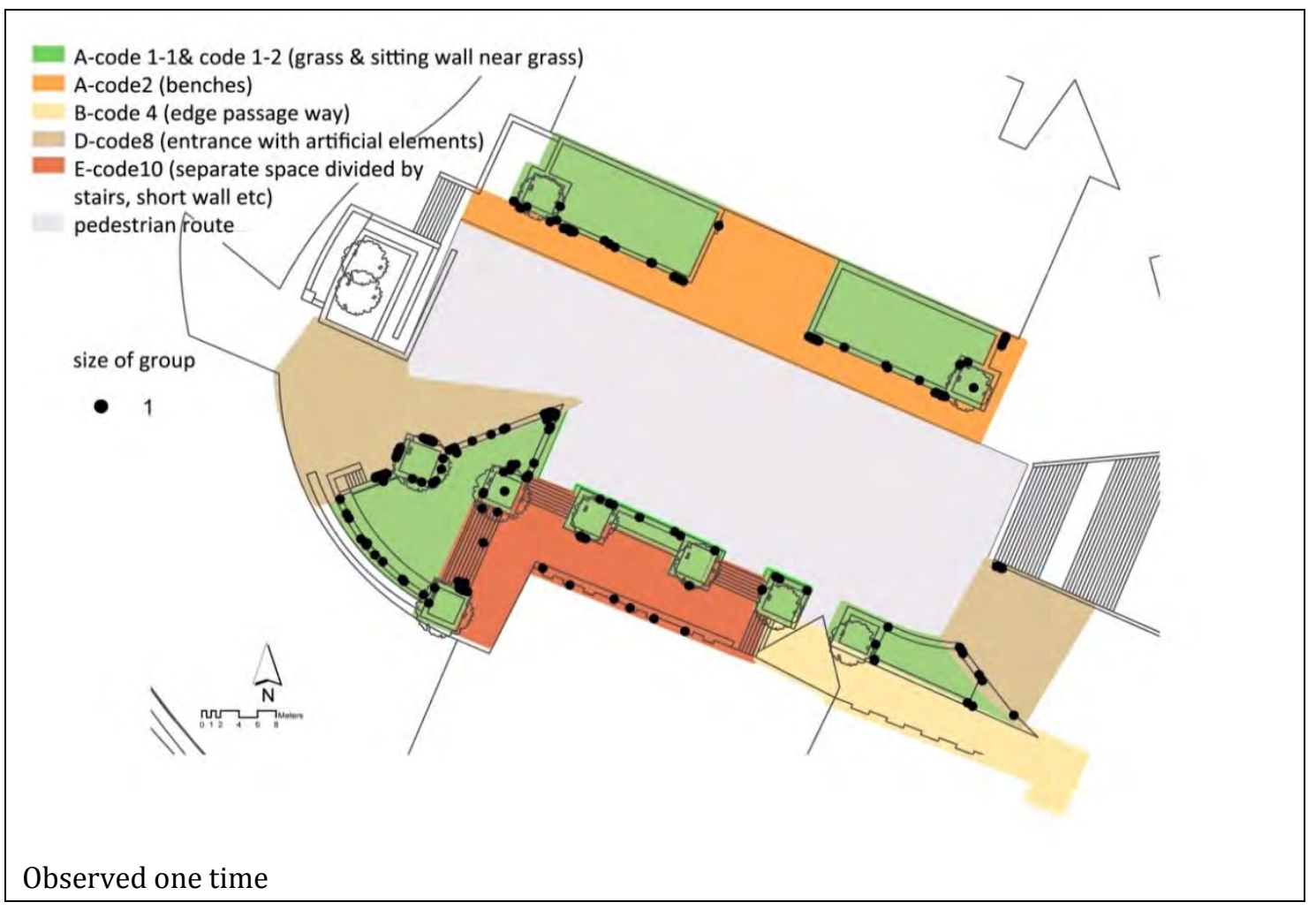




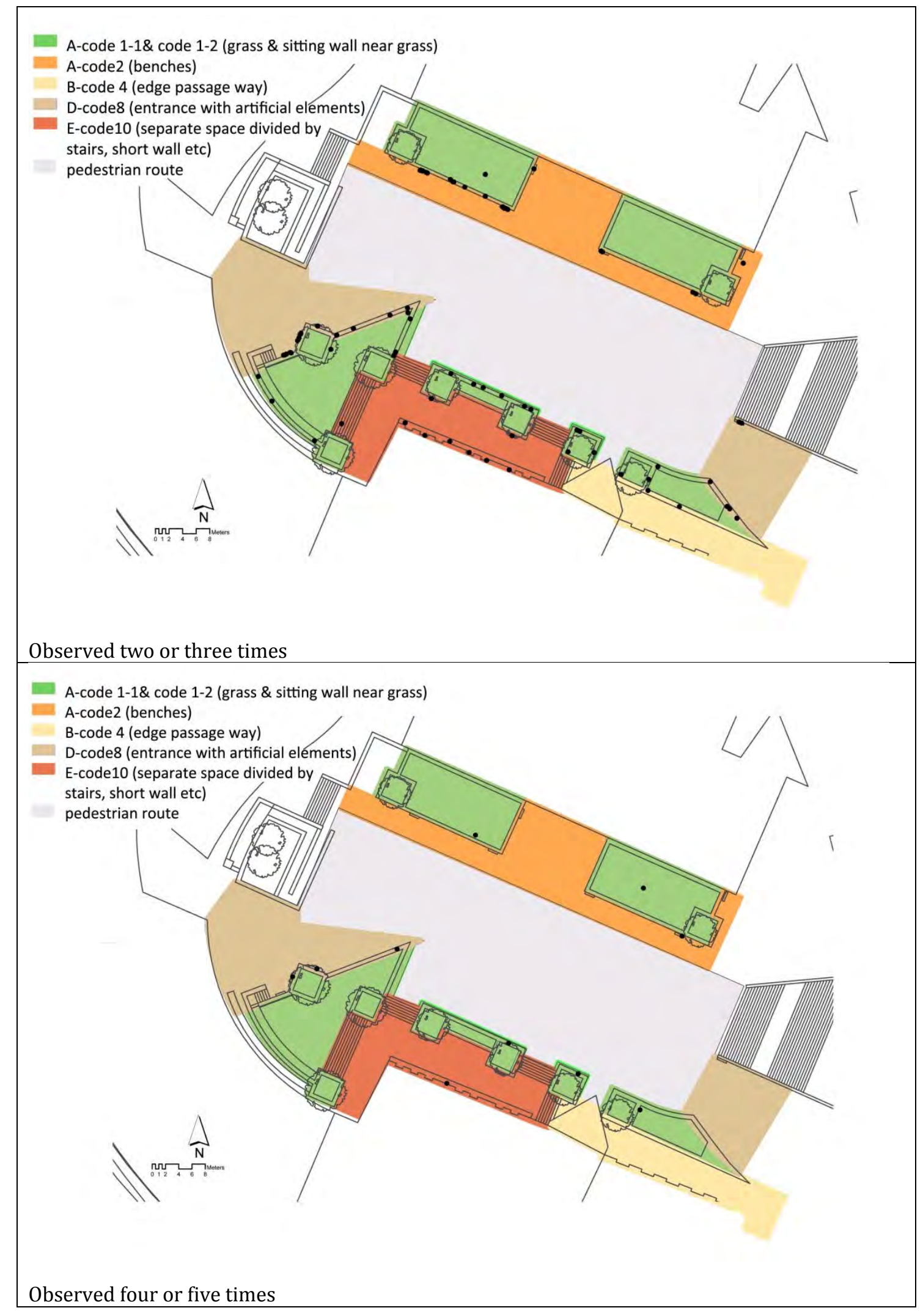




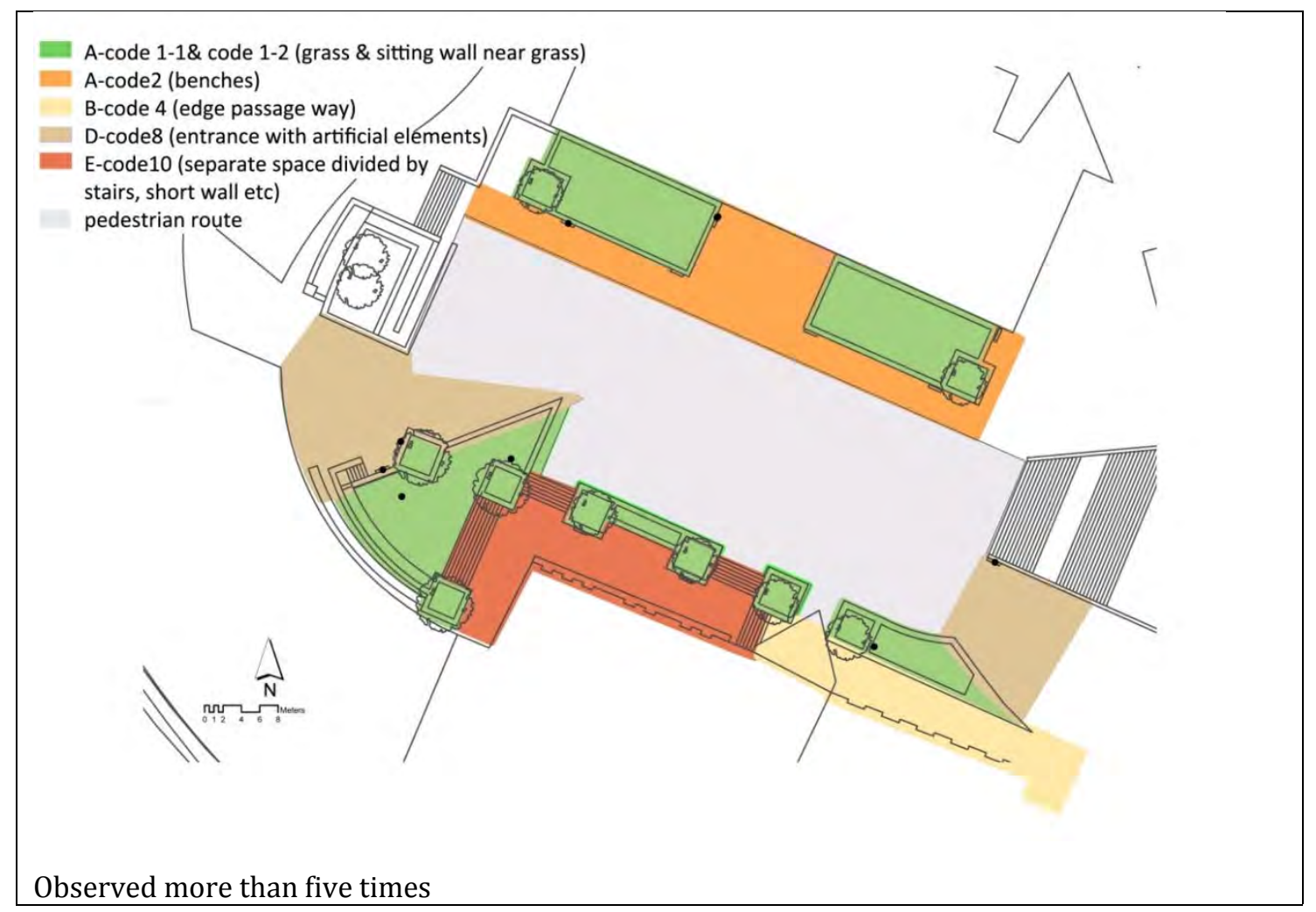

Figure 6-33: Length of stay, Civic Square

\subsection{Results - Te Aro Park}

The least number of subspace categories occurred in Te Aro Park and these are shown and described in Figures 6-34 and 6-35.

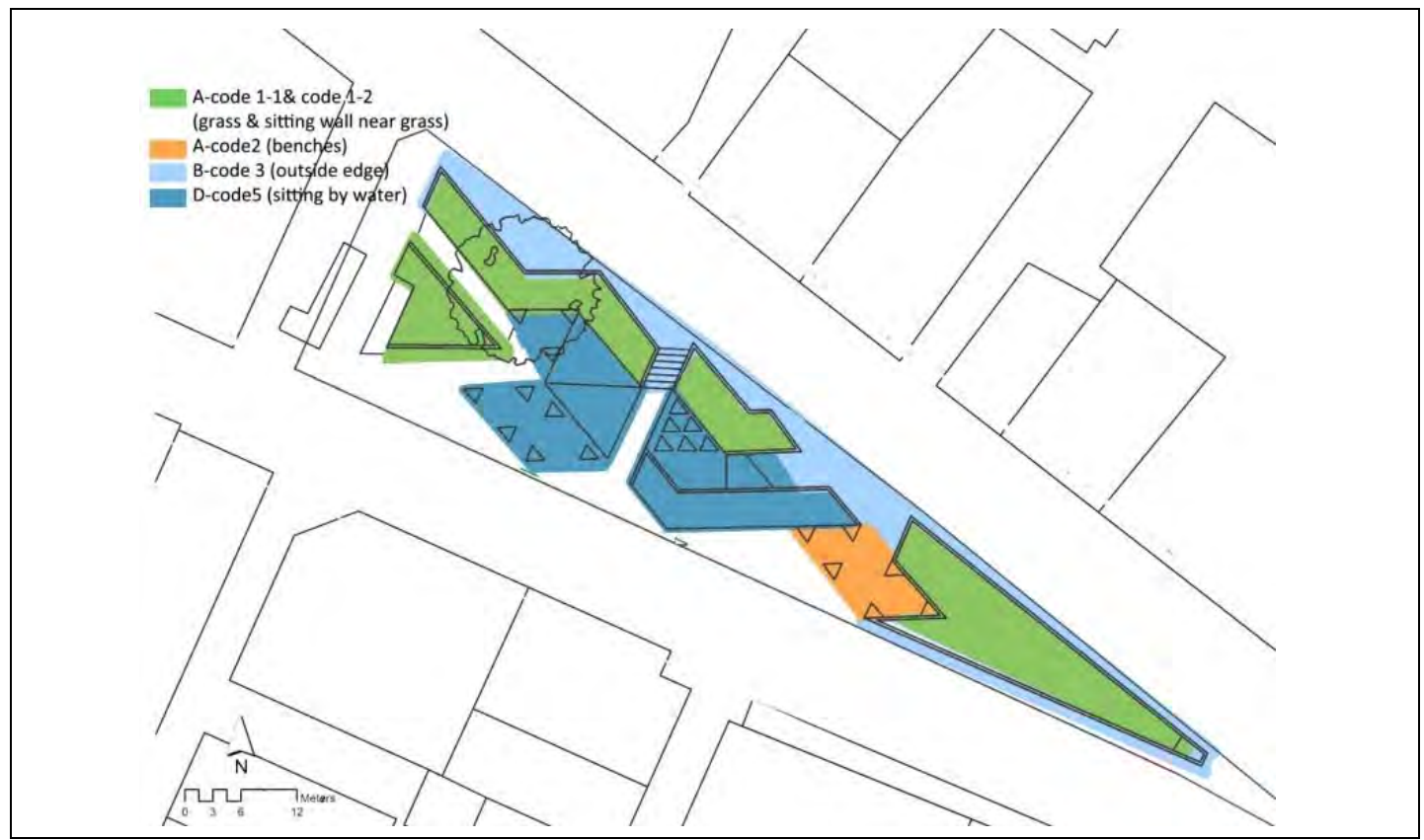

Figure 6-34: Subspaces in Te Aro Park 


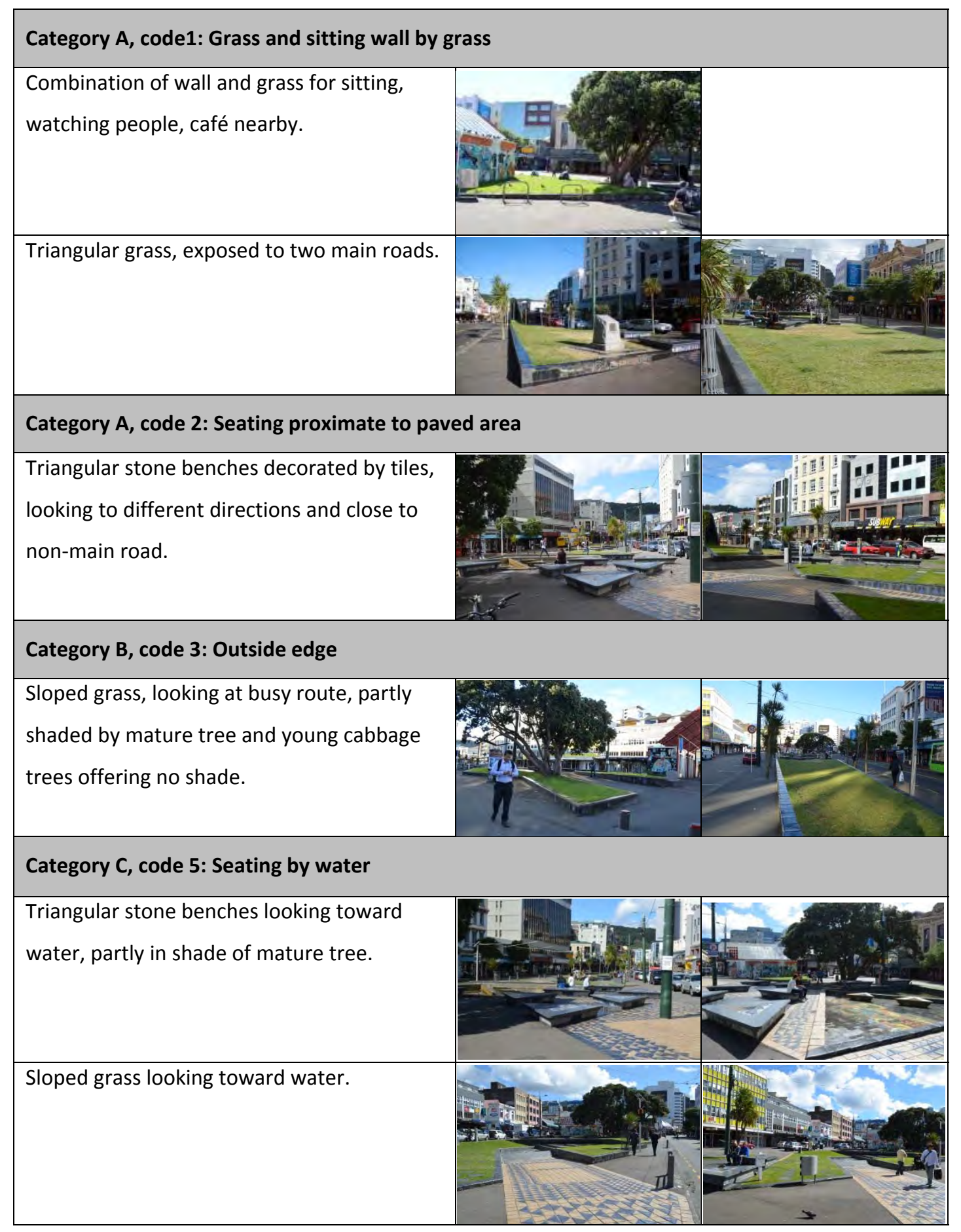

Figure 6-35: Description of subspaces, Te Aro Park

\subsubsection{Number of Users}

The 493 photos taken in a day between 08.00 and 17.00 (See Appendix 3) show a total of 291 people and 193 people in groups of one, two, or more used the park. The three busiest hours were $12.00-13.00,13.00-14.00$ and 14.00-15.00, with 70, 50 and 41 individual users 
in these times respectively. For rest of the day the park was occupied by an average 30 users per hour, with least users from 08.00-10.00 (Table 6-19).

Hourly use of each subspace as a percentage of its maximum occupancy each hour over the whole day indicates that except for sitting wall by grass all subspaces follow the pattern of the total use. This means their busiest time was $12.00-13.00$ with a dramatic decrease in use after 13.00. Sitting wall by grass had its own busiest time of 14.00-15.00 and experienced a decrease in use after that, rising to a second use peak during 16.0017.00. Seating in paved area experienced a sharper increase in use than other subspaces from morning to midday and its use also increased in the last hour.

Table 6-19: Number of users during one day of observation, Te Aro Park

\begin{tabular}{|c|c|c|c|c|c|c|c|c|c|c|c|}
\hline $\begin{array}{l}\text { Subspace use as } \\
\text { percentage of MO over } \\
\text { one day }\left(N^{*} 100\right) / M O\end{array}$ & & $\begin{array}{l}08.00- \\
09.00\end{array}$ & $\begin{array}{l}09.00- \\
10.00\end{array}$ & $\begin{array}{l}10.00- \\
11.00\end{array} \mid$ & $\begin{array}{l}11.00- \\
12.00\end{array}$ & $\begin{array}{l}12.00- \\
13.00\end{array}$ & $\begin{array}{l}13.00- \\
14.00\end{array}$ & $\begin{array}{l}14.00- \\
15.00\end{array}$ & $\begin{array}{l}15.00- \\
16.00\end{array}$ & $\begin{array}{l}16.00- \\
17.00\end{array}$ & Total \\
\hline \multirow[t]{2}{*}{ A-code1-2 } & $N$ & 0.00 & 2.00 & 4.00 & 2.00 & 4.00 & 5.00 & 14.00 & 4.00 & 9.00 & 44.00 \\
\hline & $P$ & $0.00 \%$ & $14.29 \%$ & $28.57 \%$ & $14.29 \%$ & $28.57 \%$ & $35.71 \%$ & $100 \%$ & $28.57 \%$ & $64.29 \%$ & \\
\hline \multirow[t]{2}{*}{ A-code 2} & $N$ & 2.00 & 0.00 & 8.00 & 18.00 & 23.00 & 20.00 & 11.00 & 8.00 & 10.00 & 100.00 \\
\hline & $\mathrm{P}$ & 8.7 & $0.00 \%$ & $34.78 \%$ & $78.26 \%$ & $100 \%$ & 86.96 & $47.83 \%$ & $34.83 \%$ & $43.48 \%$ & \\
\hline B-code 3 & $N$ & 0.00 & 0.00 & 6.00 & 4.00 & 12.00 & 7.00 & 4.00 & 6.00 & 5.00 & 44.00 \\
\hline 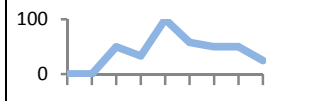 & $P$ & $0.00 \%$ & $0.00 \%$ & $50.00 \%$ & $33.33 \%$ & $100 \%$ & $58.00 \%$ & $50.00 \%$ & $50.00 \%$ & $25.00 \%$ & \\
\hline C-code 5 & $N$ & 0.00 & 7.00 & 12.00 & 7.00 & 31.00 & 18.00 & 10.00 & 13.00 & 5.00 & 103.00 \\
\hline 100 & $P$ & $0.00 \%$ & $22.58 \%$ & $38.71 \%$ & $22.58 \%$ & $100 \%$ & $58.06 \%$ & $32.26 \%$ & $41.94 \%$ & $16.13 \%$ & \\
\hline Total Park & $N$ & 2.00 & 9.00 & 30.00 & 31.00 & 70.00 & 50.00 & 41.00 & 31.00 & 27.00 & 291.00 \\
\hline$\left[\begin{array}{c}100 \\
0\end{array}\right]$ & $P$ & $2.86 \%$ & $12.86 \%$ & $42.86 \%$ & $44.29 \%$ & $100 \%$ & $71.43 \%$ & $58.57 \%$ & $44.29 \%$ & $38.57 \%$ & \\
\hline \multicolumn{12}{|c|}{ M-O: Maximum occupancy } \\
\hline \multicolumn{3}{|l|}{$\mathrm{N}$ : Number of users } & $100 \%$ & $100-80$ & \multicolumn{2}{|c|}{$80-60 \%$} & $0-40 \%$ & $40-20 \%$ & $20-0 \%$ & $0 \%$ & \\
\hline $\mathrm{P}$ : Percentage of MO & & & & & & & & & & & \\
\hline
\end{tabular}




\subsubsection{Occupancy and Preferences}

The pattern of occupancy during the day shows benches in paved areas and seating by water were used most. While sitting walls by trees and outside edge were also well used, grass was less preferred (Figure 6-36).

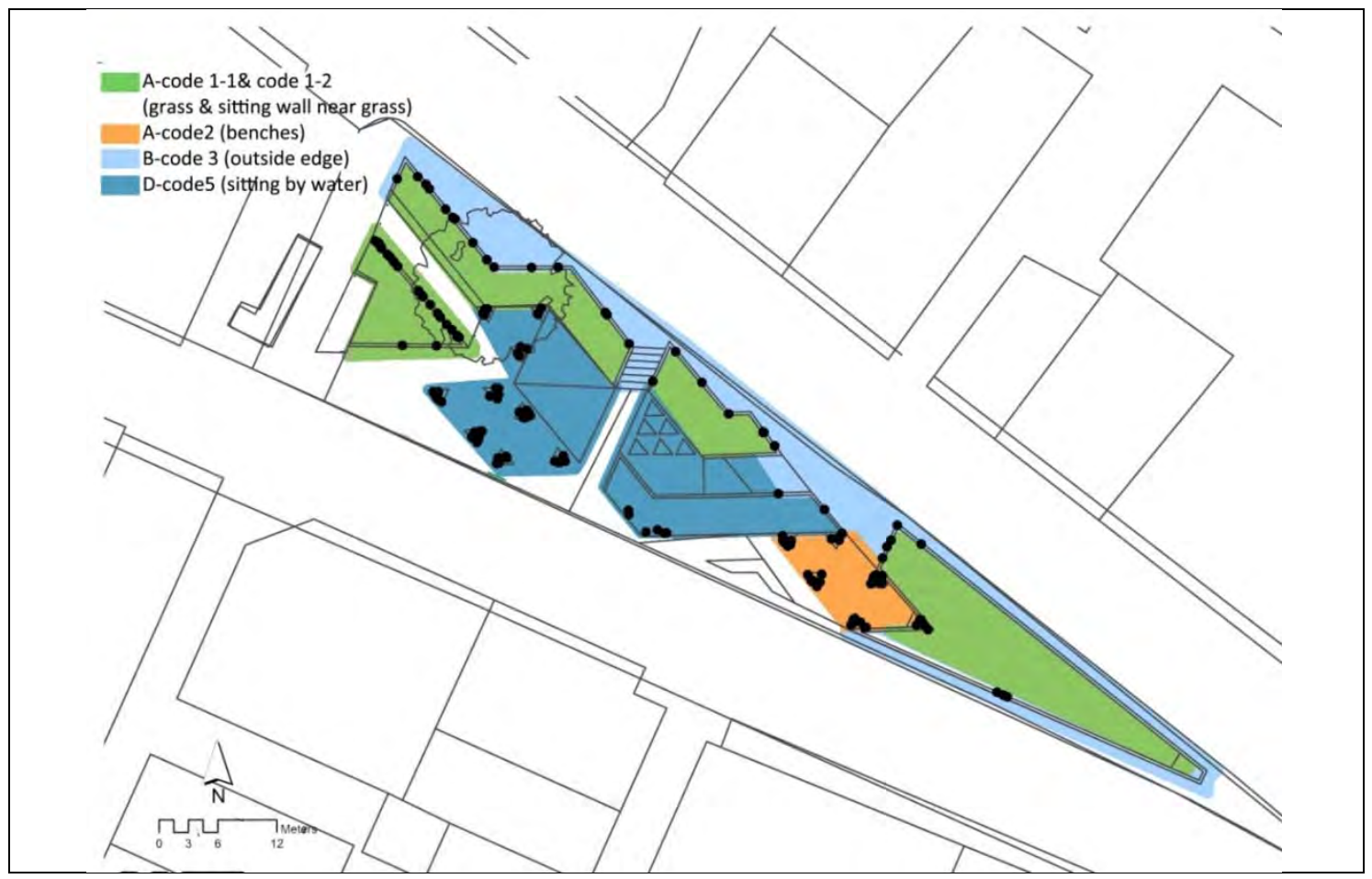

Figure 6-36: Map of occupancy during one day, Te Aro Park

From 08.00-11.00 people preferred to use the sitting wall by grass, in the north west corner and benches close to outside edges of the park (Figures 6-37.1, 6-37.2). Although most subspaces started to be used during $10.00-12.00$ grass by water and grass in the south east corner were virtually left vacant (Figures 6-37.3, 6-37.4). This pattern continued from 12.00-15.00 (Figures 6-37.5 to 6-37.7). Between 15.00-17.00 seating in paved area, seating by water in sun, and sitting wall to the north east were still used. Meanwhile outside edge lost its attraction for people (Figures 6-37.8, 6-37.9).

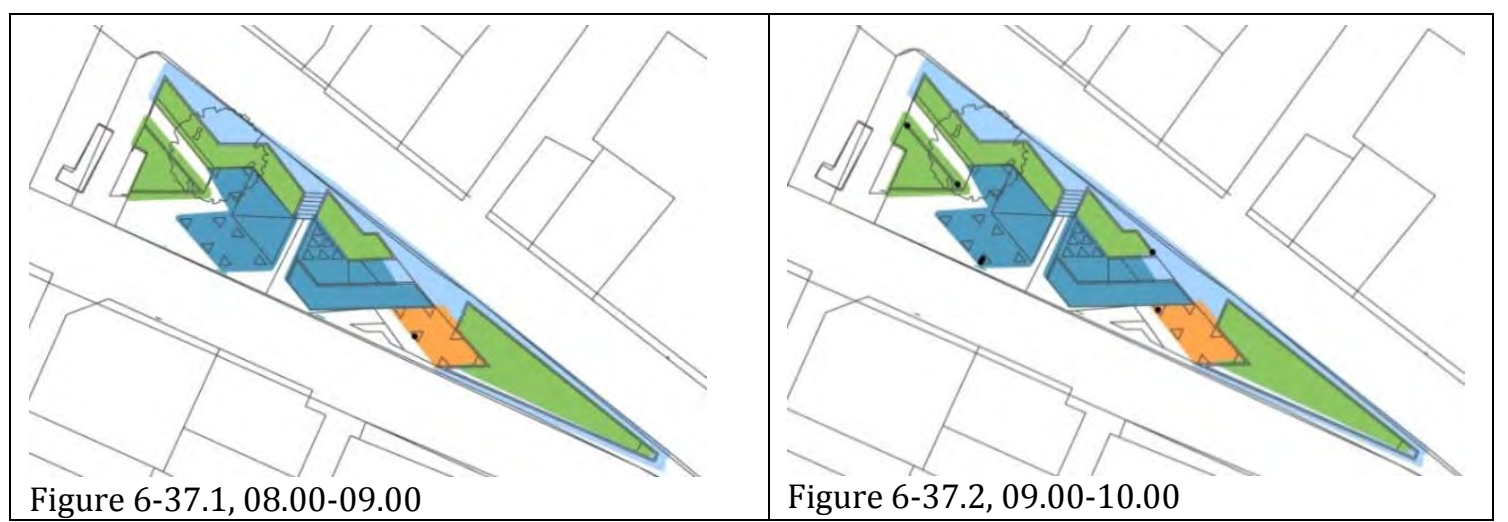




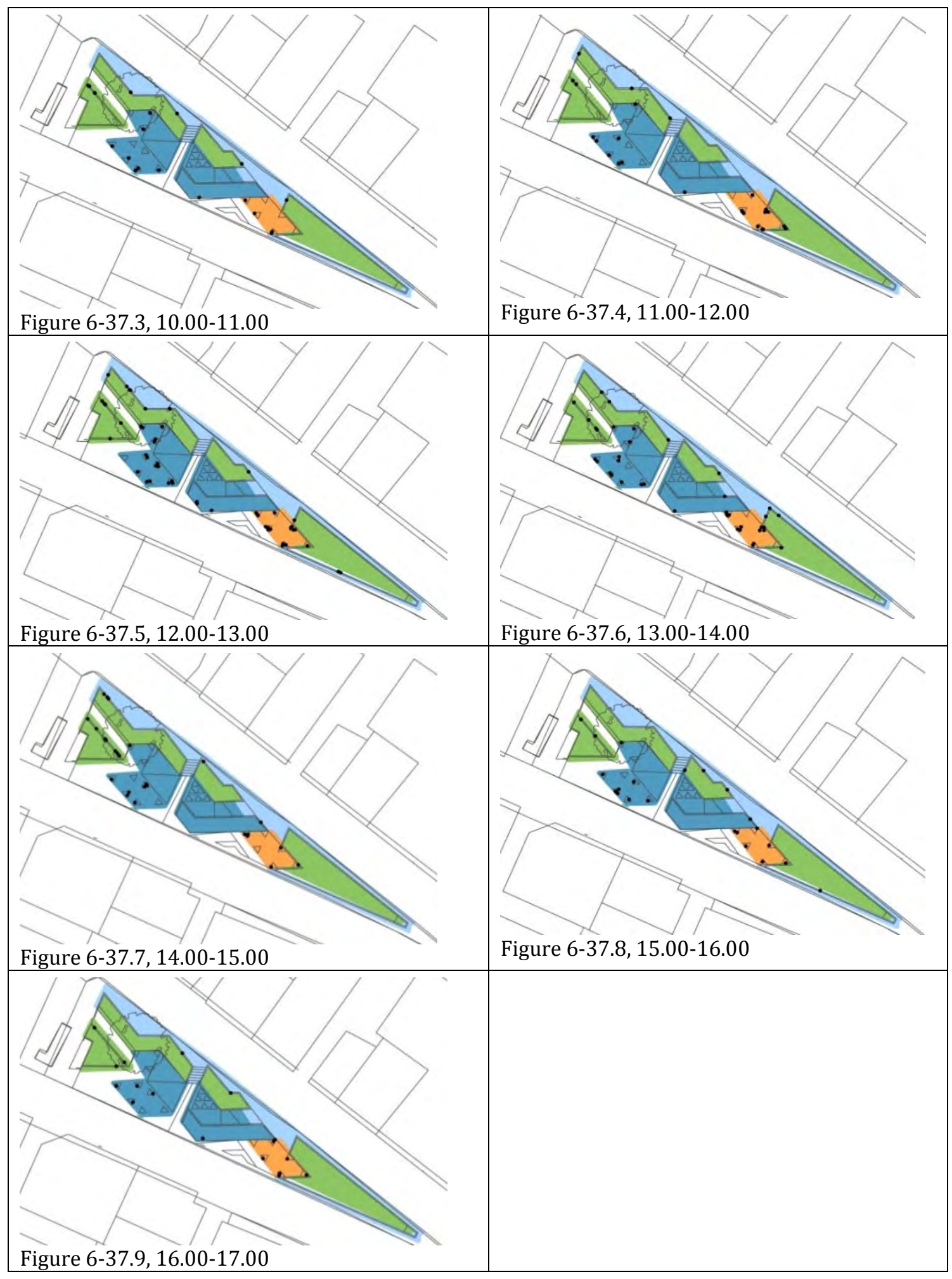

Figure 6-37: Hourly occupancy maps, Te Aro Park

\subsubsection{Size of Group}

People alone (42.27\%) and people in a group of two (35.74\%) used the park the most. Groups of three and four formed $11.34 \%$ and $6.87 \%$ of users respectively, with groups of five and six people making up the remaining $3.78 \%$. 
The percentage of people alone and in a group as part of total occupancy during the day demonstrates people in groups make up almost $60 \%$ of users both in total and for each subspace individually (Table 6-20).

Table 6-20: Use of subspaces by people alone and in groups

\begin{tabular}{|c|c|c|c|c|c|c|c|c|c|c|c|c|}
\hline & & $\begin{array}{c}08.00- \\
09.00\end{array}$ & $\begin{array}{c}09.00- \\
10.00\end{array}$ & $\begin{array}{c}10.00- \\
11.00\end{array}$ & $\begin{array}{c}11.00- \\
12.00\end{array}$ & $\begin{array}{c}12.00- \\
13.00\end{array}$ & $\begin{array}{l}13.00- \\
14.00\end{array}$ & $\begin{array}{c}14.00- \\
15.00\end{array}$ & $\begin{array}{c}15.00- \\
16.00\end{array}$ & $\begin{array}{c}16.00- \\
17.00\end{array}$ & $\mathbf{T}$ & $\mathbf{P}$ \\
\hline \multirow{3}{*}{ A-code 1-2 } & A & 0 & 2 & 4 & 2 & 4 & 3 & 0 & 0 & 0 & 15 & $34.09 \%$ \\
\hline & G & 0 & 0 & 0 & 0 & 0 & 2 & 14 & 4 & 9 & 29 & $65.91 \%$ \\
\hline & $\mathrm{T}$ & 0 & 2 & 4 & 2 & 4 & 5 & 14 & 4 & 9 & 44 & $100 \%$ \\
\hline \multirow{3}{*}{ A-code 2} & $A$ & 0 & 0 & 2 & 8 & 8 & 9 & 4 & 4 & 5 & 40 & $40.00 \%$ \\
\hline & G & 2 & 0 & 6 & 10 & 15 & 11 & 7 & 4 & 5 & 60 & $60.00 \%$ \\
\hline & $T$ & 2 & 0 & 8 & 18 & 23 & 20 & 11 & 8 & 10 & 100 & $100 \%$ \\
\hline \multirow{3}{*}{ B-code 3} & $A$ & 0 & 0 & 3 & 2 & 6 & 5 & 4 & 2 & 1 & 23 & $52.27 \%$ \\
\hline & G & 0 & 0 & 3 & 2 & 6 & 2 & 2 & 4 & 2 & 21 & $47.73 \%$ \\
\hline & $\mathrm{T}$ & 0 & 0 & 6 & 4 & 12 & 7 & 6 & 6 & 3 & 44 & $100 \%$ \\
\hline \multirow{3}{*}{ C-code 5} & A & 0 & 1 & 4 & 7 & 11 & 7 & 4 & 6 & 5 & 45 & $43.69 \%$ \\
\hline & $\mathrm{G}$ & 0 & 6 & 8 & 2 & 20 & 11 & 6 & 7 & 0 & 60 & $56.31 \%$ \\
\hline & $\mathrm{T}$ & 0 & 7 & 12 & 7 & 31 & 18 & 10 & 13 & 5 & 103 & $100 \%$ \\
\hline \multicolumn{9}{|c|}{ T: Total P: Percentage of total A: Alone G: Group } & \multicolumn{3}{|c|}{ Max ocupancy } & Vacant \\
\hline
\end{tabular}

Hourly comparision of number of people alone and in groups shows an approximately similar pattern over the day for seating, with seating by water used more by groups than people alone (Figures 6-38.2, 6-38.4). While outside edge does not show any obvious usage pattern (Figure 6-38.3), sitting wall has an interesting pattern as it was used only by people alone in the morning and by people in groups in the afternoon between 14.00 17.00 (Figure 6-38.1).

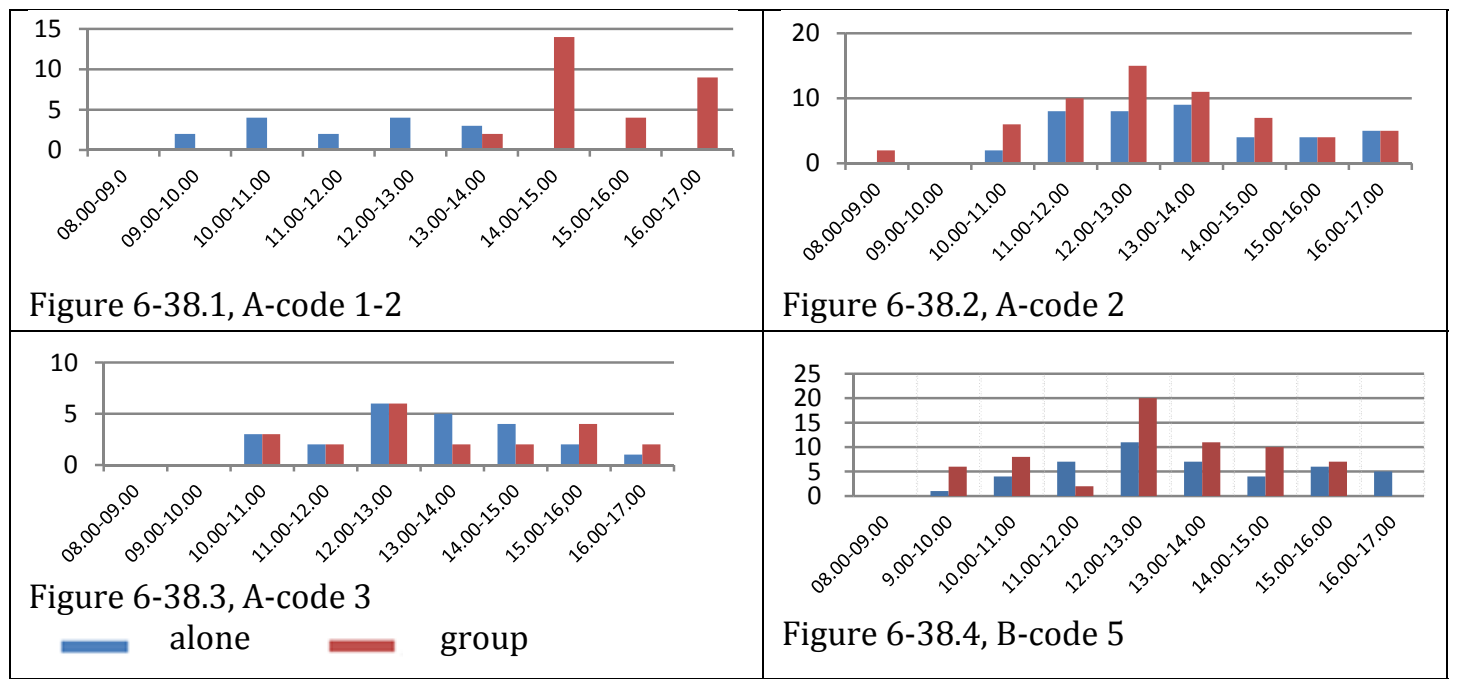

Figure 6-38: Comparison between people alone and groups, Te Aro Park

The percentage of people alone as part of the maximum occupancy of each subspace 
during the day illustrates that sitting wall is a territory for people alone until 12.00 . In contrast, people alone did not use sitting wall after 14.00 (Figure 6-39.1). While the whole park had maximum occupancy between $12.00-13.00$ seating attracted most people alone between 13.00-14.00 but followed the pattern of total uses for the rest of the day (Figure 6-39.2). Use of outside edges is similar to total use (Figure 6-39.3). Seating by water has two differences from the total use pattern, with two increases in use rather than a decrease between 10.00-12.00 and 14.00-16.00 (Figure 6-39.4).

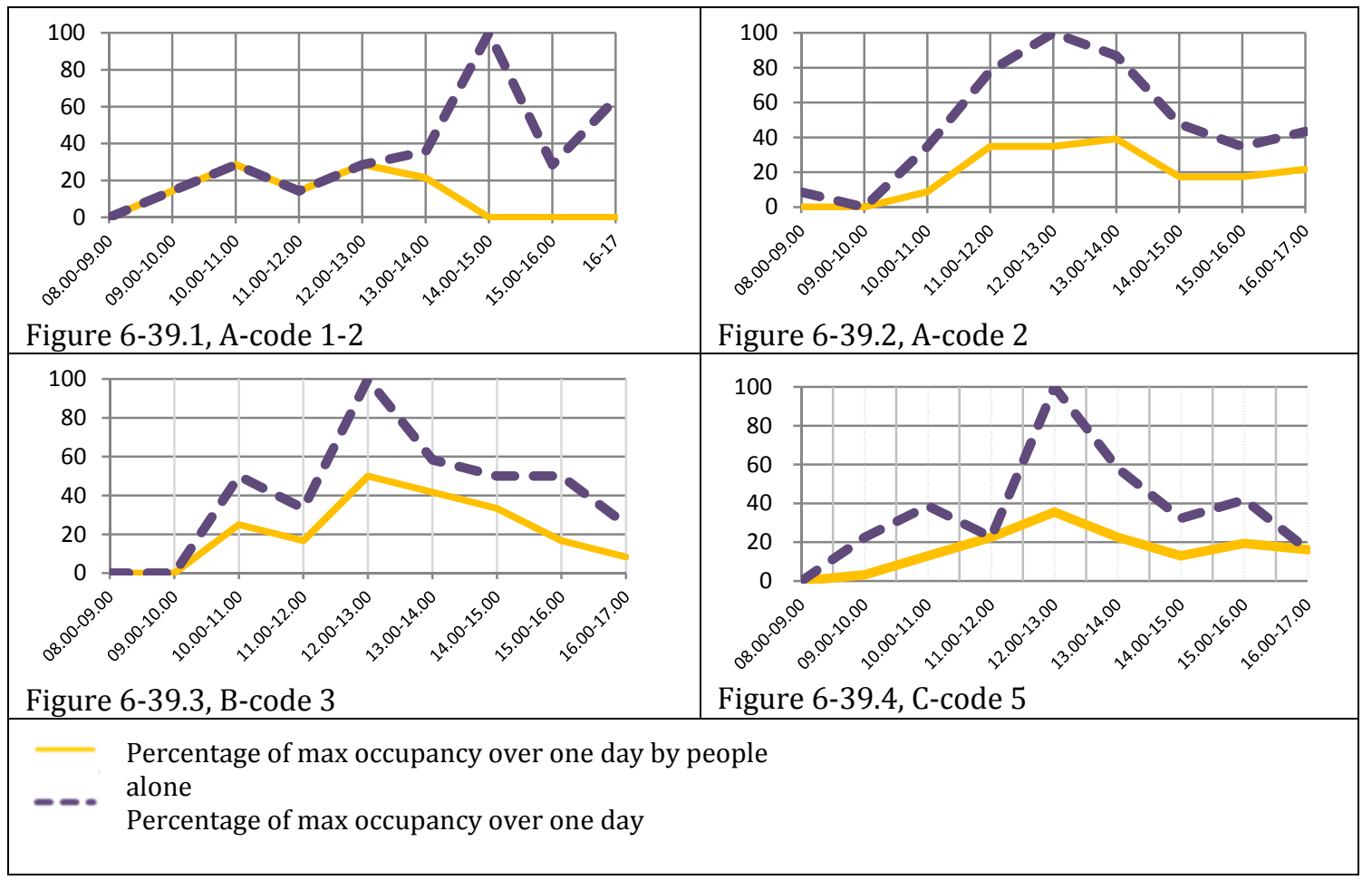

Figure 6-39: Use by people alone as percentage of maximum occupancy during day, Te Aro park

Separate occupancy maps for people alone and people in groups show the preferences for both are similar (Figure 6-40). 


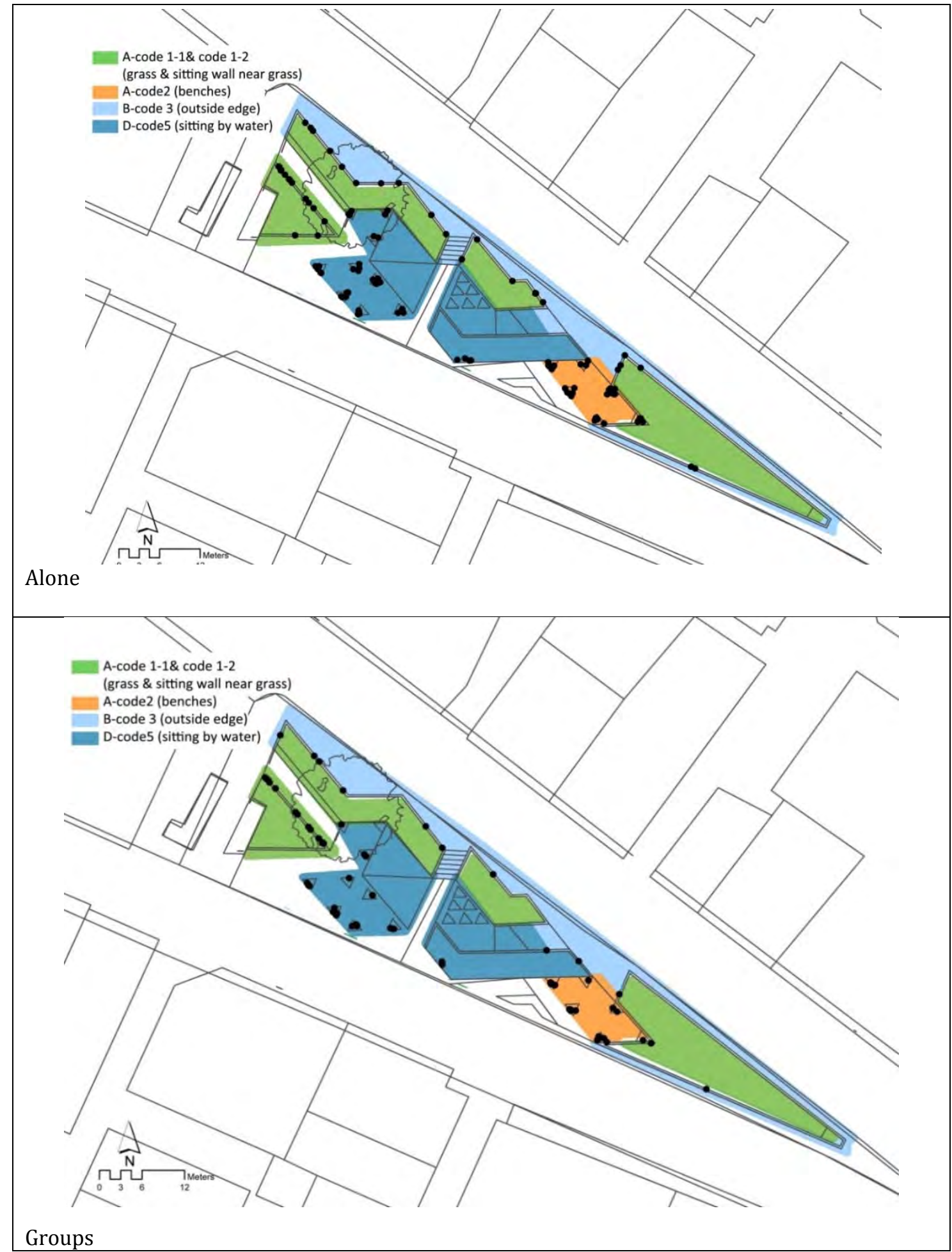

Figure 6-40: Map of occupancy by people alone and in groups, Te Aro Park

In terms of size of group, seating by water, and seating attracted larger groups, sitting wall had the most use by people in groups of two, and people alone made up half of the users of outside edge (Table 6-21). The triangular benches might be a possible reason for these differences, as they give the opportunity for people to sit around in bigger groups. 
Table 6-21: Size of group and use of subspaces, Te Aro Park

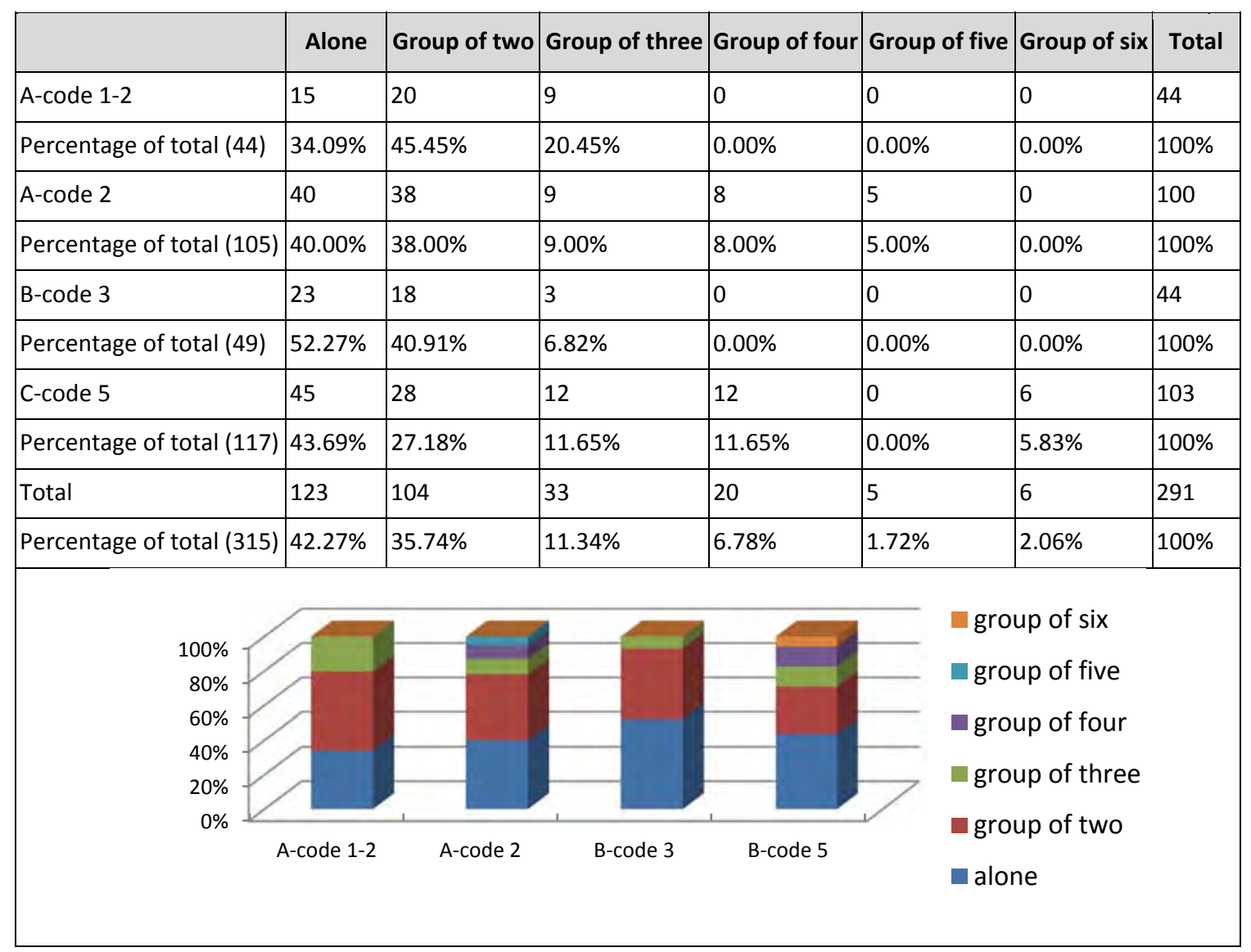

Places used by bigger groups are seating close to water and the large tree (Figure 6-41).

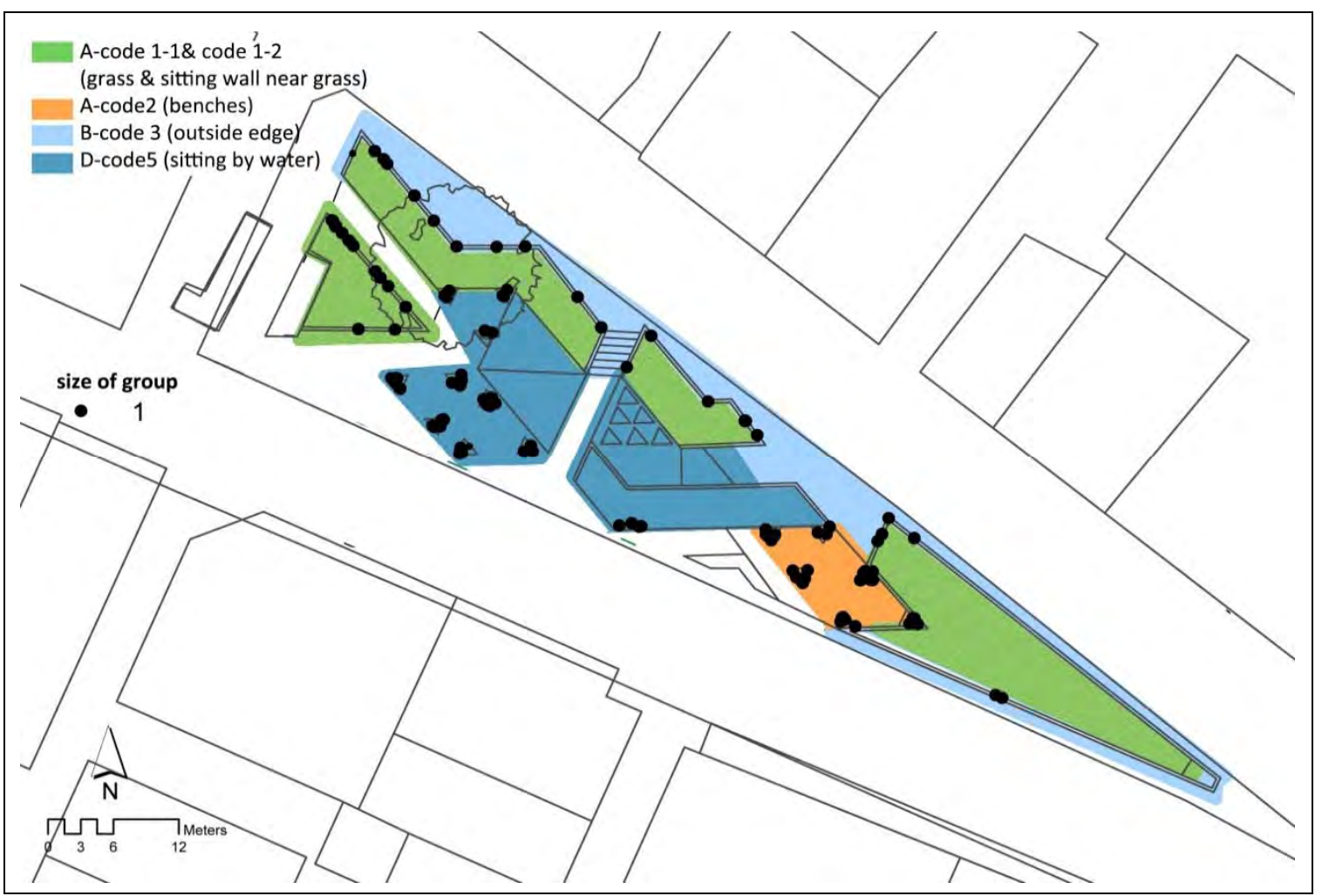




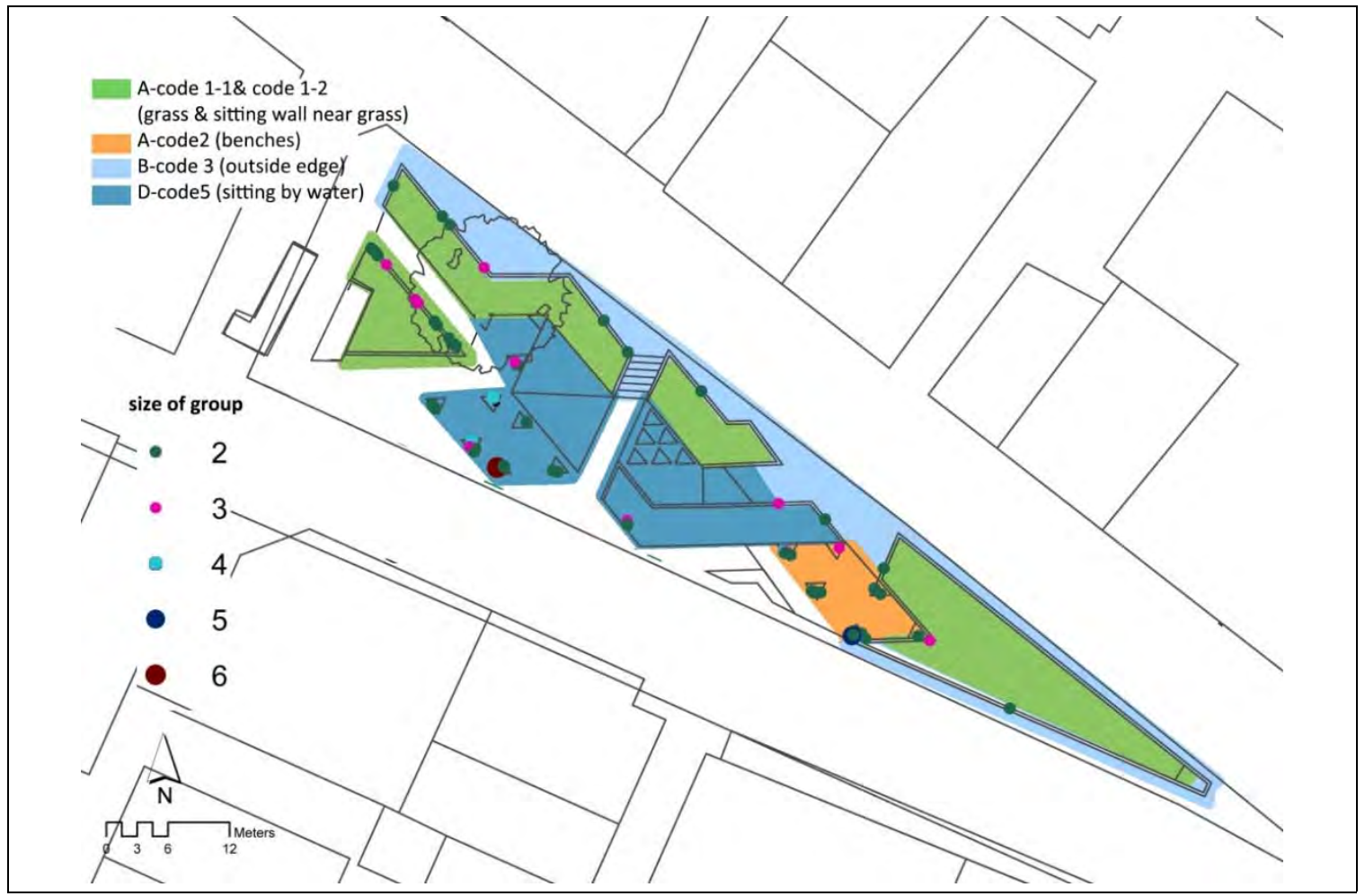

Figure 6-41: Occupancy map based on size of group, Te Aro Park

\subsubsection{Use by Age and Gender}

Analysis of photographs shows young adults are the biggest user group (41.24\%), with adults making $30.93 \%$, and teenagers $24.74 \%$ of users. Retired people and children only account for 3.09\% (Table 6-22).

Males (60.48\%) were observed more than females (37.12\%). Sitting wall and seating are mostly used by young adults. Outside edge was preferred by adults, and seating by water attracted teenagers, young adults and adults.

Table 6-22: Number of users by age and gender

\begin{tabular}{|l|c|c|c|c|c|c|c|c|c|c|c|c|c|}
\hline & Child & \multicolumn{3}{|c|}{ Teenager } & \multicolumn{3}{c|}{ Young Adult } & \multicolumn{3}{c|}{ Adult } & \multicolumn{3}{c|}{ Old Adult } \\
\hline & & Male & Female & Total & Male & Female & Total & Male & Female & Total & Male & Female & Total \\
\hline A-code 1-2 & 1 & 7 & 5 & 12 & 13 & 6 & 19 & 9 & 2 & 11 & 0 & 1 & 1 \\
\hline A-code 2 & 3 & 9 & 8 & 17 & 36 & 17 & 53 & 18 & 8 & 26 & 0 & 1 & 1 \\
\hline B-code 3 & 0 & 3 & 8 & 11 & 8 & 6 & 14 & 12 & 6 & 18 & 1 & 0 & 1 \\
\hline C-code 5 & 0 & 13 & 19 & 32 & 21 & 13 & 34 & 27 & 8 & 35 & 2 & 0 & 2 \\
\hline Total & 4 & 32 & 40 & 72 & 78 & 42 & 120 & 66 & 24 & 90 & 3 & 2 & 5 \\
\hline \% total (291) & $1.37 \%$ & $11.00 \%$ & $13.75 \%$ & $24.74 \%$ & $26.80 \%$ & $14.43 \%$ & $41.24 \%$ & $22.68 \%$ & $8.25 \%$ & $30.93 \%$ & $1.03 \%$ & $0.69 \%$ & $1.72 \%$ \\
\hline
\end{tabular}


Table 6-23: Number of groups in subspaces by gender

\begin{tabular}{|l|c|c|c|c|c|c|}
\hline & Male alone & Female alone & Male groups & Female groups & Mixed groups & Total \\
\hline A-code 1-2 & 12 & 3 & 11 & 2 & 16 & 44 \\
\hline A-code 2 & 24 & 16 & 26 & 5 & 29 & 100 \\
\hline B-code 3 & 13 & 10 & 6 & 4 & 11 & 44 \\
\hline C-code 5 & 32 & 13 & 17 & 13 & 28 & 103 \\
\hline Total & 81 & 42 & 60 & 24 & 84 & 291 \\
\hline
\end{tabular}

Use of subspaces by people alone and in groups by gender indicates the two preferred subspaces for females alone are seating and seating by water, with preferences for males alone showing the reverse pattern (seating by water and seating) (Figures 6-42, 6-46, Table 6-23). Sitting wall was mostly used by males alone and outside edge was used equally by both genders (Table 6-23). For male groups the preference for seating is significantly higher than for female groups, and almost half the latter used seating by water (Figure 6-43, 6-46, Table 6-23). Mixed groups were observed using benches, seating by water, followed by sitting walls, and ouside edge (Table 6-23). In contrast with males alone and in groups which have similar preferences, females had differen use patterns. Most females alone used seating but this received less attention from female groups (Figures 6-44, 6-45).

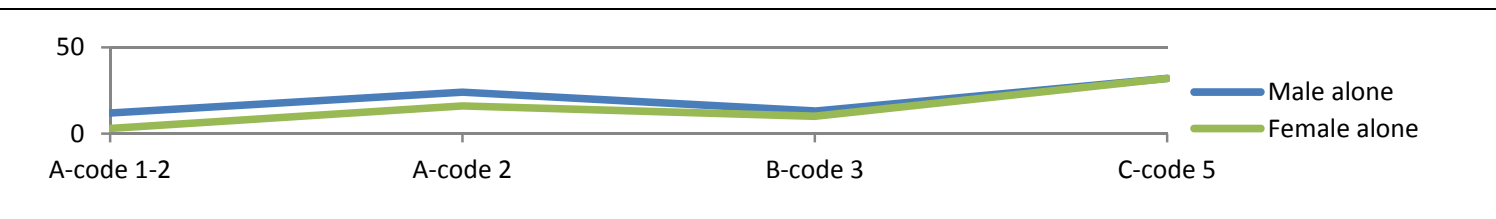

Figure 6-42: Comparison between male and female alone preferences

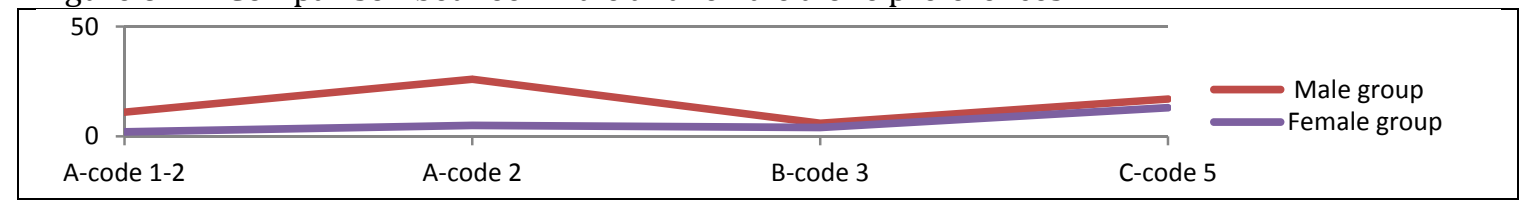

Figure 6-43: Comparison between male and female group preferences

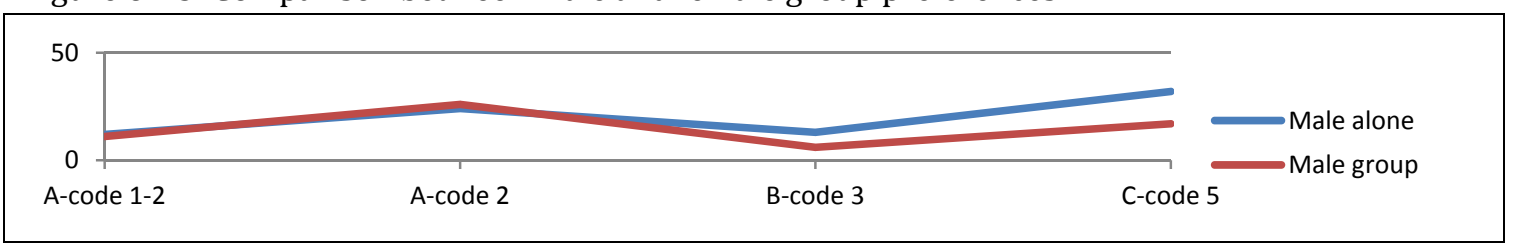

Figure 6-44: Comparison between males alone and male group preferences

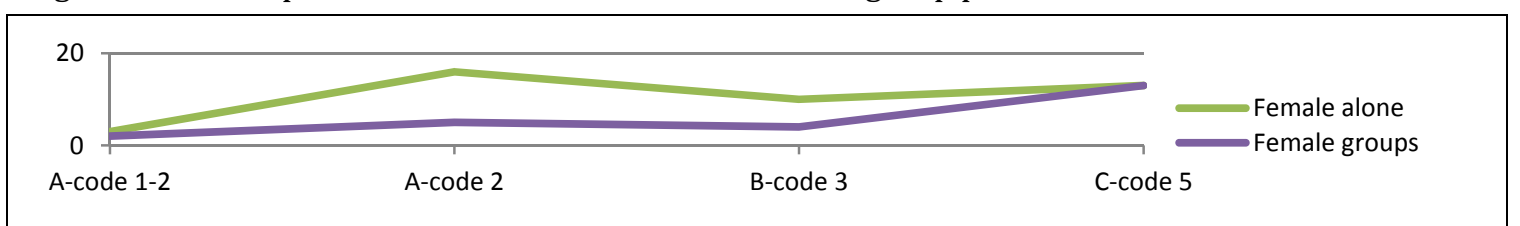

Figure 6-45: Comparison between female alone and female group preferences 
The occupancy maps show people alone made more use of shaded seating by water or sitting wall close to the tree than groups (Figure 6-46).

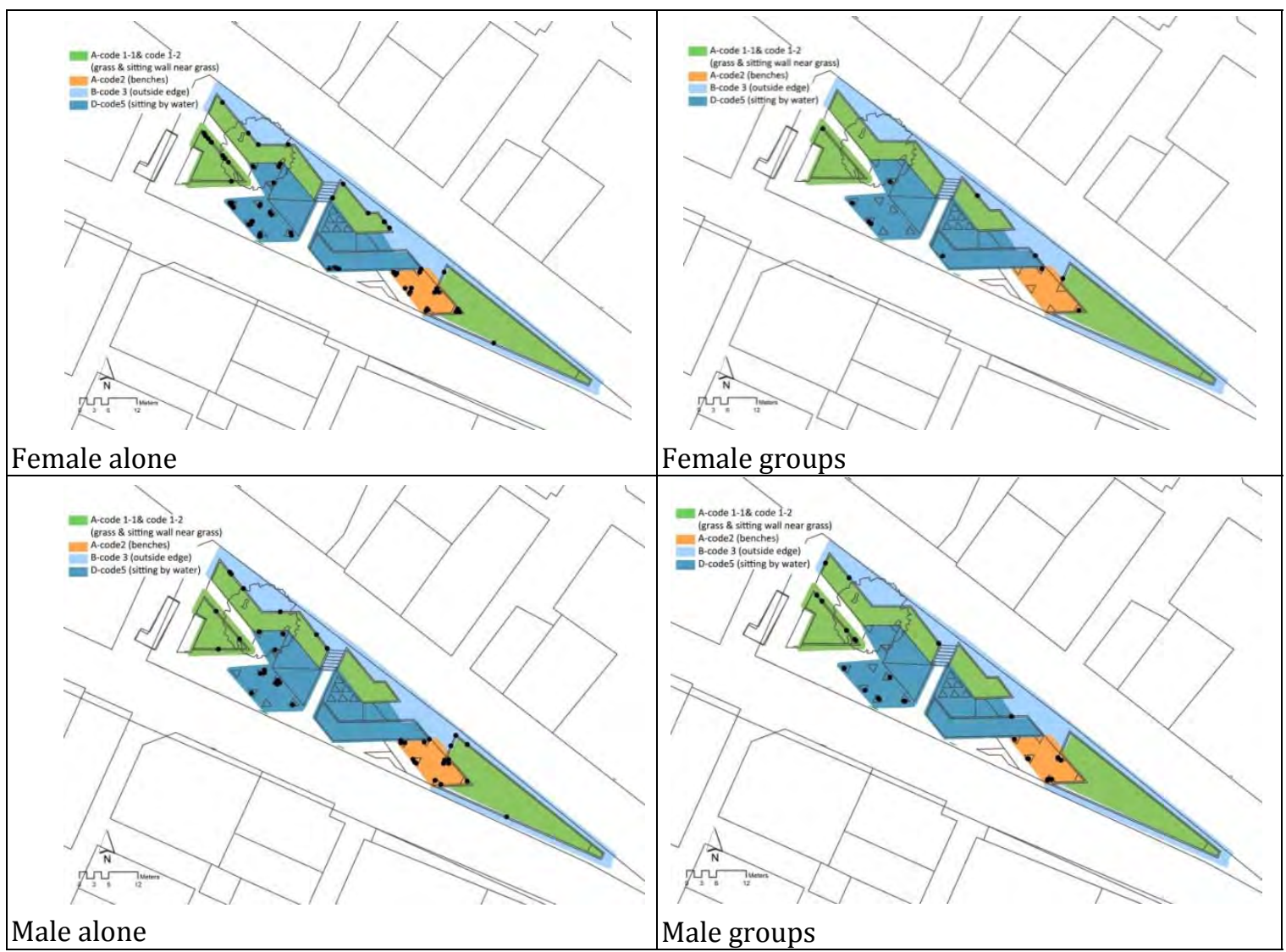

Figure 6-46: Map of occupancy for people alone and in groups by gender, Te Aro Park

\subsubsection{Activity}

People alone and in groups mostly used the park for sitting. The second dominant activity by groups is eating, but for people alone using a mobile is observed more than eating (Table 6-24, Figure 6-47).

Table 6-24: Type of activity by people alone and in groups

\begin{tabular}{|l|l|l|l|l|l|l|l|}
\hline \multicolumn{1}{|c|}{ Type of activity } & \multicolumn{3}{c|}{ Number } & \multicolumn{2}{c|}{ Type of activity } & \multicolumn{3}{c|}{ Number } \\
\hline & Alone & Group & Total & & Alone & Group & Total \\
\hline Sitting & 45 & 34 & 79 & Sitting - eating - smoking & 0 & 3 & 3 \\
\hline Sitting - eating & 31 & 22 & 52 & Standing - smoking & 0 & 1 & 1 \\
\hline Sitting - using mobile & 37 & 1 & 38 & Standing - other & 0 & 4 & 4 \\
\hline Sitting - smoking & 3 & 4 & 7 & Lying - sleeping & 1 & 0 & 1 \\
\hline Sitting - reading & 5 & 2 & 7 & & & & \\
\hline Sitting - eating - reading & 1 & 0 & 1 & & & & \\
\hline
\end{tabular}




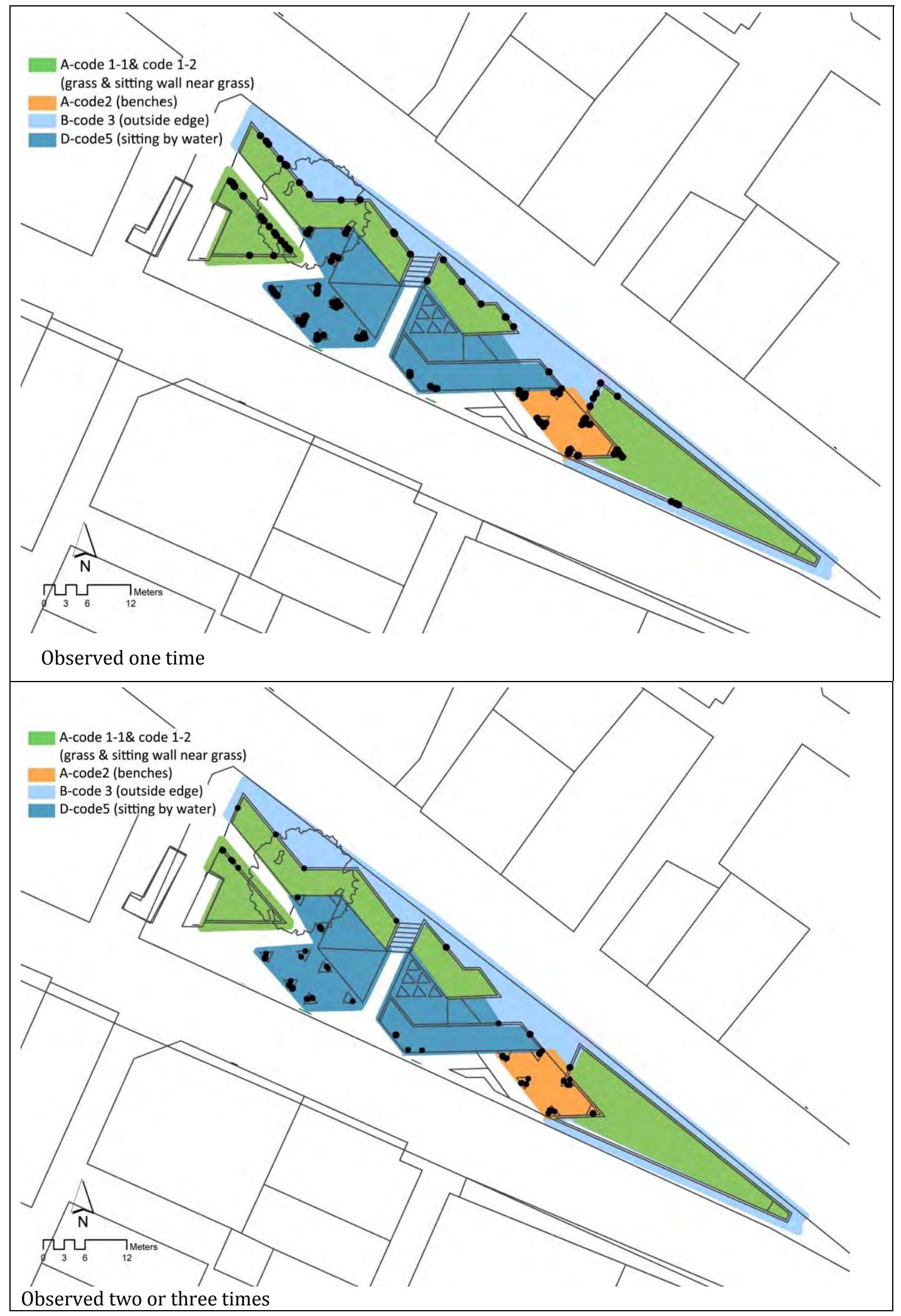




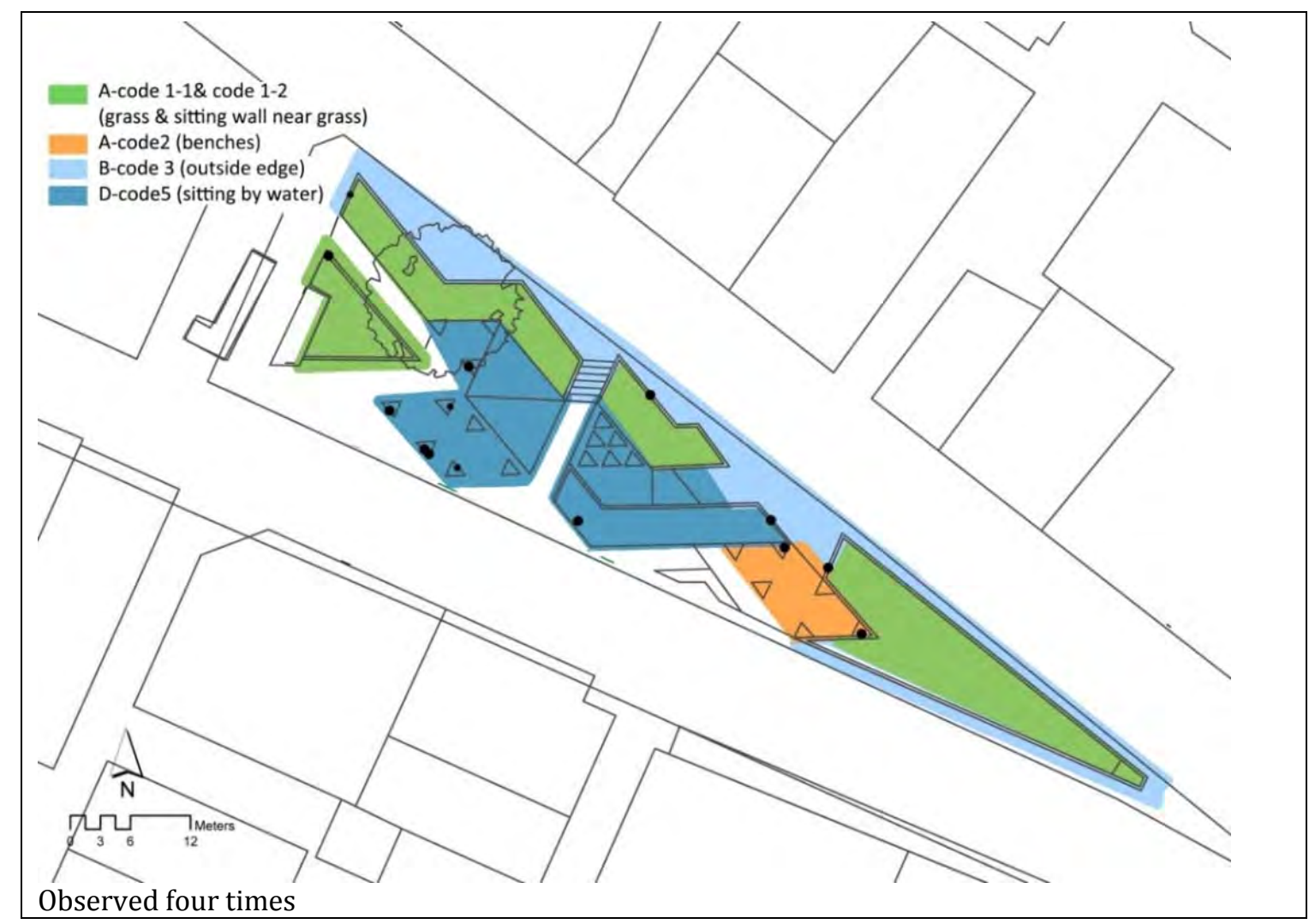

Figure 6-47: Length of stay, Te Aro Park

In terms of diversity of activities in subspaces, seating by water afforded more activities.

The dominant activities for seating in a paved area or by water are sitting, eating, and using a mobile phone. The outside edge is less used for eating, but again this may be a problem of being near busy roads because of the shape of the park (Table 6-25).

Table 6-25: Type of activity by subspace

\begin{tabular}{|l|c|c|c|c|c|c|c|c|c|}
\hline & \multicolumn{2}{|c|}{ A-code1-2 } & \multicolumn{2}{|c|}{ A-code 2 } & \multicolumn{2}{c|}{ B-code 3 } & \multicolumn{2}{c|}{ C-code 5 } & Total \\
\hline & $\mathbf{N}$ & $\mathbf{P}$ & $\mathbf{N}$ & $\mathbf{P}$ & $\mathbf{N}$ & $\mathbf{P}$ & $\mathbf{N}$ & $\mathbf{P}$ & $\mathbf{N}$ \\
\hline Sitting & 14 & $17.72 \%$ & 26 & $32.91 \%$ & 15 & $18.99 \%$ & 24 & $30.38 \%$ & 79 \\
\hline Sitting - eating & 8 & $15.38 \%$ & 19 & $36.54 \%$ & 3 & $5.77 \%$ & 22 & $42.31 \%$ & 52 \\
\hline Sitting - using mobile & 3 & $7.89 \%$ & 15 & $39.47 \%$ & 10 & $26.32 \%$ & 10 & $26.32 \%$ & 38 \\
\hline Sitting - smoking & 0 & $0.00 \%$ & 3 & $42.86 \%$ & 2 & $28.57 \%$ & 2 & $28.57 \%$ & 7 \\
\hline Sitting - reading & 1 & $14.29 \%$ & 1 & $14.29 \%$ & 1 & $14.29 \%$ & 4 & $57.14 \%$ & 7 \\
\hline Sitting - eating - reading & 0 & $0.00 \%$ & 0 & $0.00 \%$ & 0 & $0.00 \%$ & 1 & $14.29 \%$ & 1 \\
\hline Sitting - eating- smoking & 1 & $33.33 \%$ & 0 & $0.00 \%$ & 2 & $66.67 \%$ & 0 & $0.00 \%$ & 3 \\
\hline Standing - smoking & 0 & $0.00 \%$ & 0 & $0.00 \%$ & 0 & $0.00 \%$ & 1 & $100 \%$ & 1 \\
\hline Standing - other & 1 & $25 \%$ & 1 & $25 \%$ & 0 & $0.00 \%$ & 2 & $25 \%$ & 4 \\
\hline Lying - sleeping & 0 & $0.00 \%$ & 0 & $0.00 \%$ & 0 & $0.00 \%$ & 1 & $100 \%$ & 1 \\
\hline
\end{tabular}




\subsubsection{Length of Stay}

Investigation of length of stay indicates most people use the space for less than 10 minutes. Use of seating and seating by water is longer than for the other subspaces (Table 6-26).

Table 6-26: Length of stay (Group here means one person or group of two or more people)

\begin{tabular}{|l|c|c|c|c|c|c|}
\hline $\begin{array}{l}\text { Number of times group subspace } \\
\text { observed }\end{array}$ & & Observed 1 & Observed 2 & Observed 3 & Observed 4 & Total \\
\hline \multirow{2}{*}{ A-code 1-2 } & $\mathrm{N}$ & 25 & 1 & 2 & 0 & 28 \\
\cline { 2 - 7 } & $\mathrm{P}$ & $89.29 \%$ & $3.57 \%$ & $7.14 \%$ & 0 & \\
\hline \multirow{2}{*}{ A-code 2 } & $\mathrm{N}$ & 42 & 19 & 4 & 0 & 65 \\
\cline { 2 - 8 } & $\mathrm{P}$ & $64.62 \%$ & $29.23 \%$ & $6.15 \%$ & $0.00 \%$ & \\
\hline \multirow{2}{*}{ B-code 3 } & $\mathrm{N}$ & 29 & 3 & 1 & 0 & 33 \\
\hline \multirow{2}{*}{ C-code 5 } & $\mathrm{P}$ & $87.88 \%$ & $9.09 \%$ & $3.03 \%$ & $0.00 \%$ & \\
\hline
\end{tabular}

\subsection{Results - Midland Park}

Midland Park is the most diverse of the data collection sites. It has eight subspaces out of the possible ten, as shown and described in Figures 6-48 and 6-49.

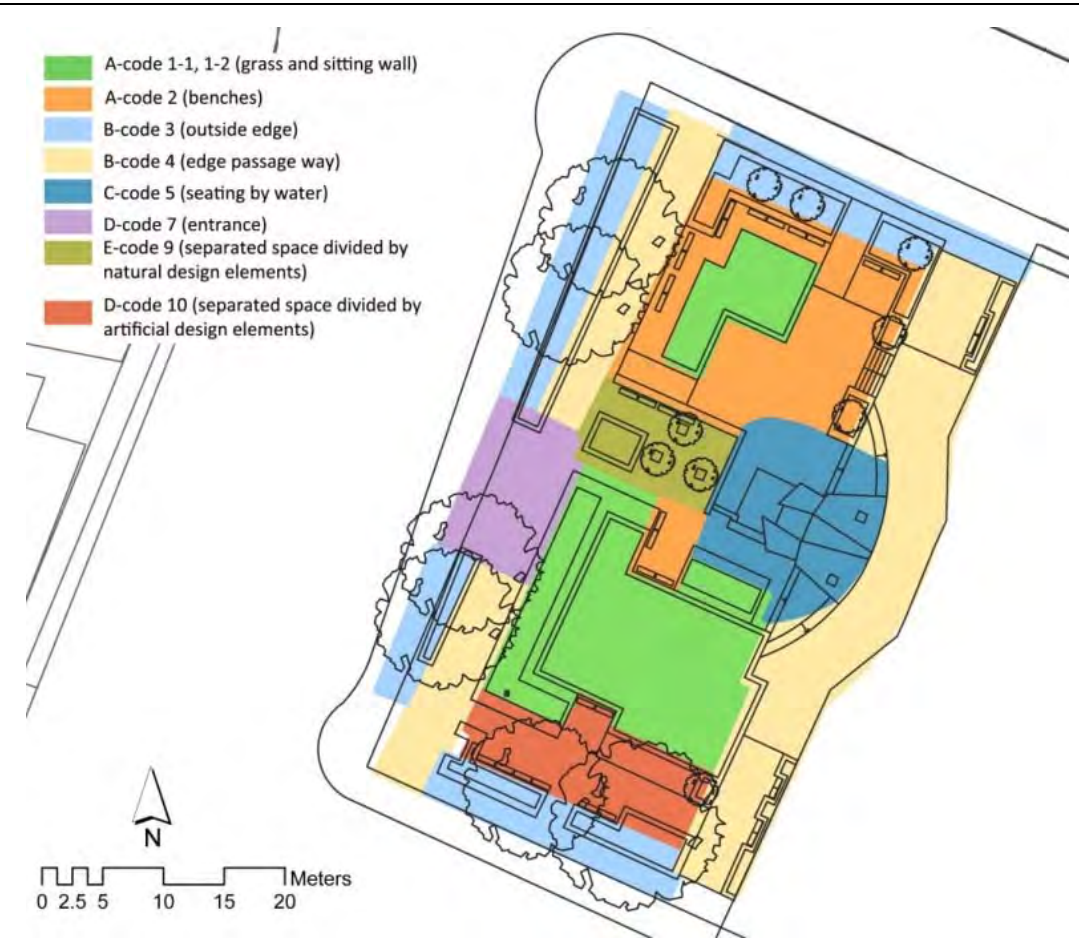

Figure 6-48: Subspaces in Midland Park 


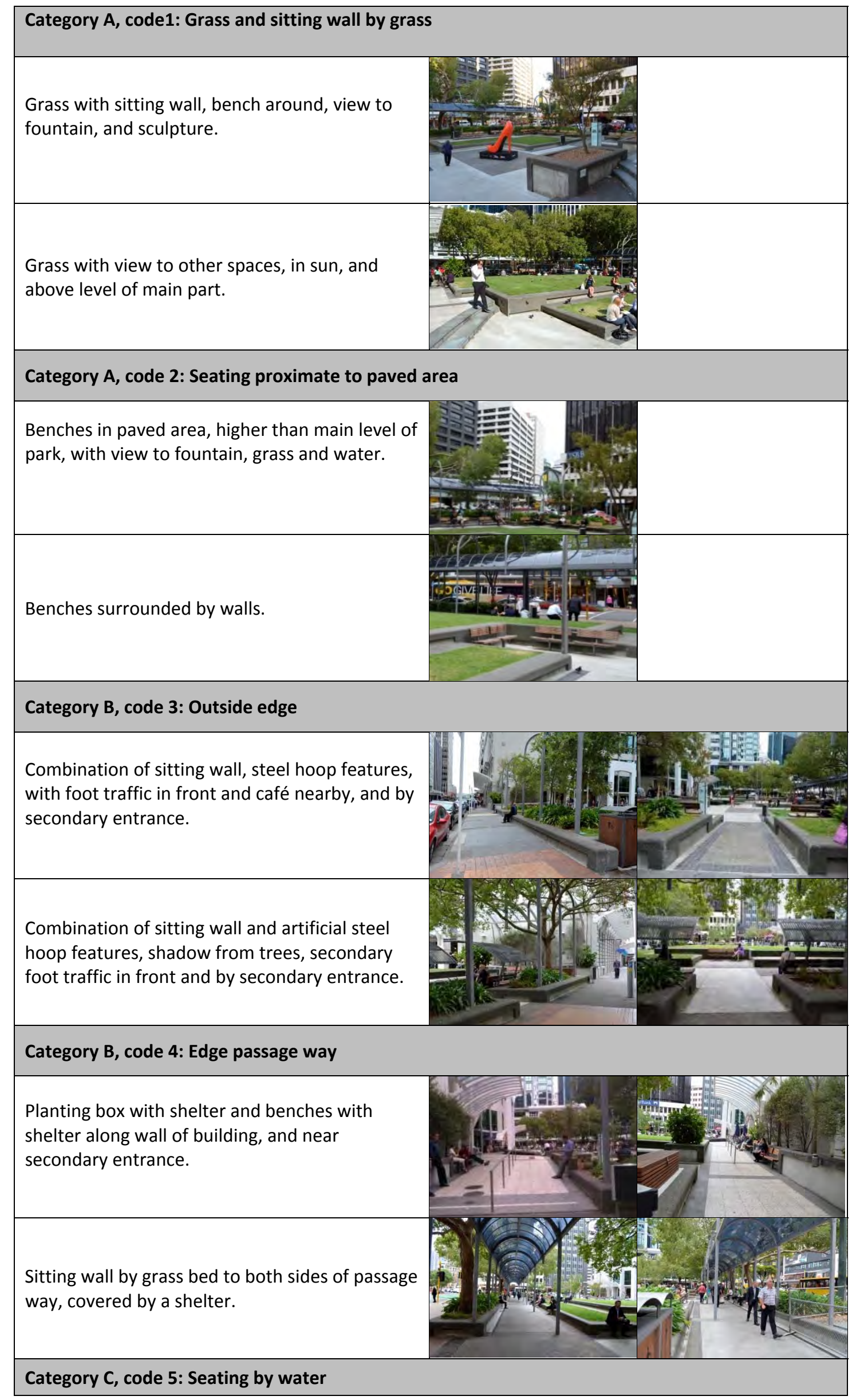




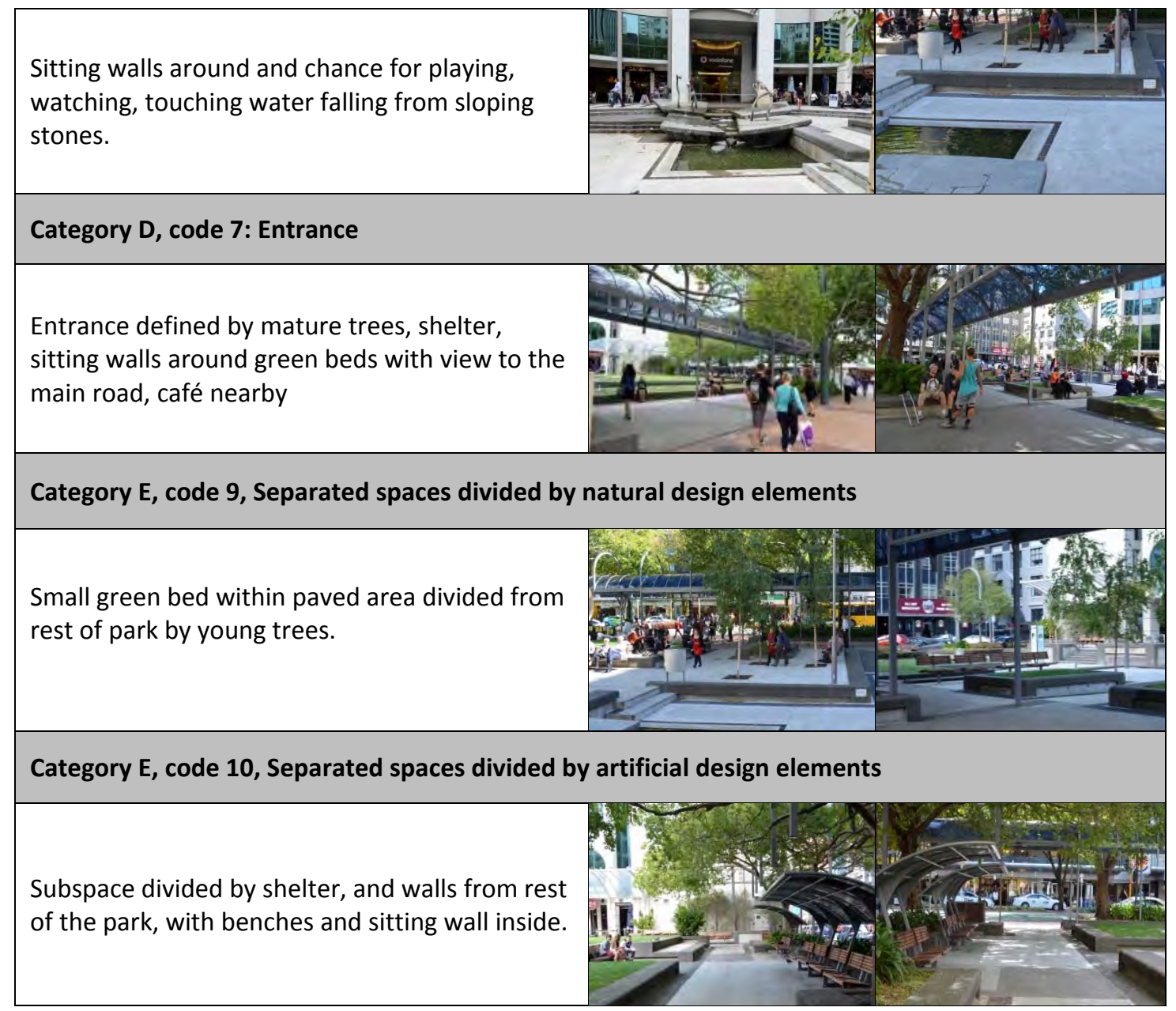

Figure 6-49: Description of subspaces, Midland Park

\subsubsection{Number of Users}

Data were collected in the form of 1000 photos taken in a day between 08.00 and 17.00 (See Appendix 4), showing a total 1404 people used the park that day of which 927 were in groups of one, two, or more persons. The two busiest hours were 12.00-13.00 and 13.00-14.00, with 460, and 341 individual users in these times respectively. There were 143 users between $13.00-14.00$ and 130 between $14.00-15.00$, followed by 119 between 11.00-12.00. The number of users decreased to 83 between $16.00-17.00$ and to 72 between 10.00-11.00, with least users from 08.00-10.00 (Table 6-27). Comparison between subspaces indicates most subspaces follow the pattern of the total use, and have their own maximum occupancy at $12.00-13.00$, with a significant decrease by 14.00 . Sitting wall and edge passage way also had their busiest time of use for the two hours 12.00-14.00. While use of spaces decreased from 14.00-17.00, edge passage way had a second peak at 15.00-16.00. Diagrams on the left of Table 6-27 represent subspace use as 
a percentage of its maximum occupancy $(\mathrm{MO})$ in one hour over the whole day. These diagrams show that while benches, edge passage way, and subspaces divided by natural elements were used during the day, entrances, grass, and outside edge were left vacant in the morning and were less used after the busy periods.

Table 6-27: Number of users during one day of observation, Midland Park

\begin{tabular}{|c|c|c|c|c|c|c|c|c|c|c|c|}
\hline $\begin{array}{l}\text { Subspace use as } \\
\text { percentage of MO over } \\
\text { one day }\end{array}$ & & $\begin{array}{l}08.00- \\
09.00\end{array}$ & $\begin{array}{l}09.00- \\
10.00\end{array}$ & $\begin{array}{l}10.00- \\
11.00\end{array}$ & $\begin{array}{l}11.00- \\
12.00\end{array}$ & $\begin{array}{l}12.00- \\
13.00\end{array}$ & $\begin{array}{l}13.00- \\
14.00\end{array}$ & $\begin{array}{l}14.00- \\
15.00\end{array}$ & $\left|\begin{array}{l}15.00- \\
16.00\end{array}\right|$ & $\begin{array}{l}16.00- \\
17.00\end{array}$ & Total \\
\hline \multirow{2}{*}{ A-code $1-1$} & $N$ & 0 & 0 & 0 & 0 & 18 & 14 & 4 & 4 & 2 & 42 \\
\hline & $P$ & $0.00 \%$ & $0.00 \%$ & $0.00 \%$ & $0.00 \%$ & $100 \%$ & $77.78 \%$ & $22.22 \%$ & $\mid 22.22 \%$ & $11.11 \%$ & $9.13 \%$ \\
\hline \multirow{2}{*}{$\begin{array}{l}\text { A-code 1-2 } \\
100 \\
0\end{array}$} & $N$ & 1 & 6 & 13 & 24 & 101 & 86 & 40 & 13 & 14 & 298 \\
\hline & $\mathrm{p}$ & $0.99 \%$ & $5.94 \%$ & $12.87 \%$ & $23.76 \%$ & $100 \%$ & |85.15\% | & $39.6 \%$ & $12.87 \%$ & $13.86 \%$ & $64.78 \%$ \\
\hline \multirow{2}{*}{ A-code 2} & $N$ & 2 & 9 & 17 & 22 & 60 & 34 & 28 & 26 & 21 & 219 \\
\hline & $P$ & $3.33 \%$ & $15.00 \%$ & $28.33 \%$ & $36.67 \%$ & $100 \%$ & $56.67 \%$ & $46.67 \%$ & $43.33 \% \mid$ & $35.00 \%$ & $22.17 \%$ \\
\hline \multirow{2}{*}{$\begin{array}{l}\text { B-code } 3 \\
100 \\
0\end{array}$} & $N$ & 1 & 1 & 3 & 16 & 44 & 23 & 10 & 10 & 7 & 111 \\
\hline & $P$ & $2.27 \%$ & $2.27 \%$ & $6.82 \%$ & $36.36 \%$ & $100 \%$ & $52.27 \%$ & $27.73 \%$ & $22.73 \%$ & $15.91 \%$ & $25.00 \%$ \\
\hline \multirow{2}{*}{$\begin{array}{l}\text { B-code } 4 \\
100 \\
0\end{array}$} & $N$ & 9 & 12 & 16 & 12 & 72 & 70 & 22 & 43 & 19 & 275 \\
\hline & $P$ & $12.50 \%$ & $16.67 \%$ & $22.22 \%$ & $16.67 \%$ & $100 \%$ & $97.22 \%$ & $30.56 \%$ & $59.72 \%$ & $26.39 \%$ & $47.61 \%$ \\
\hline \multirow{2}{*}{ C-code 5} & $N$ & 4 & 0 & 5 & 9 & 46 & 23 & 5 & 4 & 6 & 102 \\
\hline & $p$ & $8.70 \%$ & $0.00 \%$ & $10.87 \%$ & $19.57 \%$ & $100 \%$ & $50.00 \%$ & $10.87 \%$ & $8.70 \%$ & $13.04 \%$ & $22.17 \%$ \\
\hline \multirow{2}{*}{$\begin{array}{l}\text { D-code } 7 \\
100 \\
0\end{array}$} & $\mathrm{~N}$ & 0 & 0 & 0 & 2 & 20 & 12 & 5 & 3 & 0 & 42 \\
\hline & $P$ & $0.00 \%$ & $0.0 \%$ & $0.00 \%$ & $10.00 \%$ & $100 \%$ & $60.00 \%$ & $25.00 \%$ & $15.00 \%$ & $0.00 \%$ & $9.13 \%$ \\
\hline \multirow{2}{*}{$\begin{array}{l}\text { E-code } 9 \\
100 \\
0\end{array}$} & $\mathrm{~N}$ & 0 & 4 & 9 & 9 & 19 & 25 & 10 & 6 & 7 & 89 \\
\hline & $P$ & $0.00 \%$ & $16.00 \%$ & $36.00 \%$ & $36.00 \%$ & $76.00 \%$ & $100 \%$ & $40.00 \%$ & $24.00 \%$ & $28.00 \%$ & $19.25 \%$ \\
\hline \multirow[t]{2}{*}{$\begin{array}{l}\text { E-code } 10 \\
100 \\
0\end{array}$} & $N$ & 3 & 4 & 9 & 25 & 80 & 54 & 19 & 21 & 7 & 222 \\
\hline & P & $3.75 \%$ & $5.00 \%$ & $11.25 \%$ & $31.25 \%$ & $100 \%$ & $67.5 \%$ & $23.75 \%$ & $26.25 \%$ & $8.75 \%$ & $48.26 \%$ \\
\hline \multirow{2}{*}{$\begin{array}{l}\text { Total Park } \\
100 \\
0\end{array}$} & $N$ & 20 & 36 & 72 & 119 & 460 & 341 & 143 & 130 & 83 & 1404 \\
\hline & $P$ & $4.35 \%$ & $7.83 \%$ & $15.65 \%$ & $25.87 \%$ & $100 \%$ & $74.13 \%$ & $31.09 \%$ & $28.26 \%$ & $18.04 \%$ & \\
\hline \multicolumn{2}{|c|}{$\begin{array}{l}\text { M-O: Maximum occupancy MO } \\
\mathrm{N} \text { : Number of users } \\
\mathrm{P} \text { : Percentage of } \mathrm{MO}\end{array}$} & 100 & $\%$ & $80 \%$ & $80-60 \%$ & & $-40 \%$ & $40-20 \%$ & $20-0 \%$ & & $\%$ \\
\hline
\end{tabular}

\subsubsection{Occupancy and Preferences}

The pattern of occupancy during the day shows sitting walls, edge passage way and 
separate spaces divided by artificial design elements, and benches in paved areas were used most. While outside edges and separate space divided by trees were also used, entrance and grass were less preferred. The occupancy map also shows that outside edge looking at a busy street and grass surrounded by benches were used the least (Figure 650).

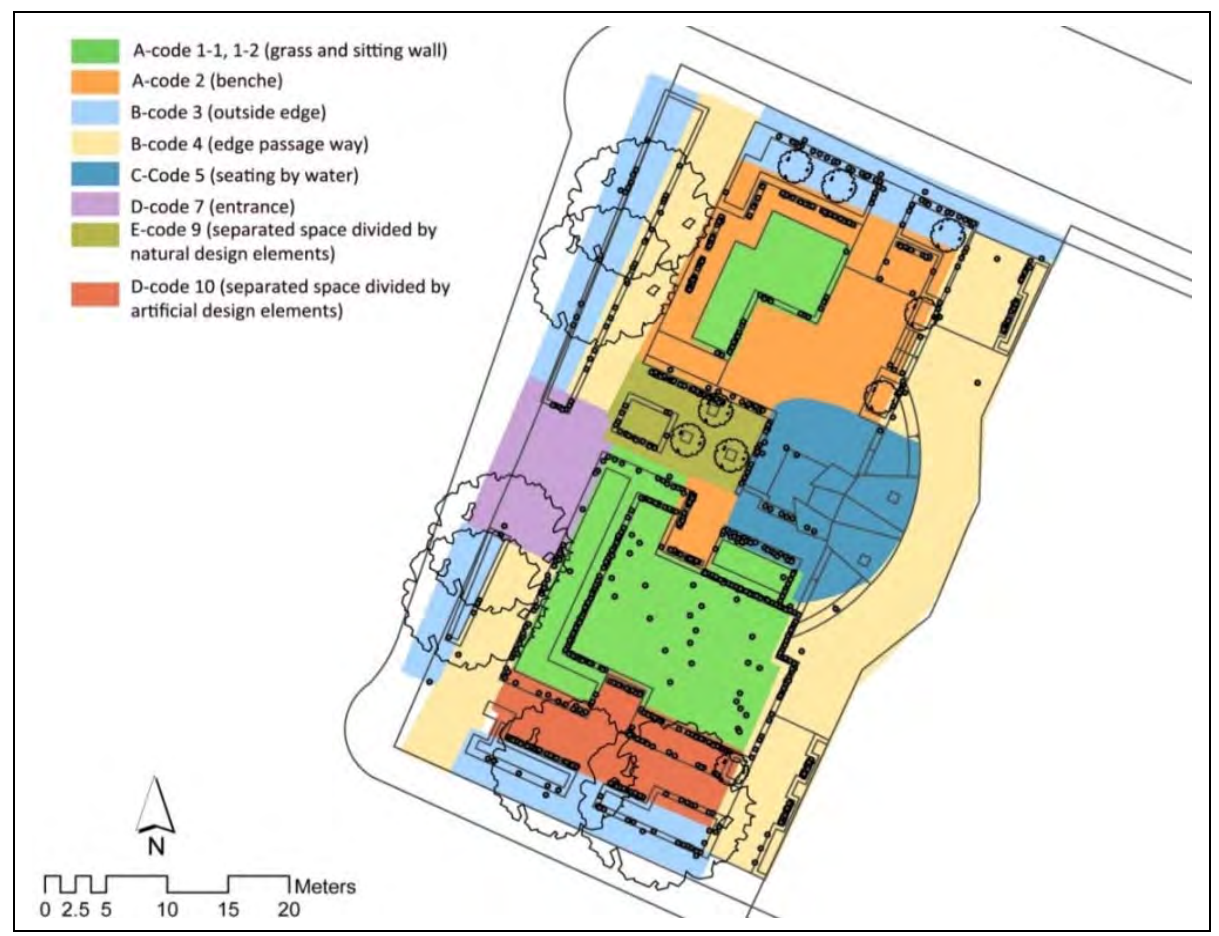

Figure 6-50: Map of occupancy during one day, Midland Park

Early use of space shows edge passage way in sun and separated space divided by natural and artificial elements were preferred (Figures 6-51.1, 6-51.2). From 10.00-11.00 sitting wall by the secondary road started to be occupied (Figure 6-51.3) and from 11.00-12.00 outside edges looking at secondary roads and sitting walls and benches started to be used (Figure 6-51.4). At midday almost all subspaces except entrance, outside edge looking at busy road, and grass areas on the north side were well used (Figure 6-51.5). This pattern continued for 13.00-14.00 (Figure 6-51.6). From 14.00-15.00 while most spaces were occupied, outside edge, entrance, and edge passage way were virtually vacant (Figure 651.7 to 6-51.9). In addition, from 14.00 onwards sitting walls also started to have fewer users. The map of the last hour of observation shows grass and sitting wall on the west side, edge passage way in the sun and separated space were preferred (Figure 6-51.9). 


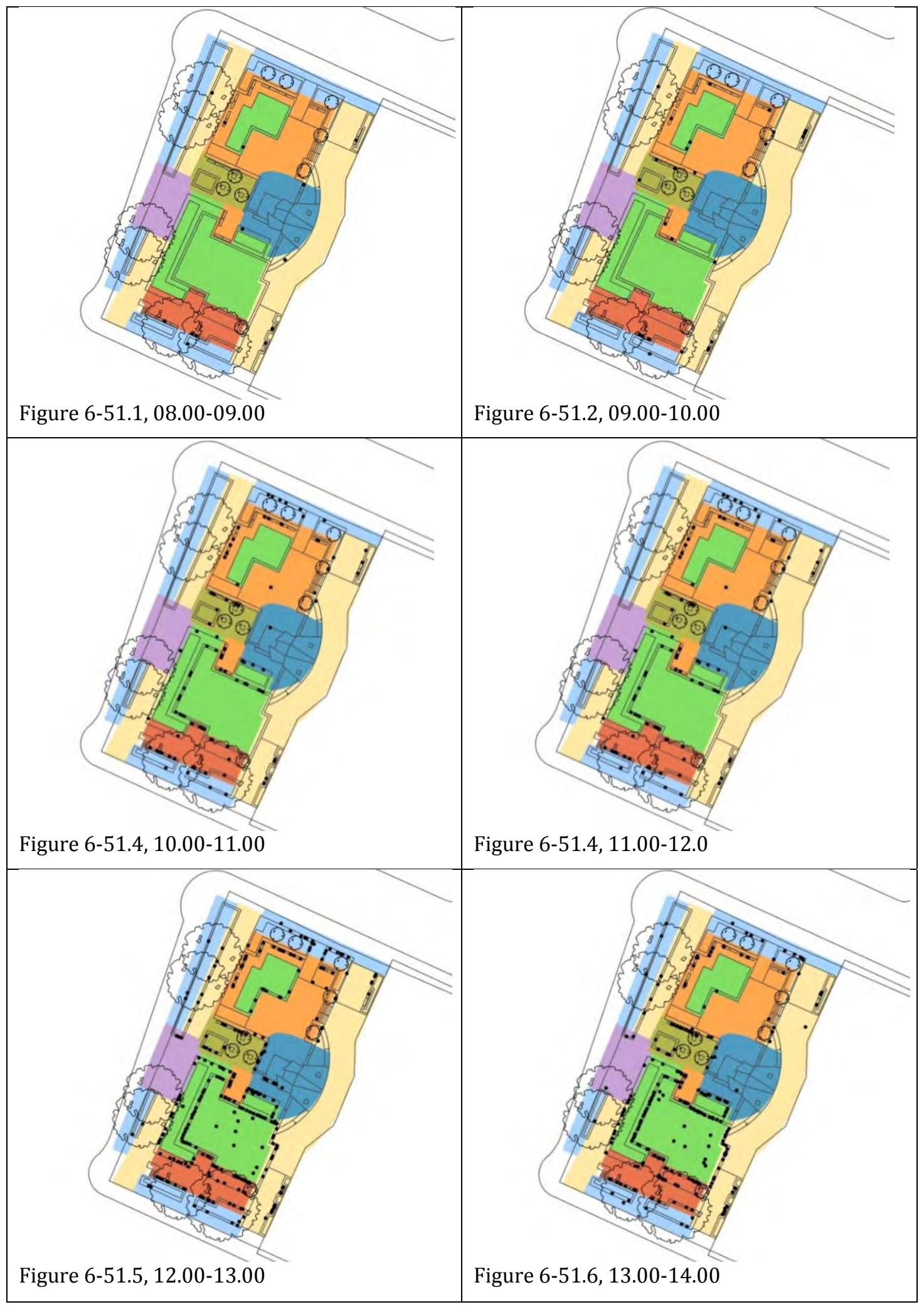




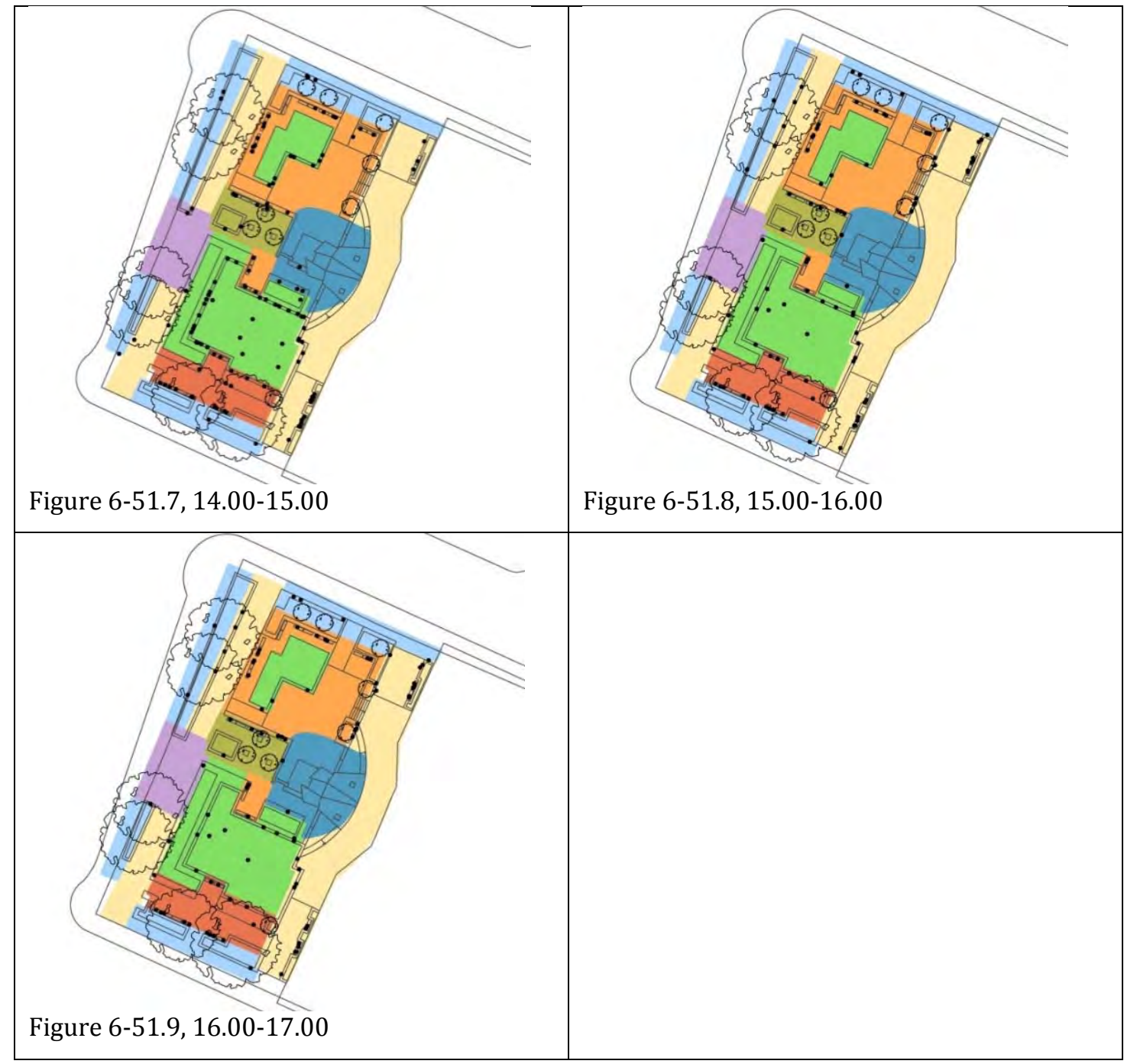

Figure 6-51: Hourly occupancy maps, Midland Park

\subsubsection{Size of Group}

Most use was by people in a group of two $(49.57 \%)$ or people alone $(37.18 \%)$, with groups of three, four, five and six people making up the remaining $13.25 \%$.

The percentage of people alone as part of total occupancy $\left(T^{*} 100 / A\right)$ for each subspace during the day demonstrates that in all subspaces the number of people in groups is more than people alone. However, the difference between number of people alone in separated space divided by artificial design elements, benches, outside edge, and edge passage way, is not significant (Table 6-28). 
Table 6-28: Use of subspaces by people alone and in groups

\begin{tabular}{|c|c|c|c|c|c|c|c|c|c|c|c|c|}
\hline & & $\begin{array}{c}08.00- \\
09.00 \\
\end{array}$ & $\begin{array}{c}09.00- \\
10.00 \\
\end{array}$ & $\begin{array}{l}10.00- \\
11.00\end{array}$ & $\begin{array}{l}11.00- \\
12.00\end{array}$ & $\begin{array}{c}12.00- \\
13.00\end{array}$ & $\begin{array}{l}13.00- \\
14.00\end{array}$ & $\begin{array}{l}14.00- \\
15.00\end{array}$ & $\begin{array}{c}15.00- \\
16.00\end{array}$ & $\begin{array}{c}16.00- \\
17.00 \\
\end{array}$ & $T$ & $\mathbf{P}$ \\
\hline \multirow{3}{*}{ A-code $1-1$} & A & 0 & 0 & 0 & 0 & 4 & 6 & 1. & 2 & 0 & 13 & $30.95 \%$ \\
\hline & G & 0 & 0 & 0 & 0 & 1 & 8 & 3 & 2 & 2 & 29 & $69.05 \%$ \\
\hline & $\mid \mathrm{T}$ & 0 & 0 & 0 & 0 & 5 & 14 & 4 & 4 & 2 & 42 & $100 \%$ \\
\hline \multirow{3}{*}{ A-code $1-2$} & A & 1 & 1 & 3 & 16 & 24 & 25 & 18 & 5 & 5. & 98 & $32.89 \%$ \\
\hline & G & 0 & 5 & 10 & 8 & 77 & 61 & 22 & 8 & 9 & 200 & $67.11 \%$ \\
\hline & $\mathrm{T}$ & 1 & 6 & 13 & 24 & 101 & 86 & 40 & 13 & 14 & 298 & $100 \%$ \\
\hline \multirow{3}{*}{ A-code 2} & A & 0 & 5 & 7 & 13 & 17 & 17 & 14 & 12 & 8 & 93 & $42.47 \%$ \\
\hline & G & 2 & 4 & 10 & 9 & 43 & 17 & 14 & 14 & 13 & 126 & $57.53 \%$ \\
\hline & $\mathrm{T}$ & 2 & 9 & 17 & 22 & 60 & 34 & 28 & 26 & 21 & 219 & $100 \%$ \\
\hline \multirow{3}{*}{ B-code 3} & A & 1 & 1 & 1 & 6 & 16 & 10 & 6 & 5 & 5 & 51 & $44.35 \%$ \\
\hline & G & 0 & 0 & 2 & 10 & 28 & 13 & 4 & 5 & 2 & 64 & $55.65 \%$ \\
\hline & $\mathrm{T}$ & 1 & 1 & 3 & 16 & 44 & 23 & 10 & 10 & 7 & 115 & $100 \%$ \\
\hline \multirow{3}{*}{ B-code 4} & A & 1 & 6 & 9 & 10 & 28 & 22 & 16 & 20 & 7 & 119 & $43.27 \%$ \\
\hline & G & 8 & 6 & 10 & 2 & 44 & 48 & 6 & 23 & 12 & 156 & $56.73 \%$ \\
\hline & $T$ & 9 & 12 & 16 & 12 & 72 & 70 & 22 & 43 & 19 & 275 & $100 \%$ \\
\hline \multirow{3}{*}{ C-code 5} & A & 0. & 0 & 2 & 2 & 9 & 7 & 3 & 0 & 0 & 23 & $22.55 \%$ \\
\hline & G & 4. & 0 & 3 & 7 & 37 & 16 & 2 & 4 & 6 & 79 & $77.5 \%$ \\
\hline & $T$ & 4 & 0 & 5 & 9 & 46 & 23 & 5 & 4 & 6 & 102 & $100 \%$ \\
\hline \multirow{3}{*}{ D-code 7} & A & 0 & 0 & 0 & 0 & 3 & 2 & 1 & 1 & 0 & 7 & $16.67 \%$ \\
\hline & G & 0 & 0 & 0 & 2 & 17 & 10 & 4 & 2 & 0 & 35 & $83.33 \%$ \\
\hline & $\mathrm{T}$ & 0 & 0 & 0 & 2 & 20 & 12 & 5 & 3 & 0 & 42 & $100 \%$ \\
\hline \multirow{3}{*}{ E-code 9} & A & 0 & 2 & 2 & 5 & 5 & 3 & 4 & 2 & 3 & 26 & $29.21 \%$ \\
\hline & G & 0 & 2 & 7 & 4 & 14 & 22 & 6 & 4 & 4 & 63 & $70.79 \%$ \\
\hline & $T$ & 0 & 4 & 9 & 9 & 19 & 25 & 10 & 6 & 7 & 89 & $100 \%$ \\
\hline \multirow{3}{*}{ E-code 10} & A & 3 & 4 & 7 & 13 & 21 & 17 & 12 & 8 & 7 & 92 & $41.44 \%$ \\
\hline & G & 0 & 0 & 2 & 12 & 59 & 17 & 7 & 13 & 0 & 130 & $58.56 \%$ \\
\hline & $\mathrm{T}$ & 3. & 4 & 9 & 25 & 80 & 54 & 19 & 21 & 7 & 222 & $100 \%$ \\
\hline \multicolumn{9}{|c|}{ T: Total P: \% of total A: Alone G: Groups } & \multicolumn{3}{|c|}{ Max ocupancy } & Vacant \\
\hline
\end{tabular}

Hourly comparison of number of people alone and in groups shows that for $12.00-13.00$ grass attracted more people alone and was only used by groups during $16.00-17.00$ (Figure 6-52.1). Sitting walls were occupied more by people in groups than alone, and the difference between these at the two busiest times is large (Figure 6-52.2). Unlike these two subspaces, seating was used almost equally by people alone and in groups over the day (Figure 6-52.3). Outside edge, except between 11.00-14.00 (lunch time), was always occupied more by people alone than in groups (Figure 6-52.4). Edge passage way attracted more groups than people alone, significantly between 08.00-09.00, at lunch time and 16.00-17.00, with a reverse pattern between 11.00-12.00 and 14.00-15.00 (Figure 6-52.5). Seating by water was prefered by groups over the day (Figure 6-52.6). Entrance was the least popular place but was well used for the two busiest hours. mostly by people in groups (Figure 6-52.7). 


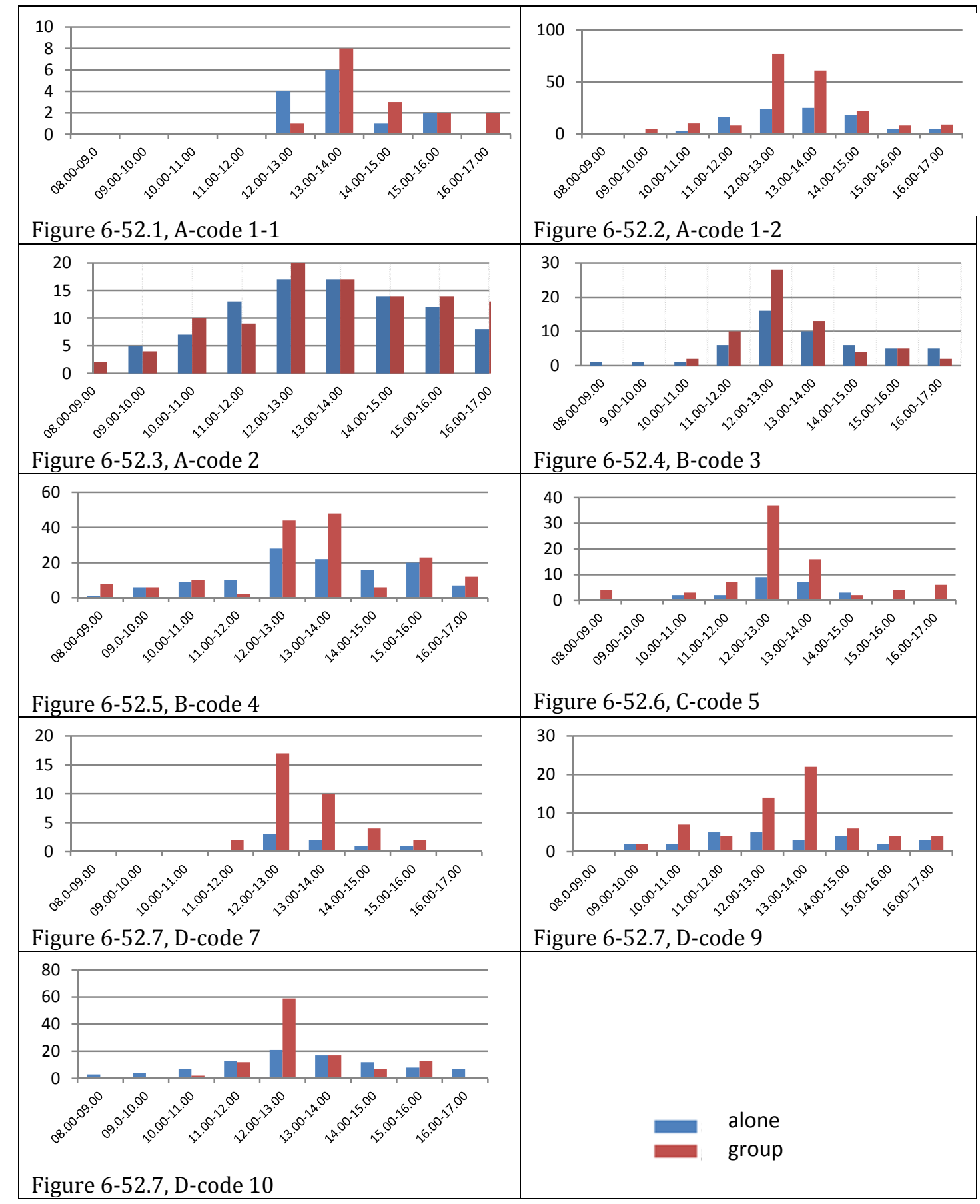

Figure 6-52: Comparison between people alone and in groups

The percentage of people alone as part of the maximum occupancy of each of subspace during the day illustrates that in all subspaces there are more groups than people alone. Over the day less than $30 \%$ of maximum occupancy is people alone (Figures 6-53.1 to 653.9). Except for sitting walls (Figure 6-53.2) and space separated by natural design elements (Figure 6-53.8) the pattern of subspace use by people alone follows the pattern of total use. Use of sitting wall by grass by people alone is more sustained than for total use of sitting wall. Occupancy started from 10.00-11.00, but experienced a smoother 
growth in number of users than did total use over the day (Figure 6-53.2). The number of people alone using separated space divided by natural elements increased from 8.00 12.00 and, with some fluctuation, started at around $20 \%$ of maximum occupancy (Figure 6-53.7). In all subspaces people alone have maximum occupancy between $12.00-13.00$ with a sharp decrease after that. However edge passageway has two peaks between 12.00-13.00 and 15.00-16.00 (Figure 6-53.5).

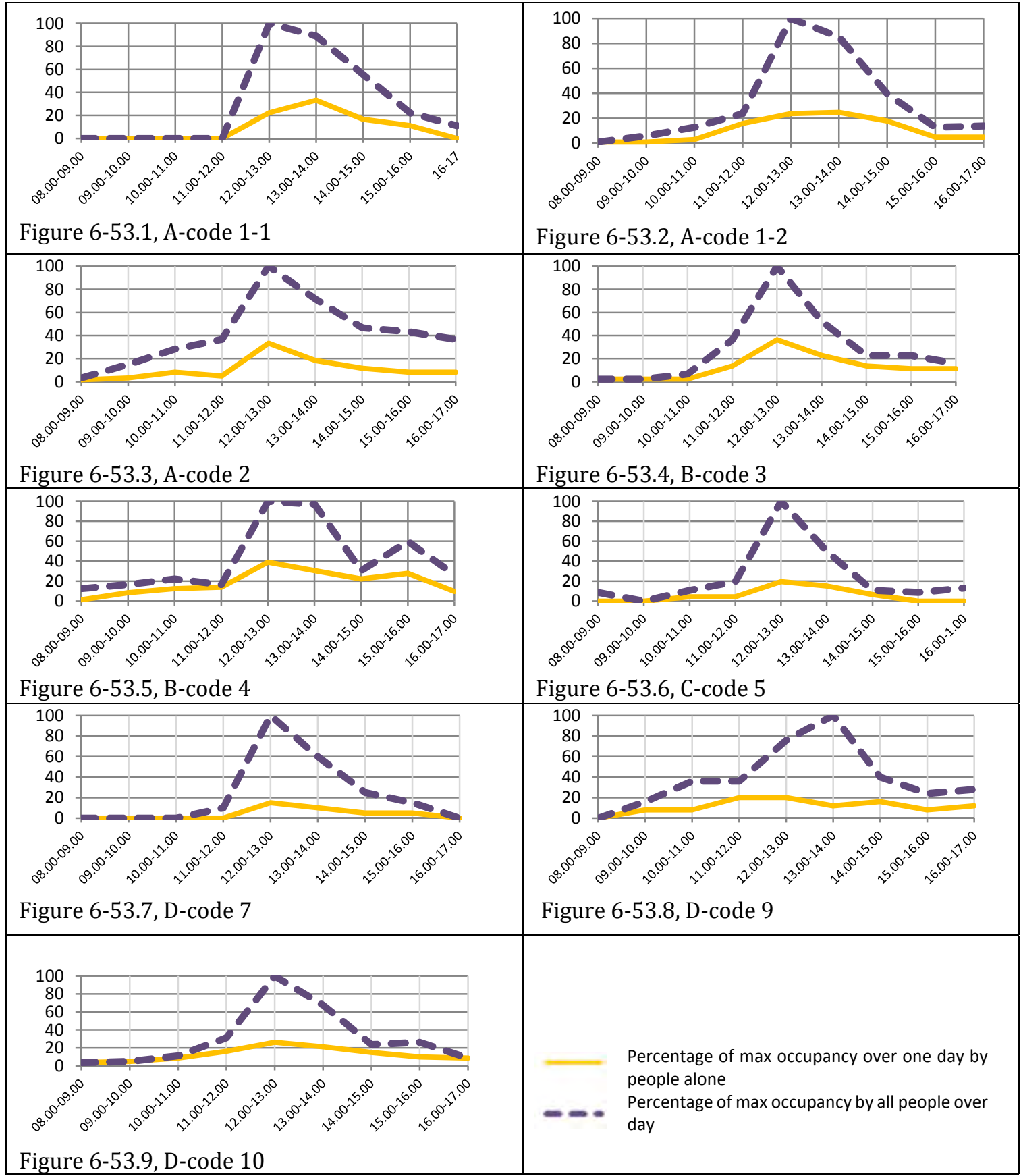

Figure 6-53: Percentage of maximum occupancy by people alone, Midland Park, no repeat counting

The separate occupancy maps for people alone and in groups (Figure 6-54) do not show any big differences. However groups used grass more than people alone. 


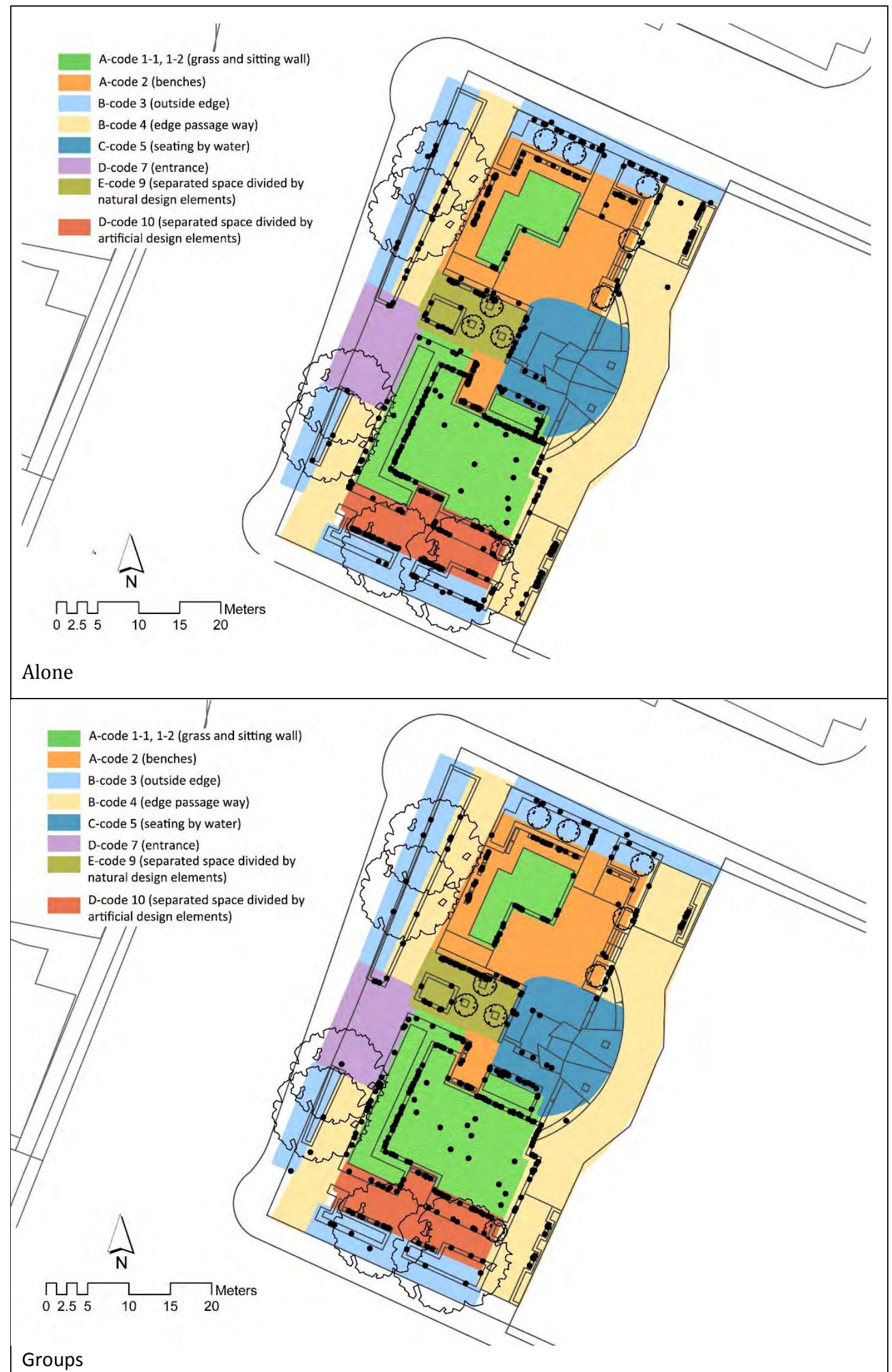

Figure 6-54: Map of occupancy by people alone and groups, Midland Park

Comparison between subspaces in terms of group size shows that the larger groups were 
seen in outside edge, edge passage way, and separated spaces divided by artificial design elements. Other subspaces were occupied by people alone or by groups of two or three (Table 6-29). While benches were only occupied by people alone or groups of two, grass and entrance were more occupied by groups of three than other subspaces (Figure 6-55).

Table 6-29: Size of group and use of subspaces, Midland Park

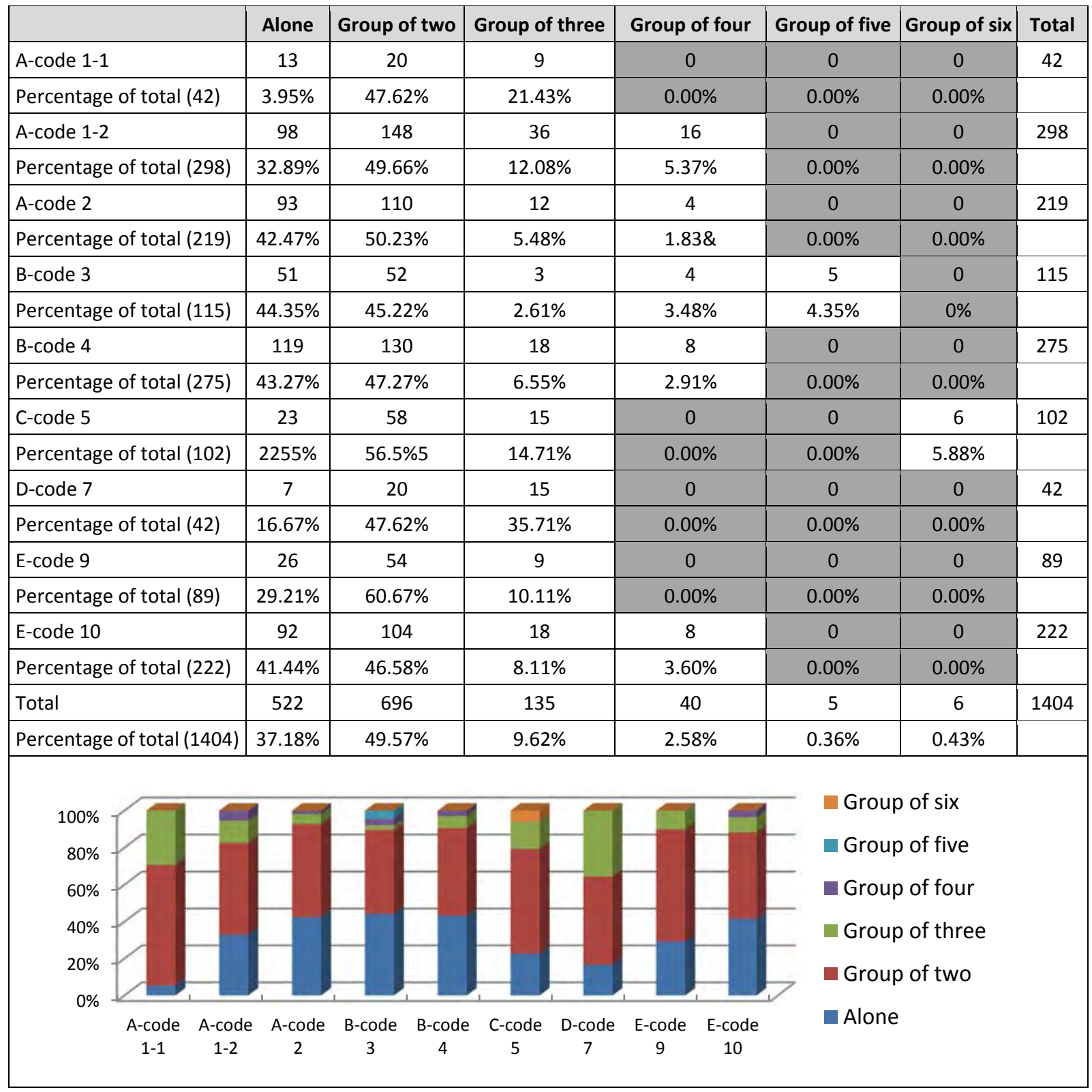




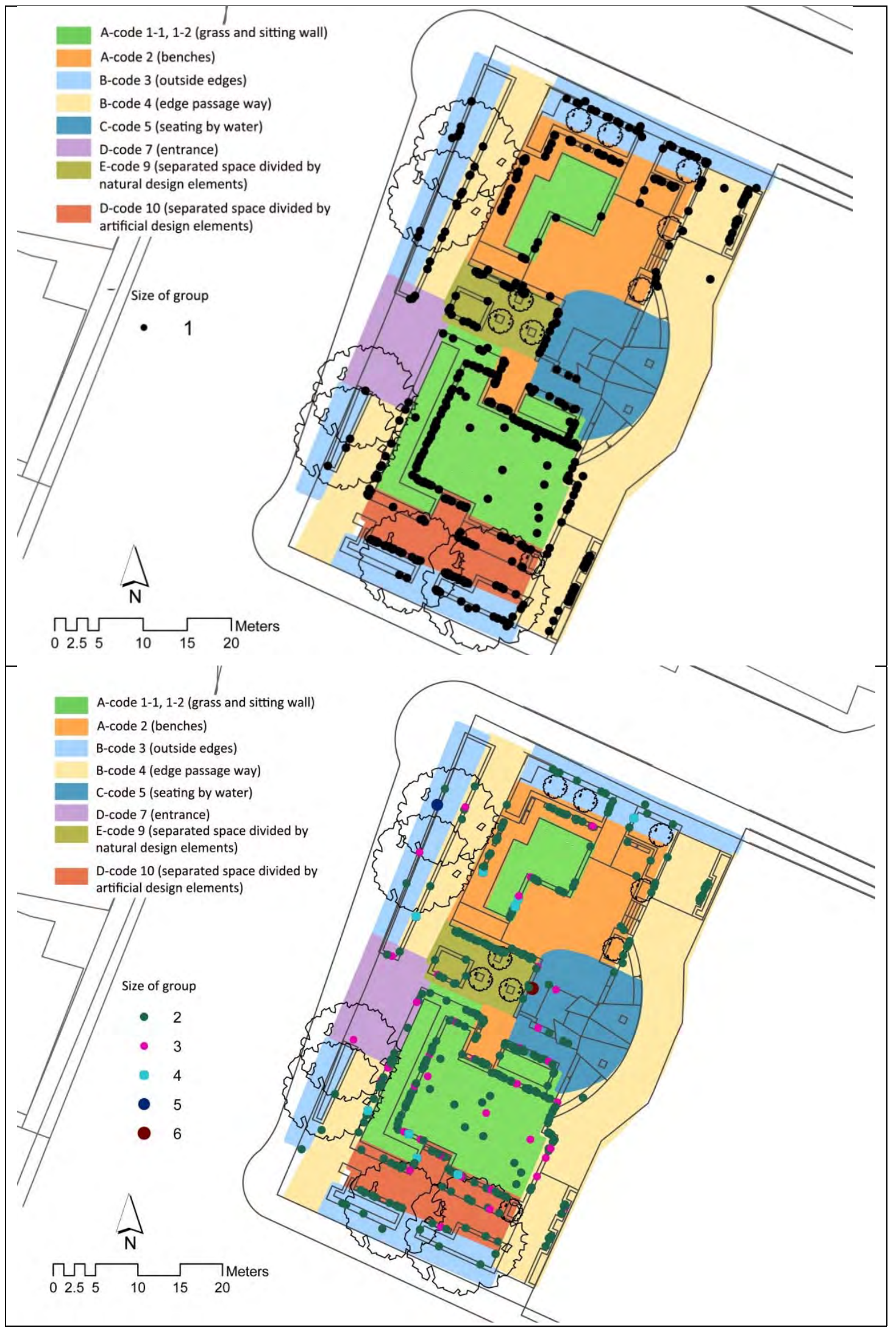

Figure 6-55: Occupancy map based on size of group 


\subsubsection{Use by Age and Gender}

Analysis of photographs shows young adults and adults make up $71.36 \%$ of users, teenagers $24.43 \%$, and retired people and children account for $4.92 \%$. Females and males were seen in equal numbers. Grass is mostly used by teenagers and young adults. Sitting wall, seating by water and separated space divided by artificial elements were used most by young adults. Edge passageway and outside edge attracted adults and young adults in the same quantity. Entrance was used most by teenagers and young adults (Table 6-30).

Table 6-30: Number of users by age and gender

\begin{tabular}{|c|c|c|c|c|c|c|c|c|c|c|c|c|c|}
\hline & \multirow[t]{2}{*}{ Child } & \multicolumn{3}{|c|}{ Teenager } & \multicolumn{3}{|c|}{ Young Adult } & \multicolumn{3}{|c|}{ Adult } & \multicolumn{3}{|c|}{ Retired } \\
\hline & & Male & Female & Total & Male & Female & Total & Male & Female & Total & Male & Female & Total \\
\hline A-code 1-1 & 1 & 9 & 17 & 26 & 5 & 6 & 11 & 2 & 2 & 4 & 0 & 0 & 0 \\
\hline A-code 1-2 & 7 & 35 & 46 & 81 & 59 & 66 & 125 & 42 & 39 & 81 & 2 & 2 & 4 \\
\hline A-code 2 & 7 & 13 & 28 & 41 & 38 & 30 & 68 & 49 & 49 & 98 & 3 & 2 & 5 \\
\hline B-code 3 & 2 & 5 & 13 & 18 & 23 & 22 & 45 & 22 & 27 & 49 & 0 & 1 & 1 \\
\hline B-code 4 & 4 & 17 & 44 & 61 & 42 & 60 & 102 & 39 & 60 & 99 & 7 & 2 & 9 \\
\hline C-code 5 & 7 & 3 & 15 & 18 & 27 & 21 & 48 & 18 & 11 & 29 & 0 & 0 & 0 \\
\hline D-code7 & 1 & 10 & 7 & 17 & 9 & 7 & 16 & 3 & 5 & 8 & 0 & 0 & 0 \\
\hline E-code 9 & 0 & 8 & 14 & 22 & 14 & 14 & 28 & 19 & 17 & 36 & 0 & 3 & 3 \\
\hline E-code 10 & 2 & 16 & 43 & 59 & 48 & 53 & 101 & 37 & 17 & 54 & 4 & 2 & 6 \\
\hline Total & 31 & 116 & 227 & 343 & 265 & 279 & 544 & 231 & 227 & 458 & 16 & 12 & 28 \\
\hline \multirow[t]{2}{*}{$\begin{array}{l}\text { Percentage of } \\
\text { total (1404) }\end{array}$} & $2.21 \%$ & $8.26 \%$ & $16.17 \%$ & $24.43 \%$ & $18.87 \%$ & $19.87 \%$ & $38.74 \%$ & $16.45 \%$ & $16.17 \%$ & $32.62 \%$ & $1.14 \%$ & $0.85 \%$ & $1.99 \%$ \\
\hline & & \multicolumn{3}{|c|}{$24.43 \%$} & \multicolumn{6}{|c|}{$71.36 \%$} & & & \\
\hline
\end{tabular}

Use of subspaces by people alone and in groups by gender indicates that females alone and in groups use the park more than males (Table 6-31), while there are more males in mixed groups than females. The preferred subspaces for being alone are generally similar for both genders (Figures 6-56, 6-60, Table 6-31). There are fewer male groups than female groups (Figure 6-57, 6-60, Table 6-31). The order of preferred subspaces for males alone and in groups is similar. An equal number of males alone and in groups use grass and, except for entrance, males alone use all subspaces more than males in groups (Table 6-31, Figures 6-58, 6-60). No difference was seen between females alone and in groups for all subspaces (Table 6-31, Figures 6-59, 6-60). Mixed groups were observed using sitting wall, benches and passageway, followed by separated space divided by artificial elements (Table 6-31). 
Table 6-31: Number of groups in subspaces by gender

\begin{tabular}{|l|l|l|l|l|l|l|}
\hline & Male alone & Female alone & Female group & Male group & Mixed group & Total \\
\hline A-code 1-1 & 4 & 9 & 9 & 7 & 13 & 42 \\
\hline A-code 1-2 & 48 & 50 & 65 & 50 & 85 & 298 \\
\hline A-code 2 & 48 & 45 & 28 & 22 & 76 & 219 \\
\hline B-code 3 & 24 & 27 & 23 & 13 & 28 & 115 \\
\hline B-code 4 & 51 & 68 & 66 & 29 & 61 & 275 \\
\hline C-code 5 & 15 & 8 & 24 & 18 & 37 & 102 \\
\hline D-code7 & 2 & 5 & 9 & 16 & 10 & 42 \\
\hline E-code 9 & 13 & 13 & 25 & 18 & 20 & 89 \\
\hline E-code 10 & 47 & 45 & 36 & 23 & 71 & 222 \\
\hline Total & 252 & 270 & 285 & 196 & 401 & 1404 \\
\hline
\end{tabular}

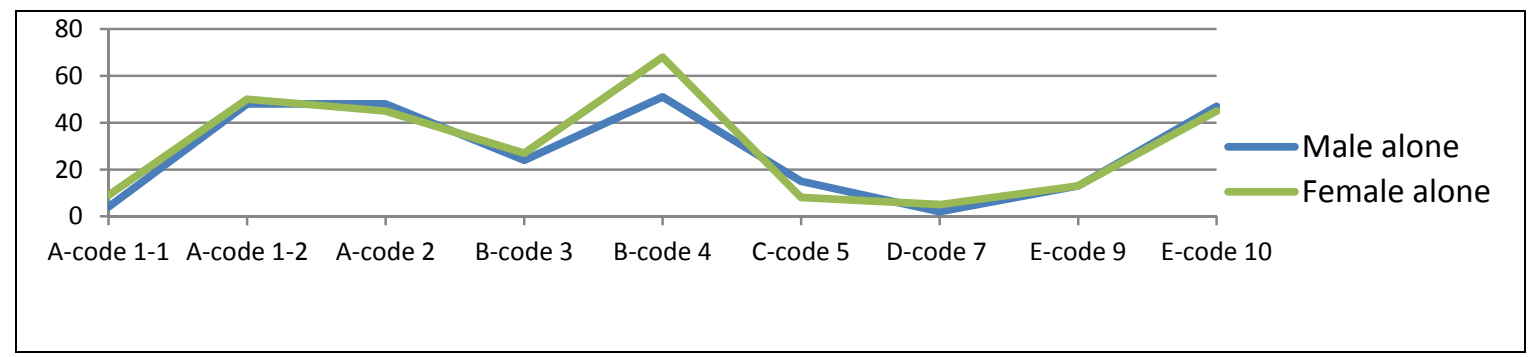

Figure 6-56: Male and female preferences when alone

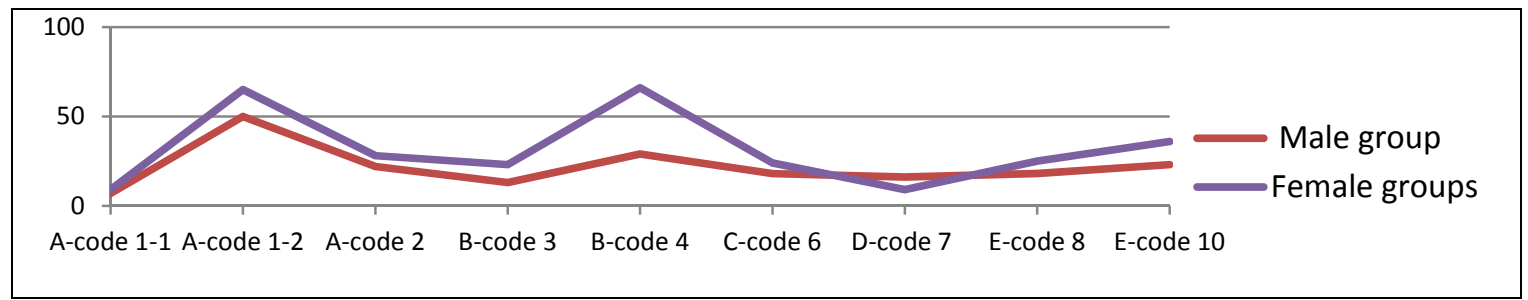

Figure 6-57: Male and female group preferences

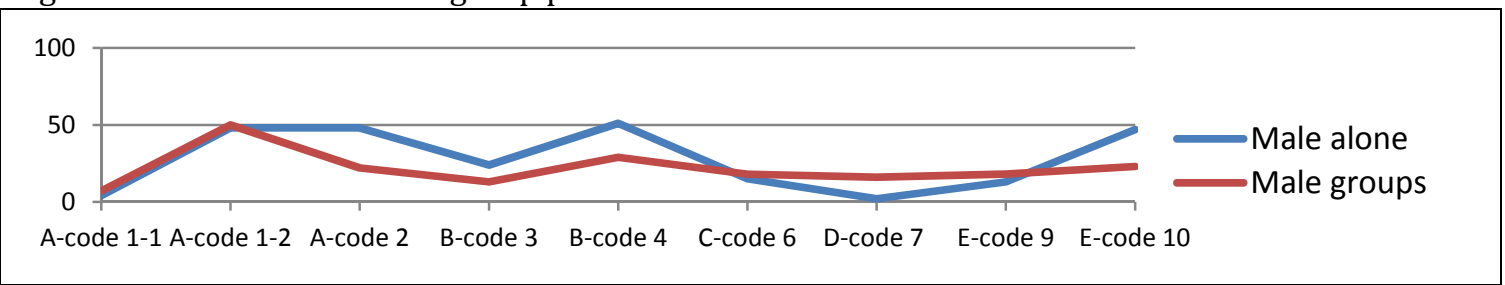

Figure 6-58: Preferences for males alone and in groups

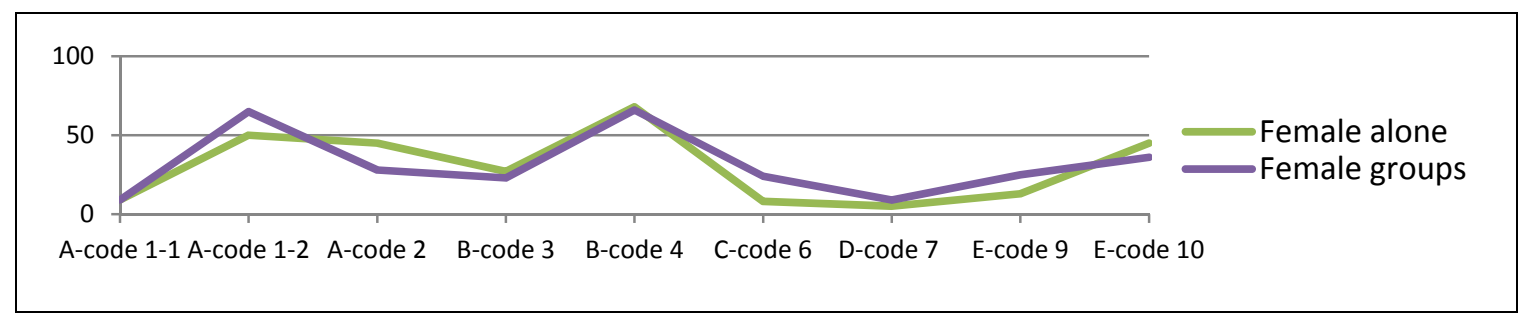

Figure 6-59: Preferences for females alone and in groups 


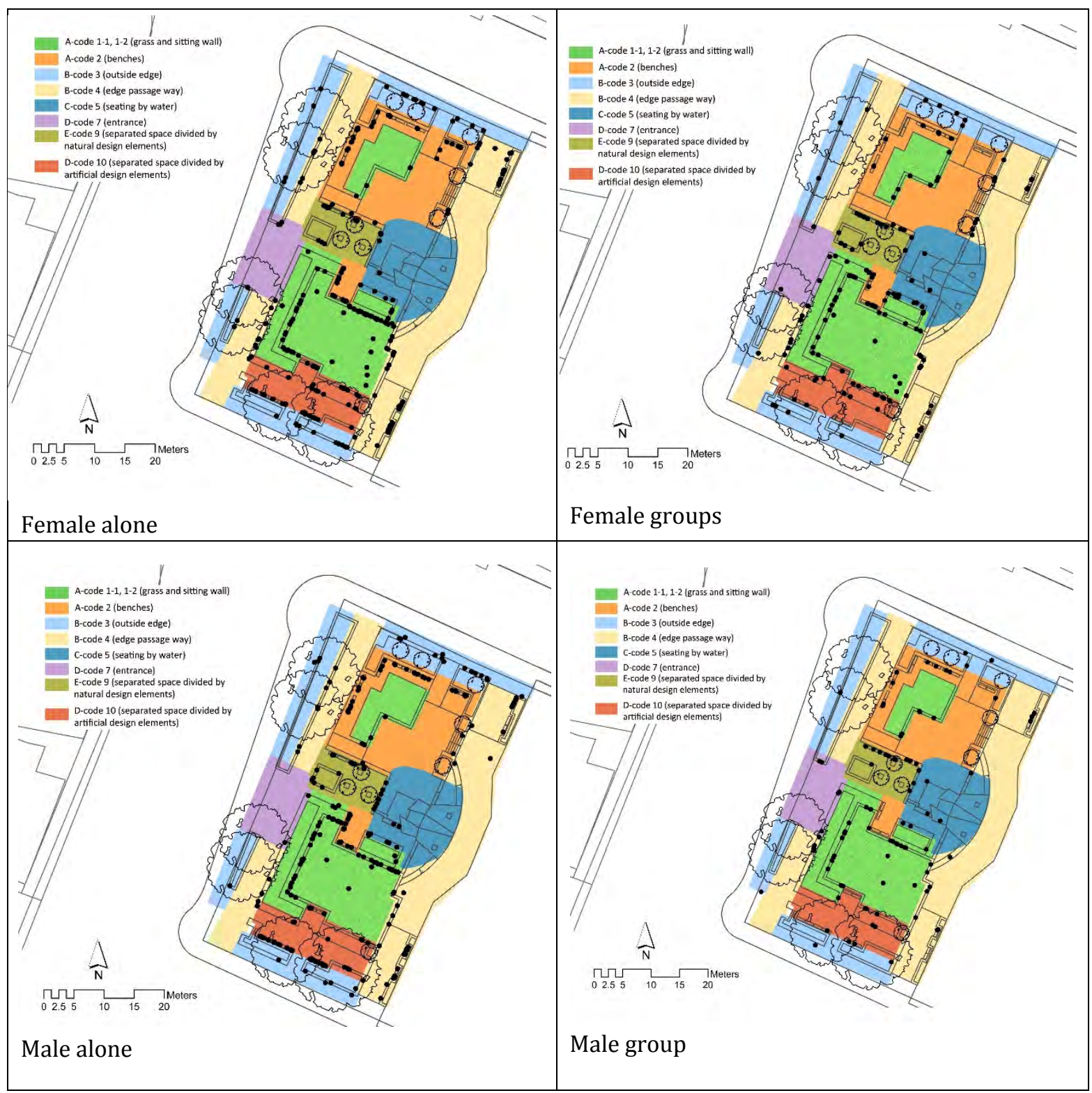

Figure 6-60: Map of occupancy for people alone and in groups by gender

\subsubsection{Activity}

Activities recorded for each group show Midland Park is mostly used for sitting and eating, sitting, and sitting and using a mobile phone. Sitting and reading or smoking and standing were observed less. Other activities like standing and using a mobile phone or smoking were also observed. A few instances of lying and playing were also seen (Table 6-31). 
Table 6-32: Type of activity by people alone and in groups

\begin{tabular}{|l|c|c|c|l|c|c|c|}
\hline \multicolumn{1}{|c|}{ Type of activity } & \multicolumn{3}{c|}{ Number } & \multicolumn{2}{c|}{ Type of activity } & \multicolumn{3}{c|}{ Number } \\
\hline & Alone & Group & Total & & Alone & Group & Total \\
\hline Sitting & 131 & 157 & 288 & Seating - eating- smoking & 1 & 3 & 4 \\
\hline Sitting - eating & 139 & 204 & 343 & Standing & 10 & 17 & 27 \\
\hline Sitting - using mobile & 130 & 6 & 136 & Standing - smoking & 9 & 1 & 10 \\
\hline Sitting - smoking & 33 & 11 & 44 & Standing - using mobile phone & 8 & 1 & 9 \\
\hline Sitting - reading & 51 & 3 & 54 & Lying & 2 & 0 & 2 \\
\hline Sitting - eating - reading & 2 & 1 & 3 & Playing & 1 & 1 & 2 \\
\hline Sitting - eating - using mobile & 5 & 0 & 5 & & & & \\
\hline
\end{tabular}

People in groups make more use of Midland Park for sitting and eating, sitting and standing, while sitting and smoking or using a mobile phone and standing and smoking were observed for people alone.

In terms of diversity of activities in subspaces, sitting wall, edge passageway, benches, and outside edge afforded more activities, with similar activity levels in the other subspaces (Table 6-33).

Table 6-33: Activity in subspaces

\begin{tabular}{|c|c|c|c|c|c|c|c|c|c|c|c|c|c|c|c|c|c|c|c|}
\hline & \multicolumn{2}{|c|}{$\begin{array}{c}\text { A-code } \\
1-1\end{array}$} & \multicolumn{2}{|c|}{$\begin{array}{c}\text { A-code } \\
1-2\end{array}$} & \multicolumn{2}{|c|}{$\begin{array}{c}\text { A-code } \\
2\end{array}$} & \multicolumn{2}{|c|}{$\begin{array}{c}\text { B-code } \\
3\end{array}$} & \multicolumn{2}{|c|}{$\begin{array}{c}\text { B-code } \\
4\end{array}$} & \multicolumn{2}{|c|}{$\begin{array}{c}\text { C-code } \\
5\end{array}$} & \multicolumn{2}{|c|}{$\begin{array}{c}\text { D-code } \\
7\end{array}$} & \multicolumn{2}{|c|}{$\begin{array}{c}\text { E-code } \\
9\end{array}$} & \multicolumn{2}{|c|}{$\begin{array}{c}\text { E-code } \\
10\end{array}$} & \multirow[t]{2}{*}{ Total } \\
\hline & $\mathbf{N}$ & $\mathbf{P}$ & $\mathbf{N}$ & $\mathbf{P}$ & $\mathbf{N}$ & $\mathbf{P}$ & $N$ & $\mathbf{P}$ & $\mathbf{N}$ & $\mathbf{P}$ & $\mathbf{N}$ & $\mathbf{P}$ & $\mathbf{N}$ & $\mathbf{P}$ & $\mathbf{N}$ & $\mathbf{P}$ & $\mathbf{N}$ & $\mathbf{P}$ & \\
\hline Sitting & 9 & $3.13 \%$ & 54 & $18.75 \%$ & 57 & $19.79 \%$ & 28 & $9.72 \%$ & 57 & $19.79 \%$ & 15 & $5.21 \%$ & 5 & 1.74 & 21 & $7.29 \%$ & 42 & $14.58 \%$ & 288 \\
\hline Sitting - eating & 8 & $2.33 \%$ & 87 & $25.36 \%$ & 58 & $16.91 \%$ & 16 & $4.66 \%$ & 51 & $14.87 \%$ & 30 & $8.75 \%$ & 10 & $2.92 \%$ & 23 & $6.71 \%$ & 60 & $17.49 \%$ & 343 \\
\hline Sitting - using mobile & 5 & $3.68 \%$ & 26 & $19.12 \%$ & 17 & $12.5 \%$ & 14 & $10.29 \%$ & 37 & $27.21 \%$ & 4 & $2.94 \%$ & 3 & $2.21 \%$ & 5 & $3.68 \%$ & 25 & $18.38 \%$ & 136 \\
\hline Sitting - smoking & 0 & $0.00 \%$ & 3 & $6.82 \%$ & 5 & $11.36 \%$ & 9 & $20.45 \%$ & 5 & $34.09 \%$ & 2 & $4.55 \%$ & 0 & $0.00 \%$ & 1 & $2.77 \%$ & 9 & $20.45 \%$ & 44 \\
\hline Sitting - reading & 1 & $1.85 \%$ & 12 & $22.22 \%$ & 10 & $18.52 \%$ & 2 & $3.70 \%$ & 10 & $18.52 \%$ & 0 & $0.00 \%$ & 0 & $0.00 \%$ & 5 & $9.26 \%$ & 14 & $25.93 \%$ & 54 \\
\hline $\begin{array}{l}\text { Sitting - eating - } \\
\text { reading }\end{array}$ & 0 & $0.00 \%$ & 1 & $33.33 \%$ & 1 & $33.33 \%$ & 0 & $0.00 \%$ & 1 & $33.33 \%$ & 0 & $0 \%$ & 0 & $0.00 \%$ & 0 & $0.00 \%$ & 0 & $0.00 \%$ & 3 \\
\hline $\begin{array}{l}\text { Sitting - eating - using } \\
\text { mobile }\end{array}$ & 0 & $0.00 \%$ & 1 & $20.00 \%$ & 1 & $20.00 \%$ & 0 & $0.00 \%$ & 0 & $0.00 \%$ & 1 & $20.00 \%$ & 0 & $0.00 \%$ & 0 & $0.00 \%$ & 2 & $40.00 \%$ & 5 \\
\hline $\begin{array}{l}\text { Seating - eating- } \\
\text { smoking }\end{array}$ & 0 & $0 \%$ & 1 & $25.00 \%$ & 0 & $0.00 \%$ & 0 & $0.00 \%$ & 2 & $50.00 \%$ & 0 & $0.00 \%$ & 1 & $25.00 \%$ & 0 & $0.00 \%$ & 0 & $0.00 \%$ & 4 \\
\hline Standing & 0 & 0 & 1 & $3.75 \%$ & 3 & $11.11 \%$ & 9 & $33.33 \%$ & 7 & $25.93 \%$ & 4 & $14.81 \%$ & 2 & $7.41 \%$ & 1 & 3.70 & 0 & 0 & 27 \\
\hline Standing - smoking & 0 & $0.00 \%$ & 0 & $0.00 \%$ & 0 & $0.00 \%$ & 1 & $10.00 \%$ & 9 & $90.00 \%$ & 0 & $0.00 \%$ & 0 & $0.00 \%$ & 0 & $0.00 \%$ & 0 & $0.00 \%$ & 10 \\
\hline $\begin{array}{l}\text { Standing - using } \\
\text { mobile phone }\end{array}$ & 0 & $0.00 \%$ & 2 & $22.22 \%$ & 1 & $11.11 \%$ & 1 & $11.11 \%$ & 3 & $33.33 \%$ & 1 & $11.11 \%$ & 1 & $11.11 \%$ & 0 & $0.00 \%$ & 0 & $0.00 \%$ & 9 \\
\hline Lying & 2 & $100 \%$ & 0 & $0.00 \%$ & 0 & $0.00 \%$ & 0 & $0.00 \%$ & 0 & $0.00 \%$ & 0 & $0.00 \%$ & 0 & $0.00 \%$ & 0 & $0.00 \%$ & 0 & $0.00 \%$ & 2 \\
\hline Playing & 1 & $50 \%$ & 0 & $0.00 \%$ & 0 & $0.00 \%$ & 0 & $0.00 \%$ & 0 & $0.00 \%$ & 1 & $50.00 \%$ & 0 & $0.00 \%$ & 0 & $0.00 \%$ & 0 & $0.00 \%$ & 2 \\
\hline
\end{tabular}




\subsubsection{Length of Stay}

Except for grass, $60-70 \%$ of users were only observed once in all subspaces. Longer stays were seen in separated space divided by artificial feature, sitting wall by grass, benches, and edge passageway. People used the entrance for a short stay. Users of sitting walls and benches were mostly observed in one or two photos, and grass attracted people for a longer time (Table 6-34).

Table 6-34: Length of stay (Group here means one person or group of two or more people)

\begin{tabular}{|c|c|c|c|c|c|c|c|c|c|c|}
\hline $\begin{array}{l}\text { Number of times grol } \\
\text { observed }\end{array}$ & & One & Two & Three & Four & Five & Six & Seven & Eight & Nine \\
\hline \multirow[t]{2}{*}{ A-code 1-1 } & $\mathrm{N}$ & 15 & 4 & 4 & 3 & 0 & 0 & 0 & 0 & 0 \\
\hline & $P$ & $57.69 \%$ & $15.38 \%$ & $15.38 \%$ & $11.54 \%$ & $0.00 \%$ & $0.00 \%$ & $0.00 \%$ & $0.00 \%$ & $0.00 \%$ \\
\hline \multirow{2}{*}{ A-code 1-2 } & $\mathrm{N}$ & 127 & 47 & 9 & 3 & 1 & 0 & 0 & 0 & 1 \\
\hline & $\mathrm{P}$ & $67.55 \%$ & $25 \%$ & $4.79 \%$ & $1.60 \%$ & $0.53 \%$ & $0.00 \%$ & $0.00 \%$ & $0.00 \%$ & $0.53 \%$ \\
\hline \multirow{2}{*}{ A-code 2} & $\mathrm{~N}$ & 108 & 34 & 6 & 3 & 2 & 0 & 0 & 0 & 0 \\
\hline & $\mathrm{P}$ & $70.59 \%$ & $22.22 \%$ & $3.92 \%$ & $1.96 \%$ & $1.31 \%$ & $0.00 \%$ & $0.00 \%$ & $0.00 \%$ & $0.00 \%$ \\
\hline \multirow{2}{*}{ B-code 3} & $\mathrm{~N}$ & 61 & 14 & 4 & 1 & 0 & 0 & 0 & 0 & 0 \\
\hline & $\mathrm{P}$ & $76.25 \%$ & $17.5 \%$ & $5.00 \%$ & $1.25 \%$ & $0.00 \%$ & $0.00 \%$ & $0.00 \%$ & $0.00 \%$ & $0.00 \%$ \\
\hline \multirow{2}{*}{ B-code 4} & $\mathrm{~N}$ & 142 & 30 & 15 & 4 & 0 & 1 & 0 & 0 & 0 \\
\hline & $\mathrm{P}$ & $73.96 \%$ & $15.63 \%$ & $7.81 \%$ & $2.08 \%$ & $0.00 \%$ & $0.52 \%$ & $0.00 \%$ & $0.00 \%$ & $0.00 \%$ \\
\hline \multirow[t]{2}{*}{ C-code 5} & $\mathrm{~N}$ & 36 & 19 & 2 & 0 & 0 & 1 & 0 & 0 & 0 \\
\hline & $P$ & $62.07 \%$ & $32.76 \%$ & $3.45 \%$ & $0.00 \%$ & $1.72 \%$ & $0.00 \%$ & $0.00 \%$ & $0.00 \%$ & $0.00 \%$ \\
\hline \multirow[t]{2}{*}{ D-code 7} & $N$ & 16 & 6 & 0 & 0 & 0 & 0 & 0 & 0 & 0 \\
\hline & $\mathrm{P}$ & $72.73 \%$ & $27.27 \%$ & $0.00 \%$ & $0.00 \%$ & $0.00 \%$ & $0.00 \%$ & $0.00 \%$ & $0.00 \%$ & $0.00 \%$ \\
\hline \multirow[t]{2}{*}{ E-code 9} & $\mathrm{~N}$ & 35 & 18 & 2 & 0 & 1 & 0 & 0 & 0 & 0 \\
\hline & $\mathrm{P}$ & $62.5 \%$ & $32.14 \%$ & $3.57 \%$ & $0.00 \%$ & $1.79 \%$ & $0.00 \%$ & $0.00 \%$ & $0.00 \%$ & $0.00 \%$ \\
\hline \multirow[t]{2}{*}{ E- code 10} & $\mathrm{~N}$ & 96 & 31 & 14 & 7 & 0 & 1 & 1 & 1 & 0 \\
\hline & $P$ & $63.58 \%$ & $20.53 \%$ & $9.27 \%$ & $4.64 \%$ & $0.00 \%$ & $0.66 \%$ & $0.66 \%$ & $0.66 \%$ & $0.00 \%$ \\
\hline
\end{tabular}

Occupancy maps indicate places occupied longer are grass and separated space divided by artificial elements (Figure 6-61). 


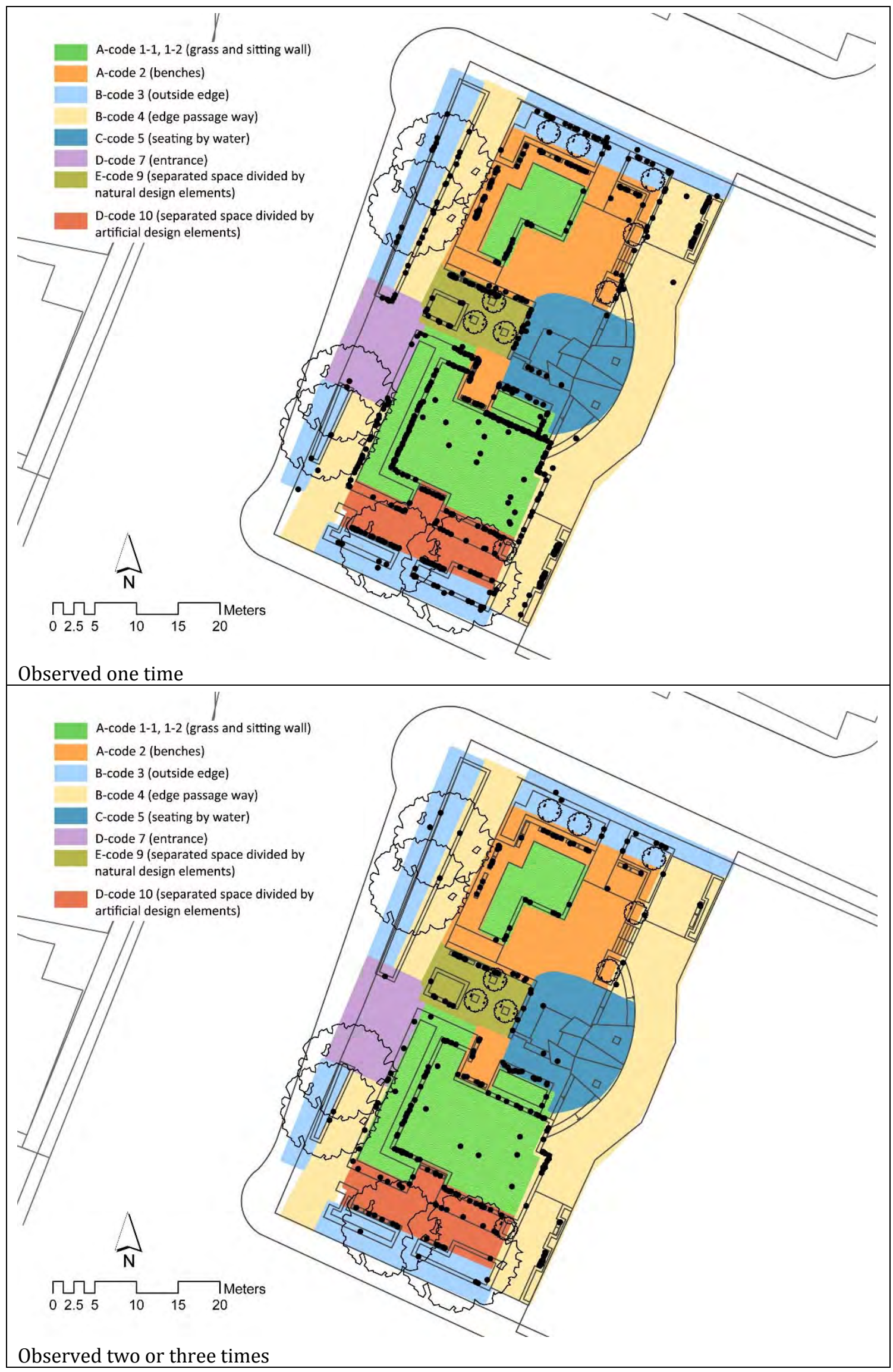




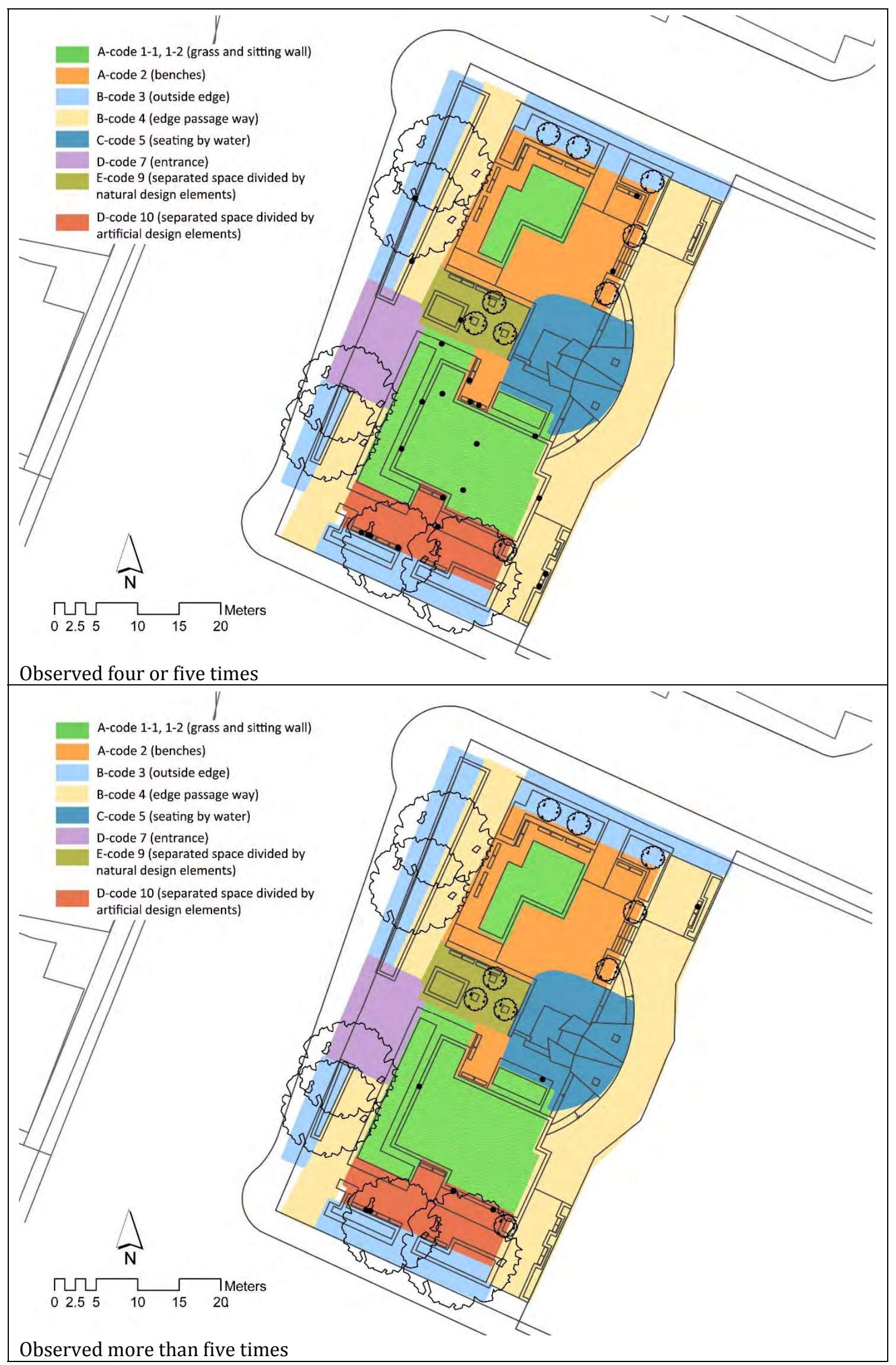

Figure 6-61: Length of stay, Midland Park 


\subsection{Summary of Results}

Results from the four data collection sites are summarized in Table 6-35. Patterns of preferred use differed across them. In Glover Park benches in paved area, grass, sitting walls by grass and seating by sculpture were the four preferred subspaces. While these were used over the day, entrances, edge passage way and outside edge were mostly used at lunch time. In Civic Square benches and entrance are two popular subspaces although sitting walls and separated space divided by steps were also well used, especially at lunch time. Grass and edge passage way were less used. In Te Aro Park benches and seating around water attracted more users, with outside edge and sitting walls used less and grass never used. In Midland Park sitting walls, separated space divided by artificial design elements and benches and edge passage way were the four favourite subspaces. Outside edge, seating by water and separate space divided by natural elements were also used. Grass and entrance were used the least. This is in contrast to Glover Park, where grass was used much more, especially by people in groups (Table 6-35).

Comparison between use of subspaces by people alone and people in groups (Table 6-36) indicates that grass attracted people in groups more than people alone. In two instances (Te Aro and Midland Parks) sitting walls attracted more people in groups than alone. Outside edge in all cases and separate space in Civic Square are occupied by people alone and in groups equally. Although both offer seating by a focal point, seating by sculpture (Glover Park) attracted people alone while seating by water (Midland Park) was more occupied by people in groups (especially people with children). Separated space in Midland Park either divided by natural or artificial elements was preferred by people in groups. Entrance with natural elements had different users in Midland Park and Glover Park, attracting people in groups and people alone respectively. 
Table 6-35: Comparison of subspace use as a percentage of its maximum occupancy

\begin{tabular}{|c|c|c|c|c|}
\hline Subspace Site & Glover Park & Civic Square & Te Aro Park & Midland Park \\
\hline $\begin{array}{l}\text { A-code 1-1 } \\
\text { (grass) }\end{array}$ & 100 & $\left.\begin{array}{r}100 \\
0\end{array}\right]$ & $\left.\begin{array}{r}100 \\
0\end{array}\right]$ & $\left.\begin{array}{r}100 \\
0\end{array}\right]$ \\
\hline $\begin{array}{l}\text { A-code } 1-2 \\
\text { (sitting wall) }\end{array}$ & 100 & & & \\
\hline A-code 2 (benches) & & & & \\
\hline B-code 3 (outside edge) & & & & \\
\hline $\begin{array}{l}\text { B-code } 4 \\
\text { (edge passage way) }\end{array}$ & 100 & & & \\
\hline $\begin{array}{l}\text { C-code } 5 \text { (seating by } \\
\text { water) }\end{array}$ & & & & \\
\hline $\begin{array}{l}\text { C-code } 6 \text { (seating by } \\
\text { sculpture) }\end{array}$ & 100 & & & \\
\hline $\begin{array}{l}\text { D-code } 7 \text { (entrance with } \\
\text { natural elements) }\end{array}$ & & & & \\
\hline $\begin{array}{l}\text { D-code } 8 \text { (entrance with } \\
\text { artificial elements) }\end{array}$ & & $\left.\begin{array}{c}100 \\
0\end{array}\right]$ & & \\
\hline $\begin{array}{l}\text { E-code } 9 \text { (space } \\
\text { separated by natural } \\
\text { elements) }\end{array}$ & & & & $\begin{array}{r}100 \\
0 . \\
\end{array}$ \\
\hline $\begin{array}{l}\text { E-code } 10 \text { (space } \\
\text { separated by artificial } \\
\text { elements) }\end{array}$ & & $\begin{array}{r}100 \\
0\end{array}$ & & 100 \\
\hline Total use & & 100 & & \\
\hline
\end{tabular}


Table 6-36: Use of subspaces by people alone and in groups

\begin{tabular}{|c|c|c|c|c|c|c|c|c|}
\hline \multirow{2}{*}{$\begin{array}{rr}\text { Subspace } & \\
\text { Site }\end{array}$} & \multicolumn{2}{|c|}{ Glover Park } & \multicolumn{2}{|c|}{ Civic Square } & \multicolumn{2}{|c|}{ Te Aro Park } & \multicolumn{2}{|c|}{ Midland Park } \\
\hline & alone & group & alone & group & alone & group & alone & group \\
\hline A-code $1-1$ (grass) & $18.29 \%$ & $81.71 \%$ & $8.82 \%$ & $91.18 \%$ & & & $30.95 \%$ & $69.05 \%$ \\
\hline $\begin{array}{l}\text { A-code 1-2 (sitting wall by } \\
\text { grass) }\end{array}$ & $60.00 \%$ & $40.00 \%$ & $52.08 \%$ & $47.92 \%$ & $34.09 \%$ & $65.91 \%$ & $32.98 \%$ & $67.11 \%$ \\
\hline A-code 2 ( benches) & $65.22 \%$ & $34.78 \%$ & $53.76 \%$ & $46.24 \%$ & $40.00 \%$ & $60.00 \%$ & $42.47 \%$ & $57.53 \%$ \\
\hline B-code 3 (edge passage way) & $50.00 \%$ & $50.00 \%$ & $71.43 \%$ & $28.57 \%$ & & & $44.35 \%$ & $55.65 \%$ \\
\hline B-code 4 (outside edge) & $46.43 \%$ & $53.57 \%$ & & & $52.27 \%$ & $47.73 \%$ & $43.27 \%$ & $56.73 \%$ \\
\hline C-code 5 (seating by water) & & & & & $43.69 \%$ & $56.31 \%$ & $22.55 \%$ & $77.50 \%$ \\
\hline C-code 6 (seating by sculpture) & $60.00 \%$ & $40.00 \%$ & & & & & & \\
\hline $\begin{array}{l}\text { D-code } 7 \text { ( entrance with } \\
\text { natural elements) }\end{array}$ & $60.00 \%$ & $40.00 \%$ & & & & & $16.67 \%$ & $83.33 \%$ \\
\hline $\begin{array}{l}\text { D-code } 8 \text { (entrance with } \\
\text { artificial elements) }\end{array}$ & & & $68.88 \%$ & $31.12 \%$ & & & & \\
\hline $\begin{array}{l}\text { E-code } 9 \text { (separate space with } \\
\text { natural elements) }\end{array}$ & & & & & & & $29.21 \%$ & $70.79 \%$ \\
\hline $\begin{array}{l}\text { E-code } 10 \text { (separated space } \\
\text { with artificial elements) }\end{array}$ & & & $52.17 \%$ & $47.83 \%$ & & & $41.44 \%$ & $58.56 \%$ \\
\hline
\end{tabular}

Table 6-37: Length of stay ( $1=$ once, $2=$ twice,$\geq 3=$ three or more times) in four data collection sites

\begin{tabular}{|c|c|c|c|c|c|c|c|c|c|c|c|c|}
\hline Subspace & & over p & ark & & vic Squa & are & & Aro $\mathrm{Pa}$ & & Mic & dland $\mathbf{P}$ & Park \\
\hline & 1 & 2 & $\geq 3$ & 1 & 2 & $\geq 3$ & 1 & 2 & $\geq 3$ & 1 & 2 & $\geq 3$ \\
\hline A-code $1-1$ (grass) & $46.34 \%$ & $29.27 \%$ & $24.39 \%$ & $50.00 \%$ & 12.5 & $37.50 \%$ & $0.00 \%$ & $0.00 \%$ & $0.00 \%$ & $57.69 \%$ & $15.38 \%$ & $26.93 \%$ \\
\hline $\begin{array}{l}\text { A-code 1-2 (sitting wall } \\
\text { by grass) }\end{array}$ & $72.44 \%$ & $13.79 \%$ & $23.77 \%$ & $71.28 \%$ & $20.21 \%$ & $8.51 \%$ & $89.29 \%$ & $3.57 \%$ & $7.14 \%$ & $67.55 \%$ & $25.00 \%$ & $7.45 \%$ \\
\hline A-code 2 ( benches) & $63.16 \%$ & $23.68 \%$ & $13.16 \%$ & $70.00 \%$ & $18.57 \%$ & $11.43 \%$ & $64.60 \%$ & $29.23 \%$ & $6.15 \%$ & $70.59 \%$ & $22.22 \%$ & $7.19 \%$ \\
\hline $\begin{array}{l}\text { B-code } 3 \text { (edge passage } \\
\text { way) }\end{array}$ & $88.24 \%$ & $11.76 \%$ & $0.00 \%$ & $0.00 \%$ & $0.00 \%$ & $0.00 \%$ & $87.88 \%$ & $9.09 \%$ & $3.03 \%$ & $76.25 \%$ & $17.5 \%$ & $6.25 \%$ \\
\hline B-code 4 (outside edge) & $72.22 \%$ & $27.78 \%$ & $0.00 \%$ & $50.00 \%$ & $50.00 \%$ & $0.00 \%$ & $0.00 \%$ & $0.00 \%$ & $0.00 \%$ & $73.96 \%$ & $15.63 \%$ & $10.41 \%$ \\
\hline $\begin{array}{l}\text { C-code } 5 \text { (seating by } \\
\text { water) }\end{array}$ & $0.00 \%$ & $0.00 \%$ & $0.00 \%$ & $0.00 \%$ & $0.00 \%$ & $0.00 \%$ & $74.63 \%$ & $14.93 \%$ & $10.44 \%$ & $62.07 \%$ & $32.67 \%$ & $5.26 \%$ \\
\hline $\begin{array}{l}\begin{array}{l}\text { C-code } 6 \text { (seating by } \\
\text { sculpture) }\end{array} \\
\end{array}$ & $62.50 \%$ & $25.00 \%$ & $2.50 \%$ & $0.00 \%$ & $0.00 \%$ & $0.00 \%$ & $0.00 \%$ & $0.00 \%$ & $0.00 \%$ & $0.00 \%$ & $0.00 \%$ & $0.00 \%$ \\
\hline \begin{tabular}{|l|} 
D-code 7 (entrance \\
with natural elements) \\
\end{tabular} & $0.00 \%$ & $0.00 \%$ & $0.00 \%$ & $0.00 \%$ & $0.00 \%$ & 0.005 & $0.00 \%$ & $0.00 \%$ & $0.00 \%$ & $72.73 \%$ & $27.27 \%$ & $0.00 \%$ \\
\hline $\begin{array}{l}\text { D-code } 8 \text { (entrance } \\
\text { with artificial elements) }\end{array}$ & $100 \%$ & $0.00 \%$ & $0.00 \%$ & $61.84 \%$ & $27.12 \%$ & $0.00 \%$ & $0.00 \%$ & $0.00 \%$ & $0.00 \%$ & $0.00 \%$ & $0.00 \%$ & $0.00 \%$ \\
\hline $\begin{array}{l}\text { E-code } 9 \text { (separate } \\
\text { space with natural } \\
\text { elements) }\end{array}$ & $0.00 \%$ & $0.00 \%$ & $0.00 \%$ & $0.00 \%$ & $0.00 \%$ & $0.00 \%$ & $0.00 \%$ & $0.00 \%$ & $0.00 \%$ & $62.5 \%$ & $32.14 \%$ & $5.36 \%$ \\
\hline $\begin{array}{l}\text { E-code } 10 \text { (separated } \\
\text { space with artificial } \\
\text { elements) }\end{array}$ & $0.00 \%$ & $0.00 \%$ & $0.00 \%$ & $69.70 \%$ & $18.18 \%$ & 12.125 & $0.00 \%$ & $0.00 \%$ & $0.00 \%$ & $63.58 \%$ & $20.53 \%$ & $15.89 \%$ \\
\hline
\end{tabular}

Further investigation also shows the greatest percentage of people observed more than three times for all data collection sites were using grass, and this was followed by sitting 
wall by grass in Glover Park, and separated space by artificial elements in Midland Park (Table 6-37).

Grass and benches in Glover Park afforded more diverse activities while sitting wall in both Civic Square and Midland Park and seating by water in Te Aro Park have more affordance when it comes to activities (Table 6-38).

Table 6-38: Number of activities in subspaces

\begin{tabular}{|c|c|c|c|c|}
\hline Subspace & $\begin{array}{c}\text { Glover } \\
\text { Park }\end{array}$ & $\begin{array}{c}\text { Civic } \\
\text { Square }\end{array}$ & $\begin{array}{c}\text { Te Aro } \\
\text { Park }\end{array}$ & $\begin{array}{c}\text { Midland } \\
\text { Park }\end{array}$ \\
\hline A-code $1-1$ ( grass) & 9 & 4 & 0 & 6 \\
\hline A-code 1-2 (sitting wall by grass) & 7 & 8 & 6 & 10 \\
\hline A-code 2 (benches) & 9 & 7 & 6 & 9 \\
\hline B-code 3 (edge passage way) & 5 & 0 & & 7 \\
\hline B-code 4 (outside edge) & 7 & & 6 & 9 \\
\hline C-code 5 (seating by water) & & 4 & 9 & 7 \\
\hline C-code 6 (seating by sculpture) & 2 & & & \\
\hline D-code 7 (entrance with natural elements) & 4 & & & 6 \\
\hline D-code 8 (entrance with artificial elements) & & 7 & & \\
\hline E-code 9 (separate space with natural elements) & & & & 5 \\
\hline E-code 10 (separated space with artificial elements) & & 8 & & 6 \\
\hline
\end{tabular}

Between all four data collection sites, Glover Park attracted young adults and teenagers more than the other sites. Adults made more use of the other sites (Table 6-39) especially at lunch and afternoon tea times, which is probably because of their proximity to work places.

Table 6-39: Number of people by age in the four sites

\begin{tabular}{|c|c|c|c|c|c|c|c|c|c|c|c|c|c|c|c|}
\hline \multicolumn{4}{|c|}{ Glover park } & \multicolumn{4}{|c|}{ Civic Square } & \multicolumn{4}{|c|}{ Te Aro Park } & \multicolumn{4}{|c|}{ Midland Park } \\
\hline $\mathbf{T}$ & YA & A & OA & $\mathbf{T}$ & YA & A & OA & $\mathbf{T}$ & YA & A & OA & $\mathbf{T}$ & YA & A & OA \\
\hline $35.5 \%$ & $44.21 \%$ & $14.9 \%$ & $4.03 \%$ & $36.96 \%$ & $36.71 \%$ & $23.04 \%$ & $2.03 \%$ & $24.74 \%$ & $41.24 \%$ & $30.93 \%$ & $1.72 \%$ & $24.43 \%$ & $38.74 \%$ & $32.62 \%$ & $1.99 \%$ \\
\hline$=$ teer & nagers & $Y A=$ & young & adults & $A=c$ & adults & $O A=C$ & Old Adul & & & & & & & \\
\hline
\end{tabular}

\subsection{Discussion}

This study investigated people's behaviour in different subspaces across four data collection sites with a focus on the effect of natural elements on the use of space by looking at length of stay, number of users, size of groups, and type of activity. Results were 
based on the theory that diversity in activity shows affordance (Lang, 1994). Additionally, diversity in user groups also shows affordance, and this is demonstrated by the gender and estimated age of the users.

Except for Glover Park, all sites have one peak time and attract most users at lunch time. The two peak use times suggest Glover Park is active for longer (Table 6-35). Looking at the users indicates that for Glover Park most are teenagers and young adults, and length of stay is more than for the other sites where users come from nearby workplaces to have lunch. This also suggests going to Glover Park is a deliberate decision, rather than an opportune use, which argues for its success. As Whyte (1980) claimed, social space should be a destination and people should decide to go there.

The role of natural elements and their contribution to social activity is dependent on their situation in the design of the park. For trees to provide natural shade, which seems to be sought by users, size is important, whereas for grass size, location and shape is critical and for water being touchable may be significant in attracting people. It seems a well-designed site, such as Glover Park, with appropriate grass and mature trees attracts younger people who gather in larger groups for a longer time, showing it affords diverse activity. People are found more around the touchable water in Midland Park than around the harder to reach water in Te Aro Park.

Availability of trees should increase the use of place (Coley et al., 1997). Use of trees in the early morning in Glover Park, when being in the sun might be more pleasant, shows that apart from their climatic benefit they also seem to have psychological benefit by creating shade and sense of enclosure (Whyte, 1980). Use of places near trees in all subspaces in Glover Park and over the day illustrate the effect of trees is not limited to shade but suggests they provide a more intimate place and enhance the use of space by providing a level of enclosure and defining a place for larger groups to gather. Comparison of use of grass in morning and afternoon shows the effect of sun is not as strong as the effect of trees, as places shaded by trees are used even in early morning and late afternoon when people might be looking for the warmth of the sun. However trees need to be mature enough and have a clean place for sitting under their canopy. This seems to happen in Glover Parks where the trees work well and attract more people for a longer time. In contrast, the mature tree in Te Aro Park does not have clean seating under it, and 
is less used. Examples of immature trees with non-maintained green were seen in Civic Square and these also were not well used. This supports the finding of Kuo et al. (1998) that grass and surface maintenance enhances activity in a place by bringing a sense of safety. However trees around the edge also need to be mature enough as edges with immature trees around Te Aro Park and in Glover Park were not used well while the two outside edges in Midland Park with mature trees were used at lunch time.

Grass is well used when it has good shape and size. The small piece of grass in Civic Square and the triangular grass in Te Aro Park were never used during the time of observation. Location of grass is important too. People feel uncomfortable knowing they are being observed while sitting or lying on grass. The non-use of some grass in Civic Square and in Midland Park supports this finding. Grass also seems to be a more popular subspace for teenagers and young adults. Sitting wall by grass is preferred to the seating place near a building in Civic Square.

The water features in Midland Park and Te Aro Park seem to have no significant effect on use. This conflicts with other studies which claim water enhances social activity (Huang, 1998), and has a has psychological effect (Ulrich, 1981; Ulrich \& Addoms, 1981). However, this study did not interview people on their feelings about water, so these results may not be complete. Additionally, the sound of water may affect people's feelings, rather than being close to it, but this would not be revealed by behaviour mapping. However the touchable water in Midland Park did attract families with children, suggesting water makes an attractive place (Nasar, 1994; Sherrod \& Downs, 1974).

The pleasantness of the sun was seen in use of some subspaces like grass in Glover Park and separate space divided by artificial elements in Civic Square. Grass under the shade of a building was never used across the four sites, while the enclosed sunny place in Civic Square was pleasant for people having lunch. Comparison between uses of the two edge passage ways in Midland Park is strong evidence for the effect of the sun, as the passage way in the sun looking on to the park was well used while the passage way shaded by the shelter and close to the footpath was not used.

Regarding the types of activity which each subspaces afforded, it seems that different subspaces are the most popular for each site but that all of these popular subspaces include natural elements. 
Looking closely at people in groups and alone shows not only that people in groups make more use of grass but also that the big difference between these two categories occurs for the artificial entrance in Civic Square (attracting people alone) and entrance with natural elements in Midland Park (attracting people in groups). The affordance of natural elements in attracting people in groups is also significant when comparing space separated by natural and artificial elements. While the artificial type attracts more people alone those with natural elements attract many more group users.

Looking at the artificial elements indicates benches dramatically increase the use of subspaces. Benches not only in paved areas but also in entrances and separated space are well used. Comparing Civic Square entrance with other entrances shows not only that it has benches but it also has a particular character (being a space that links the footpath to the main square). It is thus not completely inside Civic Square and is a favourite place for people alone and those staying for a short time. The separated space divided by artificial elements in Midland Park has benches and was well used while the same subspace in Civic Square does not have enough benches and was only used at lunch time. The strong role of orientation of benches was seen in Te Aro Park where the triangular benches attracted bigger groups as people can sit close without having to look at each other.

Artificial elements which defined enclosed space like the shelter in Midland Park and the recesses in the wall in Civic Square contributed to social activity as people use these spaces because of their level of privacy. This privacy can be provided by natural or artificial elements.

\subsection{Conclusion}

Study Three observed use of subspaces of small public spaces in a city centre that varied in the amount and arrangement of natural design elements. Subspace comparisons were made within sites and similar subspaces were compared between sites. Natural elements were absent from some subspaces. The within site comparisons indicate that the presence of subspaces with natural elements is important and that their design and location in the context matters. Comparisons between natural elements in the small public spaces found that trees and grass seemed to have more effect than water features. Trees were used because they appeared to define enclosed space and grass afforded 
more activity for bigger groups. However, size, shape and place, and maintenance of trees and grass affects the number of users (e.g. grass areas in the shade or with a triangular shape were left relatively unused). Benches and sitting walls or shelters, either natural or artificial, were used which indicates that design elements which provide places to sit enhance use of small public spaces in the city centre. Sunlight and shadow is another factor that was found to be important in the use of public space. Subspaces with solid shadow from surrounding buildings were less used than areas shaded with natural elements like trees. A link between age group and uses of subspaces was also found in the data. Grass areas were mostly used by teenagers. Overall, the results of Study Three suggest that length of stay, user age groups and types of activities are related to design elements and their use is enhanced where these include natural features. 


\title{
Chapter 7 Conclusion
}

\author{
"Individuals do not become directly attached to the physical features \\ of a place but rather to the meaning that those features represent" \\ (Gifford, 2014, p. 561).
}

A review of relevant literature found that nature has been an important design element for public space in settlements throughout history and that in urban centres today, natural design element are used to sustain activity in small public spaces. In offering a theoretical explanation for this observation, the Theory of Place was examined and found to provide an inadequate theoretical model to describe the relationship between nature and use of public space. In the Theory of Place, the linkages between design elements, meaning and behaviour remain uncrystallised (Lewicka, 2011). To address this issue this thesis proposed using Affordance Theory to describe place (from the Theory of Place) in terms of designed space. Using this combined theoretical framework, the affordance of place was examined using data collected through structured questionnaires and behavioural observation in small public spaces in an urban centre. The research found that preference for and use of public space is a function of the affordance of natural and artificial design elements. That is, the affordance of place provides a theoretical basis for describing the relationship between design elements and social activity in small public spaces in urban centres.

\subsection{Summary of Results}

\subsubsection{Study One: Affordance of Design Elements}

The structure of Theory of Place was evident in the MDS spatial representations of the data. The facets described the structure of the data. The regional separation of natural and artificial elements was a function of type of activity and the cognitive and affective affordance of design elements. This indicates that natural elements utilised in design as features, surfaces, or furnishings encourage social activity (behavioural affordance) 
through the meaning (cognitive-affective affordance) they hold for users of the space. Natural elements enhance positive initial feelings more than artificial elements, and people prefer to have nature as part of the overall design of public space whether being alone or with friends. In the affordance of place, a preference for natural design elements over artificial is consistent with previous research (S. Kaplan, 1995; Tyrväinen et al., 2014; Ulrich, 1986; Ulrich \& Addoms, 1981; Ulrich et al., 1991; Van den Berg et al., 2014).

\subsubsection{Study Two: Design Elements in Public Space}

Study Two investigated preferences for natural elements in combination with other elements. The results of this study were then used as a basis for Study Three. The results found that people not only prefer nature but they prefer subspaces where nature has been integrated as a meaningful design element. The three situations of being alone, with friends, or chance contact with new people formed three separated regions in the MDS spatial representation. Further, the order of preferences in these three different situations was different. This indicates people's actions in a place depend on how the physical setting meets human needs and shapes their concept (Carr et al., 1992; Lang, 1994). Review of part three of the second survey, which asked people for their opinions about the data collection sites, emphasised this issue. People gauge places in different situations based on affordance of the physical setting. Crowded places like Midland Park and places with pedestrian routes seem safer for being with the family. Civic Square with its potential to attract tourists or visitors (the local Visitor Information Centre is very close to Civic Square, and it is on the route from the CBD to the Wellington waterfront) emerged as the best place for chance contact.

The higher preference found for subspaces using natural elements over similar artificial subspaces supports previous findings of the importance of nature in urban contexts ( $R$. Kaplan, 1983). Although in Study Two the regions for artificial and natural elements were not as obvious as in Study One, for each pair of natural/artificial subspaces, the natural subspaces still received a higher score. However, the mixed cluster of preferred natural and artificial elements indicates design elements should be meaningful in the context of design. For example while in Study One features, whether natural or artificial, were preferred over surfaces in all situations, in Study Two when people were asked to judge design elements for certain functions, grass received a higher rating followed by trees 
when being with friends, as these were perceived to afford a bigger group.

\subsubsection{Study Three: Observed Behaviour in Public Space}

Study Three validated the theoretical approach of Study One through observation. The observation of social activity in small public places indicated that natural design elements are related to social activity. For example, grass with an appropriate shape (Figure 7-1) and location, and trees with suitable shade (Figure 7-2) attract more people in groups for a longer time.

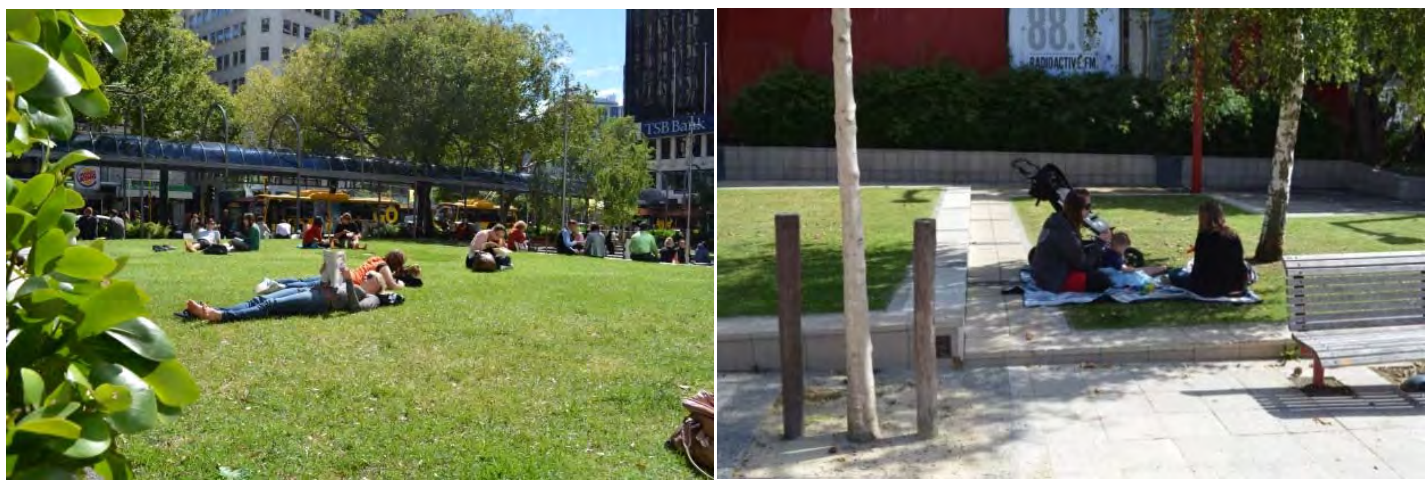

Figure 7-1: Grass with appropriate shape attracts people in groups, Ghavampour, 2013
Figure 7-2: Trees with appropriate shade attract people for a longer time, Ghavampour, 2013

This finding is consistent with previous research on the relationship between trees and grass, and social activity (Coley et al., 1997; Kuo, Sullivan, et al., 1998). Sitting close to trees, whether in their shade, even in the early morning, or beside them in sunshine is a preferred activity.

In the behaviour mapping the sharp line between use of natural and artificial elements was not as obvious as it was in Study One. However, when subspaces afford place, the observations showed natural design elements enhanced use of space more than those designed using artificial elements.

\subsection{Implications for Theory}

Natural elements are important for people, and natural design elements are more important than artificial ones. A preference for natural elements over artificial, as found in the theoretical model (Study One) based on the theory, indicates the link between meaning and activity emphasised in the Theory of Place. The intense use of places close 
to natural elements as observed in behaviour mapping is further evidence for this finding. Although this importance has been mentioned in design guidelines it has not hitherto been tested using a theoretical framework.

Affordance theory is an appropriate tool for describing the linkage between the components of Theory of Place. Study One found a theoretical basis (Affordance Theory) with which to link nature and activity and Study Three was used to validate the finding of a relationship between natural design elements and social activity. In comparing the results of these two studies, the theoretical models of Place and Affordance can be used to describe the observed preferences by users of small public spaces. Integration of Theory of Place, Affordance Theory, and facet theory was a useful method for studying a place.

This research provided detailed studies of preferences and use of small public spaces in a city centre. Because in Theory of Place it is not clear how to define the linkage between three components, the research used Affordance Theory to fill this gap. However, it might be argued that Theory of Place includes affordance but the lack of a clear description of the process of place making puts more focus on the physical nature of place and process, which in current studies tends to give more focus to the people components like individual differences (Lewicka, 2011).

\subsection{Implications for Design Practice}

This thesis used theoretical and applied research to examine the relationship between natural design elements and social activity in public space. Comparison of the results of Study Two and Three indicates an understanding of theory is important for design. An understanding of theory can enhance an understanding of the reasons behind the success or failure of public space. An increased emphasis on theory avoids the designer's inevitable focus on surface appearance that is criticized by Montgomery (1989), and emphasises the necessity of using both theoretical and practical methods and approaches when investigating public spaces. This is where most design guidelines fail.

Investigation of the link between meaning and activity through observation is an inferential interpretation which gives rise to the need to use complementary theoretical 
research with reliable predictive power. Canter raises a need for theory in environmental studies.

\begin{abstract}
"[Theory] is a means of identifying the crucial aspects of any phenomena and representing the general relationships between those aspects and the conditions under which those relationships will hold. Theories go beyond any particular instance or set of data to indicate generalities that allow us to extrapolate beyond specific examples. That is the power of science and the reason why it has had such world-changing influence. It allows us to take results from the past in one context and use them confidently to predict what will happen under similar, but not identical, conditions in the future" (Canter, 2008, p: 664 ).
\end{abstract}

While designers should consider theory in design they should also be aware of the importance of creating a good combination of design elements, based on enhancing human needs and as addressed in the theories. Results of observation suggest successful public spaces are those that are designed based on the principles in the theories, thus avoiding design based on designers' opinions.

Physical setting should have meaning to which people can relate. Non-used subspaces indicate people are not able to perceive a positive meaning for the combination of design elements in a context. This indicates the difference between potential and actualized affordance. Unlike the two theoretically based studies (Studies One and Two) which gauge the effect of the potential affordance of nature in social activity in a place, in behaviour mapping actualized affordances of place are examined. Non-used natural elements like vacant grass (Figure 7-3), or vacant natural edges (Figure 7-4) support studies that state affordance should be perceived by individuals to be utilized (Gibson, 1979; Greeno, 1994; Heft, 1989; Kyttä, 2003). This means that only including these design elements without thought to their meaning will not guarantee that they will be used. 


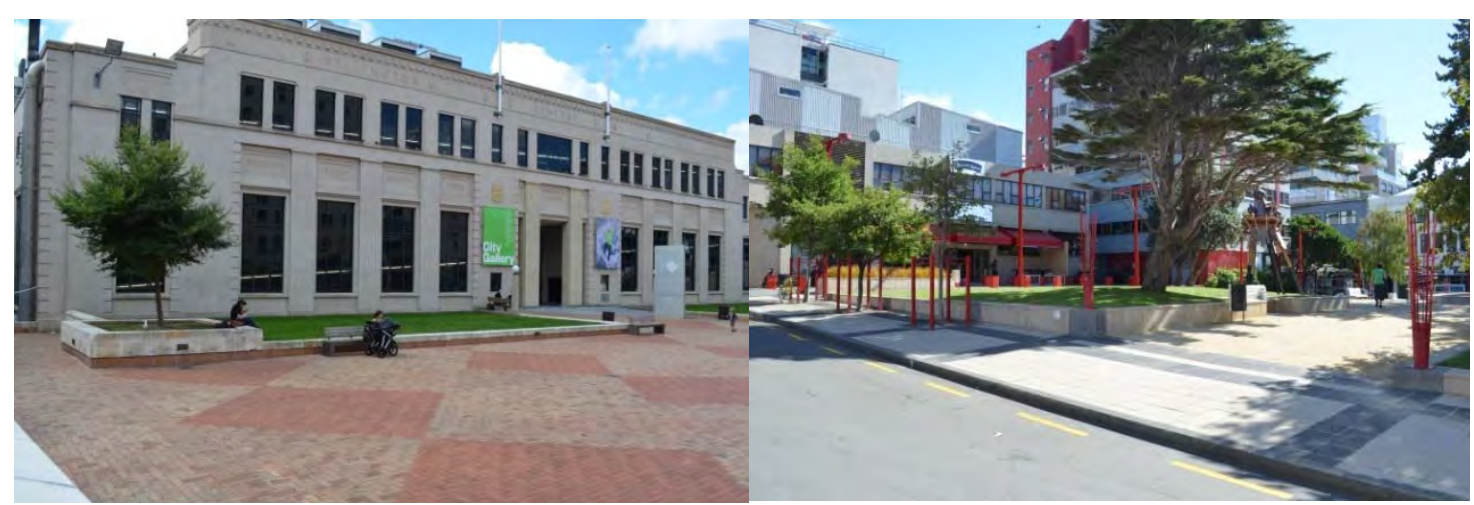

Figure 7-4: Vacant grass under Building shade, Ghavampour, 2013

Figure 7-5: Vacant edge with natural elements, Ghavampour, 2013

While naturalness is a way to increase the use of space, the observed popularity of some artificial subspaces again indicates that for design elements to enhance activity they should facilitate needs and have meaning for people. Thus other elements that have meaning and to which people can relate improve activity. Looking at the successful artificial subspaces shows these are the ones that provide physical and psychological comfort (benches and shelter). An interesting example is the benches in Te Aro Park. While overall it does not seem to be a successful space, its artificial benches with their triangular shape (Figure 7-5) are preferred to all natural subspaces. This satisfaction with the seating was also seen in part three of Study Two where Te Aro Park was the best place regarding its available seating. Another example is the separated spaces defined by the recesses in the wall of Civic Square (Figure 7-6). These recesses provide appropriate enclosure which people like to sit in at lunch time. This also accords with the results of Nasar and Abdulkarim (2014), where seats were also seen to be restorative.

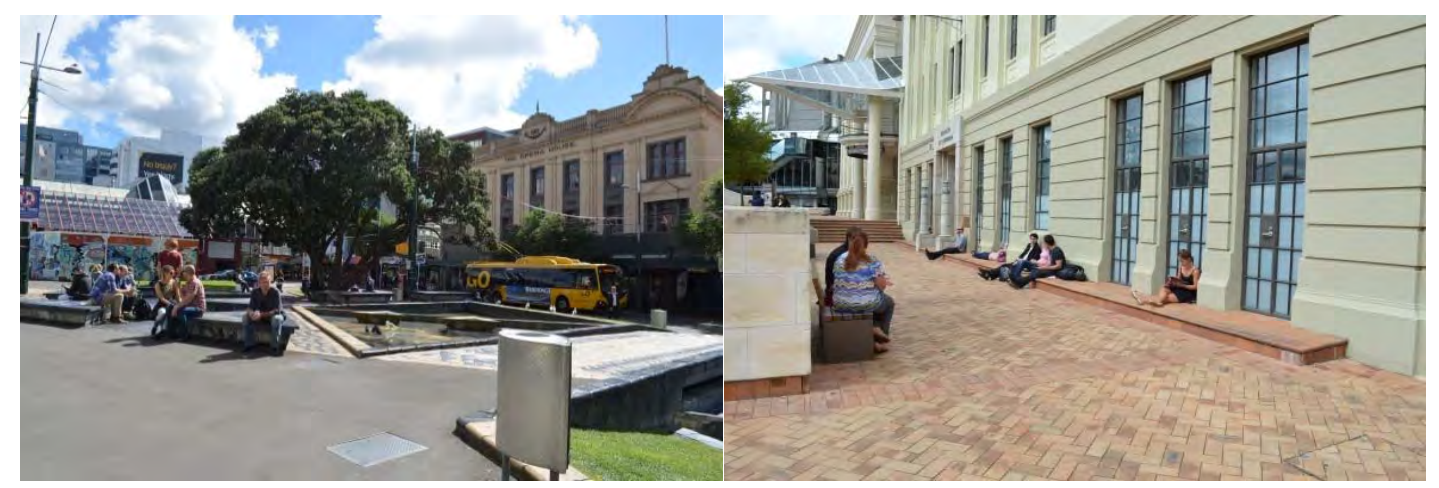

Figure 7-6: Benches with triangular shape, Ghavampour, 2013

Figure 7-7: Recesses and sense of enclosure, Ghavampour, 2013

This again raises a need to relate design to the context, in a way that is perceived as useful by people, and emphasises the need to use design elements in a meaningful way. All this 
evidence indicates artificial design elements are not always meaningless and can enhance social activity.

\subsection{Implications for Design Research Methods}

Facet Theory was found to be a reliable method for studying place. This method for evaluating hypothesised relationships has been used for research in social disciplines and architecture but is not common or widely used in urban design.

Integration of Photography and GIS was introduced as a methodology for behaviour mapping. While this method was more accurate than using a manual paper and pencil approach, the time spent for transferring data was similar. Use of this method reduced the number of observers required, however, and was appropriate for a crowded place. The usability of this method in practice was tested in a meeting with Wellington City Council, where they were surprised by the popularity of Glover Park, which they thought was not well liked or used, and the benches in Te Aro Park, which again they perceived as unsuccessful design. In a cursory view places like Midland Park seem to be successful while a deeper study indicates that use of place should not only be measured by counting people. The number of uses is only part of an investigation into successful small public spaces. However, although mapping behaviour as in this research was interesting for Wellington City Council, they are continuing with manual pedestrian counts of users of public spaces.

\subsection{Strengths and Limitations}

Multiple methods were used in this thesis to make a comprehensive study of public space. While theories have helped theoreticians to predict levels of social activity in public space and find out more about the affordance of place, there actualized affordance of place was examined through observation. This study used both surveys to investigate theoretical preferences and observation to measure the affordance of natural elements for social activity.

The preference surveys (using Facet Theory) provided a theoretical investigation of place, independent of the local context. The mapping of observed behaviour highlighted 
differences with an emphasis on the context (location and local preference) of public space.

Natural design elements as design elements assisting in creating meaning for people were used as an example to test the theory. Nature was used in general terms without taking into account any personal ideas of nature related to specific types of landscape. Thus Study One was a testing of theory using a comparison between affordance of natural elements and artificial elements.

Observation was limited to one day and if it was done in different weather conditions or in different seasons this might lead to different findings. This limited research was able to test the theoretical model, and compare between natural and artificial elements. In the behaviour mapping the pattern of people's behaviour was also analysed based on this model. There are so many design elements that may affect people's behaviour, and while this thesis looked at their behaviour through the lens of natural / artificial, it may be argued that natural design elements do not always work, as the results show, and other design elements also enhance social activity. Here a discussion about short term and long term effect arises. While it seems that natural elements have a long standing effect, artificial design elements may have a short term effect and their effect could change with time or change in the taste of the users. However this effect was not studied in this thesis. This could be answered by doing participatory behaviour mapping or through interviews. Using facet theory with its focus on theory testing was a decision that gave the opportunity to test a theory that has not been tested in experimental study. Interviews were another option for this investigation of place. However, this study was not based in grounded theory so interviews were not a good substitute for the facet approach. Interviews could only be a comprehensive method when combined with behaviour mapping in further study.

This research tried to draw out the main important subspaces and examine their affordance based on human needs, which has not been done in any studies up to date. However, this can always be improved. Using theories in design research and applying these to design elements which have long standing meaning for people is important for the design of small public spaces. The distinction between a study of an underlying nomothetic process and a study observing idiosyncratic manifestations of that process 
has important implications for design and short term place marketing. Designs based on preferences at a particular point in time may fit users' needs at that time and receive favourable evaluations, but cannot accommodate users with different tastes or change in taste over time. Successful places in the short term become placeless spaces in need of regeneration. This is why designers should be wary of design based on the results of a preference survey, as such design may increase activity short term but need redevelopment long term as the design ideas fall out of favour with the users.

\subsection{Implications for Future Research}

The findings of this research could be used to create a model for a public space and this could then be tested through use of a focus group to compare different design scenarios for the space. Deeper study on the effect of natural elements in terms of other properties of nature like sound, colour, or other psychological effects, could be another possible area for further study. As mentioned in Study Three, neither the two surveys nor the behaviour mapping focused on this aspect. Thus a participatory behaviour mapping could be a fourth study emanating from this research.

The literature review found similar preferences for nature over the built environment across different cultures mostly looking at the large scale and this is another opportunity for investigation by applying these ideas to small urban spaces. Studying behaviour in a place in different seasons is another possible further study for this research. As another example of further research, this study uses space syntax for determining macro design characteristics yet space syntax can be used at the micro scale to predict uses of space in relation to design elements.

As discussed before, a theoretical model is needed to be sure that designs meet users' needs, are flexible, and yet are not tied to fashion. However, the model needs to be expanded to distinguish between short term and long term increases in the use of public space. Designs based on market surveys of user needs may generate short term increases in use that cannot be sustained. Further research on the theoretical model to enable a distinction between short term and long term increases in social activity is required to assist the development of successful public spaces in urban centres. This research did, however, measure the contribution of natural design elements in the use of place. Only 
in Study Three were the uses of different subspaces compared over a day. This showed these elements are more likely to contribute to the sustained use of place. This suggests the need for investigating the effect of design elements in the sustained use of the space over a long period. Although the behavioural study indicated that even in the short term (one day) natural elements are more effective than artificial ones and are more likely to enhance sustained use of space, this still needs further research for its verification.

\subsection{Final Comment}

The findings of this thesis indicate a need for co-operation between researchers and practitioners for the design of a successful public space. Theory (Study One) and observation (Study Three) suggest that incorporating theory in design is a reliable framework for creating meaningful public spaces. This is in line with the suggestions of Schon $(1983,1991)$ and Malbert (1998) for researcher-practitioner participation. In urban design this lack of participation can lead to the failure of Theory of Place in explaining the linkage between meaning, physical setting, and activity (essential for creating a sense of place). This in turn can lead to inadequate design tools. Too often designers rely on a checklist of design attributes without considering the real needs of the local user population and the context of place. The application of 'place' as a design tool has lost connection with the ecological tradition that is implicit in the relational models of place (Canter, 1976; Relph, 1976). Place is not a bounded territory of three discrete entities, but a niche described as a system of experiences including the social and cultural aspects of activities occurring in context (Canter, 1997). This research has reinforced this by revealing the importance of natural elements in the design of small urban public spaces. 


\section{Bibliography}

Abdulkarim, D., \& Nasar, J. L. (2014). Are livable elements also restorative? Journal of environmental psychology, 38(0), 29-38.

Agnew, J. A. (1987). Place and politics: The geographical mediation of state and society. Boston: Allen \& Unwin.

Alexander, C., Ishikawa, S., \& Silverstein, M. (1977). A pattern language: Towns, buildings, construction. New York: Oxford University Press.

Appleton, J. (1996). The experience of landscape. London, New York: Wiley.

Appleyard, D. (1978). Urban trees, urban forests: What do they mean? Paper presented at the National Urban Forestry Conference, State University of New York Colledge, Syracuse, NY.

Applyard, D. (1981). Livable street. Berkeley: University of California Press.

Architectural Centre. (2011). Making porridge pancakes: Te Aro Park. Retrieved January, 2014, from http://architecture.org.nz/2011/06/24/making-porridge-pancakes-tearo-park-2/

Arefi, M. (1999). Non-place and placelessness as narratives of loss: Rethinking the notion of place. Journal of Urban Design, 4(2), 179-193.

Arendt, H. (1958). The human condition. Chicago: University of Chicago Press.

Balling, J. D., \& Falk, J. H. (1982). Development of visual preference for natural environments. Environment and behavior, 14(1), 5-28.

Banerjee, T. (2001). The future of public space: beyond invented streets and reinvented places. Journal of the American Planning Association, 67(1), 9-24.

Bechtel, R. B., \& Zeisel, J. (1987). Observation: The world under a glass. In R. B. Bechtel, R. W. Marans \& W. M. Michelson (Eds.), Methods in environmental and behavioral research (pp. 11-40). New York: Van Nostrand.

Beer, A. R. (1991). Urban design: The growing influence of environmental psychology. Journal of environmental psychology, 11(4), 359-371.

Benn, S. I., \& Gaus, G. F. (1983). Public and private in social life. London, New York: St. Martin's Press.

Bettencourt, L. M., Lobo, J., Helbing, D., Kühnert, C., \& West, G. B. (2007). Growth, innovation, scaling, and the pace of life in cities. Proceedings of the National Academy of Sciences, 104(17), 7301-7306.

Boyer, E. L. (1990). Scholarship reconsidered: Priorities of the professoriate. Stanford, CA.: Carnegie Foundation for the advancement for teaching.

Breines, S. (1969). Planning for pedestrians. In W. N. Seymour (Ed.), Small urban spaces: The philosophy, design, sociology, and politics of vest-pocket parks and other small urban open spaces (pp. 13-22). New York: New York University Press.

Brill, M. (1989). Transformation, nostalgia, and illusion in public life and public place. In I. Altman \& E. H. Zube (Eds.), Public places and spaces. New York: Plenum Press. 
Brown, J. M. (2012). Designing reserach using facet theory. In J. M. Brown \& E. A. Campbell (Eds.), Cambridge Handbook of Psychology (pp. 795-802). Cambrig. Retrieved from http://dx.doi.org/10.1017/CBO9780511730290.097.

Brush, R. O., \& Shafer, E. L. (1975). Application of a landscape-preference model to land management. Landscape Assessment: Values, Perceptions, \& Resources. EH Zube, RO Brush \& JG Fabos, eds.

Budruk, M., Thomas, H., \& Tyrrell, T. (2009). Urban green spaces: A study of place attachment and environmental attitudes in India. Society and Natural Resources, 22(9), 824-839.

Busch, L. (1989). Irony, tragedy, and temporality in agricultural systems, or, how values and systems are related. Agriculture and Human Values, 6(4), 4-11.

Canter, D. (1977a). The psychology of place. London: Architectural Press.

Canter, D. (1982). Facet approach to applied research. Perceptual and Motor Skills, 55(1), 143-154.

Canter, D. (1983a). The potential of Facet Theory for applied social psychology. Quality \& Quantity, 17(1), 35-67.

Canter, D. (1983b). The Purposive Evaluation of Places: A Facet Approach. Environment and behavior, 15(6), 659-698.

Canter, D. (1997b). The facets of place. In G. T. Moore \& R. W. Marans (Eds.), Toward the integration of theory, methods, research and utilization (Vol. 4, pp. 110-145). New York: Plenum Press.

Canter, D. (2008). Do we need a metatheory of the built environment? Building Research \& Information, 36(6), 663-667.

Canter, D., \& Kenny, C. (1981). The multivariate structure of design evaluation: A cylindrex of nurses' conceptualizations. Multivariate Behavioral Research, 16(2), 215-236.

Canter, D., \& Kenny, C. (1982). Approaches to environmental evaluation: an introduction. Applied Psychology, 31(2), 145-151.

Canter, D., \& Rees, K. (1982). A multivariate model of housing satisfaction. Applied Psychology, 31(2), 185-207.

Carmona, M. (2010). Public places, urban spaces:The dimensions of urban design (2nd ed.). Amsterdam; Boston: Architectural Press/Elsevier.

Carmona, M., de Magalhães, C., \& Hammond, L. (2008). Public space:The management dimension. New York: Routledge.

Carr, S., Francis, M., Rivlin, L., \& Stone, A. (1992). Public space. Cambridge, U.K.: Cambridge University Press.

Casey, E. S. (1997). The fate of place: A philosophical history. Berkeley: University of California Press

Catt, R. (1995). Small urban spaces. Structural Survey, 13(2), 21-25.

Chadwick, G. F. (1966). The park and the town. London: Architectural Press. 
Chiesura, A. (2004). The role of urban parks for the sustainable city. Landscape and Urban Planning, 68(1), 129-138.

Cities. (2014). Urban design theory and practice:some questions for future reserach. Retrieved Aguest, 2014, from http://developmentandurbanism.com/urbandesign-theory-practice-some-questions-for-future-research/

Coley, R. L., Sullivan, W. C., \& Kuo, F. E. (1997). Where Does Community Grow? The social context created by nature in urban public housing. Environment and behavior, 29(4), 468-494.

Cosco, N. G., Moore, R. C., \& Islam, M. Z. (2010). Behavior mapping: A method for linking preschool physical activity and outdoor design. Medicine \& Science in Sports \& Exercise, 42(3), 513-519.

Cranz, G. (1978). Changing roles of urban Parks - from pleasure ground to open space. Landscape and Urban Planning, 22(3), 9-18.

Cresswell, T. (2009). Place. In K. Rob \& T. Nigel (Eds.), International Encyclopedia of Human Geography (pp. 169-177). Oxford: Elsevier.

Crouch, D. P. (1981). The historical development of urban open space In L. Taylor (Ed.), Urban open spaces (Rev. ed.). New York: Rizzoli.

Crowe, N. (1995). Nature and the idea of a man-made world: An investigation into the evolutionary roots of form and order in the built environment. Cambridge, Mass.: MIT Press.

Dempsey, N. (2008). Quality of the built environment in urban neighbourhoods. Planning, Practice \& Research, 23(2), 249-264.

Dempsey, N. (2012). Neighbourhood Design: Green Space and Parks. In S. J. Smith (Ed.), International Encyclopedia of Housing and Home (pp. 12-20). San Diego: Elsevier.

Dovey, K. (2010). Becoming places: Urbanism/architecture/identity/power. London; New York: Routledge.

Driver, B. L., \& Greene, P. (1977). Man's nature: Innate determinants of response to natural environments. Paper presented at the Symposium-FAir. USD Forest Service Report NE:30 Whashington, D.C.

Deapartment of Economic and Social Affairs. (2009), World Population Prospects: The 2004 Revision: United Nations.

Elden, S. (2009). Space In K. Rob \& T. Nigel (Eds.), International Encyclopedia of Human Geography (pp. 262-267). Oxford: Elsevier.

Evans, G. W., Smith, C., \& Pezdek, K. (1982). Cognitive maps and urban form. Journal of the American Planning Association, 48(2), 232-244.

Fajardo, J. (2007). Small squares: Mini plazas. Barcelona: Monsa.

Forsyth, A., Musacchio, L., \& Fitzgerald, F. (2005). Designing small parks: a manual addressing social and ecological concerns. New Jersy: John Wiley \& Sons, Inc.

Francis, M. (1987). Urban open spaces. Advances in environment, behaviour, and design, $1,7$. 
Francis, M. (1989). Control as a dimension of public-space quality. In I. Altman \& E. H. Zube (Eds.), Public places and spaces (Vol. 10, pp. 147-172). New York: Plenum Press.

Francis, M. (2003). Urban open space: Designing for user needs (Vol. 3). Washington, DC: Island Press.

Frank, L., Engelke, P., \& Schmid, T. (2003). Health and community design: The impact of the built environment on physical activity. Washington DC: Island Press.

Gehl, J. (1987). Life between buildings: Using public space. Washington, DC: Island Press.

Gehl, J., \& Gemzoe, L. (1996). Public spaces-public life. Copenhagen: Arkitektens Forlag.

Gehl, J., \& Gemzøe, L. (2003). New city spaces (3rd ed.). Copenhagen: Danish Architectural Press.

Gehl , J., \& Wellington City Council. (2004). City to waterfront: Public spaces and public life study: Wellington, October 2004. Wellington, N.Z.: Wellington City Council.

Getz, D. A., Karow, A., \& Kielbaso, J. J. (1982). Inner city pereferences for trees and urban foresty programs1 Age, 20, 20-30.

Gibson, J. J. (1950). The perception of the visual world. Boston: Houghton Mifflin.

Gibson, J. J. (1977). The Theory of Affordance. In R. E. Shaw \& J. Bransford (Eds.), Peceiving, acting, and knowing. Hillsdale, N.J.: Elrbaum.

Gibson, J. J. (1979). The ecological approach to visual perception. Boston: Houghton Mifflin.

Gifford, R. (2014). Environmental psychology matters. Annual review of psychology, 65, 541-579.

Glacken, C. J. (1967). Traces on the Rhodian shore; nature and culture in Western thought from ancient times to the end of the eighteenth century. Berkeley: University of California Press.

Gold, J. R. (1980). An introduction to behavioural geography. Oxford; New York: Oxford University Press.

Gold, S. M. (1976). Social benefits of trees in urban environments. International journal of environmental studies, 10(1), 85-90.

Gold, S. M. (1977). Neighborhood Parks the nonuse phenomenon. Evaluation Review, 1(2), 319-328.

Golicnik, B. (2011). Analysis of patterns of spatial occupancy in urban open space using behaviour maps and GIS. Urban Design International, 16(1), 36-50.

Golicnik, B., \& Marusic, D. (2012). Behavioural maps and GIS in place evaluation and design. In B. M. Alam (Ed.), Application of Geographic Information System (pp. 113-138).

Golicnik, B., \& Thompson, C. W. (2010). Emerging relationships between design and use of urban park spaces. Landscape and Urban Planning, 94(1), 38-53.

Gordon, C. (2011). Midland Park. Landscape Architecture New Zealand, Jul(10), 21-23.

Gough, G. (1985). Resaons for slimming and weight loss. In D. V. Canter (Ed.), Facet Theory: 
Approaches to social research (pp. 245-259). New York: Springer.

Grahn, P., \& Stigsdotter, U. A. (2003). Landscape planning and stress. Urban Forestry \& Urban Greening, 2(1), 1-18.

Greeno, J. G. (1994). Gibson's affordances. Psychological Review(101), 336-342.

Greider, T., \& Garkovich, L. (1994). Landscapes: The social construction of nature and the environment. Rural Sociology, 59(1), 1-24.

Groat, L. (1984). Public opinion of contextual fit. Journal of American Institute of Architects, 73, 72-75.

Groves, M. A. (1992). Beyond spatial representation. Quality and Quantity, 26(1), 49-59.

Groves, M. A., \& Wilson, V. F. (1993). To move or not to move? Factors influencing the housing choice of elderly persons. Journal of Housing For the Elderly, 10(1-2), 3347.

Gustafson, P. (2001). Meanings of place: Everyday experience and theoretical conceptualizations. Journal of environmental psychology, 21(1), 5-16.

Gutman, L. (1968). A general nonmetric technique for finding the smallest coordinate space for a configuration of points. Psychometrika, 33(4), 469-506.

Guttman, L. (1954). A new approach to factor analysis: The radex. In P. F. Lazarsfeld (Ed.), Mathematical Thinking in the Social Sciences (pp. 258-348). New York: Free Press.

Guttman, L. (1965). A faceted definition of intelligence. Scripta hierosolymitana, 14, 166181.

Guttman, R., \& Greenbaum, C. W. (1998). Facet Theory: Its Development and Current Status. European Psychologist, 3(1), 13-36.

Halprin, L. (1981). The collective perception of cities. In L. Taylor \& Cooper-Hewitt Museum. (Eds.), Urban open spaces (Rev. ed.). New York: Rizzoli.

Halprin, L. (1982). Urban Rituals. In L. Taylor (Ed.), Cities: The forces that shape them. New York, Copper Hewitt Museum: Rizzoli.

Hans, S., Bernstein, V., \& Marcus, J. (1985). Some uses of the facet approach in childhood development. In D. V. Canter (Ed.), Facet Theory: Approaches to social research (pp. 151-172). New York: Springer.

Heft, H. (1989). Affordances and the body: An intentional analysis of Gibson's ecological approach to visual perception. Journal for the theory of social behaviour, 19(1), 130.

Heidegger, M. (1971). Building, dwelling, thinking In Poetry, language, thought (pp. 143162). New York: Harper \& Row

Herzog, T. R., Kaplan, S., \& Kaplan, R. (1982). The prediction of preference for unfamiliar urban places. Population and Environment, 5(1), 43-59.

Holden, G. (2012). A Model for Producing Reliable Urban Design Guidelines. Paper presented at the 46th Annual Conference-Architectural Science AssociationBuilding on Knowledge: Theory and Practice, Gold Coast. 
Huang, S.-C. L. (2006). A study of outdoor interactional spaces in high-rise housing. Landscape and Urban Planning, 78(3), 193-204.

Hubbard, P. J. (1992). Environment-behaviour studies and city design: A new agenda for research? Journal of environmental psychology, 12(3), 269-279.

Hull, R. B., \& Harvey, A. (1989). Explaining the emotion people experience in suburban parks. Environment and behavior, 21(3), 323-345.

Ittelson, W. H. (1973). Environment perception and contemporary perceptual theory. Environment and cognition, 1-19.

Ittelson, W. H., Rivlin, L. G., \& Proshansky, H. M. (1970). The use of behavioral maps in environmental psychology. In W. H. Ittelson, L. G. Rivlin \& H. M. Proshansky (Eds.), Environmental psychology: Man and his physical setting (pp. 658-668). New York: Holt, Rinehart \& Winston.

Iwashita, H. (1988). Pocket park. Tokyo, Japan: Process Architecture Pub. Co.

Jacobs, J. (1961). The death and life of great American cities. New York: Vintage Books.

Jacobs, J. (1969). The uses of neigborhood Parks. In W. N. Seymour (Ed.), Small urban spaces: The philosophy, design, sociology, and politics of vest-pocket parks and other small urban open spaces (pp. 43-58). New York: New York University Press.

Jamieson, S. (2004). Likert scales: how to (ab) use them. Medical Education, 38(12), 12171218.

Jenkins, H. S. (2008). Gibson's "affordances": Evolution of a pivotal concept. Journal of Scientific Psychology, 12(2008), 34-45.

Joardar, S. D. (1977). Emotional and behavioral responses of people to urban plazas: A case study of downtown Vancouver. (PhD), University of British Columbia.

Jones, K., \& Wills, J. (2005). The invention of the park: Recreational landscapes from the garden of eden to disney's magic kingdom. Cambridge: Polity.

Jordaan, T., Puren, K., \& Roos, V. (2008). The meaning of place-making in planning: historical overview and implications for urban and regional planning: review article. Acta Structilia: Journal for the Physical and Development Sciences, 15(1), 91-117.

Kaplan, R. (1983). The role of nature in the urban context. In I. Altman \& K. Christensen (Eds.), Environment and behavioural studies (Vol. 6, pp. 127-161). New York: Plenum Press.

Kaplan, S. (1987). Aesthetics, affect, and cognition environmental preference from an evolutionary perpective. Environment and behavior, 19(1), 3-32.

Kaplan, S. (1995). The restorative benefits of nature: Toward an integrative framework. Journal of environmental psychology, 15(3), 169-182.

Kaplan, S., \& Kaplan, R. (1978). Humanscape: Environment for people (S. Kaplan \& R. Kaplan Eds.). Ann Arbor Mich: Ulrich.

Kaplan, S., \& Kaplan, R. (1982). Cognition and environmnet: Coping in an uncertain world. New York: Praeger. 
Kaplan, S., Kaplan, R., \& Brown, T. (1989). Environmental Preference. Environment and Behaviour, 21(5), 509-530.

Kaplan, S., Kaplan, R., \& Wendt, J. S. (1972). Rated preference and complexity for natural and urban visual material. Perception \& Psychophysics, 12(4), 354-356.

Karmanov, D., \& Hamel, R. (2008). Assessing the restorative potential of contemporary urban environment (s): Beyond the nature versus urban dichotomy. Landscape and Urban Planning, 86(2), 115-125.

Kirk, W., Lösch, A., \& Berlin, I. (1963). Problems of geography. Geography, 48(4), 357-371.

Knecht, C. (2004). Urban nature and well-being: Some empirical support and design implications. Berkeley Planning Journal, 1, 82-108.

Knox, P. (2005). Creating ordinary places: Slow cities in a fast world. Journal of Urban Design, 10(1), 1-11.

Kruskal, J. B. (1964). Multidimensional scaling by optimizing goodness of fit to a nonmetric hypothesis. Psychometrika, 29(1-27).

Kuo, F. E., Bacaicoa, M., \& Sullivan, W. C. (1998). Transforming inner-city landscapes trees, sense of safety, and preference. Environment and behavior, 30(1), 28-59.

Kuo, F. E., Sullivan, W., Coley, R., \& Brunson, L. (1998). Fertile Ground for Community: Inner-City neighborhood common spaces. American Journal of Community Psychology, 26(6), 823-851.

Kuo, F. E., \& Sullivan, W. C. (2001). Aggression and violence in the inner city. Environment and Behaviour, 33(4), 543-571.

Kyttä, M. (2003). Children in outdoor contexts: Affordances and independent mobility in the assessment of environmental child friendliness. (Ph.D), Helsinki University of Technology.

Lang, J. (1994). Urban design: The American experience. New York: Van Nostrand Reinhold.

Lapage, W. (2007). Parks for life: Moving the goal posts, changing the rules, and expanding the field. State College, Pennsylvania: Venture Publishing, Inc.

Lawrence, H. W. (1993). The greening of the squares of London: transformation of urban landscapes and ideals. Annals of the Association of American Geographers, 83(1), 90-118.

Lefebvre, H. (1991). The production of space. Oxford, U.K.: Blackwell.

Lennard, S. H. C., \& Lennard, H. L. (1987). Livable Cities: People and Places: Social and Design Principles for the Future of the City. New York: Gondolier Press

Lennard, S. H. C., \& Lennard, H. L. (1995). Livable cities observed: A source book of images and ideas for city officials, community leaders, architects, planners and all other committed to making their cities livable. Carmel, CA: Gondolier Press.

Levy, S. (2005). Guttman, Louis. Encyclopedia of social measurement, 2, 175-188.

Levy, S., \& Guttman, L. (1985). A faceted cross-cultural analysis of some core social values. In D. V. Canter (Ed.), Facet Theory: Approaches to social research (pp. 205-221). 
New York: Springer.

Lewicka, M. (2011). Place attachment: How far have we come in the last 40 years? Journal of environmental psychology, 31(3), 207-230.

Linovski, O., \& Loukaitou-Sideris, A. (2013). Evolution of Urban Design Plans in the United States and Canada What Do the Plans Tell Us about Urban Design Practice? Journal of Planning Education and Research, 33(1), 66-82.

Longstaffe-Gowan, T. (2012). The London Square: Gardens in the midst of town. New Haven: Yale University Press.

Lynch, K. (1960). The image of the city. Cambridge, Mass.: Massachusetts Institute of Technology Press.

Lyons, E. (1983). Demographic correlates of landscape preference. Environment and Behaviour, 15(4), 487-511.

Madanipour, A. (1996). Design of urban space: An inquiry into a socio-spatial process. Chichester; New York: Wiley.

Madanipour, A. (2003). Public and private spaces of the city. New York: Routledge.

Marcus, C. C. (1982). The aesthetics of family housing: The residents' viewpoint. Landscape Research, 7(3), 9-13.

Marcus, C. C., \& Francis, C. A. (1998). People places: Design guidelines for urban open space (2nd ed.). New York: Van Nostrand Reinhold.

Marcus, C. C., \& wischemann, T. (1998). Campus outdoor spaces. In C. C. Marcus \& C. A. Francis (Eds.), People places: Design guidelines for urban open space (pp. 175-206). New York: Van Nostrand Reinhold.

Markus, T. A. (1982). Order in space and society: Architectural form and its context in the Scottish Enlightenment (Vol. 1882). Edinburgh: Mainstream.

Markus, T. A. (1987). Buildings as classifying devices. Environment and Planning B: Planning and Design, 14(4), 467-484.

Martyn, R. (2011). Dreamy city without green spaces: Glover Park Project. Retrieved January 2014, from http://www.enjoy.org.nz/node/1156.

Marx, K. (1977). Capital (Vol. 1). London: Lawrence and Wishart.

Maslow, A. H. (1954). Motivation and personality (2d ed.). New York: Harper \& Row.

Massey, D. B. (1994). Space, place, and gender. Cambridge: Polity Press.

McGlynn, S., Smith, G., Alcock, A., Murrain, P., \& Bently, I. (1985). Responsive environments. Amesterdam, Boston: Architectural Press.

McHarg, I. L. (1969). Design with nature. New York: John Wiley \& Sons.

McIntosh, C. (2005). Gardens of the gods : Myth, magic and meaning. London: I. B. Tauris.

McLeod, S. A. (2007). Maslow's Hierarchy of Needs. Retrieved Aguest 2014, from http://www.simplypsychology.org/maslow.html

Mehta, V. (2006). Lively streets: Exploring the relationship between build environment and social behaviour. (PhD), University of Maryland. 
Michelson, W. M. (1975). Behavioural research methods in environmental design: Dowden, Hutchinson \& Ross.

Miskell, B., \& Straatviet, R. (2011). Central city framework. Retrieved January, 2012, from http://www.wellington2040.co.nz,

Montgomery, J. (1998). Making a city: Urbanity, vitality and urban design. Journal of Urban Design, 3(1), 93-116.

More, T. A. (1985). Central city parks: A behavioural perspective. Burlington: School of Natural Resources, University of Vermont.

Motloch, J. L. (2000). Introduction to landscape design (2 ed.). New York: Wiley.

Moudon, A. V. (1992). A catholic approach to organizing what urban designers should know. Journal of Planning Literature, 6(4), 331-349.

Mumford, L. (1969). The philosophy of urban open space. In W. N. Seymour (Ed.), Small urban spaces: The philosophy, design, sociology, and politics of vest-pocket parks and other small urban open spaces (pp. 13-22). New York: New York University Press.

Murray, C. (n.d.). A Critical and Interdisciplinary Theory for Urban Design. Retrieved Aug 2014, from http://www.henley.ac.uk/people/person/dr-claudia-murray/

Nasar, J. L. (1989). Perception, cognition, and evaluation of urban places. In I. Altman \& E. H. Zube (Eds.), Public places and spaces (Vol. 10, pp. 31-56). New York: Plenum Press.

Nasar, J. L. (1994). Urban design aesthetics the evaluative qualities of building exteriors. Environment and behavior, 26(3), 377-401.

Neuvonen, M., Sievänen, T., Tönnes, S., \& Koskela, T. (2007). Access to green areas and the frequency of visits-a case study in Helsinki. Urban Forestry \& Urban Greening, 6(4), 235-247.

Nielsen, T. S., Hovgesen, H. H., Lassen, C., \& Godtved, S. (2005). The potential for the exploration of activity patterns in the urban landscape with GPS-positioning and electronic activity diaries. Paper presented at the International Conference for Integrating Urban Knowledge and Practice, Gothenburg.

Nilsson, K., Sangster, M., Gallis, C., Hartig, T., De Vries, S., Seeland, K., \& Schipperijn, J. (2011). Forests, trees and human health. Dordrecht: Springer Science, Business Media B.V.

Norberg - Schulz, C. (1996). The phenomenon of place. In K. Nesbitt (Ed.), Theorizing a New Agenda for Architecture: An anthology of Architectural Theory 1965-1995 (pp. Ch 9 ). New York: Princeton Architectural Press.

Nordh, H., Alalouch, C., \& Hartig, T. (2011). Assessing restorative components of small urban parks using conjoint methodology. Urban Forestry \& Urban Greening, 10(2), 95-103.

Nordh, H., Hartig, T., Hagerhall, C. M., \& Fry, G. (2009). Components of small urban parks that predict the possibility for restoration. Urban Forestry \&amp; Urban Greening, 8(4), 225-235. doi: 10.1016/j.ufug.2009.06.003 
Nordh, H., \& Østby, K. (2013). Pocket parks for people-A study of park design and use. Urban Forestry \& Urban Greening, 12(1), 12-17.

Palermo, P. C. (2014). What ever is happening to urban planning and urban design? Musings on the current gap between theory and practice. City, Territory and Architecture, 1(7), 1-9.

Paquot, T. (2005). City and Nature, a Missed Opportunity? Diogenes, 52(3), 65-74.

Pasaogullari, N., \& Doratli, N. (2004). Measuring accessibility and utilization of public spaces in Famagusta. Cities, 21(3), 225-232.

Pearce, D., Barbier, E., \& Markandya, A. (1990). Sustainable development: economics and environment in the Third World. London: Edward Elgar.

Peschardt, K. K., \& Stigsdotter, U. K. (2013). Associations between park characteristics and perceived restorativeness of small public urban green spaces. Landscape and Urban Planning, 112, 26-39.

Porteous, J. D., \& Douglas, J. (1977). Environment \& behaviour: Planning and everyday urban life. Reading, Mass.: Addison-Wesley

Prest, J. M., \& Prest, J. (1981). The Garden of Eden: The botanic garden and the re-creation of paradise: New Haven and London: Yale University Press.

Project for public space. (2000). How to turn a plae around: A handbook for creating successful public spaces. New York: Project for Public Spaces.

Proshansky, H. M., Fabian, A. K., \& Kaminoff, R. (1983). Place-identity: Physical world socialization of the self. Journal of environmental psychology, 3(1), 57-83.

Punter, J. (1991). Participation in the design of urban space. Landscape Design, 200, 2427.

Putnam, R. D. (1995). Bowling alone: America's declining social capital. Jouenal of Democeacy, 6, 68.

Putnam, R. D. (1996). The strange disappearance of civic America. American Prospect, 24, 34-49.

Rapoport, A. (1977). Human aspects of urban form: towards a man-environment approach to urban form and design. Oxford: Pergamon Press

Rapoport, A. (1982). The meaning of the built environment: A nonverbal communication approach. Beverly Hills: Sage Publications.

Rapoport, A., \& Hawkes, R. (1970). The perception of urban complexity. Journal of the American Institute of Planners, 36(2), 106-111.

Relph, E. C. (1976). Place and placelessness. London: Pion.

Robbins, I., S. (1969). Tenants' garden in public housing. In W. N. Seymour (Ed.), Small urban spaces: The philosophy, design, sociology, and politics of vest-pocket parks and other small urban open spaces (pp. 139-148). New York: New York University Press.

Robert, N. B., Richard, M., Sullivan, M. W., Ann, S., \& Tipton, M. S. (1985). Habits of the heart: Individualism and commitment in Americanlife. New York: Harper \& Row. 
Rostami Bookani, S. (2013). Exploring the effect of changing public transit on users' behaviour in Saint George's square. (M A thesis), The University of Guelph, Ontario, Canda.

Russell, J. A., \& Pratt, G. (1980). A description of the affective quality attributed to environments. Journal of personality and social psychology, 38(2), 311.

Schipperijn, J., Bentsen, P., Troelsen, J., Toftager, M., \& Stigsdotter, U. K. (2013). Associations between physical activity and characteristics of urban green space. Urban Forestry \& Urban Greening, 12(1), 109-116.

Schon, D. A. (1983). The reflective practitioner: How professionals think in action. New York Basic Books.

Schon, D. A. (1991). The reflective practitioner: How professionals think in action. Great Britain: Arena, Ashgate Publishing Limitted.

Seamon, D., \& Sowers, J. (2008). Place and Placelessness, Edward Relph. In P. Hubbard, R. Kitchin \& G. Valentine (Eds.), Key texts in human geography (pp. 43-51). London: Sage.

Sennet, R. (1978). The Fall of Public Man: On the social psychology of capitalism. New York: Cambridge University Press.

Seymour, W. N. (1969). An introduction to small urban spaces. In W. N. Seymour (Ed.), Small urban spaces: the philosophy, design, sociology, and politics of vest-pocket parks and other small urban open spaces (pp. 3-10). New York: New York University Press.

Shaftoe, H. (2008). Convivial urban spaces: Creating effective public places. London ; Sterling, VA: Earthscan in association with the International Institute for Environment and Development.

Sheehy, N. (2004). Fifty key thinkers in psychology: Psychology Press.

Sheets, V. L., \& Manzer, C. D. (1991). Affect, cognition, and urban vegetation: Some effects of adding trees along city streets. Environment and Behaviour, 23(3), 285-304.

Sherrod, D. R., \& Downs, R. (1974). Environmental determinants of altruism: The effects of stimulus overload and perceived control on helping. Journal of Experimental Social Psychology, 10(5), 468-479.

Shirom, A. (1991). A facet-theoretic approach toward theorizing in labor relations. Paper presented at the Third International Facet Theory Conference, Jerusalem.

Sitte, C. (1986). City planning according to artistic principles. New York: Rizzoli.

Skjaeveland, O., \& Garling, T. (1997). Effects of interactional space on neighbouring. Journal of environmental psychology, 17(3), 181-198.

Smardon, R. C. (1988). Perception and aesthetics of the urban environment: Review of the role of vegetation. Landscape and Urban Planning, 15(1), 85-106.

Smith, T., Nelischer, M., \& Perkins, N. (1997). Quality of an urban community: A framework for understanding the relationship between quality and physical form. Landscape and Urban Planning, 39(2), 229-241. 
Soja, E. W. (1980). The socio-spatial dialectic. Annals of the Association of American Geographers, 70(2), 207-225.

Southworth, M. (1989). Theory and practice of contemporary urban design: a review of urban design plans in the United States. Town Planning Review, 60(4), 369.

Squizlers (Lane et al). (2011). Te Aro Park, Memorial Cairn. Retrieved January 2014, from http://www.sculptures.org.nz/tours/courtenay/memorial-cairn

Steele, F. (1973). Physical settings and organizational development. Reading, Mass.: Addison-Wesley.

Stevens, S. S. (1946). On the theory of scales of measurement (Vol. 103): Bobbs-Merrill, College Division.

Stigsdotter, U. K., Ekholm, O., Schipperijn, J., Toftager, M., Kamper-Jørgensen, F., \& Randrup, T. B. (2010). Health promoting outdoor environments-Associations between green space, and health, health-related quality of life and stress based on a Danish national representative survey. Scandinavian Journal of Public Health, 36, 411-417.

Stokols, D. (1995). The paradox of environmental psychology. American Psychologist, $50(10), 821$.

Strydom, W., \& Puren, K. (2013). A participatory approach to public space design as informative for place-making. Challenges of Modern Technology, 4, 33-40.

Sullivan, W. C., Kuo, F. E., \& Depooter, S. F. (2004). The fruit of urban nature vital neighborhood spaces. Environment and behavior, 36(5), 678-700.

Svensson, E. (2001). Guidelines to statistical evaluation of data from rating scales and questionnaires. Journal of Rehabilitation Medicine, 33(1), 47-48.

Tay, L., \& Diener, E. (2011). Needs and subjective well-being around the world. Journal of personality and social psychology, 101(2), 354.

Taylor, A. F., Kuo, F. E., \& Sullivan, W. C. (2002). Views of nature and self-discipline: evidence from inner city children. Journal of environmental psychology, 22(1-2), 49-63.

Ter, Ü. (2011). Quality criteria of urban parks: The case of Alaaddın Hill (Konya-Turkey). African Journal of Agricultural Research, 6(23), 5367-5376.

Thayer Jr, R. L., \& Atwood, B. G. (1978). Plants, complexity, and pleasure in urban and suburban environments. Environmental Psychology and Nonverbal Behavior, 3(2), 67-76.

Thompson, C. W. (2002). Urban open space in the 21st century. Landscape and Urban Planning, 60(2), 59-72.

Tibbalds, F. (1992). Making people-friendly towns: Improving the public environment in towns and cities. Harlow, England: Longman.

Tuan, Y.-F. (1974a). Space and place: Humanistic perspective. In Gale \& G. Olsson (Eds.), Philosophy in geography. Dordrecht, Boston: D. Reidel Pub. Co.

Tuan, Y.-F. (1974b). Topophilia: a study of environmental perception, attitudes, and values. 
Englewood Cliffs, N.J.,: Prentice-Hall.

Tuan, Y.-F. (1977). Space and place: The perspective of experience. Minneapolis: University of Minnesota Press.

Tuan, Y.-F. (1978). Raw Emotion to Intellectual Delight-Landscape's Affective Domain. Landscape Architecture, 132-134.

Tuan, Y.-F. (1979). Landscapes of fear. New York: Pantheon Books.

Tuan, Y.-F. (1980). Rootedness versus sense of place. Landscape, 24(1), 3-8.

Tyrväinen, L., Ojala, A., Korpela, K., Lanki, T., Tsunetsugu, Y., \& Kagawa, T. (2014). The influence of urban green environments on stress relief measures: A field experiment. Journal of environmental psychology, 38(0), 1-9. doi: http://dx.doi.org/10.1016/i.jenvp.2013.12.005

Ulrich, R. S. (1976). Urbanization and garden aesthetics. Paper presented at the Longwood Seminars, 8 Longwood Botanic Gardens, Kennett Square, 4-8.

Ulrich, R. s. (1977). Visual Landscape preference: A model and application. ManEnvironment System, 4(1), 17-23.

Ulrich, R. S. (1981). Natural versus urban scenes some psychophysiological effects. Environment and Behaviour, 13(5), 523-556.

Ulrich, R. S. (1983). Aesthetic and affective response to the natural environment. In I. Altman \& J. F. Wohlwill (Eds.), Human Behavior and Environment: Advances in Theory and Research (Vol. 6, pp. 85-125). New York: Plenum Press.

Ulrich, R. S. (1986). Human responses to vegetation and landscapes. Landscape and Urban Planning, 13, 29-44.

Ulrich, R. S., \& Addoms, D. L. (1981). Psychological and recreational benefits of a residential park. Journal of Leisure Research, 13(1), 43-65.

Ulrich, R. S., Simons, R. F., Losito, B. D., Fiorito, E., Miles, M. A., \& Zelson, M. (1991). Stress recovery during exposure to natural and urban environments. Journal of environmental psychology, 11(3), 201-230.

Van den Berg, A. E., Hartig, T., \& Staats, H. (2007). Preference for nature in urbanized societies: stress, restoration, and the pursuit of sustainability. Journal of Social Issues, 63(1), 79-96.

Van den Berg, A. E., Jorgensen, A., \& Wilson, E. R. (2014). Evaluating restoration in urban green spaces: Does setting type make a difference? Landscape and Urban Planning, 127(0), 173-181. doi: http://dx.doi.org/10.1016/j.landurbplan.2014.04.012

Velarde, M. D., Fry, G., \& Tveit, M. (2007). Health effects of viewing landscapes:Landscape types in environmental psychology. Urban Forestry \& Urban Greening, 6(4), 199212.

Ward, L. M. (1977). Multidimensional scaling of the molar physical environment. Multivariate Behavioural Research, 12(1), 23-42.

Ward, L. M., \& Russell, J. A. (1981). The psychological representation of molar physical 
environments. Journal of Experimental Psychology: General, 110(2), 121.

Wellington City Council. (2008). Venue Web: CAD files of theatrical and performance venues. Retrieved May, 2011, from http://www.venueweb.co.nz/north/10 wellington/civic sq/civic.htm

Whyte, W. H. (1980). The social life of small urban spaces. Washington, D.C.: Conservation Foundation.

Williams, R. (2005). Ideas of nature. In R. Williams (Ed.), Culture and Materialism (2nd ed., pp. 67-85). London, New York: Verso.

Wohlwill, J. F. (1973). The environment is not in the head. Environmental Design Research, 2, 166-181.

Wohlwill, J. F. (1976). Environmental aesthetics: The environment as a source of affect. In I. Altman \& J. F. Wohlwill (Eds.), Human Behaviour and Environment: Advances in Theory and Research (Vol. 1). New York: Plenum Press.

Wohlwill, J. F. (1982). The visual impact of development in coastal zone areas. Coastal Management, 9(3-4), 225-248.

Wohlwill, J. F. (1983). The concept of nature: A psychologist's view. In J. F. Wohlwill \& I. Altman (Eds.), Human behaviour \& environment: Advances in theory \& research (Vol. 6, pp. 5-37). New York: Plenum Press.

Yan, W., \& Forsyth, D. A. (2005). Learning the behaviour of users in a public space through video tracking. Paper presented at the Application of Computer Vision, Breckenridge, $\mathrm{CO}$.

Yik, M., Russell, J., \& Steiger, J. (2011). A 12-point circumplex structure of core affect. Emotion, 11(4), 705-731.

Young, T. (1995). Modern urban parks. Geographical Review, 535-551.

Zajonc, R. B. (1980). Feeling and thinking: Preferences need no inferences. American Psychologist, 35(2), 151.

Zeisel, J. (1984). Inquiry by design: Tools for environment-behaviour research (Vol. 5). Cambrige U.K: Cambridge University Press.

Zion, R. L. (1969). Parks where the people are: the small midtown Park. In W. N. Seymour (Ed.), Small urban spaces: The philosophy, design, sociology, and politics of vestpocket parks and other small urban open spaces (pp. 13-22). New York: New York University Press.

Zube, E. H. (1973). The natural history of urban trees. Natural History, 82(9), 48-51.

Zube, E. H., Pitt, D. G., \& Anderson, T. W. (1975). Perception and prediction of scenic resource values of the Northeast. In E. Zube, R. Brush \& J. Fabos (Eds.), Landscape Assessment: Values, Perceptions, \& Resources. Stroudsburg: Dowden, Hutchinson \& Ross.

Zucker, P. (1970). Town and square, from the agora to the village green ([1st M.I.T. Press paperback ed.). Cambridge: M.I.T. Press. 


\section{Appendix 1 \\ Study One Questionnaire}


Dear Sir/ Madam

\section{Thank you for your interest in this survey Toward cities with welcoming, friendly and sociable public spaces}

I am a graduate in Landscape Architecture undertaking PhD research at Victoria University of Wellington. My PhD topic is sustaining public space in the city centre. I am conducting a survey to find out how people think about small outdoor public spaces in the city centre, such as the place you are now using.

I believe that for designing welcoming and friendly outdoor public space in the city centre we need to know what people imagine a good place to be. Therefore, I would like to know which kinds of places people like to go to, which elements they like more within these places and why.

As a person who has decided to use one of these outdoor spaces, I would like to ask you some questions as I believe your ideas will help toward planning more sustainable cities.

\section{It is anticipated that answering the questions will take maximum 15 minutes.}

This questionnaire consists of three parts. In the first part are questions about your age, occupation etc. The second part has several questions about your opinion of small public places. The third part is questions about this place.

If you have any questions or would like to discuss the research in more depth, please contact me by email: ghavamense@myvuw.ac.nz or by telephone: 0220742026. My primary supervisor, Professor Brenda Vale, can also be contacted by email: brenda.vale@vuw.ac.nz

If you are willing to participate in this research, please complete the attached consent form and questionnaire and return them to me.

\section{Thank you for your time}

Ensiyeh Ghavampour

Master in Landscape Architecture

$\mathrm{PhD}$ in Architecture candidate 


\section{Consent form}

\section{Sustaining public space in the city centre}

If you consent to take part in this research, I can confirm that access to your answers will be restricted to myself and my two supervisors and will be kept in a password-protected file. Five years after the conclusion of the research, these will be wiped. You are free to refuse to answer any of the questions without explanation. Parts of the thesis may be published in academic or professional journals and shared at academic or professional conferences. Approval from the Human Ethics Committee (No: 19428) has been obtained for this research.

The completed thesis will be available for you to read in the VUW School of Architecture and Design Library from the end of 2014 onwards.

Please sign and date below to validate this consent form.

I consent to participate in this research as part of a PhD in Architecture. I understand that the completed thesis will be deposited in Victoria University Library and that parts of the thesis may be published in academic or professional journals and shared at academic or professional conferences.

Signature:

Date:

Thank you for your participation in this research 
PART ONE

Please complete the questionnaire as completely as possible. There are no right or wrong answers, and your responses will be kept confidential

a. What is your gender?

Male $\square$ Female

b. What ethnicity do you consider yourself?

$\square$ NZ European $\square$ Maori $\square$ European $\square$ Pacific $\square$ Asian

Middle Eastern/Latin $\square$ American/ African $\square$ Other (please specify)

c. How old are you? ......... Years

d. What is the postcode or name of the suburb in which you live?

e. How long have you lived in Wellington?

f. What is the highest level of education you have completed?

$\square$ Tertiary (university, college) $\square$ Trade qualification $\square$ Secondary school

Other (please specify)

g. What is your current occupation?
Public service
Private Company
Self-employed
Work at home
Student
Not employed
Retired

Other

h. Do you work in the city centre?

$\square$ Yes $\square$ No

i. How often do you spend time in the public spaces in the city centre?

not at all once 2 or 3 times once a week 2 or 3 times most days every day a month a month a week

j. Tick the box that best reflects the importance of each of the following features in a public space for you, with 1 being most important and 7 least important.

- Trees and shrubs

- Amenities like café,

- Water features

- Street furniture

- Sculpture, decoration

- Grass and lawn

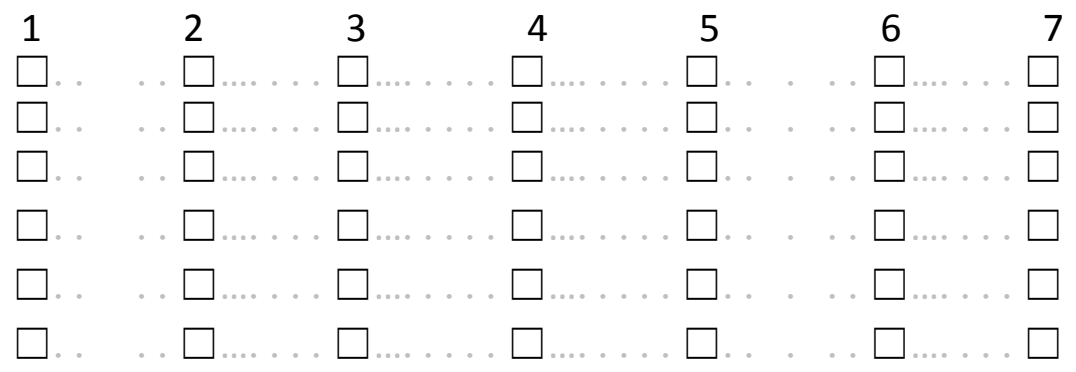

k. What are you favourite public spaces in the city centre? 
$\square$ 1- Midland Park

$\square$ 2- Grey Street

$\square$ 3- Post office Square

$\square$ 4- Queens Wharf Square

$\square$ 5- Frank Kitts Park

$\square$ 6- Jack Ilott Green $\square 7$ - Civic Square

$\square$ 8- Denton Park

$\square$ 9- Cuba mall 3

$\square 10$ Te Aro Park

$\square$ 11- Cuba Mall

$\square$ 12-Glover Park $\square$ 13- Cuba Mall1

$\square$ 14- Cobblestone Park

$\square$ 15- Courtenary PL West

$\square$ 16- Courtenary PL East

$\square$ 17- Waitiangi Park

$\square$ 18- Others please specify

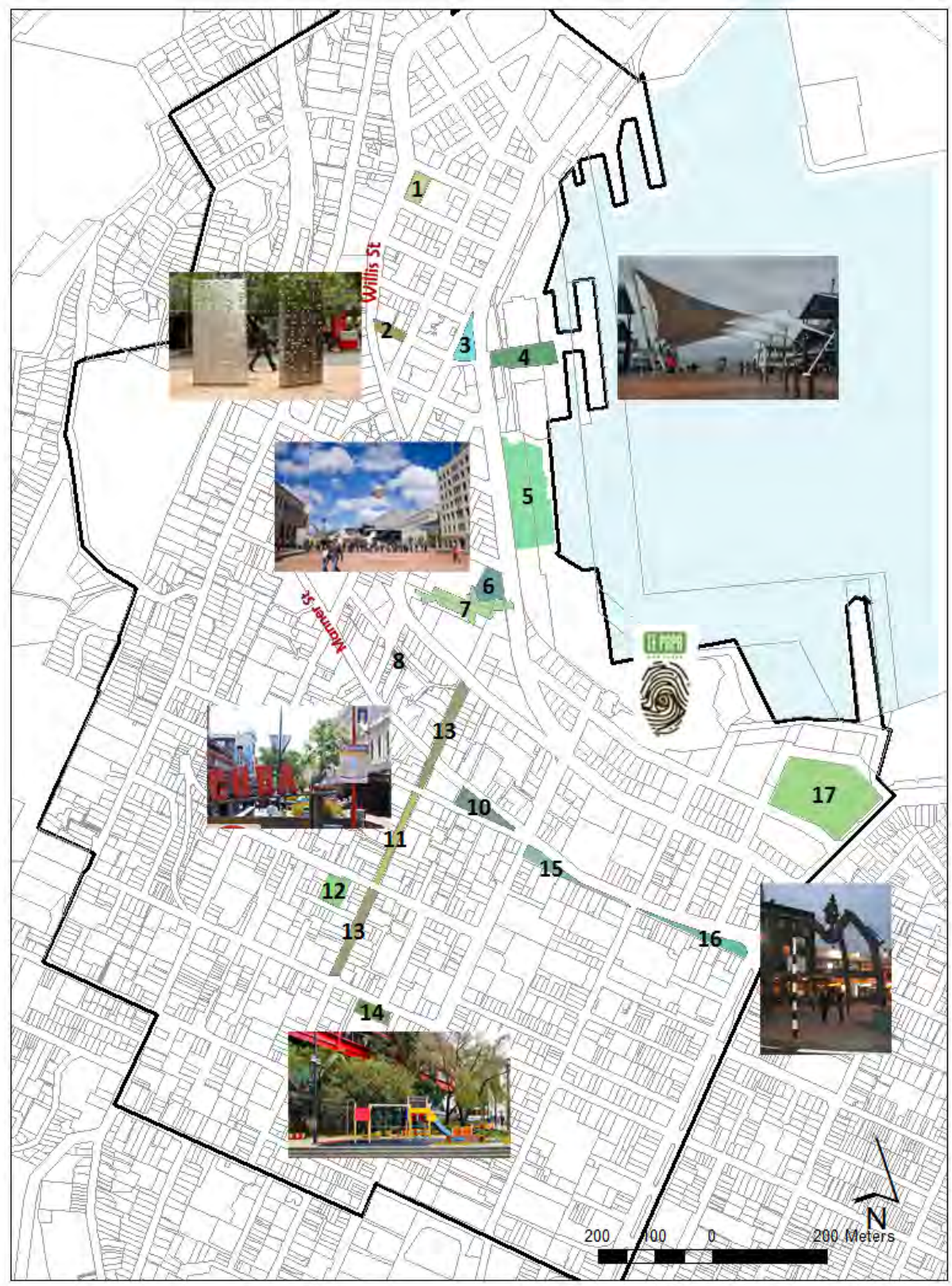


For questions 1 to 12 please tick the box that best reflects your level of agreement with each statement. For the first 6 questions assume that you are choosing a place to spend time alone and for question 6-12 assume that you are using a public open space with your friends or family.

1.When I spend time by myself in public spaces, I prefer to be in places with wood and stone furnishings because the place is ...

strongly moderately slightly neutral slightly moderately strongly disagree disagree disagree agree agree agree

- relaxing and has a special character

- exciting and has a special character

- relaxing and has a clear structure

- exciting and has a clear structure

2. When I spend time by myself in public spaces, I prefer to be in places with plastic and metal furnishing because the place is ... strongly moderately slightly neutral slightly moderately strongly
disagree disagree disagree

- relaxing and has a special character

- exciting and has a special character

- relaxing and has a clear structure

- exciting and has a clear structure

3. When I spend time by myself in public spaces, I prefer to be in places with grass, stone or wooden surfaces because the place is ...

strongly moderately slightly neutral slightly moderately strongly disagree disagree disagree agree agree agree

- relaxing and has a special character

- exciting and has a special character

- relaxing and has a clear structure

- exciting and has a clear structure

4.When I spend time by myself in public spaces, I prefer to be in places with painted, concrete or tiled surfaces because the place is ...

strongly moderately slightly neutral slightly moderately strongly disagree disagree disagree agree agree agree

- relaxing and has a special character

- exciting and has a special character

- relaxing and has a clear structure

- exciting and has a clear structure 
5.When I spend time by myself in public spaces, I prefer to be in places with trees, water and plant features because the place is ...

strongly moderately slightly neutral slightly moderately strongly disagree disagree disagree agree agree agree

- relaxing and has a special character

- exciting and has a special character

- relaxing and has a clear structure

- exciting and has a clear structure

6. When I spend time by myself in public spaces, I prefer to be in places with sculptures, artefacts and decorative features because the place is ...

strongly moderately slightly neutral slightly moderately strongly disagree disagree disagree agree agree agree

- relaxing and has a special character

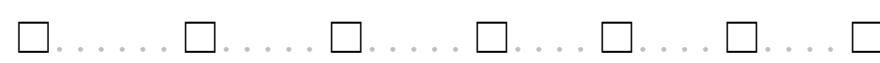

- exciting and has a special character

- relaxing and has a clear structure

- exciting and has a clear structure

7.When I spend time with my friends in public spaces, I prefer to be in places with wood and stone furnishings because the place is ... $\begin{array}{llccc}\text { strongly moderately } & \text { slightly neutral } & \text { slightly moderately } & \text { strongly } \\ \text { disagree disagree disagree } & \text { agree } & \text { agree } & \text { agree }\end{array}$

- relaxing and has a special character

- exciting and has a special character

- relaxing and has a clear structure

- exciting and has a clear structure

8. When I spend time with my friends in public spaces, I prefer to be in places with plastic and metal furnishings because the place is ...

strongly moderately slightly neutral slightly moderately strongly

- relaxing and has a special character

disagree disagree disagree agree agree agree

- exciting and has a special character

- relaxing and has a clear structure

- exciting and has a clear structure

9. When I spend time with my friends in public spaces, I prefer to be in places with grass, stone or wooden surfaces because the place is ...

strongly moderately slightly neutral slightly moderately strongly disagree disagree disagree agree agree agree

- relaxing and has a special character

- exciting and has a special character

- relaxing and has a clear structure

- exciting and has a clear structure

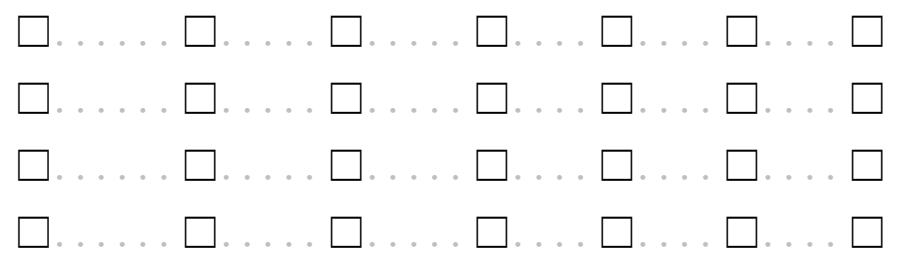


10. When I spend time with my friends in public spaces, I prefer to be in places with painted, concrete or tiled surfaces because the place is ...

strongly moderately slightly neutral
disagree dightly moderately strongly

- relaxing and has a special character

- exciting and has a special character

- relaxing and has a clear structure

- exciting and has a clear structure

11. When I spend time with my friends in public spaces, I prefer to be in places with trees, water and plant features because the place is...

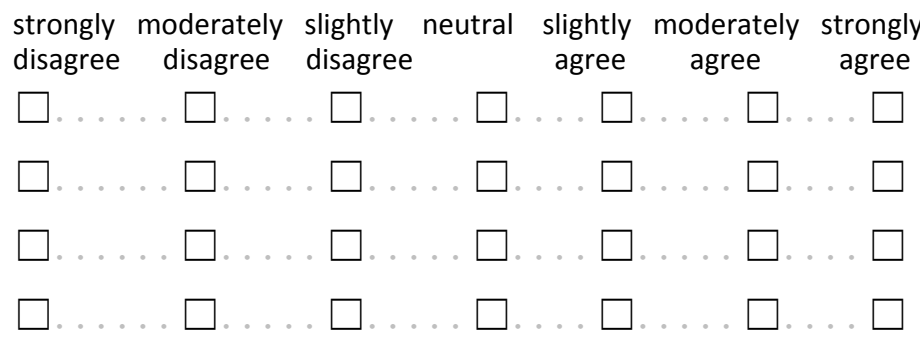

- relaxing and has a special character disagree disagree disagree agree agree agree

- exciting and has a special character

- relaxing and has a clear structure

- exciting and has a clear structure

12.When I spend time with my friends in public spaces, I prefer to be in places with sculptures, artefacts and decorative features because the place is ...

$\begin{array}{llll}\text { strongly moderately slightly neutral slightly moderately strongly } & \text { sog } \\ \text { disagree disagree disagree } & \text { agree agree } & \text { agree }\end{array}$

- relaxing and has a special character

- exciting and has a special character

- relaxing and has a clear structure

- exciting and has a clear structure

i. Please add any further comments you have about the design of public open space. 
Appendix 2

Study Two Questionnaire 
Dear Sir/ Madam

\section{Thank you for your interest in this survey Toward cities with welcoming, friendly and sociable public spaces}

I am a graduate in Landscape Architecture undertaking PhD research at Victoria University of Wellington. My PhD topic is sustaining public space in the city centre. I am conducting a survey to find out how people think about small outdoor public spaces in the city centre, such as the place you are now using.

I believe that for designing welcoming and friendly outdoor public space in the city centre we need to know what people imagine a good place to be. Therefore, I would like to know which kinds of places people like to go to, which elements they like more within these places and why.

As a person who has decided to use one of these outdoor spaces, I would like to ask you some questions as I believe your ideas will help toward planning more sustainable cities.

It is anticipated that answering the questions will take maximum 15 minutes.

This questionnaire consists of three parts. In the first part are questions about your age, occupation etc. The second part has several questions about your opinion of small public places. The third part is questions about this place.

If you have any questions or would like to discuss the research in more depth, please contact me by email: ghavamense@myvuw.ac.nz or by telephone: 0220742026. My primary supervisor, Professor Brenda Vale, can also be contacted by email: brenda.vale@vuw.ac.nz

If you are willing to participate in this research, please complete the attached consent form and questionnaire and return them to me.

\section{Thank you for your time}

Ensiyeh Ghavampour

Master in Landscape Architecture

PhD in Architecture candidate 


\title{
Consent form
}

\section{Sustaining public space in the city centre}

If you consent to take part in this research, I can confirm that access to your answers will be restricted to myself and my two supervisors and will be kept in a password-protected file. Five years after the conclusion of the research, these will be wiped. You are free to refuse to answer any of the questions without explanation. Parts of the thesis may be published in academic or professional journals and shared at academic or professional conferences. Approval from the Human Ethics Committee (No: 19428) has been obtained for this research.

The completed thesis will be available for you to read in the VUW School of Architecture and Design Library from the end of 2014 onwards.

Please sign and date below to validate this consent form.

I consent to participate in this research as part of a PhD in Architecture. I understand that the completed thesis will be deposited in Victoria University Library and that parts of the thesis may be published in academic or professional journals and shared at academic or professional conferences.

Signature:

Date:

Thank you for your participation in this research

\author{
Ensiyeh Ghavampour \\ Master in Landscape Architecture \\ PhD in Architecture candidate
}


PART ONE

Please answer the questionnaire as completely as possible. There are no right or wrong answers, and your responses will be kept confidential

a. What is your gender?

$\square$ Male $\square$ Female

b. What ethnicity do you consider yourself?
NZ European
Maori
European
Pacific
Asian

Middle Eastern/Latin $\square$ American/ African $\square$ Other (please specify)

c. How old are you? ........ Years

d. What is the postcode or name of the suburb in which you live?

e. How long have you lived in Wellington?

$f$. What is the highest level of education you have completed?

Tertiary (university, college) $\square$ Trade qualification $\square$ Secondary school

Other (please specify)

g. What is your current occupation?

Public service $\square$ Private Company $\square$ Self-employed $\square$ Work at home

Student $\square$ Not employed $\square$ Retired $\quad \square$ Other.

h.Do you work in the city centre?

\section{Yes $\square$ No}

i.How often do you spend time in the public spaces in the city centre?

not at all once 2 or 3 times once a wee 2 or 3 time most days every day a month a month a week

j. Tick the box that best reflects the importance of each of the following factors in public space for you, with 1 being most important and 7 least important.

Various grass areas for sitting

Variety of benches

Fountain, pool, trees as focal points

Public art, sculpture and decorative features

Sunny and shady areas using trees and shrubs

Sunny and shady areas using man-made shelters Intimate spaces created by trees and plants

Intimate spaces created by steps and low walls

Trees and plants with appropriate scale around the edge

Buildings with appropriate scale around the edge

Native and local plants

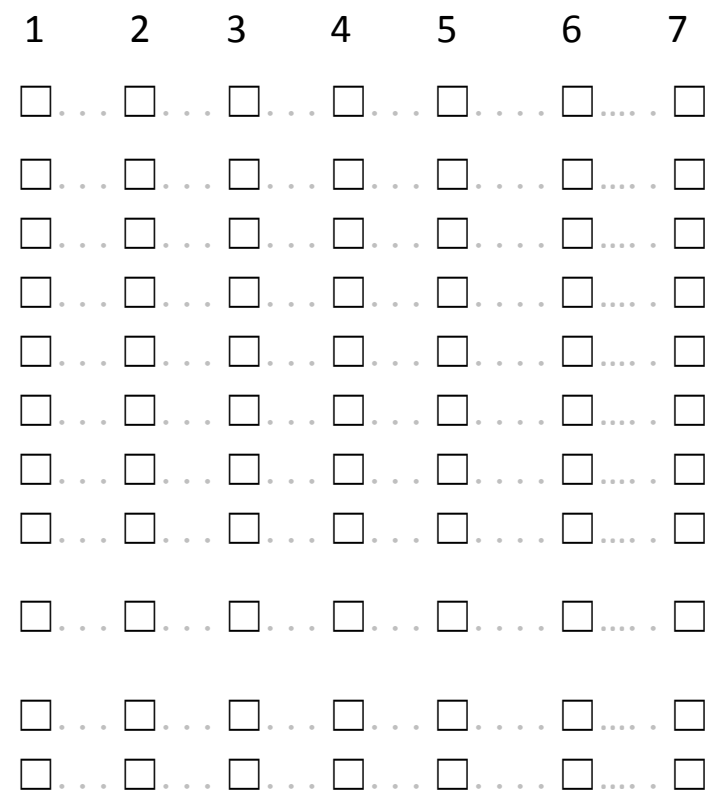


Familiar architectural style

$\begin{array}{lllllll}1 & 2 & 3 & 4 & 5 & 6 & 7\end{array}$

Well maintained greenery

Clean and well kept surfaces

Welcoming and visible threshold or entrance defined by trees and plants

Welcoming and visible threshold or entrance defined by man made elements

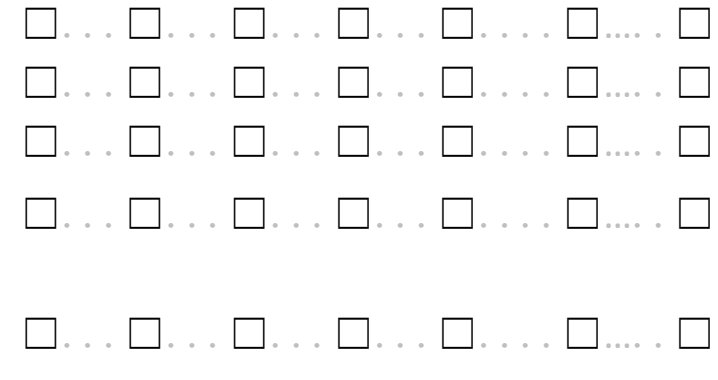

k. For which activity do you usually come to a public open space? Please tick all that apply

$\begin{array}{ll}\square \text { 1- walking through } & \square \text { 7- meeting with family or friends } \\ \square \text { 2- sitting, watching } & \square \text { 8- walking or playing with dog } \\ \square \text { 3- reading } & \square \text { 9- watching local events or festivals } \\ \square \text { 4- working } & \square \text { 10- exercise/sport } \\ \square \text { 5- eating/ drinking } & \square \text { 11- relaxing and seeing nature } \\ \square \text { 6- talking on the phone } & \square \text { 12- other (please specify) }\end{array}$




\section{PART TWO}

\section{For questions 1 to 32 please tick one box in each line that best reflects your level of agreement with each statement.}

1a. Public spaces which have grass areas for sitting, and also people around are pleasant for...

- Meeting friends or being with my family strongly moderately slightly neutral slightly moderately strongly disagree disagree disagree agree agree agree

- Chance contact with new people

- Spending time alone and watching people

1b. Public spaces which have grass areas for sitting, and also nearby places to eat are pleasant for...

- Meeting friends or being with my family strongly moderately slightly neutral slightly moderately strongly disagree disagree disagree agree agree agree

- Chance contact with new people

- Spending time alone and watching people

2a. Public spaces which have different types of bench, and also people around are pleasant for...

- Meeting friends or being with my family strongly moderately slightly neutral slightly moderately strongly disagree disagree disagree agree agree agree

- Chance contact with new people

- Spending time alone and watching people

$2 b$. Public spaces which have different types of bench, and also nearby places to eat are pleasant for...

- Meeting friends or being with my family

- Chance contact with new people

- Spending time alone and watching people

strongly moderately slightly neutral slightly moderately strongly disagree disagree disagree agree agree agree

3a. Public spaces which have places to sit around fountain, pool, trees, and also people around are pleasant for...

- Meeting friends or being with my family strongly moderately slightly neutral slightly moderately strongly disagree disagree disagree agree agree agree

- Chance contact with new people

- Spending time alone and watching people

$\square \ldots . . \square \ldots . . \square \ldots \square, \ldots, \square \ldots \square \ldots . \square$

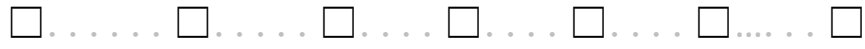

3b. Public spaces which have places to sit around fountain, pool, trees, and also nearby places to eat are pleasant for...

- Meeting friends or being with my family

- Chance contact with new people

- Spending time alone and watching people strongly moderately slightly neutral slightly moderately strongly disagree disagree disagree agree agree agree

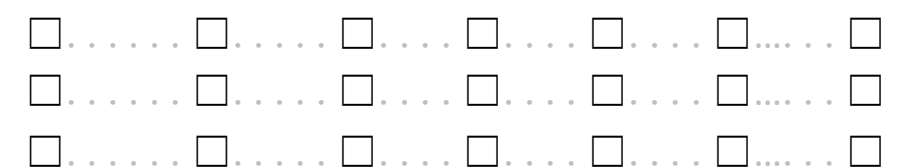


4a. Public spaces which have places to sit around public art, sculpture and decorative features, and also people around are pleasant for...

strongly moderately slightly neutral slightly moderately strongly disagree disagree disagree agree agree agree

- Meeting friends or being with my family

- Chance contact with new people

- Spending time alone and watching people

4b. Public spaces which have places to sit around public art, sculpture and decorative features, and also nearby places to eat are pleasant for...

strongly moderately slightly neutral slightly moderately strongly disagree disagree disagree agree agree agree

- Meeting friends or being with my family

- Chance contact with new people

- Spending time alone and watching people

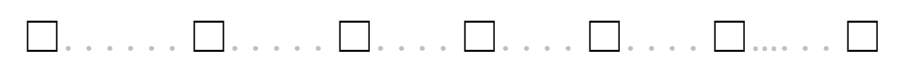

5a.Public spaces which have sunny and shady areas using trees and shrubs, and also people around are pleasant for...

- Meeting friends or being with my family strongly moderately slightly neutral slightly moderately strongly disagree disagree disagree agree agree agree

- Chance contact with new people

- Spending time alone and watching people

5b.Public spaces which have sunny and shady areas using trees and shrubs, and also nearby places to eat are pleasant for...

- Meeting friends or being with my family strongly moderately slightly neutral slightly moderately strongly disagree disagree disagree agree agree agree

- Chance contact with new people

- Spending time alone and watching people

6a. Public spaces which have sunny and shady areas using man-made shelters, and also people around are pleasant for...

strongly moderately slightly neutral slightly moderately strongly disagree disagree disagree agree agree agree

- Meeting friends or being with my family

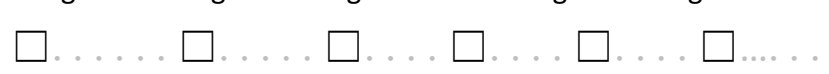

- Chance contact with new people

- Spending time alone and watching people

6b. Public spaces which have sunny and shady areas using man-made shelters, and also nearby places to eat are pleasant for...

strongly moderately slightly neutral slightly moderately strongly disagree disagree disagree agree agree agree

- Meeting friends or being with my family

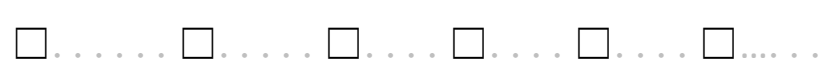

- Chance contact with new people

- Spending time alone and watching people 
7a. Public spaces which have intimate spaces created by trees and plants, and also people around are pleasant for...

strongly moderately slightly neutral slightly moderately strongly disagree disagree disagree agree agree agree

- Meeting friends or being with my family

- Chance contact with new people

- Spending time alone and watching people

7b. Public spaces which have intimate spaces created by trees and plants, and also nearby places to eat are pleasant for...

- Meeting friends or being with my family strongly moderately slightly neutral slightly moderately strongly disagree disagree disagree agree agree agree

- Chance contact with new people

- Spending time alone and watching people

8a. Public spaces which have intimate spaces created by steps and low walls, and also people around are pleasant for...

- Meeting friends or being with my family strongly moderately slightly neutral slightly moderately strongly disagree disagree disagree agree agree agree

- Chance contact with new people

- Spending time alone and watching people

8 b. Public spaces which have intimate spaces created by steps and low walls, and also nearby places to eat are pleasant for...

strongly moderately slightly neutral slightly moderately strongly disagree disagree disagree agree agree agree

- Meeting friends or being with my family

- Chance contact with new people

- Spending time alone and watching people

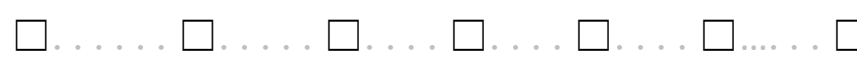

9a. Public spaces which have trees and plants with appropriate scale around the edge, and also people around are pleasant for...

strongly moderately slightly neutral slightly moderately strongly disagree disagree disagree agree agree agree

- Meeting friends or being with my family

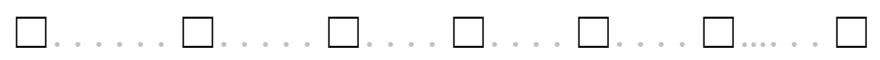

- Chance contact with new people

- Spending time alone and watching people

9b. Public spaces which have trees and plants with appropriate scale around the edge, and also nearby places to eat are pleasant for...

strongly moderately slightly neutral slightly moderately strongly disagree disagree disagree agree agree agree

- Meeting friends or being with my family

- Chance contact with new people

- Spending time alone and watching people

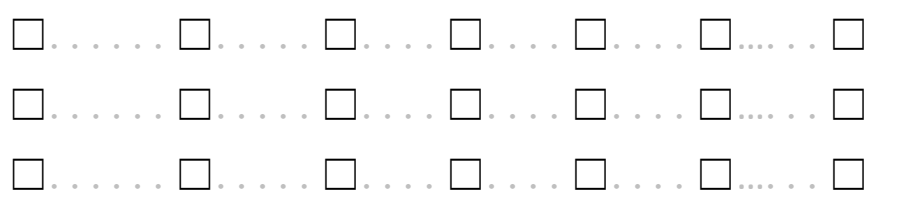


10a. Public spaces which have buildings with appropriate scale around the edge, and also people around are pleasant for...

- Meeting friends or being with my family strongly moderately slightly neutral slightly moderately strongly disagree disagree disagree agree agree agree

- Chance contact with new people

- Spending time alone and watching people

10b. Public spaces which have buildings with appropriate scale around the edge, and also nearby places to eat are pleasant for... strongly moderately slightly neutral slightly moderately strongly
disagree disagree disagree

- Meeting friends or being with my family

- Chance contact with new people

- Spending time alone and watching people

11a. Public spaces which have native and local plants and also people around are pleasant for...

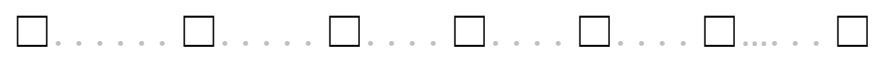

- Meeting friends or being with my family

strongly moderately slightly neutral slightly moderately strongly disagree disagree disagree agree agree agree

- Chance contact with new people

- Spending time alone and watching people

11b. Public spaces which have native and local plants, and also nearby places to eat are pleasant for...

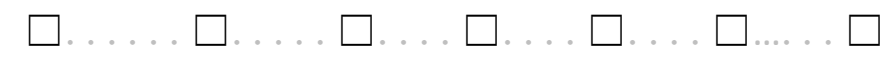$$
\text { pleasant for... }
$$

- Meeting friends or being with my family

- Chance contact with new people

- Spending time alone and watching people strongly moderately slightly neutral slightly moderately strongly
disagree disagree disagree

12a. Public spaces which have familiar architectural style, and also people around are pleasant for...

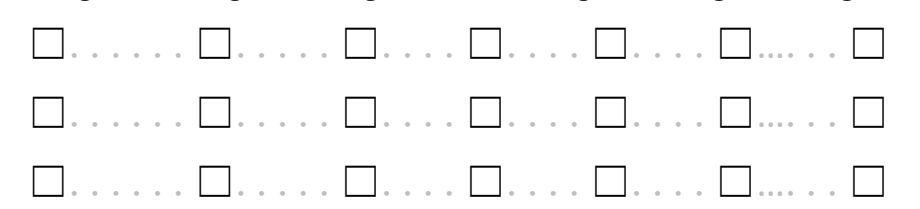

- Meeting friends or being with my family strongly moderately slightly neutral slightly moderately strongly disagree disagree disagree agree agree agree

- Chance contact with new people

- Spending time alone and watching people

12b. Public spaces which have familiar architectural style, and also nearby places to eat are pleasant for...

- Meeting friends or being with my family strongly moderately slightly neutral slightly moderately strongly disagree disagree disagree agree agree agree

- Chance contact with new people

- Spending time alone and watching people

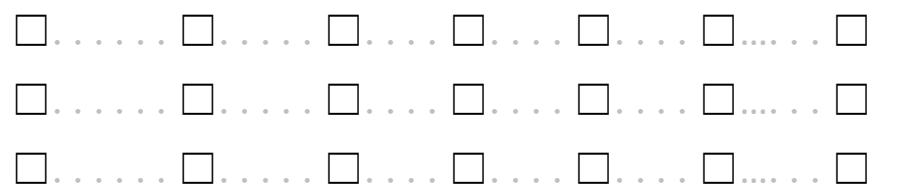


13a. Public spaces which have well maintained greenery, and also people around are pleasant for...

strongly moderately slightly neutral slightly moderately strongly disagree disagree disagree agree agree agree

- Meeting friends or being with my family

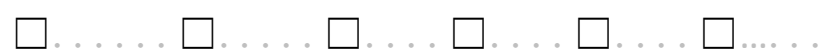

- Chance contact with new people

- Spending time alone and watching people

13b. Public spaces which have well maintained greenery, and also nearby places to eat are pleasant for...

- Meeting friends or being with my family

- Chance contact with new people

- Spending time alone and watching people

strongly moderately slightly neutral slightly moderately strongly disagree disagree disagree agree agree agree

14a. Public spaces which have clean and well-kept surfaces, and also people around are pleasant for...

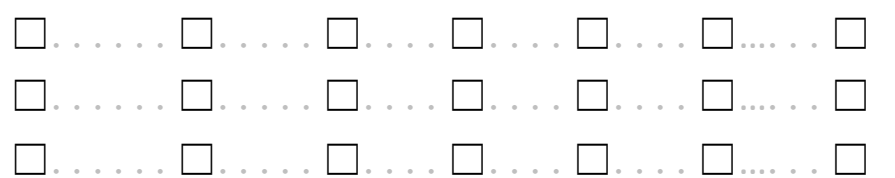

- Meeting friends or being with my family

- Chance contact with new people

- Spending time alone and watching people

strongly moderately slightly neutral slightly moderately strongly disagree disagree disagree agree agree agree

14b. Public spaces which have clean and well-kept surfaces, and also nearby places to eat are pleasant for...

strongly moderately slightly neutral slightly moderately strongly disagree disagree disagree agree agree agree

- Meeting friends or being with my family $\square \ldots . . \square \ldots . . \square \ldots \square, \ldots \square \ldots \square \ldots . . . \square$

- Chance contact with new people

- Spending time alone and watching people

15a. Public spaces which have welcoming and visible threshold or entrance defined by trees and plants, and also people around are pleasant for...

strongly moderately slightly neutral slightly moderately strongly disagree disagree disagree agree agree agree

- Meeting friends or being with my family

- Chance contact with new people

- Spending time alone and watching people

15b. Public spaces which have welcoming and visible threshold or entrance defined by trees and plants, and café, or nearby places to eat are pleasant for...

strongly moderately slightly neutral slightly moderately strongly

- Meeting friends or being with my family disagree disagree disagree agree agree agree

- Chance contact with new people

- Spending time alone and watching people

16a. Public spaces which have welcoming and visible threshold or entrance defined by manmade elements, and also people around are pleasant for... 
- Meeting friends or being with my family

- Chance contact with new people

- Spending time alone and watching people

strongly moderately slightly neutral slightly moderately strongly disagree disagree disagree agree agree agree

16b. Public spaces which have welcoming and visible threshold or entrance defined by manmade elements, and café, or nearby places to eat are pleasant for...

strongly moderately slightly neutral slightly moderately strongly disagree disagree disagree agree agree agree

- Meeting friends or being with my family

- Chance contact with new people

- Spending time alone and watching people

\section{PART THREE}

\section{Please give your ideas for making (name of the place) a better public space}

1. I think ....... park is a pleasant place for spending time alone

\section{Because}

\begin{tabular}{|c|c|c|c|c|c|}
\hline $\begin{array}{l}\text { strongly } \\
\text { disagree }\end{array}$ & $\begin{array}{l}\text { moderately } \\
\text { disagree }\end{array}$ & $\begin{array}{l}\text { slightly } \\
\text { disagree }\end{array}$ & neutral & $\begin{array}{l}\text { slightly } \\
\text { agree }\end{array}$ & $\begin{array}{c}\text { moderately } \\
\text { agree }\end{array}$ \\
\hline
\end{tabular}

2. I think ....... park is pleasant place for chance contact with new people

\section{Because}

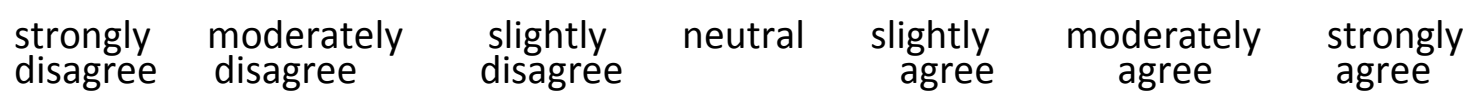

3. I think park is pleasant place for meeting my friend(s) or being with my family.

\section{Because}

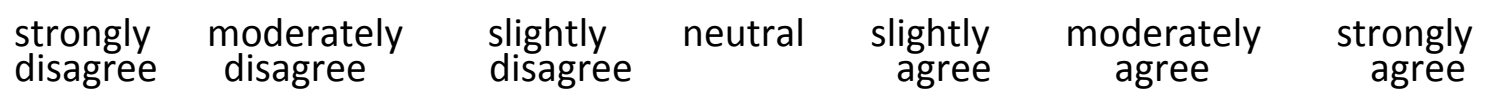

4. On the scale of 1-7 (with 1 not at all and 7 completely) how satisfied are you with the available seating in (name of the place)

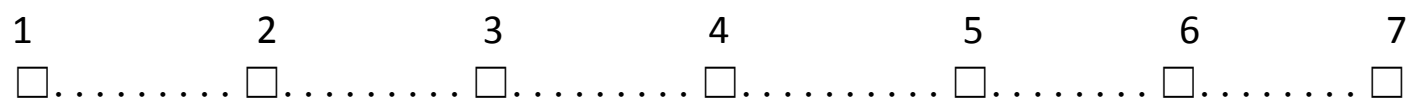

\section{Because}

5. On the scale of 1-7 (with 1 not at all and 7 completely) how satisfied are you with the amount of greenery in the (name of the place) 


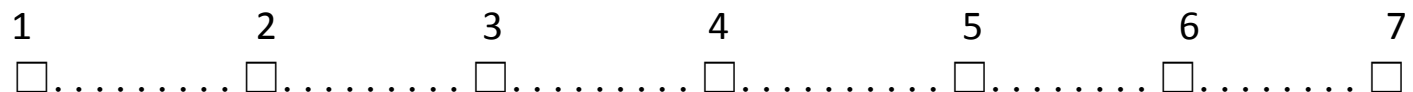

\section{Because}

6. On the scale of 1-7 (with 1 not at all and 7 completely) how satisfied are you with size and scale of (name of the place)

$\begin{array}{lccccc}1 & 2 & 3 & 4 & 5 & 6\end{array}$

\section{Because}

7. On the scale of 1-7 (with 1 not at all and 7 completely) how satisfied are you with the location of (name of the place)

$\begin{array}{rrrrrr}2 & 3 & 4 & 5 & 6 & 7\end{array}$

$\begin{array}{rrrrrr}2 & 3 & 4 & 5 & 6 & 7\end{array}$

$\begin{array}{rrrrrr}2 & 3 & 4 & 5 & 6 & 7\end{array}$

7

\section{Because}

8. What makes this park special for you?

Because

9. Which features of (place) do you prefer?

10. Please add any further comments you have about the design of public open space 


\section{Appendix 3 \\ Comparison of Study Participants and Data Collection Dates}

Ethics approval for surveys obtained on $4^{\text {th }}$ September 2012, with approval memo for survey two on $8^{\text {th }}$ October 2012 and for photography on $1^{\text {st }}$ December 2012.

Appendix 3 Table 1: Dates for data collection

\begin{tabular}{|l|l|l|l|l|}
\hline Study One & \multicolumn{4}{|l|}{ From $7^{\text {th }}$ Oct 2012 to $11^{\text {th }}$ Dec 2012} \\
\hline Study Two & \multicolumn{4}{|l|}{ From $7^{\text {th }}$ Nov 2012 to $17^{\text {th }}$ Nov 2012} \\
\hline Study Three & Te Aro Park & Midland Park & Civic Square & Glover Park \\
\hline & $20^{\text {th }}$ Mar 2013 & $21^{\text {st }}$ Mar 2013 & $25^{\text {th }}$ Mar 2013 & $27^{\text {th }}$ Mar 2013 \\
\hline
\end{tabular}


Appendix 3 Table 2: Comparison of participants in Studies One and Two

\begin{tabular}{|c|c|c|c|c|c|c|c|c|c|c|}
\hline \multirow[t]{3}{*}{ Gender } & & Female & Male & \begin{tabular}{|l|} 
No \\
respond
\end{tabular} & & & & & & \\
\hline & Study 1 & $48.73 \%$ & $49.36 \%$ & $1.91 \%$ & & & & & & \\
\hline & Study 2 & $57.5 \%$ & $42.5 \%$ & & & & & & & \\
\hline \multirow[t]{3}{*}{ Age } & & $\begin{array}{l}\text { Age - } \\
\text { range }\end{array}$ & Mean age & & & & & & & \\
\hline & \begin{tabular}{|l|} 
Study 1 \\
\end{tabular} & $\begin{array}{l}14-64 \\
\text { years }\end{array}$ & 31.8 & & & & & & & \\
\hline & Study 2 & \begin{tabular}{|l|}
$14-75$ \\
years
\end{tabular} & $\begin{array}{l}28.82 \\
\text { years }\end{array}$ & & & & & & & \\
\hline \multirow{2}{*}{$\begin{array}{l}\text { Average } \\
\text { living in } \\
\text { wellington }\end{array}$} & Study 1 & 10 years & & & & & & & & \\
\hline & Study 2 & $\begin{array}{l}11.86 \\
\text { years }\end{array}$ & & & & & & & & \\
\hline \multirow[t]{3}{*}{ Ethnicity } & & $\begin{array}{l}\text { NZ } \\
\text { European }\end{array}$ & Asian & European & Maori & \begin{tabular}{|l|} 
Middle \\
Eastern/Latin
\end{tabular} & Pacific & $\begin{array}{l}\text { American } \\
\text { /African }\end{array}$ & \begin{tabular}{|l} 
Other \\
ethnicity
\end{tabular} & \\
\hline & Study 1 & $61.4 \%$ & $8.90 \%$ & $13.9 \%$ & $3.85 \%$ & $1.90 \%$ & $0.00 \%$ & $2.50 \%$ & $2.50 \%$ & \\
\hline & Study 2 & $58.10 \%$ & $11.30 \%$ & $10.60 \%$ & $5.60 \%$ & $2.50 \%$ & $1.30 \%$ & $0.00 \%$ & $7.50 \%$ & \\
\hline \multirow[t]{3}{*}{ Education } & & Tertiary & Secondary & Trade & $\begin{array}{l}\text { Less than } \\
\text { that }\end{array}$ & No respond & & & & \\
\hline & Study 1 & $67.70 \%$ & $23.40 \%$ & $6.30 \%$ & $1.33 \%$ & $1.3 \%$ & & & & \\
\hline & Study 2 & $65.00 \%$ & $29.71 \%$ & $1.90 \%$ & $2.50 \%$ & $0.89 \%$ & & & & \\
\hline \multirow[t]{3}{*}{ Occupation } & & Students & $\begin{array}{l}\text { Working } \\
\text { in a } \\
\text { private } \\
\text { company }\end{array}$ & $\begin{array}{l}\text { Working } \\
\text { in public } \\
\text { service }\end{array}$ & $\begin{array}{l}\text { Self- } \\
\text { employed }\end{array}$ & Not employed & Retired & $\begin{array}{l}\text { Work at } \\
\text { home }\end{array}$ & Other & \begin{tabular}{|l} 
No \\
respond
\end{tabular} \\
\hline & Study 1 & $22.8 \%$ & $30.40 \%$ & $15.80 \%$ & $13.90 \%$ & $7.00 \%$ & $1.30 \%$ & $3.20 \%$ & $1.30 \%$ & $4.40 \%$ \\
\hline & Study 2 & $31.30 \%$ & $28.10 \%$ & $21.90 \%$ & $6.30 \%$ & $5.00 \%$ & $1.30 \%$ & $1.30 \%$ & $1.90 \%$ & $3.10 \%$ \\
\hline \multirow[t]{3}{*}{ Work place } & & CBD & $\begin{array}{l}\text { Out of } \\
\text { CBD }\end{array}$ & & & & & & & \\
\hline & Study 1 & $53.80 \%$ & $46.20 \%$ & & & & & & & \\
\hline & Study 2 & $62.50 \%$ & $37.50 \%$ & & & & & & & \\
\hline \multirow[t]{3}{*}{$\begin{array}{l}\text { Frequently } \\
\text { of use }\end{array}$} & & Every day & $\begin{array}{l}2 \text { or } 3 \\
\text { times a } \\
\text { week }\end{array}$ & Most days & $\begin{array}{l}\text { One a } \\
\text { week }\end{array}$ & $\begin{array}{l}2 \text { or } 3 \text { times a } \\
\text { month }\end{array}$ & $\begin{array}{l}\text { Once a } \\
\text { month }\end{array}$ & Not at all & \begin{tabular}{|l|} 
No \\
respond
\end{tabular} & \\
\hline & Study 1 & $7.60 \%$ & $33.50 \%$ & $24.10 \%$ & $12.70 \%$ & $15.80 \%$ & $3.80 \%$ & $0.60 \%$ & $1.90 \%$ & \\
\hline & Study 2 & $11.30 \%$ & $33.10 \% \%$ & $22.50 \%$ & $15.00 \%$ & $12.50 \% y$ & $3.80 \%$ & & & \\
\hline
\end{tabular}




\section{Appendix 4 \\ Pilot testing for Photographic Interval}

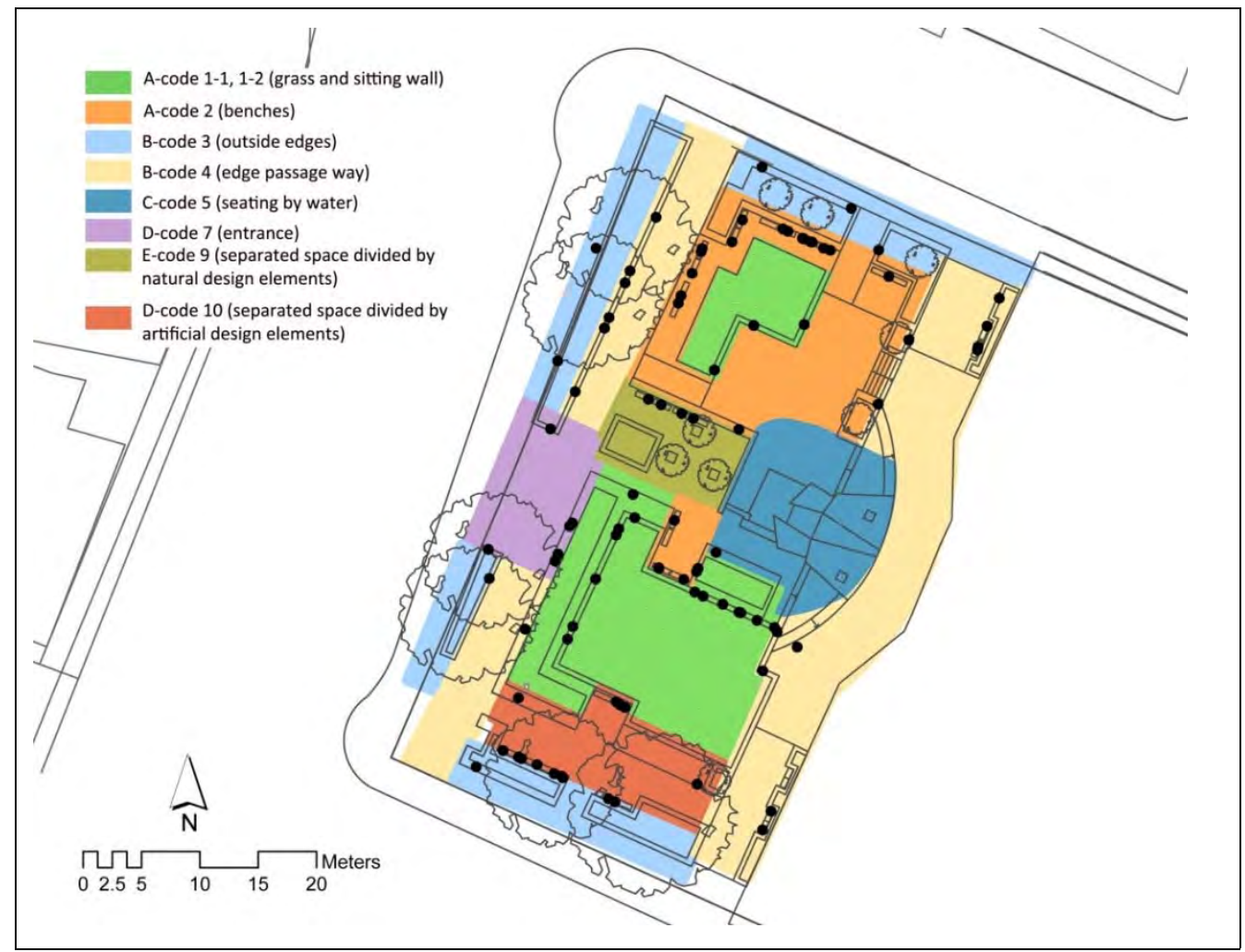

Appendix 4 Figure 1: Uses of space with 5 minute intervals 


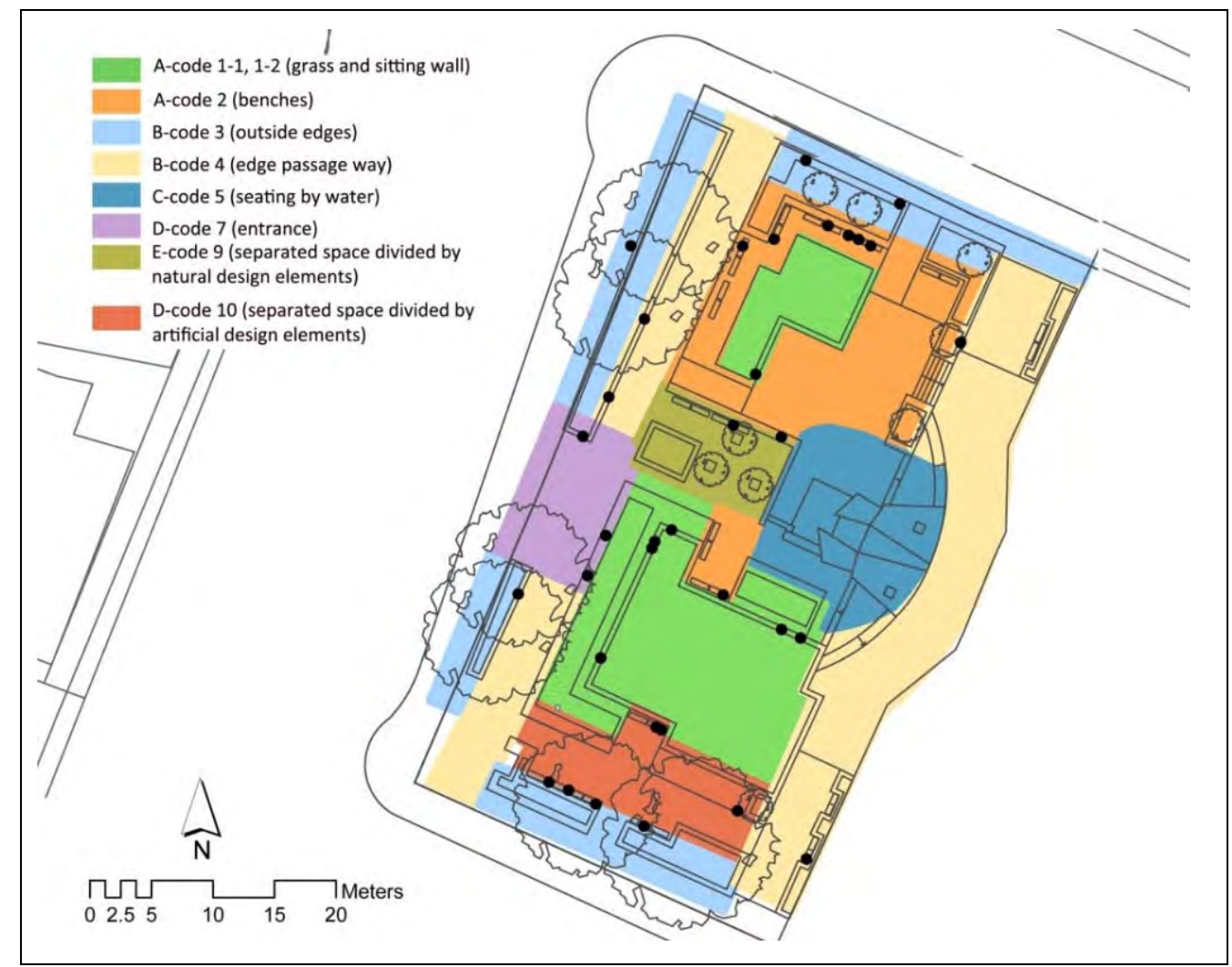

Appendix 4 Figure 2: Uses of space with 10 minute intervals

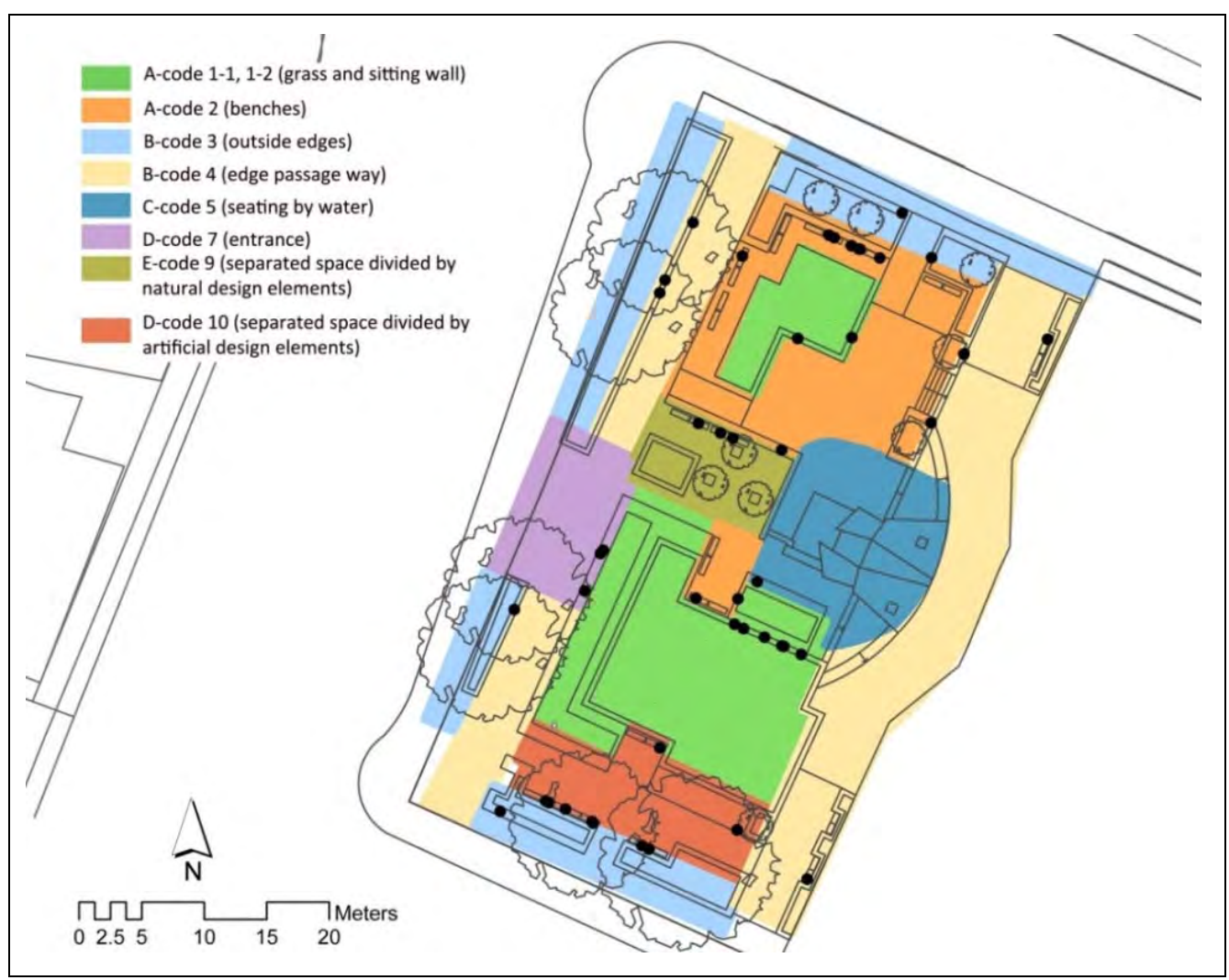

Appendix 4 Figure 3: Uses of space with 15 minute intervals 